\title{
Post-Oruanui supereruption recovery, reconstruction and evolution of Taupo volcano, New Zealand
}

\author{
by
}

\section{Simon James Barker}

\author{
A thesis \\ submitted to Victoria University of Wellington \\ in partial fulfilment of the requirements for the degree of \\ Doctor of Philosophy in Geology \\ Victoria University of Wellington \\ School of Geography, Environment and Earth Sciences \\ Thesis Advisor: Prof Colin J.N. Wilson
}

Wellington, New Zealand

November 2014 
(C) 2014

Simon J. Barker All Rights Reserved 


\section{ABSTRACT}

This thesis research presents geochemical perspectives on the magmatic recovery of Taupo volcano (New Zealand) in the aftermath of the 25.4 ka Oruanui supereruption. Following the Oruanui, and after only $\sim 5 \mathrm{kyr}$ of quiescence, Taupo erupted three small volume $\left(\sim 0.1 \mathrm{~km}^{3}\right)$ dacitic units, followed by another $\sim 5 \mathrm{kyr}$ break, and then the modern sequence from $\sim 12$ ka onwards of 25 rhyolitic units organised into 3 geochemically distinct subgroups (SG1-SG3). The eruptive units are stratigraphically constrained over exceptionally short time intervals, providing fine-scale temporal snapshots of the magma system. In this thesis I compare and contrast whole-rock, mineral and glass compositions of Oruanui and post-Oruanui magmas through time to investigate the post-supereruption reconstruction and evolution of Taupo through to the latest eruption.

Despite overlapping vent sites and crustal source domains between the Oruanui and post-Oruanui eruptions, U/Th disequilibrium model-ages in zircons from Taupo SG1 rhyolites (erupted $12 \mathrm{ka}-10 \mathrm{ka}$ ) and SG2 rhyolites (erupted $7 \mathrm{ka}-2.6 \mathrm{ka}$ ) imply the presence of only minor inheritance of crystals from the Oruanui magma source. PostOruanui model-age spectra are instead typically centred close to eruption ages with subordinate older pre-300 ka equiline grains. U-Pb dating of these equiline grains shows that both 300-450 ka plutonic-derived and pre-100 Ma greywacke basement-derived zircons are present. The former largely coincide in age with zircons from the $350 \mathrm{ka}$ Whakamaru eruption products, and are dominant over greywacke in young units which were vented within the published Whakamaru caldera outline. Despite multiple ages and vent sites, trace element compositions are broadly similar in zircons, regardless of their ages. However, a small subset of zircons analysed from SG1 rhyolites have notably high concentrations of $\mathrm{U}, \mathrm{Th}, \mathrm{P}, \mathrm{Y}^{+}(\mathrm{REE})^{3+}$ and $\mathrm{Nb}$ but with only minor changes in $\mathrm{Hf}$ and Ti. SG2 zircons typically have higher Sc, reflecting large-scale changes in melt chemistry and crystallising mineral phases with time. The age spectra indicate that most Oruanui zircons were removed by thermally induced dissolution immediately following the supereruption. U-Th ages from individual post-Oruanui eruptions show consistent inheritance of post-Oruanui grains with model ages that centre between the temporally separated but geographically overlapping eruption groups, generating model-age modes. Within the statistical limitations of the isotopic measurements, we interpret these repeated modes to be significant, resulting from incorporation of crystal populations from cyclic post-Oruanui periods of magmatic cooling and crystallisation, acting within a crustal protolith chemically independent of that which built the Oruanui. Cooling periods alternate with times of rejuvenation and eruption, in some cases demonstrably 
accompanying syn-eruptive regional rifting and mafic injection. Not only were the processes that developed the supersized Oruanui magma body unusually rapid, but this huge magma system was effectively reset and rebuilt on a comparably short timescale.

Major and trace element whole rock, glass and mineral chemistry of postOruanui eruptive products indicate how the host magma system re-established and evolved. The dacite units show wide variations in melt inclusion compositions and strongly zoned minerals consistent with interaction of less-evolved mafic magmas at a depths of $>8 \mathrm{~km}$, overlapping with the inferred base of the old Oruanui mush system. The dacites reflect the first products of the rebuilding silicic magma system, as most of the Oruanui mush was reconfigured or significantly modified in composition following thermal fluxing accompanying post-caldera collapse readjustment. The first (SG1) rhyolites erupted from $12 \mathrm{ka}$ formed through shallow fractionation (4-5 km depth) and cooling of a parental melt similar in composition to the earlier dacite melts, with overlapping melt inclusion and crystal core compositions between the two magma types. For the younger rhyolite units, fine-scale temporal changes in melt chemistry and mineral phase stability occur over time, which are closely linked to the development, stabilisation and maturation of a new and likely unitary rhyolite mush system at Taupo. The new mush system is closely linked to and sometimes physically interacts with the underlying mafic melts, which are similar in composition to those involved in the Oruanui eruption and provide the long-term thermal and chemical driving force for magmatism. We consider that the new mush body has expanded to $>250 \mathrm{~km}^{3}$ (and possibly up to $1000 \mathrm{~km}^{3}$ ) but has not yet been located by geophysical investigations.

For the most recent SG3 eruptions, the system once again underwent widespread destabilisation, resulting in increased levels of melt extraction from the silicic mush. Trends in whole-rock chemistry and close links between melt inclusions and mineral zoning with earlier units indicates that the $35 \mathrm{~km}^{3}$ Unit Y (Taupo eruption) melt dominant body formed in response to mafic disruption of the silicic mush pile. Associated Fe-Mg diffusion timescales in orthopyroxene suggest that Taupo is capable of changing behaviour and generating large eruptible melt bodies on timescales as short as decades to centuries. The 232 AD Unit Y eruption culminated from a critical combination of high differential tectonic stress build up, and increased potency in the silicic magma system resulting from elevated levels of mafic magma input, resulting in one of the largest and most violent worldwide Holocene eruptions. The post-Y magma system then responded to further disruption with the eruption of sub-lacustrine dome(s). Taupo is considered to be capable of rapidly recovering in its modern form to continue its hyperactive eruptive behaviour on timescales that are of human interest and concern. 


\section{Acknowledgments}

During my PhD project I have had the pleasure of meeting and working with some great people, all of whom have made this a truly enjoyable adventure.

Firstly, none of this research would have been made possible without the support and encouragement of my supervisor and mentor Colin Wilson. Colin, your passion towards volcanology and high quality research has been truly inspirational. From excessively strong coffee to climbing sheer cliffs to get a single sample, you have taught me so much about how to get it done right. Thanks for all the extra time you have put in with fieldwork, lab work and extra trips to Bishop and Yellowstone to give me a great perspective of what can be achieved.

This project was funded by a Victoria Doctoral Scholarship and from a Marsden grant awarded to Prof Wilson from the Royal Society of New Zealand. Thank you to NZ Forest Managers (Jules and Colin) and Timberlands who kindly allowed access to Lake Taupo Forest and Waimihia Forest for sample collection. George (MF1) Cooper and Katie Jacobs provided assistance in the field. Many people have helped with lab work and solving many unforeseen issues. Thanks to Marc-Alban Millet and Sabrina Lange in the geochem labs, and Joe Hiess and John Gamble for providing much appreciated encouragement and advice. Diane Seward, Jiao Ruohong and Bruce Charlier helped set up the zircon separation method and provided much appreciated advice. Euan Smith is thanked for his statistical modeling expertise. Stewart Bush provided thin sections and guidance with polishing equipment. Andrea, Peter and Condor are thanked for helping setting up the Element 2 for trace element work. Ian Schipper and Melissa Rotella provided much appreciated help with EPMA and also with FTIR sample prep and analysis. Joe Wooden, Trevor Ireland, Matt Coble, John Foster, Peter Holden and Brad Ito are thanked for their help and assistance in the SHRIMP labs at Stanford and ANU.

Thank you to the many office mates who I have shared great times with through the years including: Aidan 'I like' Allan, Katy Chamberlain, Jiao Ruohong, Ben 'Hammer' Hines, George 'Them magmas' Cooper and Chris 'Condor' Conway. Condor is especially thanked for the many vicious/akushitsuna missions in the labs and in Japan, and for helping with thesis printing and binding while I was away from the nest... chur to you brother. To all other past and present comrades in SGEES, Alexa, John Creech, Ramona, Matt 'the gull' Ryan, Jenni, Nacho, Katie Collins, Kolja, James Muirhead, George and Sarah, Mike Rosenburg, Denise, Rich, Elliot, Shane, Shaun, Loretta and anyone I've missed, thank you. Special mention must go to the esteemed members of the VUW OBC, who shared many feasts amongst the glorious company of gentlemen. Birds of Prey FC provided a great outlet on the field. Tim Little is thanked for the many fishing sessions in the yak and boat and for helping refine my beer making. Cheers!

To my family (Mum, Higgins, Claire and Carl) for providing ongoing encouragement, love and advice through the years, stay sharp. Thank you to Chris and Dan Rotella for great summers and white Christmases in Canada and for supporting Melissa and I in the final stages. Finally, none of this would have been possible without the love and support of my partner and best friend Melissa. As one adventure comes to a close, another one starts. I am so excited about our future together. 


\section{Table of Contents}

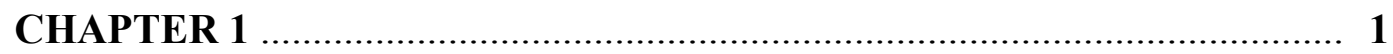

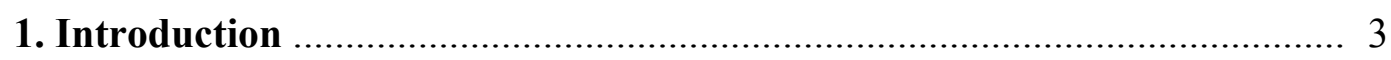

1.1 Motivation for research ……………………………………………... 3

1.2. Thesis objectives and outline ............................................................... 4

1.3. Understanding silicic magmatic processes …………………………….... 7

1.3.1. The crystal mush model .................................................................. 7

1.3.2. Large silicic magma systems ........................................................ 9

1.3.3. Supereruptions and supervolcanoes …………………………….... 10

1.4. Investigating silicic magmatic processes ............................................ 12

1.5. Geologic background ........................................................................... 14

1.5.1. The Taupo Volcanic Zone ............................................................. 14

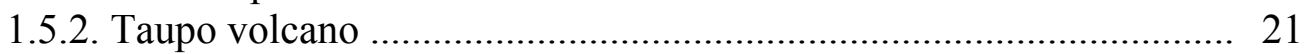

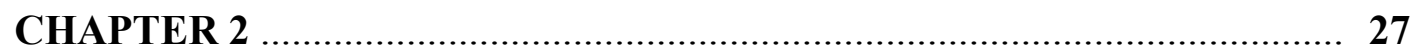

2. Eruptive Stratigraphy \& Sample Collection .............................................. 29

2.1. Eruptive stratigraphy of Taupo volcano ................................................. 29

2.2. Field work \& sampling ....................................................................... 33

2.2.1. Units $\Psi, \Omega \&$ A (post-Oruanui dacites) ......................................... 33

2.2.2. Unit B (Karapiti Tephra) ……………………………………..... 36

2.2.3. Unit C (Poronui Tephra) ................................................................. 39

2.2.4. Unit D (inferred Acacia Bay Dome) …………………………….... 39

2.2.5. Unit E (Opepe Tephra) ................................................................. 40

2.2.6. Unit F (inferred Motutaiko Island dome) .......................................... 41

2.2.7. Unit $\mathrm{G}$ and $\mathrm{H}$ (Motutere Tephra) .................................................... 42

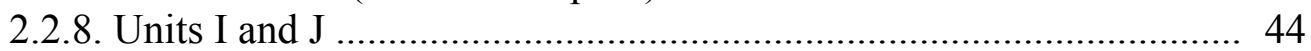

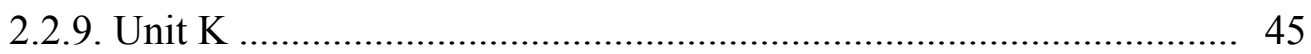

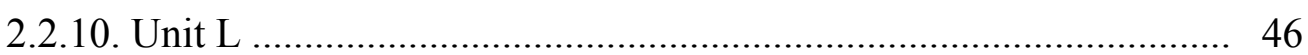

2.2.11. Unit M .............................................................................. 46

2.2.12. Unit $\mathrm{N}$.................................................................................. 47

2.2.13. Unit $\mathrm{O}$.............................................................................. 48

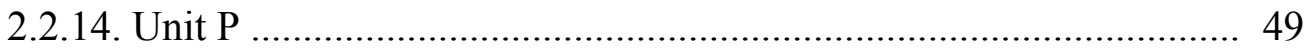

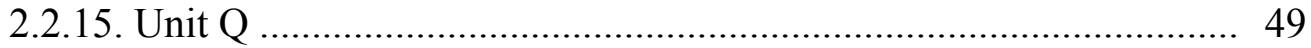

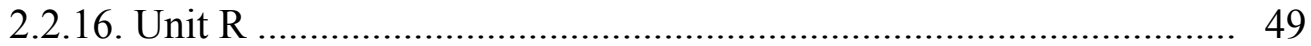

2.2.17. Unit $\mathrm{S}$ (Waimihia Tephra) ........................................................ 50

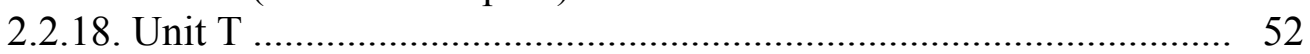

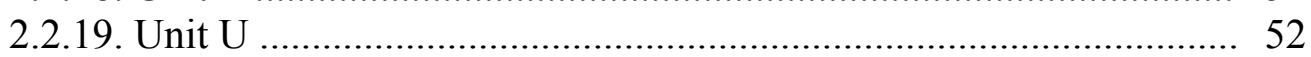

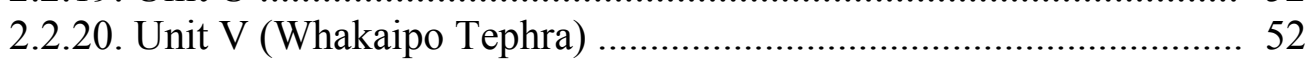

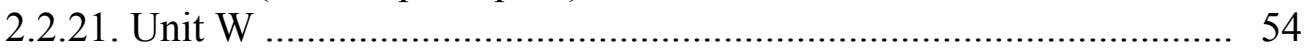

2.2.22. Unit X (Mapara Tephra) ………………………………………... 55

2.2.23. Unit $Y$ (Taupo Tephra) ............................................................... 56

2.2.24. Unit $Z$ (Floated giant pumices) ………………………………...... 61

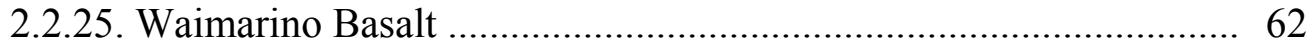




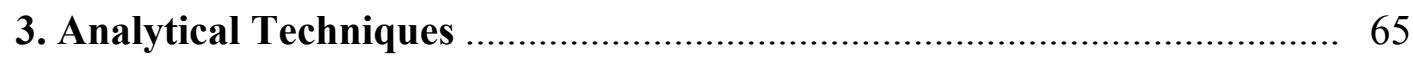

3.1. General sample preparation procedure ….......................................... 65

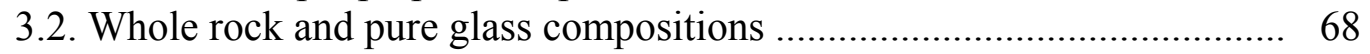

3.2.1. XRF: Whole-rock major and minor elements ............................ 68

3.2.2. Solution ICP-MS: Trace elements ........................................... 72

3.3. In-situ mineral and glass compositions ............................................... 74

3.3.1. Electron microprobe (EPMA): Major and minor elements ............. 74

3.3.2. Laser-ablation-ICP-MS: Trace elements in amphibole .................. 81

3.4. FTIR: Glass $\mathrm{H}_{2} \mathrm{O}$ and $\mathrm{CO}_{2}$ concentrations ...................................... 82

3.5. Ion microprobe: Zircon age dating and trace elements ........................ 85

CHAPTER 4

4. Post-supereruption Magmatic Reconstruction of Taupo Volcano (New Zealand), as Reflected in Zircon Ages and Trace Elements - Barker et al. (2014a) - Published in Journal of Petrology ................................................... 93

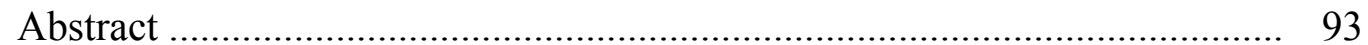

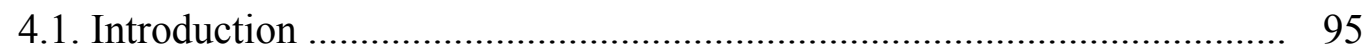

4.2. Geological background ............................................................... 97

4.3. Analytical techniques .................................................................. 100

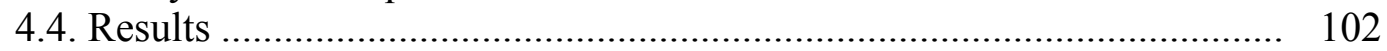

4.4.1. U-Th model ages ............................................................. 102

4.4.2. U-Pb ages ........................................................................... 104

4.4.3. Trace element compositions ................................................. 108

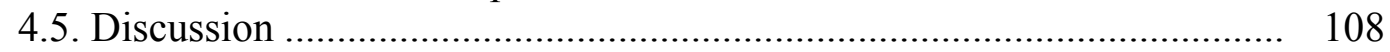

4.5.1. Relationship between the pre- and post-Oruanui magma systems ... 110

4.5.2. Determining the nature and timing of post-supereruption zircon growth

4.5.2.1. Significance of age peaks identified in the post-Oruanui SIMS U-Th data ….................................................. 115

4.5.2.2. Controls on the timing of zircon growth in the post-Oruanui magma ...................................................................... 118

4.5.3. Zircon compositions as tracers of changing melt compositions ...... 122

4.6. Conclusion ................................................................................ 124

CHAPTER 5

5. Fine-Scale Temporal Recovery, Reconstruction and Evolution of a PostSupereruption Magmatic System: Taupo (New Zealand) - Barker et al. (2014b) - Manuscript prepared for Contributions to Mineralogy \& Petrology ... 129

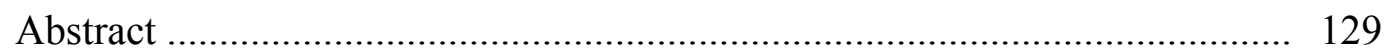

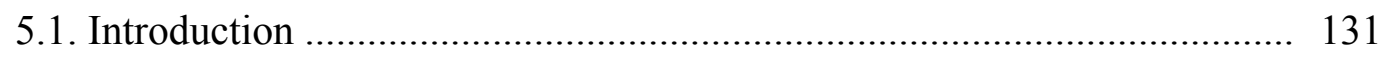

5.2. Eruptive stratigraphy and sampling .............................................. 134 
5.3. Analytical techniques ...................................................................... 138

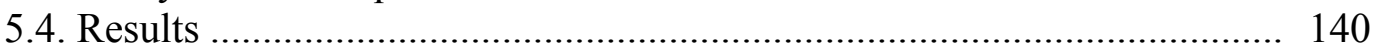

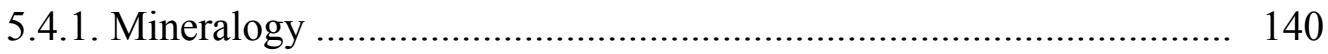

5.4.2. Whole rock major and trace element compositions .......................... 142

5.4.3. Glass and melt inclusion compositions …………………………...... 147

5.4.4. Crystal chemistry and compositional zoning ................................... 152

5.4.5. Intensive parameters .................................................................... 158

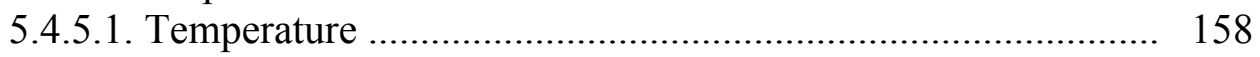

5.4.5.2. Oxygen fugacity .................................................................. 163

5.4.5.3. Melt volatile contents ........................................................... 163

5.4.5.4. Pressure ………………………………………………....... 164

5.5. Discussion ............................................................................ 165

5.5.1. Comparisons between Oruanui and post-Oruanui magma

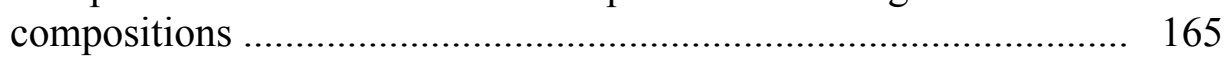

5.5.2. Post-supereruption reorganisation and reconstruction of Taupo's

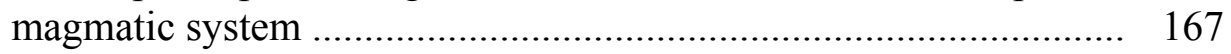

5.5.2.1. Origin and significance of the $\sim 21-17 \mathrm{ka}$ dacites ................... 167

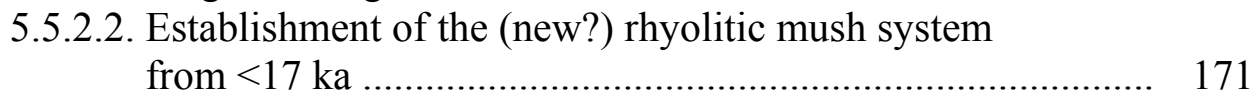

5.5.2.3. Relationships between the temporally separated rhyolitic

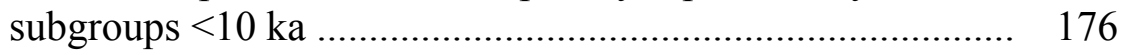

5.5.2.4. The role of mafic magmas ..................................................... 178

5.5.3. Summary of Taupo's magmatic system through time ..................... 180

5.5.3.1. The contemporary magmatic system .................................... 186

5.5.4. Taupo's post-supereruptive behaviour: typical or unique in a

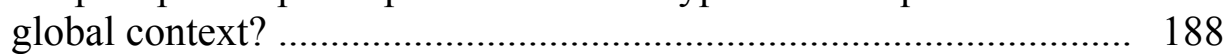

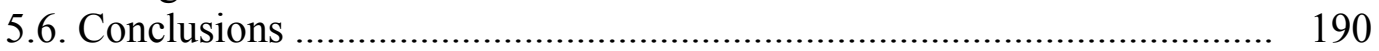

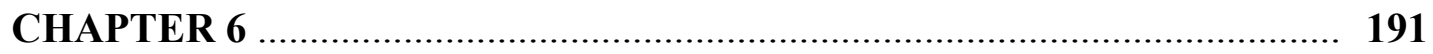

6. Magmatic Timescales and Processes Leading to the Catastrophic 232 AD Taupo Eruption - Manuscript in preparation ................................................ 193

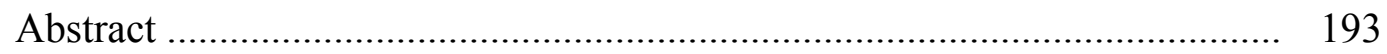

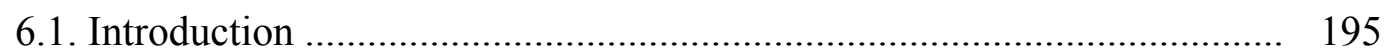

6.2. Eruptive stratigraphy and sampling ................................................... 197

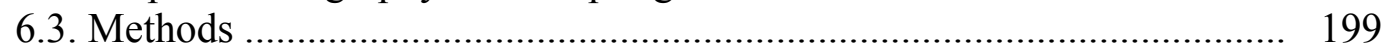

6.3.1. Whole-rock major and trace element chemistry .............................. 199

6.3.2. Electron microprobe analysis ....................................................... 200

6.3.3. Diffusion modelling in orthopyroxene ………………................... 200

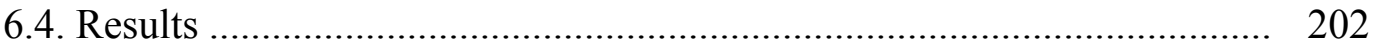

6.4.1. Trends in whole-rock chemistry .................................................. 202

6.4.2. Textural and compositional characteristics of crystals .................... 204

6.4.3. Fe-Mg diffusion timescales in orthopyroxene …………………...... 208

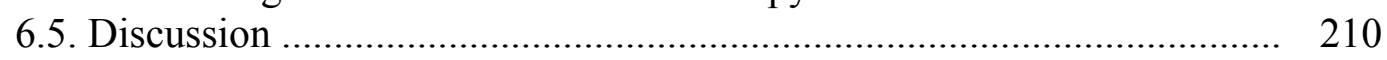

6.5.1. Relationship between the SG2 and SG3 magma systems .............. 210

6.5.2. Rates and mechanisms of melt mobilisation prior to the $232 \mathrm{AD}$

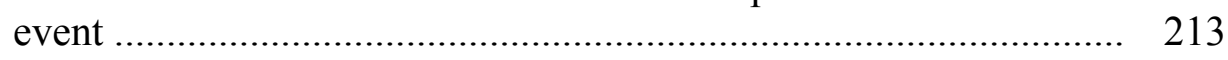

6.5.3. Post-232 AD volcanism and magmatic adjustment ......................... 219 
7.1. Key findings

7.1.1. How did Taupo's magmatic system react to the evacuation of $\geq 530 \mathrm{~km}^{3}$ of magma?

7.1.2. Did the Oruanui eruption act to reset Taupo's silicic magma system, or was it just another large eruption from a long lived magma reservoir that has continued activity on a smaller scale to the present day?

7.1.3. Can any of the components (crystals, melts) from the Oruanui magmatic system be identified in the post-Oruanui sequence?? .....

7.1.4. How long did it take the magmatic system to recover, reorganise or rebuild following the supereruption?

7.1.5. How and why do the post-Oruanui magmas change in composition through time and what processes do these changes reflect

7.1.6. How has the structure of the magmatic system changed through time, and what is its current state?

7.1.7. What controls the wide variations in eruptive sizes and styles at Taupo

7.1.8. Over what time scales is Taupo capable of producing another eruption and what might control its size and eruptive behaviour?...

7.2. Limitation, issues and remaining questions

7.2.1. Challenges with estimating intensive parameters

7.2.2. A lack of experimental constraints on the behaviour of the Taupo rhyolite compositions

7.2.3. The need for high resolution geophysical imaging at Taupo .......... 240

7.2.4. The need for better determination of $\mathrm{Fe}-\mathrm{Mg}$ diffusion coefficients.. 241

7.3. Future directions and suggestions for further research

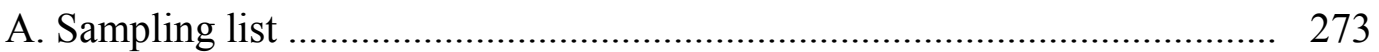

B. Representative zircon cathodoluminescence images ............................. 275

C. Zircon U/Th SHRIMP data ............................................................. 279

D. Zircon U/Pb SHRIMP data ........................................................... 291

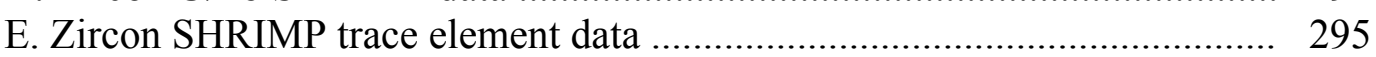

F. 2-component Gaussian mixture models ............................................... 309

G. XRF major and minor element data .................................................... 315

H. Solution-ICPMS trace element data .................................................... 319

I. EPMA glass and melt inclusion data ..................................................... 329 
J. EPMA mineral major and minor element data

K. LA-ICP-MS mineral trace element data ............................................... 611

L. FTIR melt inclusion volatile data ...................................................... 623

M. Orthopyroxene textures in BSE ....................................................... 627

N. Orthopyroxene diffusion profiles ................................................. 637

\section{List of Figures}

Figure 1.1. Schematic illustration of the crystal mush model .......................... 8

Figure 1.2. Schematic illustration of a large silicic magma chamber ................ 10

Figure 1.3. Tectonic map of the North Island of New Zealand ......................... 15

Figure 1.4. Geological map of the Taupo Volcanic Zone region ....................... 16

Figure 1.5. Cumulative eruptive volumes vs. time for the central TVZ ............. 17

Figure 1.6. Composite profile across the central TVZ incorporating MT-data .... 18

Figure 1.7. Eruptive volume vs. time for the Taupo/Maroa and Okataina area .... 19

Figure 1.8. Interplay between magmatic and tectonic processes in the TVZ ....... 20

Figure 1.9. U/Th zircon age spectra from two Taupo area magma systems .......... 22

Figure 1.10. Schematic crustal cross section for the Oruanui system ................ 24

Figure 2.1. Regional stetting and structural features of Taupo volcano ............. 32

Figure 2.2. Map of Taupo area showing sample locations ............................... 34

Figure 2.3. New sample locations for Unit A …........................................... 35

Figure 2.4. Inferred vent locations for the Subgroup 1 eruptions and subunits .... 36

Figure 2.5. Stratigraphic section and photo of sampling units B3 and D .......... 37

Figure 2.6. Sample location for units B3, D, E3 and S ................................ 38

Figure 2.7. Sample location for Unit C .......................................................... 39

Figure 2.8. Sample location for subunit E1 on Mapara Road ........................... 41

Figure 2.9. Inferred vent locations for the Subgroup 2 eruptions and subunits .... 42

Figure 2.10. Sample location for Unit F ....................................................... 43

Figure 2.11. Sample location for Unit H, Hinemaiaia and basal Unit S1 ........... 44

Figure 2.12. Sample location for Unit I ................................................... 45

Figure 2.13. Sample location for Unit L lava ................................................. 47

Figure 2.14. Stratigraphic section and photo of sampling units M, N, O and P... 48

Figure 2.15. Sample location for Unit R ...................................................... 50

Figure 2.16. Stratigraphic section and clast-type abundances for Unit S ............. 51

Figure 2.17. Stratigraphic section and photo of sampling units U, Y1 and Y2 _... 53

Figure 2.18. Sample location for Unit V ......................................................... 54

Figure 2.19. Inferred vent location for the Subgroup 3 eruptions and subunits .... 55

Figure 2.20. Sample location for Unit X .................................................... 56

Figure 2.21. Stratigraphic section and photo of sampling units Y2 and Y3 …..... 59

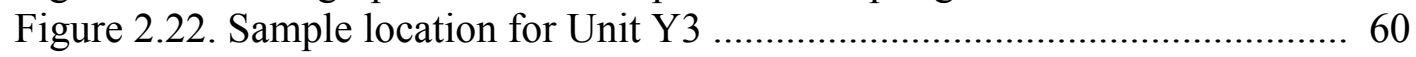

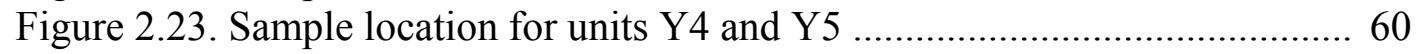

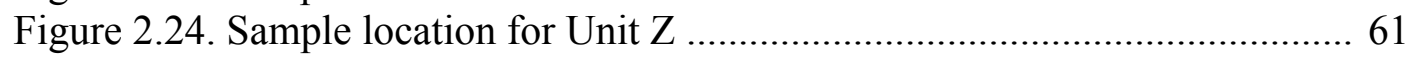

Figure 2.25. Sample location for the Waimarino Basalt Formation ..................... 62

Figure 3.1. Sample preparation for whole-rock powder, glass and crystals ......... 66

Figure 3.2. Pictures of the products of heavy liquid glass-mineral separation ...... 67

Figure 3.3. Images of typical melt inclusions in plagioclase ........................... 84

Figure 4.1. Regional setting and structural features of the TVZ ...................... 98 
Figure 4.2. ${ }^{87} \mathrm{Sr} /{ }^{86} \mathrm{Sr}$ in Taupo-Maroa region magmas over the last $50 \mathrm{kyr}$.......... 99

Figure 4.3. Zircon equiline diagrams and histograms for SG1 eruptions ............. 103

Figure 4.4. Zircon equiline diagrams and histograms for SG1 eruption subunits.. 105

Figure 4.5. Zircon equiline diagrams and histograms for SG2 eruptions .............. 106

Figure 4.6. Comparison of U-Pb age histograms for xenocrystic zircons ............. 107

Figure 4.7. Trace elements vs. U-Th ages for Oruanui and post-Oruanui zircons . 109

Figure 4.8. Comparison of summary U-Th age histograms and PDF curves ....... 111

Figure 4.9. Results of Gaussian mixture models ............................................ 117

Figure 4.10. Fe-Ti oxide and zircon saturation temperature estimates ................. 119

Figure 4.11. Trace elements and temperatures for Oruanui zircons .................... 121

Figure 5.1. Regional setting, structural features and eruptive history of the TVZ.. 133

Figure 5.2. Major element variation diagrams for Taupo and Waimarino ............ 143

Figure 5.3. Trace elements in Oruanui and post-Oruanui pumice and mafics ..... 148

Figure 5.4. Trace elements for bulk pumices and lavas compared to glass ......... 149

Figure 5.5. Melt inclusion and glass major elements for units $\Psi, \Omega$, A and SG1.. 151

Figure 5.6. Melt inclusion and glass major elements for SG2 and SG3 .............. 151

Figure 5.7. BSE images and compositions of mineral types in the post-Oruanui.. 153

Figure 5.8. CPX major element variation diagrams ....................................... 154

Figure 5.9. OPX and plagioclase major element variation diagrams .................. 155

Figure 5.10. Major element variation diagrams for zones within OPX and Plag .. 156

Figure $5.11 \mathrm{Fe}-\mathrm{Ti}$ oxide compositions and intensive parameters ........................ 157

Figure 5.12. Intensive parameters and trace elements for amphiboles ................. 160

Figure 5.13. Mineral-mineral-melt magmatic temperature estimates .................... 161

Figure 5.14. Representative plagioclase BSE image and composition profile ...... 168

Figure 5.15. Inferred chemical evolution pathways for post-Oruanui magmas ... 172

Figure 5.16. Magmatic conditions in the post-Oruanui magmas and experiments. 175

Figure 5.17. Inferred structural changes from the Oruanui to post-Oruanui ......... 181

Figure 5.18. Inferred structural changes from SG2 to SG3 ............................... 184

Figure 6.1. Map of Lake Taupo's structural and volcanic caldera features .......... 197

Figure 6.2. OPX element maps from Unit Y .................................................... 202

Figure 6.3. Major and trace element whole rock variations .............................. 203

Figure 6.4. BSE images and compositions from SG2, SG3 and Unit Z .............. 206

Figure 6.5. OPX and plagioclase compositional histograms SG3 and Unit Y ..... 207

Figure 6.6. OPX model timescale estimates from Fe-Mg inter-diffusion ............. 209

Figure 6.7. Post-Oruanui Sr-isotope compositions through time ....................... 211

Figure 6.8. Three-way coupling between tectonics, mafic and silicic magmatism. 220

Figure 7.1. Inferred structural changes in Taupo's magmatic system with time ... 229

Figure 7.2. Eruptive volume vs. temperature, mafic input and tectonic stress ...... 236

Figure F.1. SG1 mixture model ................................................................... 312

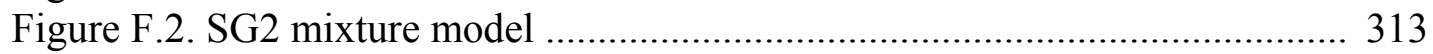

Figure F.3. Combined mixture model .......................................................... 314

\section{List of Tables}

Table 2.1. Post-Oruanui eruptive stratigraphy of Taupo volcano 
Table 3.1. Precision and accuracy for the XFR internal standard WS-E ............ 69

Table 3.2. Precision and accuracy for the XFR internal standard OU-3 .............. 70

Table 3.3. Repeat samples analysed by XRF ..................................................... 71

Table 3.4. Precision and accuracy for ICP-MS trace element standard BCR-2 ... 75

Table 3.5. Precision and accuracy for ICP-MS trace element standard TPI ........ 76

Table 3.6. Repeat samples analysed by ICP-MS............................................ 77

Table 3.7. Precision and accuracy of EPMA clinopyroxene................................. 79

Table 3.8. Precision and accuracy of EPMA orthopyroxene.................................79

Table 3.9. Precision and accuracy of EPMA plagioclase ................................... 79

Table 3.10. Precision and accuracy of EPMA olivine ........................................ 79

Table 3.11. Precision and accuracy of EPMA amphibole ................................ 79

Table 3.12. Precision and accuracy of EPMA Fe-Ti oxide................................. 80

Table 3.13. Precision and accuracy of EPMA glass ......................................... 80

Table 3.14. Precision and accuracy for LA-ICP-MS standard BCR-2G ............. 83

Table 3.15. Precision of SHRIMP trace element standard MAD ........................ 88

Table 5.1. Post-Oruanui eruptive stratigraphy from Taupo volcano .................... 135

Table 5.2. Mineralogy of post-Oruanui eruptive units ...................................... 141

Table 5.3. Mineral-mineral and mineral-melt modelled temperature estimates .... 159

Table 6.1. Major and trace element compositions from SG2, SG3 and Unit Y ... 205

Table 6.2. OPX textural populations within SG3 units ................................... 208

Table 6.3. Melt accumulation rates fro SG3 magmas and the Oruanui eruption... 216

Table A.1. Post-Oruanui eruptions and materials sampled for zircon analysis .... 274

Table C.1. SG1 zircon SHRIMP U/Th data ................................................ 280

Table C.2. SG2 zircon SHRIMP U/Th data ................................................... 287

Table D.1. Zircon SHRIMP U/Pb data ........................................................... 292

Table E.1. SG1 zircon trace element data ..................................................... 296

Table E.2. SG2 zircon trace element data ...................................................... 300

Table E.3. Oruanui zircon trace element data .................................................... 303

Table G.1. XRF whole-rock major and minor element data .......................... 316

Table H.1. Solution ICP-MS trace element data ........................................... 320

Table I.1. Dacite glass selvedge and melt inclusion EPMA data ..................... 330

Table I.2. SG1 glass selvedge and melt inclusion EPMA data ......................... 345

Table I.3. SG2 glass selvedge and melt inclusion EPMA data ......................... 357

Table I.4. SG3 glass selvedge and melt inclusion EPMA data ......................... 369

Table J1. Clinopyroxene EPMA major element data ..................................... 374

Table J2. Orthopyroxene EPMA major element data ........................................ 404

Table J3. Plagioclase EPMA major element data .............................................. 478

Table J4. Ilmenite EPMA major element data .................................................. 559

Table J5. Magnetite EPMA major element data ................................................. 573

Table J6. Amphibole EPMA major element data ............................................ 587 
Table K.1. LA-ICPMS mineral trace element data . 612

Table L.1. FTIR volatile data 624 


\section{Publications arising from this thesis}

\section{Journal articles}

Barker, S. J., Wilson, C. J. N., Smith, E. G. C., Charlier, B. L. A., Wooden, J. L., Hiess, J. \& Ireland, T. R. (2014a). Post-supereruption magmatic reconstruction of Taupo volcano (New Zealand), as reflected in zircon ages and trace elements. Journal of Petrology 55, 1511-1533.

\section{Conference abstracts}

Barker, S. J., Wilson, C. J. N. \& Schipper, I. C. (2014). Fine-Scale Temporal Reconstruction and Evolution of the Post-Supereruption Magma System at Taupo Volcano, New Zealand. Poster presented at the 2014 Goldschmidt conference, Sacramento, U.S.A.

Barker, S. J., Wilson, C. J. N., Smith, E. G. C., Wooden, J. L. \& Charlier, B. L. A. (2013). PostSupereruption magmatic recovery at Taupo volcano. Poster presented at the 2013 IAVCEI meeting, Kagoshima, Japan.

Barker, S. J., Wilson, C. J. N., Wooden, J. L. Allan, A. S. R. \& Charlier, B. L. A. (2013). PostSupereruption magmatic recovery at Taupo volcano. Poster presented at the 2013 GeoPRISMS meeting, Wellington, New Zealand.

Barker, S. J., Wilson, C. J. N., Baker, J. A., Wooden, J. L. \& Charlier, B. L. A. (2012). PostSupereruption magmatic recovery at Taupo volcano. Poster, presented at the AGU fall meeting, San Francisco, U.S.A. 

CHAPTER 1 


\section{INTRODUCTION}

\subsection{Motivation for research}

The study of large silicic magmatic systems offers many challenges, with global examples often displaying huge variability in eruptive size, frequency and repose intervals. In particular, one central issue is determining how the magmatic system reorganises and evolves through time following the largest caldera-forming eruptions. 'Supereruptions' are defined as those that release $\geq 10^{15} \mathrm{~kg}$ or $450 \mathrm{~km}^{3}$ of magma or $>1000 \mathrm{~km}^{3}$ of pyroclastic material (Mason et al., 2004; Sparks et al., 2005; Miller \& Wark, 2008). Such events are relatively rare in the geological record, but are identified as one of the largest-scale environmental threats to humanity (Self, 2006; Self \& Blake, 2008). The formal description recently given to supereruptions and supervolcanoes (defined as the host volcano to a supereruption) as terms in the literature has led to a rapid succession of studies attempting to understand how, and on what timescales, volcanic systems can accumulate such large volumes of magma and subsequently release them in catastrophic events (for reviews see Elements Magazine, Volume 4(1), 2008). However, less commonly focussed on is how a supervolcano and its host magmatic system reacts and recovers following a supereruption. Does the supereruption act to reset the magmatic system and the volcano's eruptive behaviour, or does it merely represent another, exceptionally large eruption from a long-lived magmatic system? In turn, does a single supereruption in the history of a volcano mean that it is necessarily capable of such behaviour in the future, and if so, how long would it take for the appropriate magmatic system to re-establish? A world-class example from which to investigate such questions is Taupo volcano in the Taupo Volcanic Zone, North Island, New Zealand (Wilson et al., 1995). The modern outline of Lake Taupo was largely formed in the catastrophic Oruanui supereruption at $\sim 25.4 \mathrm{ka}$, which released $\geq 530 \mathrm{~km}^{3}$ of magma (Wilson et al., 2006; Allan et al., 2012; Vandergoes et al., 2013). However, $<5 \mathrm{kyr}$ after this event, Taupo returned to erupting on a smaller scale, although more frequently than prior to the Oruanui event (Wilson, 1993; Sutton et al., 2000). In total, there have been 28 eruptions following the Oruanui supereruption, 25 of which occurred in the last $12 \mathrm{kyr}$ and the largest of which occurred only 1800 years ago in $232 \pm 5 \mathrm{AD}$ (Wilson, 1993; Hogg et al., 2012; Table 1). A renewal of activity at Taupo (or the threat 
of an eruption) would have overwhelming social and economic consequences for New Zealand, regardless of the actual size of the eruption, because of perceptions arising from the destructive nature of the $232 \mathrm{AD}$ eruption. The high frequency of eruptions from Taupo provides an ideal opportunity to investigate the ways in which large silicic magmatic systems operate, and what conditions might lead to 'normal' or 'super-sized' behaviour. Such investigations are vital for understanding the dynamics of supervolcanoes and building a framework for future hazard assessment.

\subsection{Thesis objectives and outline}

The processes which occur within magmatic systems can be tracked by the temporal evolution of their petrology and the chemical and isotopic compositions of the erupted magma (i.e., pyroclasts or lava) and its crystal cargo(es). The young age, excellent exposure and preservation of post-Oruanui eruption deposits at Taupo volcano provide a high-resolution temporal record of activity on a scale, typically from decades to centuries (Wilson, 1993; Sutton et al., 2000), that is unequalled for any silicic volcano worldwide. The chronostratigraphy and physical volcanology of these deposits have been previously investigated in detail by Wilson (1993), providing an excellent context utilised in this thesis for sampling and relating individual events of widely varying sizes, eruption styles and vent locations. The research presented here also builds on and benefits greatly from the contextual information provided by the studies of Sutton (1995) and Sutton et al. (1995, 2000), that established the bulk geochemical characteristics of the post-Oruanui eruption products. Sutton et al. $(1995,2000)$ reported that three eruption units produced immediately following the Oruanui from 20.5-17 ka were dacitic in composition, and the limited field data collected by Wilson (1993) showed that they were vented in the northern segment of Lake Taupo. The remaining 25 eruptions are clustered into three chemically distinct rhyolitic subgroups, erupted from multiple vent sites around the caldera in discrete periods from 11.8 to 9.95, 7.05 to 2.75 and 2.15 to $1.8 \mathrm{ka}$. However, limited knowledge exists about how these eruptions are linked to each other in terms of magma genesis and magmatic system evolution, or how they are linked to the earlier large-scale Oruanui magmatic system. Exactly how and why the magmatic system has changed over time remains unclear and open to investigation (Sutton et al., 1995). In this project I will combine well constrained field studies with cutting-edge analytical techniques to interpret the origin and evolution of chemical and isotopic characteristics of pumices, minerals and 
glasses in the sequence of post-Oruanui eruptions. I will provide a detailed chemical perspective on the structure and reestablishment of Taupo's magmatic system since the 25.4 ka supereruption. Some of the key questions that will be addressed as being of particular relevance to this research are as follows:

1. How did Taupo's magmatic system react to the evacuation of $\geq 530 \mathrm{~km}^{3}$ of magma?

2. Did the Oruanui eruption act to reset Taupo's silicic magma system, or was it just another large eruption from a long lived magma reservoir that has continued activity on a smaller scale to the present day?

3. Can any of the components (e.g. crystal cargo, melts) from the Oruanui magmatic system be identified in the post-Oruanui sequence?

4. How long did it take the magmatic system to recover, reorganise or rebuild following the supereruption?

5. How and why do the post-Oruanui magmas change in composition through time and what processes do these changes reflect?

6. How has the structure of the magmatic system changed through time, and what is its current state?

7. What controls the wide variations in eruptive sizes and styles at Taupo?

8. Over what time scales is Taupo capable of producing another eruption and what might control its size and eruptive behaviour?

These specific questions (and others) are addressed in a series of chapters, structured around a common theme of understanding the post-supereruption recovery and reconstruction of Taupo's magmatic system through combined geochemical and field studies. CHAPTERS 2 and 3 provide a detailed presentation of how samples were collected in the field, prepared and analysed for their chemical properties. CHAPTERS 4 to 6 are written as manuscripts and are either peer-reviewed published works (CHAPTER 4: Journal of Petrology) or in a style suitable for submission as individual journal articles. Although CHAPTERS 4 to 6 serve as self-contained studies, each chapter progressively builds on the information from the preceding ones, to form a single coherent thesis. The only changes in the thesis to the published works are for the sake of styling and consistency (e.g. references to relevant supplementary information). 
This thesis is organised into seven chapters as outlined below:

CHAPTER 1 introduces the motivation and contextual reasoning behind this research. It reviews our current understanding of silicic magmatic processes and how these processes can be investigated and interpreted using petrological and geochemical approaches. I also identify some current knowledge gaps that my research aims to address. This chapter introduces the geological background of Taupo volcano in the Taupo Volcanic Zone (TVZ), and outlines the key volcanological and geochemical features established by previous studies.

CHAPTER 2 covers the field work component of this research. This chapter outlines the eruptive stratigraphy of Taupo volcano for context and shows where specific samples were collected in the field for analysis. It gives a step-by-step account of each of the 28 eruption deposits from Taupo and the properties of the material collected in this study.

CHAPTER 3 gives a detailed account of the methods used to prepare and analyse samples for their various components and geochemical properties. This chapter also provides a guide to the analytical techniques used, and their limitations and uncertainties in the context of this research.

CHAPTER 4 presents a peer-reviewed manuscript article published in Journal of Petrology, centred around U/Th disequilibrium age-dating and trace element analysis of zircons extracted from the post-Oruanui eruptions (Barker et al., 2014a). Comparisons and contrasts are made between the zircon U/Th model-age spectra and trace element compositions of the zircons and the Oruanui and post-Oruanui magmas. These comparisons are used to interpret the reconstruction of Taupo's magmatic system following the Oruanui supereruption. In addition, $\mathrm{U} / \mathrm{Pb}$ ages of inherited xenocrystic zircons are explored to interpret variation in the sources of assimilated country rock between eruptions where the inherited zircon component is significant.

CHAPTER 5 is a manuscript currently under review in Contributions to Mineralogy and Petrology that presents a detailed investigation of whole-rock, glass and mineral chemistry between the 28 post-Oruanui eruptions (Barker et al., 2014b). This chapter investigates fine-scale temporal changes in magma chemistry to interpret how Taupo's magmatic system reacted to and was rebuilt in the aftermath of the Oruanui 
supereruption. It considers the origins of the early erupted dacite magmas as well as the processes driving minor changes in melt chemistry through time for the three rhyolite subgroups, with important implications for the most recent eruptions and current magmatic state of Taupo volcano.

CHAPTER 6 is a manuscript in preparation for submission. It presents a study on the most recent (Subgroup 3) eruptions from Taupo with the aim of investigating the processes and timescales that led to one of the largest Holocene eruptions on Earth, the Taupo eruption (Unit Y) at 232 AD. It builds upon the results of previous chapters with combined geochemistry and element diffusion modelling to show how Taupo's magmatic system operates and changes on exceptionally rapid timescales, approaching those of human interest.

Chapter 7 summarises the key findings of this research, re-visiting some of the main research questions raised in CHAPTER 1. This chapter also discusses the remaining gaps in knowledge and identifies opportunities for future research.

\subsection{Understanding silicic magmatic processes}

\subsubsection{The crystal mush model}

Evolved silicic magmas of dacite to rhyolite composition $\left(>63 \% \mathrm{SiO}_{2}\right)$ have traditionally been viewed in igneous petrology as forming predominantly (although not always) through fractional crystallisation processes from magmas of less evolved compositions (e.g. Hildreth, 1981; Michael, 1983; Cameron, 1984; Bacon \& Druitt, 1988; Brophy, 1991; Bachmann \& Bergantz, 2004). Such processes are often accompanied by assimilation of crustal material through partial melting or physical mixing, which can significantly alter the chemical characteristics of the magma (e.g. elevated ${ }^{87} \mathrm{Sr} /{ }^{86} \mathrm{Sr}$ ratios: Hildreth \& Moorbath, 1988). Open-system fractional crystallisation was originally viewed as requiring the removal of progressively more evolved crystalline phases through gravitational settling in the melt (e.g. Bowen, 1928; Martin \& Nokes, 1988). However, one of the difficulties in explaining how large silicic magma bodies could form through crystal settling is the fact that melt-crystal separation efficiency will decline with increasing melt viscosity, dramatically increasing the amount of time required, and the size of a magma reservoir required to form an evolved silicic melt (Shaw, 1965; Hawkesworth et al., 2000; Eichelberger et al., 2006). The 
conceptual crystal mush model took the traditional model of fractional crystallisation and turned it on its head (see Hildreth, 2004; Bachmann \& Bergantz, 2004 for overviews). Rather than removing the crystals from the melt, the crystal mush model focused on separating the melt from the crystals (Figure 1.1).

The crystal mush model is largely based on links between plutons and volcanic systems (Bachmann \& Bergantz, 2004; Hildreth, 2004; Marsh, 2004; Bachmann et al., 2007; Lees, 2007). The central idea behind mush formation is that as the degree of crystallinity increases in a magma, either by advancement of the solidification front with time as the magma cools (e.g. Marsh, 1988, 1996) or through decompression induced crystallisation (e.g. Sisson \& Grove, 1993; Moore \& Carmichael, 1998; Annen et al., 2006; Brophy, 2009), the physical behaviour of the magma body undergoes significant changes (Figure 1.1). Once the crystallinity of the magma reaches a critical threshold (>45-60 vol. \%: Marsh, 1988; Vigneresse et al., 1996), the viscosity increases dramatically and the magma becomes an interlocking network of crystals containing interstitial residual melt (Figure 1.1b). A crystal mush zone consists of rigid or semirigid magma composed of a framework of touching crystals and interstitial melt, which can be best described as rigid sponge (Hildreth, 2004). The formation of crystal mush zones in the upper crust has been proposed as the driving mechanism behind large longlived silicic systems in which batholith-scale bodies of crystal-rich intermediate magmas can generate voluminous evolved melt-dominant magma bodies (e.g. Hildreth,

\section{Schematic representation of the crystal mush model}

(a)

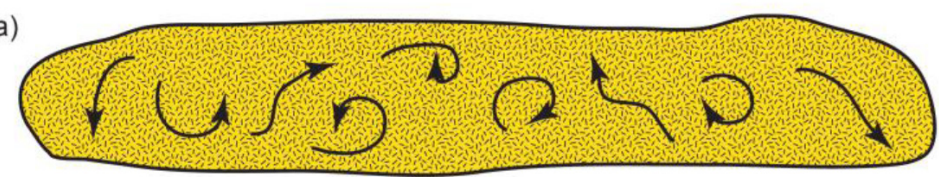

$<45 \%$ crystals. Convection leads to dynamic stirring of crystals and melt.

(b)

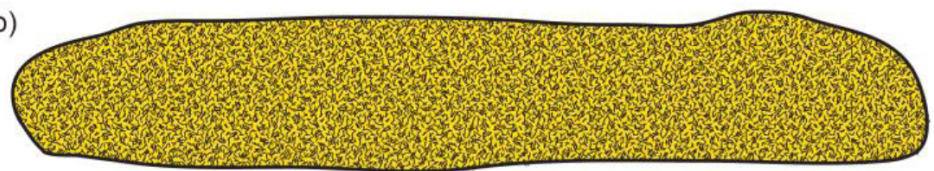

$<\mathbf{4 5}$ to $\mathbf{5 0 \%}$ crystals. Rheological lock-up. Convection stops. Crystal framework is still permeable. Melt extraction begins via compaction and crystal micro-settling.

(c)

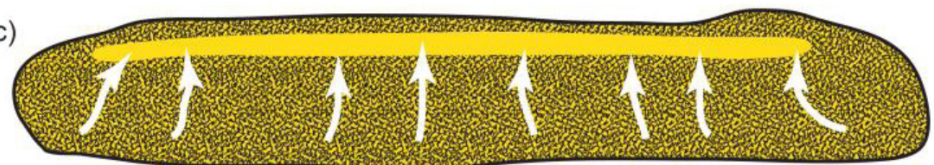

Melt accumulation. Expulsion of liquid generates a melt-rich rhyolitic lens above a crystalline residue and below a solidification front.
Figure 1.1. Schematic illustration of the crystal mush model (modified from Allan, 2013 after Bachman \& Bergantz, 2004). Formation of silicic melt from the mush is envisaged as a three step process where (a) the less evolved melt cools to the point where it reaches rheological lock up at (b), from which an evolved liquid can be extracted to form a crystal-poor rhyolite magma in (c). See text for discussion. 
2004; Wilson et al., 2006; Hildreth \& Wilson, 2007). Several mechanisms have been proposed for separation of liquid from the crystal network (Figure 1.1c), including forceful expulsion of the interstitial melt through either compaction or deformation (e.g. Vigneresse et al., 1996; Bachman \& Bergantz, 2004), by solidification front instabilities (Marsh, 1996), gas-driven filter pressing (Sisson \& Bacon, 1999) or gas sparging (Bachman \& Bergantz, 2006).

\subsubsection{Large silicic magma systems}

The revolutionary concept of the crystal mush model as the driving force behind largescale silicic magmatism caused an adaptation of the commonly used terms 'magma chamber' and 'magmatic system' in the literature. Modern concepts of silicic magmatic systems must therefore incorporate not only the molten and readily eruptible material, but also the zones within, around and beneath the eruptible melt body (termed the magma reservoir: Hildreth \& Wilson, 2007; Bachmann \& Bergantz, 2008) (Figure 1.2). In this thesis, the definition sketch model of Hildreth \& Wilson (2007) is used to describe the various components of the silicic magmatic system. The granitoid zone represents a crystallised rind which separates the magma chamber (the areas where melt is present), but remains physically and chemically linked to the melt-bearing zones as it is subject to re-melting and resorption. The zone of concentrated liquid (the melt dominant zone) is melt that can be partly to fully tapped during eruption. The eruptible magma in general may only form a small portion of the much larger system and in fact be a transient feature (Bachman \& Bergantz, 2004; Allan et al., 2013). The mush region supplies melt and any entrained crystals to the melt dominant zone and contains enough melt to allow mixing of material throughout the magma chamber or from recharge events, and may be partially tapped during the largest eruptions. All the boundaries between zones are envisaged to fluctuate in time and space with changing thermal and fluid flux, and are largely controlled by rheological differences which reflect changes in melt/crystal ratios. The region below the mush zone (which may be termed the reservoir) further includes the chamber's feeder zone and the heterogeneous crustal column (consisting of dikes, melt rich pods, and permeable mush zones: Marsh, 2004) from which recharge batches intermittently add to the overlying chamber. The overall magmatic system would still further include partially molten supply domains in underlying crust and mantle. The simplified magmatic system outlined by Hildreth \& Wilson (2007) provides a framework to interpret silicic magma processes, but is considered to vary greatly on a volcano-specific basis with a huge number of important 


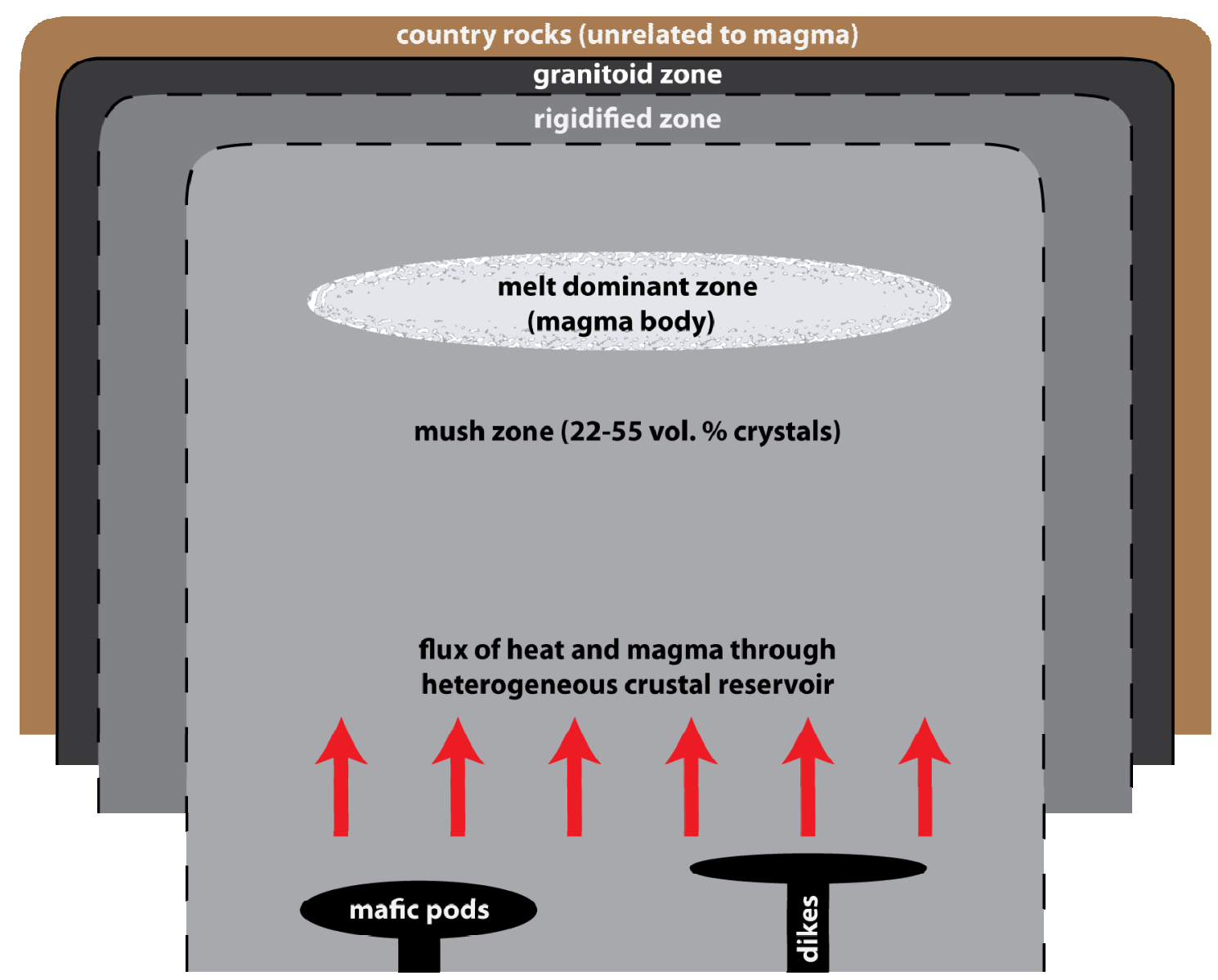

Figure 1.2. Schematic illustration of a large silicic magmatic system modified from Hildreth \& Wilson (2007). See text for further description.

variables including mafic magma flux, depth of crystallisation, tectonic stress regime, geothermal heat flow, and the chemical and physical properties of the magma(s).

\subsubsection{Supereruptions and supervolcanoes}

The terms 'supereruption' and 'supervolcano' have been recently introduced in the literature to describe the largest explosive volcanic eruptions and their source volcanoes (e.g. Rampino \& Self, 1992; Mason et al., 2004). A supereruption is defined as an explosive eruption with a total erupted volume of $10^{15} \mathrm{~kg}$ of magma, that is equivalent to $>450 \mathrm{~km}^{3}$, or $\sim 1000 \mathrm{~km}^{3}$ of pyroclastic material and are almost always silicic in magma composition (Mason et al., 2004; Sparks et al., 2005; Self, 2006; Miller \& Wark, 2008). Such vast eruptive volumes are difficult to comprehend and are 2-3 orders of magnitude larger than the most voluminous historic eruptions (e.g. $1980 \mathrm{Mt}$ St. Helens: $1 \mathrm{~km}^{3}$, 1883 Krakatau: $20 \mathrm{~km}^{3}$ of pyroclastic material). To put supereruption volumes into perspective, $1000 \mathrm{~km}^{3}$ of pyroclastic material would cover the entire North Island of New Zealand with $\sim 8.5 \mathrm{~m}$ of pumice and ash. Supereruptions only occur globally at intervals of $\sim 250,000$ years during the Quaternary (Mason et al., 2004), but 
their source volcanoes (labelled as 'supervolcanoes' from their largest eruptions) almost inevitably produce numerous other eruptions of varying sizes at much shorter time intervals (Wilson, 2008).

A key issue with supervolcanoes is determining how the processes and timescales involved in the generation and accumulation of 'super-sized' magma bodies compare with those that result in relatively small eruptions. Do exceptionally large eruptible bodies of magma take correspondingly longer to be generated (e.g. Smith, 1979; Shaw, 1985; Trial \& Spera, 1992; Reid, 2008), or are the processes and timescales involved broadly similar to those of small eruptions but at a super-sized extreme (e.g. Wilson \& Charlier, 2009)? How are vast volumes of melt-rich magma able to accumulate and be held in the shallow crust without prematurely erupting and what factors determine the precise moment of eruption (Allan et al., 2012; Caricchi et al., 2014; Malfait et al., 2014)? In turn, many questions arise about what happens to the host magmatic system in the aftermath of a supereruption. The evacuation of huge amounts of magma will undoubtedly have significant effects on the wider sub-volcanic reservoir, as well as the overall structure of the regional crust. However, the changes which occur to the structure of the magmatic system as a whole (Figure 1.2) and the chemical composition of the melts it produces remains largely unexplored. Global examples of supervolcanoes suggest that post-supereruption magmatic behaviour varies from rapid (thousands to tens of thousands of years) resurgence of less evolved magmatic dregs (e.g. Valles: Stix et al., 1988; Phillips et al., 2007; Toba: Chesner, 2012; La Pacana: Lindsay et al., 2001; Long Valley: McConnell et al., 1995; Hildreth, 2004) or rapid construction of a post-caldera composite cone (e.g. Aira: Aramaki, 1984), through to longer-term (hundreds of thousands of years) systematic tapping of magma incorporating recycled hydrothermally altered crystal mush or caldera infill (e.g. Yellowstone caldera: Bindeman et al., 2001; Girard \& Stix, 2009; Vazquez et al., 2009). But to what extent do these examples represent contrasts in different modes of operation or the expression, timing and preservation of volcanism? In older examples, the uncertainties of the method employed to date eruptions is often larger than the interval between potential eruptive episodes (e.g. $10^{4}-10^{5}$ years using ${ }^{40} \mathrm{Ar} /{ }^{39} \mathrm{Ar}$ and U$\mathrm{Pb}$ systematics, e.g. Simon et al., 2008). Short-term magmatic expression through closely spaced eruptions and preservation are critical factors for interpreting the immediate post-eruptive magmatic evolution of a supervolcanic system. 


\subsection{Investigating silicic magmatic processes}

The processes which occur in the development and evolution of large silicic magma systems cannot generally be observed directly. Geophysical techniques (e.g. seismic studies, ground deformation, electrical resistivity) and gas monitoring provide important clues as to the current surface expression and/or the presence of melt or fluids at depth at a given time (e.g. Lowenstern \& Hurwitz, 2008: Farrell et al., 2014). However, there are currently no soundly based criteria for taking a given set of geophysical observations of unrest at a caldera volcano and using them to reliably forecast or predict the likelihood, size or timing of a future event (e.g. Ellis et al., 2007 for the Taupo case). Instead, the processes which occur within a magmatic system in the lead up to eruption are often inferred from the geological record, through the study of past eruptions and their products (e.g. Wilson \& Walker, 1985). The physical and chemical properties of the erupted magma (i.e. pumice or lava) and its crystal cargo can be used to interpret the variable components of a magmatic system and the conditions of storage prior to past eruptions (see Blundy \& Cashman, 2008 and references therein). Driving recent studies of large silicic magmatic systems are advances in micro-analytical techniques, where fine details can be interpreted from subtle, yet important changes in chemistry and linked to petrographic observations of zoning and interfaces within crystals. By pinpointing the range of processes and conditions which change in the magmatic system in the lead up to eruption, important insights can be gained to help develop a framework for hazard assessment and future monitoring.

In general, there are three geochemical approaches that can be used (often in concert) to investigate igneous processes:

1. Whole-rock chemistry. Whole-rock or 'bulk' compositions are considered to represent the magma at the time of eruption and can include a variable mixture of volcanic glass, minerals and inclusions (xenoliths). The final product used for chemical analysis is typically a representative powdered fraction of the whole sample to achieve a volume of material with small scale homogeneity for analysis. This approach yields a good overall measure of magma chemistry but fine details or heterogeneities may be overprinted by the fact that the analysis is a mixture of multiple components that could be from a diverse range of sources.

2. Crystal specific studies. This approach focuses on the crystalline mineral phases present in the eruption products that either grew in the erupted magma (phenocrysts), were introduced from a precursory or chemically related magma 
(antecrysts), or were from a foreign source such as country rock or chemically unrelated magmas (xenocrysts) (Bacon \& Lowenstern, 2005; Charlier et al., 2005; Hildreth \& Wilson 2007). Minerals can record in their chemical zonation processes that occur prior to eruption, and typically occur individually or within clusters of multiple crystals in the host glass. By studying the nature and zonation of crystals present in a rock it is possible to reconstruct the crystal history and magmatic processes occurring in a magmatic system. Recent developments in analytical studies have resulted in high resolution imaging and fine-scale chemical analysis of individual crystal zones. By modelling diffusive modification across mineral boundaries it is possible to constrain the timescales of magmatic events (Morgan \& Blake, 2006; Chakraborty, 2008; Costa, 2008; Saunders et al., 2012; Allan et al., 2013). In addition, experimental studies of mineral-mineral and mineral-melt equilibria allow the intensive conditions of melt storage (e.g. temperature, pressure and oxygen activity) to be estimated (see Blundy \& Cashman, 2008; Putirka, 2008 for reviews). Different minerals record processes at different rates which largely reflect contrasts in crystal structure and elemental diffusion rates. Some minerals, such as zircon, contain radiogenic isotopes which can be measured to estimate their age of formation and interpret timescales relevant to magmatic system accumulation and evolution, as well as any interaction with surrounding country rock (see Ireland \& Williams, 2003 for review). Minerals or zones within single crystals can be measured for their unique Sr-isotopic composition to interpret the timing of melt interaction with recharging melts or radiogenic wall rock (Knesel et al., 1999; Charlier et al., 2008).

3. Glass chemistry. Bulk glass represents the melt phase minus any contamination from crystalline phases that either grew in the magma (and hence took specific elements from the melt), or were introduced from a separate source (and hence brought in specific elements). Groundmass glass chemistry therefore reflects the final evolutionary point of the magma at the time of eruption. Heterogeneities amongst glass in both single pumices and tephras using in situ techniques can help identify multiple magma sources, melt mixing and/or dissolution of host minerals (Cooper et al., 2012). In addition, melt can be trapped as inclusions within minerals at their time of formation (Wallace et al., 1999). Melt pockets preserve vital information about the chemical evolution of the melt and the 
relative content of volatile components (e.g. $\mathrm{H}_{2} \mathrm{O}, \mathrm{CO}_{2}$ ) that are largely lost in the groundmass glass during decompression.

A wealth of information can be gained from the chemical compositions of erupted magmas and their various components. However, the compositional variability within and/or between eruptions from an open magmatic system is often chaotic, and rather than falling along a liquid line of descent, chemical variations between discrete magma batches can be expected (Bohrson \& Spera, 2001; Eichelberger et al., 2006). Trying to identify or match a set of processes from an eruptive sequence can be made complicated by a range of constantly changing variables such as magma recharge rate, mixing between melts, assimilation and the amount/type of crystals incorporated or inherited into the eruptible melt. In this thesis, a multidisciplinary approach of whole-rock, glass and crystal-specific studies has been used to interpret the multiple contributing processes and conditions of magma storage through time at Taupo.

\subsection{Geological background}

\subsubsection{The Taupo Volcanic Zone}

The Taupo Volcanic Zone (TVZ) in the North Island of New Zealand is the southernmost extension of the $\sim 2800 \mathrm{~km}$ long Tonga-Kermadec subduction system, where oceanic convergence meets the continental crust of Zealandia (Cole, 1990; Gamble et al., 1996: Figure 1.3). The TVZ coincides with a structurally and magmatically segmented rift system within a basement of greywacke, resulting from westward subduction of the Pacific Plate beneath the Australian Plate. Comprehensive reviews of the TVZ and its structural, geological, geochemical and petrological features can be found in Cole et al. (1995), Wilson et al. (1995, 2009), Houghton et al. (1995), Leonard et al. (2010), Rowland et al. (2010) and Seebeck et al. (2014). In particular, the TVZ is notable as one of the most frequently active and voluminous rhyolite systems on Earth, characterised by its high geothermal heat flow (4200 MW), frequent volcanism, and closely distributed normal faults (Bibby et al., 1995; Wilson et al., 1995, 2009; Rowland \& Sibson, 2001; Villamor \& Berryman, 2001, 2006: Figure 1.4). The TVZ has been active for the past $\sim 2 \mathrm{Ma}$, with the onset of large-scale silicic volcanism at around 1.85 Ma (Chambefort et al., 2014). The modern TVZ shows regional magmatic segregation, with andesitic strato-volcanoes located towards the SW/NE margins, and a central, overwhelmingly rhyolite-dominated caldera volcano region (Figure 1.4). 
There are two rhyolite volcanoes in the central TVZ considered to be the focus of current activity: Taupo and Okataina (Figure 1.4). However, the overall volcanic history of the central TVZ is complex and diverse with at least eight large caldera systems identified as active over the past $1.6 \mathrm{Ma}$, with over 25 caldera-forming eruptions over

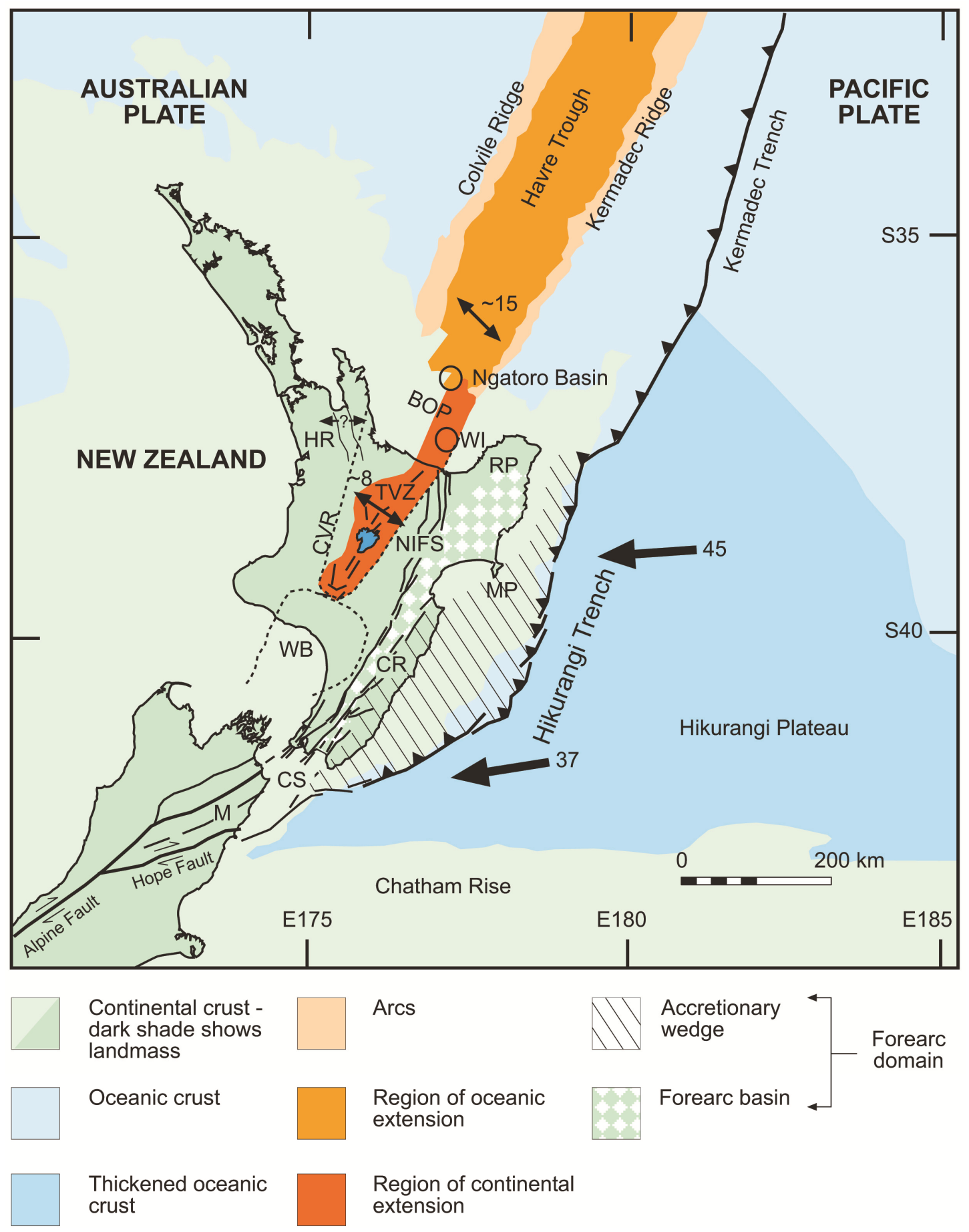

Figure 1.3. Map of the North Island of New Zealand highlighting the key tectonic components (from Wilson et al., 2008, courtesy of J.V Rowland). Forearc domain after Ballance (1993) and Chanier et al. (1999). Double arrows indicate the direction and rate of extension in $\mathrm{mm} / \mathrm{yr}$ across the TVZ (Darby \& Meertens, 1995; Wallace et al., 2004) and Havre Trough (Parson \& Wright, 1996). Single arrows give direction and rate of relative Australian - Pacific plate motion in mm/year (DeMets et al., 1994). BOP = Bay of Plenty; CR = Coastal Ranges; CS = Cook Strait; CVR = Central Volcanic Region (Stern, 1985; Stern \& Davy, 1987); HR = Hauraki Rift; M = Marlborough; MP = Mahia Peninsula; NIFS = North Island Fault System (Beanland, 1995; Mouslopoulou et al., 2007a,b); RP = Raukumara Peninsula; WB = Wanganui Basin (Stern et al., 1993; Naish et al., 2005); WI = White Island. 
this time period (Wilson et al., 2009). The total eruptive volume from this $125 \mathrm{x} 60 \mathrm{~km}$ zone amounts to $>6000 \mathrm{~km}^{3}$, a minimum estimate given the presence of other large eruptions recorded as tephras in deep-sea cores, and evidence for numerous smaller explosive and effusive eruptions (Figure 1.5a). Over the past $61 \mathrm{ka}$ the central TVZ has erupted $780 \mathrm{~km}^{3}$ of magma, of which $\sim 82 \%$ was released in three large caldera-forming

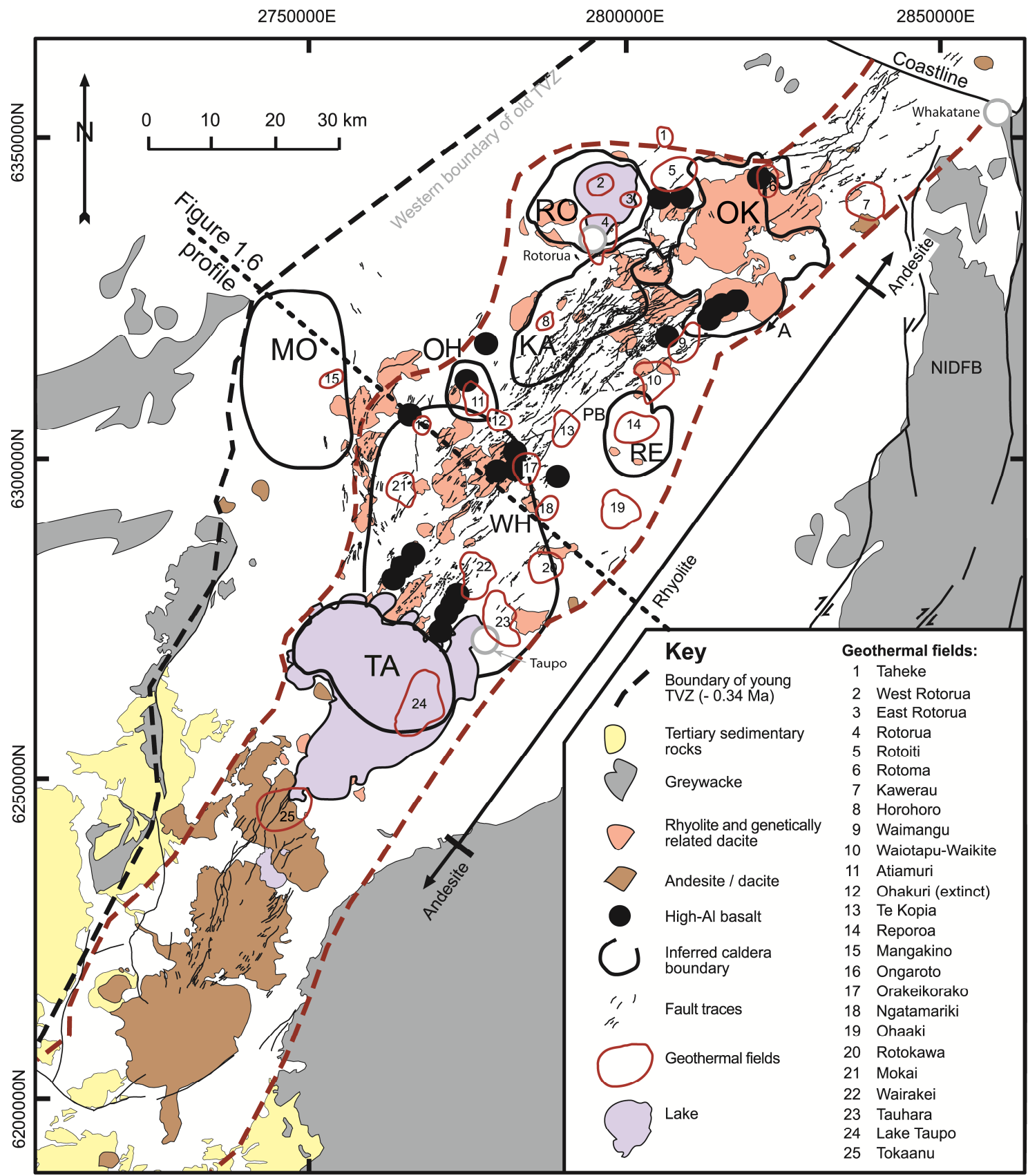

Figure 1.4. Geology of the TVZ region showing major structural, volcanic and geothermal features with major caldera outlines for reference (after Grindley, 1960; Healy et al., 1964; Graham et al., 1995; Houghton et al., 1987; Wilson et al., 2008). Caldera boundaries are after Nairn et al. (1994) and Gravley et al. (2007) and labelled where TA is Taupo, WH is Whakamaru, OH is Ohakuri, MO is Mangakino, RE is Reparoa, KA is Kapenga, RO is Rotorua and OK is Okataina. Boundaries of the TVZ are modified after Wilson et al. (1995) and Villamor \& Berryman (2001, 2006). The black-dashed old TVZ boundary is defined on volcanic and structural grounds by the location of early vents up until $350 \mathrm{ka}$ (Wilson et al., 1995). The red-dashed young TVZ boundary is based on vents active from $350 \mathrm{ka}$ to present. NIFS = North Island Fault System (Beanland, 1995). Low-resistivity zones have been used to delimit geothermal fields (after Bibby et al., 1995). 

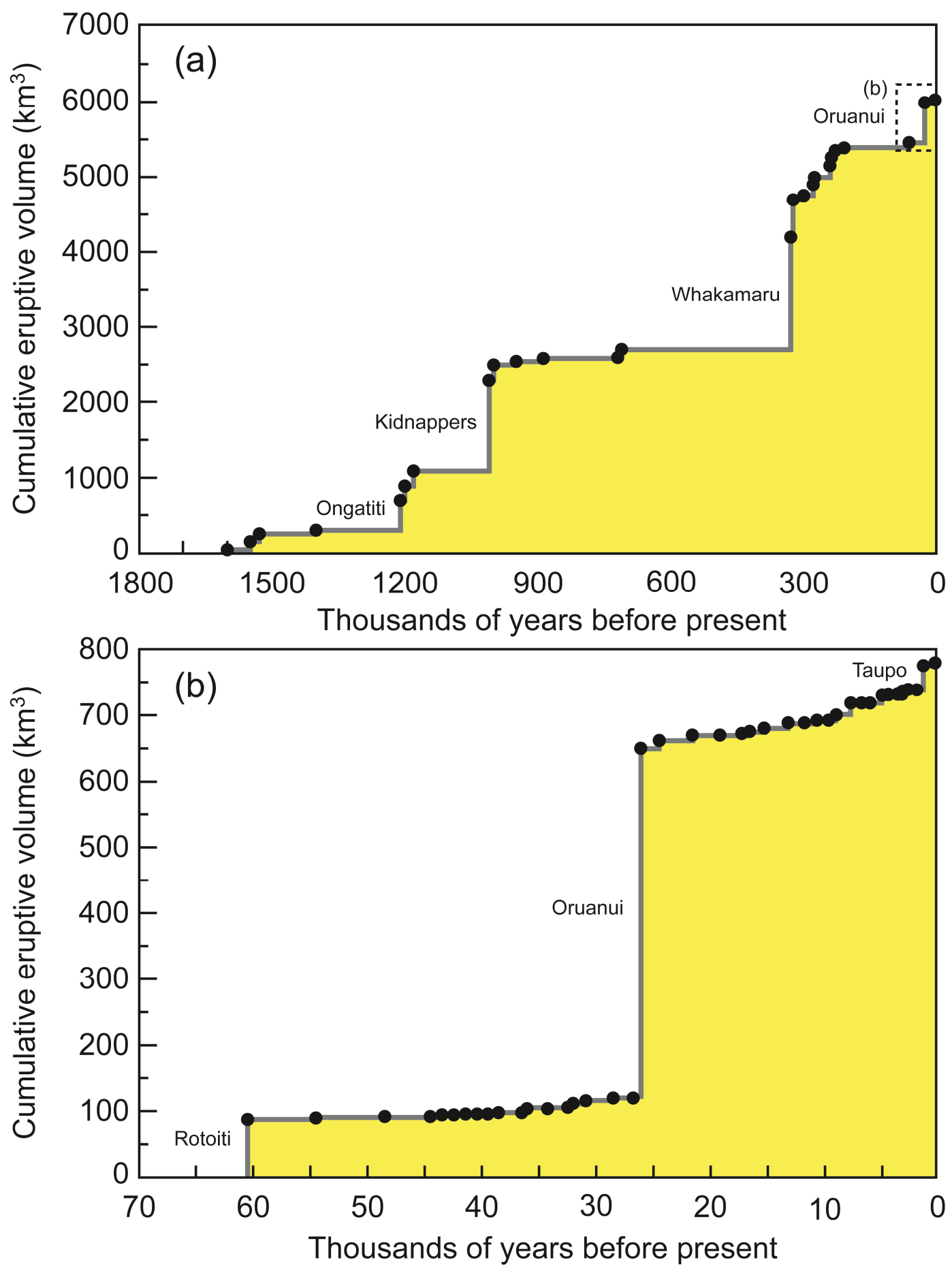

Figure 1.5. Cumulative eruptive volumes versus time for the central TVZ during (a) the past $1.8 \mathrm{Ma}$ of caldera-forming eruptions only with supereruptions labelled and inset dotted box referring to area show in (b) for all eruptions over the past $70 \mathrm{ka}$ with the three caldera forming events labelled. Figure modified from Wilson et al. (2009).

eruptions at 61, 25.4 and $1.8 \mathrm{ka}$ (Figure 1.5b). Average eruption rates are estimated at $\sim 13 \mathrm{~km}^{3} / \mathrm{kyr}$, while the geothermal flux represents another $\sim 50 \mathrm{~km}^{3} / \mathrm{kyr}$ of intrusions into the middle crust during this time period (Bibby et al., 1995; Wilson et al., 2009). The high rate of magma production during this time indicates that the TVZ is currently the most active and productive rhyolite system on Earth. The TVZ is undoubtedly is a consequence of exceptionally high heat flow, however, there is currently no consensus 
as to why that heat flux should be so high, with diverse and controversial explanations ranging from crustal fusion and plastic deformation (Hochstein, 1995), through to mantle upwelling and decompression (Reyners, 2013).

The present-day TVZ is an actively rifting arc, with geodetically measured widening ranging from $<7 \mathrm{~mm} / \mathrm{yr}$ at the southern end to $15 \mathrm{~mm} / \mathrm{yr}$ at the northern coastline (Darby \& Meertens, 1995; Darby et al., 2000; Wallace et al., 2004). Although the structural surface features of the TVZ are reasonably well known, the vertical variations in crustal structure and inter-relationships of the basement pre-volcanic rocks and faults are not well constrained (Figure 1.6). In particular, the continuity of basement greywacke terrains across the TVZ, although punctuated by plutons and feeder intrusions, has been inferred by some studies (e.g. Grindley, 1960), but discounted by others who consider that the sub-volcanic crust has been wholly replaced by intrusives (e.g. Stern, 1985). Geophysical techniques (seismic reflection and refraction, electrical resistivity, magnetotellurics, gravity) have been used to develop structural models of the subsurface of the TVZ across certain areas (Stern, 1979; Rogan, 1982; Stern \& Davey, 1987; Stagpoole, 1994; Bibby et al., 1995; Risk et al., 1999; Harrison \& White, 2004, 2006; Stratford \& Stern, 2004, 2006, 2008). Although useful in determining crustalscale features, these studies are unable to uniquely define the sub-volcanic basement (Figure 1.6; Sherburn et al., 2003; Heise et al., 2007; Harrison \& White, 2006; Stratford $\&$ Stern, 2008). This is particularly the case for the region beneath Taupo volcano, which poses further challenges for geophysical detection of subsurface features through

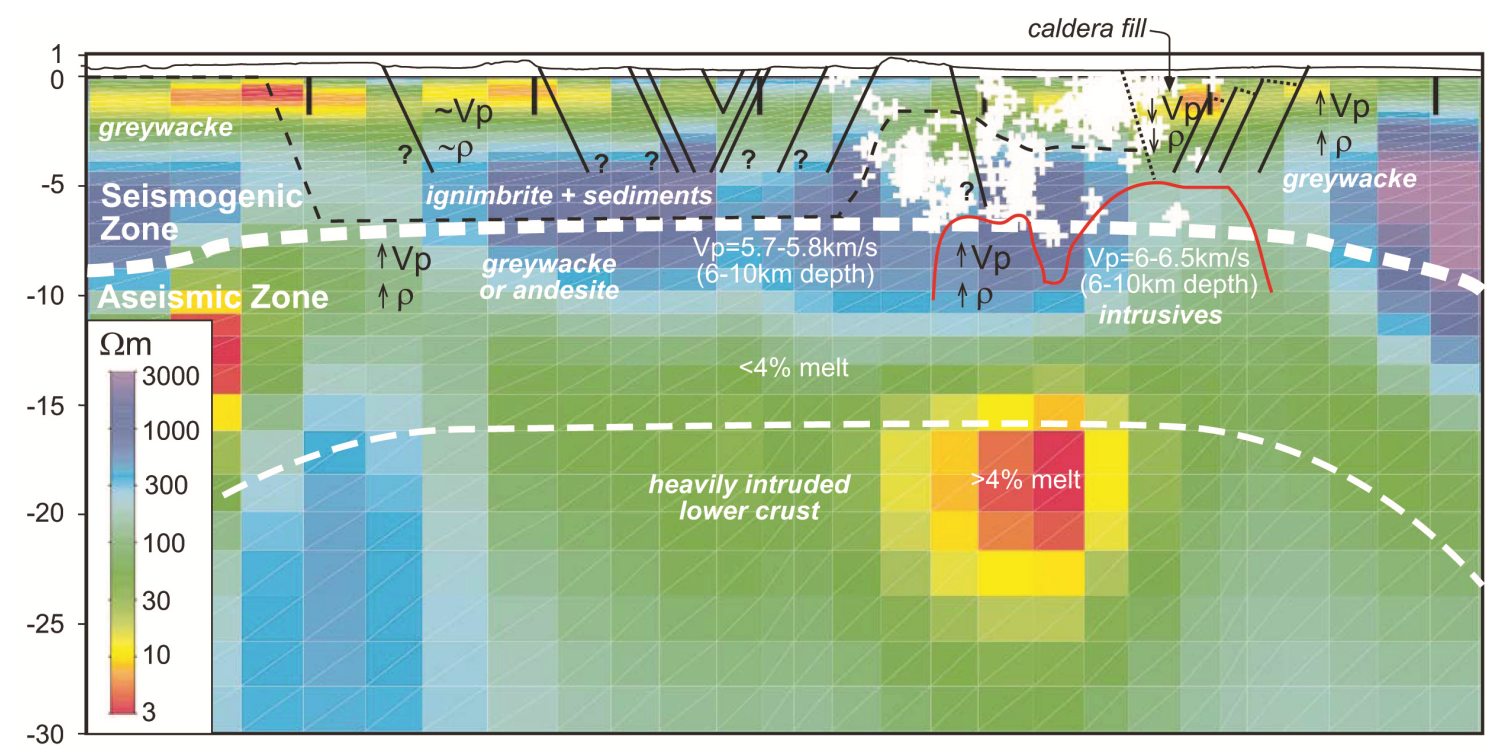

Figure 1.6. Composite profile across the central TVZ incorporating MT-data (Heise et al., 2007); $\mathrm{V}_{\mathrm{p}}$ data (Sherburn et al., 2003); resistivity data (Bibby et al., 1998) and structural data (Rowland \& Sibson, 2001). Location of cross section profile is shown by dotted black line on Figure 1.4. Figure modified from Wilson et al. (2008). Depth scale is in $\mathrm{km}$. 
the presence of New Zealand's largest body of freshwater combined with significant volumes of weak, low-velocity volcaniclastic deposits which degrade the quality of signal for seismological studies (Ellis et al., 2007).

The majority of silicic volcanism over the young $(<61 \mathrm{ka})$ history of the TVZ has been restricted to the Taupo area in the southern part of the central TVZ and Okataina in the northern part (Figures 1.4, 1.5b and 1.7). Eruptive frequencies and volumes from both Taupo and Okataina change significantly over this period, largely centred around the Oruanui eruption from Taupo at $25.4 \mathrm{ka}$ (Wilson \& Charlier, 2009; Charlier \& Wilson, 2010; Vandergoes et al., 2013; Figure 1.7). Striking features of the patterns of volcanism at Taupo and Okataina over the past $61 \mathrm{ka}$ are the huge range of eruptive volumes (over 4 orders of magnitude at Taupo) and the apparent closely

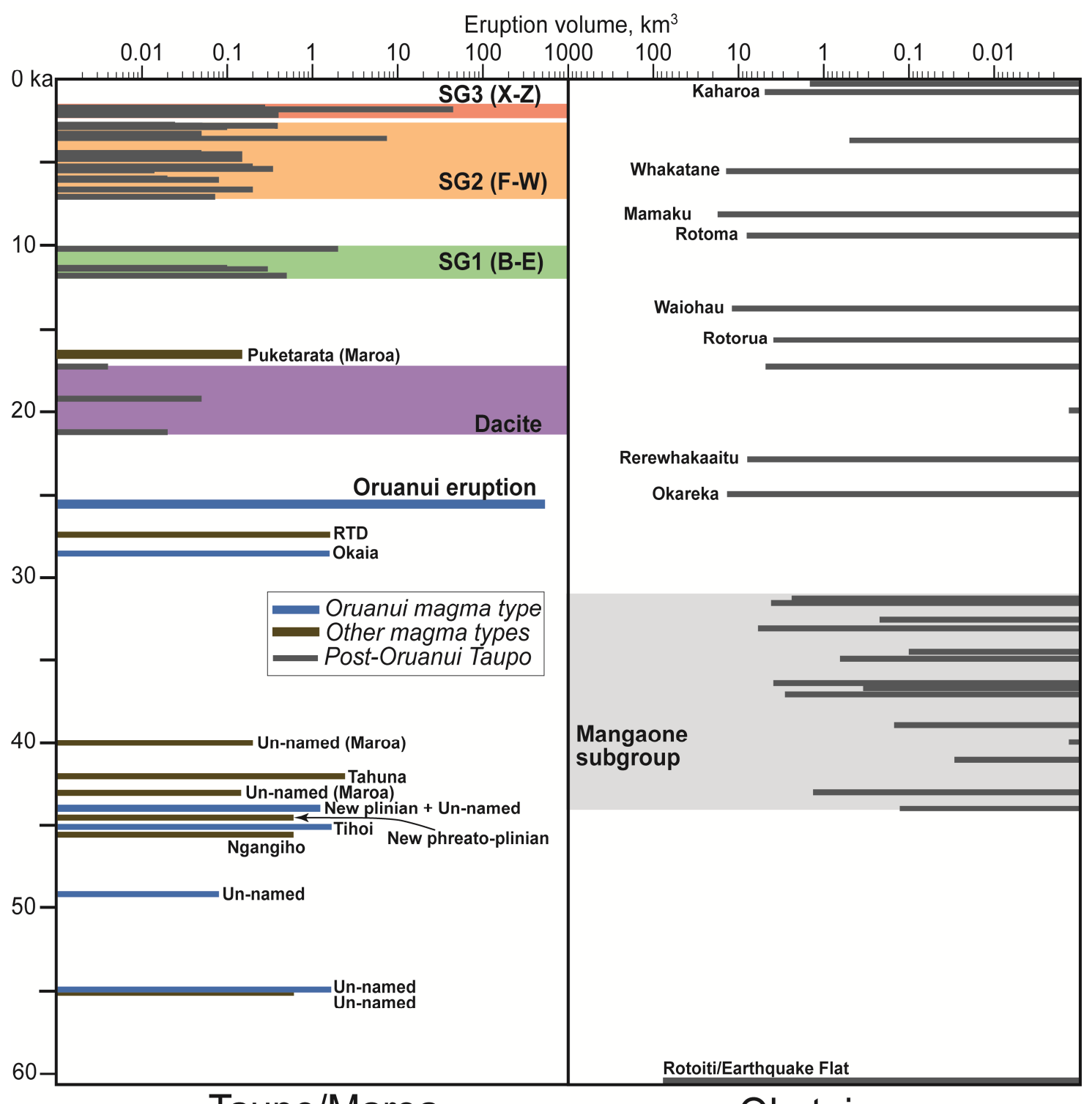

\section{Taupo/Maroa}

\section{Okataina}

Figure 1.7. Eruptive volume (in logarithmic scale) versus time for all eruptive activity from the Taupo/Maroa area and Okataina since the $61 \mathrm{ka}$ Rotoiti eruption. Ages and volumes after Wilson et al. (2009). Figure modified from Charlier \& Wilson (2010) and references therein. 
interdependent relationship between the two calderas. For example, during periods of quiescence at Taupo, Okataina seems to be more active. In addition, after the Oruanui eruption, Okataina largely changed in behaviour from close temporally spaced and small eruptions, to less frequent larger sized $\left(>1-10 \mathrm{~km}^{3}\right)$ eruptions (Figure 1.7). Close linkages between volcanic centres are commonly observed in the history of the TVZ (e.g. Kohn \& Topping, 1978; Nairn et al., 1998; Gravley et al., 2007) and have been attributed to an important three-way interplay in the central TVZ between silicic magmatism, mafic magmatism and tectonism (Wilson et al., 2008, 2009; Rowland et al., 2010; Figure 1.8). As described by Rowland et al. (2010) the interdependency of these three processes can be envisaged as a three-component linkage, with each processes represented by an eccentric temporal cycle (Figure 1.8). The conditions of the tectonic stress state, the potency of the silicic system to erupt, and supply of mafic magmas from depth closely interact, and largely determine the magnitude, style and frequency of volcanism (Wilson et al., 2009; Rowland et al., 2010).
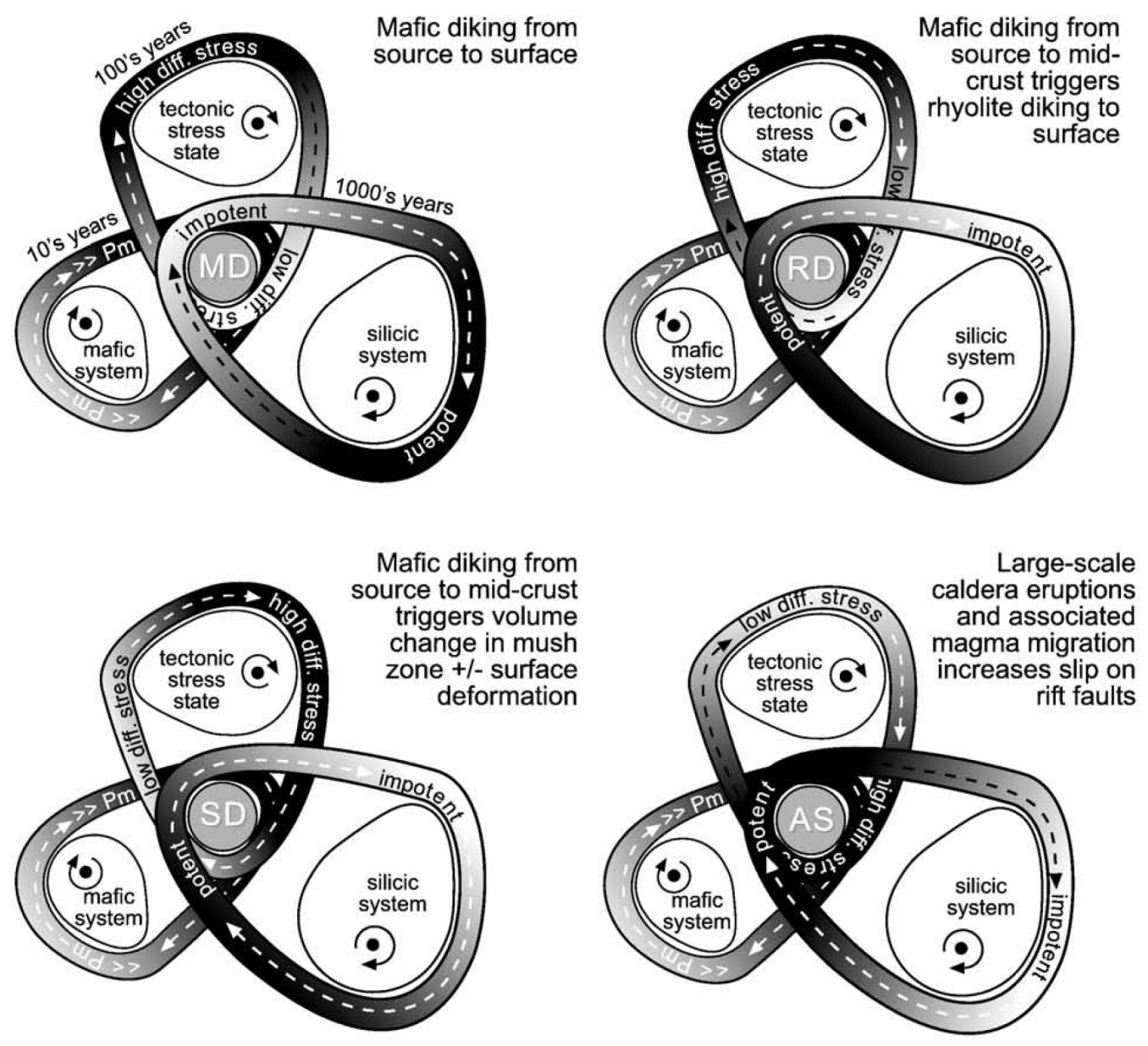

Figure 1.8. Conceptual models for the interplay between the magmatic and tectonic processes in operation in the central TVZ, assuming a single reference parameter defines the condition of each interacting process (from Rowland et al., 2010). $\mathrm{MD}=$ mafic diking, $\mathrm{RD}=$ rhyolite diking, $\mathrm{SD}=$ surface deformation and AS = anomalous fault slip in association with colossal-scale caldera eruptions. Mafic magma is assumed readily available and defined by magma pressure, $\mathrm{Pm}$. 


\subsubsection{Taupo volcano}

The eruptive record from Taupo volcano postdates the $350 \mathrm{ka}$ Whakamaru eruption but is poorly defined prior to $\sim 60 \mathrm{ka}$ due to burial and destruction by young voluminous pyroclastic units (Wilson et al., 1995). Although clusters of the major vent sites between Maroa and Taupo are geographically discrete, scattered rhyolite domes occur in the region between the two systems and the boundary between them is arbitrarily positioned (Wilson et al., 1986). Sutton et al. (1995) defined a boundary between Maroa and Taupo based on minor differences in magma chemistry and the fact that the majority of the Maroa eruptions occurred prior to $150 \mathrm{ka}$ (Leonard, 2003). Early activity from Taupo from 350 to $65 \mathrm{ka}$, is poorly constrained by age data and represented mostly by domes and associated subordinate pyroclastic units from areas southwest, southeast and north of the modern lake (Sutton et al., 1995).

The onset of modern explosive activity from Taupo is defined as commencing shortly after the Rotoiti event from Okataina (Wilson et al. 1995; Figure 1.7). The period between $\sim 65 \mathrm{ka}$ and $25 \mathrm{ka}$ was dominated by small pyroclastic eruptions from vents now concealed beneath Lake Taupo, in close conjunction with a series of small but chemically distinct eruptions from Maroa volcano and the northern segment of Taupo (Wilson et al., 1995; Sutton et al., 1995; Wilson \& Charlier 2009; Figure 1.9). As shown by Sutton et al. (1995), some magmas erupted from vents mainly around Taupo had chemical and mineralogical characteristics similar to the later erupted Oruanui magma. A second subgroup of eruptions referred to as 'NE-dome-type' magmas (Sutton et al., 1995), had higher crystal contents, biotite as an additional crystal phase and contrasting ${ }^{87} \mathrm{Sr} /{ }^{86} \mathrm{Sr}$ ratios to the Oruanui-type magmas (Wilson \& Charlier, 2009). In addition, the Oruanui-type magmas and one additional eruption 'New Plinian' from the northern segment have a similar $\sim 95$ ka model-age peak zircons to the older second peak in the Oruanui magma (Wilson \& Charlier, 2009; Figure 1.9). The Oruanui-type magmas are therefore interpreted as precursory leaks from the mush system that gave rise to the climactic Oruanui supereruption.

The Oruanui supereruption marks a change in eruptive behaviour both at Taupo and at Okataina (Figure 1.7). The eruption released $>530 \mathrm{~km}^{3}\left(>1100 \mathrm{~km}^{3}\right.$ of pyroclastic material) of magma over several months in a prolonged 10-phase episodic eruption (Wilson, 2001; Wilson et al., 2006; Allan et al., 2013). At $25.4 \mathrm{ka}$, the Oruanui eruption is the world's youngest example of a supereruption (Wilson 2001; Wilson et al., 2006; Vandergoes et al., 2013; Allan et al., 2014). The eruption was spasmodic and pyroclastic density current (PDC) deposits were generated throughout the eruption, as 


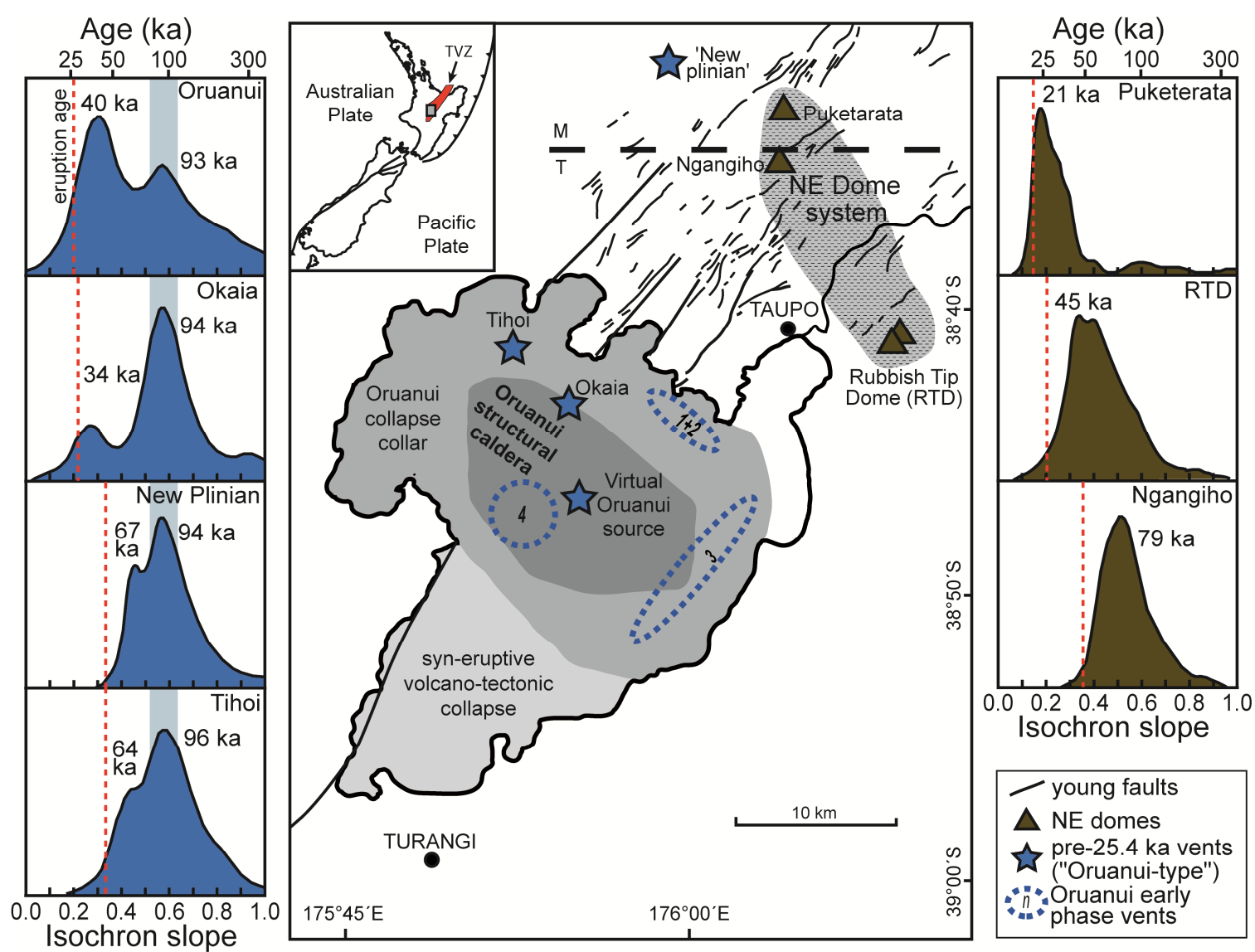

Figure 1.9. Summary of $U / T h$ zircon age spectra from selected eruption deposits of two contemporaneously active silicic magma systems in the Taupo area: the Oruanui-type magma (blue) and NE dome-type magma (brown). The position of the coloured stars marks the approximate vent sites for the eruptions. The Oruanui and its precursor eruptions share a common older peak of zircons with a peak crystallisation age around 95 ka highlighted in light blue. The dashed line separating Taupo (T) and Maroa (M) is from Sutton et al. (1995). Modified from Wilson \& Charlier (2009).

shown by interbedded relationships with the fall units (Wilson, 2001). The energy of these PDCs increased as the eruption progressed, reaching peak distances of $\sim 90 \mathrm{~km}$ from source during phase 8 , then markedly decreased during phase 9. Maximum pumice and lithic clast sizes in the early eruption deposits constrain the approximate positions of the vent openings during phases 1-4 (Wilson, 2001; Figure 1.9). During phases 1 and 2 activity was confined to the northern margin of the modern Lake Taupo. Phase 3 occurred with unzipping of an elongate NNE-SSW trending vent structure down the eastern margin of the modern lake and phase 4 activity focused on a more westerly vent near the centre of the modern lake. Vent positions for the later phases are unable to be constrained, but all occurred within the modern Lake Taupo (Wilson, 2001). The major collapse and establishment of the Oruanui structural caldera to its maximum extent is inferred to have occurred during the climactic phase 10 in the final stages of the eruption. 
The Oruanui eruption is unusual, not only because of its sheer size, but because of the multiple inferred components of its magmatic system. Several geochemical studies on the Oruanui eruption have provided a detailed overview of how the Oruanui magmatic system was rapidly built and then erupted (Sutton et al., 1995; Charlier et al., 2005; Wilson et al., 2006; Wilson \& Charlier, 2009; Allan et al., 2012, 2013; Allan, 2013). The juvenile material erupted in the Oruanui was $>99 \%$ rhyolite, with a minor $(<1 \%)$ component of mafic magma (Sutton et al., 1995; Wilson et al., 2006). The mafic magma is expressed as discrete scoria clasts of two compositional lineages which spikes in abundance in the deposits of phases 3+4, 7 and 9 (Wilson, 2001). Investigation of pumice compositions have shown that there were a complex range of rhyolite melts involved, with a uniform high silica rhyolite (HSR) being dominant, but an additional low-silica rhyolite (LSR) was present, as well as a biotite-bearing (BtB) magma that was introduced syn-eruptively from a 'NE-dome-type' source (Wilson et al., 2006; Allan et al., 2012, 2014: Figure 1.10). The presence of a minor component of foreign BtB pumice in phases 1 and 2 of the eruption was used by Allan et al. (2012) to suggest that the BtB magma from the NE-dome system was introduced into the Oruanui vent by diking, and that the eruption was modulated by tectonic stresses associated with rifting processes (Figure 1.10). An additional striking feature of the Oruanui magmatic system is the apparent rapid nature of the way the eruptible melt-dominant body was formed. Although the broader Oruanui mush source likely developed over tens of thousands of years, the eruptible melt-dominant magma body was accumulated in at most 3000 years as shown by differences in zircon model-age spectra and average ages between it and the 30 ka Okaia eruption, despite their coincidence in vent locations (Wilson \& Charlier, 2009: Figure 1.9). Element diffusion modelling in orthopyroxene also indicates rapid melt assembly, starting $\sim 1600$ years prior to eruption and peaking at 230 years (Allan et al., 2013). In addition, minor contributions of melt and crystals from Quaternary intrusions and greywacke metasediments were likely assimilated into the magma body up to the point of eruption (Liu et al. 2006; Charlier et al. 2008). The wealth of previous studies on the Oruanui magmatic system, including a detailed preeruptive crustal cross section (Wilson et al., 2006; Allan, 2013; Figure 1.10) provides an excellent framework from which to interpret supervolcanic processes and the conditions leading to post-supereruption recovery.

Despite evacuating $>530 \mathrm{~km}^{3}$ of magma, Taupo continued erupting only $\sim 5 \mathrm{kyr}$ after the Oruanui supereruption, although on a smaller, but more frequent scale. In total, there have been 28 eruptions following the Oruanui supereruption, 25 of which occurred 


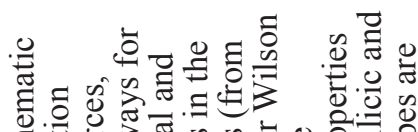

过. 을

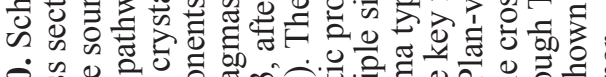

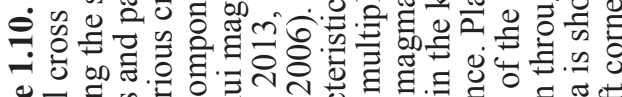

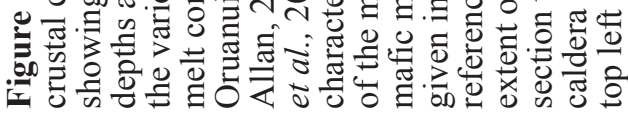
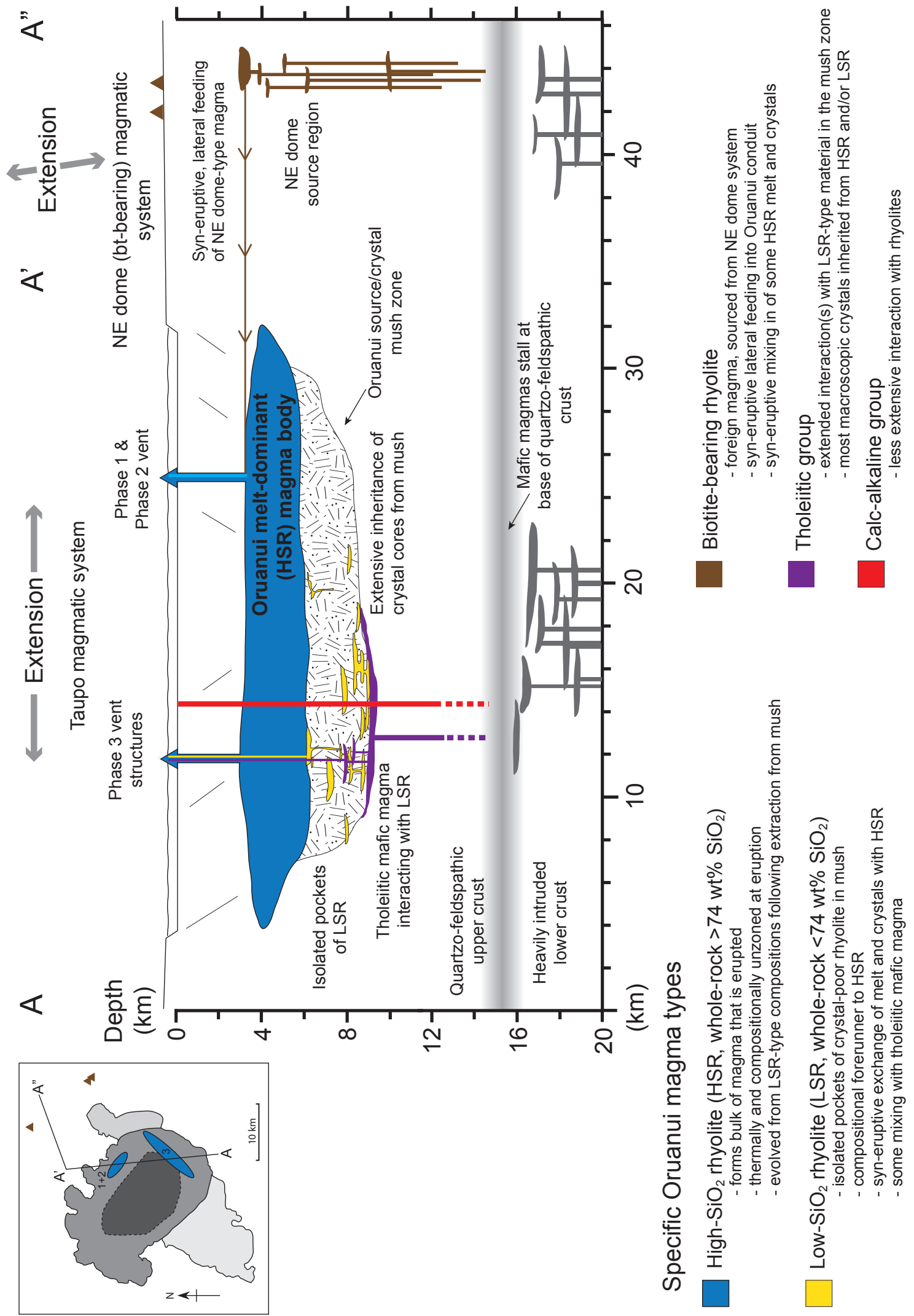

है

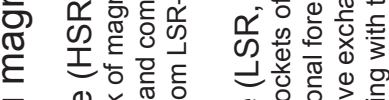

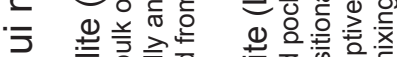
空 क人 O 它 
in the last $12 \mathrm{kyr}$ (Wilson, 1993). A detailed review of eruptive stratigraphy during this post-Oruanui time period is presented in CHAPTER 2. Previous work on the postOruanui eruptions have shown that in the aftermath of the Oruanui eruption, Taupo changed in behaviour, to erupt a series of temporally geochemically distinct subgroups from geographically overlapping vent sites around Lake Taupo (Sutton et al., 1995, 2000; Smith et al., 2005). Eruption units produced immediately following the Oruanui supereruption from 21-17 ka were dacitic in composition and vented in the northern segment of the caldera (units $\Psi, \Omega$ and A; Figure 1.7). The remaining eruptions are clustered into three temporally and chemically distinct rhyolitic subgroups (SG1-3), erupted from multiple vent sites in discrete periods from 11.8 to $9.95 \mathrm{ka}$ (SG1: units BE), 7.05 to $2.75 \mathrm{ka}$ (SG2: units F-W) and 2.15 to $1.8 \mathrm{ka}$ (SG3: units X-Z) (Wilson, 1993; Sutton et al., 2000). However, questions remain as to how the rhyolitic system rebuilt and re-established itself following the supereruption, and how the geochemically distinct magmas relate through time (e.g. Sutton et al., 2000). In particular, how and in what form did the mush system and deeper root zone rebuild? How does the new system compare in structure to, and does it have the same components as the Oruanui system shown in Figure 1.10? The previous studies of the post-Oruanui eruptions provide a good framework to further investigate magmatic recovery in the post-supereruption environment. In this study, I will build upon the findings of Sutton et al. (2000) and Smith et al. (2005) to investigate the post-Oruanui trends in whole-rock, glass and mineral compositions to compare and contrast with the recent findings of Allan (2013). This study will address fundamental questions relating to the processes and timescales involved with the generation, storage and eruption of silicic magma in Taupo's young magmatic system. 


\section{CHAPTER 2}




\section{2: ERUPTIVE STRATIGRAPHY \& SAMPLE COLLECTION}

\subsection{Eruptive stratigraphy of Taupo volcano}

Multiple studies have outlined the various periods of Taupo's eruptive history, which together provide a detailed picture of its late Quaternary and Holocene activity (Healy, 1964; Vucetich \& Pullar, 1964, 1969, 1973; Vucetich \& Howorth 1976; Wilson et al., 1984, 1986, 1995; Froggatt \& Lowe, 1990; Wilson, 1993, 2001; Sutton et al., 1995; Leonard, 2003; Wilson \& Charlier, 2009; Leonard et al., 2010; Table 2.1). Taupo's early eruptive record prior to $65 \mathrm{ka}$ is poorly understood due to burial by young voluminous pyroclastic units, but it is apparent that the onset of modern explosive activity commenced shortly after the Rotoiti event from the nearby Okataina volcano (Wilson et $a l ., 1995)$. The period between $\sim 65 \mathrm{ka}$ and $25 \mathrm{ka}$ was dominated by small pyroclastic eruptions from vents now concealed beneath Lake Taupo, in close conjunction with a series of small but chemically distinct eruptions from Maroa volcano to the north of Taupo (Wilson et al., 1995; Wilson \& Charlier, 2009; Figures 1.9 and 2.1). At 25.4 ka, the voluminous Oruanui supereruption occurred, causing large caldera collapse at Taupo (Wilson, 2001; Vandergoes et al., 2013). The eruption occurred over 10-phases in a prolonged episodic phreatomagmatic event, erupting $>530 \mathrm{~km}^{3}$ of magma, mostly in the final phase of the eruption that also produced a distinctively large and widespread ignimbrite that engulfed the central North Island (Wilson, 2001; Wilson et al., 2006; Van Eaton \& Wilson, 2013). Early tephrochronological studies established a sequence of nine tephra formations in the time period following the Oruanui eruption (Baumgart, 1954; Healy, 1964; Vucetich \& Pullar, 1973; Froggatt \& Lowe, 1990). Although successful in identifying the major Holocene units which were separated by long time breaks represented by clear palaeosols, these studies missed many minor (but crucial) palaeosols and thin, often bioturbated tephra units. A re-examination and reinterpretation of Taupo's post-Oruanui stratigraphy by Wilson (1993) identified 28 eruption units that vary widely in their eruption size and style (Table 2.1, Figure 2.1). For convenience, these eruptions and their accompanying deposits were labelled by letter, with the two oldest units denoted by the Greek letters $\Psi$ and $\Omega$, and the remaining units simply labelled from oldest to youngest as Unit A through Z (Table 2.1). The 28 


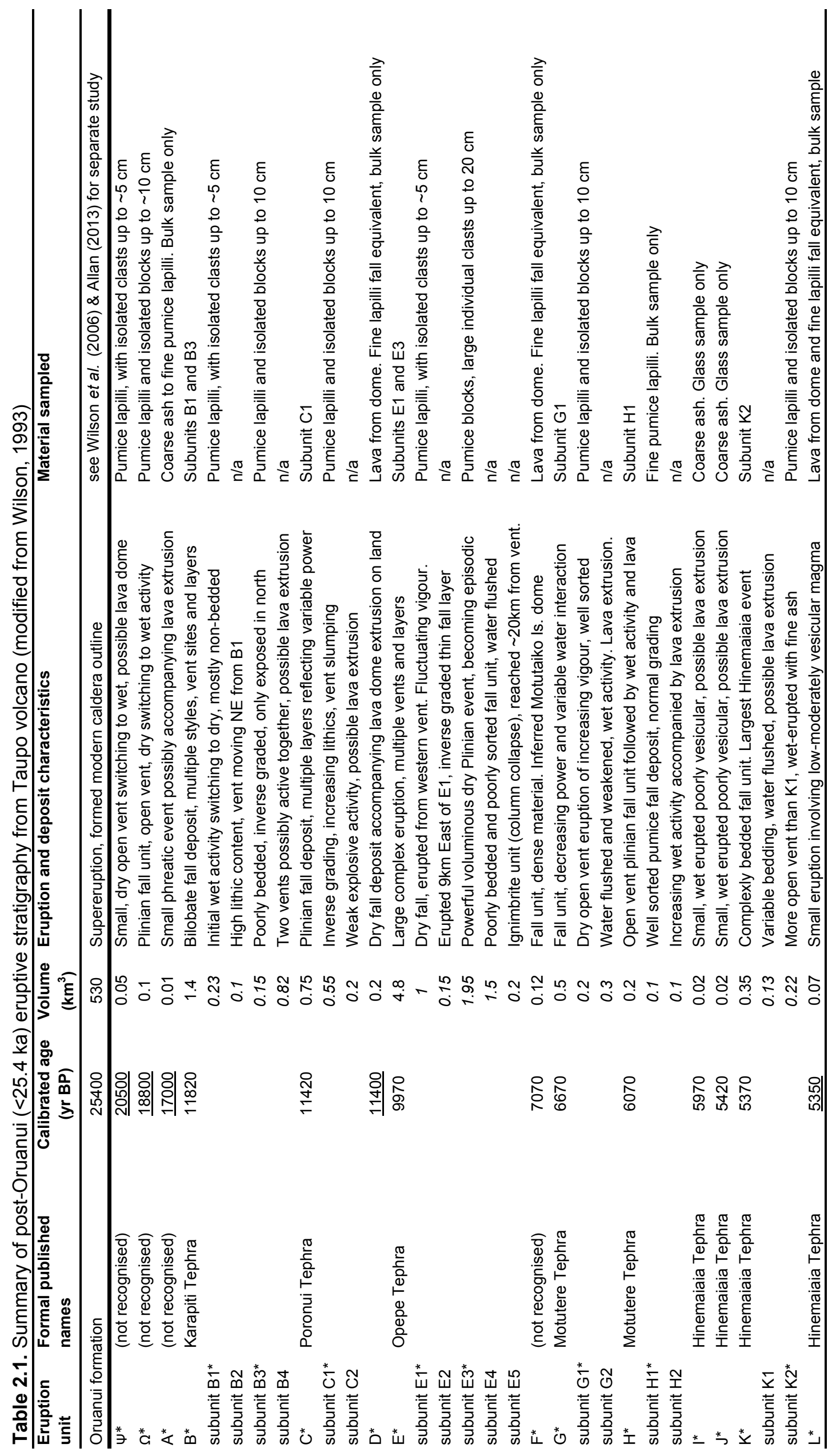




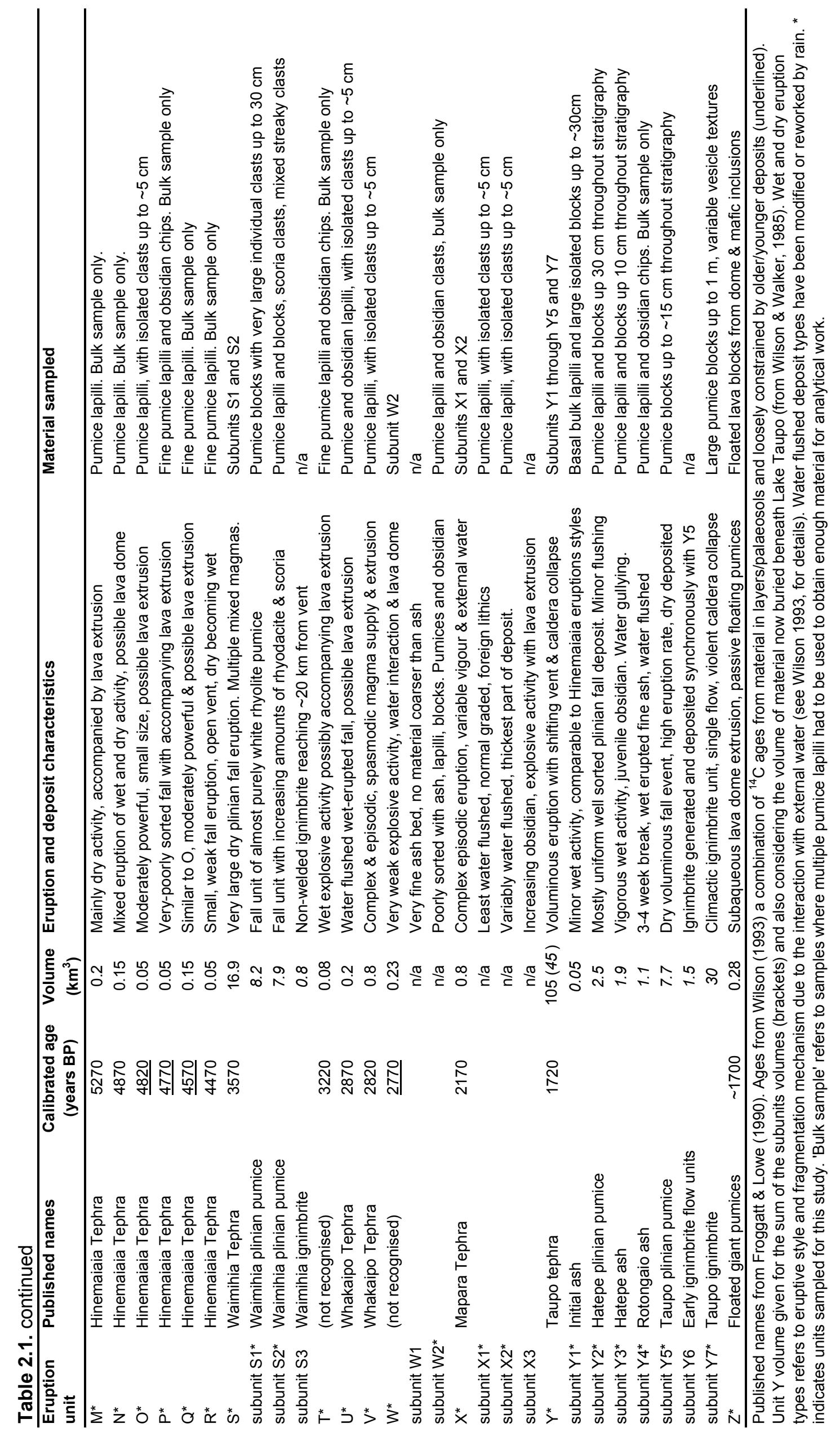




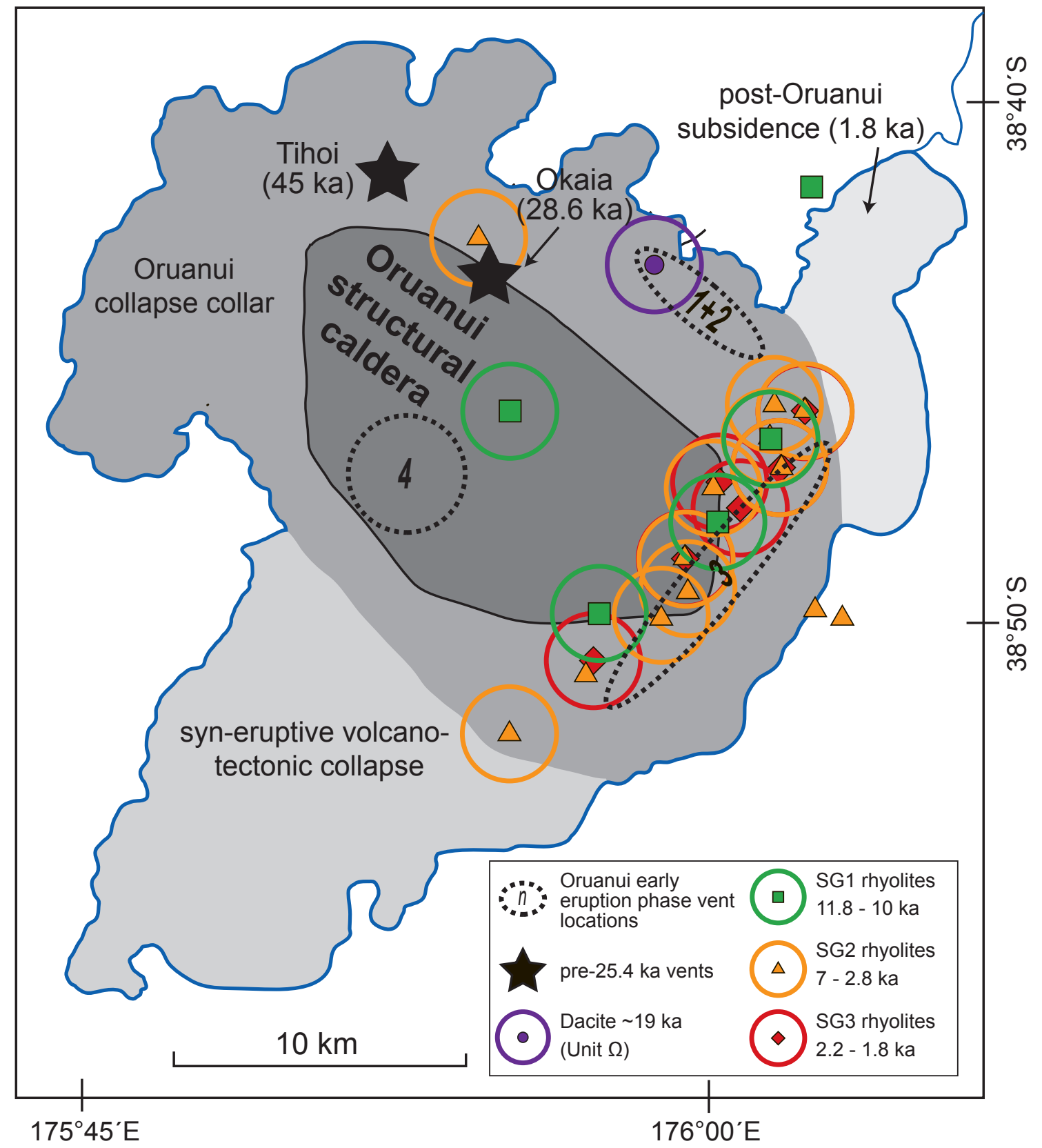

Figure 2.1. Regional setting and structural features of Taupo volcano (modified from Wilson, 1993, Wilson et al., 2006 and Wilson \& Charlier, 2009). Areas defined under Lake Taupo are the structural elements of the Oruanui caldera and subsequent collapse events, from Wilson (2001). Pre-Oruanui vent sites and ages are after Wilson \& Charlier (2009), and vent sites for the first 4 phases of the Oruanui are from Wilson (2001). Inferred vent sites and ages for the post-Oruanui eruption groups are modified from Wilson (1993), with circles representing uncertainty on specific vent location (not shown on subaerial lava domes). 
eruptions were later split into four groups based on broad chemical variations with time by Sutton et al. (1995; 2000) (Figure 2.1). Eruptions immediately following Oruanui from 20.5-17 ka were dacitic in composition and vented in three eruptions (Dacites: units $\Psi, \Omega$ and A) in the northern segment of the Oruanui caldera (Figure 2.1). The remaining 25 eruptions clustered into three chemically distinct rhyolites erupted from multiple vent sites around the caldera in discrete periods from $\sim 11.8$ to 9.95 (Subgroup 1 rhyolites, units $\mathrm{B}$ to $\mathrm{E}$ ), 7.05 to 2.75 (Subgroup 2 rhyolites, units $\mathrm{F}$ to $\mathrm{W}$ ) and 2.15 to 1.8 ka (Subgroup 3 rhyolites, units $\mathrm{X}, \mathrm{Y}$ and $\mathrm{Z}$ ).

\subsection{Field work \& sampling}

Critical to understanding the post-Oruanui evolution of Taupo's magma system is precise sampling of the most appropriate material from each individual eruption. This study involved the collection of various materials from each eruption within the welldefined eruptive stratigraphy of Wilson (1993) (Table 2.1). In addition to basic stratigraphy, Wilson (1993) provided (where discernible) isopach maps with inferred vent locations (Figure 2.1) and 'type-localities' that best defined the specific characteristics of each deposit. Utilising this existing knowledge, along with new sampling locations found with modern infrastructural developments around the Taupo region over the past 20 years (e.g. new highway cuttings and forestry roads), the largest and freshest possible juvenile material from each post-Oruanui eruption was collected for chemical analysis (Figure 2.2). Below, a brief summary of each of the eruption deposits or products is given (see also Table 2.1), along with descriptions of the deposits and specific field sites from which samples were collected.

\subsubsection{Units $\Psi, \Omega \&$ A (post-Oruanui dacites)}

The first eruptions from Taupo following the Oruanui eruption were distinctive in both their magma composition and vent location. Inferred ages from palaeosol and loess thicknesses and bracketing with dated tephras from Maroa and Okataina volcanoes suggest that these three dacite units were erupted between $20.5-17 \mathrm{ka}$, with a $\pm 5-10 \%$ age uncertainty (Wilson, 1993). All three eruptions were small volume $\left(<0.1 \mathrm{~km}^{3}\right)$ and their associated deposits are found in the region north-northeast of Lake Taupo. Although all three units are considered to be from similar vent sites, Unit $\Omega$ was the only unit from which adequate thickness data could be obtained to generate an isopach 

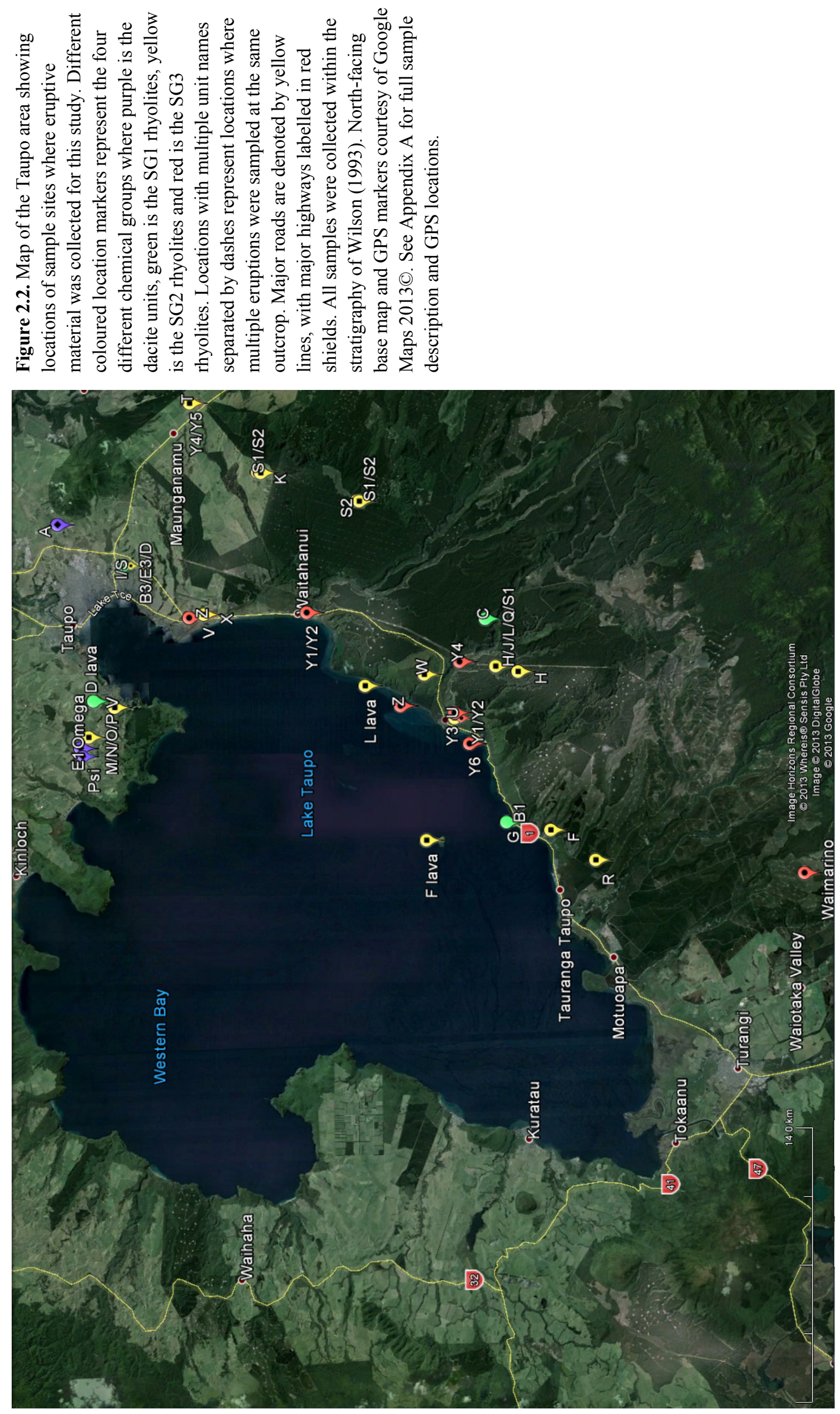
map and inferred vent location, that was demonstrated to be in an area slightly south of the modern northern shoreline around Kaiapo Bay (Figure 2.1; Wilson, 1993). The dacites were notably the only post-Oruanui units sourced from this part of the caldera, in an area that largely overlaps with the inferred vent locations of phases 1 and 2 of the Oruanui eruption (Wilson, 2001). A selection of large lapilli or small block-sized and notably crystal-rich pumices were collected from both Unit $\Psi$ and Unit $\Omega$ at the typelocalities of Wilson (1993) on Mapara Road (Table 2.1; Figure 2.2; see Figures 2 and 4 of Wilson, 1993). Both units along Mapara Road are clearly underlain by loess and older sediments of the Huka Falls Formation and then covered by the younger Holocene tephra Unit B (Karapiti). For Unit A, a new location in the south wall of an excavation at the Taupo Rubbish Tip was found that was thicker and coarser than any location described by Wilson (1993) (Figure 2.3). At this locality, Unit A is extremely well preserved at $\sim 15 \mathrm{~cm}$ thick and contains fine lapilli pumices and obsidian chips up to 4-5 $\mathrm{mm}$ in size (Figure 2.3). It is underlain by thin and wispy andesite tephra beds (likely derived from Tongariro Volcano Centre to the south), loess, and an $8 \mathrm{~cm}$ thick greenishgrey bed with small pumiceous crystal rich lapilli, interpreted to be Unit $\Omega$. The base of the exposure is made up of a $\sim 1 \mathrm{~m}$ thick accretionary lapilli-rich fall bed and 1-2 $\mathrm{m}$ thickness of fine grained ignimbrite from the Oruanui eruption. Above the Unit A tephra is a distinctive, local hydrothermal eruption breccia, bedded loess, and then the succession of Holocene rhyolitic tephras (Figure 2.3).
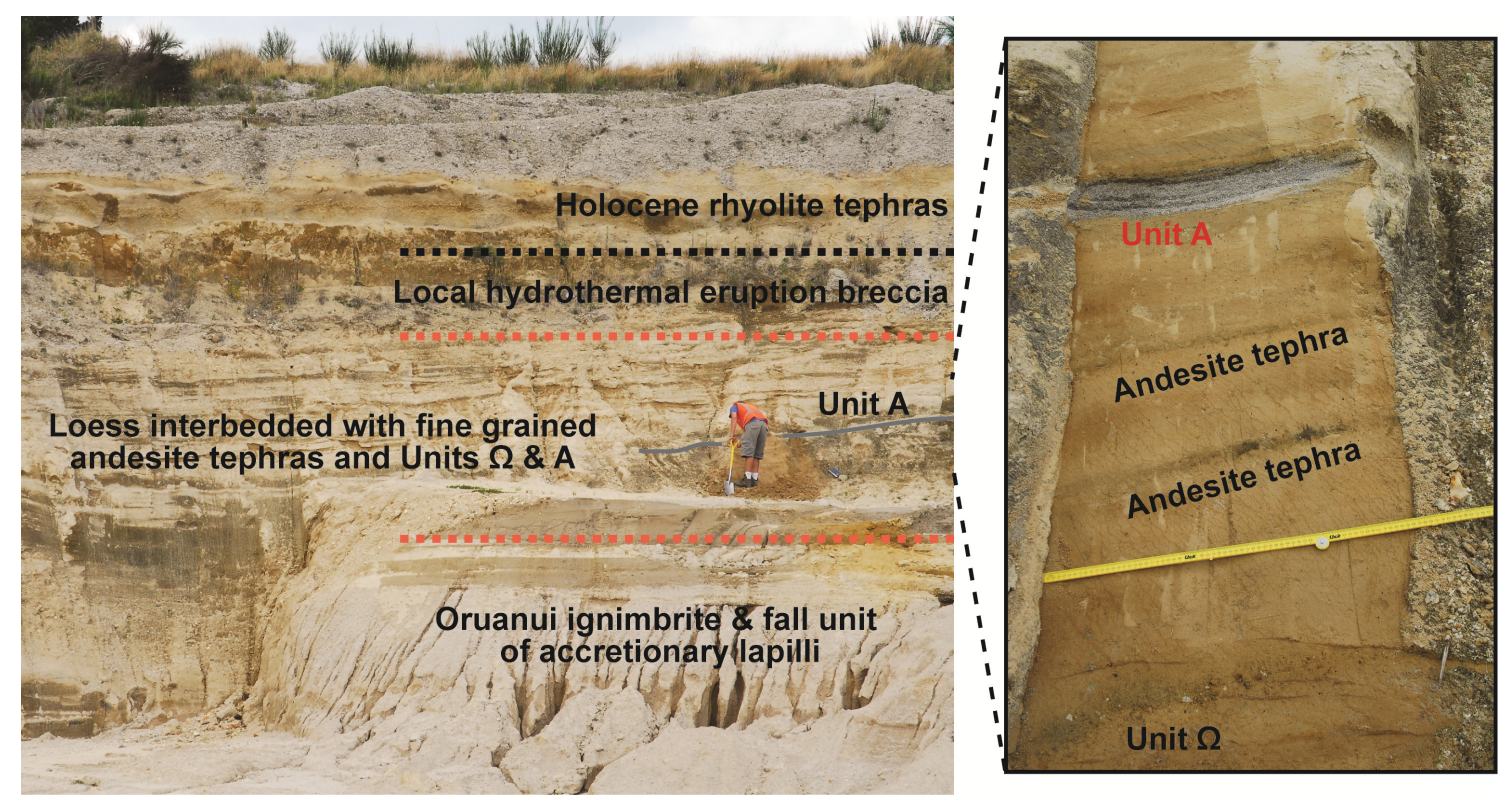

Figure 2.3. New sampling location for Unit A at the Taupo-Broadlands Rubbish Tip. Total outcrop height in the left photo is $\sim 10 \mathrm{~m}$ (human for scale). Enlarged photo on right showing the detail of the Unit A and the bracketing tephras contains an $80 \mathrm{~cm}$ ruler for scale. 


\subsubsection{Unit B (Karapiti Tephra)}

Unit B or the 'Karapiti Tephra' is first of the Holocene succession of rhyolite deposits from Taupo volcano dated at $\sim 11.8$ ka (Vucetich \& Pullar, 1973; Wilson, 1993). Unit B is a bilobate fall deposit, where it shows contrasting bedding to the northeast and southeast of Lake Taupo (Wilson, 1993). When divided into four subunits (B1 to B4) based on bedding characteristics, Wilson (1993) identified that there was likely a major shift in vent position (and wind direction) during the early stages of the eruption. Unit B is therefore interpreted to have resulted from dyke emplacement along a $\sim 10 \mathrm{~km}$ fissure (Figure 2.4; cf. Froggatt, 1981a). The earliest activity (B1) was a dry, open-vent Plinian eruption from a vent to the southwest. Activity then migrated to the northeast (B2), before breaking out in increasingly explosive open-vent eruption (B3) and then continuing from both the dry northeast vent (B4) and simultaneously erupting from the now flooded wet southwest vent (Wilson, 1993).

Due to its unusual eruptive behaviour with vent migration, two subunits of Unit B were collected for this study; subunit B1 sourced from the southern vent and subunit B3 from the northern vent. Because of large differences in vent location and wind direction between the subunits (and hence grain size at each location), B1 and B3 were

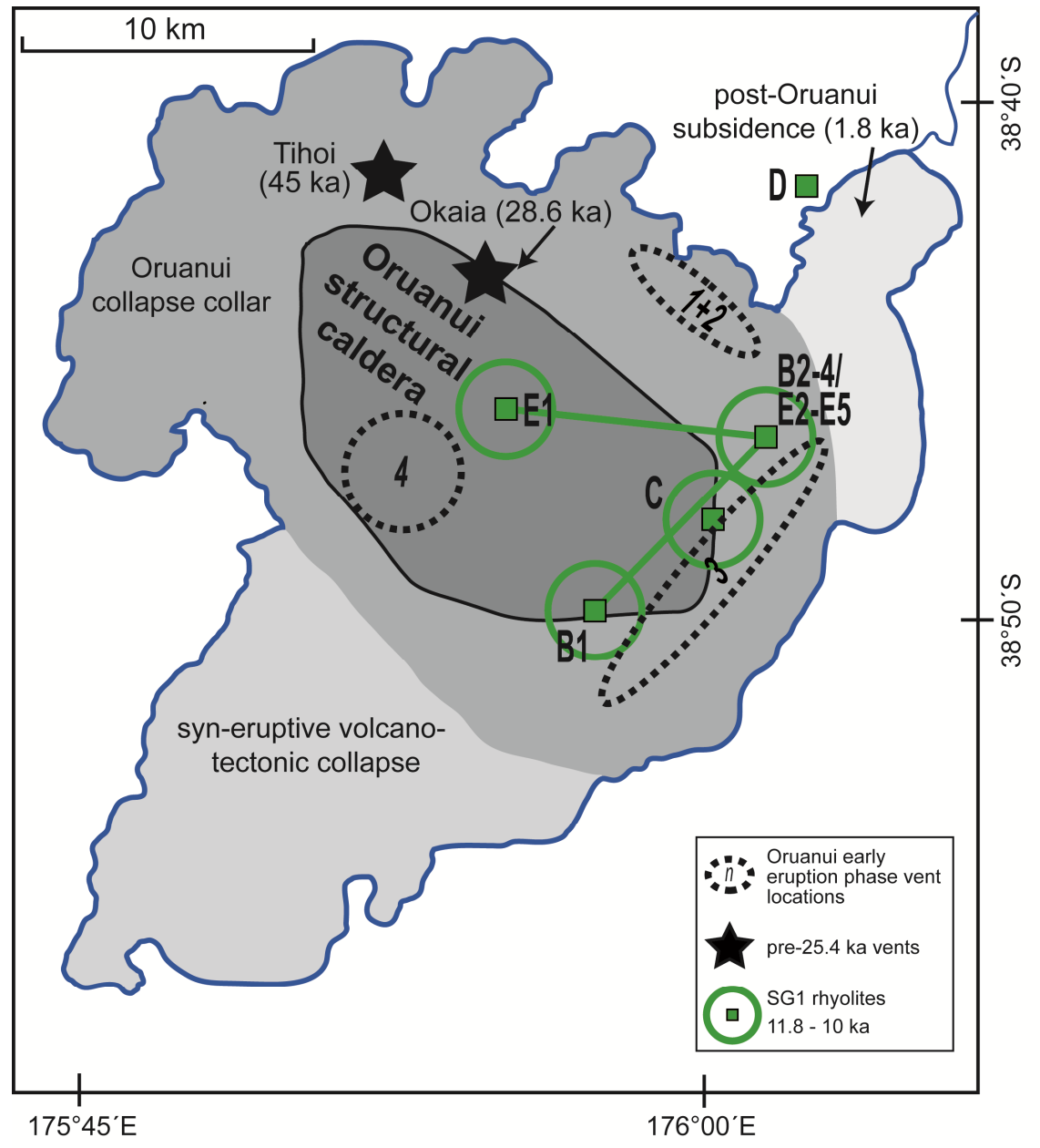

Figure 2.4. Inferred vent locations for the Subgroup 1 (SG1) eruptions and subunits. Tie lines link vent sites where there was a shift in vent location during the eruption. Modified from Wilson (1993) All other details as in Figure 2.1. 
collected from separate locations (Figure 2.2). Unit B1 was collected from a location identified by Wilson (1993) on a hill close to State Highway 1 (SH1) via forestry road access off Mission Bay Road, where the largest maximum pumice sizes are recorded, with lapilli up to $\sim 5-6 \mathrm{~cm}$ (Figure 2.2). At this location, Unit B1 is clearly overlying Oruanui material and is covered with younger Holocene tephras, and a notably thick section of Unit G. Unit B3 was sampled at a new location to the northeast on the recently excavated SH1 Taupo bypass road (Figure 2.2) that clearly shows all subunits (B1-B4) with pumices in B3 up to $\sim 10 \mathrm{~cm}$ in size. Unit B is underlain by a palaeosol over reworked fine-grained Oruanui ignimbrite, and covered by a thin palaeosol, then Unit $\mathrm{C}$ and Unit D, and a thick palaeosol followed by Unit E (Figure 2.5, 2.6).

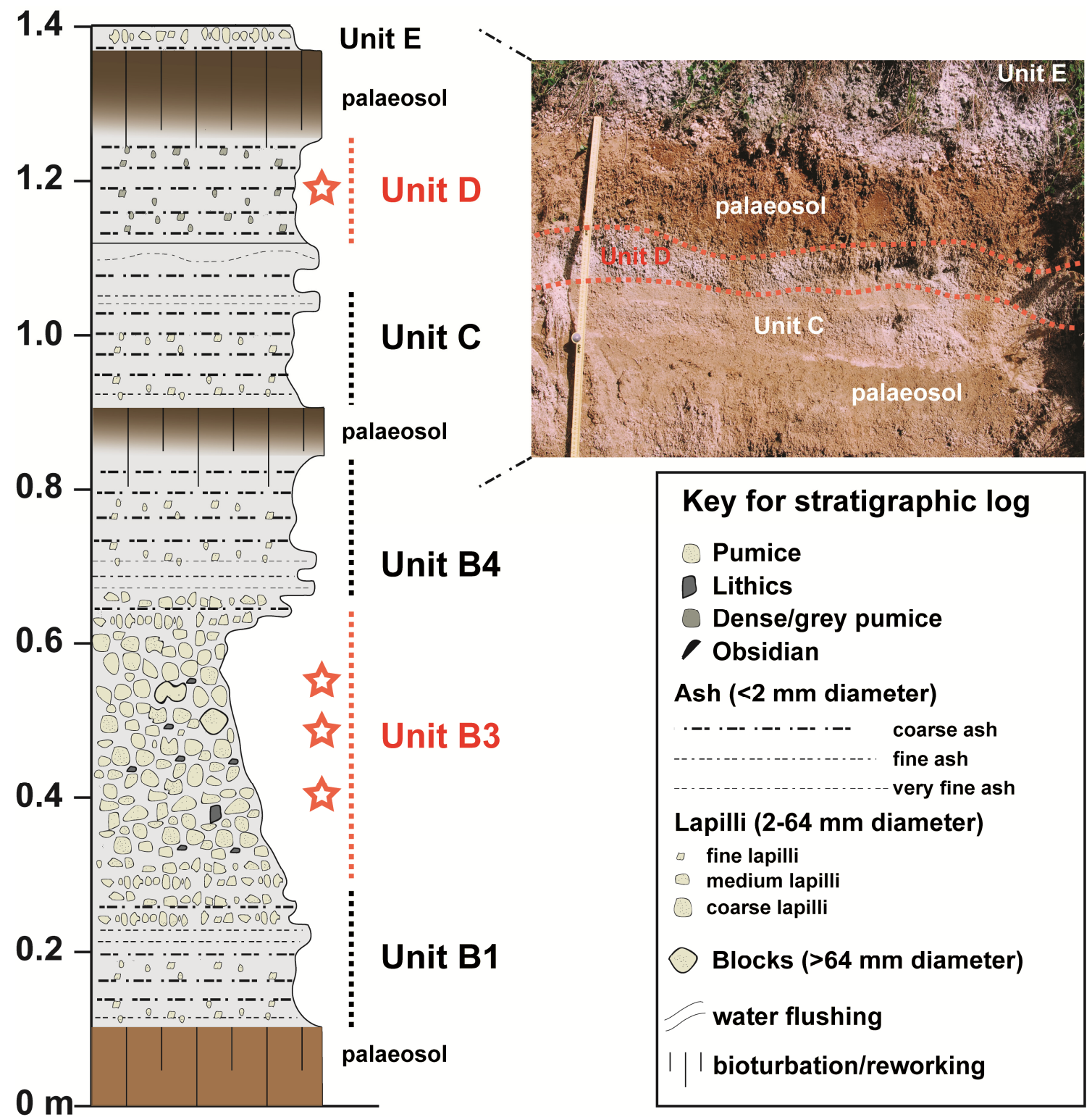

Figure 2.5. Stratigraphic section and matching photo from the sampling location for units B3 and D (tephra) on the new SH1 Taupo bypass. Red stars represent approximate sampling location of pumices. 


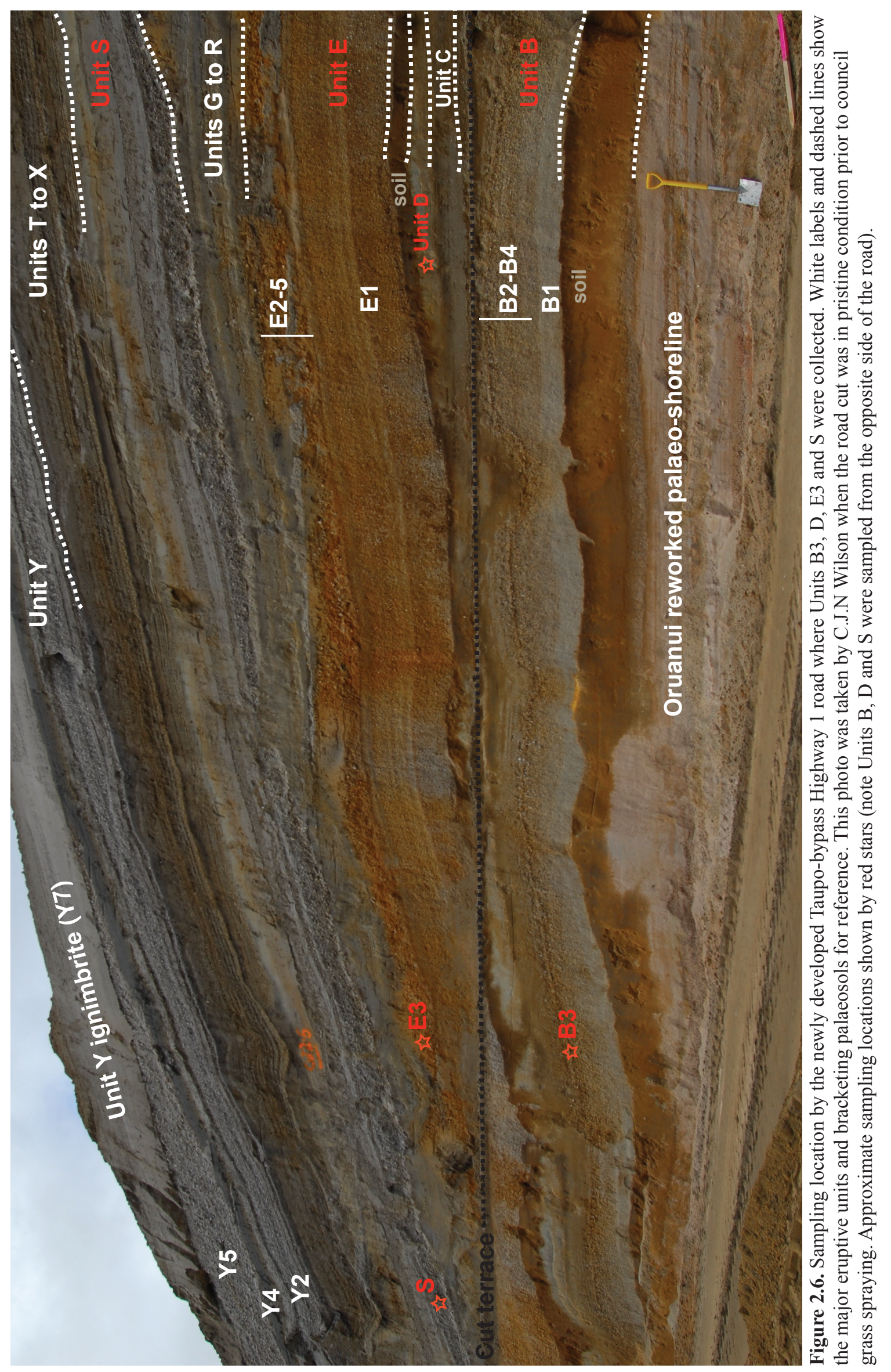




\subsubsection{Unit C (Poronui Tephra)}

Unit $\mathrm{C}$ or the 'Poronui Tephra' is the second post-Oruanui rhyolite eruption from Taupo, dated at $\sim 11.4 \mathrm{ka}$ (Vucetich \& Pullar, 1973; Wilson, 1993). Wilson (1993) separated the plinian event into two subunits (C1 and $\mathrm{C} 2)$, which were likely derived from the same vent (Figure 2.4) and represent a small time break and change in eruptive intensity. Inverse grading early within the deposit is indicative of an increasingly powerful eruption that then likely experienced vent slumping and eventual waning as suggested by increasing lithic contents within the final stages of $\mathrm{C} 1$ (Wilson, 1993). The C1-C2 time break was followed by weakly explosive activity and possible lava extrusion before ceasing. The largest possible pumices from Unit C1 were sampled from the typelocality of Wilson (1993) by the access road to the Hinemaiaia C power station (Figure 2.2, Figure 2.7).

\subsubsection{Unit D (inferred Acacia Bay Dome)}

Unit D is a minor fall unit defined by Wilson (1993) between Unit C and Unit E, unusual in both its eruptive style and inferred vent location. It is only separated from Unit C by a very minor weathering horizon that Wilson (1993) interprets to represent less than a few years to decades. It is generally found as fine to coarse ash, with the juvenile component moderately to poorly vesicular and angular, accompanied by minor

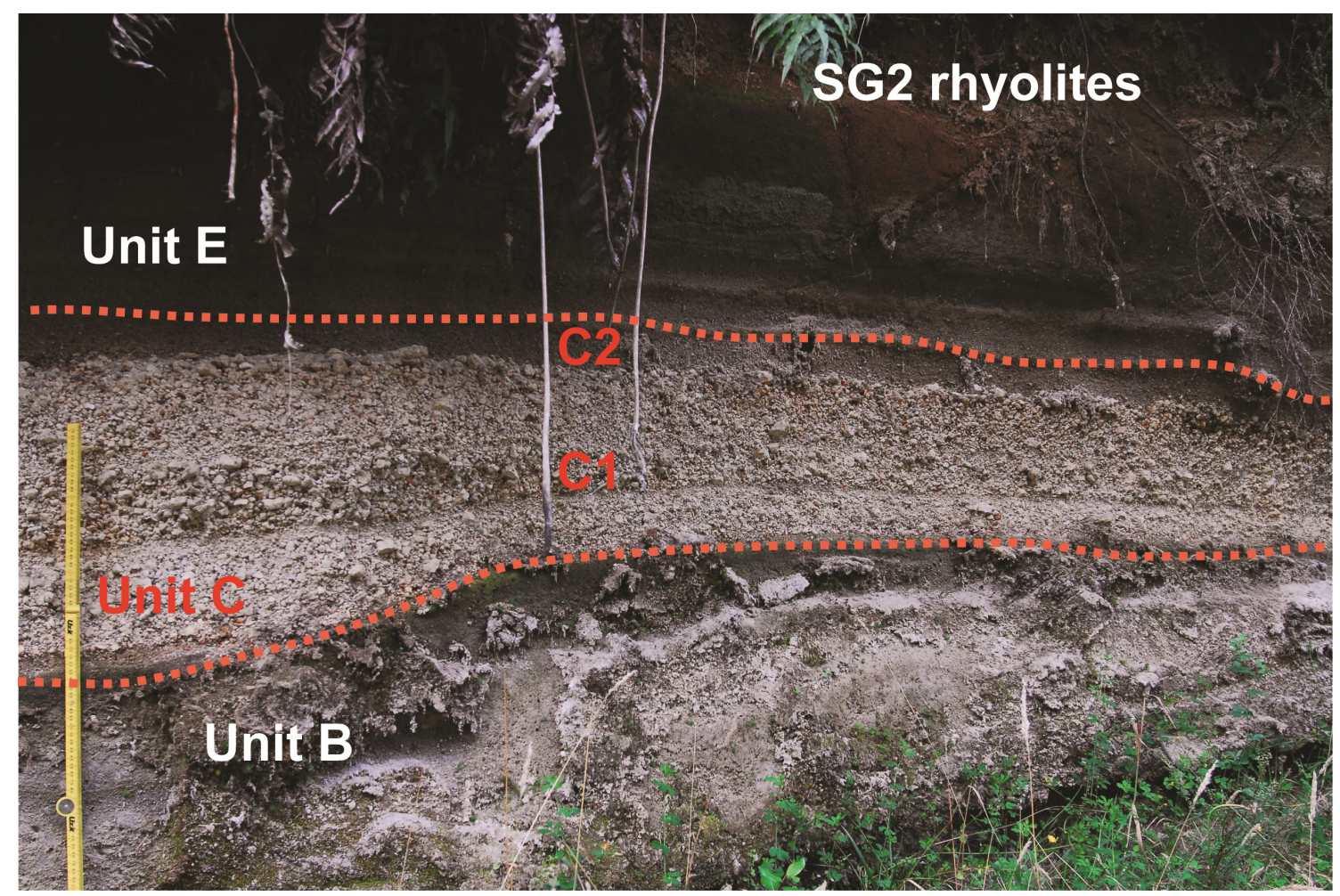

Figure 2.7. Road cutting by Hinemaiaia $\mathrm{C}$ power station from which Unit $\mathrm{C}$ pumices were collected. Yellow ruler is $60 \mathrm{~cm}$. Sampled unit is shown in red, bracketing units B and E are shown in white. 
amounts of obsidian. Unit D is therefore interpreted to represent minor explosive activity likely accompanying a dome-building event. Wilson (1993) proposed that the Unit D fall material was the fall deposit associated with a lava dome located in Acacia Bay (Figure 2.2). The inferred Unit D vent location separates it from the remaining Subgroup 1 (SG1) rhyolites as it falls outside the main caldera boundary formed during the Oruanui eruption (Figure 2.4). Both material from the Unit D fall material and the Acacia Bay lava dome were collected for analysis. Fine pumiceous lapilli and coarse ash was collected from the Unit D fall deposit at the same location as Unit B3 on the recently excavated SH1 Taupo bypass road (Figure 2.6), where it shows evidence for a short time break from the underlying Unit $C$ fall material (Figure 2.5). Large fresh blocks of pumiceous glassy lava representing the Acacia Bay dome were collected from an exposure on Acacia Heights Drive (Figure 2.2). Localised vapour phase alteration was common in the dome carapace and altered material was avoided or removed.

\subsubsection{Unit E (Opepe Tephra)}

Unit E or the 'Opepe Tephra' is the final and largest eruption of the SG1 rhyolites at $\sim 10$ ka (Vucetich \& Pullar, 1973; Wilson, 1993; Sutton et al., 1995). The associated deposit and overlying soil was originally defined by Vucetich \& Pullar (1973) and then later separated into four fall deposit subunits (E1-E4) and a non-welded ignimbrite (E5) by Wilson (1993). Isopach/isopleth maps and stratigraphic distinction implies that there were two vents active successively during the eruption (Wilson, 1993). The eruption started as a dry open-vent eruption (E1) from a vent located in the middle of the Oruanui structural caldera (Figure 2.4). Fluctuations in eruption vigour caused varying grainsize and lithic-rich bands, leading Wilson (1993) to further divide E1 in to two volumetrically subequal portions E1a and E1b. Activity then switched with the waning of the central vent to a new vent located $\sim 10 \mathrm{~km}$ to the east, overlapping with the past vent location for Unit B (Figure 2.4). Vesicular matrix material in E2-E4 indicates wet deposition, and water likely infiltrated the vent during the weakest parts of the eruption to cause water-flushed deposits. Subunit E3 marks the most powerful and voluminous part of the eruption (bulk volume $\sim 2 \mathrm{~km}^{3}$ ), which then weakened to form the waterflushed subunit E4. The final stages of the eruption is marked by a thin but widespread ignimbrite (E5) that was likely caused by column collapse after the E3-E4 sequence.

Due to the multiple vent nature of the Unit E eruption, two subunits were selected for analysis; E1 and E3. Subunit E1 (erupted from the western vent) was collected in the north of Taupo, from a road cutting on Mapara Road (Figure 2.8), where 
maximum sized pumices have been recorded (Figures 13 and 14 from Wilson, 1993). At this location only the first erupted material from E1a was sampled (Figure 2.8). Subunit E3 (erupted from the eastern vent) was collected from the same Highway 1 cutting (loc 3051 ) as Unit B3 (Figure 2.6). At this location very large pumices up to $20 \mathrm{~cm}$ in size were collected from the top of a road cutting terrace, where E3 is notably coarse, and clearly underlain by thick but notably finer grained E1.

\subsubsection{Unit F (inferred Motutaiko Island dome)}

The first erupted of the SG2 group of rhyolites at $\sim 7.1 \mathrm{ka}$, Unit F is a thin bilobate fall deposit identified by Wilson (1993) within a post-Unit E palaeosol, mainly exposed around the southwest region of Taupo. The deposit is poorly sorted and consists mainly of fine ash with minor amounts of medium ash to fine lapilli that is moderately to poorly vesicular pumice through to obsidian chips. These distinctive features along with isopach mapping led Wilson (1993) to identify a vent location for Unit F in a region of Lake Taupo now occupied by Motutaiko Island (Figure 2.9). Previously, Motutaiko Island was suggested by Froggatt (1981b) to be the source for the Poronui Tephra (Unit C), however, isopach maps and the stratigraphy of Wilson (1993) precludes this.

Samples used in this study were collected from both the inferred lava dome source at

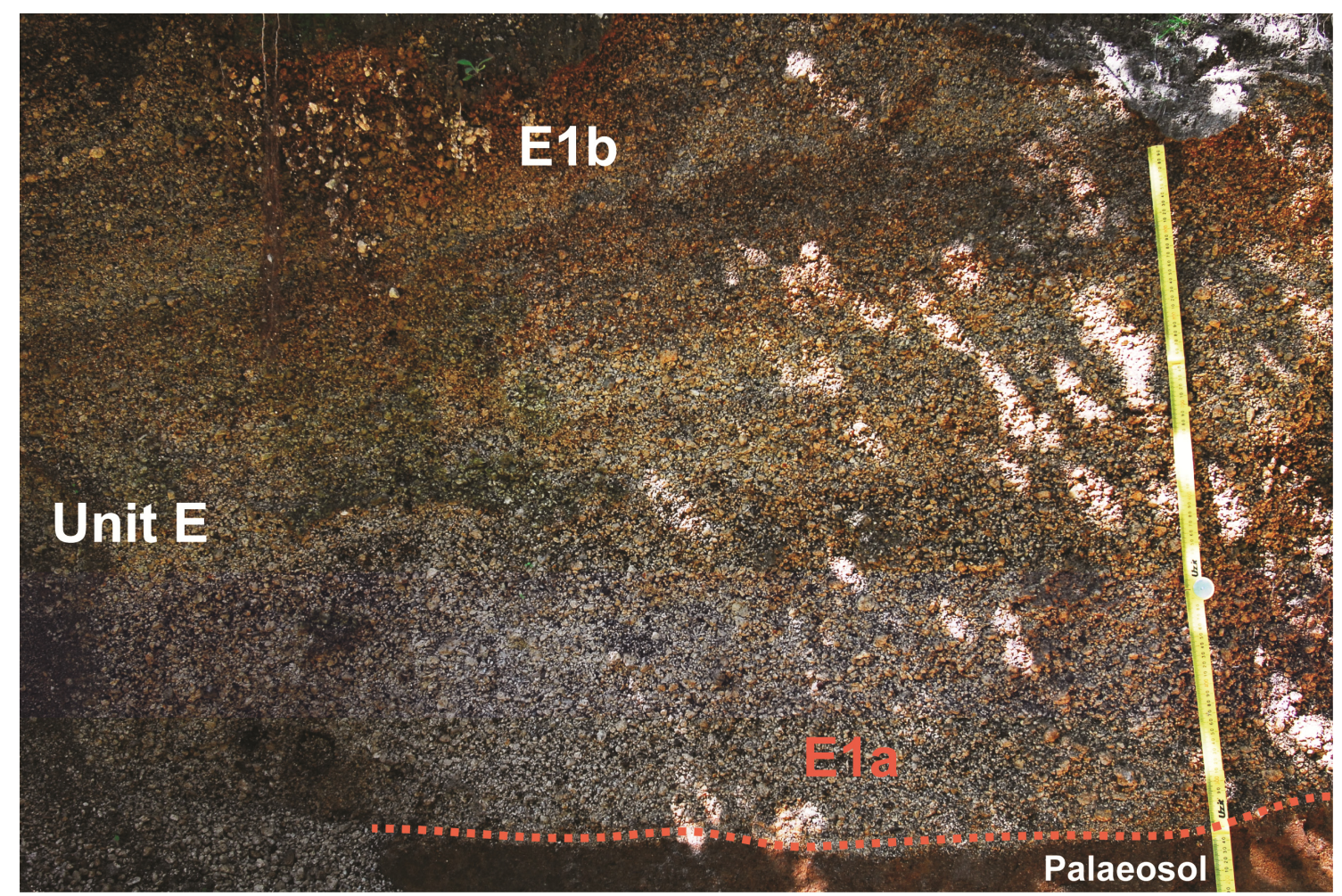

Figure 2.8. Photo of the sampling location for subunit E1 on Mapara Road (loc 914). The red dashed line marks the start of Unit E. Only pumices within the lowest $35 \mathrm{~cm}$ of this deposit were collected from E1a. Yellow ruler is $\sim 70 \mathrm{~cm}$ for scale. 


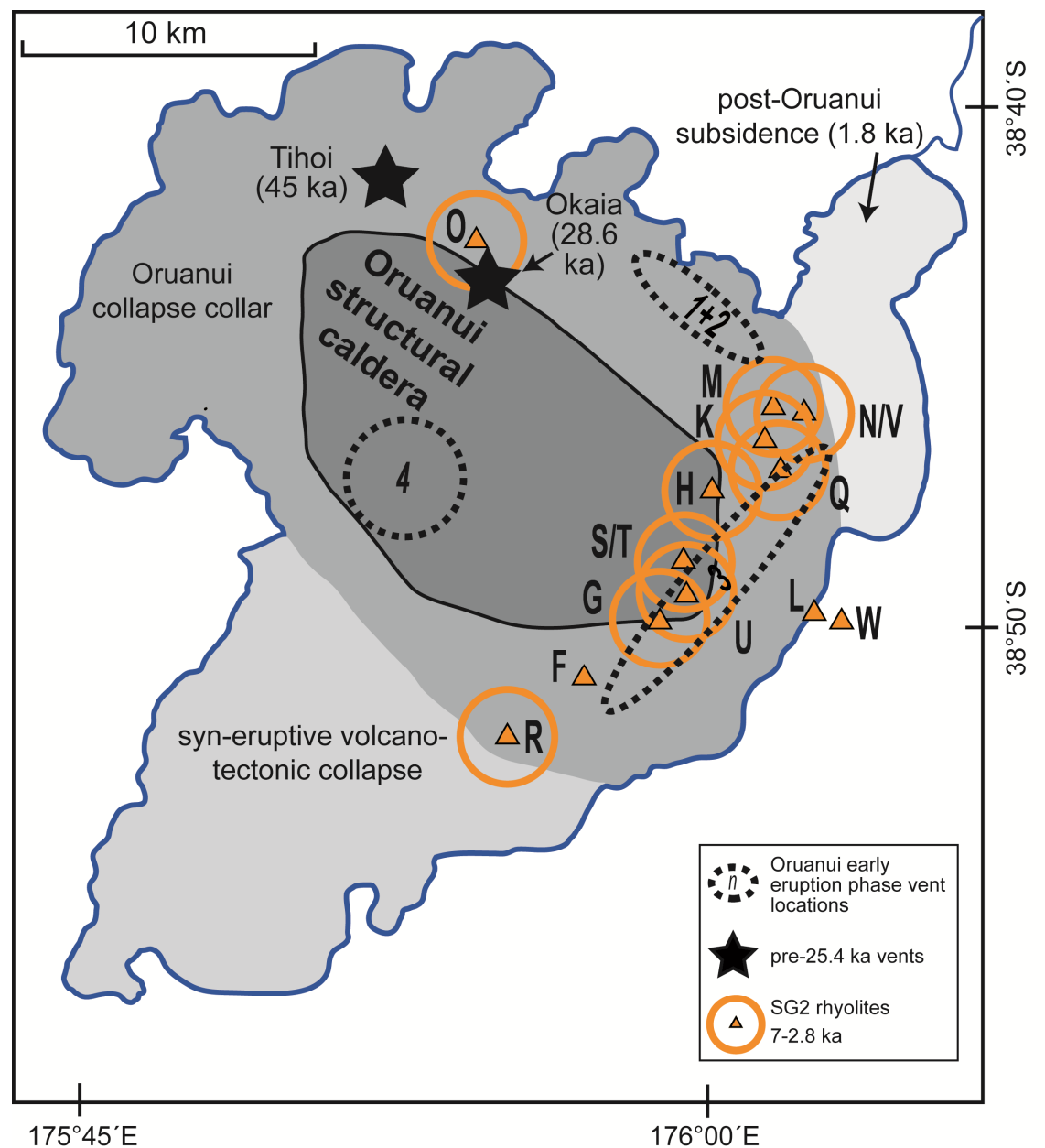

Figure 2.9. Inferred vent locations for the Subgroup 2 (SG2) eruptions and subunits. Modified from Wilson (1993) All other details as in Figure 2.1.

Motutaiko Island and from the fall deposit equivalent from a road cutting on Mission Bay Road in Lake Taupo Forest (Figure 2.2). The fall unit location was sampled from the type-locality given by Wilson (1993), where Unit F is clearly underlain by Unit E and mixed in with the post-Unit E palaeosol, and then overlain by Unit G (Figure 2.10a). Fresh lava fragments from the Motutaiko Island dome were collected from the southwestern side of the island (Figure 2.10b,c). Unit F is considered to be distinctive in Taupo's history as it is the second most southerly vent in the post-Oruanui rhyolites and it marks a subtle shift in magma chemistry from the SG1 rhyolites (Sutton et al., 2000).

\subsubsection{Units $G$ and $H$ (Motutere Tephra)}

The stratigraphy within this period of Taupo's eruptive history is complex, with multiple assigned tephra formation names and corrections over time. Initially, all eruptions following the Opepe Tephra (Unit E) up until the Waimihia Tephra (Unit S) were assigned to a single 'Hinemaiaia Tephra Formation' by Vucetich \& Pullar (1973). This was later divided by Froggatt (1981c) into the 'Motutere Tephra Formation' followed by the Hinemaiaia Tephra Formation. Wilson (1993) then further divided the Motutere 

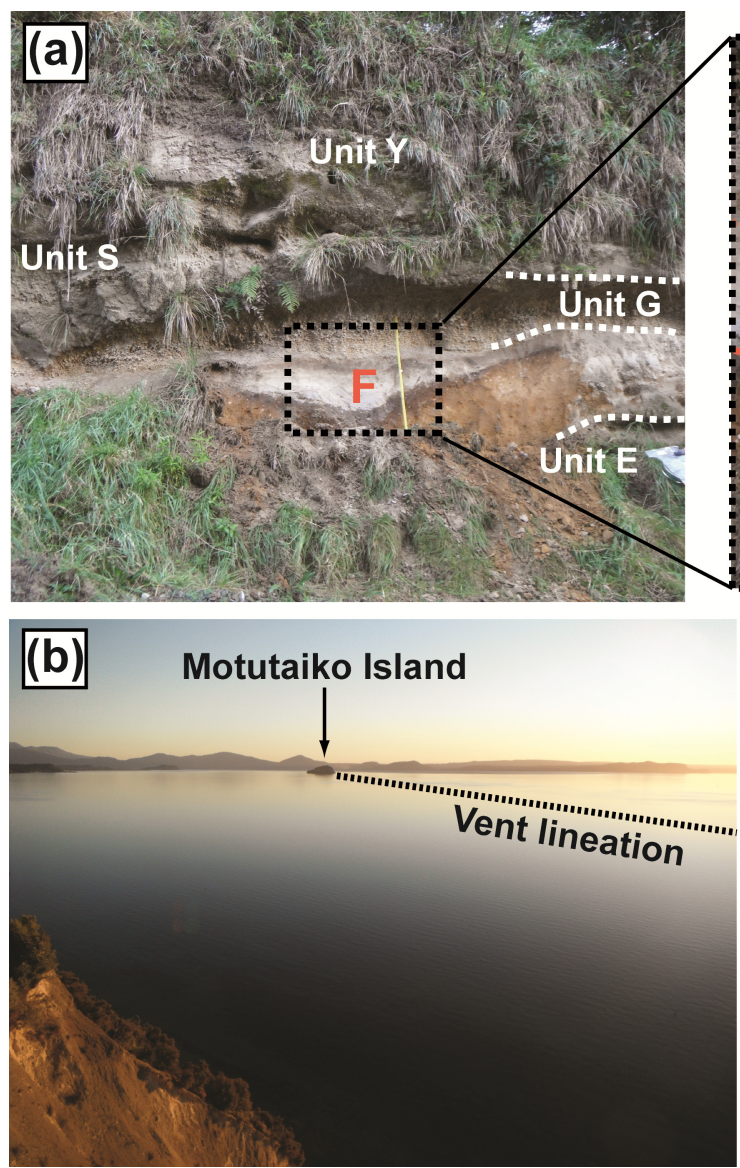

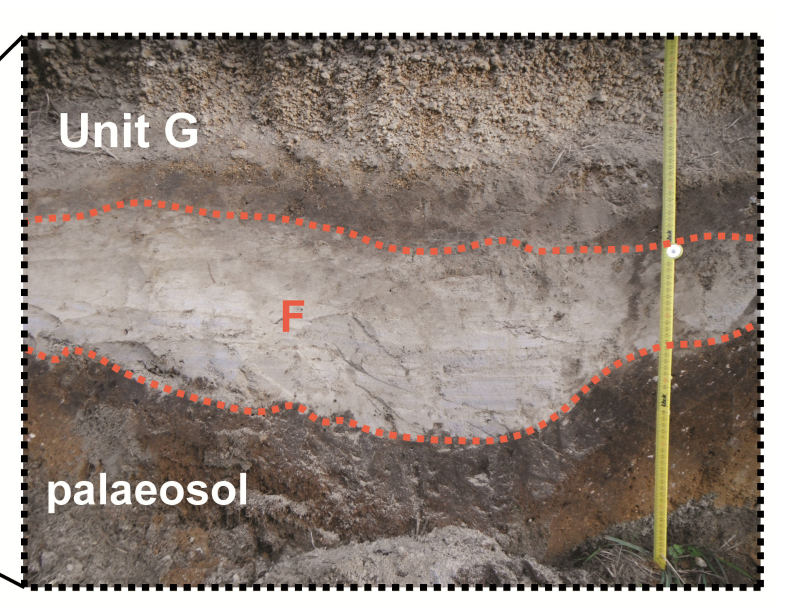

(c)

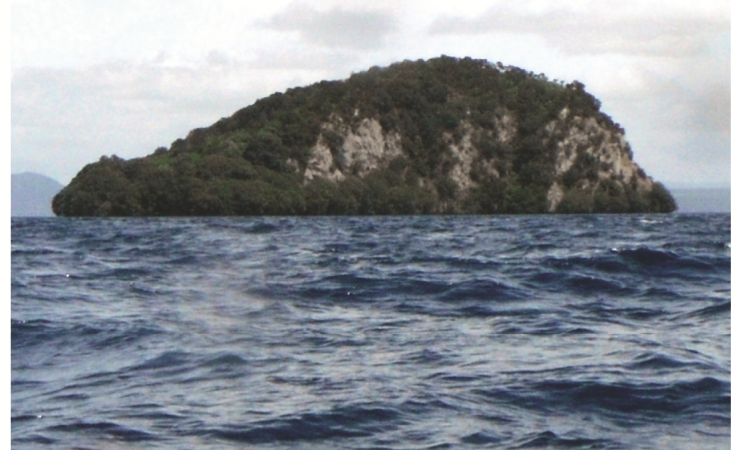

Figure 2.10. Sampling locations for Unit F. a) Road cutting on Mission Bay Road in Taupo forest where the Unit F fall deposit was sampled from the type-locality of Wilson (1993). Ruler is $70 \mathrm{~cm}$ for scale. b) View of the inferred Unit F lava dome Motutaiko Island, from atop of the White Cliffs on the eastern shoreline of Lake Taupo. Dotted line marks the inferred vent alignments between the island and the vents to the northeast for the SG2 rhyolites. c) Close up view of the Motutaiko Island lava dome.

Tephra into two units $(\mathrm{G}$ and $\mathrm{H})$ separated by a palaeosol and indentified 10 further units within the Hinemaiaia Tephra Formation (units I through R). Many of these units are separated by only minor (but still distinctive) palaeosols, representing a change in behaviour at Taupo as eruptions became more frequent, but smaller in volume.

Unit $G$ is represented by a fall unit that was separated into two subunits and dated at $\sim 6.7 \mathrm{ka}$ by Wilson (1993). G began as an open-vent, dry eruption of increasing vigour (G1) that was followed by a likely change in wind direction and water-flushing (G2), with an eventual termination in wet activity possibly accompanying lava extrusion. Isopach maps indicate a vent location slightly northeast of Motutaiko Island (Figure 2.9). Pumice lapilli and isolated blocks up to $\sim 10 \mathrm{~cm}$ were collected for analysis from Unit G1, at the same sampling location as Unit B1 on a hill close to State Highway 1 (SH1) via forestry road access off Mission Bay Road (Figure 2.2). This location was chosen due to the good exposure and size of pumices that could be found, as demonstrated by the isopleth maps of Wilson (1993). 
A thin palaeosol separates Unit G from Unit H. Like G, Unit H consists of two subunits and is very similar in its eruptive sequence and vent position within the eastern part of Lake Taupo (Figure 2.9). The eruption began as a dry, open-vent (H1), then reduced in power with accompanying wet activity (H2), followed by likely lava extrusion, as suggested by increasing amounts of poorly vesicular pumice and obsidian chips in the top of the fall deposit (Wilson, 1993). Two samples inferred to be from Unit $\mathrm{H}$ were collected for this study (Figure 2.2). The first sample was collected from the type-locality given by Wilson (1993) for Unit G on Te Heu Heu Road (loc 2379), where the palaeosol between Unit $\mathrm{G}$ and $\mathrm{H}$ is clear and well developed (Figure 2.11a). Dating of this palaeosol led Wilson (1993) to provide Unit $\mathrm{H}$ an assigned age of $\sim 6.1$ ka. The second was collected on Opawa Road, the Hinemaiaia type-locality (loc 2380) from Wilson (1993), where Unit $\mathrm{H}$ is clearly underlain by Unit $\mathrm{G}$ and overlain by the younger Hinemaiaia sequence (Figure 2.11b).

\subsubsection{Units I and $J$}

Units I and $\mathrm{J}$ are the first of the Hinemaiaia sequence of eruptions identified within the stratigraphy of Wilson (1993). These two deposits represent some of the smallest recognised post-Oruanui eruptions and their preservation is restricted to thin layers of
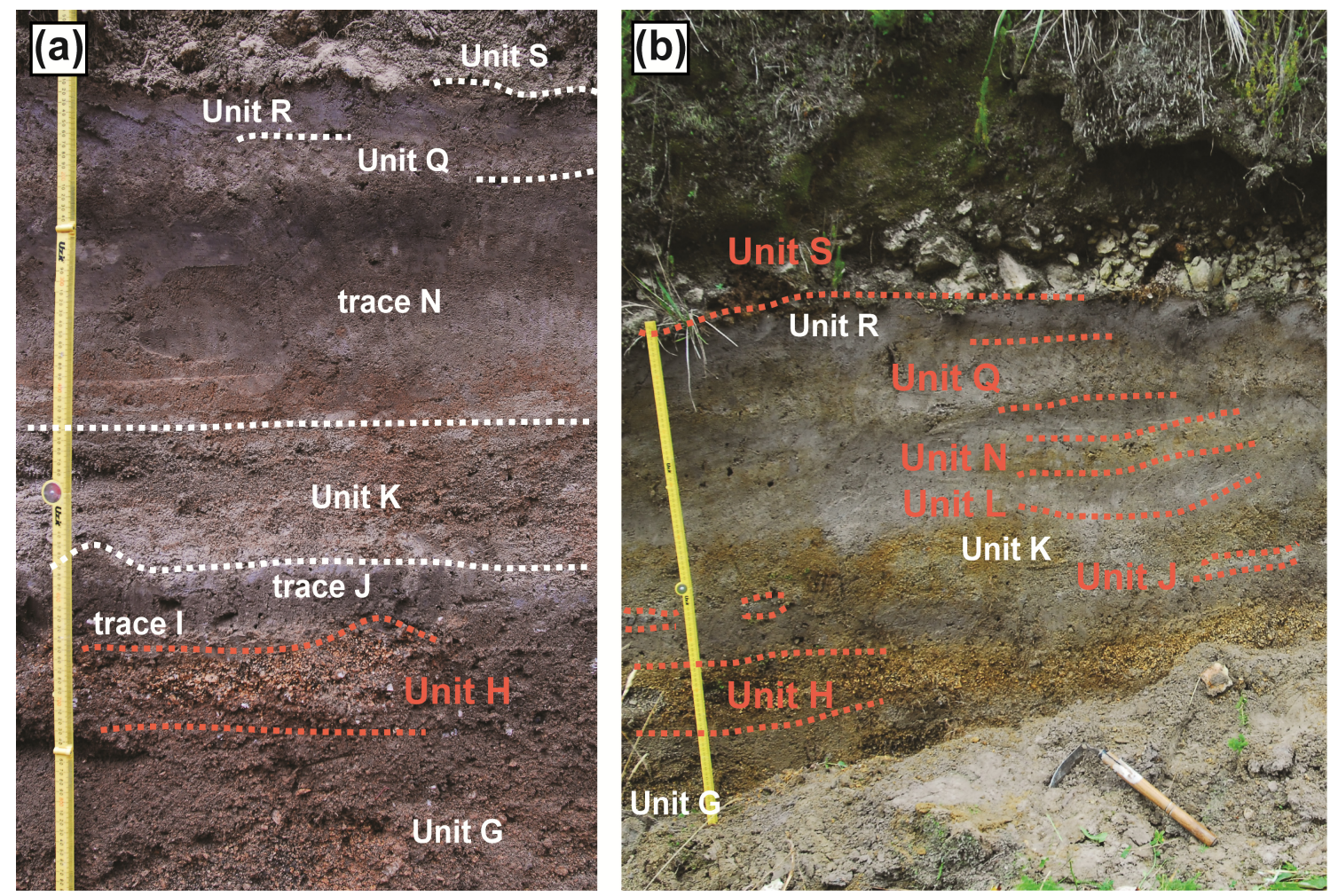

Figure 2.11. Sampling locations for Unit H, various Hinemaiaia units (J, L, N and Q) and basal Unit S1. a) First sampling location for Unit $\mathrm{H}$ in road cutting on Te Heu Heu Road with bracketing tephras. Loc 2379 from Wilson (1993). b) Hinemaiaia type-locality 2380 on Opawa Road. Sampled units are in red, bracketing units are in white. Ruler is $\sim 1 \mathrm{~m}$ for scale. 
fine ash in a limited number of locations within Lake Taupo Forest (Wilson, 1993).

Their limited exposure restricts detailed isopach mapping, but is suggestive of sources within the eastern part of Lake Taupo. Both I and $\mathrm{J}$ are similar in appearance, being mid-grey and rich in fine ash and dense juvenile obsidian, indicative of wet eruptive activity and possible lava extrusion. They are separated by a thin palaeosol at loc 2379 (Figure 2.11a), where Wilson (1993) dated charcoal from the intervening soil between units $\mathrm{H}$ and I, providing an age estimate of $\sim 6 \mathrm{ka}$ for Unit I and $\sim 5.4 \mathrm{ka}$ for Unit J. Unit I was collected from the same Highway 1 cutting (loc 3051) that units B3 and E3 were collected from (Figure 2.6). At this locality, Unit I is patchy but appears as a distinctive mid grey layer below bioturbated Unit K but above a thick palaeosol above upper Unit E (Figure 2.12). This locality was chosen because of the clear distinction with the overlying Unit $\mathrm{K}$, and because Unit $\mathrm{J}$ (which is similar in appearance) is only recorded in the stratigraphy of Wilson (1993) further south, avoiding confusion (see Figure 22 of Wilson, 1993). Unit J was collected from a distinctive layer within the Hinemaiaia typelocality on Opawa Road (loc 2380: Figure 2.11b), where it is clearly underlain by Unit $\mathrm{H}$, then $\mathrm{a} \sim 10 \mathrm{~cm}$ palaeosol and overlain by Unit $\mathrm{K}$.

\subsubsection{Unit $K$}

Unit $\mathrm{K}$ is the largest and most widespread of the Hinemaiaia units at $<5.4 \mathrm{ka}$ (Table 2.1), forming a complexly bedded fall unit that is divided into two based on grainsize

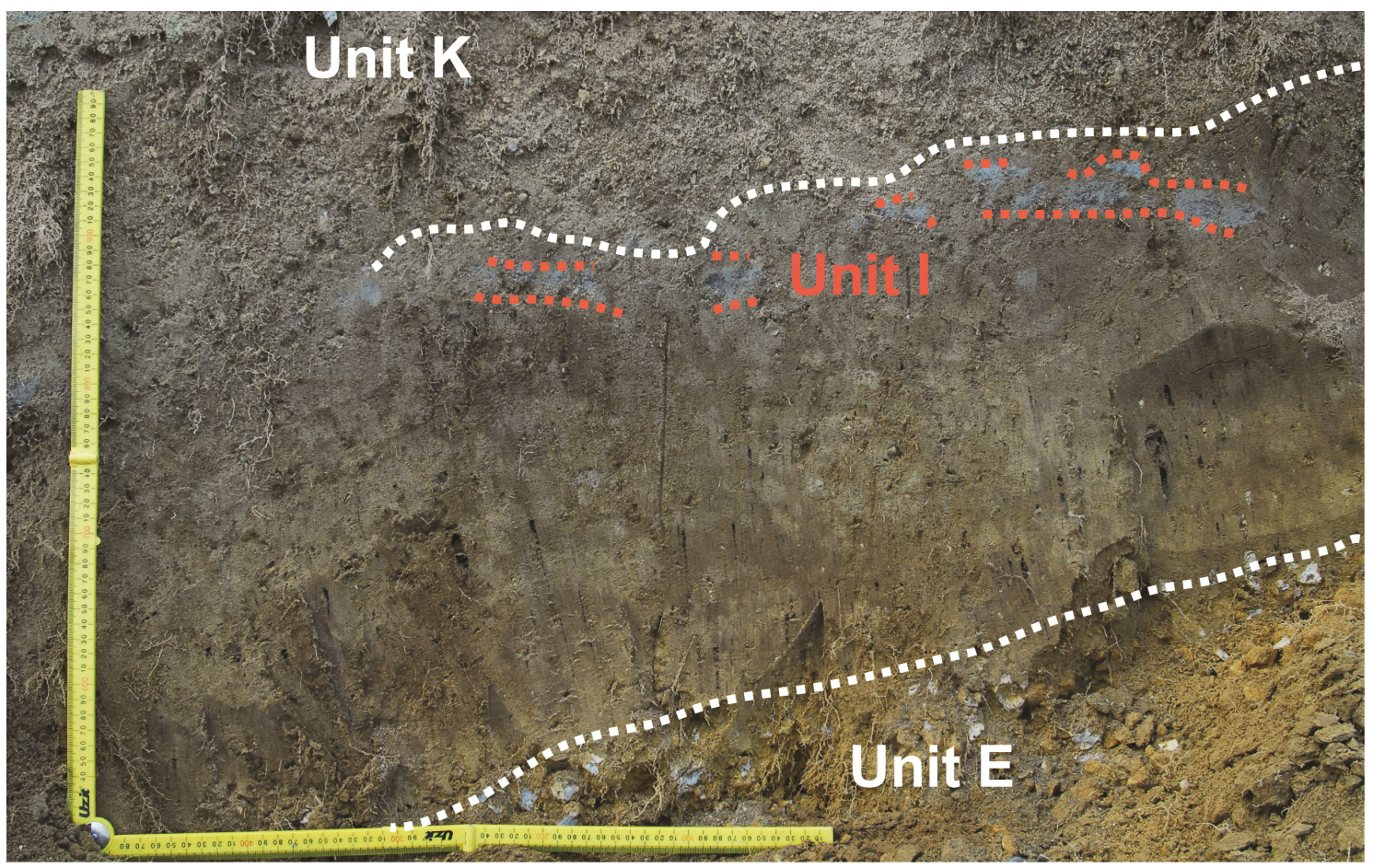

Figure 2.12. Sampling location for Unit I within the new Highway 1 Taupo bypass road cutting at locality 3051 . Ruler is $50 \mathrm{~cm}$ in either direction for scale. 
changes (Wilson, 1993). The initial part of the deposit (K1) has normal grading and is water flushed with lithics dominated by obsidian, suggesting possible lava extrusion accompanied the eruption (Wilson, 1993). Isopach data indicates a vent in the northeastern part of Lake Taupo (Figure 2.9). The second part of the deposit (K2) is defined by an increase in grainsize and an influx of fines rich matrix, suggesting a variable increase in eruption vigour, with more open-vent style of activity from a similar vent source (Wilson, 1993). Two bands within K2 are the coarsest within the eruption deposit and were targeted for sample collection. Pumices from Unit K were collected from the Waimihia Forest (Figure 2.2), where K2 is thickest and coarsest (see loc 35, and Figure 25 from Wilson, 1993), and is clearly underlain by earlier Hinemaiaia units and covered by Unit M, and then coarse Unit S.

\subsubsection{Unit L}

Unit L is reported by Wilson (1993) as a thin fall deposit exposed only in the southeastern Taupo region. The deposit is separated from Unit K by a thin palaeosol, interpreted to represent only a few decades time break and thus providing an age estimate of $\sim 5.3 \mathrm{ka}$. The Unit $\mathrm{L}$ fall deposit is defined at the Hinemaiaia type-locality 2380 (Figure 2.11b), where it consists of poorly sorted fine ash to lapilli. Pumices are moderately vesicular and there is an abundance of obsidian lithics, suggesting the eruption was accompanied by possible lava extrusion. Pumices and obsidian were collected from this type-locality on Opawa Road (Figure 2.2 and 2.11b). Limited exposure of the Unit L tephra means that the isopach maps of Wilson (1993) only roughly estimated a source within the central eastern region of Lake Taupo. Further field work since has identified a likely vent location for the Unit L tephra around the White Cliffs on the eastern edge of Lake Taupo (Figure 2.9). At this location, an obsidian rich lava dome is exposed in the shoreline cliffs below Unit Y ignimbrite (Figure 2.13a). At lake level, where exposed, the lava is overlain by Unit Y ignimbrite but is mostly devitrified, and therefore deemed not suitable for analysis in this study (Figure 2.13b). Above the top of the White Cliffs, there are fresher sections of lava exposed within the thick vegetation where fragments of glassy obsidian were collected in situ for comparison with the Unit L tephra (Figure 2.13c,d).

\subsubsection{Unit M}

Unit M is defined as a dry-type eruption by Wilson (1993), which is mainly found as a normally graded fines-poor fall deposit in the northeast region of Taupo. Lithics are 

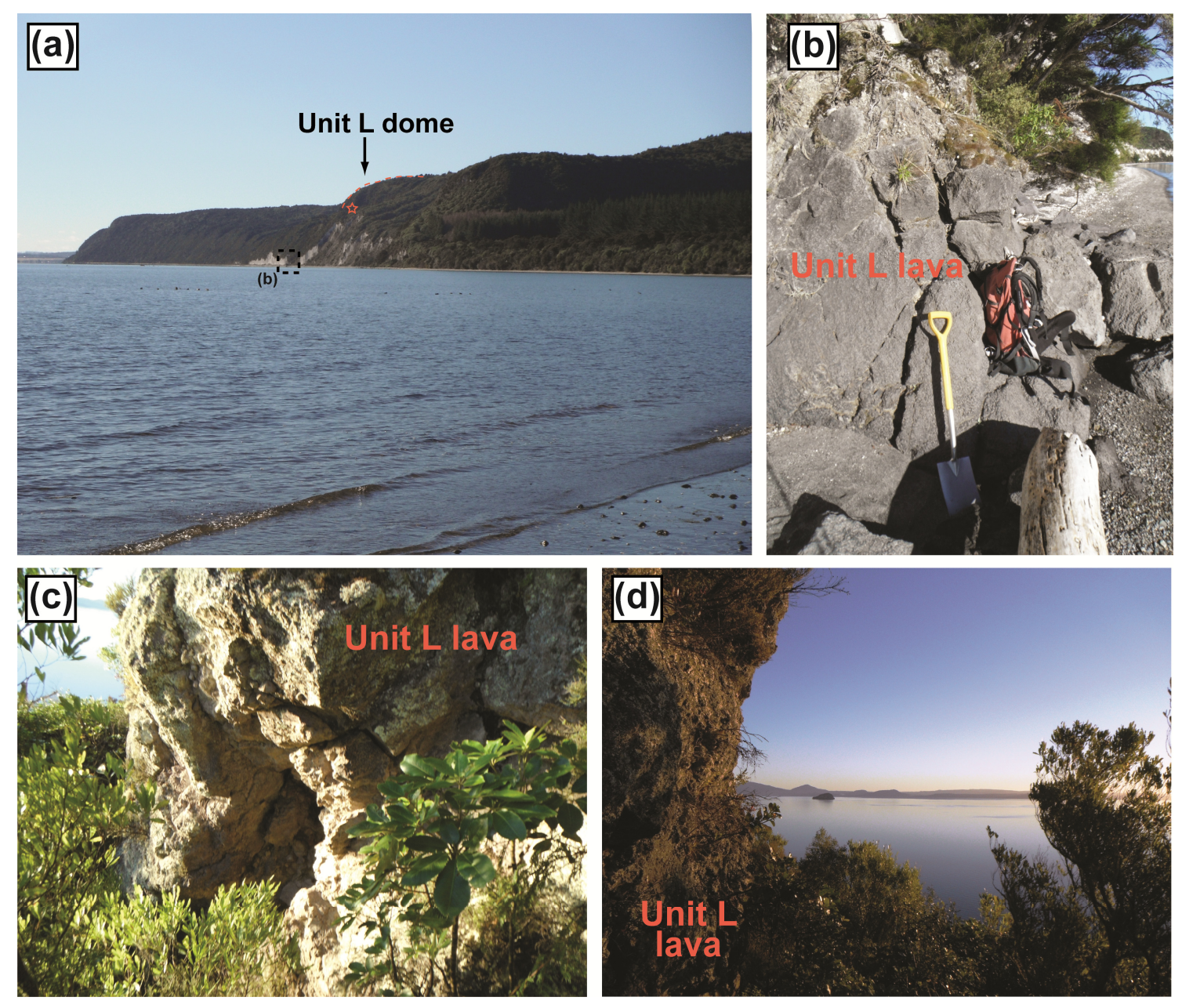

Figure 2.13. Sampling location for Unit L lava from the White Cliffs on the eastern shoreline of Lake Taupo. a) North-facing view of the White Cliffs from the shoreline of Lake Taupo $4 \mathrm{~km}$ north of Hatepe and the Hinemaiaia river outlet. Inset black box denotes approximate location of photo (b). Red star indicates approximate sampling location of the Unit L lava. b) Devitrified lava at lake level inferred to be from the Unit L dome, overlain by the Unit Y ignimbrite. c) Outcrop of obsidian lava from the top of the White Cliffs where the Unit L lava sample was collected. d) South-facing view of the Unit L lava outcrop with Lake Taupo and Motutaiko Island in the background. The base of the cliff consists of massive lava that is covered by weathered lava and then ignimbrite.

dominated by obsidian, suggesting the eruption accompanied lava extrusion from a vent located at the northern end of the SG2 vent lineation (Wilson, 1993; Figure 2.9). Age dating of a well developed palaeosol following units L and M led Wilson (1993) to estimate an eruption age of $<5.3 \mathrm{ka}$ for Unit M (Table 2.1). Pumice from Unit M was collected from a well exposed Hinemaiaia section on Mapara Road, $\sim 100$ m east of the intersection with Highland Drive (Figure 2.2 and 2.14). This road cutting was recorded as the type-locality (loc 2355) for Unit $\mathrm{N}$ and later Hinemaiaia units by Wilson (1993).

\subsubsection{Unit $N$}

A time break of $\sim 300$ years following the Unit M eruption was then followed by the eruption of the Unit $\mathrm{N}$ fall deposit, described as a mixed wet and dry deposit by Wilson 


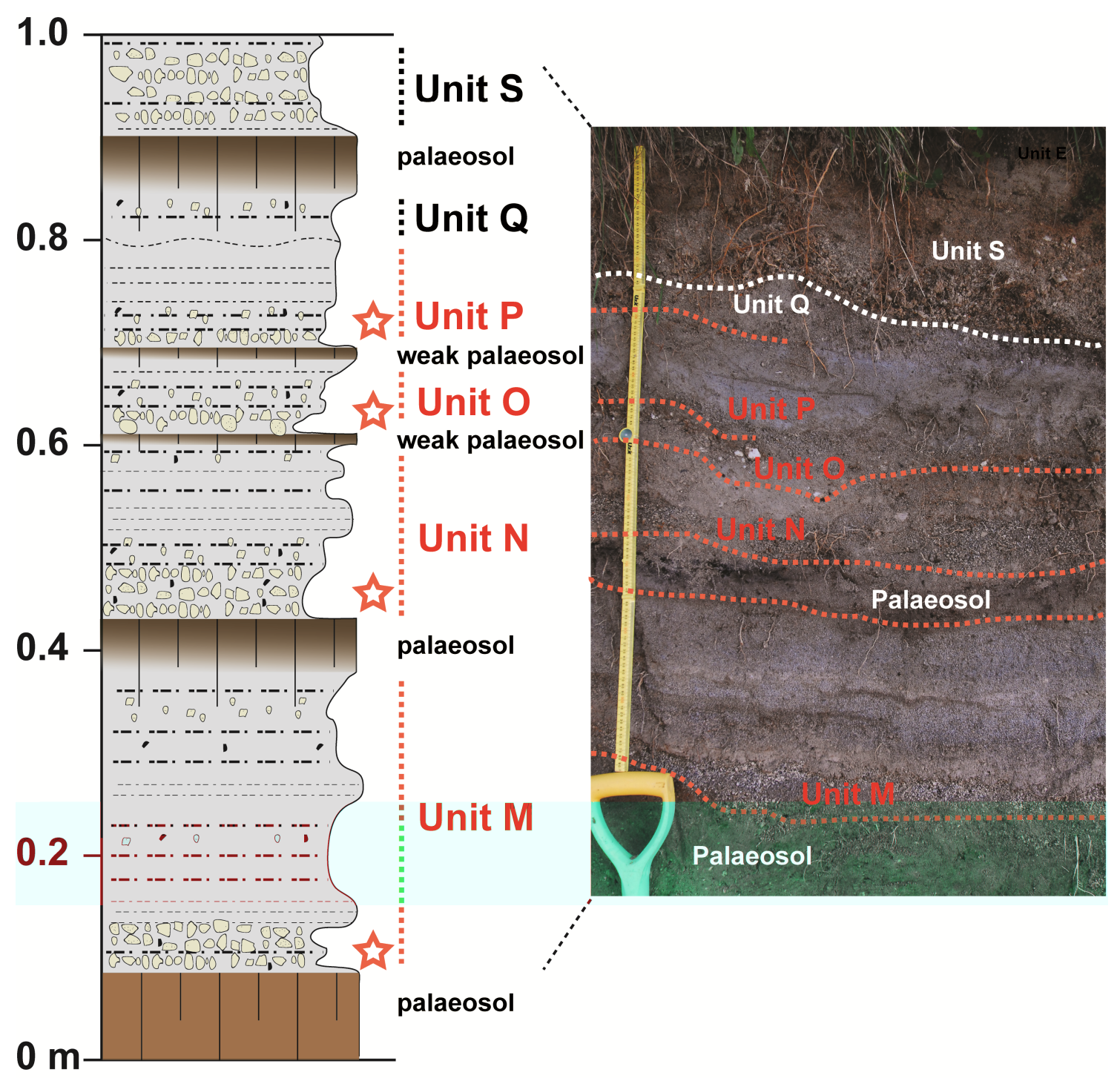

Figure 2.14. Stratigraphic section and matching photos from the type locality and sampling location for units M, N, O and P. Red stars represent approximate sampling location of pumices. Stratigraphic log details as in Figure 2.5.

(1993) with obsidian lithics suggestive of accompanying lava extrusion. Unit $\mathrm{N}$ was similar to Unit $\mathrm{M}$ as it was small in size at $\sim 0.15 \mathrm{~km}^{3}$ and vented from the northern end of the SG2 vent lineation (Figure 2.9). Unit N pumices were collected from the typelocality on Mapara Road, where it is clearly underlain by Unit M and a carbonaceous palaeosol and covered by later Hinemaiaia units (Figure 2.14).

\subsubsection{Unit O}

Unit $\mathrm{O}$ was a small but powerful eruption by Hinemaiaia standards and is unique in the SG2 sequence as its inferred vent location lies off the main vent lineation in the northwestern side of Lake Taupo (Figure 2.9; Wilson, 1993). Its deposits are defined by a thin, fines-poor basal lapilli layer and then poorly sorted ash separated from Unit $\mathrm{N}$ by incipient soil development and bioturbation, interpreted to represent a few decades time 
break. Lithic clasts are dominantly obsidian, indicative of accompanying lava extrusion (Wilson, 1993). Unit O pumices were collected from the same type-locality as for Unit $\mathrm{N}$ on Mapara Road (Figure 2.14).

\subsubsection{Unit $P$}

The Unit P deposit is a very poorly sorted fall layer, separated from Unit O by only a thin layer of soil development and bioturbation, inferred to represent a few decades time break (Wilson, 1993; Table 2.1). Limited isopach data restrict precise location of the vent for Unit $\mathrm{P}$, but it is only exposed to the north of Taupo and rapidly thins indicating small volume. Coarse ash was collected from inferred Unit P from the same typelocality as units $\mathrm{N}$ and $\mathrm{P}$ on Mapara Road (Figure 2.14).

\subsubsection{Unit Q}

Unit $\mathrm{Q}$ is a thin, poorly preserved fall deposit preserved in the east of Taupo in the preUnit S palaeosol, with an assigned age of $\sim 4.6 \mathrm{ka}$ (Table 2.1; Wilson, 1993). The fall deposit is poorly sorted and obsidian lithics indicate possible lava extrusion accompanied this moderately powerful eruption. Isopach maps suggest a vent location in the northern segment of the SG2 main vent lineation (Figure 2.9). Unit Q was collected from the type-locality defined by Wilson (1993) on Opawa Road (loc 2380), where it is clearly underlain by Unit $\mathrm{N}$ and overlain by thin Unit R and then thick Unit $\mathrm{S}$ (Figure 2.11b).

\subsubsection{Unit R}

The final eruption of the Hinemaiaia sequence, Unit R is described as a small volume, relatively weak, but open-vent eruption (Wilson, 1993). The Unit R fall deposit is only found in the southeast of Taupo with a fines poor, normally graded basal deposit overlain by a poorly sorted and water flushed layer that is often bioturbated into the overlying soil. Dating of the overlying pre-Unit S soil provides an estimated age of $\sim 4.5$ $\mathrm{ka}$ (Wilson, 1993). Unit $\mathrm{R}$ is unique in the Hinemaiaia sequence as it is interpreted to be from a vent further south than Motutaiko Island (Figure 2.9). Coarse ash and fine lapilli from the Unit R eruption were collected from the type locality described by Wilson (1993) (Figure 2.15), where the deposit is clearly underlain by traces of older Hinemaiaia units and then covered by a thick palaeosol and the Unit S (Waimihia) deposit. 


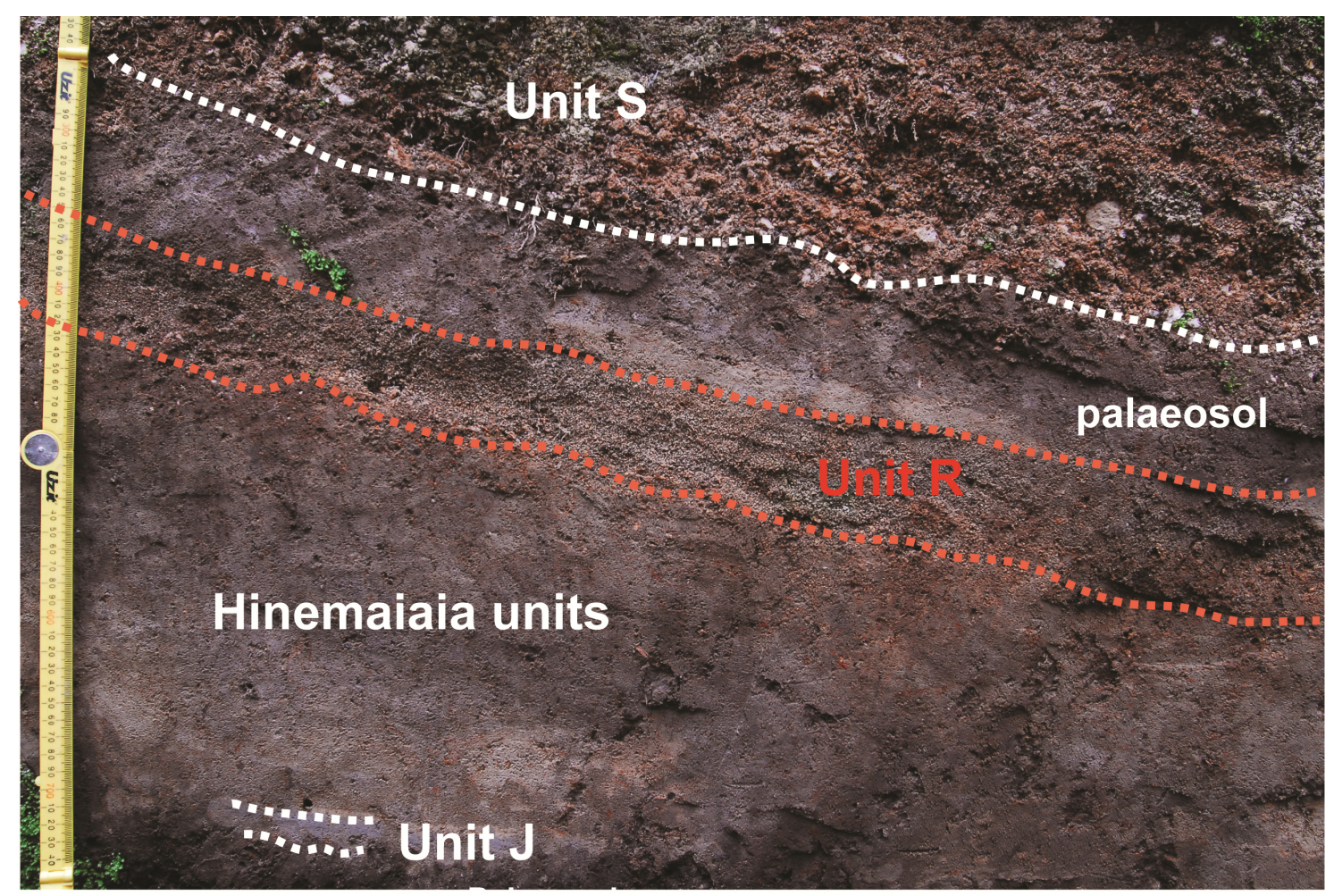

Figure 2.15. Sampling location for the Unit R deposit from the type locality of Wilson (1993) on Whataroa Road, $100 \mathrm{~m}$ from junction with Hingapo Road (loc 2359). Ruler is $50 \mathrm{~cm}$ for scale.

\subsubsection{Unit S (Waimihia Tephra)}

The 'Waimihia Tephra' is recognised as one of the largest young plinian fall deposits in the TVZ at 3.6 ka (Healy, 1964; Walker, 1981a; Froggatt \& Lowe, 1990; Blake et al., 1992; Wilson, 1993; Table 2.1). Labelled Unit $\mathrm{S}$ in the post-Oruanui eruption sequence (Wilson, 1993), the Waimihia eruption is unusual in its eruptive size and products. The deposit consists of a large pumice fall deposit (Walker, 1981a) and a late-stage nonwelded ignimbrite. The fall unit is split into two subunits, the lower Waimihia (S1) and the upper Waimihia (S2), which have different dispersal axes but similar grainsize characteristics and volume, indicative of equally powerful phases of sustained plinian activity (Walker, 1981a; Blake et al., 1992; Wilson, 1993). The Waimihia eruption is an archetypical example of a mixed-magma eruption (Blake et al., 1992). Subunit S1 contains almost purely white rhyolitic pumice, with a minor $(<5 \%)$ but increasing proportion of rhyodacite and streaky mixed pumices and very minor $(<0.05 \%)$ andesitic scoria (Figure 2.16). Subunit S2 contains up to $28 \%$ rhyodacite (that decreases in abundance towards the top of the deposit) and $\sim 0.2-0.8 \%$ scoria clasts (that increase in abundance towards the top of the deposit) (Blake et al., 1992). Isopleth maps indicate a similar vent location for subunits S1 and S2 and the deposits show little evidence for water interaction or lava extrusion throughout the eruption (Walker, 1981a). Subunit S3 is a non-welded ignimbrite that is found up to $20 \mathrm{~km}$ from source and is associated 

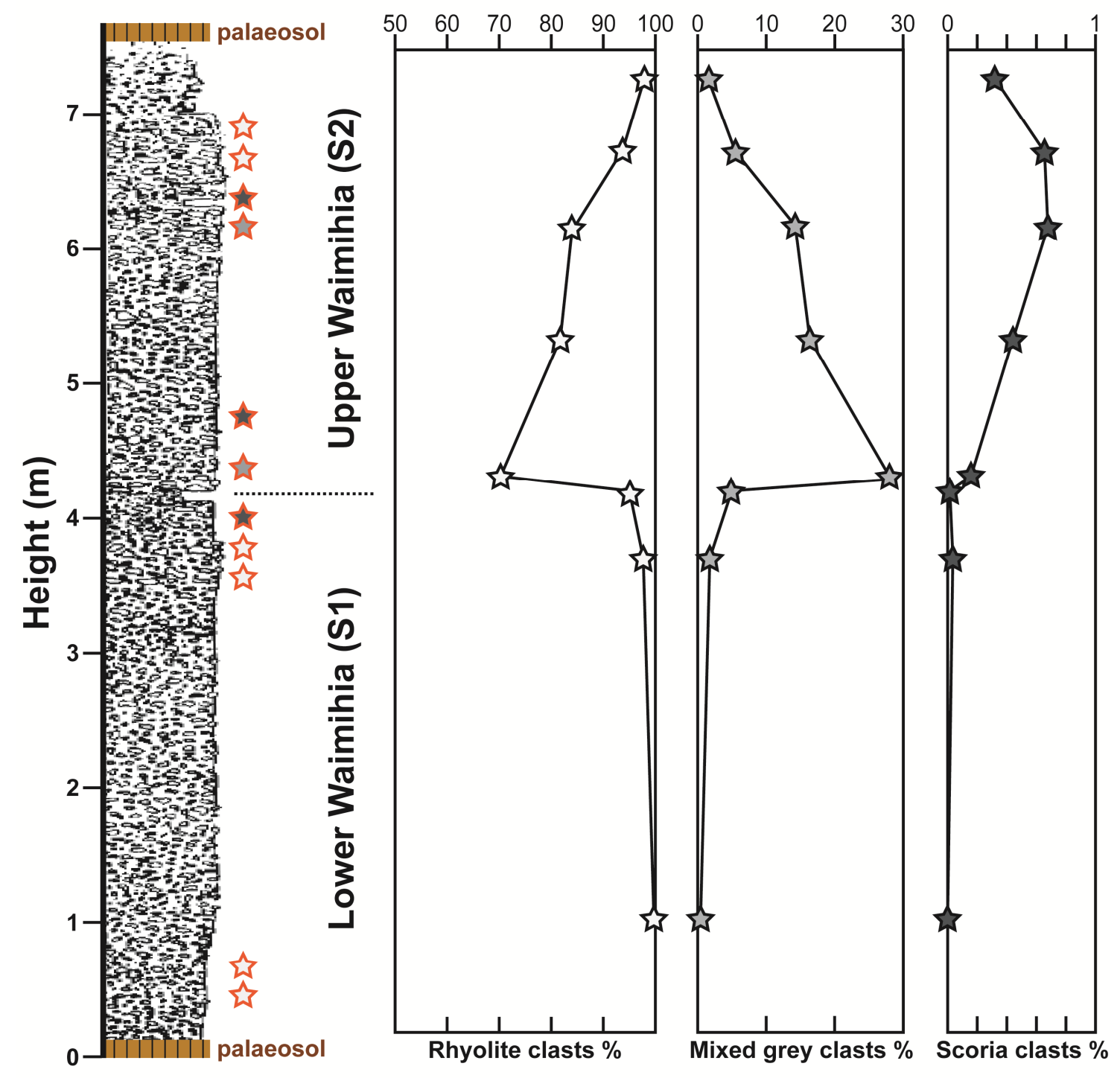

Figure 2.16. Stratigraphic section and clast-type abundances for the reference location where Unit $S$ pumice and scoria were collected (modified from Blake et al., 1992). Red stars indicate approximate sampling location of the different clast types, with fill representing the three clasts types where white is rhyolite, light grey is mixed rhyodacite and dark grey is andesite scoria.

with the late stage waning of the S2 eruption plume (Wilson, 1993).

Pumice and scoria were collected for this study from both subunits S1 and S2 from multiple locations in the Waimihia Forest close to the reference locality on High Level Road described by Walker (1981a) and Blake et al. (1992) (Figure 2.2 and 2.16). Rhyolite clasts were collected from multiple levels throughout the lower and upper fall units as the forestry road cut through the deposit, and rhyodacite and scoria clasts were dominantly collected from the lower-upper contact and the upper fall unit where they are most abundant (Figure 2.16). In addition, large white rhyolite clasts were collected from the Hinemaiaia type-locality on Opawa Road which represent the very basal Unit $\mathrm{S}$ material that clearly rests on the older Hinemaiaia units (Figure 2.11b). Multiple large 
pumices from subunit S1 were also collected for bulk zircon separates from the same Highway 1 cutting (loc 3051) as Unit B3 and E3 (Figure 2.6).

\subsubsection{Unit T}

Wilson (1993) identified an additional tephra unit in the palaeosol above the Waimihia tephra, with an assigned age of $\sim 3.2 \mathrm{ka}$. Unit $\mathrm{T}$ is described as a thin poorly sorted and matrix rich deposit with abundant angular obsidian fragments indicative of wet explosive activity accompanying extrusive activity (Table 2.1). Isopach/isopleth maps are poorly constrained due to limited exposure to the east of Lake Taupo but suggest a vent of similar location to Unit S (Wilson, 1993; Figure 2.9). Pumice lapilli and obsidian were collected from a Unit $\mathrm{T}$ deposit within a road cutting on Highway 5, a reference location from Wilson (1993) (loc 2398; Figure 41 of Wilson, 1993).

\subsubsection{Unit U}

Originally recorded as part of the Whakaipo Tephra Formation by Vucetich \& Pullar (1973), Wilson (1993) identified Unit U as a separate tephra between Unit T and Unit $\mathrm{V}$, with charcoal in the palaeosol yielding an age estimate of $2.9 \mathrm{ka}$. Unit $\mathrm{U}$ is defined as a very poorly sorted deposit, rich in vesicular ash matrix, with lithics dominated by fresh black obsidian (Wilson, 1993). The deposit is bilobate and isopach/isopleth maps indicate a vent similar in location to the Waimihia eruption (Unit S) (Figure 2.9). Pumice from Unit U was collected from a forestry road cutting on Te Heu Heu Road, at the type locality described by Wilson (1993). At this location, Unit U is clearly underlain by Unit $\mathrm{T}$ and reworked sediments from the Waimihia eruption, then overlain by a thin palaeosol, Unit V, Unit X and then a large section of Unit Y (Figure 2.17, loc 2378).

\subsubsection{Unit V (Whakaipo Tephra)}

The 'Whakaipo Tephra' was originally described by Vucetich \& Pullar (1973) to include Unit U, but then later re-interpreted by Wilson (1993) to represent two separate events split by a thin palaeosol. $C^{14}$ dating by Froggatt \& Lowe (1990) led to an eruption age estimate of $\sim 2.8 \mathrm{ka}$. Unit V is described as a well-bedded fall deposit arising from a complex and episodic eruption with variable magma supply rate and water interaction (Wilson, 1993; Table 2.1). Isopach data are bilobate and indicative of a vent located in the northeast segment of Lake Taupo (Figure 2.9). Pumices from Unit V were collected for this study from two localities (Figure 2.2). The first locality was the reference 


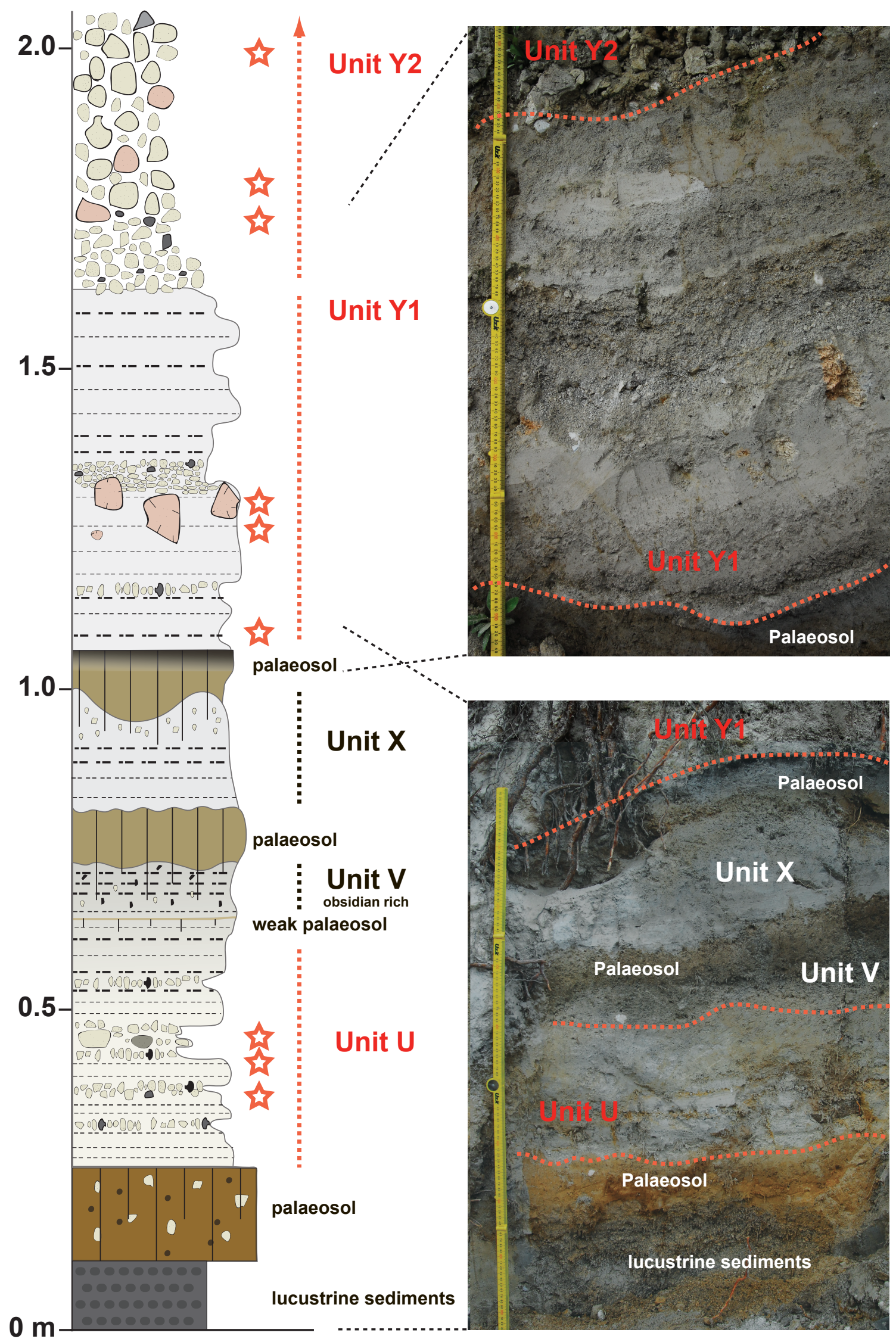

Figure 2.17. Stratigraphic section and matching photos from the type locality and sampling location for Unit U and Units Y1 (initial ash) and Y2 (Hatepe plinian). Red stars represent approximate sampling location of pumices. Stratigraphic log details as in Figure 2.5. 
locality given by Wilson (1993) on a fossil shoreline cliff on the eastern shore of Lake Taupo near SH1 (loc 2345), where Unit V underlies lacustrine sediments and Unit X. However, the majority of pumices were weathered and stained by overlying sediments at this location. Additional samples were therefore collected from a new location on the Wakeman Road bypass in Acacia Bay (Figure 2.2, 2.18). At this locality, Unit V pumices were much fresher and clearly underlain by a weak palaeosol then Unit $U$ and overlain by Unit X.

\subsubsection{Unit W}

Unit W was identified by Wilson (1993) as a localised, small volume fall deposit overlying Unit V in eastern Taupo, exposed along SH1 between Hatepe and Waitahanui. Field relationships indicate a time break of only a few decades between units V and W (Table 2.1; Wilson, 1993). The Unit W fall deposit is poorly sorted and dominated by obsidian ranging from ash to block sizes, interpreted to reflect weak explosive activity accompanying lava extrusion. The fall deposit changes rapidly moving away from the type locality defined by Wilson (1993) on the Ouaha Hill stretch of SH1, indicating a vent in close proximity. Wilson (1993) therefore suggested that the Ouaha Hill lava dome was likely the source for Unit W (Figure 2.9). Notably, this is off the main lineation of SG2 vents but passes closely to the inferred vent for the earlier Unit L eruption. Obsidian fragments were collected for this study from the type locality road cutting on SH1 described by Wilson (1993).

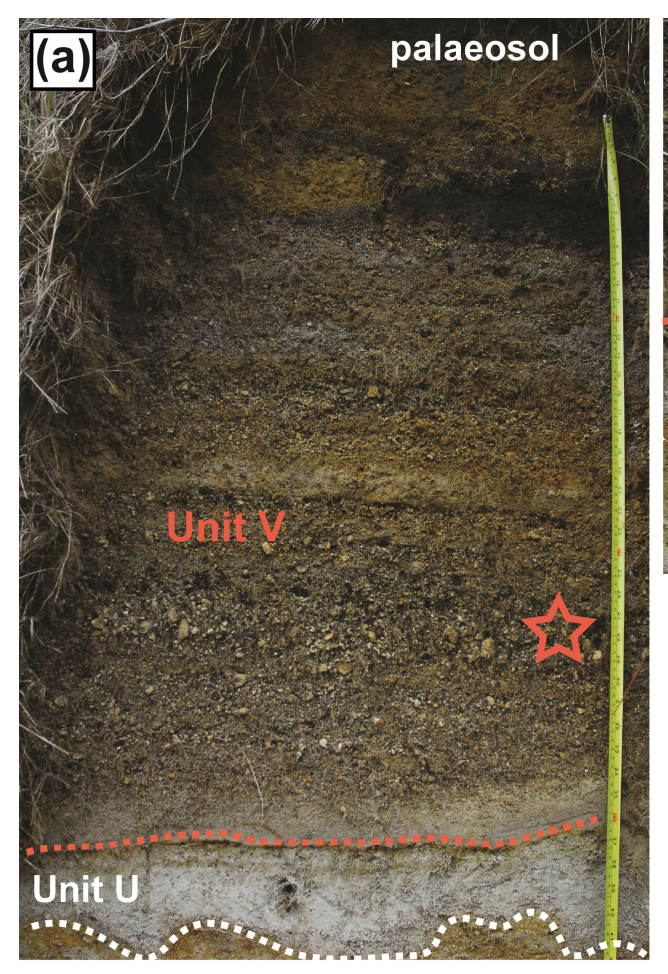

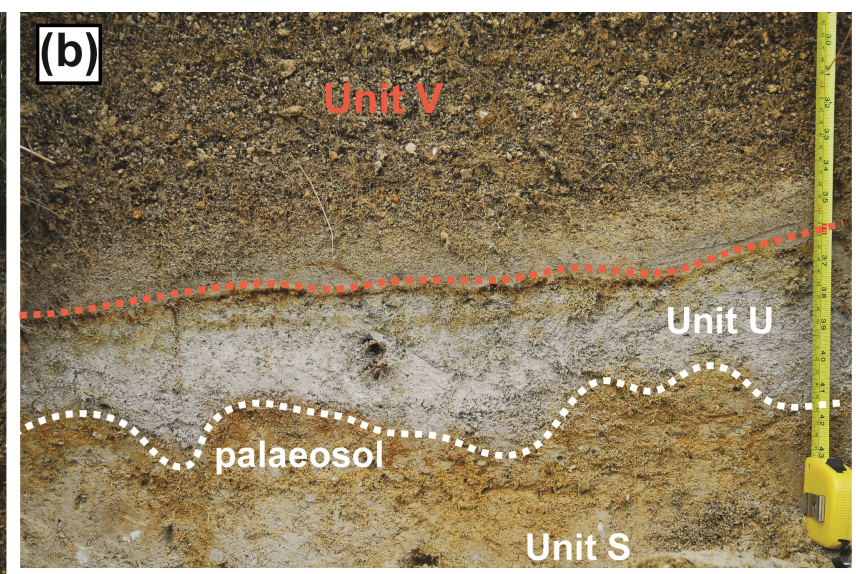

Figure 2.18. Sampling location for Unit V by the newly developed Acacia Bay bypass on Wakeman Road. a) The complete succession of Unit V with the sampling area denoted by the red star. Unit $\mathrm{X}$ is not shown but overlies the top of $\mathrm{V}$ and a $15 \mathrm{~cm}$ thick palaeosol. Measuring tape is $110 \mathrm{~cm}$. b) Close up photo from the base of (a) showing the thin but distinct palaeosol between Unit U and Unit V. Measuring tape is $40 \mathrm{~cm}$. 


\subsubsection{Unit X (Mapara Tephra)}

The 'Mapara Tephra Formation' was described by Vucetich \& Pullar (1973) and later reinterpreted and labelled as Unit X by Wilson (1993). The Unit X eruption is the first of the SG3 rhyolites, with an assigned age of $\sim 2.2$ ka (Froggatt \& Lowe, 1990; Wilson, 1993). The Unit X fall deposit is complexly bedded, variably but non-systematically water-flushed, and split into three subunits X1-X3 based on bedding characteristics. Subunit X1 is normally graded and the least water-flushed and thinnest subunit, demarcated from X2 by the onset of significant water-flushing, poor sorting and rounding of pyroclasts (Wilson, 1993). X2 is the thickest subunit, with multiple vaguely bedded layers. X3 is distinguished by increasing lithic abundance and obsidian or poorly vesicular pumice fragments indicative of extrusive activity. Unit X as a whole represents a complex, moderately powerful eruption that experienced variable eruption rate and water interaction (Wilson, 1993; Table 2.1). Isopach data indicates a single vent for Unit $\mathrm{X}$ in the northeast region of Lake Taupo, overlapping with the earlier Unit $\mathrm{V}$ eruption (Figure 2.19).

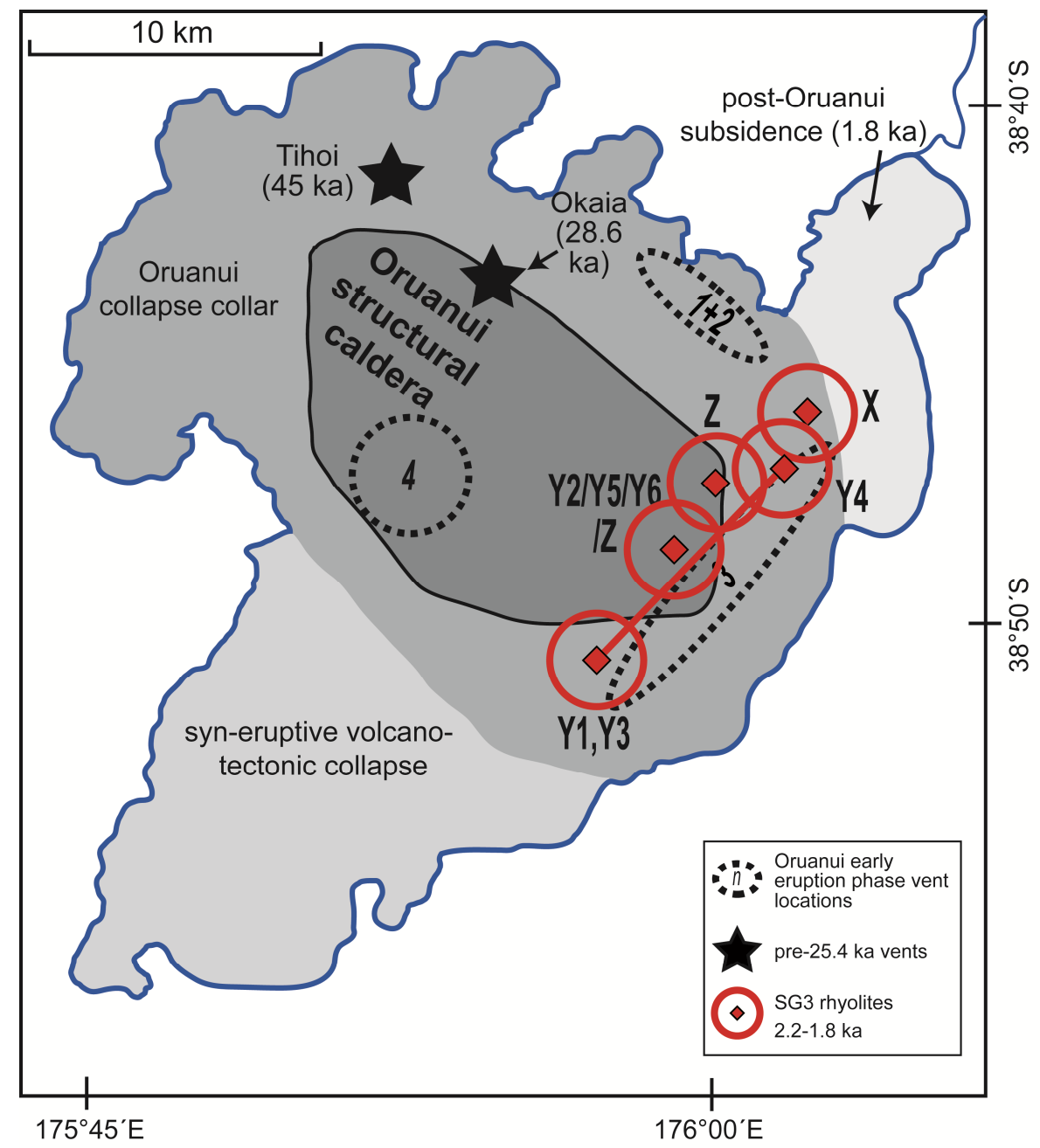

Figure 2.19. Inferred vent locations for the Subgroup 3 (SG3) eruptions and subunits. Modified from Wilson (1993) All other details as in Figure 2.1. 
Pumices from Unit X were collected from the reference locality described by Wilson (1993) on a fossil shoreline cliff on the eastern shore of Lake Taupo near SH1 (loc 2345) (Figure 2.2). At this locality, Unit $\mathrm{X}$ is underlain by lacustrine sediments and Unit V, and overlain by Unit Y (Figure 2.20a, see also Figure 48 from Wilson, 1993). Pumice were sampled from the bottom $30 \mathrm{~cm}$ of the deposit (X1), and from the top contact (X3) that was notably rich in lithics and obsidian clasts (Figure 2.20b).

\subsubsection{Unit Y (Taupo Tephra)}

The 'Taupo Tephra' was first described in detail by Healy (1964) and is recognised as the youngest and largest pyroclastic eruption from Taupo in the post-Oruanui sequence. The Taupo eruption, or Unit Y, as labelled by Wilson (1993), is the second largest known eruption globally in the last 2000 years, and the most powerful eruption in the past 5000 years (Houghton et al., 2010). Average $C^{14}$ dating by Froggatt \& Lowe (1990) led to an eruption age estimate of $\sim 1.8 \mathrm{ka}$ (Wilson, 1993). However, the exact historical date of the Taupo eruption has been a matter of debate with several lines of evidence producing contrasting ages. Initial estimates based on a putative correlation between Roman and Chinese records of atmospheric phenomena were used by Wilson et al. (1980) to suggest a calendar date of ca. AD 186. This was supported by precise dating of a layer of sulphuric acid in the GISP2 (Greenland) ice sheet, dated at AD 181 \pm 2 , inferred to have been derived from the Taupo-eruption-generated sulphate aerosols
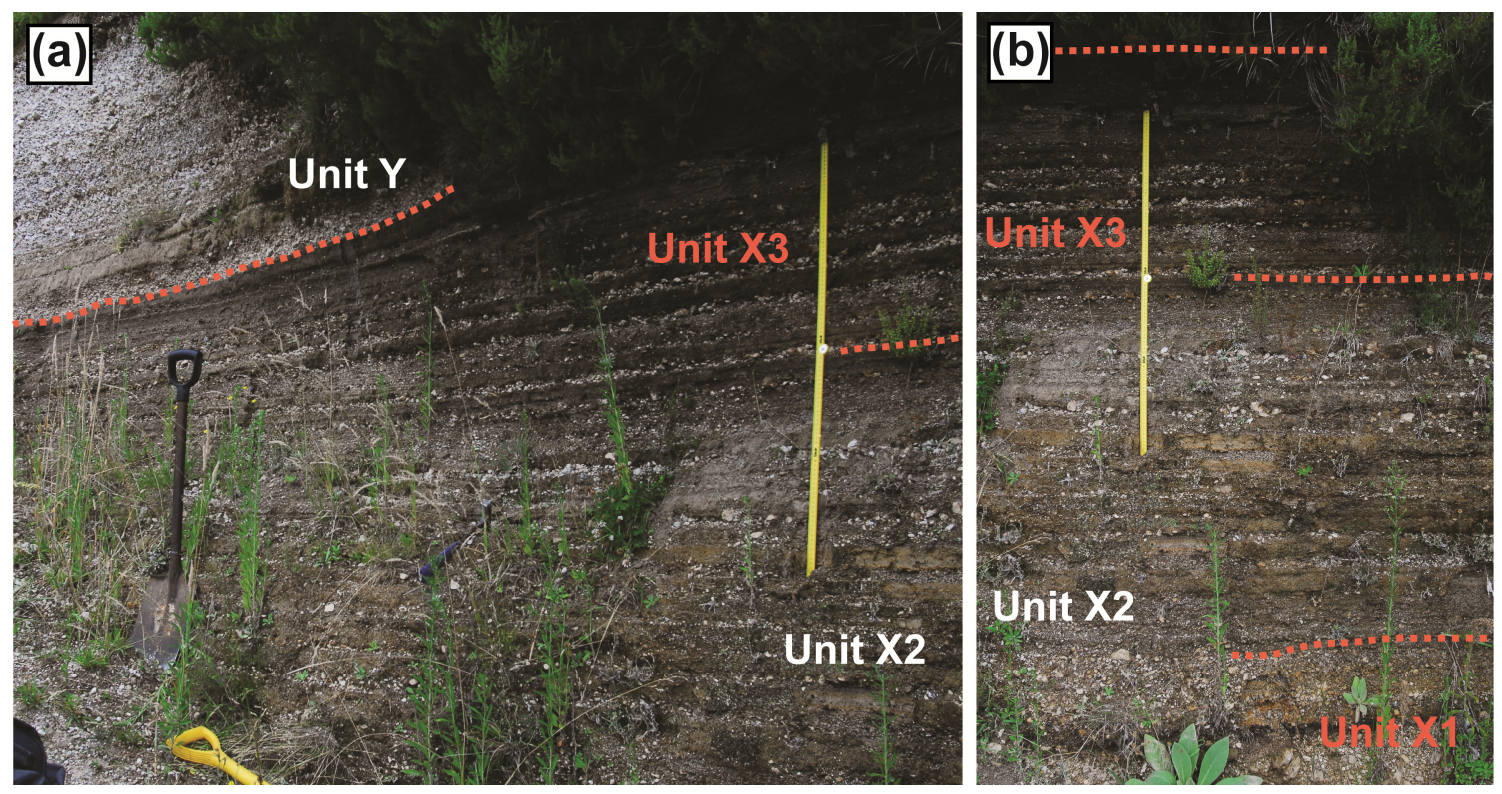

Figure 2.20. Sampling location for Unit X (Mapara Tephra) at the reference locality of Wilson (1993). Subunits X1 and X3 were sampled for the first and last erupted material. a) Subunits X2-X3 covered by the products of the Unit Y eruption. b) Close up of the Unit X deposit where subunits X1 and X3 were sampled. Ruler is $1 \mathrm{~m}$ for scale. 
(Zielinski et al., 1994). However, later $C^{14}$ calibrated ages by Sparks et al. (1995) and 25 wiggle matched high-precision $\mathrm{C}^{14}$ dates on Kauri trees buried by the eruption (Hogg et al., 2012) suggest a younger eruption date of AD $232 \pm 5$ that is adopted in this study.

Eruption Y has been the subject of multiple detailed physical volcanology studies due to its young age, large size and variable eruptive style (Walker, 1980, 1981a, b; Wilson, 1985, 1993; Wilson \& Walker, 1985; Smith \& Houghton, 1995; Smith, 1998; Houghton et al., 2010, 2014). The associated deposits are split into seven subunits based on widespread changes in eruptive intensity, degrees of magma:water interaction and apparent shifting vent positions (Healy, 1964; Froggatt, 1981d; Wilson \& Walker, 1985; Wilson, 1993; Smith \& Houghton, 1995; Houghton et al., 2010; Table 2.1). The first erupted material (Y1-initial ash layer) is fine grained and poorly sorted, representing minor wet activity, comparable in size, eruptive mechanisms and dispersal to many of the smaller Hinemaiaia events (Wilson, 1993). The second phase of the eruption (Y2- Hatepe plinian pumice) produced a well sorted deposit, representing a sustained eruption period where water was restricted from entering the vent (Walker, 1981a). Vent shifting or widening and erosion towards the end of Y2 allowed water to infiltrate the eruption plume to generate a period of vigorous phreatomagmatic 'wet' activity (Y3-Hatepe ash). Subunits Y1-Y3 were erupted from a vent or possibly two vents located in the eastern part of Lake Taupo, in the southern end of the eastern vent lineation with a total eruptive volume similar to Unit E (Figure 2.2, 2.19; Table 2.1; Wilson, 1993; Smith \& Houghton, 1995; Houghton et al. 2010). After a short time break the eruption then continued from a vent located to the northeast of the Y1-Y3 vent (Figure 2.19; Smith \& Houghton, 1995; Houghton et al. 2010). Subunit Y4 (Rotongaio ash) represents another phase of phreatomagmatic activity which generated a poorly sorted, typically fine grained but variably bedded deposit rich in juvenile obsidian fragments, indicating significant fluctuations in magma:water interaction accompanying outgassing and dome extrusion (Wilson, 1993; Smith \& Houghton, 1995; Houghton et al. 2010). Dry activity then commenced (likely overlapping with the $\mathrm{Y} 4$ phase) from a new central vent overlapping with the Horomatangi Reefs (Figure 2.19), producing a deposit notably wide in its dispersal across the North Island (Walker, 1980). Subunit Y5 (Taupo plinian pumice) is characterized by fluctuations in mass discharge rate and punctuated short-lived partial column collapses generating low-energy co-plinian pyroclastic density currents (Y6-Early ignimbrite flow units) (Wilson \& Walker, 1985). The Taupo eruption climaxed in its final stages with the eruption of a widespread low- 
aspect ratio unwelded ignimbrite (Y7-Taupo ignimbrite) that was emplaced in about 400 seconds by an extremely energetic, pyroclastic density current travelling at more than 200-300 m/s over $\sim 20000 \mathrm{~km}^{2}$ (Wilson, 1985; Wilson \& Walker, 1985). Subunit Y7 was the most voluminous phase of Unit $Y$, ejecting $>30 \mathrm{~km}^{3}$ of material (Table 2.1)

The Unit $Y$ eruption is unique in the post-Oruanui sequence of eruptions, having the largest eruptive volume by 5-6 fold and resulting in further caldera collapse (Figure 2.1; Table 2.1; Wilson, 1993; Davy \& Caldwell, 1998). In this study, subunits Y1-Y5 and $\mathrm{Y} 7$ have been sampled in detail to investigate chemical variations throughout the Taupo eruption. Y6 has not been sampled as it erupted synchronously with Y5. Material from Y1 (initial ash) was collected from the same type locality as for Unit U on Te Heu Heu Road described by Wilson (1993), where it recorded at its thickest and coarsest (Figures 2.2, 2.17). Isolated blocks that were notably brittle and pink oxidised along with fine lapilli representing the very first-erupted material were sampled. Single pumices from subunit Y2 (Hatepe plinian) were also collected from this location (Figure 2.17) and additional samples were collected throughout the Y2 eruptive deposit and the Y2-Y3 transition from a road cutting near SH1, $1 \mathrm{~km}$ South of Waitahanui village (Figure 2.2). At this location, Y2 clearly overlies Y1 and then transitions into alternating fine grained and coarse layers, reflecting dilute gravity current and rain-flushed beds (Talbot et al., 1994; Figure 2.21). Subunit Y3 (Hatepe ash) was collected from a locality in close proximity to the Y1/Y2 type locality sample site, slightly further up Te Heu Heu Road (Figure 2.2). At this location, pumices were extracted from a coarse band equivalent to layer Ha-C of Smith \& Houghton (1995) (Figure 2.22). Subunit Y4 (Rotongaio ash) was collected from two different locations (Figure 2.2). Coarse lapilli clasts of glassy obsidian and low-vesicularity pumices were collected at an exposure in a forestry road drainage pit off Opawa Road in the Taupo forest, representing material erupted during the middle-phases of Y4. Additional obsidian and pumices were collected from the Y4-Y5 transition from a road cutting on SH5 (Figure 2.2; Figure 2.23). Pumices were also sampled at this location from multiple levels throughout the overlying Y5 (Taupo plinian) deposit. Subunit Y7 (Taupo ignimbrite) was sampled from a typical $>10 \mathrm{~m}$ thick proximal layer 2 deposit in the southern cliffs of Hallets Bay (Figure 2.2; Wilson, 1985). As ignimbrite material may include mixed pumices from earlier eruptive phases, only exceptionally large (decimetre-sized) pumice blocks were collected. Large pumices are considered to most likely represent juvenile material from Y7 as such pumice sizes are uncommon in earlier phases and where present in Y5 they are typically pink oxidised. 


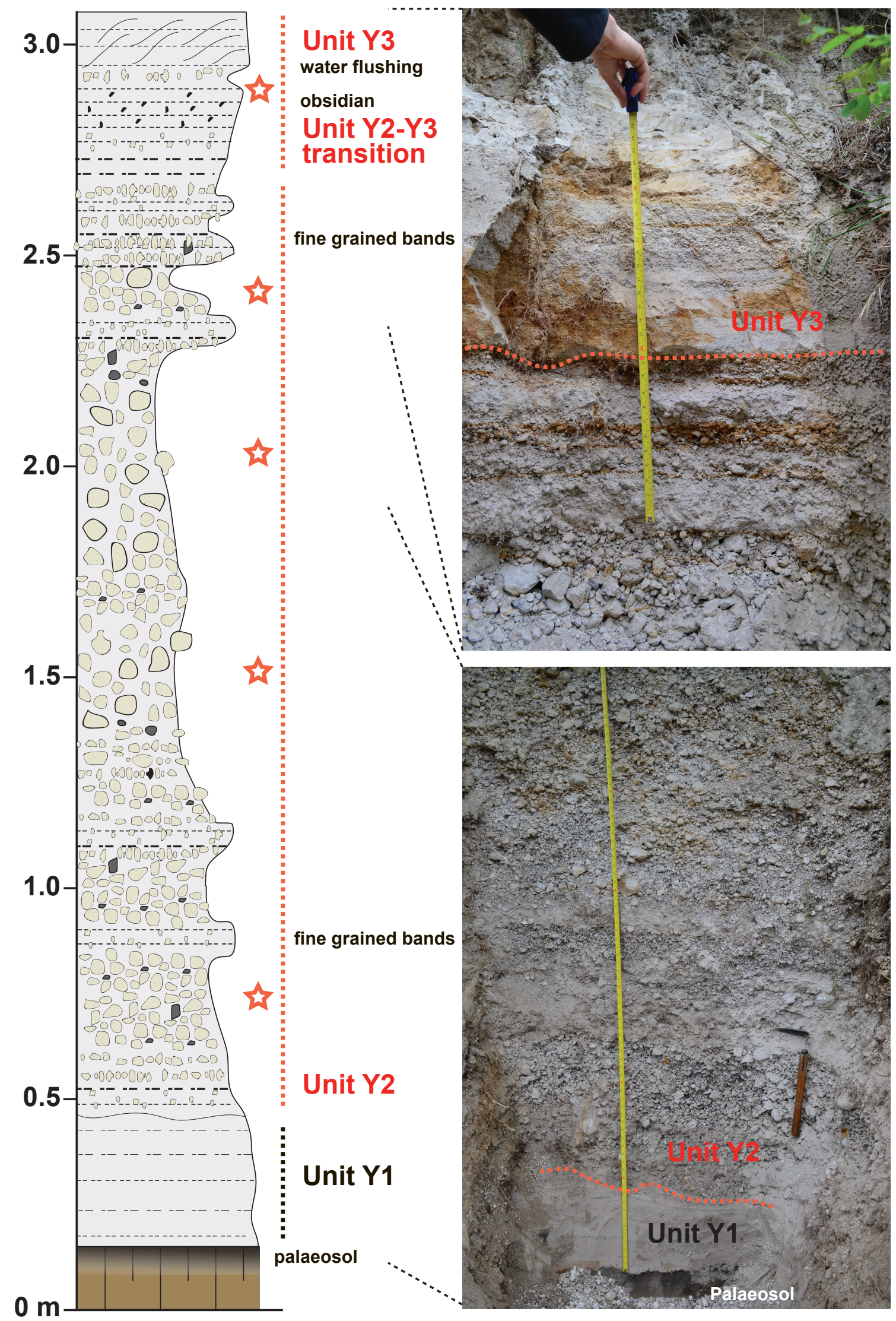

Figure 2.21. Stratigraphic section and matching photos from the sampling location for Unit Y2 (Hatepe plinian) and the Y2-Y3 (Hatepe ash) transition. Red stars represent approximate sampling location of pumices. Fine grained beds within Y2 represent proximal gravity currents and water flushing (Talbot et al., 1994). Stratigraphic log details as in Figure 2.5. 


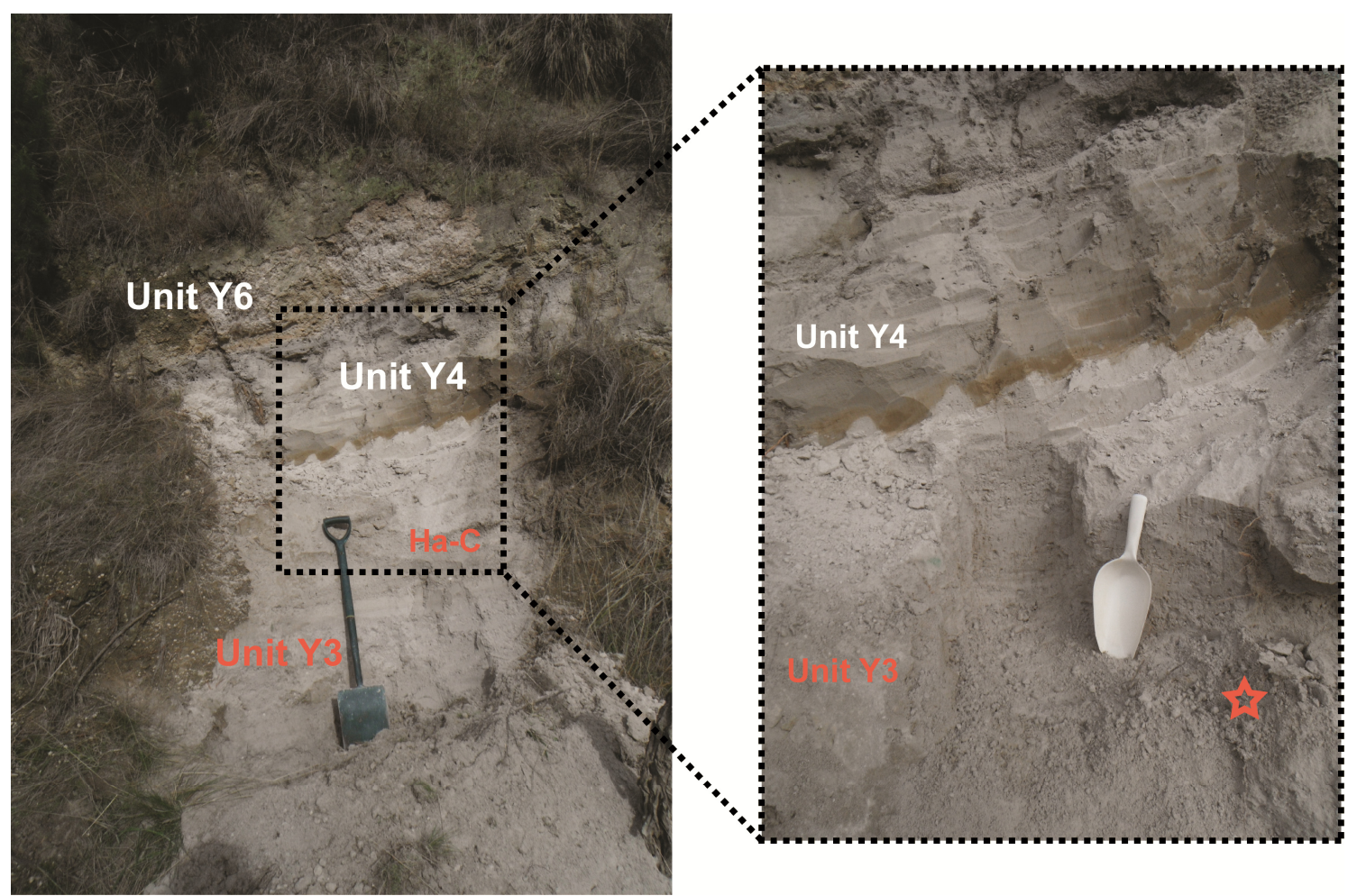

Figure 2.22. Sampling location for Unit Y3 (Hatepe ash). Note the contact between Y3 and Y4 (Rotongaio ash) is erosional. Ha-C refers to the coarse layer 3 in the Hatepe ash (Smith \& Houghton, 1995 ) from which the pumices were sampled as denoted by the red star. Green spade is $\sim 1 \mathrm{~m}$ for scale.

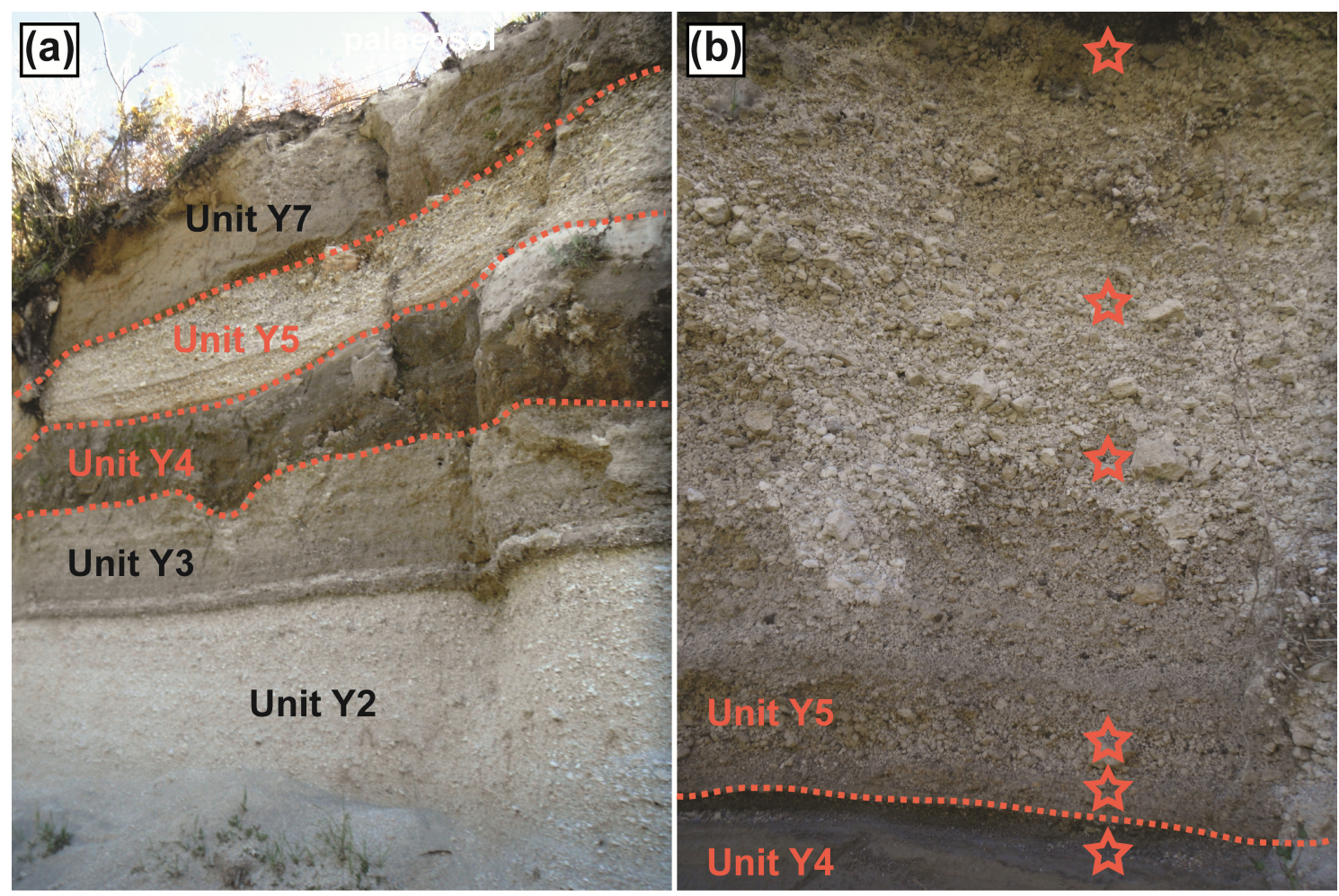

Figure 2.23. Sampling location for Unit Y4(Rotongaio ash)-Y5 (Taupo plinian) transition and Y5 at a road cutting on the SH5 Taupo-Napier road. (a) Photo of subunits Y2-Y5 and Y7 where fully exposed at road level. (b) Close up of the obsidian rich Y4-Y5 transition and the Y5 sequence at road level. Red stars represent approximate sampling location of pumices and obsidian throughout the stratigraphy. 


\subsubsection{Unit Z (Floated giant pumices)}

Blocks of pumiceous rhyolite lava up to several meters in size were reported by Wilson $\&$ Walker (1985) in the post-Unit Y lake sediments, $<10 \mathrm{~m}$ above modern lake level.

These pumice blocks have prismatic jointing and vesicle textures that indicate they were derived from a sublacustrine lava dome but had a low enough overall density to spall off and float into place (Houghton et al. 2010; Rotella et al., 2013). Post-Unit Y blockage of the Waikato river outlet from Lake Taupo resulted in overfilling of the lake basin by $\sim 34 \mathrm{~m}$ over a period of 15-20 years, before breaching triggered the release of $\sim 20 \mathrm{~km}^{3}$ of water down the Waikato river (Wilson et al., 1997; Manville et al., 1999; Riggs et al., 2001). This time gap prior to the lake re-filling in the post-Unit Y period was used to suggest that the giant floated pumices are from a separate eruption and hence labelled Unit Z by Wilson (1993). Both the Horomatangi Reefs and the Waitahanui Bank are considered as likely sources for the Unit Z dome carapace material, as they post-date the Taupo eruption and are covered in glassy pumiceous rhyolite debris (Figure 2.19; Wilson \& Walker, 1985; Houghton et al., 2010). Two floated giant pumices were sampled for this study (Figure 2.2). The first was a large fragment $\sim 8 \mathrm{~m}$ across with prismatic jointing located in an open field $\sim 1 \mathrm{~km}$ south of the SH1 Taupo-bypass/airport roundabout, about $10 \mathrm{~m}$ above current lake level (Figure 2.24a). The second sample was collected from a blocky and brittle fragment now being re-exposed in the eastern lake shoreline ledge between Hatepe and the White Cliffs (Figure 2.2, 2.24b).
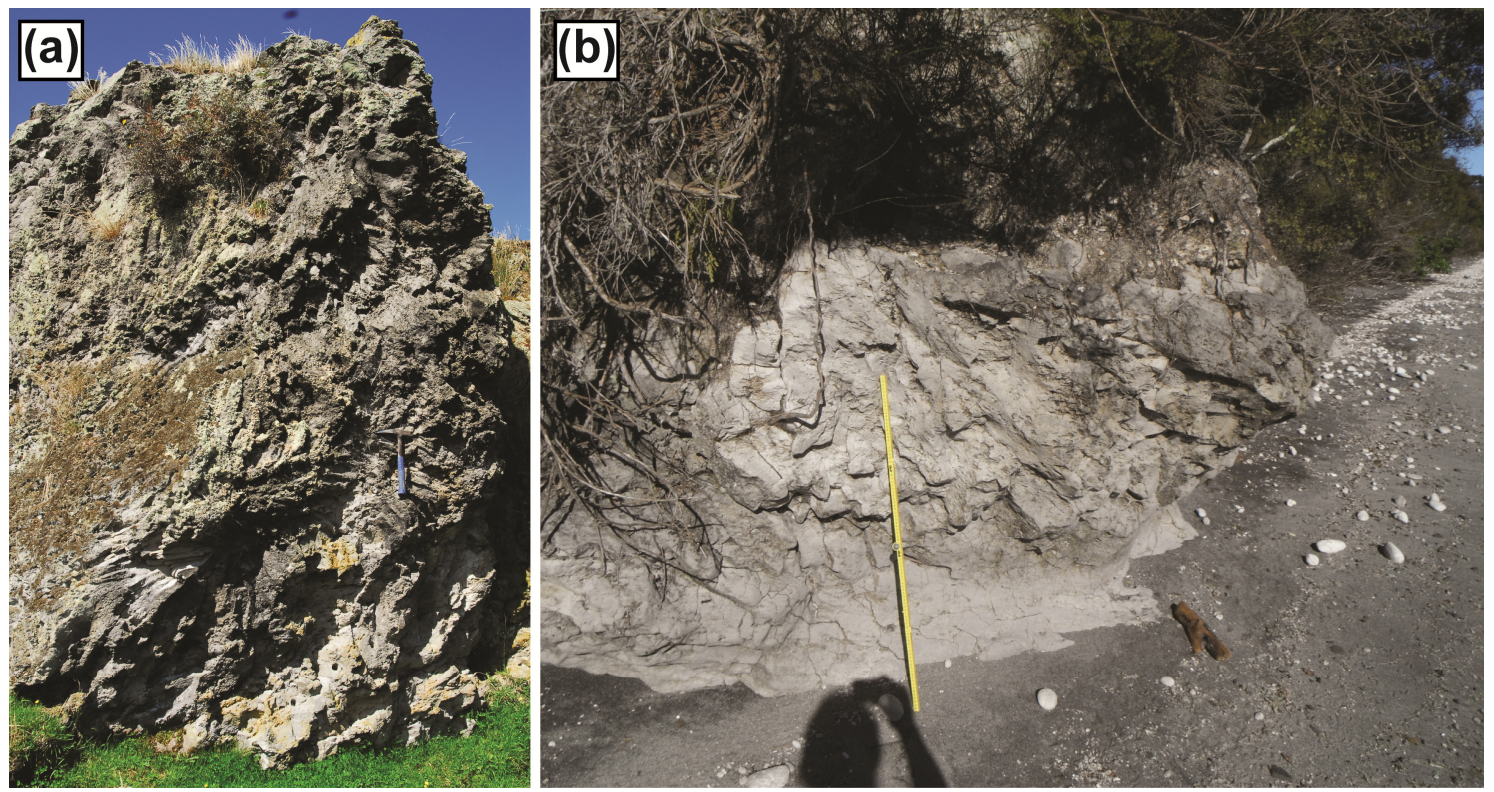

Figure 2.24. Sampling location for Unit Z (Floated giant pumices) from a) $1 \mathrm{~km}$ south of the SH1 Taupobypass roundabout and $b$ ) the eastern lake shoreline between Hatepe and the White cliffs. 


\subsubsection{Waimarino Basalt}

Lava fragments from a small monogenetic basaltic volcano, the Waimarino Basalt Formation, were sampled for comparison with post-Oruanui basaltic andesite compositions. The Waimarino basalt is located directly $\sim 16 \mathrm{~km}$ south of the most southernmost vent of Taupo volcano, less distance than that between the inferred Unit D and Unit F vent sites (Figure 2.2). Hackett (1985) first described the Waimarino Basalt Formation as post-350 ka and most likely post-Oruanui in age $(<25.4 \mathrm{ka})$. This poorly constrained age estimate was inferred from the presence of the Rangataiki/Whakamaru Ignimbrite (350 ka) underlying the basaltic cone, but with the absence of the Oruanui formation, inferred to be eroded from atop the Whakamaru Ignimbrite. The basaltic cone is then covered with a series of andesitic tephras $\mathrm{C}^{14}$ dated at $\sim 13.8 \mathrm{kyr}$ BP $(\sim 17 \mathrm{ka}$ calibrated) and the products of the Unit Y eruption from Taupo (Topping, 1973; Hackett, 1985; Figure 2.25). The assigned age of the Waimarino Basalt is therefore somewhere between $25.4 \mathrm{ka}$ (Oruanui) and the inferred age of the andesite tephras. Although poorly constrained, this age estimate is in accordance with the exceptionally fresh glassy appearance of the Waimarino Basalt, and the lack of erosion. Multiple pyroclasts were collected from a spatter-fed scoria fall bed on the western side of the Waimarino scoria cone (Figure 2.25).

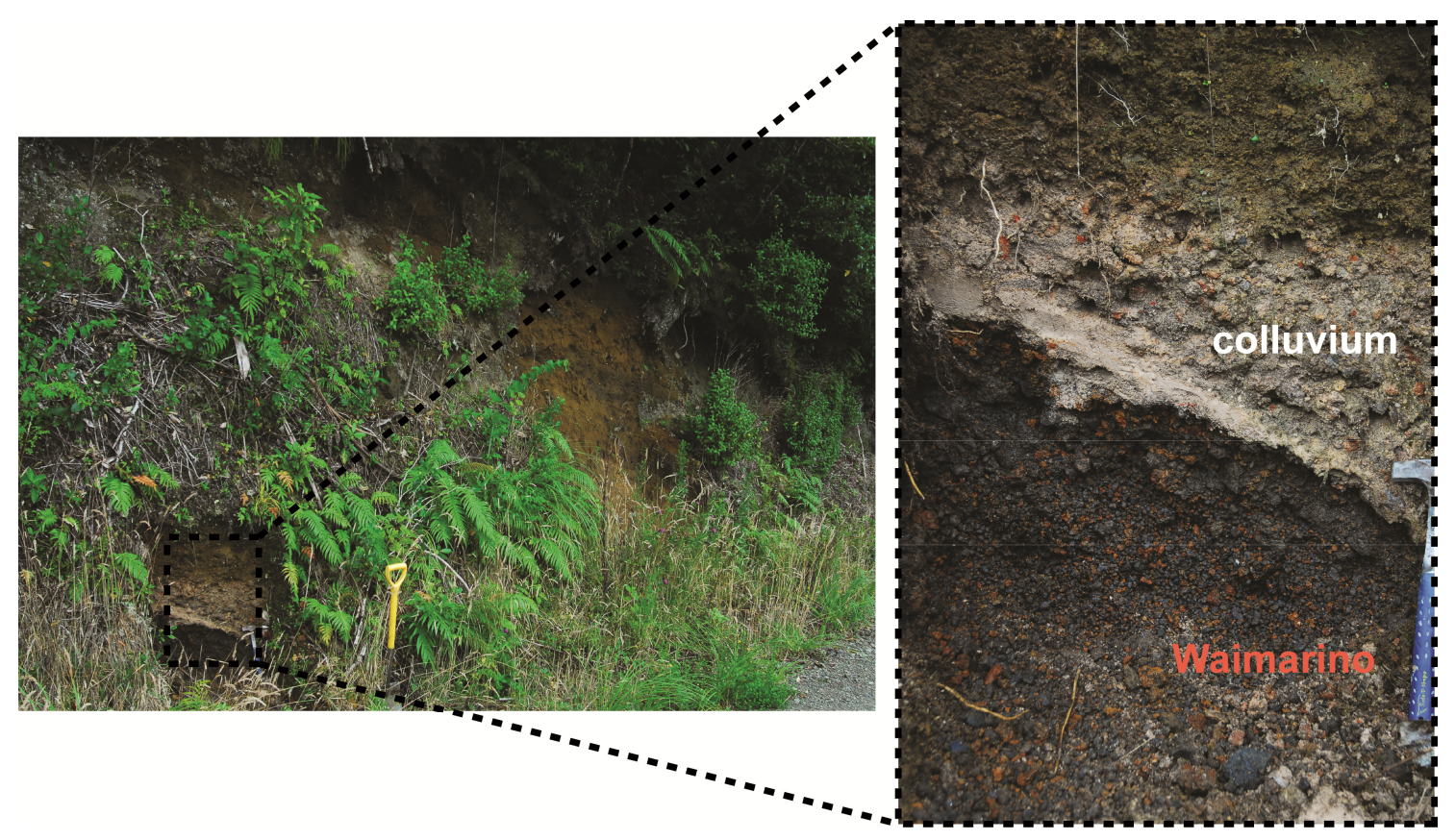

Figure 2.25. Sampling location for the post-Oruanui aged Waimarino Basalt Formation, located to the south of Taupo caldera. Inset photo shows contact between the spatter-fed Waimarino fall bed and colluvium with reworked rhyolitic pumice and andesite tephras. Rock hammer is $\sim 30 \mathrm{~cm}$ for scale. 


\section{CHAPTER 3}




\section{3: ANALYTICAL TECHNIQUES}

\subsection{General sample preparation procedure}

The range of eruption sizes and styles in the post-Oruanui sequence generated deposits with largely varying dispersal and grainsize characteristics (Wilson, 1993; CHAPTER 2, Table 2.1). In each case, the largest possible material deemed to be juvenile (produced by the eruption) was collected from each deposit for analysis. In some cases (e.g. large explosive eruptions: Unit S and Unit Y), abundant large lapilli or blocks could be sampled throughout the eruptive stratigraphy, with enough material obtainable from single pyroclasts for analysis. Large fragments of lava could also be collected insitu from subaerial exposures for effusive eruptions (e.g. eruptions D, F, and L). However, for many deposits (especially in the Hinemaiaia sequence: units I-R), the maximum sized material available was not sufficient for single-clast analyses. In such cases multiple lapilli of similar appearance and size were separated by sieving of bulk samples and combined to obtain enough material for analysis. In the smallest eruptions (e.g. units I and J) only ash grade material was available. In these examples the ash was carefully picked and scanned under a binocular microscope to ensure that only pumiceous and angular material of inferred juvenile origin was selected for analysis.

As outlined in CHAPTER 1, three different geochemical approaches have been used in this study to investigate magmatic processes; whole-rock (bulk) chemistry, crystal specific studies and glass chemistry. To obtain material for these three different approaches, samples were put through a rigorous procedure to separate the different components required (Figure 3.1). Prior to processing samples were repeatedly rinsed, scrubbed and put in an ultra-sonic bath to remove any adhering ash or lithic material, with a final rinse done in Milli-Q (ultra-clean water with resistivity >18.2 M $\Omega$ ). Lapilli or block-sized material was coarsely crushed in a Rocklabs Boyd crusher to $\sim 2 \mathrm{~mm}$ fragments. The splitting action of the slowly rotating steel plates in the Boyd crusher allowed crystals to fall out of the splitting pumice without being fragmented, which is otherwise a common problem encountered during impact splitting. The coarsely crushed lapilli/ blocks or picked ash samples were then manually split into two equal portions, with one portion sieved to $<2 \mathrm{~mm}$ size from crystal-glass separation and the other reserved for whole-rock powdering in an agate TEMA ring mill (Figure 3.1). For the crystal-glass portion, any material larger than $2 \mathrm{~mm}$ was reduced in size by hand using 


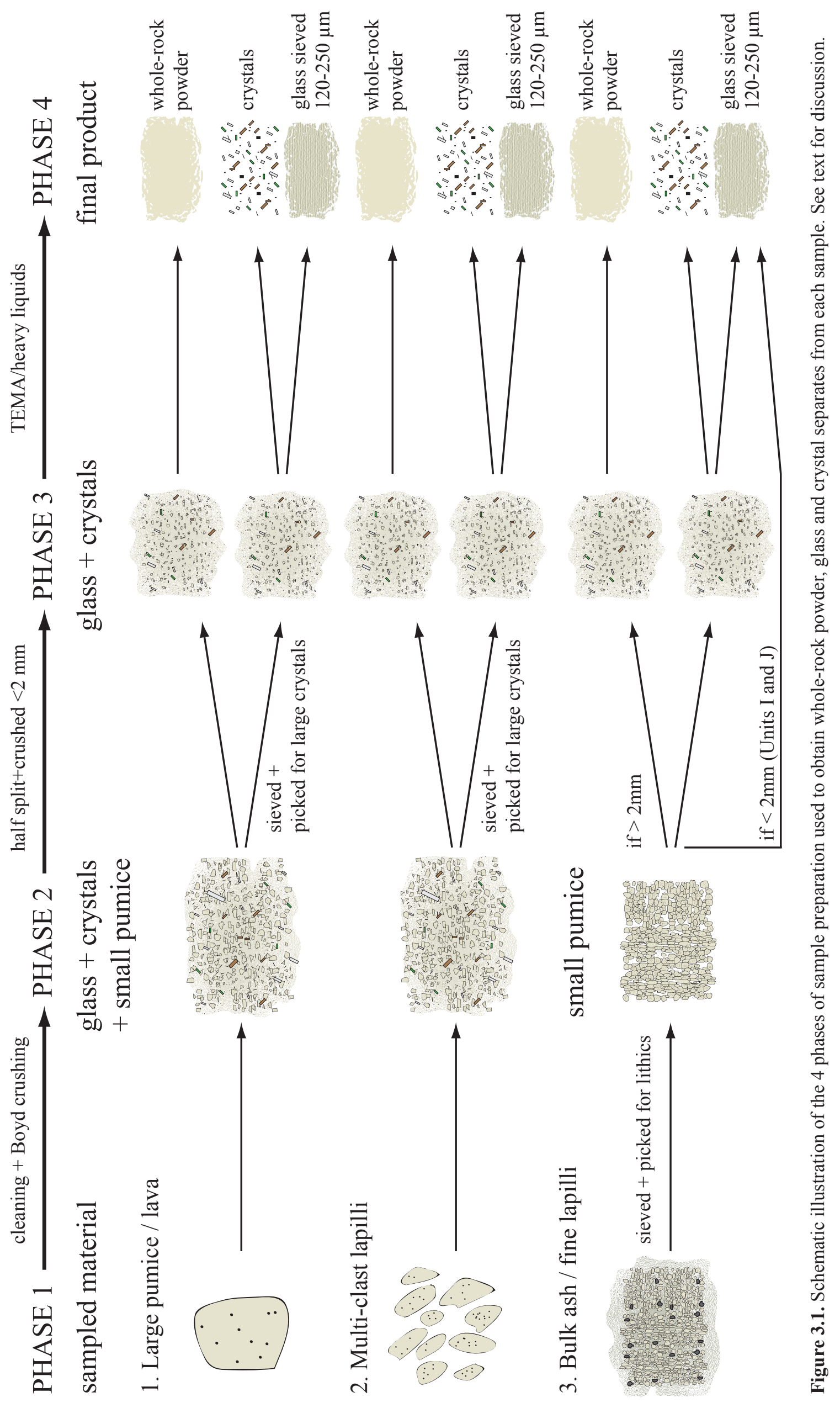


an agate mortar and pestle. The $2 \mathrm{~mm}$ size fraction was noted to achieve the most efficient crystal-glass separation during crushing for most pumice samples, without necessarily breaking up larger crystals but still separating the full range of crystal sizes observed (Figure 3.2). From this final size fraction, large crystals were manually picked out and the rest of the material was put through lithium-polytungstate (LST) heavy liquid reduced to a specific gravity of $2.4-2.5 \mathrm{~g} / \mathrm{cm}^{3}$. This step separated the relatively heavy individual minerals (ranging from plagioclase at $\sim 2.7 \mathrm{~g} / \mathrm{cm}^{3}$ to magnetite at $\sim 5.2$ $\mathrm{g} / \mathrm{cm}^{3}$ ) from the light rhyolite glass groundmass (with a density of $<2.4 \mathrm{~g} / \mathrm{cm}^{3}$ ) (Figure 3.2). As the whole glass-mineral proportion of the sample was weighed before and after mineral separation, a weight percentage crystal concentration could be calculated for each sample. The calculated crystal concentration is considered to represent a minimum concentration as some minerals may have been left in the light fraction because of air bubbles or significant amounts of adhering pumice glass. However, samples put through the heavy liquid separation procedure multiple times at set size fractions did not show significant differences in total crystal contents following the first round of separation,
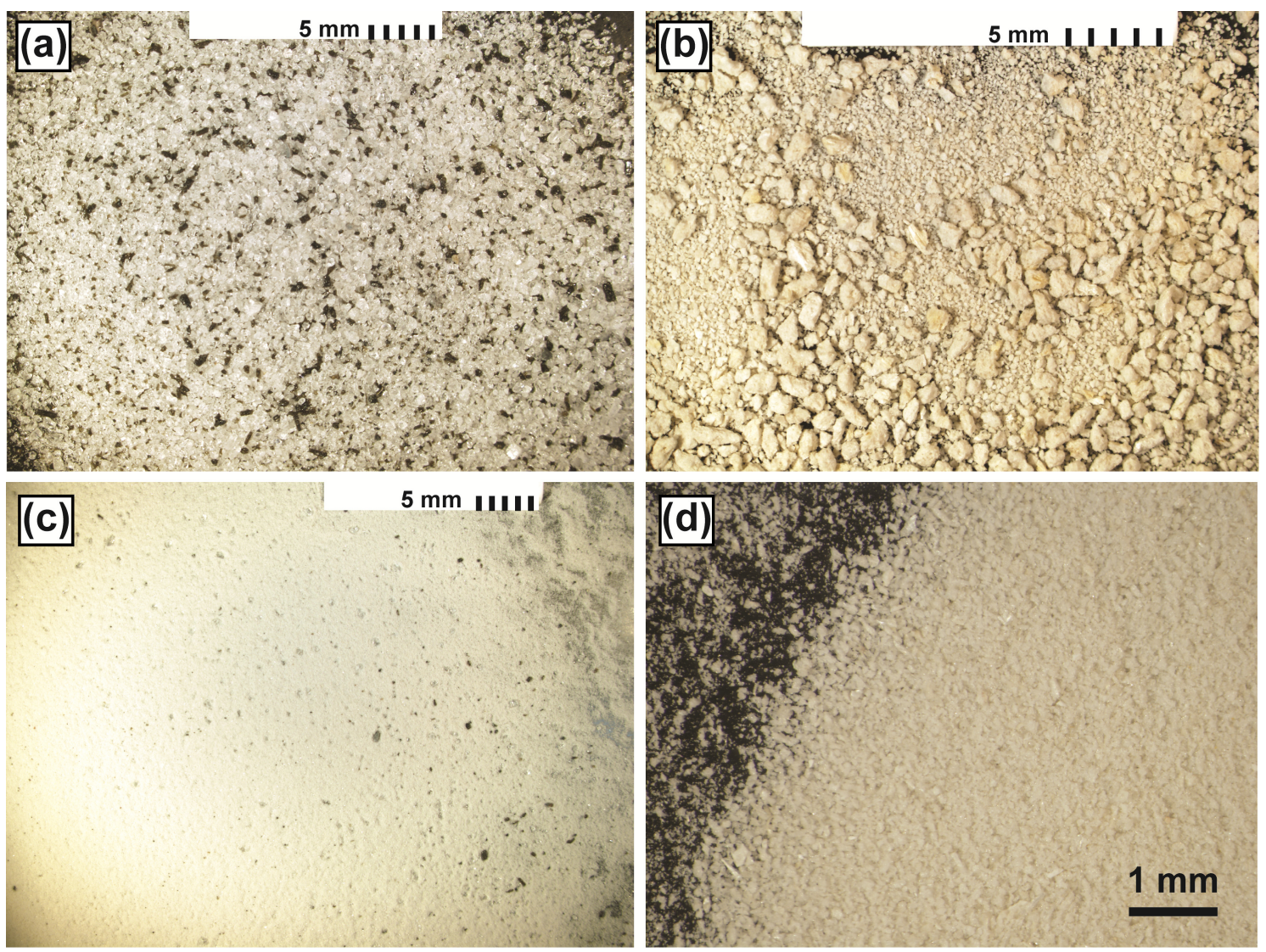

Figure 3.2. Images of the products of heavy liquid glass-mineral separation. a) Pure crystal concentration from the heavy fraction of the first round of LST. Total weight of crystals is $\sim 3.5 \mathrm{~g}$ or $4.3 \mathrm{wt} . \%$ of the total original whole sample. b) Light pre-sieving glass concentration from first round of LST. c) Sieved $125-250 \mu \mathrm{m}$ fraction from LST lights with minor crystal contamination $(<0.1 \mathrm{~g}$ of crystals, or $3 \%$ of the total crystal concentration). d) Final 125-250 $\mu \mathrm{m}$ pure glass separate after a second round of LST. 
with $>95 \%$ of crystals effectively removed during the first LST step (Figure 3.2). To obtain a pure glass separate the light material from the LST step was then wet sieved to 125-250 $\mu \mathrm{m}$ and either put through a second round of LST, or water panned (Figure $3.2 \mathrm{c}, \mathrm{d})$. The light glass fraction was then repeatedly soaked and rinsed in deionised water and then Milli-Q in a sonic bath to remove any contaminants from the LST heavy liquid and manually checked under the microscope in crossed polars for purity.

For 26 of the post-Oruanui eruptions at least one sample from each eruption was selected for the full whole-rock/glass/mineral preparation procedure (Figure 3.1). In addition, multiple samples from each eruption went through the whole-rock preparation procedure step only to check for chemical homogeneity (or lack thereof) throughout the eruption. For units I and J, however, only the glass phase could be obtained for analysis because the only material available was fine ash samples (see CHAPTER 2). For dense microlite-rich lavas or mafic inclusions, no glass sample was obtained and crystal concentrations were determined by thin-section image analysis.

\subsection{Whole rock and pure glass compositions}

\subsubsection{XRF: Whole-rock major and minor elements}

Whole rock major element analyses were carried out using an $\mathrm{ARL}^{\circledR} 8420+$ dual goniometer wavelength dispersive X-ray fluorescence (XRF) spectrometer at the Open University, United Kingdom. Major elements were determined for whole-rock powders by the formation and analysis of fused lithium metaborate glass discs following the methods of Ramsey et al. (1995). Glass disks were formed by mixing 1 part by weight $(0.70 \mathrm{~g})$ of rock powder (dried at $\left.110^{\circ} \mathrm{C}\right)$ with 5 parts by weight of dried lithium metaborate flux and fusing in a muffle furnace for 15 minutes at $1100{ }^{\circ} \mathrm{C}$ in $95 \% \mathrm{Pt}$ 5\% Au crucibles. Loss-on-ignition (LOI) measurements were undertaken on dried rock powders by heating in a pre-ignited aluminium crucible to $1000{ }^{\circ} \mathrm{C}$ for $1 \mathrm{hr}$ and recording percentage weight loss. Two internal standards were run at the beginning and end of each batch; Whin Sill Dolerite (WS-E) and OU-3. Approximate 2 standard deviation (2 SD) analytical precisions determined by 18 replicate analyses of the same standards for elements are generally $<2$ relative \% (Tables 3.1 and 3.2). Average values from each standard also closely agree with recommended values (within $\sim 1 \%$ offset), indicating that the XRF analysis had a high degree of accuracy. Duplicated samples run multiple times generally have lower precisions, most likely due to heterogeneities in the pumice or whole-rock powders (Table 3.3). 


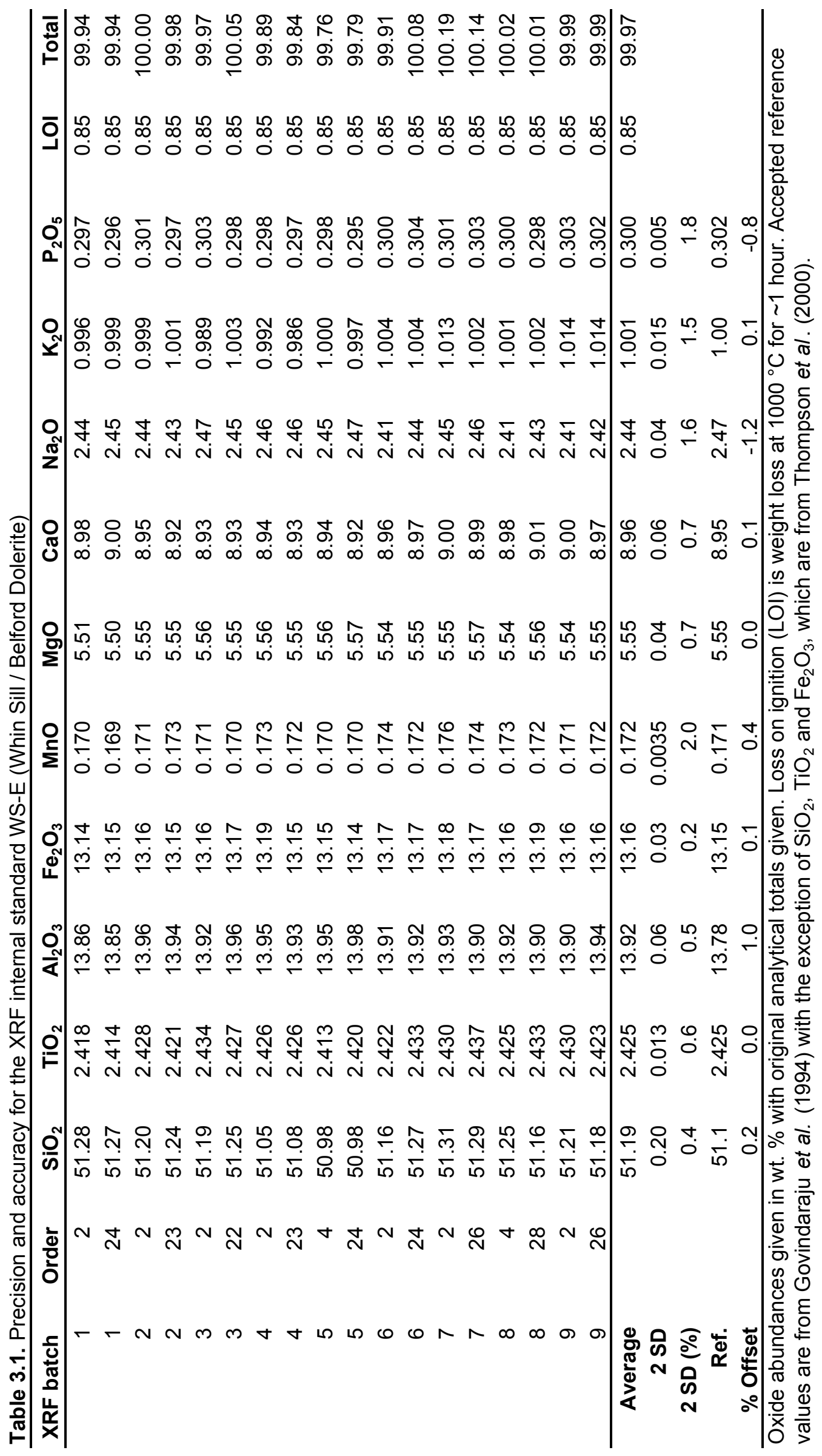




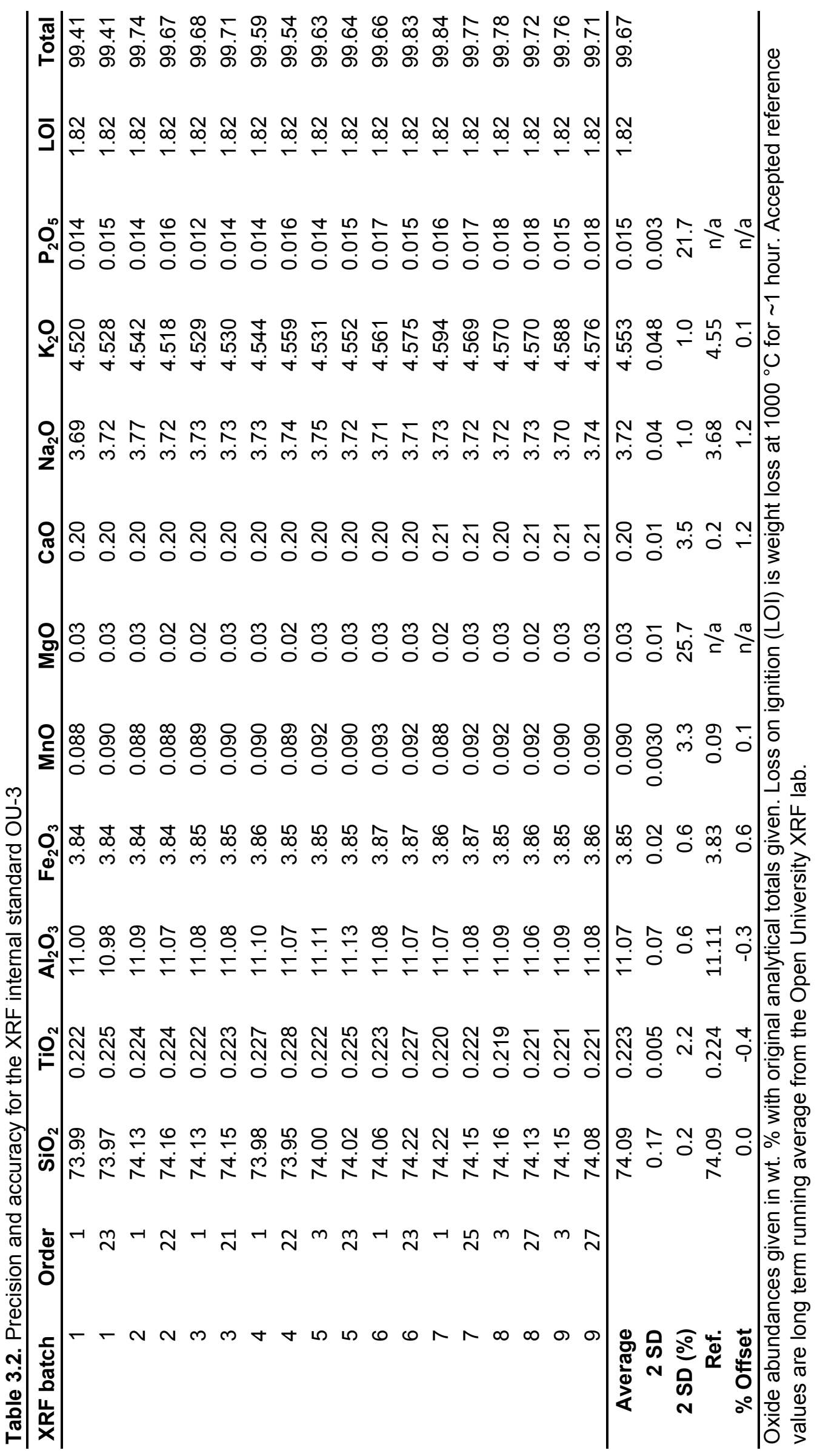




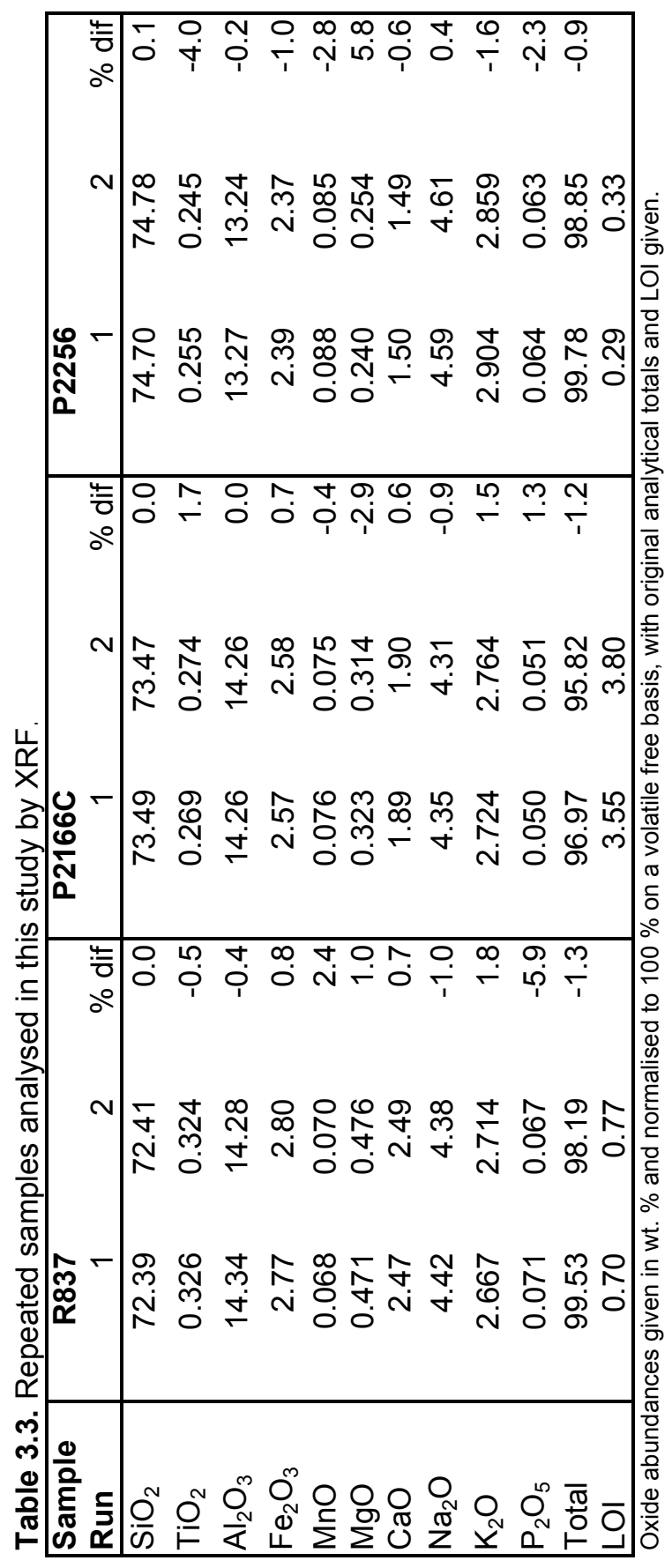




\subsubsection{Solution ICP-MS: Trace elements}

Samples selected for trace element analyses were processed in the ultra-clean geochemistry laboratory facility at Victoria University of Wellington (VUW), New Zealand. The ultra-clean chemical separation laboratory is positively pressured with air filtered to Class 100, and equipped with four PicoTrace Class 10 laminar flow workstations to minimise the risk of contamination. Only SeaStar ${ }^{\mathrm{TM}}$ (SS) grade ultrapure acids (all key metals $<10 \mathrm{ppt}$ ) were used for trace element sample preparation. Other acids used in final stages of beaker preparation were analytical reagent (AR) grade acids, distilled to produce sub-boiled (SB) distilled acids. Acid dilutions were made with Milli-Q water and their molarities were checked using a density meter. Trace element concentrations were determined for both whole-rock powders and concentrated glass separates. Sample powders were taken from the same batch of rock powder that was used for XRF major element chemistry. Approximately $50 \mathrm{mg}$ of sample was weighed on a high precision balance to $\pm 0.0001 \mathrm{~g}$ in pre-cleaned $23 \mathrm{~mL}$ Savillex screwtop teflon beakers wrapped with a thin layer of aluminium foil around the outside base to reduce static charge. Samples and international reference materials were dissolved by conventional digestion methods using $\sim 2 \mathrm{~mL}$ concentrated hydrofluoric acid (29 M HF) and $\sim 0.5 \mathrm{~mL} \mathrm{HNO}_{3}\left(16 \mathrm{M} \mathrm{HNO}_{3}\right)$ in sealed Savillex beakers heated on a hotplate to $120^{\circ} \mathrm{C}$ for 3-4 days to ensure complete digestion. Once the sample was completely digested, the solution was evaporated to incipient dryness (not overly dry to avoid sample loss and formation of insoluble fluorides), refluxed twice in $\sim 2 \mathrm{~mL}$ of concentrated $\mathrm{HNO}_{3}$ and taken again to incipient dryness. The sample cake was then refluxed in $\sim 5 \mathrm{~mL}$ of $6 \mathrm{M} \mathrm{HCl}$ overnight and the solution was checked to make sure the sample had completely dissolved. The $\mathrm{HCl}$ was evaporated and the sample cake was taken up again in $\sim 2 \mathrm{~mL}$ of concentrated $\mathrm{HNO}_{3}$ for two days. The sample was once again evaporated and then taken up in $9 \mathrm{~mL}$ of $1 \mathrm{M} \mathrm{HNO}_{3}$ to reflux for a further 2-3 days to form a final solution, which was run through a centrifuge at $2000 \mathrm{rpm}$ for ca. 5 minutes to make sure that the sample was fully in solution and no solids remained. The final solution was carefully transferred into pre-cleaned $10 \mathrm{~mL}$ polyethylene centrifugetubes and precisely weighed on a high precision balance $( \pm 0.0001 \mathrm{~g})$ ensuring all drops were removed from the beaker. To form a dilution of the sample, a $50 \mu \mathrm{L}$ aliquot was transferred and precisely weighed into another clean $10 \mathrm{~mL}$ c-tube (centrifuge-tube), which was topped up with $\sim 9 \mathrm{~mL}$ of $1 \% \mathrm{HNO}_{3}$ and weighed again so that a final dilution of the sample could be accurately calculated. 
Whole rock and pure glass trace element analysis was carried out by solution inductively coupled plasma mass spectrometry (ICP-MS), using a Thermo-Fisher Element2 sector-field ICP-MS equipped with an ESCI auto sampler at VUW using methods similar to those of Eggins et al. (1997). In this study ${ }^{43} \mathrm{Ca}$ was used for an internal correction, as $\mathrm{CaO}$ concentrations of sample powders had previously been determined to $\pm 1 \%$ by XRF or $\pm 5 \%$ by EPMA (see section 3.3.1). This method allows any major changes or inconsistencies, which may be caused by sample loss during sample preparation, to be monitored and corrected. The ICP-MS was tuned using a 10 ppb multi element standard diluted to $1 \mathrm{ppb}$, where instrumental conditions such as torch position and carrier/make-up gas flow were adjusted to achieve the lowest relative standard deviation (RSD), typically $<1-2 \%$, and to optimise sensitivity. This step was then repeated for the calibration standard, BHVO-2. Oxide generation was monitored using measured $\mathrm{UO}^{+} / \mathrm{U}^{+}$ratios $(<6-7 \%), \mathrm{BaO}^{+} / \mathrm{Ba}^{+}(<0.2 \%)$ and $\mathrm{Ba}^{++} / \mathrm{Ba}^{+}(<5 \%)$. To assess the quality of the data, multiple isotopes from some elements (e.g. ${ }^{90} \mathrm{Zr}$ and ${ }^{91} \mathrm{Zr}$ ) were included in the analysis, generally producing concentrations within $\pm 0.5 \%$. The Element 2 was operated at increased mass resolution for selected isotopes to resolve the elemental peak from common spectral interferences (e.g. ${ }^{45} \mathrm{Sc},{ }^{47} \mathrm{Ti},{ }^{51} \mathrm{~V},{ }^{52} \mathrm{Cr},{ }^{59} \mathrm{Co}$, ${ }^{60} \mathrm{Ni},{ }^{63} \mathrm{Cu},{ }^{66} \mathrm{Zn},{ }^{69} \mathrm{Ga}$ ) or to reduce counts in highly abundant isotopes (e.g. ${ }^{23} \mathrm{Na},{ }^{25} \mathrm{Mg}$, ${ }^{27} \mathrm{Al},{ }^{43} \mathrm{Ca},{ }^{55} \mathrm{Mn}$ ). Each sample solution was measured for a total time of $240 \mathrm{~s}$. Prior to introduction of each sample the background counts were measured and assessed for the same count time using a $1 \% \mathrm{SS} \mathrm{HNO}_{3}$ acid blank. Following sample analyses, the autosampler lines and ICP-MS were washed out in two consecutive rinse cycles in $1 \%$

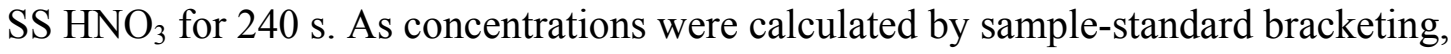
samples were typically run in a looping sequence starting with the primary standard (BHVO-2), followed by 3 samples, a secondary standard (USGS standard BCR-2 or in house matrix-matched standard TPI), and finishing back on the primary standard. Total procedural blanks for solution ICP-MS were within background count levels on all measured elements. Abundances of individual trace elements were calculated relative to a bracketing standard (BHVO-2) using the following relationships:

$$
\begin{aligned}
& \text { Sample } C_{i}=\left(\text { Sample }_{C P S} / \text { BHVO }_{C P S}\right) x\left(\text { Sample }_{\text {Dil }} / \text { BHVO }_{\text {Dil }}\right) x \text { ref. } \\
& \text { Sample } C_{i}(\text { Ca corrected })=e q .(1) x\left(C_{c a} X R F(\text { or EPMA }) / C_{c a} I C P-M S\right)
\end{aligned}
$$

where $C_{i}$ and $C_{C a}$ are the concentrations of the measured isotope x and $\mathrm{Ca}$, respectively, and $X_{D i l}$ is the concentration of material in the dilution aliquots. The reference values for 
BHVO-2 were compiled from Georem preferred values (http://georem.mpchmainz.gwdg.de/). Only samples which had $<5 \%$ deviation of $C_{c a} I C P-M S$ from $C_{c a} X R F$ or EPMA were accepted. Significantly higher or lower values indicated that material may have been lost or added during preparation of the dilutions.

Two secondary standards, BCR-2 (USGS reference basalt) and TPI (bulk powder of a single large Taupo ignimbrite clast), were analysed at regular intervals across each analysis session to assess the accuracy and precision of solution-ICP-MS in this study. Approximate 2 SD analytical precisions derived from 21 replicate analyses of BCR-2 are $< \pm 6-7 \%$ for most trace elements (exceptions are $\mathrm{Cu}$ at $<10 \%$, $\mathrm{Li}$ and $\mathrm{Cs}$ at $<15 \%, \mathrm{~Pb}$ at $<20 \%$ and $\mathrm{Nb}$ at $\sim 30 \%$ ) (Table 3.4 ). BCR-2 trace element analyses are accurate to $\leq 5 \%$ (most are $<1-2 \%$ ), apart from $\mathrm{Li}, \mathrm{Cr}, \mathrm{Ni}$ and $\mathrm{Nb}$ at $<10 \%$ and $\mathrm{Cu}$ at $\sim 20 \%$. From replicate analysis of the TPI standard, most trace elements are precise to $\pm 6-7 \%$ with similar exceptions to BCR-2 (Table 3.5). Importantly, the reproducibility for the matrix-matched TPI standard reflects not only the precision of the analytical technique for samples of this composition, but also the reliability of the preparation procedure used for pumice samples and the homogeneity of the powders used for analysis. High levels of reproducibility ( $<5-10 \%$ offsets) for most elements are also evident through samples that were analysed multiple times in different analytical sessions using separate dilutions (Table 3.6).

\subsection{In-situ mineral and glass compositions}

Minerals and glass (including groundmass glass and melt inclusions) were analysed using in-situ techniques. For dense lava samples or mafic inclusions, analyses were performed on polished thin sections. In such cases, mineral orientations were often random and only a small number of each mineral phase was typically present in each section. However, for samples that underwent the glass-mineral separation procedure (see section 3.1), large numbers of each mineral phase were manually picked under binocular microscope according to size and appearance. Minerals were then aligned along their c-axis (where discernible) on double sided tape and set into $25 \mathrm{~mm}$ epoxy disc mounts that were set and then polished to expose the cores of the crystals.

\subsubsection{Electron microprobe (EPMA): Major and minor elements}

Mineral and glass major and minor element chemistry and crystal back-scattered 


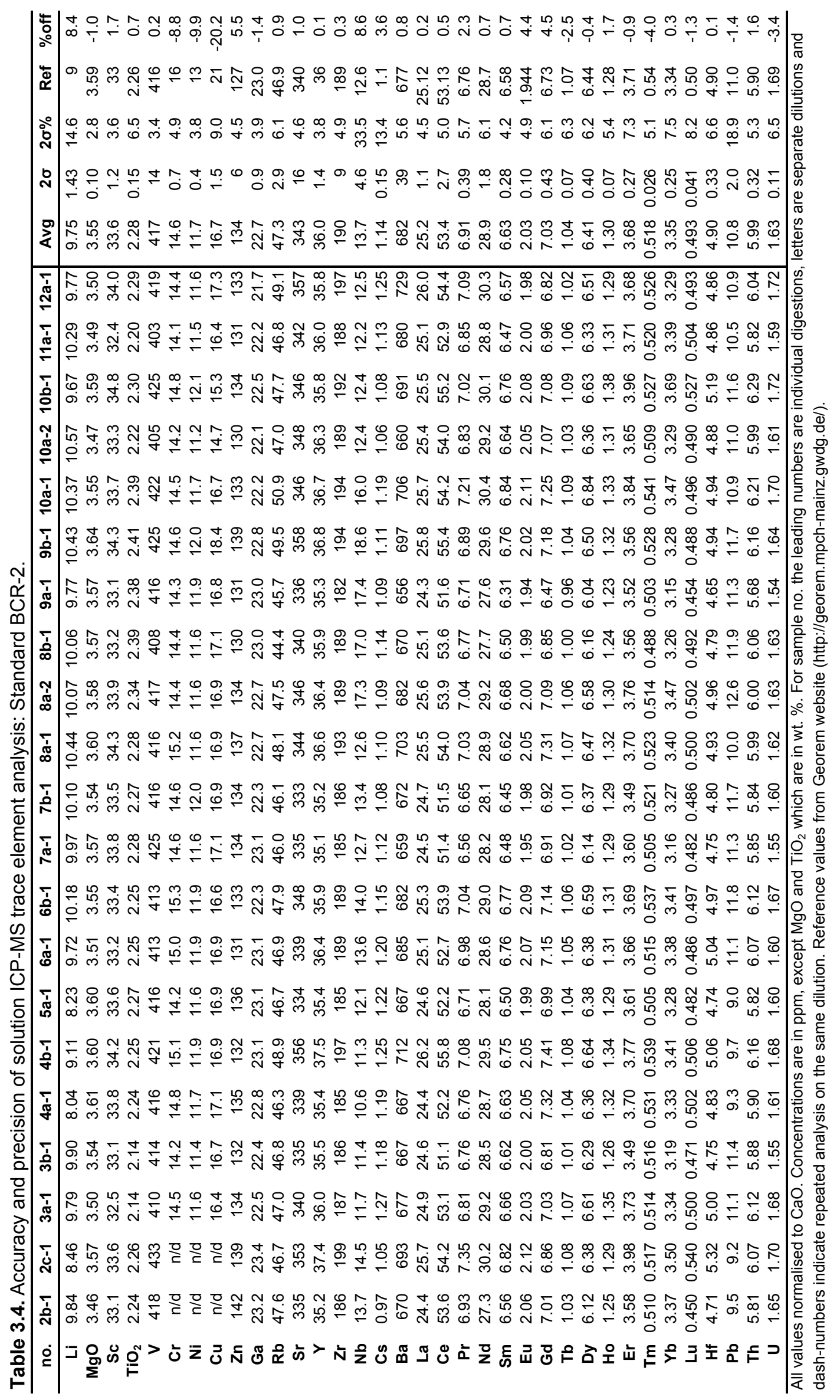




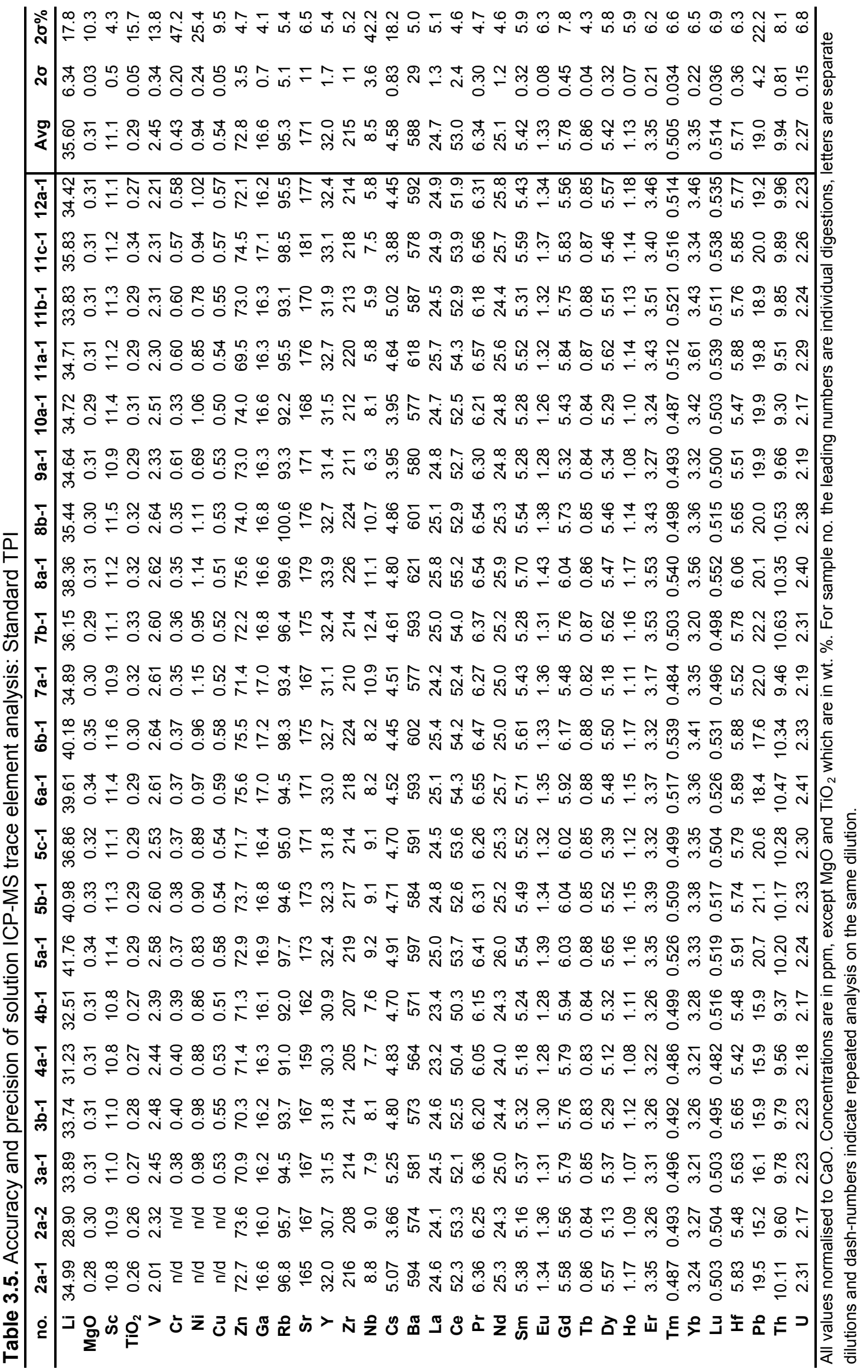




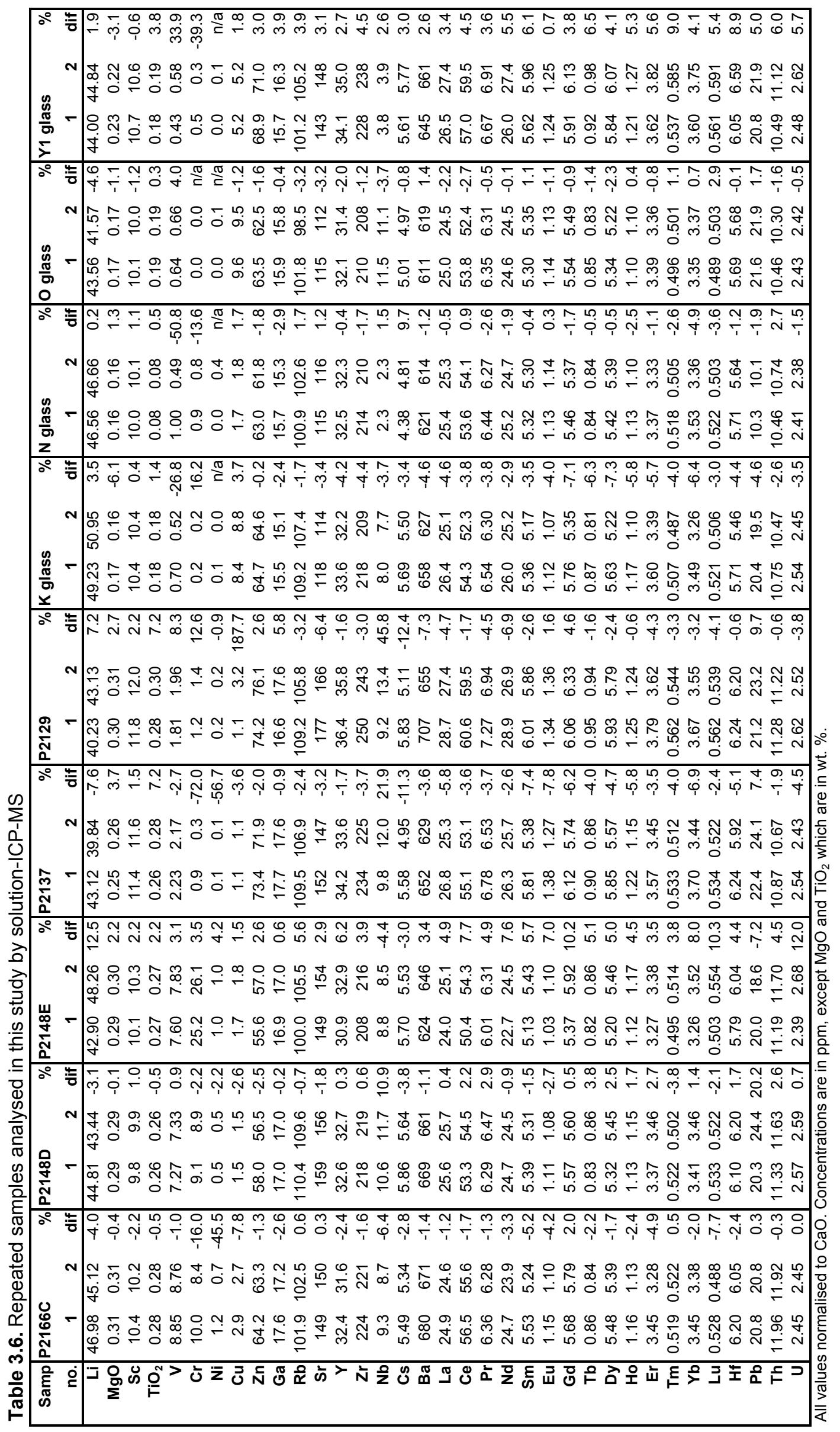


probe micro-analyser (EPMA) at VUW. The JXA 8230 is equipped with 5 wavelength dispersive X-ray spectrometers (WDS), an energy dispersive X-ray spectrometer (EDS), and highly sensitive detectors for acquisition of BSE and secondary electron (SEI) images. Thin sections and epoxy mounts were coated with a ca. $25 \mathrm{~nm}$ film of carbon prior to analysis. To reduce matrix effects, the EPMA was calibrated for quantitative measurements using international mineral standards of similar composition to the materials being analysed. For elements at lower abundance (e.g. $<1$ wt. \%), calibration was carried out on synthetic oxide standards. Calibration was carried out by a 60 seconds peak-search on each element, and a 30 seconds background measurement. For minerals with low alkali contents such as olivine, clinopyroxene, orthopyroxene and FeTi oxides, measurements were performed using a focussed beam with a high current of $20 \mathrm{nA}$ and an accelerating voltage of $15 \mathrm{kV}$. For minerals such as plagioclase and amphibole with significant levels of alkali elements, the current was reduced to $12 \mathrm{nA}$. For matrix glasses and melt inclusions, the electron beam was defocused to a diameter of $10 \mu \mathrm{m}$, and the current was further reduced to $8 \mathrm{nA}$ also with reduced count times for $\mathrm{Na}$ to minimise alkali loss. Samples were typically measured for 30 seconds, and background levels for 15 seconds, with $\mathrm{Na}$ in glass being the only exception which was analysed for only 10 seconds on peak. Alkali elements such as $\mathrm{Na}$ and $\mathrm{K}$ were measured first. All element concentrations were calculated using the ZAF correction method (where $\mathrm{Z}$ is atomic number, $\mathrm{A}$ is absorption and $\mathrm{F}$ is fluorescence) (see Carpenter, 2008 and references therein).

Calibrated standards and secondary standards were run as unknowns to monitor instrumental drift and the precision and accuracy of the EPMA throughout analytical sessions. For all analyses, the calibrated standard produced total oxide values within $\sim 2$ wt. \% of the reference values. As shown in Tables 3.7-3.13, approximate 2 SD analytical precisions calculated from repeat analyses of standards are generally $<5 \%$ for elements which occur in concentrations $>1 \mathrm{wt}$. \%. For elements at lower concentrations, precisions decrease with decreasing relative concentration. The same is true for accuracy, where elements in higher concentration are generally accurate to within $<5$ wt. \%. For glass analyses three additional secondary standards were run to assess the precision and accuracy (Table 3.13a-d), which can be influenced by volatile losses during analysis (Blundy \& Cashman, 2008). The glass standards span a wide compositional range from basalt (VGA-99) to rhyolite (ATHO, VG568). For elements that occur in concentrations $>1 \mathrm{wt} . \%$, accuracy and precision is generally $<10 \%$. At high concentrations (e.g. $>10 \mathrm{wt}$. \%), accuracy and precision improves to $<3-4 \%$. 
Table 3.7. Precision and accuracy of clinopyroxene major element analysis by EPMA: Kakanui augite $(n=67)$

\begin{tabular}{rrrrrrrrrrr} 
& $\mathbf{S i O}_{2}$ & $\mathrm{TiO}_{2}$ & $\mathbf{A l}_{2} \mathbf{O}_{3}$ & $\mathbf{C r}_{2} \mathbf{O}_{3}$ & $\mathbf{F e O}$ & $\mathbf{M n O}$ & $\mathbf{M g O}$ & $\mathbf{C a O}$ & $\mathbf{N a}_{2} \mathbf{O}$ & Total \\
\hline Average & 50.66 & 0.80 & 8.77 & 0.14 & 6.35 & 0.13 & 16.73 & 15.79 & 1.29 & 100.65 \\
Max & 52.43 & 0.86 & 11.90 & 0.21 & 6.71 & 0.18 & 17.13 & 16.25 & 1.36 & 101.68 \\
Min & 48.75 & 0.75 & 8.33 & 0.01 & 6.18 & 0.09 & 13.93 & 13.70 & 1.20 & 98.16 \\
$2 \sigma$ & 0.85 & 0.05 & 0.80 & 0.08 & 0.21 & 0.05 & 0.75 & 0.57 & 0.07 & 1.01 \\
$\% 2 \sigma$ & 1.7 & 6.4 & 9.2 & 60.4 & 3.3 & 37.8 & 4.5 & 3.6 & 5.6 & 1.0 \\
ref value & 50.73 & 0.74 & 8.73 & 0.15 & 6.34 & 0.13 & 16.65 & 15.82 & 1.27 & 100.4 \\
\% offset & -0.1 & 8.2 & 0.5 & -9.5 & 0.2 & -1.2 & 0.5 & -0.2 & 1.4 & 0.3 \\
\hline Reference values from Jarosewich et al. (1980) and Klügel et al. (2005)
\end{tabular}

Table 3.8. Precision and accuracy of orthopyroxene major element analysis by EPMA: Hypersthene standard $(n=273)$

\begin{tabular}{rrrrrrrrrrr} 
& $\mathbf{S i O}_{2}$ & $\mathrm{TiO}_{2}$ & $\mathbf{A l}_{2} \mathrm{O}_{3}$ & $\mathbf{C r}_{2} \mathbf{O}_{3}$ & $\mathbf{F e O}$ & $\mathbf{M n O}$ & $\mathbf{M g O}$ & $\mathbf{C a O}$ & $\mathbf{N a}_{2} \mathrm{O}$ & Total \\
\hline Average & 53.95 & 0.10 & 1.24 & 0.66 & 15.20 & 0.48 & 26.83 & 1.53 & 0.01 & 100.01 \\
Max & 59.29 & 0.32 & 1.87 & 0.91 & 16.50 & 0.59 & 28.05 & 2.01 & 0.05 & 105.53 \\
Min & 52.34 & 0.00 & 0.80 & 0.00 & 14.14 & 0.00 & 25.78 & 1.15 & 0.00 & 97.92 \\
$2 \sigma$ & 1.42 & 0.10 & 0.32 & 0.25 & 0.60 & 0.11 & 0.81 & 0.25 & 0.02 & 1.94 \\
$\% 2 \sigma$ & 2.6 & 97.2 & 25.8 & 37.4 & 4.0 & 23.7 & 3.0 & 16.2 & $>100$ & 1.9 \\
ref value & 54.09 & 0.16 & 1.23 & 0.75 & 15.22 & 0.49 & 26.79 & 1.52 & $<0.05$ & 100.3 \\
$\%$ offset & -0.3 & -35.6 & 1.1 & -12.5 & -0.1 & -1.8 & 0.2 & 0.8 & n/a & -0.2 \\
\hline Reference values from Jarosewich $e t a l .(1980)$ & & & & & &
\end{tabular}

Refence values from Jarosewich et al. $(1980)$

Table 3.9. Precision and accuracy of plagioclase major element analysis by EPMA: Labradorite plagioclase $(\mathrm{n}=214)$

\begin{tabular}{rrrrrrrrrr} 
& $\mathbf{S i O}_{2}$ & $\mathrm{TiO}_{2}$ & $\mathbf{A l}_{2} \mathbf{O}_{3}$ & $\mathbf{F e O}$ & $\mathbf{M g O}$ & $\mathbf{C a O}$ & $\mathbf{N a}_{2} \mathbf{O}$ & $\mathbf{K}_{2} \mathbf{O}$ & Total \\
\hline Average & 51.08 & 0.02 & 30.91 & 0.33 & 0.13 & 13.69 & 3.42 & 0.21 & 99.79 \\
Max & 52.67 & 0.06 & 32.20 & 0.61 & 0.30 & 14.39 & 3.96 & 0.53 & 102.35 \\
Min & 49.07 & 0.00 & 29.14 & 0.05 & 0.02 & 12.89 & 2.88 & 0.00 & 96.00 \\
$2 \sigma$ & 1.08 & 0.02 & 0.69 & 0.32 & 0.06 & 0.36 & 0.26 & 0.27 & 1.56 \\
$\% 2 \sigma$ & 2.1 & $>100$ & 2.2 & 96.3 & 50.3 & 2.6 & 7.5 & $>100$ & 1.6 \\
ref value & 51.25 & 0.05 & 30.91 & 0.46 & 0.14 & 13.64 & 3.45 & 0.18 & 100.1 \\
\% offset & -0.3 & -53.1 & 0.0 & -28.0 & -9.2 & 0.3 & -0.9 & 16.8 & -0.3 \\
\hline Reference values from Jarosewich et al. (1980)
\end{tabular}

Table 3.10. Precision and accuracy of olivine major element analysis by EPMA: Springwater olivine standard $(\mathrm{n}=6)$

\begin{tabular}{|c|c|c|c|c|c|c|c|c|}
\hline & $\mathrm{SiO}_{2}$ & $\mathrm{Cr}_{2} \mathrm{O}_{3}$ & $\mathrm{FeO}$ & MnO & $\mathrm{MgO}$ & $\mathrm{NiO}$ & $\mathrm{CaO}$ & Total \\
\hline Average & 38.91 & 0.02 & 16.72 & 0.20 & 43.54 & 0.04 & 0.01 & 99.44 \\
\hline Max & 39.05 & 0.04 & 17.05 & 0.31 & 43.64 & 0.12 & 0.02 & 99.72 \\
\hline Min & 38.76 & 0.00 & 16.39 & 0.01 & 43.39 & 0.00 & 0.01 & 99.07 \\
\hline $2 \sigma$ & 0.21 & 0.04 & 0.51 & 0.30 & 0.19 & 0.11 & 0.01 & 0.51 \\
\hline$\% 2 \sigma$ & 0.6 & 219.3 & 3.1 & 149.3 & 0.4 & $>100$ & 69.5 & 0.5 \\
\hline ref value & 38.95 & 0.02 & 16.62 & 0.3 & 43.58 & $n / d$ & $n / d$ & 99.47 \\
\hline$\%$ offset & -0.1 & 2.5 & 0.6 & -34.1 & -0.1 & $\mathrm{n} / \mathrm{d}$ & $\mathrm{n} / \mathrm{d}$ & 0.0 \\
\hline
\end{tabular}

Table 3.11. Precision and accuracy of amphibole major element analysis by EPMA: Engels amphibole standard $(n=35)$

\begin{tabular}{rrrrrrrrrrr} 
& $\mathrm{SiO}_{2}$ & $\mathrm{TiO}_{2}$ & $\mathrm{Al}_{2} \mathrm{O}_{3}$ & $\mathbf{F e O}$ & $\mathbf{M n O}$ & $\mathbf{M g O}$ & $\mathbf{C a O}$ & $\mathrm{Na}_{2} \mathrm{O}$ & $\mathbf{K}_{2} \mathrm{O}$ & Total \\
\hline Average & 41.81 & 0.86 & 11.65 & 19.32 & 0.68 & 9.17 & 11.45 & 1.53 & 0.90 & 97.41 \\
$\mathrm{Max}$ & 43.36 & 1.01 & 12.40 & 20.24 & 1.13 & 10.34 & 11.69 & 1.63 & 1.04 & 99.02 \\
$\mathrm{Min}$ & 40.67 & 0.73 & 11.02 & 18.41 & 0.00 & 8.35 & 11.01 & 1.37 & 0.81 & 95.08 \\
$2 \sigma$ & 1.33 & 0.20 & 0.76 & 0.96 & 0.42 & 1.15 & 0.33 & 0.13 & 0.12 & 1.97 \\
$\% 2 \sigma$ & 3.2 & 22.6 & 6.5 & 5.0 & 61.2 & 12.6 & 2.9 & 8.5 & 13.2 & 2.0 \\
ref value & 42.14 & 0.94 & 12.09 & 19.05 & 0.63 & 8.67 & 11.56 & 1.63 & 0.91 & 97.62 \\
\% offset & -0.8 & -8.2 & -3.6 & 1.4 & 7.6 & 5.8 & -0.9 & -6.4 & -1.2 & -0.2 \\
\hline
\end{tabular}


Table 3.12. Precision and accuracy of Fe-Ti oxides major element analysis by EPMA: IImenite standard $(\mathrm{n}=260)$

\begin{tabular}{|c|c|c|c|c|c|c|c|c|}
\hline & $\mathrm{SiO}_{2}$ & $\mathrm{TiO}_{2}$ & $\mathrm{Al}_{2} \mathrm{O}_{3}$ & $\mathrm{FeO}$ & MnO & $\mathrm{MgO}$ & $\mathrm{CaO}$ & Total \\
\hline Average & 0.01 & 45.67 & 0.02 & 46.64 & 4.89 & 0.28 & 0.00 & 99.05 \\
\hline Max & 0.04 & 47.20 & 1.11 & 48.28 & 5.81 & 0.32 & 0.06 & 101.11 \\
\hline Min & 0.00 & 44.23 & 0.00 & 44.54 & 4.35 & 0.25 & 0.00 & 97.25 \\
\hline $2 \sigma$ & 0.02 & 0.88 & 0.14 & 1.09 & 0.49 & 0.03 & 0.01 & 1.40 \\
\hline$\% 2 \sigma$ & $\mathrm{n} / \mathrm{a}$ & 1.9 & $\mathrm{n} / \mathrm{a}$ & 2.3 & 10.1 & 9.1 & $\mathrm{n} / \mathrm{a}$ & 1.4 \\
\hline ref value & $\mathrm{n} / \mathrm{d}$ & 45.7 & $n / d$ & 46.54 & 4.77 & 0.31 & $\mathrm{n} / \mathrm{d}$ & 97.28 \\
\hline$\%$ offset & & -0.1 & & 0.2 & 2.6 & -8.1 & & 1.8 \\
\hline
\end{tabular}

Table 3.13. Precision and accuracy of glass major element analyses by EPMA

a) $T 1-G$ standard $(n=83)$

\begin{tabular}{rrrrrrrrrrrr} 
& $\mathrm{SiO}_{2}$ & $\mathrm{TiO}_{2}$ & $\mathrm{Al}_{2} \mathrm{O}_{3}$ & $\mathbf{F e O}$ & $\mathbf{M n O}$ & $\mathbf{M g O}$ & $\mathbf{C a O}$ & $\mathrm{Na}_{2} \mathbf{O}$ & $\mathbf{K}_{\mathbf{2}} \mathrm{O}$ & $\mathbf{C l}$ & Total \\
\hline Average & 58.60 & 0.71 & 16.94 & 6.34 & 0.08 & 3.74 & 6.93 & 3.28 & 1.98 & 0.01 & 98.61 \\
Max & 60.12 & 0.75 & 17.34 & 6.78 & 0.15 & 3.88 & 7.17 & 3.73 & 2.10 & 0.03 & 100.72 \\
$\mathrm{Min}$ & 55.82 & 0.59 & 16.54 & 5.52 & 0.00 & 3.54 & 6.65 & 2.90 & 1.74 & 0.00 & 95.02 \\
$2 \sigma$ & 1.98 & 0.40 & 0.40 & 0.52 & 0.07 & 0.17 & 0.24 & 0.39 & 0.13 & 0.01 & 2.62 \\
$\% 2 \sigma$ & 3.38 & 56.39 & 2.35 & 8.23 & 82.57 & 4.43 & 3.52 & 11.80 & 6.67 & $>100$ & 2.66 \\
ref value & 58.6 & 0.755 & 17.1 & 6.44 & 0.127 & 3.75 & 7.1 & 3.13 & 1.96 & 0.011 & 98.96 \\
\% offset & 0.0 & -6.4 & -1.0 & -1.5 & -33.1 & -0.2 & -2.4 & 4.8 & 1.3 & -34.7 & -0.4 \\
\hline
\end{tabular}

Reference values from Jochum et al. (2006)

b) ATHO standard $(n=100)$

\begin{tabular}{rrrrrrrrrrrr} 
& $\mathrm{SiO}_{2}$ & $\mathrm{TiO}_{2}$ & $\mathrm{Al}_{2} \mathrm{O}_{3}$ & $\mathbf{F e O}$ & $\mathbf{M n O}$ & $\mathbf{M g O}$ & $\mathbf{C a O}$ & $\mathrm{Na}_{2} \mathrm{O}$ & $\mathbf{K}_{\mathbf{2}} \mathrm{O}$ & $\mathrm{Cl}$ & Total \\
\hline Average & 75.25 & 0.22 & 12.19 & 3.14 & 0.08 & 0.08 & 1.71 & 3.71 & 2.69 & 0.03 & 99.10 \\
Max & 77.08 & 0.27 & 12.53 & 3.48 & 0.16 & 0.13 & 1.77 & 4.59 & 2.85 & 0.06 & 101.18 \\
$\mathrm{Min}$ & 72.50 & 0.04 & 11.74 & 2.19 & 0.00 & 0.00 & 1.59 & 2.22 & 2.46 & 0.00 & 94.81 \\
$2 \sigma$ & 2.27 & 0.31 & 0.31 & 0.51 & 0.06 & 0.05 & 0.07 & 0.62 & 0.15 & 0.03 & 2.45 \\
$\% 2 \sigma$ & 3.02 & $>100$ & 2.56 & 16.33 & 71.14 & 70.44 & 4.08 & 16.86 & 5.39 & 92.02 & 2.47 \\
ref value & 75.6 & 0.255 & 12.2 & 3.27 & 0.106 & 0.103 & 1.7 & 3.75 & 2.64 & 0.043 & 99.67 \\
\% offset & -0.5 & -12.7 & -0.1 & -3.9 & -24.2 & -24.6 & 0.7 & -1.1 & 1.9 & -21.0 & -0.6 \\
\hline
\end{tabular}

Reference values from Jochum et al. (2006)

c) VG568 standard ( $\mathrm{n}=95)$

\begin{tabular}{rrrrrrrrrrrr} 
& $\mathrm{SiO}_{2}$ & $\mathrm{TiO}_{2}$ & $\mathrm{Al}_{2} \mathrm{O}_{3}$ & $\mathbf{F e O}$ & $\mathbf{M n O}$ & $\mathbf{M g O}$ & $\mathbf{C a O}$ & $\mathrm{Na}_{2} \mathrm{O}$ & $\mathbf{K}_{2} \mathrm{O}$ & $\mathbf{C l}$ & Total \\
\hline Average & 76.64 & 0.05 & 12.09 & 1.05 & 0.01 & 0.01 & 0.49 & 3.61 & 4.90 & 0.10 & 98.93 \\
Max & 78.04 & 0.14 & 12.35 & 1.84 & 0.05 & 0.05 & 0.67 & 3.99 & 5.13 & 0.14 & 100.52 \\
$\mathrm{Min}$ & 73.66 & 0.00 & 11.75 & 0.71 & 0.00 & 0.00 & 0.42 & 1.94 & 4.46 & 0.01 & 95.61 \\
$2 \sigma$ & 2.19 & 0.25 & 0.25 & 0.33 & 0.03 & 0.02 & 0.08 & 0.65 & 0.23 & 0.05 & 2.38 \\
$\% 2 \sigma$ & 2.86 & $>100$ & 2.07 & 31.48 & $>100$ & $>100$ & 15.46 & 17.89 & 4.76 & 50.68 & 2.40 \\
ref value & 76.96 & 0.08 & 12.17 & 1.08 & 0.02 & 0.03 & 0.45 & 3.52 & 4.93 & 0.101 & 99.34 \\
\% offset & -0.4 & -40.4 & -0.6 & -3.1 & -33.8 & -56.6 & 9.9 & 2.4 & -0.7 & -2.7 & -0.4 \\
\hline \multicolumn{2}{r}{ Reference values from Jarosewich et al. (1980) }
\end{tabular}

Reference values from Jarosewich et al. (1980)

d) Scapolite standard for $\mathrm{Cl}$ only $(\mathrm{n}=16)$

\begin{tabular}{rrrrrrrrr} 
& $\mathrm{SiO}_{2}$ & $\mathrm{Al}_{2} \mathbf{O}_{3}$ & $\mathbf{F e O}$ & $\mathbf{C a O}$ & $\mathbf{N a}_{2} \mathbf{O}$ & $\mathbf{K}_{2} \mathbf{O}$ & $\mathbf{C l}$ & Total \\
\hline Average & 52.05 & 24.14 & 0.05 & 11.03 & 6.91 & 0.82 & 1.42 & 96.13 \\
Max & 55.25 & 25.50 & 0.09 & 13.94 & 11.18 & 0.93 & 1.57 & 97.89 \\
Min & 48.69 & 22.77 & 0.00 & 3.72 & 4.87 & 0.23 & 1.33 & 93.25 \\
$2 \sigma$ & 5.29 & 1.98 & 0.06 & 7.18 & 4.63 & 0.39 & 0.10 & 2.90 \\
$\% 2 \sigma$ & 10.17 & 8.19 & 130.94 & 65.13 & 66.99 & 47.06 & 7.23 & 3.01 \\
& & & & & & & & \\
ref value & 49.78 & 25.05 & 0.17 & 13.58 & 5.2 & 0.94 & 1.43 & 96.15 \\
\% offset & 4.6 & -3.6 & -73.3 & -18.8 & 32.9 & -12.8 & -0.8 & 0.0 \\
\hline
\end{tabular}




\subsubsection{Laser-ablation-ICP-MS: Trace elements in amphibole}

Amphibole trace element compositions were measured in-situ using a New Wave deep UV laser (193 nm solid state), coupled with an Agilent 7500CS ICP-MS at VUW. As was the case for solution-ICP-MS analyses, a major element such as ${ }^{43} \mathrm{Ca}$ or ${ }^{29} \mathrm{Si}$ which had previously been determined to $\pm 5 \%$ by EPMA was used as an internal standard for secondary data normalisation. The exact location of the probe spot used on each mineral of interest was recorded during EPMA so that the same area could be analysed for trace element compositions and corrected to a specific $\mathrm{Ca}$ or Si value. Because there are no widely available, well characterised trace element standards for amphibole, the basaltic glass BHVO-2G was employed as the calibration standard. Tuning and optimisation of signal sensitivity and stability was achieved by rastering across the standard and adjusting the inflow of ultra-pure He gas. Data were acquired under a static, circular laser beam of 25 or $35 \mu \mathrm{m}$ diameter pulsed at $\sim 5 \mathrm{~Hz}$. As for solution-ICP-MS, instrumental conditions were adjusted for the analyses of both the standards and a representative sample to achieve the lowest RSD and to optimise sensitivity. Plasma torch conditions were optimised so that the element oxide production (estimated from measured $\mathrm{ThO}^{+} / \mathrm{Th}^{+}$ratios) were $<1 \%$. Prior to analysis pulse/analog $(\mathrm{P} / \mathrm{A})$ factors were measured on all relevant elements to ensure that the ICP-MS correctly performs the adjustment when switching between pulse (low concentration) and analog (high concentration) counting modes. This $\mathrm{P} / \mathrm{A}$ switching is required if an element has a high enough concentration which results in a count rate $>1 \times 10^{6}$ counts per second. A typical analytical run consisted of a looping sequence, starting with the bracketing standard, followed by 5 samples and finishing with the standard. Samples and standards were ablated for a total of 60 seconds, followed by a 90 second washout of the ablation cell. As for solution-ICP-MS, abundances of individual trace elements were calculated relative to the bracketing standard, analysed under identical conditions. Background count rates were measured for 60 seconds prior to analysis of each sample and the mean background was subtracted from the mean count-per-second rates measured during ablation.

In this study, the Iolite software package and the internal standard data reduction scheme of Hellstrom et al. (2008) was used to process the raw LA-ICMPS data. Processing of LA-ICP-MS data involved using time-resolved signals across several masses during each analysis to identify and remove any data compromised by the incidental ablation of inclusions beneath or beside the polished surface (Allan, 2013). The USGS basaltic glass standard BCR-2G was analysed as a secondary standard at 
regular intervals across each analysis session to assess the accuracy and precision of LA-ICP-MS in this study. Approximate 2 SD analytical precisions derived from 15 replicate analyses of $\mathrm{BCR}-2 \mathrm{G}$ are $< \pm 10 \%$ for most trace elements (exceptions are Gd to $\mathrm{Yb}$ at $<15-20 \%$ ) (Table 3.14). BCR-2G trace element analyses are accurate to $\leq 10 \%$, apart from $\mathrm{Cu}$ and $\mathrm{Zn}$ at $<20 \%$. Many of the trace elements with low precisions for BCR-2G are typically found at higher concentrations in amphibole resulting in significantly higher counts and thus higher expected precisions than for BCR-2G.

\subsection{FTIR: Glass $\mathrm{H}_{2} \mathrm{O}$ and $\mathrm{CO}_{2}$ concentrations}

Large melt inclusions up to $200 \mu \mathrm{m}$ in size were noted within interior zones of plagioclase from dacite units $\Psi$ and $\Omega$ during crystal picking and EPMA analysis (Figure 3.3). The majority of these melt inclusions are dark brown in colour, spherical to ellipsoidal in shape and often contain small vapour bubbles. To further investigate the volatile contents of the melts prior to eruption, $\mathrm{H}_{2} \mathrm{O}$ and $\mathrm{CO}_{2}$ concentrations in plagioclase-hosted melt inclusions were determined by Fourier transform infrared spectroscopy (FTIR) using a Varian FTS Stingray 7000 Micro Image Analyser at the Japan Agency for Marine-Earth Science and Technology (JAMSTEC). Samples were prepared as doubly-polished FTIR wafers, whereby individual crystals with large melt inclusions were handpicked from bulk crystal separates under binocular microscope and set into heat-sensitive crystal bond cement on a glass slide. The crystals in the hardened epoxy were then polished down with sandpaper and then 6,3 and $1 \mu \mathrm{m}$ diamond polishing pads to expose the melt inclusion at the surface. The crystal-bond was softened on a hotplate and the plagioclase crystal was flipped over so the opposite unpolished face of the crystal was exposed. The crystal was once again polished down until the melt inclusion was exposed on both sides within a thin wafer of crystal bond (Figure 3.3d). The delicate nature of the crystals often resulted in broken fragments and/or the destruction or loss of samples (Figure 3.3c). In such cases, the process was restarted on a new crystal. In many cases, the abundance and size of melt inclusions meant that several individual inclusions could be exposed within a single wafer.

Replicate analyses ( $n=3-5$ to assess data quality) on each inclusion included collection of both reflection and transmission FTIR spectra. Spectra were collected across the near- and mid-IR ranges $\left(8300-800 \mathrm{~cm}^{-1}\right)$ using a heated ceramic (globar) source and a $\mathrm{KBr}$ beamsplitter. Background and sample spectra were collected with 512 scans at $8 \mathrm{~cm}^{-1}$ resolution, using spot sizes from $20-100 \mu \mathrm{m}^{2}$ as appropriate for each 


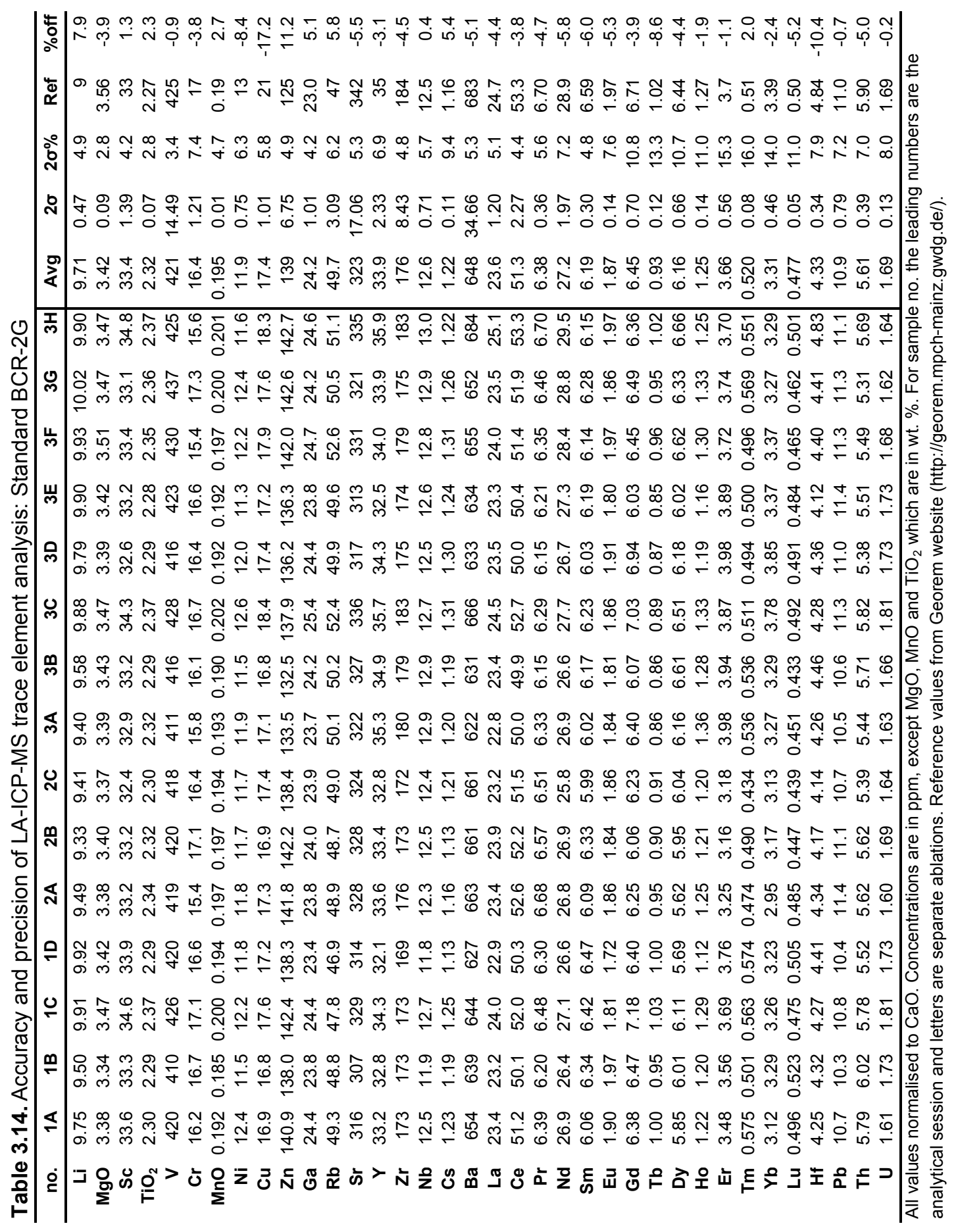



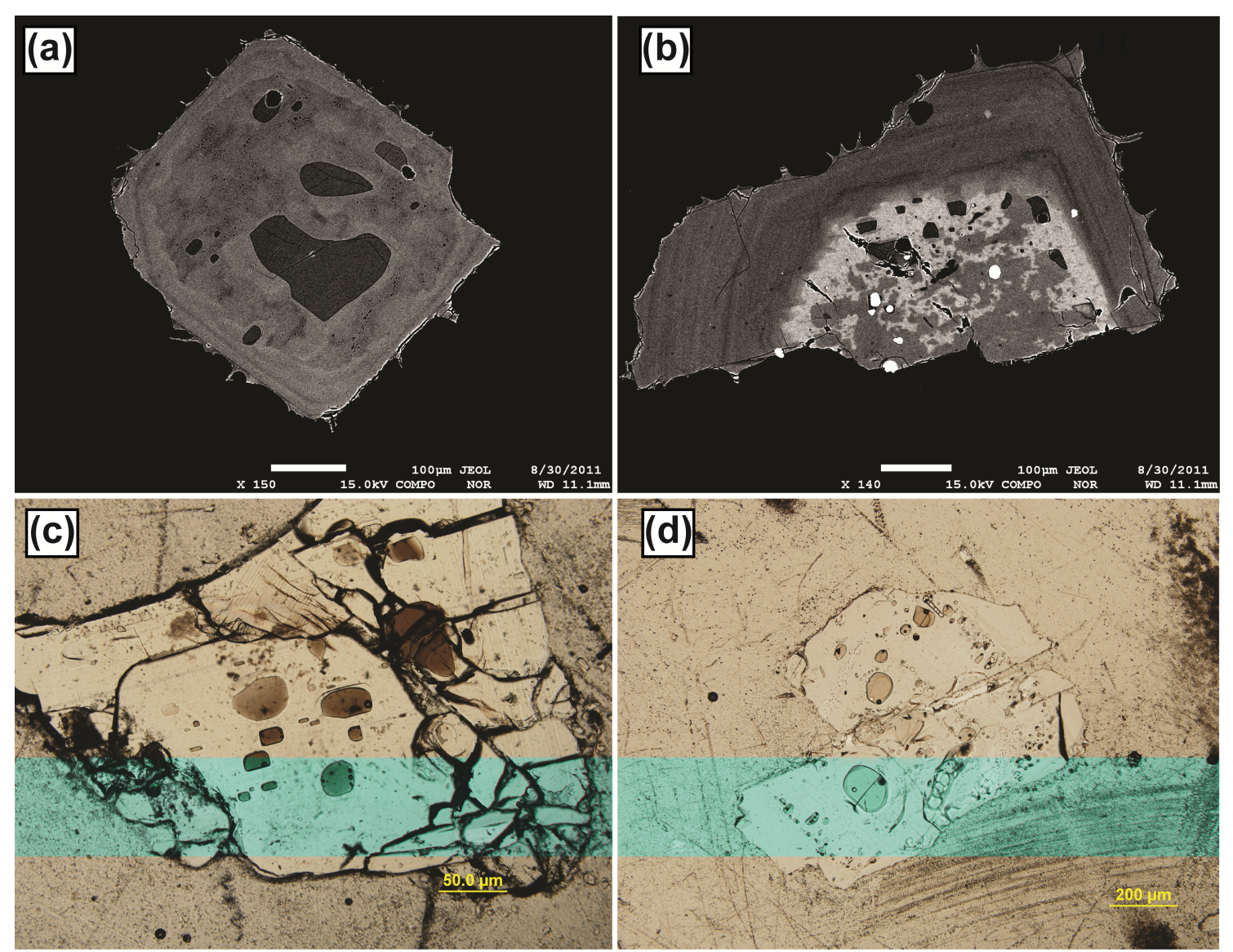

Figure 3.3. Images of typical melt inclusions found within plagioclase crystals from the post-Oruanui dacites. a) BSE image of large melt inclusions within the core of a crystal. b) BSE image of melt inclusions surrounding the resorbed interior of a crystal. c) Photo taken in transmitted light on a binocular microscope of multiple melt inclusions (with vapour bubbles) within a final FTIR wafer which started to crack whilst being thinned. d) Similar to (c) but with a pristine final wafer and large melt inclusions within a crystal core surrounded by alignments of smaller melt inclusions.

inclusion, as focused with an attached UMA 600 microscope. Backgrounds were taken on a gold-coated disk for reflection and through a $\mathrm{KBr}$ disk for transmission.

Interference fringes on reflectance spectra were used to determine the beampath, or inclusion thickness exactly at each analytical spot (Tamic et al., 2001; Wysoczanski \& Tani, 2006; Nichols \& Wysoczanski, 2007) using a refractive index of 1.48 (Okumura et al., 2003). Absorbance peak heights were determined from transmission spectra using Varian Win-IR Pro software (v3.3.1.014), and were converted to concentrations using the Beer-Lambert law. Parameters included the reflectance-determined thicknesses, a nominal rhyolite glass density of $2.3 \mathrm{~g} \mathrm{~cm}^{-3}$ (Okumura et al., 2003) and the following molar absorptivities: 1.86 mol.cm ${ }^{-1}$ for molecular $\mathrm{H}_{2} \mathrm{O}\left(\mathrm{H}_{2} \mathrm{O}_{\text {mol }}\right)$ at $5200 \mathrm{~cm}^{-1}$ (Ihinger et al., 1994); 1.50 mol.cm ${ }^{-1}$ for OH- at $4500 \mathrm{~cm}^{-1}$ (Ihinger et al., 1994); and 1214 mol.cm ${ }^{-1}$ for $\mathrm{CO}_{2}$ mol. at $2350 \mathrm{~cm}^{-1}$ (Behrens et al., 2004). As FTIR spectroscopy is a non destructive technique, further analyses were later undertaken on selected inclusions by EPMA for corresponding major and minor element compositions. 


\subsection{Ion microprobe: Zircon age dating and trace elements}

Zircon has been recorded as an accessory mineral phase occurring in variable, but generally minor $(<1.2 \mathrm{mg} / \mathrm{kg})$ concentrations in rhyolitic eruptives from Taupo (Charlier et al., 2005). As such, large quantities of samples were selected for zircon investigations and put through a rigorous 8-step procedure to ensure enough zircon crystals were obtained for analysis (Figure 3.4). Samples consisted of multiple pumices or blocks of pumiceous dome carapace typically weighing $>1 \mathrm{~kg}$ and up to $10 \mathrm{~kg}$ for Unit S. Each sample was thoroughly cleaned to remove any adhering ash or lithics and Boyd crushed, sieved, TEMA milled and then wet-sieved to $>250 \mu \mathrm{m}, 250-125 \mu \mathrm{m}, 125-63 \mu \mathrm{m}$ and $<63 \mu \mathrm{m}$ fractions. Heavy minerals were separated using a Wilfley gravity table to obtain an initial concentrate from bulk crushed material for the $250-125 \mu \mathrm{m}$ and $125-63 \mu \mathrm{m}$ size fractions. This initial separate was then put through LST heavy liquid to remove any remaining crystals with a specific gravity of $<2.8 \mathrm{~g} / \mathrm{cm}^{3}$ such as plagioclase. A strong hand magnet was then hovered over the remaining sample to remove strongly magnetic Fe-Ti oxides and the rest of the material was run through a Frantz ${ }^{\circledR}$ electromagnetic separator to divide the crystals by their magnetic susceptibility. This separation stage usually required multiple passes of the material with gradual reductions in the current to $<0.15 \mathrm{amps}$, with zircon remaining in the low magnetic susceptibility fraction. To fully remove any other low magnetic susceptibility crystals, the heavy nonmagnetic zircon fraction was put through a final stage of heavy liquid separation using methylene iodide to remove any remaining minerals with a specific gravity $<3.2 \mathrm{~g} / \mathrm{cm}^{3}$ such as remaining pyroxene. The final product from this preparation procedure yielded zircon crystals with minor amounts of apatite. The final separate was then cleaned in acetone and handpicked as required to produce a pure zircon fraction. The majority of zircons obtained in this study were in the $63-125 \mu \mathrm{m}$ size fraction, with very few zircons recovered that were larger than $125 \mu \mathrm{m}$. As for EPMA mounts, zircons were mounted in epoxy resin, polished to expose the cores of the grains and then imaged by plain light under a microscope and then on a SEM using cathodoluminescence (CL). Mounts were then coated with $\sim 100 \mathrm{~nm}$ of Au and placed in a vacuum chamber overnight.

Zircon analyses for U-Th disequilibrium dating were carried out by secondaryion mass spectrometry (SIMS) using Sensitive High-Resolution Ion MicroprobeReverse Geometry (SHRIMP-RG) at the USGS-Stanford facility, with techniques modified from those of Charlier \& Wilson (2010). Prior to data acquisition, a $50 \mu \mathrm{m} \mathrm{x}$ 
$50 \mu \mathrm{m}$ square region was rastered for $2 \mathrm{~min}$ to remove the Au surface coating and any contamination. Ions were then sputtered from zircons with 14-17 nA ${ }^{16} \mathrm{O}_{2}{ }^{-}$primary ion beam focussed to a 35-40 $\mu \mathrm{m}$ spot. Data were collected in 6 scans per point for ${ }^{90} \mathrm{Zr}_{2}{ }^{16} \mathrm{O},{ }^{180} \mathrm{Hf}^{16} \mathrm{O},{ }^{206} \mathrm{~Pb},{ }^{207} \mathrm{~Pb},{ }^{208} \mathrm{~Pb},{ }^{230} \mathrm{Th}^{16} \mathrm{O},{ }^{232} \mathrm{Th}^{16} \mathrm{O},{ }^{235} \mathrm{U}^{16} \mathrm{O}$ and ${ }^{238} \mathrm{U}^{16} \mathrm{O}$. Dwell times ranged from 2 to $60 \mathrm{~s}$ for each peak. To allow for low $\mathrm{U}$ contents of the zircons ${ }^{230} \mathrm{Th}^{16} \mathrm{O}$ and the background (at mass $246.16 \mathrm{u}$ ) were measured for $60 \mathrm{~s}$ on each scan. Analyses that produced low ${ }^{230} \mathrm{Th}^{16} \mathrm{O}$ counts within $3 \mathrm{SD}$ uncertainty overlap with the background were discarded ( $<5$ analyses in total). Additionally, a measurement at mass 244 (corresponding to ${ }^{232} \mathrm{Th}^{12} \mathrm{C}^{+}$) for $10 \mathrm{~s}$ was used to check for beam impinging on the epoxy and, if significantly higher than background, the measurement was discarded ( $<10$ analyses in total). A U-Th fractionation factor was empirically determined by repeated analyses of multiple zircon standards run on the same mounts as the unknowns. The standards included: MAD (Madagascar green: Barth \& Wooden, 2010) as the concentration standard, R33 (Black et al., 2004), VP10 (1200 Ma granitoid, Joshua Tree National Park, CA; A. P. Barth and J. L. Wooden, unpublished data) and zircons from the $0.77 \mathrm{Ma}$ Bishop Tuff fall deposit (Chamberlain et al., 2014a). Given their ages, ${ }^{238} \mathrm{U}$ and ${ }^{230} \mathrm{Th}$ activities in these zircon standards are at secular equilibrium and after the application of a U-Th fractionation factor, the calculated $\left({ }^{230} \mathrm{Th} /{ }^{238} \mathrm{U}\right)$ (values in parentheses denote activity ratios) should equal unity, determined on a mount-by-mount basis using the measured ${ }^{238} \mathrm{U}^{16} \mathrm{O}^{+} / 230 \mathrm{Th}^{16} \mathrm{O}^{+}$ratios. Calculated fractionation factors from each analytical session were used to correct the $\left({ }^{238} \mathrm{U} /{ }^{232} \mathrm{Th}\right)$ of the unknowns, and repeated analysis of the standards over the sessions allowed us to derive a best-estimate $1 \sigma$ error of $\pm 1.2 \%$ on the fractionation factor (see Charlier et al., 2005).

Values of the $\left({ }^{238} \mathrm{U} /{ }^{232} \mathrm{Th}\right)$ and $\left({ }^{230} \mathrm{Th} /{ }^{232} \mathrm{Th}\right)$ ratios for whole-rock (WR) samples for units B1, D, E3, G and S were previously determined by isotope-dilution thermal ionization mass spectrometry (TIMS) and reported in Charlier et al. (2005). For units $\mathrm{B} 3, \mathrm{C}, \mathrm{E} 1, \mathrm{~F}$ and $\mathrm{K}$, the $\left({ }^{230} \mathrm{Th} /{ }^{232} \mathrm{Th}\right)$ values were determined on unspiked dissolutions by multi-collector inductively coupled plasma mass spectrometry (MC-ICP-MS) using a Thermo-Finnigan Neptune instrument at the Open University, and $\left({ }^{238} \mathrm{U} /{ }^{232} \mathrm{Th}\right)$ was calculated from $\mathrm{U}$ and $\mathrm{Th}$ concentration analyses determined using a Thermo Scientific Element2 sector-field ICPMS at Victoria University of Wellington (see section 3.2.2). Previous comparisons of the two techniques used have shown that they produce identical data within analytical uncertainty (Wilson \& Charlier, 2009). ${ }^{230} \mathrm{Th}^{2}{ }^{238} \mathrm{U}$ isochron ages were calculated as two-point model ages by referencing each of the 
fractionation-corrected zircon analyses to the respective WR analysis on the equiline diagram.

$\mathrm{U}-\mathrm{Pb}$ zircon age determinations were carried out using the SHRIMP-RG instrument at the Research School of Earth Sciences, Australian National University (ANU). To minimise contamination by common $\mathrm{Pb}$, the mounts were cleaned in detergent, petroleum spirits, alcohol and $1 \mathrm{~N} \mathrm{HCl}$ with intervening rinses in distilled water. The primary beam was rastered for over an area of $35 \times 45 \mu \mathrm{m}$ prior to data acquisition to remove the gold coating and any surface contamination. Secondary ions were sputtered from zircons with a 5-6 nA primary $\mathrm{O}_{2}{ }^{-}$beam focused to a $25 \times 35 \mu \mathrm{m}$ spot. Two suites of data were collected. The first was applied to zircons from samples of eruption D and E. The mass spectrometer was cycled in six scans per spot through peaks corresponding to ${ }^{90} \mathrm{Zr}_{2}{ }^{16} \mathrm{O},{ }^{204} \mathrm{~Pb}$, background, ${ }^{206} \mathrm{~Pb},{ }^{207} \mathrm{~Pb},{ }^{208} \mathrm{~Pb},{ }^{238} \mathrm{U},{ }^{232} \mathrm{Th}^{16} \mathrm{O}$ and ${ }^{238} \mathrm{U}^{16} \mathrm{O}$. Because of the young ages of the grains and hence the low count rate, ${ }^{206} \mathrm{~Pb}$ and ${ }^{207} \mathrm{~Pb}$ were counted for 30 and $20 \mathrm{~s}$ respectively. SL-13 was used as a concentration standard (238 ppm U) and R33 was used as an age standard (420 Ma) (Black et al., 2004). To account for initial ${ }^{230} \mathrm{Th}$ disequilibrium in the ${ }^{238} \mathrm{U}^{2}{ }^{206} \mathrm{~Pb}$ decay chain, a $\mathrm{Th} / \mathrm{U}$ correction factor was applied using $\mathrm{f}=\left(\mathrm{Th} / \mathrm{U}_{\mathrm{zir}}\right) /\left(\mathrm{Th} / \mathrm{U}_{\text {magma }}\right)$ (Schärer, 1984) based on observed Th and U concentrations of zircons derived from SIMS measurements and WR Th/U values measured as previously discussed. A correction for common $\mathrm{Pb}$ was applied using the recorded ${ }^{207} \mathrm{~Pb} /{ }^{206} \mathrm{~Pb}$ values and a common $\mathrm{Pb}$ isotopic composition $\left({ }^{207} \mathrm{~Pb} /{ }^{206} \mathrm{~Pb}=0.836\right)$ for the sample age from the average crust model of Stacey \& Kramers (1975).

Zircon trace element analyses were carried out after age dating by SIMS using the SHRIMP-RG at Stanford University with a 1.5-3 nA primary beam and a focused $15 \times 12 \mu \mathrm{m}$ spot. Trace element analytical spots were not placed directly on the $\mathrm{U}-\mathrm{Pb}$ or U-Th age dating spots, but instead either the opposite growth zone as that dated was analysed or the mounts were repolished to remove the age pits prior to analysis. Trace element spots were also selected to avoid contamination by inclusions or crystal defects visible in reflected light images. Common elements that are normally found at very low concentrations in zircon were used to monitor for contamination: $\mathrm{Ca}, \mathrm{Al}, \mathrm{Na}, \mathrm{K}$ for feldspar and glass; Ca, P, F for apatite; Fe for Fe-Ti oxides; and Ca, Fe for allanite. The matrix-matched MAD zircon standard (Barth \& Wooden, 2010) was used to calibrate trace element concentrations and run at the start and finish of the analytical sessions to monitor precision (Table 3.15). Counts were normalised to a known value of ${ }^{30} \mathrm{Si}$. Approximate 2 SD analytical precisions derived from 14 replicate analyses of the MAD 
이 ฟ 닐

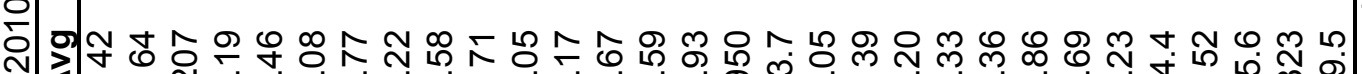

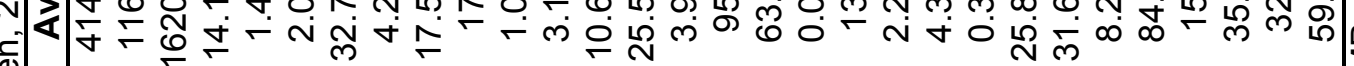
守 寸 帛 ర্ত் 元 ๘ ঠ্তু ত্ำ ฟF

Zปا 守

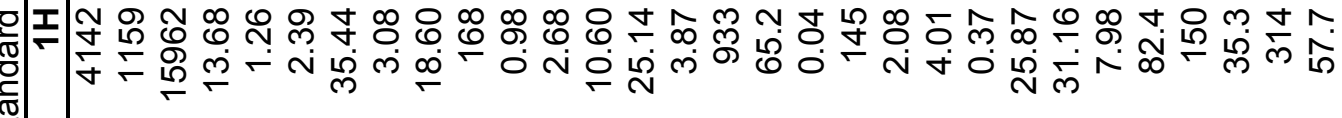
ஸు

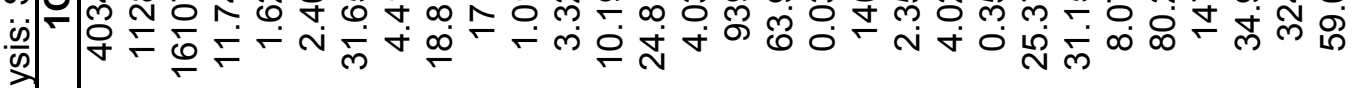

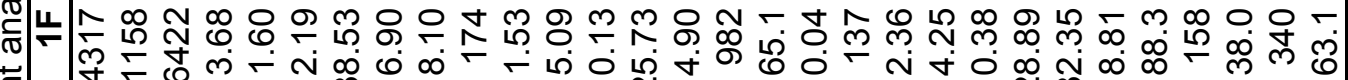
元

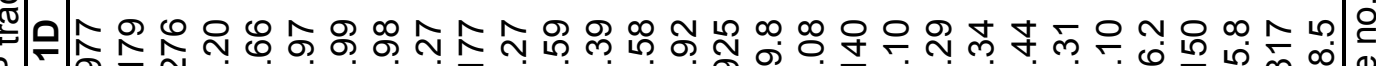
¿ 宁

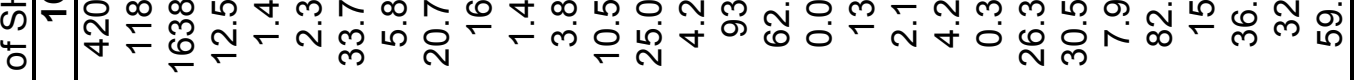
으미

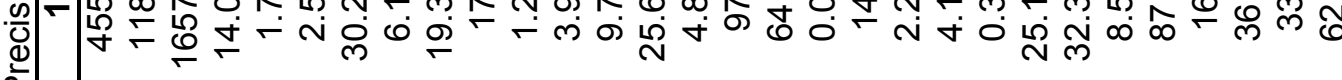
எ|テ m 息:

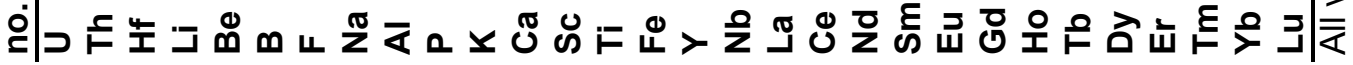


zircon standard are $< \pm 10 \%$ for most trace elements that occur in concentrations $>10$ ppm (with exceptions being Li, F, Al at 30\%) (Table 3.15). Precisions decrease significantly for elements that occur at ppm or sub-ppm levels such as $\mathrm{B}, \mathrm{Be}, \mathrm{Na}, \mathrm{K}, \mathrm{Ca}$ and La. However, many of these elements were only analysed to monitor for contamination by glass inclusions or other minerals. Rare Earth Elements (REE) are precise to $<6 \%$ for heavy-REE, and $<15 \%$ for light-REE (with La being the only exception, which typically occurs at very low concentrations) (Table 3.15). 


\section{CHAPTER 4}




\title{
4: POST-SUPERERUPTION MAGMATIC RECONSTRUCTION OF TAUPO VOLCANO \\ (NEW ZEALAND), AS REFLECTED IN ZIRCON AGES AND TRACE ELEMENTS
}

\begin{abstract}
New zircon U-Th model age and trace element data sets are presented from Taupo volcano (New Zealand), to investigate the timescales and broad-scale magmatic processes involving zircon crystallisation after the caldera-forming 25.4 ka Oruanui supereruption. Detailed ${ }^{14} \mathrm{C}$-based chronologies and controls on vent locations allow the timing and location of post-caldera eruptions to be spatially and temporally constrained to an extent not possible for any other supervolcano. After $\sim 5 \mathrm{kyr}$ of post-Oruanui quiescence, Taupo erupted three dacitic units, followed by another $\sim 5 \mathrm{kyr}$ year break, and then a sequence of rhyolitic units in three subgroups (SG1-SG3) from $12 \mathrm{ka}$ onwards. Despite overlapping vent sites and crustal source domains between the Oruanui and post-Oruanui eruptions, U-Th zircon model-ages in Taupo SG1 rhyolites (erupted from $12 \mathrm{ka}-10 \mathrm{ka}$ ) indicate only minor inheritance of crystals from the Oruanui magma source. Post-Oruanui model-age spectra are instead typically centred close to eruption ages with subordinate older pre-300 ka equiline grains in some units. $\mathrm{U}-\mathrm{Pb}$ dating of these older grains show that both 300-450 ka plutonic-derived and pre-100 Ma greywacke basement-derived zircons are present. The former largely coincide in age with zircons from the $350 \mathrm{ka}$ Whakamaru eruption products, and are dominant over greywacke in young units which were vented within the outline of the Whakamaru caldera outline. Despite multiple ages and vent sites, trace element compositions are broadly similar in zircons, regardless of their ages. However, a small subset of zircons analysed from SG1 rhyolite (units B and C) have notably high concentrations of U, Th, $\mathrm{P}, \mathrm{Y}+(\mathrm{REE})^{3+}$ and $\mathrm{Nb}$ but with only minor changes in Hf and Ti. SG2 zircons typically have higher Sc, reflecting large scale changes in melt chemistry and crystallising mineral phases with time. The age spectra indicate that most Oruanui zircons were removed by thermally induced dissolution immediately following the supereruption. UTh ages from individual post-Oruanui eruptions show consistent inheritance of postOruanui grains with model ages that centre between the temporally separated but
\end{abstract}


geographically overlapping eruption groups, generating model-age modes. Within the statistical limitations of the isotopic measurements, we interpret these repeated modes to be significant, resulting from incorporation of crystal populations from cyclic postOruanui periods of magmatic cooling and crystallisation, acting within a crustal protolith chemically independent of that which was dominant in the Oruanui system. These periods of cooling and crystallisation alternate with times of rejuvenation and eruption, in some case demonstrably accompanying syn-eruptive regional rifting and mafic injection. Not only were the processes that developed the supersized Oruanui magma body rapid, but this huge magma system was effectively reset and rebuilt on a comparably short timescale. 


\subsection{Introduction}

Large silicic magma systems play host to some of the most hazardous volcanoes on Earth, which at an extreme, are capable of erupting vast amounts of material in single events referred to as supereruptions, ejecting $\geq 10^{15} \mathrm{~kg}$ or $\sim 450 \mathrm{~km}^{3}$ of magma (Self, 2006). Numerous studies have addressed how silicic volcanic systems can accumulate large volumes of magma and release them in catastrophic caldera-forming events (e.g. Hildreth, 1981; Bachmann et al., 2002; Vazquez \& Reid, 2004; Wilson et al., 2006; Reid, 2008; Saunders et al., 2010; Allan et al., 2012, 2013; Matthews et al., 2012). Such studies typically focus on physical, geochemical and petrological investigations of products, either from precursory leaks or the climactic eruption itself. However, less widely addressed is what happens to the host magma system (i.e., the melt dominant zone, crystal mush zone and crustal reservoir of Hildreth \& Wilson, 2007) immediately following a supereruption and how, and on what timescales, the volcano moves into subsequent activity. Does the supereruption act to reset the host magma system and the volcano's eruptive behaviour, or does it merely represent another, exceptionally large eruption from a long-lived magma system?

A method which has proved invaluable in the interpretation of magmatic processes in large silicic magma systems is single-crystal dating of zircon $\left(\mathrm{ZrSiO}_{4}\right)$ by $\mathrm{U}-\mathrm{Pb}$ or U-Th-disequilibrium techniques. Zircon model-age data can provide insights into the timing and rates of magma accumulation (Brown \& Fletcher, 1999; Reid \& Coath, 2000; Vazquez \& Reid, 2002; Simon \& Reid, 2005; Wilson \& Charlier, 2009; Schmitt et al., 2010; Storm et al., 2011), the range of magmatic and crustal sources that contribute melt and crystals to the system (Reid et al., 1997; Bindeman et al., 2001; Charlier et al., 2010), and the temporal evolution of the magma system as a whole (Simon et al., 2009; Watts et al., 2012). Zircon trace element compositions can also be used with age data to infer changes in melt compositions and modal assemblages (e.g., Barth et al., 2013). However, supereruptions are inferred to occur globally only once every $\sim 10^{5}$ years (Mason et al., 2004; Miller \& Wark, 2008). Their relative scarcity in the geological record controls interpretations of the post-supereruption magmatic temporal record through the uncertainties of the geochronological techniques used. For example, fine detail of eruptive events and magmatic processes are constrained by the $10^{4}-10^{5}$ year uncertainties using ${ }^{40} \mathrm{Ar} /{ }^{39} \mathrm{Ar}$ and U-Pb systematics (e.g. Simon et al., 2008), making the study of closely spaced post-caldera magmatism difficult. In addition, there is a range of post-supereruption behaviour, varying from rapid 
(thousands to tens of thousands of years) magmatic and structural resurgence of less evolved magmatic dregs (e.g. Valles: Stix et al., 1988; Phillips et al., 2007; Toba: Chesner, 2012; La Pacana: Lindsay et al., 2001; Long Valley: McConnell et al., 1995; Hildreth, 2004) or rapid construction of a post-caldera composite cone (e.g. Aira: Aramaki, 1984), through to longer-term (hundreds of thousands of years) systematic tapping of magma incorporating recycled hydrothermally altered crystal mush or caldera infill (e.g. Yellowstone caldera: Bindeman et al., 2001; Girard \& Stix, 2009; Vazquez et al., 2009).

Here we investigate a case study of post-supereruption recovery at Taupo volcano, (Figure 4.1; Wilson et al., 1995), using ${ }^{238} \mathrm{U}_{-}^{230}$ Th disequilibrium and ${ }^{238} \mathrm{U}$ ${ }^{206} \mathrm{~Pb}$ dating techniques, coupled with trace element analyses of zircons. Taupo is source to the $530 \mathrm{~km}^{3}$ (magma) Oruanui eruption at $\sim 25.4 \pm 0.2 \mathrm{ka}$, which is the world's youngest example of a supereruption (Wilson, 2001; Wilson et al., 2006; Vandergoes et al., 2013). Taupo in particular provides a unique circumstance to investigate the development and post-caldera recovery of a large silicic magmatic system for several reasons. First, the frequency of eruptions is exceptionally rapid. Only $\sim 5 \mathrm{kyr}$ after the Oruanui eruption, Taupo resumed activity with a total of 28 eruptions to the present day (Wilson, 1993), providing frequent snapshots of the magmatic system. Second, the young age and good preservation of Taupo's eruptive products provides a highresolution age record. Eruption timings are radiocarbon dated with 1 SD (standard deviation) uncertainties of $10^{2}-10^{3}$ years, and magmatic chronologies can be interrogated by U-Th disequilibrium techniques on zircon with $10^{3}-10^{4}$ year $1 \mathrm{SD}$ uncertainties (Charlier et al., 2005; Wilson \& Charlier, 2009). Third, existing field, geochemical and petrological data provide many constraints on the broad evolution of both the pre- and post-supereruption magmatic systems (e.g. Sutton et al., 1995, 2000; Wilson et al., 2006) and for the young products of the nearby NE dome magmatic system (Figure 4.1; Sutton et al., 1995; Wilson \& Charlier, 2009). In this study we present new zircon model-age data and trace element data from eight post-Oruanui eruptions and compare and contrast them with new trace element data from Oruanui zircons, and pre-existing zircon age spectra for both the Oruanui and pre-Oruanui products (Charlier et al., 2005; Wilson \& Charlier, 2009). By comparing these data we demonstrate how Taupo's young magmatic system was destroyed and then rebuilt on rapid timescales (thousands of years), into a system that appears to have little or no direct relationship to that which previously fed a supereruption. 


\subsection{Geological background}

Taupo volcano is located in the southern part of the central Taupo Volcanic Zone (TVZ), in North Island of New Zealand (Figure 4.1; Wilson et al., 1995, 2009). Taupo volcano and its northern neighbour Maroa are superimposed on a large caldera associated with the $350 \mathrm{ka}$ Whakamaru group of ignimbrites (Figure 4.1; Wilson et al., 1986; Leonard et al., 2010). Taupo has been active in close relation with Maroa since $\sim 300 \mathrm{ka}$, but its early history is poorly known because of limited age data and burial by younger deposits (Leonard, 2003; Wilson et al., 2009). From $\sim 65$ ka, explosive activity became more focused towards vents now concealed by Lake Taupo, and minor activity from Maroa became almost exclusively accompanied by lava extrusion. Between $\sim 65$ $\mathrm{ka}$ and the Oruanui eruption $(25.4 \mathrm{ka})$, there were $\sim 11$ eruptions from the Taupo-Maroa area, with five of these linked to two distinctive magma types (Sutton et al., 1995; Wilson \& Charlier, 2009; Figure 4.1). The 'Oruanui-type' magma (Wilson et al., 2006) was of broadly similar composition and mineralogy to the Oruanui rhyolite and is considered to represent precursor leaks of that magma system (Figure 4.2). The 'NEdome-type' magma (Sutton et al., 1995), had higher crystal contents, biotite as an additional crystal phase and contrasting ${ }^{87} \mathrm{Sr} /{ }^{86} \mathrm{Sr}$ ratios to the Oruanui-type magmas (Figure 4.2; Wilson \& Charlier, 2009). It was erupted from a series of vents to the NE of the modern Lake Taupo, overlapping with Maroa lava domes (Figure 4.1).

The Oruanui event evacuated $>530 \mathrm{~km}^{3}$ of magma; $>99 \%$ rhyolitic and $<1 \%$ mafic, over 10 phases during a prolonged, episodic phreatomagmatic eruption (Wilson, 2001; Wilson et al., 2006; Van Eaton \& Wilson, 2013). Contrasts in U-Th model age spectra between zircons from the precursor Oruanui-type magmas and the Oruanui magma itself (Wilson \& Charlier, 2009) and element diffusion modelling (Allan et al., 2013 ) indicate that the $530 \mathrm{~km}^{3}$ melt-dominant body was accumulated in at most about 3000 years. Assembly of the Oruanui magma body was not only rapid, but included contributions from Quaternary intrusions and melts from greywacke metasediments that were introduced into the magma body up to the point of eruption (Liu et al., 2006; Charlier et al., 2008). Oruanui pumices show evidence for mixing in both bulk rock compositions and mineral populations, implying that any systematic zonation in the system was disrupted by vigorous convection prior to eruption (Wilson et al., 2006). In addition, during the first two eruption phases, there was lateral movement of 'NE-dometype' magma into the Oruanui vent controlled by syn-eruptive rifting (Allan et al., 2012). 


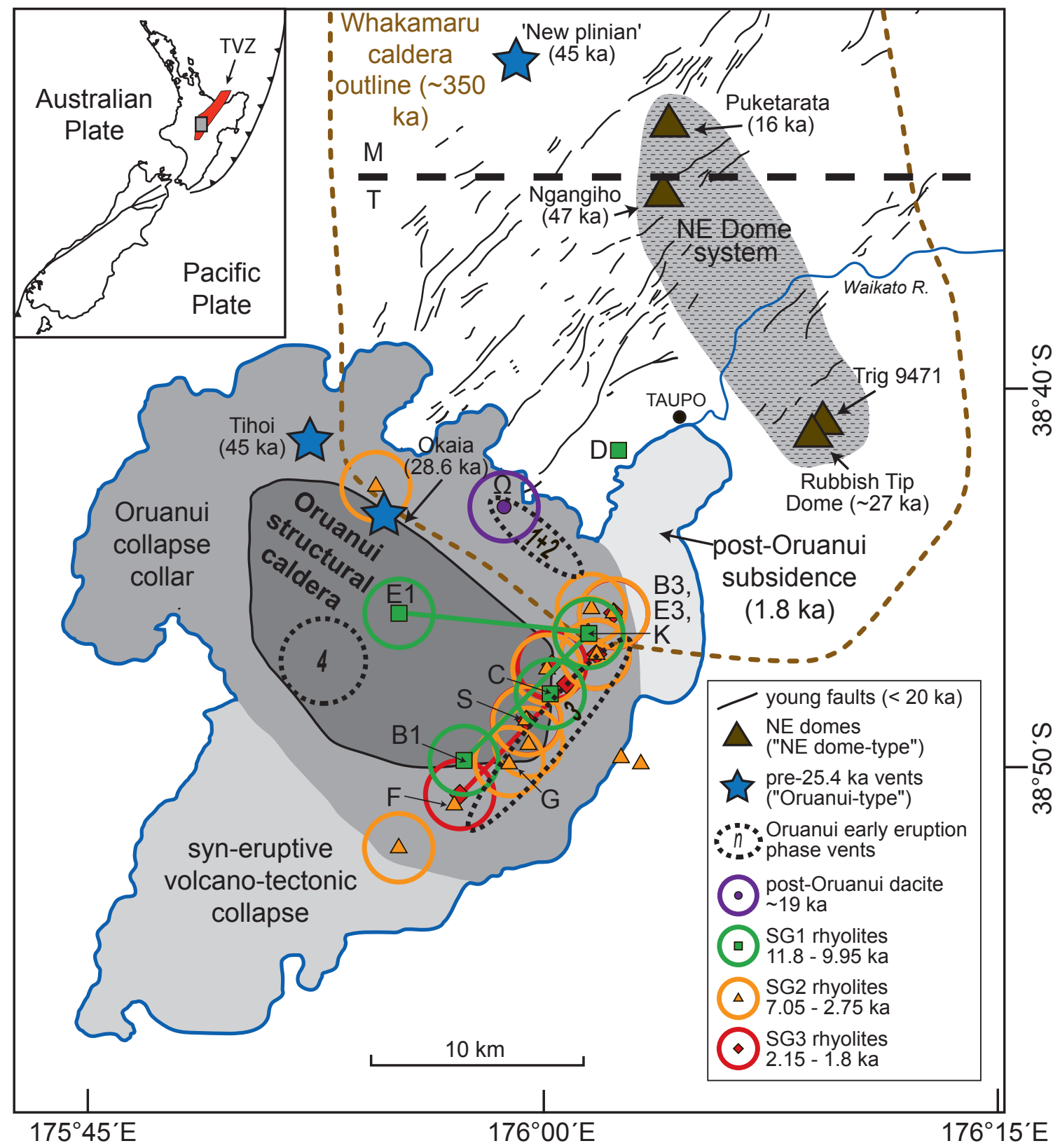

Figure 4.1. Regional setting and structural features of Taupo volcano in the Taupo Volcanic Zone (TVZ), New Zealand (map inset) (modified from Wilson \& Charlier, 2009). Lineations are young NNE-SSW surface faults. Areas defined under Lake Taupo are the structural elements of the Oruanui caldera and subsequent collapse events, from Wilson (2001). The thick black dashed line marks the arbitrary boundary between Taupo (T) and Maroa (M) volcanoes, and the thin dashed line represents the inferred Whakamaru caldera boundary (Wilson et al., 1986). Pre-Oruanui vent sites, ages and magma types are after Wilson \& Charlier (2009), and approximate vent areas for the first 4 phases of the Oruanui eruption are from Wilson (2001). Inferred vent sites and ages for the post-Oruanui eruption groups are modified from Wilson (1993), with labelled units representing eruptions investigated in this study and tie-lines representing shifting vents within single eruptions. Note the shift of vent site between the $\Omega$ dacite and rhyolites, and the cluster of vent sites near the eastern shore, especially for the recent eruptions. 


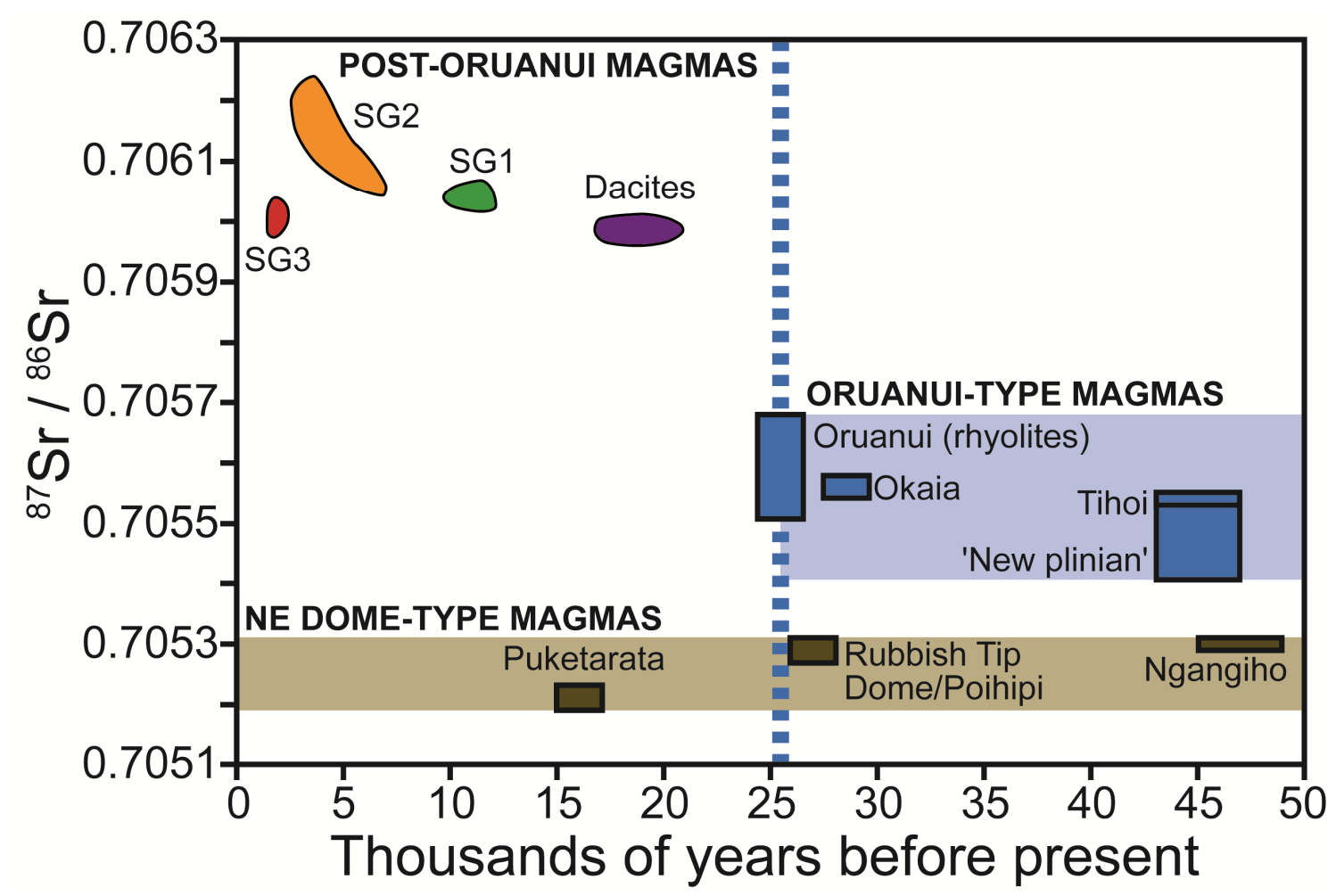

Figure 4.2. Plot showing ${ }^{87} \mathrm{Sr} /{ }^{86} \mathrm{Sr}$ variations in magmas erupted from the Taupo-Maroa region over the last $50 \mathrm{kyr}$. Note the two contrasting Oruanui-type and NE dome-type magmas erupted prior to the Oruanui supereruption, and the apparent continuity of the NE dome system, but large compositional shift in the post-Oruanui magmas despite overlapping vent sites (Figure 4.1). Inferred ages and compositions for the NE dome-type and Oruanui-type magmas are from Sutton et al. (1995), Charlier et al. (2005), Wilson et al. (2006) and Wilson \& Charlier (2009). The new $25.4 \mathrm{ka}$ eruption age for the Oruanui is from Vandergoes et al. (2013). Post-Oruanui eruption ages are from Wilson (1993), and isotopic compositions are from Sutton et al. (2000).

Following the Oruanui eruption, the behaviour of Taupo changed markedly. Temporally separated clusters of eruptions occurred from vent sites that geographically overlapped (Figure 4.1; Wilson, 1993), with chemical compositions that are distinct from Oruanui or pre-Oruanui magmas (Figure 4.2; Sutton et al., 2000; Wilson \& Charlier, 2009). The first three eruptions from 20.5-17 ka were dacitic (Unit $\Psi, \Omega$ and A), with vent sites in the northern sector of the Oruanui caldera. The remaining 25 eruptions fall into three chemically distinct rhyolitic subgroups, erupted from multiple vent sites within and beyond the caldera margin in discrete periods from $\sim 11.8$ to 9.95 (Subgroup 1, units B to E), 7.05 to 2.75 (Subgroup 2, units F to W) and 2.15 to $1.8 \mathrm{ka}$ (Subgroup 3, units X to Z: Wilson, 1993; Sutton et al., 2000).

In the post-Oruanui sequence we focus on eight eruptions from the Subgroup 1 (SG1) rhyolites (units B, C, D and E) and Subgroup 2 (SG2) rhyolites (units F, G, K and S) to investigate the post-caldera magmatic reconstruction of Taupo. For two of these eruptions (B and $\mathrm{E}$ ), we have analysed zircons from two subunits for each respective 
eruption (B1 and B3; E1 and E3) which represent products from different vents during the eruptions (Figure 4.1; Wilson, 1993). Previous work on the dacitic Unit $\Omega$ showed that its zircons are mostly inherited grains from older plutonic and country rock melts (Charlier et al., 2010), and we have carried out reconnaissance U-Pb determinations of units $\mathrm{D}$ and $\mathrm{F}$ where equiline grains dominated the zircon population analysed. We have not analysed zircons from the third subgroup of rhyolites due to their relative scarcity (Charlier et al., 2005).

\subsection{Analytical techniques}

Samples used for zircon separation consisted of multiple pumices (units B, C, E, G, K and S) or blocks of pumiceous dome carapace (units D and F) (see Appendix A for sample details). Each sample was cleaned and crushed, then sieved to 250-125 $\mu \mathrm{m}, 125$ $63 \mu \mathrm{m}$ and $<63 \mu \mathrm{m}$. Zircons were separated using conventional heavy liquid and magnetic separation methods similar to those of Charlier et al. (2005), with the additional use of a Wilfley gravity table to obtain an initial heavy mineral concentrate from bulk crushed material. The majority of zircons obtained in this study were in the 63-125 $\mu \mathrm{m}$ size fraction, with very few zircons recovered that were larger than $125 \mu \mathrm{m}$. Zircons were mounted in epoxy resin, polished to expose the cores of the grains and imaged by cathodoluminescence (CL). Representative CL images of zircon textures with corresponding age and trace element spots are presented in Appendix B.

U-Th zircon analyses were carried out by secondary-ion mass spectrometry (SIMS) using the USGS-Stanford SHRIMP-RG (Sensitive High-Resolution Ion Microprobe-Reverse Geometry) with techniques modified from those of Charlier \& Wilson (2010). Prior to data acquisition, a $50 \mu \mathrm{m} \times 50 \mu \mathrm{m}$ square region was rastered for $2 \mathrm{~min}$ to remove the Au surface coating and any contamination. Ions were then sputtered from zircons with $14-17 \mathrm{nA}^{16} \mathrm{O}_{2}{ }^{-}$primary ion beam focussed to a $35-40 \mu \mathrm{m}$ spot. Data were collected in 6 scans per point for ${ }^{90} \mathrm{Zr}_{2}{ }^{16} \mathrm{O},{ }^{180} \mathrm{Hf}^{16} \mathrm{O},{ }^{206} \mathrm{~Pb},{ }^{207} \mathrm{~Pb},{ }^{208} \mathrm{~Pb}$, ${ }^{230} \mathrm{Th}^{16} \mathrm{O},{ }^{232} \mathrm{Th}^{16} \mathrm{O},{ }^{235} \mathrm{U}^{16} \mathrm{O}$ and ${ }^{238} \mathrm{U}^{16} \mathrm{O}$. Dwell times ranged from 2 to $40 \mathrm{~s}$ for each peak. To allow for low $\mathrm{U}$ contents of the zircons ${ }^{230} \mathrm{Th}^{16} \mathrm{O}$ and the background (at mass $246.16 \mathrm{u}$ ) were measured for $60 \mathrm{~s}$ on each scan. Analyses that produced low ${ }^{230} \mathrm{Th}^{16} \mathrm{O}$ counts within 3 SD uncertainty of the background were discarded ( $<5$ analyses in total). Additionally, a measurement at mass 244 (corresponding to ${ }^{232} \mathrm{Th}^{12} \mathrm{C}^{+}$) for $10 \mathrm{~s}$ was used to check for beam impinging on the epoxy and, if significantly higher than background, the measurement was discarded ( $<10$ analyses in total). A U-Th 
fractionation factor was empirically determined by repeated analyses of multiple zircon standards run on the same mounts as the unknowns. The standards included: MAD (Madagascar green: Barth \& Wooden, 2010) as the concentration standard, R33 (Black et al., 2004), VP10 (1200 Ma, granitoid, Joshua Tree National Park, CA; A. P. Barth and J. L. Wooden, unpublished data) and zircons from the earliest Bishop Tuff fall deposit (Chamberlain et al., 2014a). Given their ages, ${ }^{238} \mathrm{U}$ and ${ }^{230}$ Th activities in these zircon standards are at secular equilibrium and after the application of a U-Th fractionation factor, the calculated $\left({ }^{230} \mathrm{Th} /{ }^{238} \mathrm{U}\right)$ should equal unity, determined on a mount-by-mount basis using the measured ${ }^{238} \mathrm{U}^{16} \mathrm{O}^{+} / 230 \mathrm{Th}^{16} \mathrm{O}^{+}$ratios. Calculated fractionation factors from each analytical session were used to correct the $\left({ }^{238} \mathrm{U} /{ }^{232} \mathrm{Th}\right)$ of the unknowns, and repeated analysis of the standards over the sessions allowed us to derive a best-estimate $1 \sigma$ error of $\pm 1.2 \%$ on the fractionation factor (see Charlier et al., 2005).

Values of the $\left({ }^{238} \mathrm{U} /{ }^{232} \mathrm{Th}\right)$ and $\left({ }^{230} \mathrm{Th} /{ }^{232} \mathrm{Th}\right)$ ratios (values in parentheses denote activity ratios) for whole-rock (WR) samples for units B1, D, E3, G and S were previously determined by isotope-dilution thermal ionization mass spectrometry (TIMS) and reported in Charlier et al. (2005). For units B3, C, E1, F and K, the $\left({ }^{230} \mathrm{Th} /{ }^{232} \mathrm{Th}\right)$ was determined on unspiked dissolutions by multi-collector inductively coupled plasma mass spectrometry (MC-ICP-MS) using a Thermo-Finnigan Neptune instrument at the Open University, and $\left({ }^{238} \mathrm{U} /{ }^{232} \mathrm{Th}\right)$ was calculated from $\mathrm{U}$ and $\mathrm{Th}$ concentration analyses determined using a Thermo Scientific Element2 sector-field ICPMS at Victoria University of Wellington. Previous comparisons of the two techniques used have shown that they produce identical data within analytical uncertainty (Wilson \& Charlier, 2009). ${ }^{230} \mathrm{Th}^{238} \mathrm{U}$ isochron ages were calculated as two-point model ages by referencing each of the fractionation-corrected zircon analyses to the respective WR analysis on the equiline diagram (see Appendix $\mathrm{C}$ for raw U-Th model age data).

$\mathrm{U}-\mathrm{Pb}$ zircon age determinations were carried out using the SHRIMP-RG instrument at the Research School of Earth Sciences, Australian National University (ANU). To minimise contamination by common $\mathrm{Pb}$, the mounts were cleaned in detergent, petroleum spirits, alcohol and $1 \mathrm{~N} \mathrm{HCl}$ with intervening rinses in distilled water. The primary beam was rastered for over an area of $35 \times 45 \mu \mathrm{m}$ prior to data acquisition to remove the gold coating and any surface contamination. Secondary ions were sputtered from zircons with a 5-6 nA primary $\mathrm{O}_{2}{ }^{-}$beam focused to a $25 \times 35 \mu \mathrm{m}$ spot. Two suites of data were collected. The first was applied to zircons from samples of eruption D and E. The mass spectrometer was cycled in six scans per spot through 
peaks corresponding to ${ }^{90} \mathrm{Zr}_{2}{ }^{16} \mathrm{O},{ }^{204} \mathrm{~Pb}$, background, ${ }^{206} \mathrm{~Pb},{ }^{207} \mathrm{~Pb},{ }^{208} \mathrm{~Pb},{ }^{238} \mathrm{U},{ }^{232} \mathrm{Th}^{16} \mathrm{O}$ and ${ }^{238} \mathrm{U}^{16} \mathrm{O}$. Because of the young ages of the grains and hence the low count rate, ${ }^{206} \mathrm{~Pb}$ and ${ }^{207} \mathrm{~Pb}$ were counted for 30 and $20 \mathrm{~s}$ respectively. The second suite of data were collected from zircons from the lava dome of eruption F. In this case, because we wanted to fingerprint the grains simply into three broad categories (greywacke; Quaternary with resolvable ${ }^{206} \mathrm{~Pb}$ counts; ${ }^{206} \mathrm{~Pb}$ not distinguishable from background) the same magnet cycle was used, but with only a single scan through the mass table. In all cases, SL-13 was used as a concentration standard (238 ppm U) and R33 was used as an age standard (420 Ma) (Black et al., 2004). To account for initial ${ }^{230} \mathrm{Th}$ disequilibrium in the ${ }^{238} \mathrm{U}_{-}{ }^{206} \mathrm{~Pb}$ decay chain, a $\mathrm{Th} / \mathrm{U}$ correction factor was applied using $\mathrm{f}=\left(\mathrm{Th} / \mathrm{U}_{\text {zir }}\right) /\left(\mathrm{Th} / \mathrm{U}_{\text {magma }}\right)$ (Schärer, 1984) based on observed Th and $\mathrm{U}$ concentrations of zircons derived from SIMS measurements and WR Th/U values measured as previously discussed. A correction for common $\mathrm{Pb}$ was applied using the recorded ${ }^{207} \mathrm{~Pb} /{ }^{206} \mathrm{~Pb}$ values and a common $\mathrm{Pb}$ isotopic composition $\left({ }^{207} \mathrm{~Pb} /{ }^{206} \mathrm{~Pb}=0.836\right)$ for the sample age from the average crust model of Stacey \& Kramers (1975). See Appendix D for further details and all sample data for U-Pb analyses.

Zircon trace element analyses were carried out after age dating by SIMS using the SHRIMP-RG at Stanford University with a 1.5-3 nA primary beam and a focused $15 \times 12 \mu \mathrm{m}$ spot. Trace element analytical spots were not made directly on the U-Pb or U-Th age dating spots, but instead the opposite growth zone as that dated was analysed or the mounts were repolished to remove the age pits prior to analysis (Appendix B). Analysis spots were also selected to avoid contamination by inclusions or crystal defects visible in reflected light images. We used common elements that are normally found at very low concentrations in zircon to monitor such contamination: $\mathrm{Ca}, \mathrm{Al}, \mathrm{Na}$, $\mathrm{K}$ for feldspar and glass; Ca, P, F for apatite; Fe for Fe-Ti oxides; and Ca, Fe for allanite. The MAD zircon standard (Barth \& Wooden, 2010) was used to calibrate trace element concentrations (see Appendix E for trace element data and standards data).

\subsection{Results}

\subsubsection{U-Th model ages}

Zircon U-Th model ages for the SG1 rhyolites show two different patterns (Figure 4.3), which reflect contrasts in vent location and style of eruption (Figure 4.1). For the pyroclastic units B, C and E, vented from within the modern Lake Taupo, age spectra are dominated by young zircons with the majority being close to eruption ages $(\sim 10-12$ 

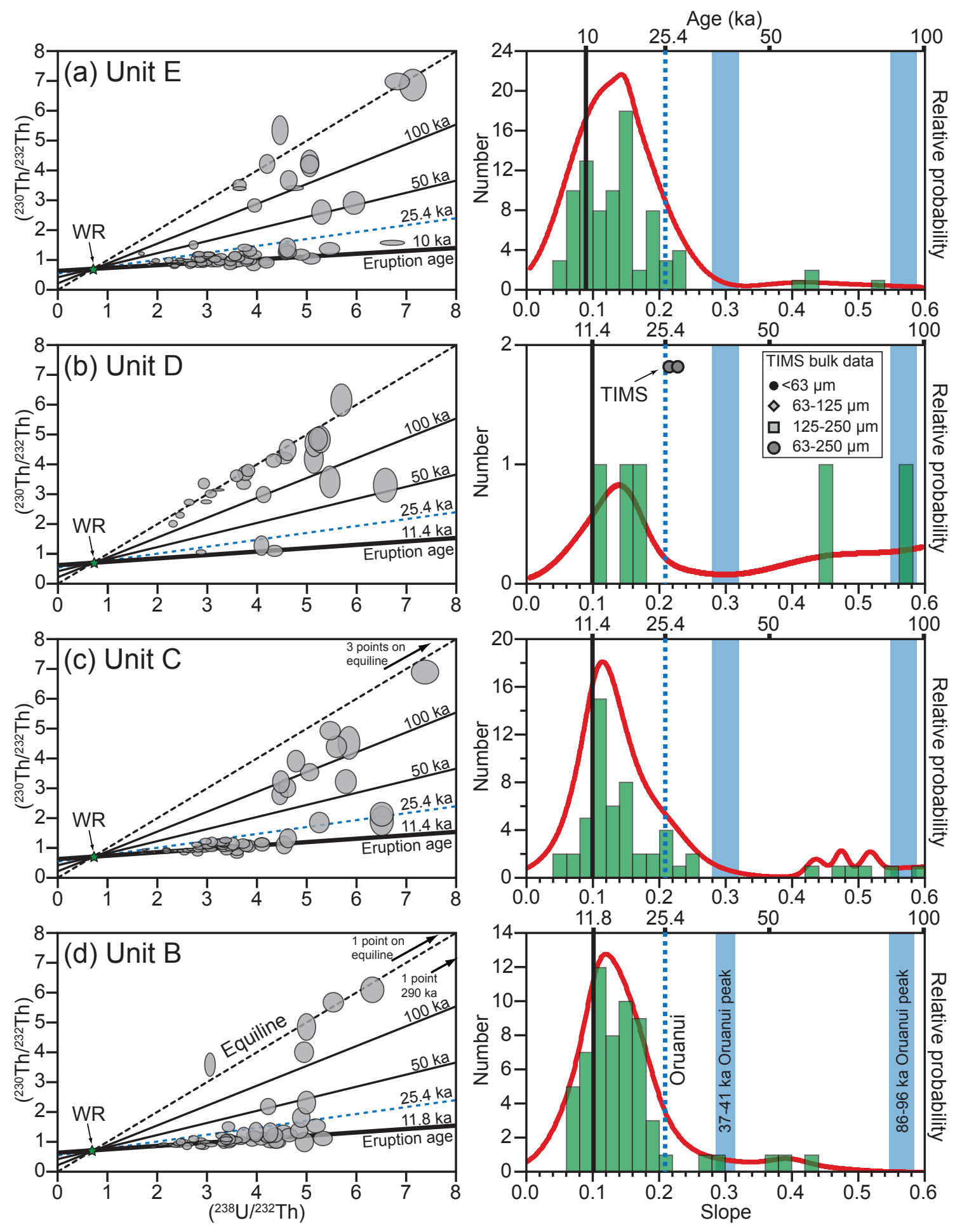

Figure 4.3. Zircon equiline diagrams and corresponding histograms for SG1 eruptions (a) Unit E (10 ka), (b) Unit D (11.4 ka), (c) Unit C (11.4 ka) and (d) Unit B (11.8 ka). Reference isochrons on $\left({ }^{230} \mathrm{Th} /{ }^{232} \mathrm{Th}\right)$ vs ${ }^{238} \mathrm{U} / 232 \mathrm{Th}$ ) equiline diagrams indicate the eruption age estimates from Wilson (1993) and 100, 200 and $300 \mathrm{ka}$. Error ellipses represent $1 \mathrm{SD}$ analytical uncertainties on $\left({ }^{230} \mathrm{Th} /{ }^{232} \mathrm{Th}\right)$ and a standard $3 \%$ error on $\left.{ }^{238} \mathrm{U} /{ }^{232} \mathrm{Th}\right)$ (see Charlier et al., 2005, for further details). An isochron slope and age was determined by referencing this isotopic data point to the whole-rock values to generate a two-point model age (see text for details). Probability density function (PDF) curves (from Isoplot: Ludwig, 2008) and histograms are based on isochron slopes derived from two-point whole-rock zircon SIMS determinations. The PDF line is based on the two-point isochron slopes, rather than the ages determined from them, as the uncertainties are symmetrical with respect to the slope value. Multi-zircon TIMS data points are from Charlier et al. (2005). The two reference Oruanui peaks are taken from Wilson \& Charlier (2009). Analytical data and model ages are given in Appendix C. 
ka, or slope 0.10 ). A subordinate number of analyses form either a tail-off to slightly older ages with secondary minor (or major for Unit E) peaks between slopes 0.14-0.20 (Figure $4.3 \mathrm{a}, \mathrm{c}, \mathrm{d}$ ). Less than $5 \%$ of zircons in these units gave equiline values corresponding to ages $>300 \mathrm{ka}$. For the eruptions that had a shift in vent (subunits B1B3 and E1-E3), there are only minor differences between the subunit age spectra, with all showing similar bimodal or skewed age populations in histograms (Figure 4.4). In contrast, Unit D, which is of much smaller volume and was erupted outside the structural caldera and modern lake (Figure 4.1), has a zircon population that is dominated by older grains which lie on or within 1 SD uncertainty of the equiline (Figure 4.3b). Only three of 25 zircons analysed from this sample (12\%) gave young post-Oruanui ages, averaging $\sim 16 \mathrm{ka}$. Notably, in our new work we recorded very few zircons with model ages matching the dominant Oruanui zircon U-Th age peaks at $\sim 37$ $41 \mathrm{ka}$ and 86-96 ka (Figures 4.3 and 4.4: Wilson \& Charlier (2009)). These data contrast somewhat with those presented in Charlier et al. (2005), and the reasons for this are considered later.

Similar trends in U-Th model-age spectra are observed in the SG2 rhyolites, which are dominated by post-Oruanui zircons (Figure 4.5). Although these samples generally had lower zircon yields (e.g. Charlier et al., 2005), they still contain phenocrystic zircons with ages within analytical uncertainty of their eruption ages. In addition, the SG2 samples also show two slightly older age populations. The first is present to some extent in all the eruption products sampled (being the dominant peak in Unit G) and overlaps with the eruption ages of the SG1 rhyolites. Despite the magnitude of the analytical uncertainties involved with individual U-Th model ages (see discussion section), this age peak is notably consistent between all the eruptions studied. A less well defined subordinate peak or upper tail, similar in position to the secondary peak observed in the SG1 rhyolites is also present in units G, K and S (Figure 4.5a-c). Unit F differs slightly from the other SG2 units as it contains a mixed proportion of 'young' and 'old' (equiline, $>300 \mathrm{ka}$ ) zircons, and no minor peak (Figure 4.5d). In similar fashion to Unit D from SG1, Unit F was of smaller volume than the other SG2 rhyolites studied, and was erupted from the most peripheral (southerly) vent site for eruptions considered in this study (Figure 4.1).

\subsubsection{U-Pb ages}

Zircons that gave U-Th ages within 1 SD uncertainty of the equiline and some grains that appeared to have distinguishable cores of contrasting texture in CL imaging were 

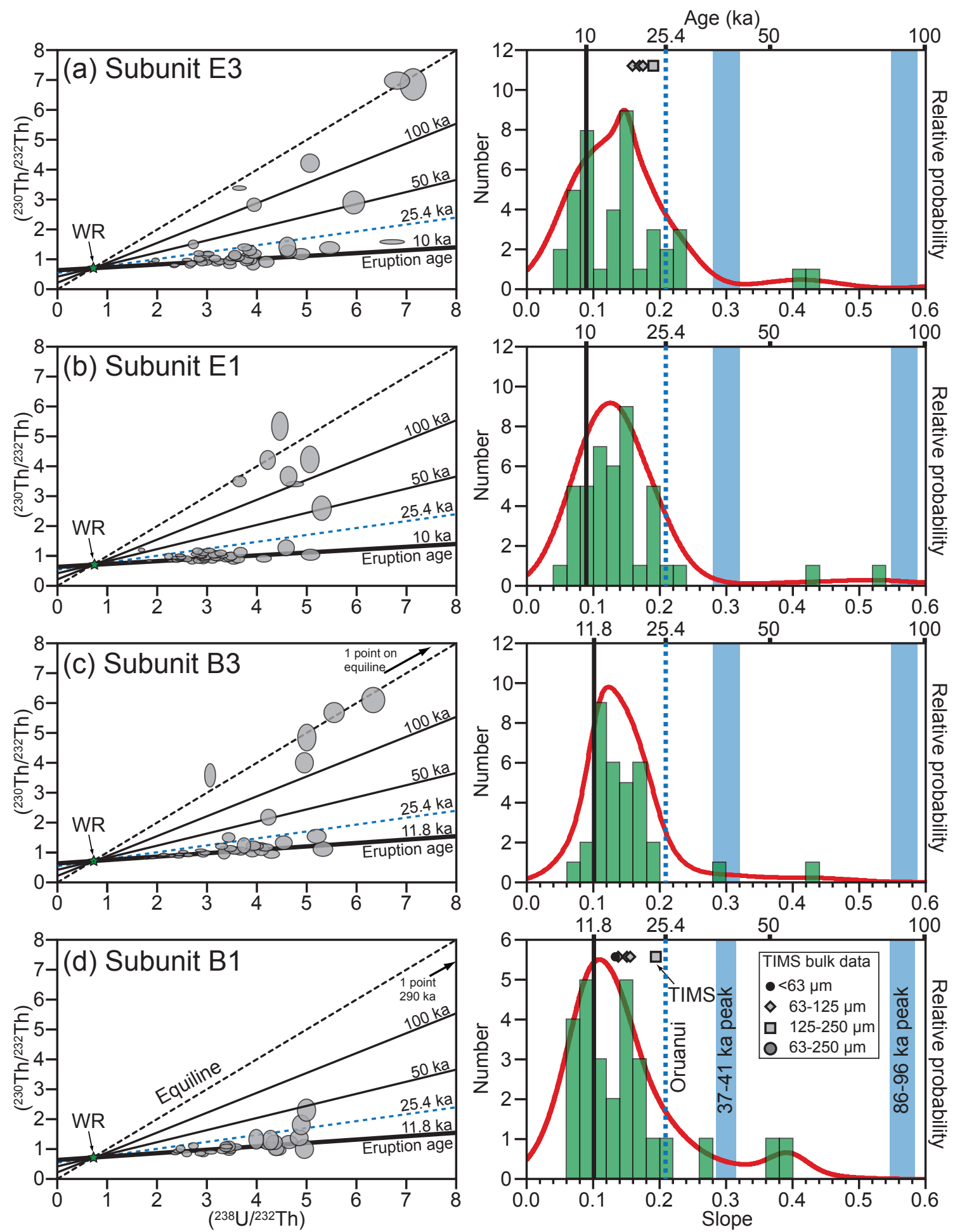

Figure 4.4. Zircon equiline diagrams and corresponding histograms for SG1 eruption subunits where there were co-eruptive shifts in vent position. (a) Subunit E3, vented from the eastern part of Taupo caldera. (b) Subunit E1 from the western-central caldera. (c) Subunit B3 from the eastern part of the caldera. (d) Subunit B1 from the southeastern segment of the caldera. Details as in Figure 4.3. Eruption vent sites are shown in Figure 4.1 (from Wilson, 1993). TIMS data are from Charlier et al. (2005).

Analytical data and model ages are given in Appendix C. 

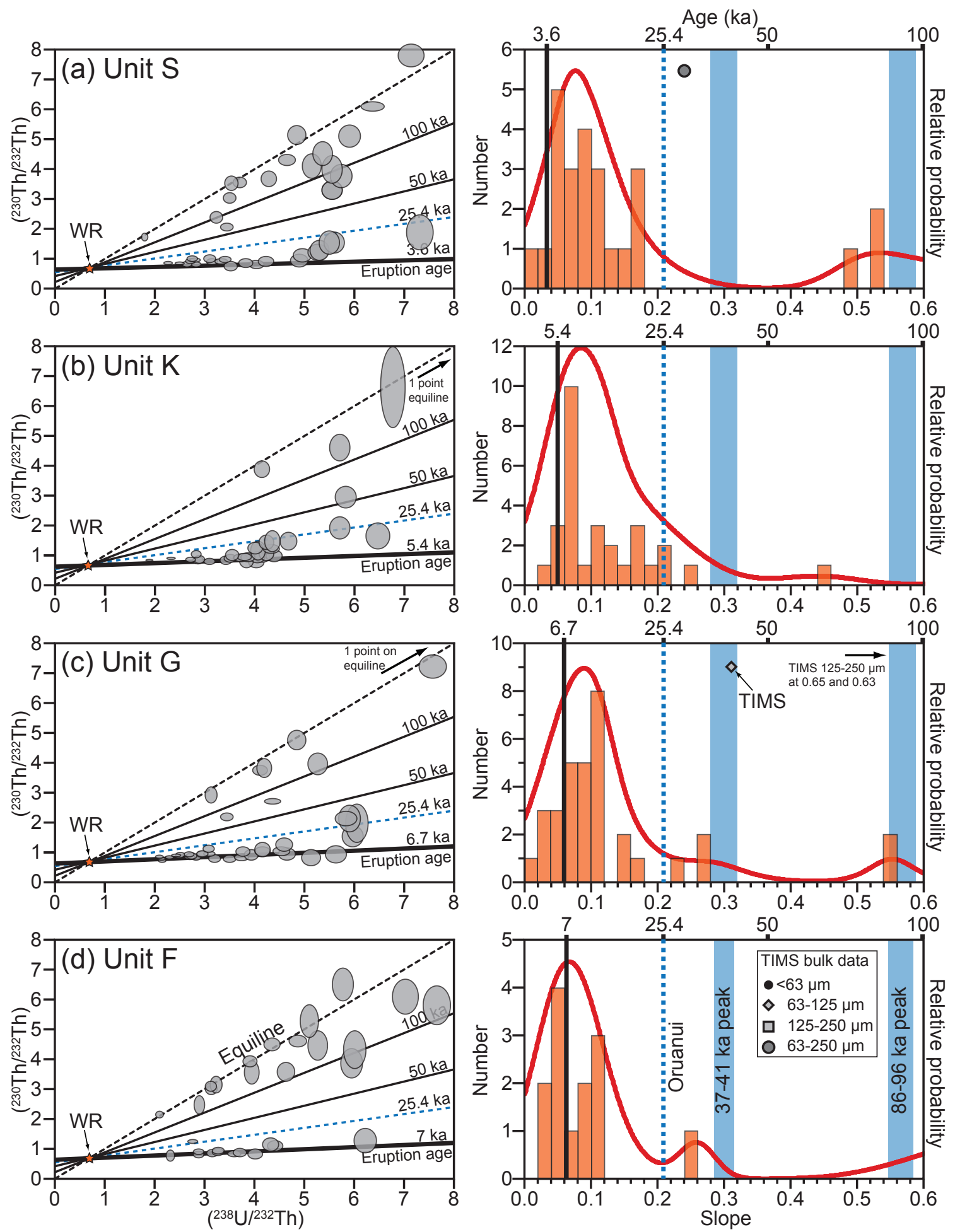

Figure 4.5. Zircon equiline diagrams and corresponding histograms for SG2 eruptions (a) Unit S (3.6 ka), (b) Unit K (5.4 ka), (c) Unit G (6.7 ka) and (d) Unit F (Motutaiko Island) (7 ka). Details as in Figure 4.3. Eruption vent sites are shown in Figure 4.1, from Wilson (1993). TIMS data are from Charlier et al. (2005). Analytical data and model ages are given in Appendix C. 
selected for further analysis by U-Pb methods (see Appendix B for CL images). In particular, zircons from Unit D and F were studied due to their contrasting U-Th modelage spectra with the other samples and their abundance of equiline grains (Figures $4.3 \mathrm{~b}$ and 4.5d; Appendix C). In addition, a few zircon cores from Unit E1 were analysed for comparison, but only a single grain gave an age of $>300 \mathrm{ka}$. For Unit D (Acacia Bay Dome), the majority of equiline zircons and distinguishable cores produced $\mathrm{U}-\mathrm{Pb}$ ages of $<500 \mathrm{ka}$, with only 1 of 30 grains analysed giving an older age of $\sim 2.5 \mathrm{Ma}$.

Interestingly, the U-Pb zircon age spectrum of the Unit D sample, which lies within the Whakamaru Caldera, closely aligns with that of the $350 \mathrm{ka}$ Whakamaru eruption (Figure 4.6, Brown \& Fletcher, 1999; Matthews, 2011). In contrast, equiline zircons from Unit F (Motutaiko Island) towards the more southerly end of Lake Taupo are predominantly pre-100 Ma in age, with only a few grains (5 of 23 analyses) identified as Quaternary in age (Appendix D).

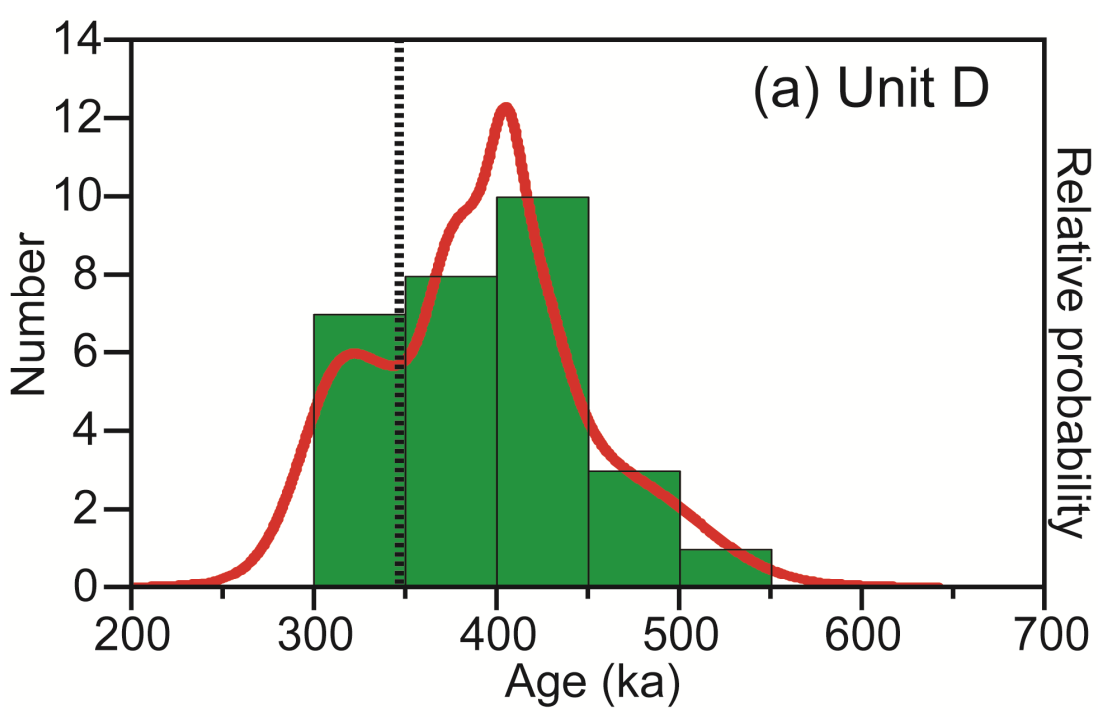

Figure 4.6. Comparison of $\mathrm{U}-\mathrm{Pb}$ age histograms (and population density curves) for xenocrystic zircons from (a) Unit D (Acacia Bay Dome), and (b) the Whakamaru ignimbrite presented by Brown \& Fletcher (1999). See text for discussion and Appendix D for raw data and ages.

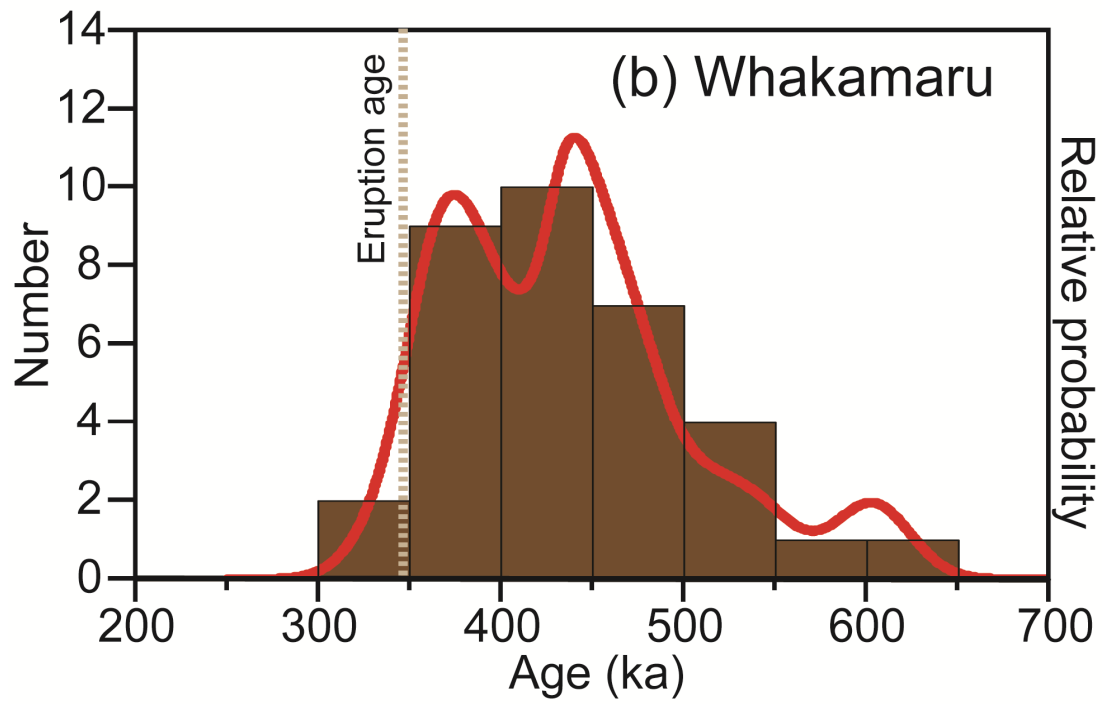




\subsubsection{Trace element compositions}

Trace element compositions were determined on the same zircon grain (and growth zone where possible) as those analysed for U-Th or U-Pb dating. In addition to the postOruanui units, zircons from Oruanui phase 1 fall deposits with previous age determinations (sample P1634: Wilson \& Charlier, 2009) were analysed for comparison. Overall, the majority of zircons analysed from the Oruanui and postOruanui zircons broadly overlap in trace element compositions, with similar U, Th, Hf, $\mathrm{Ti}, \mathrm{Y}+$ rare earth elements (REE) and $\mathrm{P}$ concentrations (Figure 4.7; Appendix E). However, a small subset of zircons (mainly core and interior analyses; Appendix B) from the SG1 rhyolite and Oruanui have significantly higher concentrations of $U, T h, P$, $\mathrm{Y}+(\mathrm{REE})^{3+}$ and $\mathrm{Nb}$ but with only minor changes in Hf and Ti concentrations. When zircons are ordered by model-age, the SG1 zircons with high concentrations in U, Th, P, $\mathrm{Y}+(\mathrm{REE})^{3+}$ and $\mathrm{Nb}$, appear to be mainly from core zones with ages between 10-20 ka (Figure 4.7). Sc and to a lesser extent Ti and P concentrations, in contrast, vary with relative ages across the whole zircon population, each showing an overall increasing trend in concentration with decreasing age. Some trace element ratios also show temporal changes. For example, $\mathrm{Yb} / \mathrm{Gd}$ decreases with younger age and is consistently lower in zircons with post-Oruanui model ages. Th/U ratios show more scattered variations, but with a small proportion of post-Oruanui zircons (especially around $\sim 10$ $20 \mathrm{ka}$ model ages) displaying increased values. Notably, the few grains determined to be of Whakamaru age, or other Quaternary, or pre-100 Ma ages are largely indistinguishable from younger grains on the basis of their trace element compositions alone (Figure 4.7).

\subsection{Discussion}

The zircon U-Th model-age spectra presented in this study provide unique insights into Taupo's young magmatic system, highlighting not only its evolution over very short timescales, but also the timing and nature of its post-supereruption recovery. One outstanding feature of the post-Oruanui U-Th model age spectra, observed in all the units sampled, is the scarcity of zircons with ages matching the distinctive Oruanui spectrum, despite the relatively short period of quiescence and the significantly contrasting eruptive masses between the voluminous Oruanui and the more modestlysized post-Oruanui events. Previous work on Taupo has highlighted how the Oruanui melt dominant body was formed over exceptionally short timescales (e.g. millennia to 

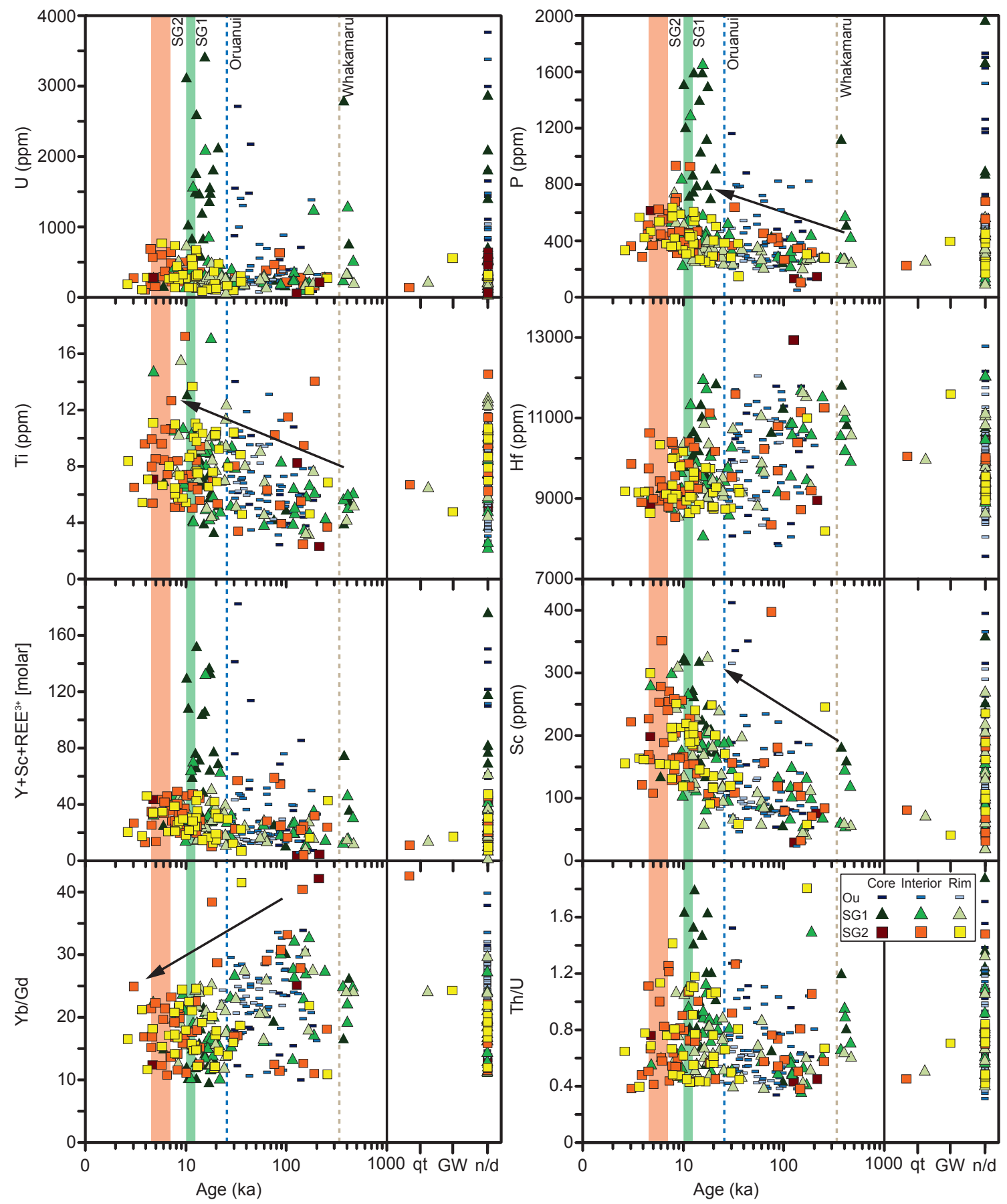

Figure 4.7. Trace element compositions and ratios versus U-Th model ages for zircons from the Oruanui $(\mathrm{Ou})$ and post-Oruanui eruptives. For grains older than $1 \mathrm{Ma}$, qt is Quaternary, $\mathrm{GW}$ is greywacke $(>100$ $\mathrm{Ma}$ ), and $\mathrm{n} / \mathrm{d}$ is not determined. The relative ages of the Whakamaru and Oruanui eruptions are shown for reference. Arrows indicate direction of change with relative age. See text for discussion. Core analysis locations refer to analyses where clear cores could be identified. Interior zones are areas between the core or middle of the crystal and the outer edge or rim area. See Appendix B for representative CL images of zircon textures with corresponding age and trace element spots. All raw trace element data and details are given in Appendix E. 
centuries: Wilson \& Charlier, 2009; Allan et al., 2013). Below we consider how that large magma system was effectively destroyed over comparably short timescales, and how the volcano adjusted, rebuilt and has maintained its new magma system.

\subsubsection{Relationship between the pre- and post-Oruanui magma systems}

The presence of the two distinctive magma systems operating in the Taupo-Maroa area in the lead-in to, and during the Oruanui eruption has been documented from several perspectives (Sutton et al., 1995; Charlier et al., 2005; Wilson \& Charlier, 2009; Allan et al., 2012). Zircons from three precursor eruptions of Oruanui-type magmas have age spectra with a prominent peak at $\sim 95 \mathrm{ka}$, indicating they were sourced from a common mush source zone (Wilson \& Charlier, 2009). Zircon age spectra from Oruanui eruption samples share this $95 \mathrm{ka} \mathrm{peak,} \mathrm{but} \mathrm{have} \mathrm{an} \mathrm{additional} \mathrm{major} \mathrm{peak} \mathrm{at} 40 \mathrm{ka}$ (Figure 4.8). The contrast between the age spectra of the Oruanui and the youngest precursory Oruanui-type eruption (Okaia) at $28.6 \mathrm{ka}$ was used to imply that despite common chemical roots, the two magma bodies were generated independently, with the Oruanui forming over $<3000$ years (Wilson \& Charlier, 2009; Allan et al., 2013).

The distinctive model-age age spectra in the pre-Oruanui eruptives means that any recycled crystals from the old system should, in principle, be identifiable through their age spectra in the post-Oruanui deposits. In contrast, we record few zircons either of Oruanui eruption age ( $25.4 \mathrm{ka}:<12 \%$ of the zircon population within $1 \mathrm{SD}$, Figure 4.8 ), or of age ranges coinciding with the $40 \mathrm{ka}$ ( $<2 \%$ of zircons) or $95 \mathrm{ka}(<5 \%$ of zircons) model-age modes in the Oruanui. Our new data contrast with the SIMS data previously presented in Charlier et al. (2005) in that there is a much greater proportion of post-Oruanui model ages obtained from zircons in both Unit B samples, more in keeping with the multi-grain TIMS ages reported by Charlier et al. (2005). The most likely reason for this is a sampling bias, where larger grains containing zones with higher $\mathrm{U}$ and Th concentrations (typically cores: Appendix B) were specifically targeted by Charlier et al. (2005). In contrast, we have analysed a mixture of both zircon rims, representing the youngest crystallisation of zircon, and cores where discernible, representing older crystallisation or possibly inherited grains (Appendix B and C). We consider this a less biased approach which more fully encompasses a representative range of zircon ages within the post-Oruanui rhyolites.

The scarcity of Oruanui eruption-aged or peak-aged (40ka or $95 \mathrm{ka}$ ) zircons indicates there was a significant change in Taupo's magmatic system following the Oruanui eruption. The paucity of Oruanui or pre-Oruanui modal age zircons in the 


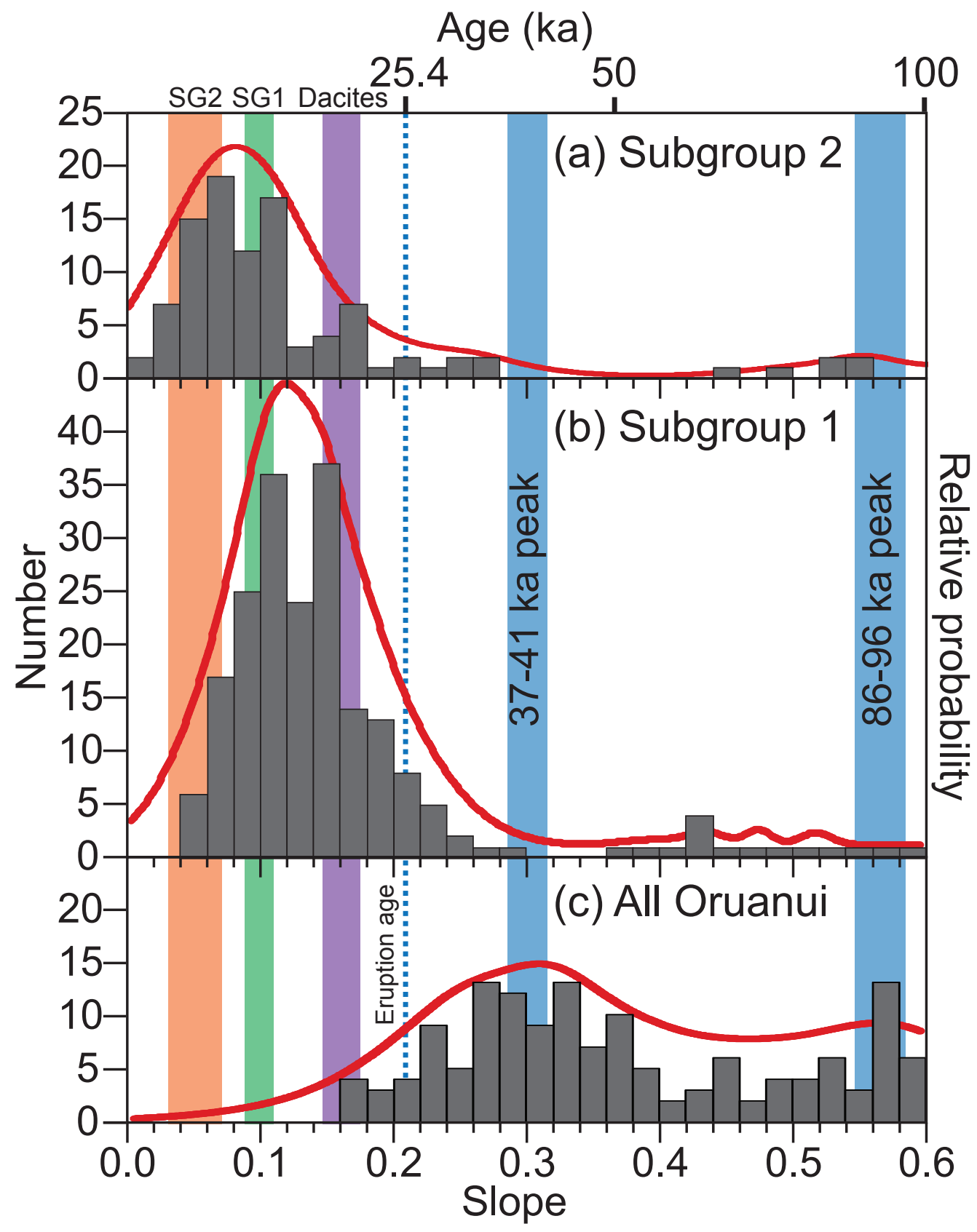

Figure 4.8. Comparison of summary U-Th age histograms (and PDF curves) for (a) all SG1 rhyolites (Units $\mathrm{B}+\mathrm{C}+\mathrm{D}+\mathrm{E}$ ), (b) SG2 rhyolites (Units $\mathrm{F}+\mathrm{G}+\mathrm{K}+\mathrm{S}$ ) and (c) all Oruanui samples (early + late phases) from Wilson \& Charlier (2009). Note the scarcity of Oruanui age or Oruanui peak-age grains in the SG1 and SG2 rhyolites, and the multiple young age modes. See Appendix C for all raw data and Wilson \& Charlier (2009) for details on the Oruanui data sets. 
younger eruptives could reflect several possible circumstances (or a combination thereof):

1) The young magmas were sourced from a different crustal volume to that of the Oruanui and pre-Oruanui magmas. We consider this to be very unlikely given the extensive implied volume of the Oruanui magma system and the geographically overlapping vent sites between the Oruanui and post-Oruanui eruptions (Figure 4.1). For example, the likely vent location for Unit $\Omega$ overlaps with the inferred vent site for phase 1 and 2 of the Oruanui and the majority of the post-Oruanui rhyolite vents largely overlap with that of phase 3 (Figure1, Wilson, 1993; Wilson, 2001). In addition, even eruptions from outlier vent sites (e.g. D or E1) have very few Oruanui eruption-aged or older peak-aged zircons (Figures 4.3 and 4.4). The potential for differences in source vertically within the crust is also considered unlikely as petrological studies suggests that the Oruanui and SG1 rhyolites were likely derived from similar shallow levels within the crust ( 5-7 km: Sutton et al., 1995; Smith et al., 2005).

2) All of the evolved melt-dominant body and mush zone was erupted in the Oruanui event, leaving little or no residual material behind with an associated zircon crystal suite. We also consider this unlikely given the large volume and crystal-poor nature of the Oruanui rhyolite and the likely volume of the counterpart magma mush root system (Wilson et al., 2006; Allan et al., 2013). Amphibole thermobarometry conducted on Oruanui low-Si $\left(<74 \% \mathrm{SiO}_{2}\right)$ and high-Si $\left(>74 \% \mathrm{SiO}_{2}\right.$ ) rhyolites suggests that the mush/source zone of the Oruanui magma system ranged between 6-12 km depth below a melt-dominant body at 3.5-6 km depth (Allan et al., 2013). This huge magma system therefore likely covered the majority of the available vertical space in the quartzo-feldspathic crust below the Taupo area (Harrison \& White, 2006) and leaves little room for crustal volumes not imprinted by Oruanui-related magmatic processes.

3) The zircons extracted from the post-Oruanui samples are dominated by the growth of young zircons and any older population is effectively masked. This is not considered to be the dominant factor for three reasons. First, the postOruanui rhyolites have relatively low zircon yields (e.g. Charlier et al., 2005) and are within a similar range of zircon saturation to the Oruanui magma (Watson, 1996; Boehnke et al., 2013). Second, some units sampled have only a small proportion of young zircons (e.g. D and F), with populations dominated by older (equiline) grains, and even these units have few Oruanui-aged zircons. 
Third, the largest post-Oruanui eruption studied (S) is roughly two orders of magnitude smaller than the Oruanui. Although the post-Oruanui magmas could be derived from localised magma pockets with correspondingly localised zircon growth, we suggest that the range of vent sites, repeated patterns of age spectra between eruptions and similar bulk rock geochemistries (Sutton et al., 2000) indicates a widespread change in the magma system.

4) The majority of the Oruanui and pre-Oruanui aged zircons were effectively removed from the crustal root zone by thermally induced dissolution in the aftermath of the Oruanui eruption and/or during the gestation process for each of the subsequent dacite to rhyolite magma batches. This cause is inferred by us to be the most plausible. Two lineages of mafic magmas played an important role in the Oruanui eruption (Wilson et al., 2006), and they are likely to have had a strong thermal influence on the syn- or post-Oruanui magma system. The postOruanui dacites yield significantly higher magma temperature estimates ( $\sim 920$ $940{ }^{\circ} \mathrm{C}$ : Sutton et al., 2000; Gelman et al., 2013) than the younger rhyolites and also display evidence for some crustal melting through strongly resorbed plagioclase (Gelman et al., 2013; S. J. Barker, unpublished data) and sparse unresorbed zircons from greywacke and Quaternary plutonic material (Charlier et al., 2010). All of the post-Oruanui magmas have ${ }^{87} \mathrm{Sr} /{ }^{86} \mathrm{Sr}$ ratios elevated over those in the Oruanui eruption products (Sutton et al., 2000; Wilson \& Charlier, 2009; Figure 4.2), which could reflect significant assimilation of crustal components immediately after the Oruanui eruption. Thermal calculations (Charlier et al., 2010) indicate that zircons incorporated into strongly zircon under-saturated, hot basaltic-andesite or dacite would only be stable for a few months to years (depending on their size fraction and surface area; Watson, 1996). If the whole Oruanui magma system underwent widespread post-eruption heating from mafic magma then the majority of the residual zircons left could have been dissolved. A minor fraction of either Oruanui and/or pre-Oruanui aged zircons, however, are still present in most samples (as previously documented by Charlier et al., 2005). The majority of Oruanui-age determinations are from resorbed zircon cores or interior zones (see Figure 4.7 or Appendix B and C for raw data), and hence represent the few zircons that partially survived thermal dissolution. The great majority of the pre-Oruanui zircons are either Whakamaru age (300-500 ka: Figure 4.6) for the northernsourced magmas (Unit D, this study; Unit $\Omega$ : Charlier et al., 2010) and therefore 
plutonic remnants, or pre-100 Ma in age (Unit F) and thus derived from the greywacke basement (Cawood et al., 1999; Adams et al., 2009; Charlier et al., 2010). These xenocrystic zircons were likely incorporated into the post-Oruanui magmas through partial assimilation or melting of country rock, and are not necessarily therefore directly related to the Oruanui magmas.

\subsubsection{Determining the nature and timing of post-supereruption zircon growth}

Two dominant analytical techniques have proven to be invaluable for dating young zircons (and other accessory minerals where applicable, e.g. apatite, allanite) in igneous rocks. First, multiple crystals can be analysed by TIMS to give a highly precise mean age of the crystal population as a whole, with uncertainties typically of $\sim 0.5-1.5 \mathrm{ka}$ (2 SD) for the young Taupo eruption units (Charlier et al., 2005). Second, discrete domains within single crystals can be analysed by SIMS to give spatially-resolved information, albeit at poorer precision. The TIMS data give a highly precise mean age, but must be treated with caution as the bulk zircon separate may represent multiple populations of diverse sources and age with no direct way of discriminating between them during preparation. As shown by Charlier et al. (2005), average TIMS model ages for post-Oruanui eruptions in some cases are $<25.4 \mathrm{ka}$ (e.g. Unit B, E; Figure 4.4), but also vary largely depending on size fractions (with smaller fractions usually being younger). In other cases (e.g. Unit D, G and S) average bulk zircon ages are older and can be interpreted (based on our data here) as mixtures of xenocrystics from plutonic or greywacke source(s) with younger magmatic grains (Figures 4.4, 4.5). In such cases, the diversity (or lack thereof) of average ages can be used as a good first-order approximation to interpret the likely variations in the makeup of zircon ages for any given sample. On the other hand, SIMS techniques yield individual model ages, allowing for the identification of zircons which are likely phenocrystic versus those that are inherited from precursor related magma systems (antecrystic) or from totally foreign magmas or country rocks (xenocrystic). SIMS analyses from our work give uncertainties that are at best $\pm 2-3 \mathrm{ka}(1 \mathrm{SD})$ for young post-Oruanui grains but more commonly around $\pm 4-8$ ka (Appendix $C$ ). In such a case, differentiating between eruptions or magmatic events (periods of zircon growth or dissolution) that are spaced within, or close to the analytical uncertainty of an individual model-age date can become difficult. Below we take into account the statistical significance of the analytical uncertainties to decide whether the clustering of model ages seen in the postOruanui SIMS data sets are real, or an artefact of the methods employed. Coupled with 
this analysis, we consider whether the similarities in clustering of model ages from successive units indicate that our measurements are accurate, despite the large uncertainties inherent in the analytical techniques.

\subsubsection{Significance of age peaks identified in the post-Oruanui SIMS U-Th data}

The dominance of zircons with model ages $<25 \mathrm{ka}$ in the post-Oruanui eruptions indicates that the majority of grains are inherent to the modern magma system. Two important questions arise from this observation:

1) Over what time period following the Oruanui eruption did the Taupo rhyolite system rebuild and zircon growth recommence?

2) Has the new magmatic system been in a steady state of recovery and/or evolution over time, and is it uniform over the geographic footprint of Taupo volcano?

Using the common approach of plotting the zircon age data in probability density histograms (using Isoplot: Ludwig, 2008), several key features are apparent (Figures 4.3, 4.4 and 4.5). The zircon model age spectra from eruptions from both the SG1 and SG2 rhyolites show multiple peaks in binned histograms, suggesting that zircon growth has not occurred evenly through time. For the SG1 rhyolites, there appears to be a consistent peak close to eruption age, with either a tail-off to older zircons, or a secondary peak between slope $0.14-0.20$. This bimodality is exemplified when all the SG1 age data are compiled into a single histogram (Figure 4.8). However, binned histograms do not take into account the variable uncertainties of the individual age determinations, bringing into question their statistical relevance in this particular study. Histogram bins have been chosen based on the lowest observed uncertainties ( \pm slope 0.02 ) in an attempt to see small scale variations in age spectra, but uncertainties on individual data points can, in some cases, cover 3-4 bin spacings (Appendix C). The multiple histogram age peaks are largely lost, however, in the relative probability curve, which takes into account the different age uncertainties of all the individual data points and effectively smoothes out the histogram on the basis that the uncertainties do not permit the model age data to be statistically distinguished from one population. For example, in several individual histograms the probability function curve is at a maximum between two modes in the histogram bars (e.g. Unit B1, Figure 4.4d), because the chosen width of the histogram bins (i.e. slope 0.02 ) are within analytical uncertainty of some of the individual (low-precision) data points. Similar issues occur with the SG2 rhyolites, which typically have an additional population of younger 
zircons and even more complicated age spectra, with some displaying two or three minor modes in histogram bins (Figure 4.5). This problem of low (but variable) precision is further exemplified when the data are plotted on commonly used $\left({ }^{230} \mathrm{Th} /{ }^{232} \mathrm{Th}\right)$ vs. $\left({ }^{238} \mathrm{U} /{ }^{232} \mathrm{Th}\right)$ equiline diagrams (Figures $4.3,4.4$ and 4.5$)$. Although equiline plots are useful for observing the overall range in isotopic systematics (that can then be converted to zircon model-ages) and also variable analytical uncertainties, any closely spaced clusters are drowned out by analyses with large uncertainties. Using these approaches, it is unclear whether the age peaks observed (and repeated) between eruptions are in fact real, and therefore represent multiple zircon populations, or are merely coincidental.

To address this we use Gaussian mixture modelling, which is commonly used to detect multiple components in $\mathrm{U}-\mathrm{Pb}$ age spectra of ancient detrital zircons and magmatic rocks (Sambridge \& Compston, 1994; Jasra et al., 2006). Mixture modelling allows for consideration of the variable uncertainties for individual data points, and uses the maximum likelihood approach to estimate best fit for a suite of ages. It is particularly useful for identifying closely-spaced age populations that cannot be easily quantitatively defined within the analytical uncertainties of the method used. Here we use a similar approach to that of Sambridge \& Compston (1994), to determine whether the post-Oruanui zircon U-Th model age spectra represent a single population within an acceptable spread, or multiple discrete populations (see Appendix F for further details). Due to the large number of U-Th analyses and apparent minor differences in age spectra over time, we performed mixture models for the SG1 rhyolites and SG2 rhyolites separately, as well as a combination of both data sets. Results are presented as contoured log-likelihoods with a 95\% confidence interval (CI) and maximum loglikelihood representing the best fit point of the model, and additionally as cumulative probability curves to show the fit of the mixture model compared to the actual data and overall mean (Figure 4.9).

For the SG1 rhyolites, a two component mixture model gives a very good overall fit to the observed age data (Figure 4.9a; Appendix F). The young population (slope (1)) is well defined with a maximum log-likelihood fit at slope 0.12 (equivalent to an age of $\sim 14 \mathrm{ka}$ ) and a relatively narrow 95\% CI between $\sim 0.10-0.13(\sim 11.5-15 \mathrm{ka})$. As the majority of the data points in this model are included in the first slope, the second slope (slope (2)) is less well constrained and shows a broader 95\% CI of slope between $\sim 0.14$ and 0.225 , with a maximum log-likelihood $\sim 0.186(22.5 \mathrm{ka})$. The second population is affected by the large uncertainties on many of the zircons with model ages 
(a) SG1 eruptions only: Maximum likelihood fit slope (1) 0.12 , slope (2) 0.186
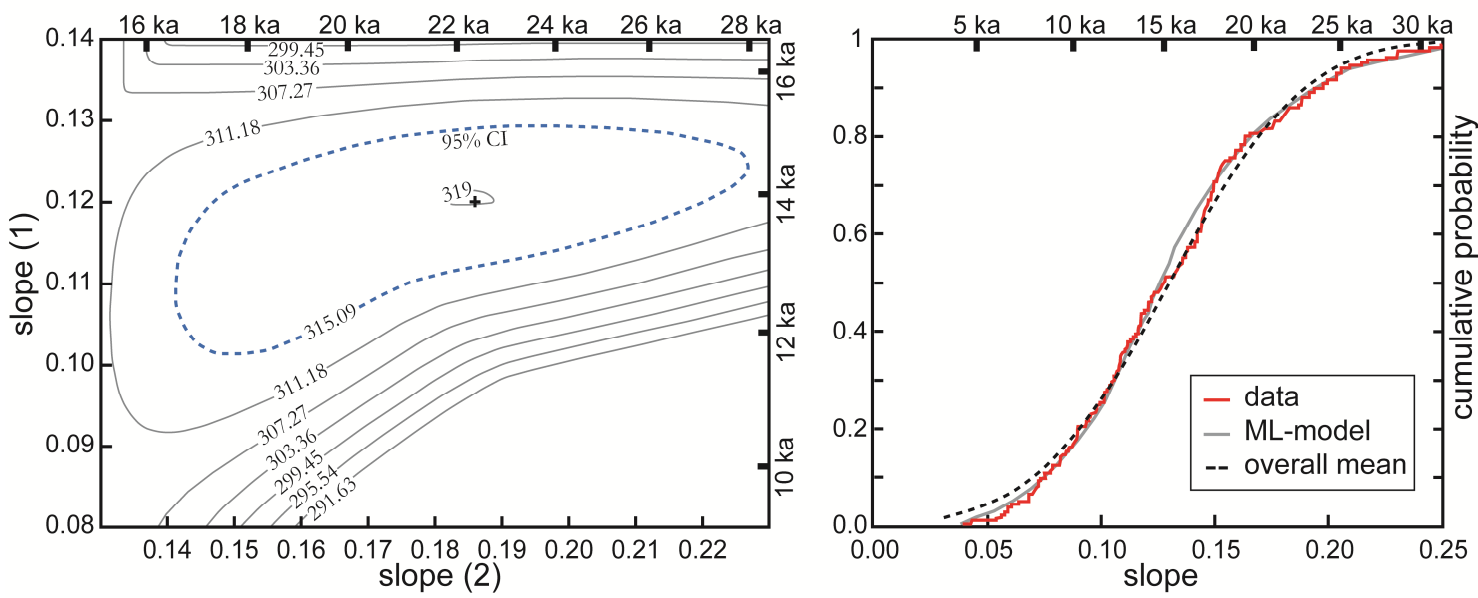

(b) All data combined: Maximum likelihood fit slope (1) 0.110 , slope (2) 0.196
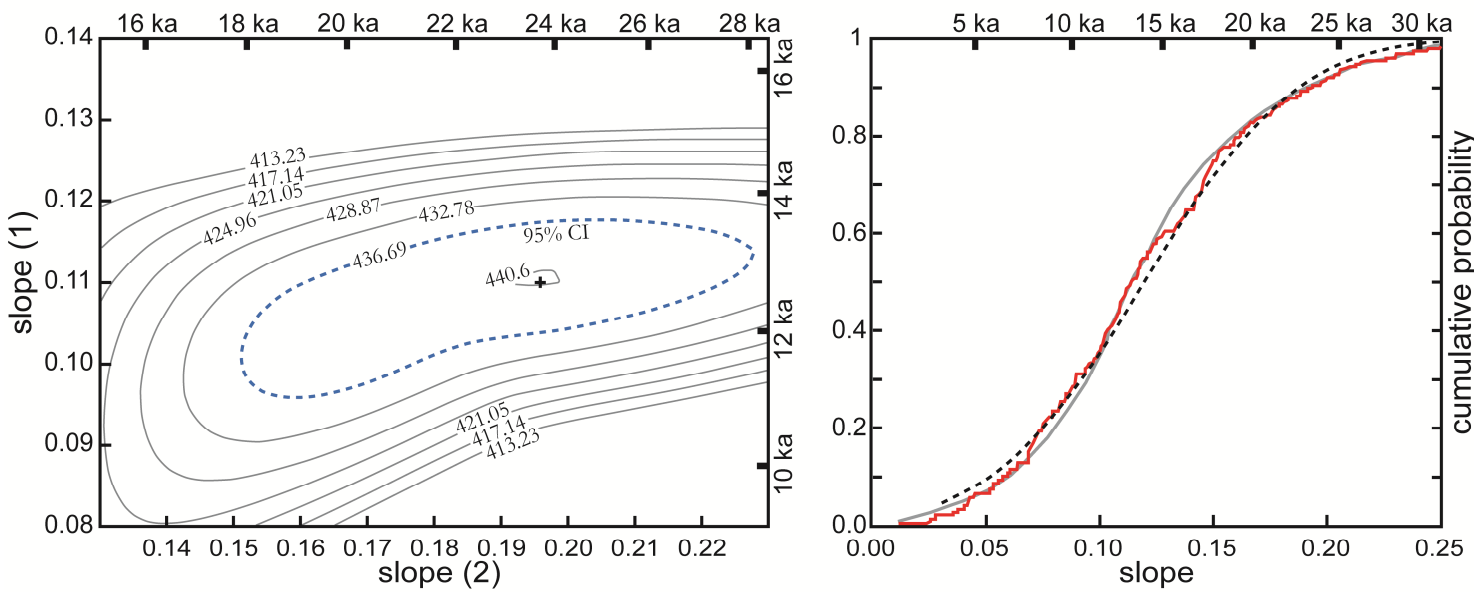

Figure 4.9. Results of Gaussian mixture models for (a) the SG1 rhyolites (units B, C, D and E) and (b) both the SG1 and SG2 data sets combined. Contours represent log-likelihoods and the dashed contour represents a 95\% confidence region for the two free parameters slope (1) and slope (2), conditional on the third factor alpha. Maximum log-likelihoods represent the best fit for the two component mixture model. Calculated model ages are plotted opposite slope from reference. See Appendix F for model details and alpha value plots.

around $\sim 20$ ka with low U concentrations (Figure 4.7; Appendix C).

For the SG2 rhyolites, the mixture model has a good fit for a younger population, with a maximum log-likelihood for slope (1) at 0.086 (9.8 ka), but with a very poorly defined slope (2) due to the low number of analyses included in this population (see Appendix F for details). The SG2 U-Th age spectra (Figure 4.8) contains two young age peaks (0.06-0.08 and 0.10-0.12) in addition to an older $\sim 0.16$ 0.18 slope peak, and a lower tail that stretches to younger ages than that observed in the SG1 age spectra. However, the number of analyses in the SG2 sample set is insufficient for the data to be modelled using a three component mixture model. Increasing the number of zircons in the populations by combining the two data sets (SG1 + SG2) produces a similar two component result as to that observed in the SG1 model, with 
slope (1) maximum log-likelihood at $0.11(12.7 \mathrm{ka})$ and $0.196(23.8 \mathrm{ka})$ for slope (2) (Figure 4.9b). In both the SG1 and SG2 data sets, the data can be modelled effectively using a two component mixture with a well-defined young population that is represented by $85-90 \%$ of the data, and a minor but poorly-defined older population. Mixture modelling therefore strongly supports the broad trends observed in the age histograms, and suggests that the multiple peaks observed in the model-age spectra are statistically significant, and reflect discrete zircon populations.

\subsubsection{Controls on the timing of zircon growth in the post-Oruanui magmas}

Zirconium saturation in magma and subsequent zircon growth is largely dependent on magma temperature ( $\mathrm{T}_{\text {magma }}$ ), $\mathrm{Zr}$ content of the melt and the cation ratio $M$ (where the parameter $M=[(\mathrm{Na}+\mathrm{K}+2 \mathrm{Ca}) /(\mathrm{Al} \cdot \mathrm{Si})]$ : Watson \& Harrison, 1983; Watson, 1996;

Boehnke et al., 2013). $\mathrm{T}_{\text {zirc }}$ is defined as the magma temperature below which zirconium saturation is reached and zircon crystallisation commences (though see Harrison et al., 2007). As shown by Charlier et al. (2005), magmas from Taupo span three scenarios of zircon growth or dissolution with variable magma temperature and composition, which we consider to be central to interpreting the trends seen in the zircon age spectra. In the first scenario, $\mathrm{T}_{\text {magma }}<\mathrm{T}_{\text {zirc }}$ where zirconium saturation in the magma is reached and zircon growth commences. The Oruanui high-Si rhyolite magma is an example of this scenario, with calculated Fe-Ti oxide temperatures of $\sim 760-790{ }^{\circ} \mathrm{C}$ closely coinciding with or slightly lower than the calculated $\mathrm{T}_{\text {zirc }}$ using the model of Watson \& Harrison (1983) (Figure 4.10). In the second scenario, $\mathrm{T}_{\text {magma }}>\mathrm{T}_{\text {zirc }}$ where the magma is above the temperature necessary for zirconium saturation and zircon dissolves, at a rate depending on the difference in temperature and the size of the zircon (Watson, 1996; Charlier et al., 2010). The post-Oruanui dacites (units $\Psi, \Omega$ and A) are examples of this scenario (Charlier et al., 2005; 2010). The third scenario falls between the first two, where $\mathrm{T}_{\text {magma }} \sim \mathrm{T}_{\text {zirc }}$ and zircon does not grow or dissolve rapidly. The post-Oruanui rhyolites studied here lie between the first and third scenarios described above, with calculated $\mathrm{T}_{\text {magma }}$ either slightly higher or similar to $\mathrm{T}_{\text {zirc }}$ within uncertainty of the Fe-Ti oxide thermometers (Figure 4.10). In such a case, small fluctuations in temperature (20$30^{\circ} \mathrm{C}$ ) over time may result in periods of crystallisation of zircon during periods of magma cooling, or slight dissolution during periods of heating.

The variability of zircon stability and growth in the post-Oruanui rhyolites is highlighted by several key features. First, there is a change in zircon abundance with eruption age despite similar calculated magma temperatures for the different eruptive 


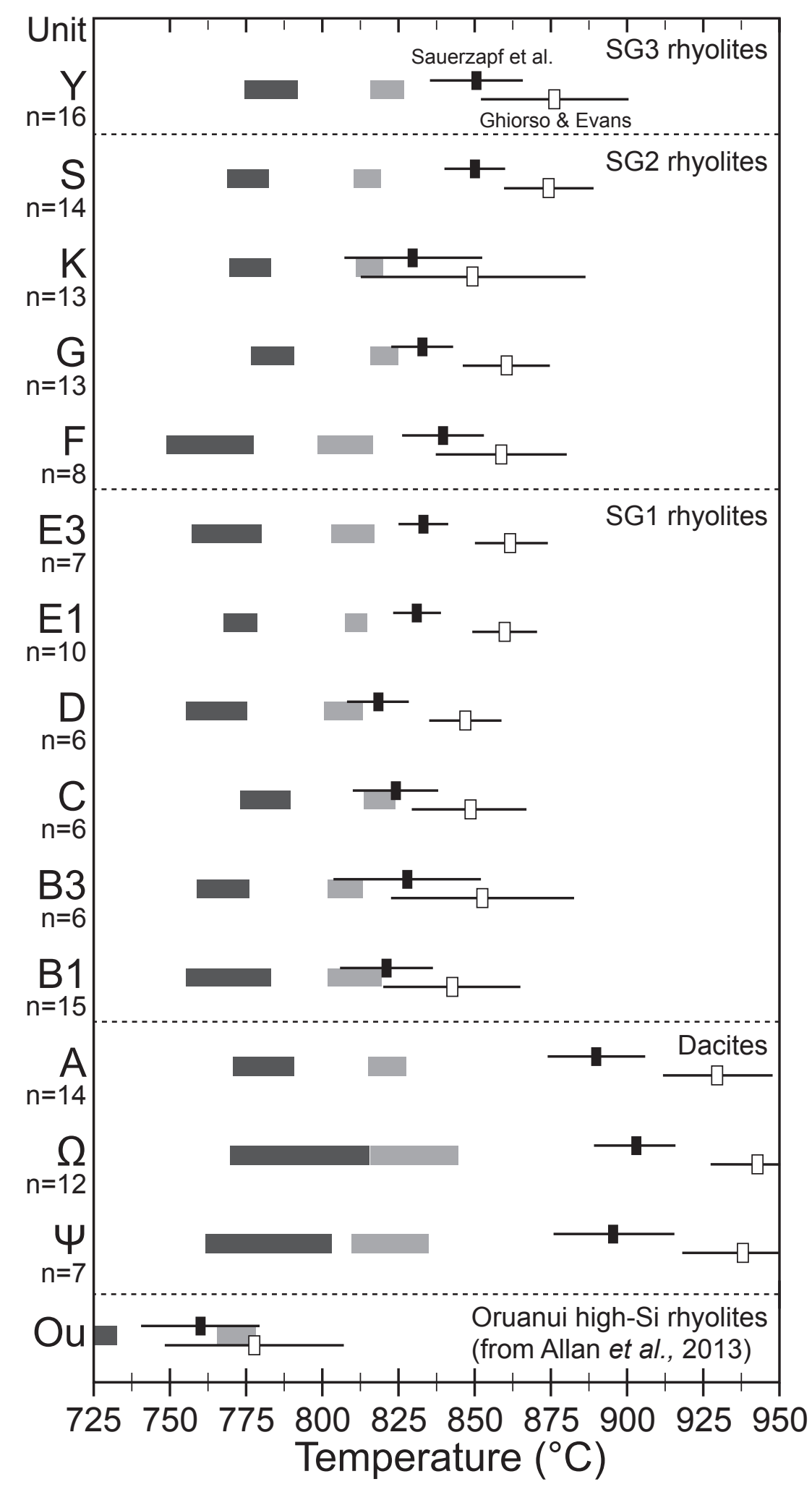

Figure 4.10. Plot showing stacked Fe-Ti oxide model-temperature estimates and two different zircon saturation temperature estimates (shaded regions). The light shaded zircon thermometer uses the equations of Watson \& Harrison (1983) and the dark shaded region uses the equations of Boehnke et al. (2013) where the parameter $\mathrm{M}=\left[(\mathrm{Na}+\mathrm{K}+2 \mathrm{Ca}) /\left(\mathrm{Al}{ }^{*} \mathrm{Si}\right)\right]$. The zircon temperature range is from the range of $\mathrm{M}$ values calculated from multiple glass compositions determined on each eruptive unit by electron microprobe analysis (EPMA) at Victoria University of Wellington. The Fe-Ti oxide temperatures were calculated using both the models of Ghiorso \& Evans (2008) (open symbols) and Sauerzapf et al. (2008) (filled symbols), where the symbols are the average temperature and the lines on either side are 2 standard deviations. $\mathrm{n}$ is the number of Fe-Ti oxide pairs, also analysed by EPMA using similar methods to Barker et al. (2013). Oxide temperatures and glass compositions for the Oruanui eruption are from Allen et al. (2013) after Wilson et al. (2006). 
units, with zircon yields between the SG1 and SG2 rhyolites decreasing by an order of magnitude (units B and E: 1.2 mg/kg; Unit G: $0.2 \mathrm{mg} / \mathrm{kg}$; Unit S: $0.03 \mathrm{mg} / \mathrm{kg}$ : Charlier et al., 2005). In addition, zircon morphology differs among the subgroups, being dominantly euhedral in the SG1 rhyolites to subhedral or anhedral in the SG2 rhyolites, suggesting that there is an accompanying reduction in relative zircon stability (Appendix B). Second, even with the presence of young zircons in the SG2 rhyolites, reflecting periods of crystallisation, their age spectra are not wholly controlled by new zircon growth, but instead reflect a mixture with older inherited zircons (Figure 4.8). Third, small increases in magma temperatures in the youngest eruptive units at Taupo which make up Subgroup 3 rhyolites (units X, Y and Z: Sutton et al., 2000; Figure 4.10) have likely resulted in zircon dissolution (or non-growth) and subsequently very low yields reported (Charlier et al., 2005).

The observed age spectra in the post-Oruanui rhyolites clearly reflects a changing magma system with fluctuating magma temperatures, resulting in an overall reduction in zircon stability and growth through time. However, large or stepwise Fe-Ti oxide model temperature changes are not recorded between individual eruptions either within or between the SG1 and SG2 rhyolite groups (Figure 4.10), making the trends in zircon ages and abundance difficult to explain based on the volcanic record alone. Due to their relatively fast diffusion rates, Fe-Ti oxides will only provide a snapshot of the magma immediately prior to quenching on eruption, and will not therefore reflect fluctuations in temperature and hence zircon growth between eruptions or eruptive subgroups. Using the Ti-in-zircon thermometer of Ferry \& Watson (2007), it is apparent that there is a gradual increase in zircon model crystallisation temperatures over time (Figure 4.11a). This trend is in good agreement with observations of zircon abundance and textures in the post-Oruanui rhyolites, and likely reflects longer term temperature changes in the magmatic system as Ti diffusion in zircon is extremely slow at these temperatures (Cherniak, 2010). Notably, the model temperatures of the Ferry \& Watson (2007) thermometer are considerably lower than the average Fe-Ti oxide temperatures, although absolute temperatures using the Ti-in-zircon thermometer are dependent on the position in the crystal and the chosen method of estimating a value of $a \mathrm{TiO}_{2}$, and are variable by several tens of degrees centigrade with these factors (Ferry \& Watson, 2007; Chamberlain et al., 2014a; Figure 4.11a).

Determining the exact timing of periods of cooling and zircon crystallisation is difficult because of the limitations of the model-age determinations. However, given the trends in the age spectra, Fe-Ti oxide and Ti-in-zircon temperatures, and the results of 

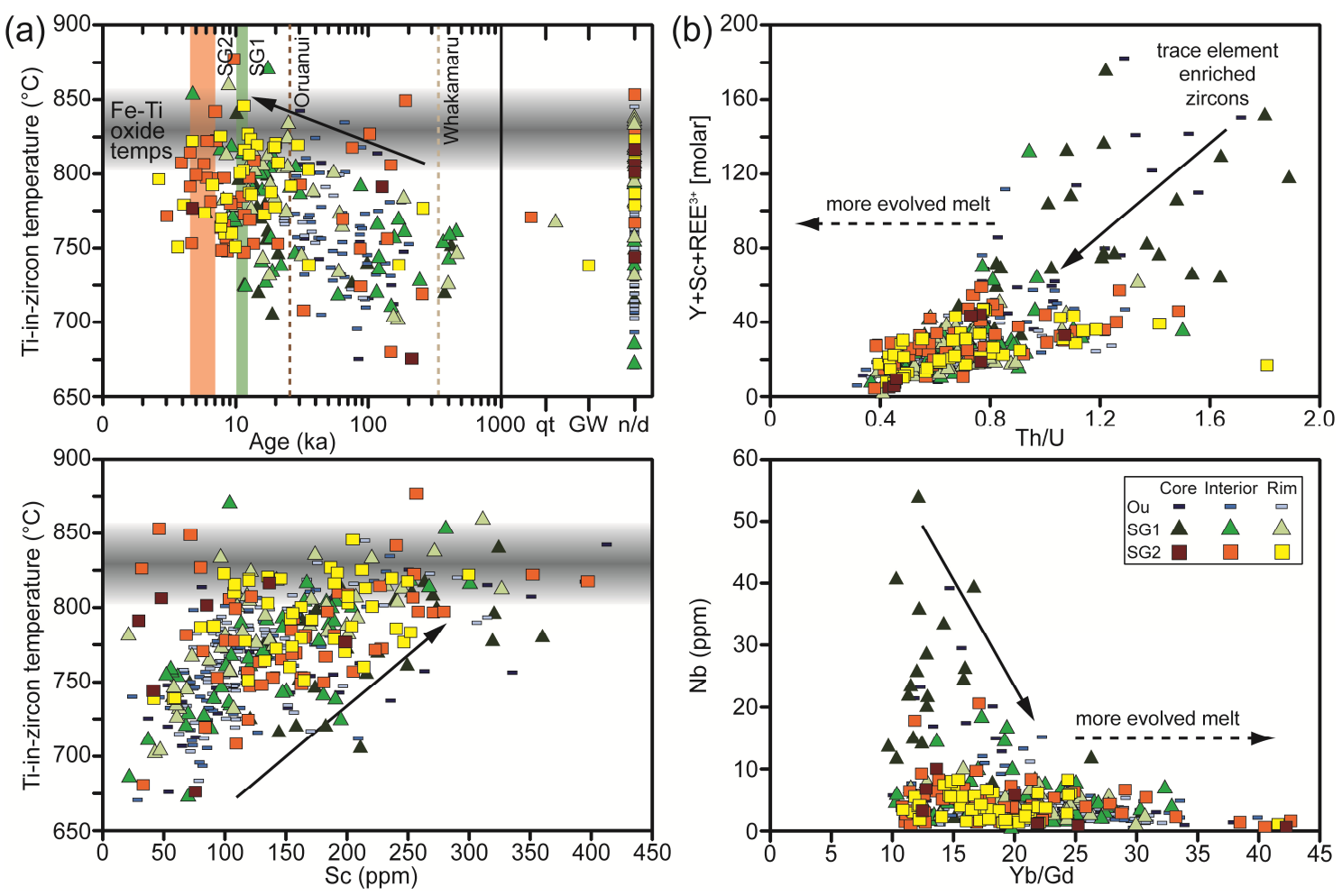

Figure 4.11. Trace element and temperature variations in the Oruanui and post-Oruanui zircon populations. (a) Plots showing positive correlations between temperature estimates with zircon age and Sc concentration using the Ti-in-zircon temperature model of Ferry \& Watson (2007). $a \mathrm{TiO}_{2}$ values for the Ti-in-zircon thermometer and magma temperatures were calculated using the Fe-Ti oxide model of Ghiorso \& Evans (2008) and Sauerzapf et al. (2008) for each eruptive unit (Fe-Ti oxide temperature range for the post Oruanui eruptions is shown by the dark shaded region). $a \mathrm{TiO}_{2}$ typically ranged between $0.50-0.55$, being slightly higher in the Oruanui magma. Fe-Ti oxide compositions for the Oruanui are from Wilson et al. (2006). (b) Variation diagrams showing zircon trace element variations with differing degrees of inferred melt evolution. Note the zircons that crystallised from the least evolved melts have anomalously high concentrations of $\mathrm{Y}+\mathrm{Sc}+(\mathrm{REE})^{3+}$ and $\mathrm{Nb}$. See discussion for details.

the mixture modelling, we consider that there are distinct periods of cooling and hence crystallisation which appear to coincide with periods of volcanic quiescence. One dominant age population is defined in the SG1 ages as likely occurring between $\sim 11.5$ ka and $\sim 15 \mathrm{ka}$, after the early dacites and just before eruption of the first rhyolites. In the SG2 rhyolites, this young population is supplemented by an additional population of zircons that likely formed post-10 ka, but cannot be statistically resolved within age uncertainties. An older age population is present that is less well defined but coincides with the immediate post-Oruanui period during which eruption of the dacites from the northern part of Lake Taupo occurred from 17-21 ka (Figure 4.1). During this period, there was no known volcanism in the southern part of Lake Taupo from which area the majority of the post-Oruanui rhyolites were vented. Although the dacite magmas were above zirconium saturation (as further supported by the scarcity of zircons in Unit D, also sourced from this area), part of the magma system to the south may have been 
cooling sufficiently to explain the older age peak observed in the SG1 and SG2 magmas. Opposing periods of cooling and crystallisation at Taupo would be periods of magma rejuvenation and subsequent heating of the magma system. Hot mafic magmas are often closely linked with rhyolitic volcanism at Taupo (e.g. Blake et al., 1992; Wilson et al., 2006) and the broader TVZ (Leonard et al., 2002; Hiess et al., 2007; Rowland et al., 2010). There is, in particular, evidence from the andesite cones south of Taupo that vigorous explosive activity there accompanied rifting and temporally bracketed the onset of SG1 rhyolitic volcanism at Taupo (Kohn \& Topping, 1978; Nairn et al., 1998). We suggest that a longer term periodicity of magma-assisted rifting processes and higher rates of influx of mafic magmas into the crust below Taupo are the cause of the 5-10 kyr periodicity that is seen in the zircon crystallisation history (during cooling and volcanic quiescence) and the clustering of eruptions into the subgroups (during rifting and volcanic activity).

\subsubsection{Zircon compositions as tracers of changing melt compositions}

In this study we have complemented zircon age determinations with trace element analyses of the same growth zones within the same crystals. Minor and trace elements of zircon have proven particularly useful as they provide valuable insights into the composition of the magma from which they formed (Luo \& Ayers, 2009; Barth et al., 2013). In addition, the very low diffusivities of most elements in zircon allow zonation and independent phases of growth to be preserved over long timescales at the observed magmatic temperatures (Cherniak, 2010). Magmatic zircon typically incorporates minor and trace amounts of lithophile elements such as Sc, Y, REE, Ti, Hf, Th, U, Nb, Ta, V and $\mathrm{P}$, which substitute for $\mathrm{Zr}$ and/or Si by either simple or coupled substitution mechanisms (for review see Hoskin \& Schaltegger, 2003). Elemental concentrations or ratios are used here to infer differing melt compositions between and within the Oruanui and post-Oruanui magma systems.

Two notable features of the combined trace element and age data provide evidence for distinct temporal variations in melt composition and conditions of crystallisation:

1. There is an overall increase in the Sc concentration with decreasing age between the Oruanui and post-Oruanui sourced zircons (Figure 4.7). We attribute these trends to differences in the ferromagnesian crystal phases that were stable in the melt at the time of zircon crystallisation. Amphibole is the most likely phase found in the Taupo eruptives that would change the concentration of Sc in the 
melt and hence zircon. Amphibole is present in Oruanui pumice, contributing up to $\sim 5 \%$ of the crystal assemblage (Wilson et al., 2006), but is relatively uncommon in the post-Oruanui eruptives (Sutton et al., 2000). In this study, amphibole was found as a minor phase in units B and $\mathrm{C}(<2-3 \%$ of the crystal assemblage), at trace levels in units D and E, and absent in all the SG2 rhyolites. As Sc is $\sim 20-40$ times more enriched in the Oruanui amphiboles than the melt (Allan et al., 2013), dissolution of amphibole would liberate Sc into the melt and make it available for substitution during zircon growth. As amphibole stability is largely dependent on temperature and water content of the melt (Ridolfi et al., 2010; Allan et al., 2013), the observed gradual heating trend with time may explain the disappearance of amphibole in younger units and the associated increase in Sc concentration in coevally crystallising zircons. In addition, Sc-rich zircons may reflect melts that have experienced recent magmatic rejuvenation. Sc concentrations are 3-4 times higher in the Oruanui mafic compositions than those observed in the rhyolites (Wilson et al., 2006). Sc is broadly positively correlated with Ti-in-zircon model temperatures, suggesting that outlier high-Sc Oruanui zircon cores generally crystallised from hotter and possibly less evolved magmas (Figure 4.11a).

2. A small subpopulation of zircon core or interior analyses from the SG1 zircons and a few outlier grains from the Oruanui have anomalously high concentrations of $\mathrm{U}, \mathrm{Th}, \mathrm{P}, \mathrm{Y}$ and $(\mathrm{REE})^{3+}$ and $\mathrm{Nb}$ (Figure 4.7). $\mathrm{U}^{4+}$ and $\mathrm{Th}^{4+}$ substitute in zircon by simple substitution with $\mathrm{Zr}^{4+}$, whereas $(\mathrm{Y}, \mathrm{REE})^{3+}$ and $\mathrm{P}^{5+}$ dominantly substitutes via xenotime substitution with $\mathrm{Zr}^{4+}+\mathrm{Si}^{4+}$ and $\mathrm{Nb}^{5+}$ couples with (Y, $\mathrm{REE})^{3+}$ for $2 \mathrm{Zr}^{4+}$ (Hoskin \& Schaltegger, 2003). The range of experimentally calculated partition coefficients for these elements in zircon cannot explain the wide compositional variations observed in the Taupo zircons (Sano et al., 2002). Sector zoned zircons in the Bishop Tuff have been recorded to show large differences in trace element concentrations (up to $3 \mathrm{x}$ ) between tips and sides in the same growth zone, suggesting that contrasting substitution mechanisms can occur within single crystals dependent on position on the crystal surface (Chamberlain et al., 2014a). However, sector zoning is relatively uncommon in zircons at Taupo, and zircons do not display parallel arrays in concentration of trace elements such as Ti, as is observed in the Bishop Tuff grains (see Appendix E). Instead, such high concentrations imply a drastic, but temporally (and spatially?) limited change in melt composition. Note that the post-Oruanui 
zircons with anomalously high trace-element concentrations are limited to a subpopulation of SG1 zircon cores with model ages that range between 10-20 ka (Figure 4.7; Appendix B and E). As previously discussed there are several key lines of evidence for Taupo's magma system likely experiencing large thermal changes due to the influx of hot magmas immediately after the Oruanui event. Dissolution of zircon, or potentially other $\mathrm{U}, \mathrm{Th}, \mathrm{P}, \mathrm{Y}$ and $(\mathrm{REE})^{3+}$ bearing minerals such as apatite (Sano et al., 2002), could then result in temporary but significant changes in melt composition. The first zircons to grow once the system reached zircon saturation (or the first zircons to grow within proximity to an area of partial melting), would then have enhanced levels of these elements. It is apparent that the zircons which grew during this period crystallised from the least evolved melts (i.e., highest $\mathrm{Th} / \mathrm{U}$ ratio and lowest $\mathrm{Yb} / \mathrm{Gd}$ ratio: Belousova et al., 2002; Barth \& Wooden, 2010) and have the highest concentration of $U$, Th, P, Y and (REE) ${ }^{3+}$, but not necessarily Sc (Figure 4.11b). Together with the U-Th zircon age spectra these observations imply that post-Oruanui heating of Taupo's magmatic system affected both the stability and composition of the zircons. Although the Oruanui grains with cores or interior zones with anomalously high concentrations of $\mathrm{U}, \mathrm{Th}, \mathrm{P}, \mathrm{Y}$ and $(\mathrm{REE})^{3+}$ do not cluster around any particular time interval (Figure 4.7), we also infer that these zircons partly grew in less evolved portions of the Oruanui magma system that experienced earlier thermal fluxes and possible dissolution prior to eruption. Less evolved melts, such as the low-Si rhyolite described by Allan et al. (2013), may be the source for such enrichments.

\subsection{Conclusion}

Zircon U-Th and U-Pb ages along with complementary trace element data yield insights into how the magmatic system at Taupo was rapidly destroyed then rebuilt after the 25.4 ka Oruanui supereruption. U-Th zircon model-ages in first-erupted SG1 rhyolites at 12 ka mostly post-date the Oruanui eruption age, indicating limited inheritance of crystals from the two dominant model-age modes (40 and $95 \mathrm{ka}$ ) in the Oruanui magma source. Subsequent eruptive units from multiple vents also contain only sparse numbers of Oruanui-aged or Oruanui peak-aged grains and are instead consistently dominated by multiple young peaks in their model-age spectra. Two lava-dominated eruptions (D and F) from vents at the northern and southern limits of young vent sites respectively 
contain a high proportion of old $\mathrm{U}-\mathrm{Th}$ equiline zircons. When dated by $\mathrm{U}-\mathrm{Pb}$ techniques these old grains are a mixture of both $300-450$ ka plutonic-derived and pre-100 Ma greywacke basement-derived grains. Plutonic-derived grains mostly match in age published zircon age determinations from the Whakamaru eruption (Brown \& Fletcher, $1999 ; 350 \mathrm{ka}$ ), and are dominant in young units from the northern part of Taupo that overlap with the proposed Whakamaru caldera outline. The scarcity of grains in the post-Oruanui units with ages that match the Oruanui or its modes is interpreted to have been caused by thermal dissolution in the immediate post-supereruption magma system, induced by instabilities resulting from the evacuation of a huge magma body and large influxes of hot mafic magma. This concept is matched by the trace element data which show a subpopulation of post-Oruanui zircons enriched in U, Th, P, Y and (REE) ${ }^{3+}$, representing crystals that grew following dissolution in the post-supereruption magma system. There is also a pronounced rise in the Sr-isotopic values recorded between the Oruanui magma compositions and the post-Oruanui eruptives (whether dacitic or rhyolitic) (Sutton et al., 2000; Wilson \& Charlier, 2009). This increase implies that the changes in the immediate aftermath of the Oruanui eruption also involved influx of a more-radiogenic source component, most logically basement greywacke. Longer term trends in zircon trace element chemistry, such as increasing Sc concentrations, reflect changing amphibole stability in the source region as the system has generated generally hotter magmas with time.

The magma system at Taupo was effectively reset following the Oruanui event, with little or no magmatic record of the preceding supersized magma system. Finer detail within the young zircon U-Th age spectra reveals the consistent inheritance of young post-Oruanui grains between the temporally spaced but geographically overlapping eruption groups. Using Gaussian mixture modelling, we interpret repeated peaks within the age spectra to be statistically significant, and result from recycling of crystals from multiple age populations. Taupo's rhyolitic system rapidly rebuilt following the Oruanui eruption, but not smoothly over time. Zircon stability in Taupo's young magma system was variable and crystallisation (and hence melt evolution) likely occurred in episodic cooling cycles, reflecting periods of volcanic quiescence and crystallisation. The modern rhyolitic subgroups are closely related, and record a system that has gradually heated over time. In conjunction with other studies on zircon age spectra at Taupo (Charlier et al., 2005; Wilson \& Charlier, 2009), we conclude that supervolcanic systems can operate on geologically rapid timescales. In the case study of Taupo, a supersized magma system was constructed over tens of millennia, finally 
assembled in centuries to millennia, and effectively destroyed and then a new magmatic system rebuilt on equally rapid timescales. 


\section{CHAPTER 5}




\title{
5: FINE-SCALE TEMPORAL RECOVERY, RECONSTRUCTION AND EVOLUTION OF A POST-SUPERERUPTION MAGMATIC SYSTEM: TAUPO (NEW ZEALAND)
}

\begin{abstract}
Supereruptions ( $>10^{15} \mathrm{~kg} \approx 450 \mathrm{~km}^{3}$ of magma) have received much attention because of the challenges in explaining how and over what time intervals such large volumes of magma are accumulated, stored, and erupted. The processes that follow supereruptions are less fully documented and, in particular, how and on what time scales the host magma system recovers into a post-caldera mode of activity. This study presents major and trace element data from whole rock, glass and minerals from eruptive products from Taupo volcano, New Zealand, to investigate how the host magma system was reestablished and evolved following the Oruanui supereruption at $25.4 \mathrm{ka}$. Taupo's young eruptive units are chronostratigraphically constrained over exceptionally short time intervals, providing fine-scale temporal snapshots of a post-supereruptive magma system. Following the Oruanui eruption, and after only $\sim 5 \mathrm{kyr}$ of quiescence, Taupo erupted three small volume $\left(\sim 0.1 \mathrm{~km}^{3}\right)$ dacitic pyroclastic units, followed by another $\sim 5$ kyr year time break, and then eruption of the modern sequence of 25 rhyolitic units starting at $\sim 12 \mathrm{ka}$. The dacites show wide variations in melt inclusion compositions and strongly zoned minerals consistent with interaction between felsic and mafic magmas at depths of $>8 \mathrm{~km}$, overlapping with the inferred basal parts of the older Oruanui silicic mush system. The dacites reflect the first products of a new silicic magma system, as most of the Oruanui magmatic root zone was effectively destroyed or significantly modified in composition by an influx of hot mafic magmas following caldera collapse. The first rhyolites erupted at 12-10 ka formed through shallow fractionation (up to 4-5 $\mathrm{km}$ depth) and cooling of melts from a source similar in composition to that generating the earlier dacites, with overlapping compositions for melt inclusions and crystal cores between the two magma types. For the younger rhyolite units, fine-scale temporal changes in melt chemistry and mineral phase stability occur, which are closely linked to the development, stabilisation and maturation of a new, probably unitary rhyolite mush system at Taupo. The new mush system was closely linked to and sometimes physically
\end{abstract}


interacted with underlying mafic melts, which (where directly sampled at $3.5 \mathrm{ka}$ ) were similar in composition to those involved in the Oruanui eruption and continued to provide long-term thermal and chemical driving forces for magmatism. For the most recent eruptions (1.8 ka), the whole magmatic system underwent widespread destabilisation, resulting from increased mafic magma flux. A large mush system $(>200$ $\mathrm{km}^{3}$ ) has been re-established at Taupo and is capable of feeding a new cycle of volcanism in the future. 


\subsection{Introduction}

Supereruptions are defined as those that eject $>10^{15} \mathrm{~kg}$ ( or $\sim 450 \mathrm{~km}^{3}$ ) of magma, equivalent to $>1000 \mathrm{~km}^{3}$ of pyroclastic material (Miller \& Wark, 2008 for overview), and are often interpreted to result from a unique set of circumstances that lead to the accumulation and mobilisation of large amounts of magma (Caricchi et al., 2014; Malfait et al., 2014). Modern concepts of large silicic magma systems suggest that significant volumes of partly molten crystal mush are required to generate the huge volumes of melt(s) required for supereruptions (Bachmann \& Bergantz, 2004, 2008; Hildreth, 2004; Glazner et al., 2004; Wilson et al., 2006; Hildreth \& Wilson, 2007; Lipman, 2007; Girard \& Stix, 2009; Wilson \& Charlier, 2009; Allan et al., 2014). Such concepts also often highlight the crucial interplay of this evolved crystal mush with a deeper-seated feeder system of less evolved mafic melts and their crystalline products. This feeder system not only supplies a heat source and fractionation products to the base of the magma reservoir, it may also affect the longevity and periodically the stability of the overlying mush system (Hildreth, 2004; Bachman \& Bergantz, 2008). The evacuation of super-eruptive volumes of magma from a chamber will then undoubtedly have significant effects on this deeper sub-volcanic reservoir, as well as the overall structure of the regional crust. Questions then arise as to how, and on what timescales, the host magmatic system rebuilds and evolves following a supereruption. For example, how does the catastrophic release of vast amounts of magma affect the structure of the magmatic system as a whole [i.e., the melt dominant zone, crystal mush zone and crustal reservoir of Hildreth \& Wilson (2007)], and the chemical composition of the melts it produces? In turn, does a single supereruption in the history of a volcano mean that it is necessarily capable of such behaviour in the future, and if so, how long would it take for the magma system to re-establish? Such questions are vital for understanding the dynamics of supervolcanoes and building a framework for future hazard assessments at potentially active supervolcanoes.

One of the biggest challenges of interpreting pre- and post-supervolcanic processes is the relative scarcity of detail about immediately pre- and post-supereruptive activity in the geological record. This scarcity arises from the lack of long-term preservation of smaller eruptive units around a supereruption and the establishment of a well constrained eruptive stratigraphy. In older examples, the uncertainties of the method employed to date eruptions is often larger than the interval between potential 
eruptive episodes (e.g. $10^{4}-10^{5}$ years using ${ }^{40} \mathrm{Ar} /{ }^{39} \mathrm{Ar}$ and U-Pb systematics: Simon et $a l ., 2008)$. Short-term magmatic expression through closely spaced eruptions and preservation of their products is a critical factor for interpreting the immediate posteruptive magmatic reorganisation of a supervolcano.

Taupo volcano, located in the central North Island of New Zealand, provides a unique opportunity to investigate the dynamics of both a pre- and post-supereruption magma system because of its young age, high eruptive frequency and the degree of preservation of its eruption products. The young eruptive history of Taupo is exceptionally well constrained by radiocarbon dating and by stratigraphic correlation with other young tephras from the Taupo Volcanic Zone (TVZ) (Wilson, 1993; Wilson et al., 2009). Taupo's caldera was primarily formed in the catastrophic 25.4 ka Oruanui event, the world's youngest supereruption, which released $>530 \mathrm{~km}^{3}\left(>1100 \mathrm{~km}^{3}\right.$ of pyroclastic material) of magma over a period of several months (Wilson, 2001; Wilson et al., 2006; Vandergoes et al., 2013; Allan et al., 2013, 2014; Figure 5.1). The Oruanui eruption was spasmodic, modulated by tectonic control and involved in its earlier stages the introduction into the active vent of a foreign rhyolite magma by diking from the contemporaneous NE dome magma system (Sutton et al., 1995; Allan et al., 2012). Contrasts between U-Th model ages from zircons extracted from the precursor 'Oruanui-type' magmas and those from the Oruanui magma itself (Wilson \& Charlier, 2009) and element diffusion modelling (Allan et al., 2013) indicates that although the broader Oruanui mush source likely developed over tens of thousands of years, the eruptible melt-dominant magma body was accumulated in at most about 3000 years. The Oruanui juvenile material was $>99 \%$ rhyolite, with a minor $(<1 \%)$ component of mafic magma (Sutton et al., 1995; Wilson et al., 2006). Further investigation of pumice compositions have shown that there were a complex range of rhyolite melts involved, with a uniform high silica rhyolite (HSR) being dominant, but an additional low-silica rhyolite (LSR) was present, as well as the invasive foreign biotite-bearing (BtB) magma from the NE dome magma system (Wilson et al., 2006; Allan et al., 2012, 2014; Figure 5.1a). In addition, crystals and melts from assimilated Quaternary intrusions and Mesozoic greywacke metasediments were likely incorporated into the magma body up to the point of eruption (Liu et al., 2006; Charlier et al., 2008). The previous studies on the Oruanui magmatic system provide an excellent framework from which to interpret supereruption-scale magmatic processes (see Allan et al., 2014).

Despite evacuating such a large volume of magma, Taupo resumed erupting only $\sim 5$ kyr after the Oruanui event, albeit on a smaller, more frequent scale. In total, 
苨

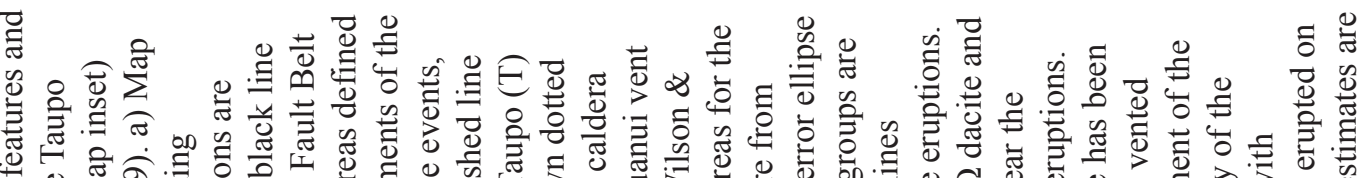

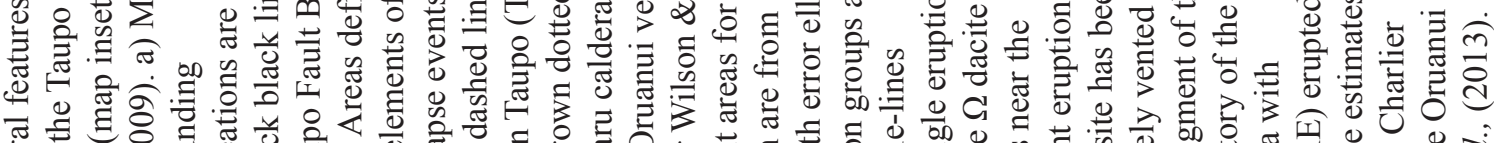

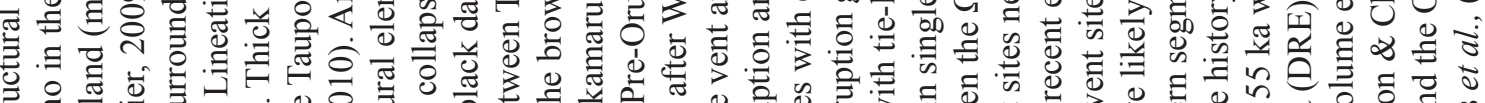

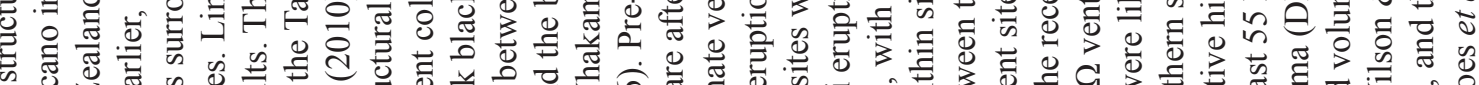

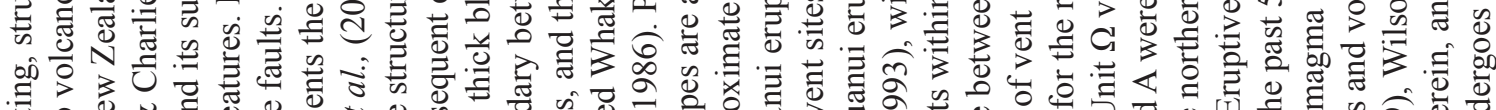

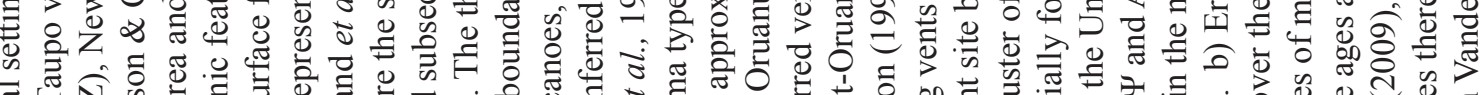

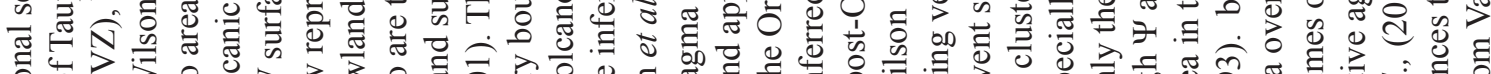

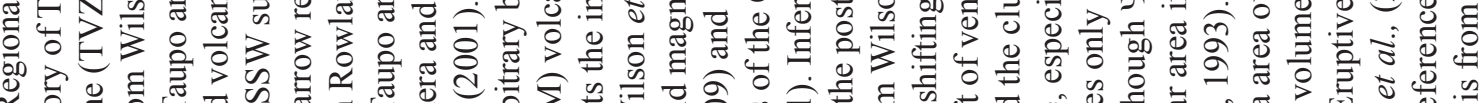

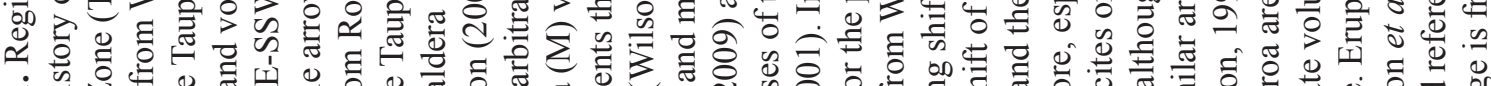

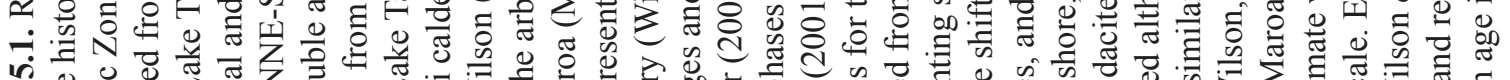

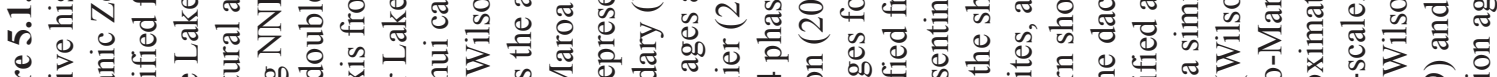

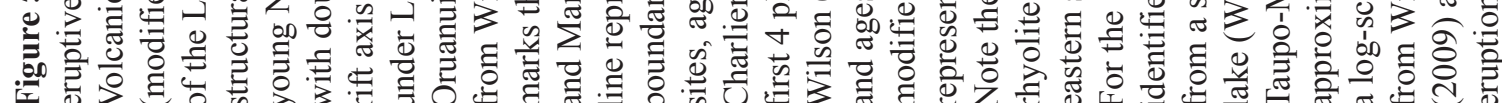
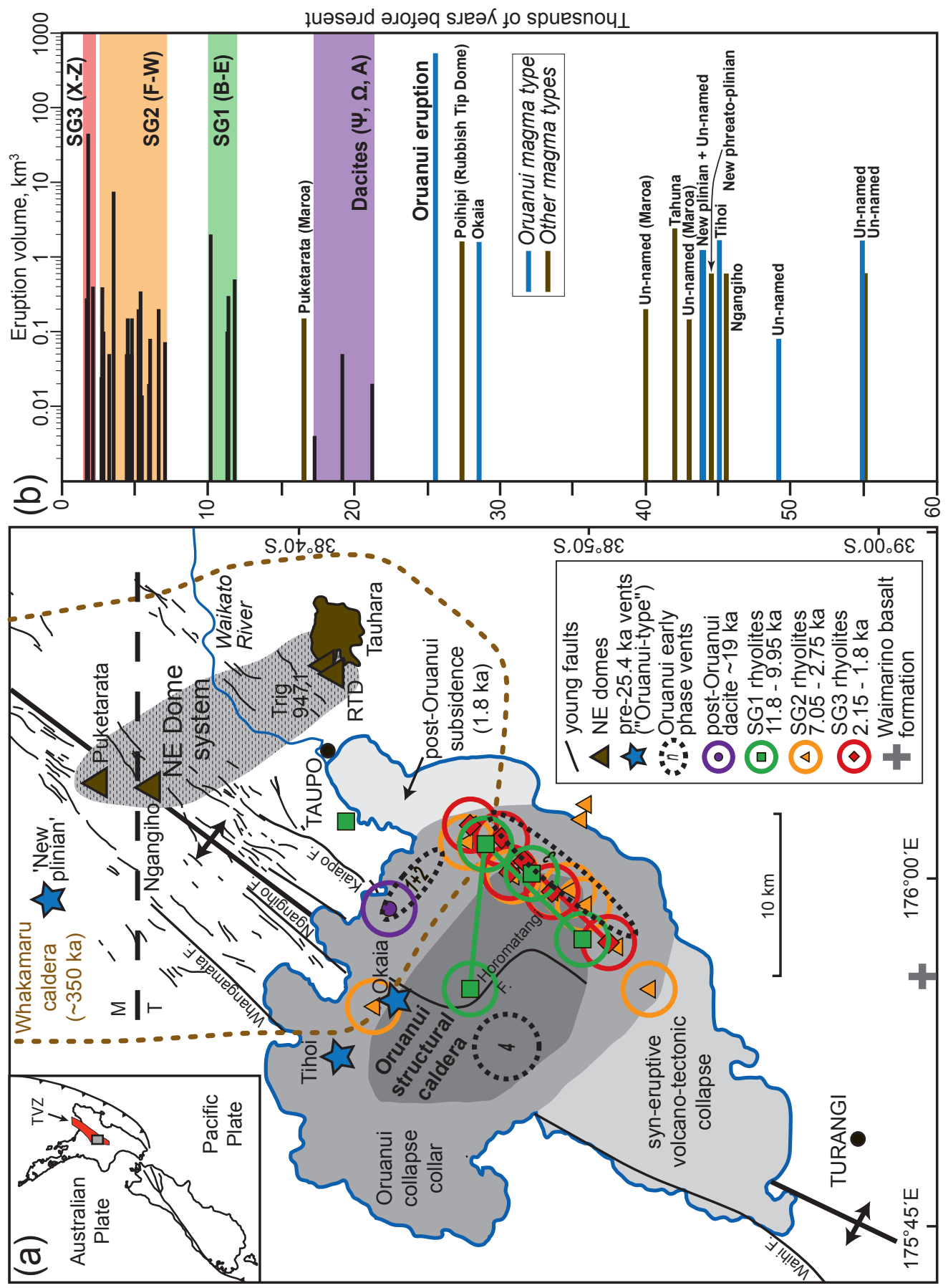
there have been 28 eruptions following the Oruanui, 25 of which occurred in the last 12 kyr, with the largest at $232 \pm 5$ AD (Wilson, 1993; Hogg et al., 2012; Figure 5.1; Table 5.1). The first post-Oruanui eruption units at $\sim 21-17$ ka were dacitic and vented in the northern segment of the Oruanui caldera (units $\Psi, \Omega$ and A). The remaining eruptions are clustered into three temporally and chemically distinct rhyolitic subgroups (SG1-3), erupted from multiple vent sites in discrete periods from 11.8 to 9.95 (SG1: units B-E), 7.05 to 2.75 (SG2: units F-W) and 2.15 to $1.8 \mathrm{ka}$ (SG3: units X-Z) (Sutton et al., 1995, 2000; Figure 5.1; Table 5.1). Taupo's magmatic system demonstrably underwent significant changes following the supereruption. For example, contrasting zircon age spectra between the Oruanui and post-Oruanui magmas suggests that the system underwent significant heating and the chronological history of the magmatic system was thermally reset (Charlier et al., 2005, 2010; CHAPTER 4: Barker et al., 2014a). However, questions remain as to how and when the rhyolitic magma system was rebuilt and re-established following the supereruption (e.g. Sutton et al., 2000). In particular, how did the mush system and deeper root zone (including the inferred underlying mafic feeder system) react to the contrasting post-supereruption environment? In what fashion did the magmatic system adjust, recover, and chemically evolve to start producing new suites of dacite and rhyolite eruptions. What are the modern components of the magma reservoir and where are they located?

This study determines a fine-scaled temporal record of magma chemistry for the 28 post-Oruanui eruptions. Major- and trace-element compositions of whole rock, glass and minerals are presented from pyroclasts and lava to constrain processes involved in Taupo's post-supereruption reconstruction through to the latest eruption only $\sim 1800$ years ago. This study demonstrates how Taupo's magma system was re-established and then evolved at multiple critical stages through its young history, to build a new unitary rhyolitic mush system that most recently fed one of the largest and most energetic Holocene eruptions on Earth.

\subsection{Eruptive stratigraphy and sampling}

The onset of modern explosive activity at Taupo commenced shortly after the Rotoiti event from the nearby Okataina volcano (Wilson et al., 1995). The period between $\sim 60$ ka and 25 ka was dominated by small pyroclastic eruptions from vents mostly now concealed beneath Lake Taupo, interspersed with a series of small but chemically 


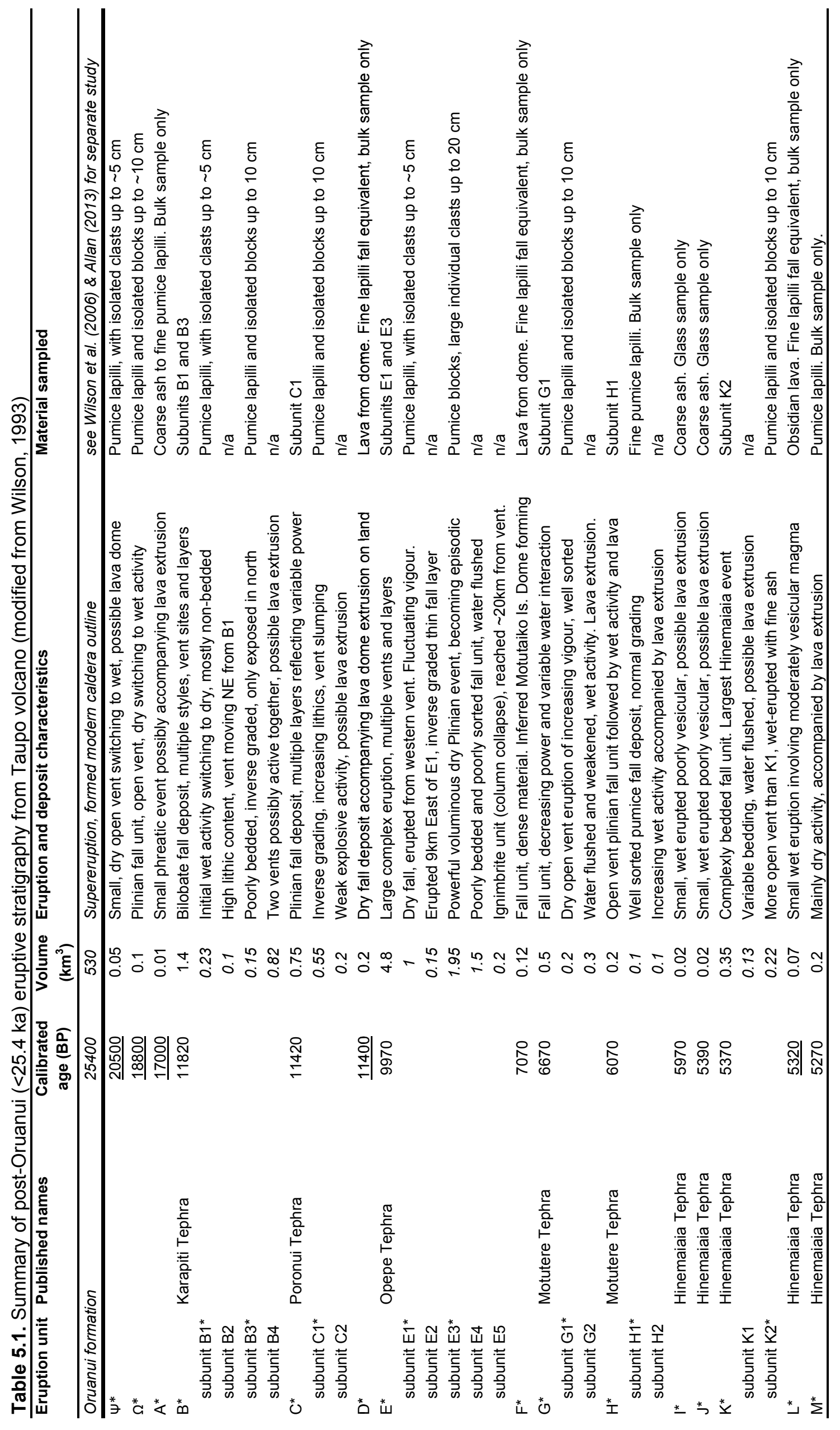




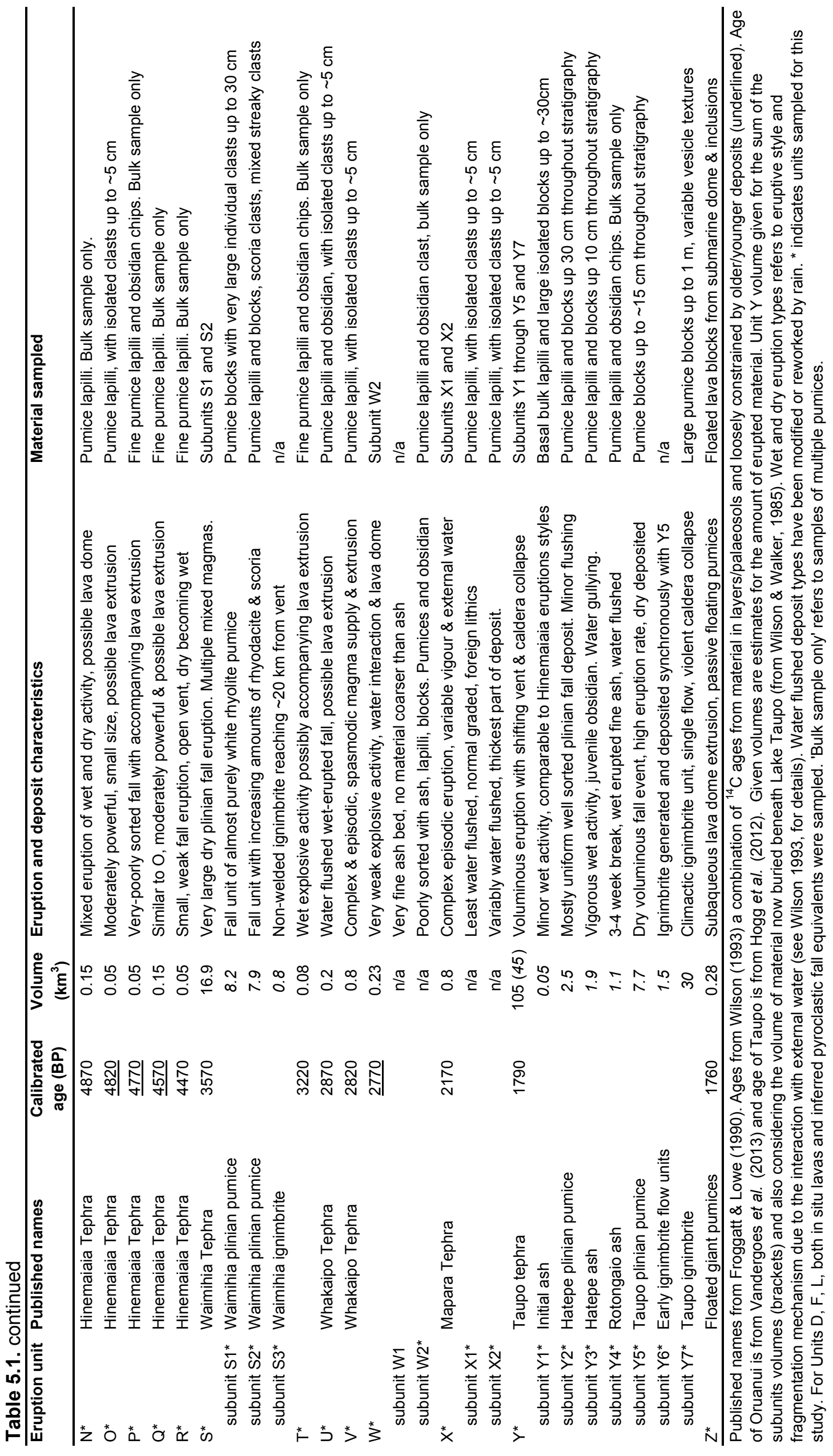


distinct eruptions from Maroa volcano to the north of Taupo (Wilson et al., 1995; Sutton et al., 1995; Wilson \& Charlier, 2009; Figure 5.1). Following the Oruanui eruption, early tephrochronological studies proposed nine tephra formations in the post25 ka time period (Baumgart, 1954; Healy, 1964; Vucetich \& Pullar, 1973; Froggatt \& Lowe, 1990). Although successful in identifying those major (mostly Holocene) units which were separated by long time breaks represented by clear palaeosols, these studies missed many minor (but crucial) palaeosols and thin, often bioturbated tephra units. A re-examination and re-interpretation of Taupo's post-Oruanui stratigraphy (Wilson, 1993 ) identified and dated 28 eruption units that varied widely in their eruption sizes and styles (Figure 5.1; Table 5.1). For convenience, the 28 eruptions and their accompanying products were labelled by letter, with the two oldest units denoted by the Greek letters $\Psi$ and $\Omega$, and the remainder labelled from oldest to youngest as A through Z. The 28 eruptions were collected into four subgroups based on broad chemical variations with time (Sutton et al., 1995; 2000; Figure 5.1).

Samples used in this study were collected within the eruptive stratigraphic framework of Wilson (1993) (CHAPTER 2). Utilising the reference and type localities listed in Wilson (1993), along with new sampling locations found with modern infrastructural developments around the Taupo region over the past 20 years (e.g. new highway cuttings and forestry roads), the largest and freshest possible juvenile materials from each post-Oruanui eruption were collected for chemical analysis (see CHAPTER 2 for a description of sampling locations). For selected eruptions that experienced a significant change in eruptive style or vent location, multiple phases of the eruptive sequence were sampled to monitor for significant variation in composition during single events (Table 5.1). For subaerial eruptions D (Acacia Bay Dome), F (Motutaiko Island) and L (White Cliffs dome), both fragments of lava and the inferred fall unit equivalents were sampled for comparison. As Unit S (Waimihia) has been noted for multiple magma compositions and mixed pumices (Blake et al., 1992; Sutton et al., 1995), endmember rhyolitic pumice, grey hybrid rhyodacite pumice and discrete mafic clasts were collected for analysis. In addition, scoria from a nearby small monogenetic basaltic volcano, the Waimarino basalt, was sampled for comparison with Oruanui and postOruanui mafic compositions. The Waimarino basalt was vented $\sim 16 \mathrm{~km}$ south of the most southernmost young vent of Taupo volcano (Figure 5.1). Hackett (1985) described the Waimarino basalt as most likely post-Oruanui in age based on the absence of overlying Oruanui ignimbrite, a lack of erosion and the exceptionally fresh appearance of the lava. Graham \& Hackett (1987) described the Waimarino basalt in the context of 
andesite petrogenesis at Ruapehu volcano, $\sim 40 \mathrm{~km}$ to the $\mathrm{SW}$, but here it is compared more directly to magmatism at Taupo due to its geographical proximity.

\subsection{Analytical techniques}

The range of eruption sizes and styles in the post-Oruanui sequence generated a variety of pyroclastic products that were collected for chemical analysis in this study (Table 5.1). In some cases (e.g. large explosive eruptions: Unit S and Unit Y), abundant large lapilli or blocks could be sampled through stratigraphic sequences with enough material obtainable from single clasts for analysis. However, for many deposits (especially in the 'Hinemaiaia Tephra' sequence of units I to R; Table 5.1), the coarsest material available was not sufficient for single-clast analyses. In such cases multiple lapilli of similar appearance and size were concentrated by sieving and combined to obtain enough material for analysis. In the smallest eruption deposits (e.g. units I and J), only medium to coarse ash could be sampled, which was carefully picked and scanned under a binocular microscope to ensure that only juvenile material was selected for analysis. Samples were repeatedly rinsed and scrubbed prior to processing and put in a sonic bath to remove any adhering ash or lithic material, with a final rinse in Milli-Q water $(>18.2$ $\mathrm{M} \Omega$ ). Lapilli or block-sized material was coarsely crushed in a Boyd crusher to $\sim 2 \mathrm{~mm}$ fragments. The crushed lapilli/ blocks or picked ash samples were then manually split into two equal portions, with one portion sieved and crushed to $<2 \mathrm{~mm}$ size and weighed for mineral-glass separation, and the other reserved for whole-rock powdering in an agate TEMA. Large crystals were manually picked from the mineral-glass fraction, and the rest of the material was put through heavy liquids reduced to a density of $2.4-2.5 \mathrm{~g} / \mathrm{cm}^{3}$ to separate groundmass glass from minerals. The light glass fraction was then sieved to $250 \mu \mathrm{m}$, repeatedly rinsed in Milli-Q water in a sonic bath to remove any contaminants from the heavy liquid and manually checked under the microscope for purity. Minerals were manually picked and mounted by crystal type and size into epoxy resin pucks and polished to expose the cores of the grains. For volatile analysis, plagioclase crystals with large melt inclusions were picked and mounted in crystal bond epoxy and prepared as doubly-polished wafers.

Whole-rock powders were analysed for major elements by X-ray fluorescence (XRF) at the Open University, United Kingdom. Approximate 2 standard deviation (2SD) analytical precisions determined by replicate analyses of the same standards for 
elements are generally $<1-3$ relative $\%$ (CHAPTER 3 ). Trace element analyses on whole -rock and pure glass separates were carried out by solution inductively coupled plasma mass spectrometry (ICP-MS). ${ }^{43} \mathrm{Ca}$ was used to perform an internal correction, as $\mathrm{CaO}$ concentrations were known to $\pm 1 \%$ from XRF. Diluted sample solutions were analysed using a Thermo Scientific Element2 sector-field ICPMS at Victoria University of Wellington (VUW). Total procedural blanks were within background levels on all measured elements. Abundances of individual trace elements were calculated by external normalization relative to a bracketing standard (BHVO-2), which was prepared and analysed under identical conditions to the samples. Approximate 2 SD analytical precisions derived from 19 replicate analyses of a secondary standard (BCR-2) are < $\pm 6-7$ relative $\%$ for most trace elements (exceptions are $\mathrm{Li}, \mathrm{Cr}, \mathrm{Cs}$, and $\mathrm{Pb}$ at $<20 \%$ and $\mathrm{Ni}, \mathrm{Cu}, \mathrm{Nb}, \mathrm{Mo}$, Ta, $\mathrm{W}$ at $>20 \%$ ) (CHAPTER 3), with accuracies also $\leq 6-7 \%$ (most are $<1-2 \%$ ), apart from $\mathrm{Cu}$ at $<20 \%$ and $\mathrm{Ta}$ at $\sim 25 \%$. For replicate analysis of an internal Taupo pumice secondary standard, most trace elements are precise to $< \pm 6-7$ relative $\%$ with similar exceptions to BCR-2 (CHAPTER 3).

Mineral major element and glass analyses were undertaken on a JEOL JXA 8230 electron probe microanalyser (EPMA) at VUW using wavelength dispersive spectrometry techniques. Operating conditions were $15 \mathrm{kV}$ voltage, with the current ranging from 20nA for pyroxene and Fe-Ti oxides, 12nA for amphibole and plagioclase, and 8nA with a defocused $10 \mu \mathrm{m}$ beam for glass with reduced count times for $\mathrm{Na}$ to minimise alkali loss. Calibrated international standards were analysed as unknowns to monitor instrumental drift and the precision and accuracy of the analyses. Approximate 2 SD analytical precisions calculated from repeated analysis of calibration standards are generally $<5 \%$ for oxides that occur in concentrations of $>1 \mathrm{wt}$. \%. For lower concentration oxides, precision degrades with decreasing relative concentration (CHAPTER 3). Amphibole trace element compositions were measured in-situ using a New Wave deep UV laser (193 nm solid state) coupled to an Agilent 7500CS ICP-MS at Victoria University of Wellington. The LA-ICP-MS data acquisition technique used ${ }^{43} \mathrm{Ca}$ as the internal standard for secondary data normalisation (Pearce et al., 1996), which had previously been determined to $\pm 5 \%$ by EPMA. Abundances of individual trace elements were calculated relative to a bracketing standard (BCR-2G or NST 612), which was analysed under identical conditions throughout the analysis sessions. Approximate 2 SD analytical precisions and accuracies of replicate analyses are $<10 \%$ for most trace elements (CHAPTER 3). 
$\mathrm{H}_{2} \mathrm{O}, \mathrm{OH}^{-}$and $\mathrm{CO}_{2}$ concentrations in plagioclase-hosted melt inclusions were determined by Fourier transform infrared spectroscopy (FTIR) using a Varian FTS Stingray 7000 Micro Image Analyser at the Japan Agency for Marine-Earth Science and Technology (JAMSTEC). Replicate analyses $(n=3-5)$ on each inclusion included the collection of both reflection and transmission FTIR spectra (CHAPTER 2). Spectra were collected across the near- and mid-IR ranges $\left(8300-800 \mathrm{~cm}^{-1}\right)$ using a heated ceramic (globar) source and a KBr beamsplitter. Background and sample spectra were collected with 512 scans at $8 \mathrm{~cm}^{-1}$ resolution, using spot sizes from $20-100 \mu \mathrm{m}^{2}$ as appropriate for each inclusion, as focused with an attached UMA 600 microscope. Backgrounds were taken on a gold-coated disk for reflection and through a $\mathrm{KBr}$ disk for transmission. Interference fringes on reflectance spectra were used to determine the beampath, or inclusion thickness at each analytical spot (Nichols \& Wysoczanski, 2007; Tamic et al., 2001; Wysoczanski \& Tani, 2006) using a refractive index of 1.48 (Okumura et al., 2003). Absorbance peak heights were determined from transmission spectra using Varian Win-IR Pro software (v3.3.1.014), and were converted to concentrations using the Beer-Lambert law. Parameters included the reflectancedetermined thicknesses, a nominal rhyolite density of $2.3 \mathrm{~g} \mathrm{~cm}^{-3}$ (Okumura et al., 2003) and the following molar absorptivities: 1.86 mol.cm ${ }^{-1}$ for molecular $\mathrm{H}_{2} \mathrm{O}\left(\mathrm{H}_{2} \mathrm{O}_{\text {mol }}\right)$ at $5200 \mathrm{~cm}^{-1}$ (Ihinger et al., 1994); $1.50 \mathrm{~mol} . \mathrm{cm}^{-1}$ for $\mathrm{OH}-$ at $4500 \mathrm{~cm}^{-1}$ (Ihinger et al., 1994); and $1214 \mathrm{~mol} . \mathrm{cm}^{-1}$ for $\mathrm{CO}_{2 \mathrm{~mol}}$ at $2350 \mathrm{~cm}^{-1}$ (Behrens et al., 2004).

\subsection{Results}

\subsubsection{Mineralogy}

The post-Oruanui eruptive products contain a limited range of mineral phases that vary systematically between eruption subgroups (Table 5.2). The first erupted dacitic units contain the highest concentration of crystals at $\sim 25 \mathrm{wt} . \%$, with dominant plagioclase, then orthopyroxene, clinopyroxene, ilmenite and magnetite. Unit A is an exception with slightly lower crystal contents: however, we consider this to reflect the fine grain size of the sample that was collected (Table 5.1), where the tephra is not representative of the bulk magma due to crystal-glass separation during fragmentation and deposition (e.g. Wolff 1985). Apatite and sulphide inclusions are common in the dacite crystals, as previously reported (Sutton et al., 2000; Gelman et al., 2013). Crystals are often found clustered together in large glomerocrysts that can reach up to $2 \mathrm{~cm}$ across. Individual 
Table 5.2. Mineralogy of post-Oruanui eruptive units

\begin{tabular}{|c|c|c|c|c|c|c|c|c|}
\hline \multirow{2}{*}{$\begin{array}{l}\text { Unit } \\
\text { Dacites }\end{array}$} & \multirow{2}{*}{$\begin{array}{l}\text { Age } \\
\text { (ka) }\end{array}$} & \multirow{2}{*}{$\begin{array}{l}\text { Mineral } \\
\text { content } \\
\text { (wt. \%) }\end{array}$} & \multirow{2}{*}{$\begin{array}{l}\text { Dominant mineral phases } \\
\text { present (in order of relative } \\
\text { abundance) }\end{array}$} & \multicolumn{5}{|c|}{$\begin{array}{l}\text { Mineral compositional range \& average crystal rim } \\
\text { compositions (in italics where determined) }\end{array}$} \\
\hline & & & & Plag An. \% & Opx Mg\# & Cpx Mg\# & Mnt & Ilm \\
\hline$\Psi$ & 20.5 & 29 & Plag, Opx, Cpx, Mnt, Ilm & $51-92(58 \pm 4)$ & $58-74(60 \pm 2)$ & $67-86(70 \pm 4)$ & $36-38$ & $79-83$ \\
\hline$\Omega$ & 18.8 & 27 & Plag, Opx, Cpx, Mnt, Ilm & $42-83(57 \pm 4)$ & $56-71(59 \pm 2)$ & $61-75(67 \pm 4)$ & $35-41$ & $80-83$ \\
\hline $\mathrm{A}$ & 17 & $17^{*}$ & Plag, Opx, Cpx, Mnt, Ilm & $48-86(57 \pm 4)$ & $55-66(60 \pm 2)$ & $67-75(70 \pm 3)$ & $36-39$ & $80-83$ \\
\hline \multicolumn{4}{|c|}{ Subgroup 1 rhyolites } & Plag An. \% & Opx Mg\# & Cpx Mg\# & Mnt & Ilm \\
\hline B1 & 11.8 & 5 & Plag, Opx, Cpx, Mnt, Ilm, $<$ Amp & $39-86(45 \pm 5)$ & $38-61(45 \pm 5)$ & $53-69(59 \pm 4)$ & $38-40$ & $88-91$ \\
\hline B3 & 11.8 & 5 & Plag, Opx, Cpx, Mnt, Ilm, <Amp & $36-85(44 \pm 4)$ & $44-63(46 \pm 4)$ & $55-68(59 \pm 4)$ & $38-40$ & $87-89$ \\
\hline $\mathrm{C}$ & 11.4 & 7 & Plag, Opx, Cpx, Mnt, Ilm, $<$ Amp & $38-74(43 \pm 4)$ & $43-71(47 \pm 3)$ & $54-65(57 \pm 4)$ & $37-39$ & $87-89$ \\
\hline$D_{\text {lava }}$ & 11.4 & 7 & Plag, Opx, Mnt, Ilm, $<<\mathrm{Cpx}+\mathrm{Amp}$ & $38-82(43 \pm 5)$ & $44-65(48 \pm 3)$ & $57-67(59 \pm 3)$ & $35-37$ & $86-88$ \\
\hline$D_{\text {tephra }}$ & 11.4 & $6^{*}$ & Plag, Opx, Mnt, Ilm, $<$ Cpx & $37-85(45 \pm 5)$ & $43-64(45 \pm 4)$ & $57-70(61 \pm 3)$ & $36-39$ & $86-89$ \\
\hline E1 & 10 & 3 & Plag, Opx, Mnt, Ilm, $<<\mathrm{Cpx}+\mathrm{Amp}$ & $35-85(43 \pm 3)$ & $44-63(46 \pm 2)$ & $55-70(61 \pm 6)$ & $38-39$ & $87-88$ \\
\hline E3 & 10 & 4 & Plag, Opx, Mnt, Ilm, $<<\mathrm{Cpx}+\mathrm{Amp}$ & $40-81(44 \pm 6)$ & $44-64(46 \pm 2)$ & $56-79(60 \pm 6)$ & $38-39$ & $87-88$ \\
\hline \multicolumn{4}{|c|}{ Subgroup 2 rhyolites } & Plag An. \% & Opx Mg\# & Cpx Mg\# & Mnt & Ilm \\
\hline $\mathrm{F}_{\text {lava }}$ & 7.1 & 7 & Plag, Opx, Mnt, Ilm & $\mathrm{n} / \mathrm{d}$ & $41-59(46 \pm 2)$ & $\mathrm{n} / \mathrm{a}$ & $41-42$ & $88-90$ \\
\hline $\mathrm{F}_{\text {tephra }}$ & 7.1 & $7^{*}$ & Plag, Opx, Mnt, Ilm & $41-57(43 \pm 2)$ & $43-56(46 \pm 1)$ & $\mathrm{n} / \mathrm{a}$ & $37-39$ & $87-89$ \\
\hline G & 6.7 & 4 & Plag, Opx, Mnt, Ilm & $38-55(40 \pm 1)$ & $45-59(47 \pm 1)$ & $\mathrm{n} / \mathrm{a}$ & $38-39$ & $87-88$ \\
\hline $\mathrm{H}$ & 6.1 & 5 & Plag, Opx, Mnt, Ilm & $39-53(42 \pm 5)$ & $44-59(46 \pm 3)$ & $\mathrm{n} / \mathrm{a}$ & $38-39$ & $87-89$ \\
\hline $\mathrm{K}$ & 5.4 & 5 & Plag, Opx, Mnt, Ilm & $34-71(42 \pm 4)$ & $38-55(45 \pm 1)$ & $\mathrm{n} / \mathrm{a}$ & $39-40$ & $88-91$ \\
\hline $\mathrm{L}_{\text {lava }}$ & 5.3 & 4 & Plag, Opx, Mnt, Ilm & $\mathrm{n} / \mathrm{d}$ & $\mathrm{n} / \mathrm{d}$ & $\mathrm{n} / \mathrm{a}$ & $\mathrm{n} / \mathrm{d}$ & $\mathrm{n} / \mathrm{d}$ \\
\hline $\mathrm{L}_{\text {tephra }}$ & 5.3 & $3 *$ & Plag, Opx, Mnt, Ilm & $39-48(43 \pm 3)$ & $43-54(45 \pm 1)$ & $\mathrm{n} / \mathrm{a}$ & $38-41$ & $87-88$ \\
\hline $\mathrm{M}$ & 5.3 & 3 & Plag, Opx, Mnt, Ilm & $35-59(41 \pm 2)$ & $44-59(46 \pm 3)$ & $\mathrm{n} / \mathrm{a}$ & $38-40$ & $87-89$ \\
\hline $\mathrm{N}$ & 4.9 & 3 & Plag, Opx, Mnt, Ilm & $38-86(42 \pm 5)$ & $43-53(45 \pm 2)$ & $\mathrm{n} / \mathrm{a}$ & $39-41$ & $87-89$ \\
\hline $\mathrm{O}$ & 4.8 & 4 & Plag, Opx, Mnt, Ilm & $34-52(43 \pm 3)$ & $42-58(44 \pm 2)$ & $\mathrm{n} / \mathrm{a}$ & $37-41$ & $87-89$ \\
\hline$P$ & 4.8 & $3 *$ & Plag, Opx, Mnt, Ilm & $39-55(41 \pm 3)$ & $41-52(44 \pm 2)$ & $\mathrm{n} / \mathrm{a}$ & $38-41$ & $87-89$ \\
\hline Q & 4.6 & $2.5^{*}$ & Plag, Opx, Mnt, Ilm & $39-64(40 \pm 1)$ & $41-54(45 \pm 1)$ & $\mathrm{n} / \mathrm{a}$ & $40-42$ & $88-89$ \\
\hline $\mathrm{R}$ & 4.5 & $3 *$ & Plag, Opx, Mnt, Ilm & $37-54(41 \pm 4)$ & $39-52(44 \pm 1)$ & $\mathrm{n} / \mathrm{a}$ & $40-41$ & $87-88$ \\
\hline $\mathrm{S}$ & 3.6 & 4.5 & Plag, Opx, Mnt, Ilm & $38-45(42 \pm 2)$ & $42-53(44 \pm 1)$ & $\mathrm{n} / \mathrm{a}$ & $41-42$ & $88-89$ \\
\hline $\mathrm{S}_{\text {mafic }}$ & 3.6 & $\mathrm{n} / \mathrm{d}$ & Plag, Cpx, Opx, Olivine, Mnt & $\mathrm{n} / \mathrm{d}$ & $\mathrm{n} / \mathrm{d}$ & $\mathrm{n} / \mathrm{d}$ & $\mathrm{n} / \mathrm{d}$ & $\mathrm{n} / \mathrm{d}$ \\
\hline $\mathrm{T}$ & 3.2 & $5.5^{*}$ & Plag, Opx, Mnt, Ilm & $35-54(40 \pm 2)$ & $39-52(44 \pm 2)$ & $\mathrm{n} / \mathrm{a}$ & $41-42$ & $88-89$ \\
\hline $\mathrm{U}$ & 2.9 & 6 & Plag, Opx, Mnt, Ilm & $\mathrm{n} / \mathrm{d}$ & $41-50(43 \pm 2)$ & $\mathrm{n} / \mathrm{a}$ & $41-43$ & $89-90$ \\
\hline $\mathrm{V}$ & 2.8 & 7 & Plag, Opx, Mnt, Ilm & $32-52(36 \pm 4)$ & $38-61(41 \pm 3)$ & $\mathrm{n} / \mathrm{a}$ & $41-43$ & $89-91$ \\
\hline$\underline{\mathrm{W}}$ & 2.8 & 5.5 & Plag, Opx, Mnt, Ilm & $31-51(39 \pm 5)$ & $37-55(43 \pm 3)$ & $\mathrm{n} / \mathrm{a}$ & $40-43$ & $89-91$ \\
\hline \multicolumn{4}{|c|}{ Subgroup 3 rhyolites } & Plag An. \% & Opx Mg\# & Cpx Mg\# & Mnt & Ilm \\
\hline $\mathrm{X}$ & 2.2 & 4 & Plag, Opx, Mnt, Ilm & $39-61(44 \pm 3)$ & $43-59(50 \pm 1)$ & $\mathrm{n} / \mathrm{a}$ & $37-38$ & $86-87$ \\
\hline Y1 & 1.8 & 3 & Plag, Opx, Mnt, Ilm & $39-51(45 \pm 2)$ & $43-59(50 \pm 1)$ & $\mathrm{n} / \mathrm{a}$ & $38-39$ & $86-88$ \\
\hline Y3 & 1.8 & 2.5 & Plag, Opx, Mnt, Ilm & $39-61(45 \pm 3)$ & $44-57(50 \pm 2)$ & $\mathrm{n} / \mathrm{a}$ & $38-40$ & $85-89$ \\
\hline Y6 & 1.8 & 2.5 & Plag, Opx, Mnt, Ilm & $39-69(46 \pm 4)$ & $43-68(50 \pm 2)$ & $\mathrm{n} / \mathrm{a}$ & $37-38$ & $86-88$ \\
\hline $\mathrm{Z}$ & 1.8 & 5.5 & Plag, Opx, Mnt, Ilm & $39-81(46 \pm 4)$ & $45-61(51 \pm 2)$ & $\mathrm{n} / \mathrm{a}$ & $40-42$ & $88-89$ \\
\hline$Z_{\text {mafic }}$ & 1.8 & $\mathrm{n} / \mathrm{d}$ & Plag, Opx, Olivine, Mnt & $\mathrm{n} / \mathrm{d}$ & $\mathrm{n} / \mathrm{d}$ & $\mathrm{n} / \mathrm{d}$ & $\mathrm{n} / \mathrm{d}$ & $\mathrm{n} / \mathrm{d}$ \\
\hline
\end{tabular}

Mineral contents calculated by heavy liquid glass and mineral separation. Lava mineral \% determined by point counting. Compositions determined by electron microprobe analysis (EPMA). For Plagioclase feldspar (Plag), Anorthite content $(\mathrm{An})=100 *(\mathrm{Ca} / \mathrm{Ca}+\mathrm{Na}+\mathrm{K})$. For Orthopyroxene $(\mathrm{Opx})$ and Clinopyroxene $(\mathrm{Cpx})$, magnesium number $(\mathrm{Mg} \#)=100 *(\mathrm{Mg} / \mathrm{Mg}+\mathrm{Fe}+\mathrm{Mn})$. All amphibole (Amp) is magnesiohorblende. Magnetite (Mnt) and Ilmenite (Ilm) compositions calculated by methods of Lepage (2003). Mineral compositional ranges include all EPMA analyses of multiple zones within multiple crystals (see Appendix J for raw data). Crystal rim compositions on euhedral shaped grains are inferred to represent the final stages of crystal growth and hence equilibrium composition with the final melt. Crystal concentrations marked with * are from coarse ash or fine lapilli samples and therefore are not deemed to be fully representative of the magma (see text for discussion). 
crystals are typically 1-2 $\mathrm{mm}$ in size, but can reach up to $1 \mathrm{~cm}$ long. In contrast, the first rhyolites in subgroup (SG) 1, units B and C, are generally crystal-poor, with $<5-7$ wt. $\%$ crystals (Table 5.2). Similar mineral phases to those observed in the dacites are present, but only minor clinopyroxene along with additional minor amphibole. Glomerocrysts are rare, and minerals are typically found as euhedral to subhedral $<1-2 \mathrm{~mm}$ single crystals. For the other eruptions in SG1 (units D and E) clinopyroxene and amphibole become increasingly rare, found at only trace amounts in Unit E where these crystal phases are small $(<1 \mathrm{~mm})$, and notably subhedral to anhedral. Lava from the Unit D dome has a slightly higher crystal content $(\sim 8 \%)$, with more common glomerocrysts along with microlite rich glass. For the remaining eruptions in SG2 and SG3, all pumices and lavas are generally crystal poor (typically $<5$ wt. \%), with mineral phases restricted to plagioclase, orthopyroxene, ilmenite and magnetite. Clinopyroxene is observed only in mixed grey pumice, scoria, or mafic inclusions found in Unit S and lava from eruption $\mathrm{Z}$, along with plagioclase, orthopyroxene, magnetite and minor olivine (Table 5.2).

\subsubsection{Whole rock major and trace element compositions}

As highlighted by Sutton et al. (2000), the post-Oruanui eruption subgroups can be distinguished by subtly different trends in whole-rock chemistry and Sr isotope composition through time. The overall major-element compositional range of pumice, lava and mafic clasts span a similar broad $\mathrm{SiO}_{2}$ range to that represented in the Oruanui eruption products (Figure 5.2a, Table 5.3). Mafic clasts and inclusions from products of eruptions $\mathrm{S}, \mathrm{Y}$ and $\mathrm{Z}$ are similar in their major element composition to the Oruanui tholeiitic basaltic-andesite to andesite clasts, and differ as such from the calcalkaline clasts which instead fall on a more similar trend to the Waimarino basalt (Figure 5.2a; Wilson et al., 2006; Allan et al., 2014). The post-Oruanui dacites fall between the composition of the mafic clasts and the rhyolitic pumice within a relatively narrow compositional range at $\sim 65 \% \mathrm{SiO}_{2}$, with only Unit A trending towards higher $\mathrm{SiO}_{2}$ due to the higher proportion of glass in the material sampled. The SG1 eruptions form separate linear trends to the other post-Oruanui eruptions on major element variation diagrams. The first SG1 product (Unit B) has the most evolved, and the last erupted (Unit E) the least evolved bulk composition, in agreement with the observed shift in mineralogy (Figure 5.2b, Table 5.3). Pumice compositions do not vary significantly with vent position and are identical within eruptive subunits that had a geographical shift in vent site (e.g. units B1-B3 and E1-E3). SG2 rhyolites have slightly higher $\mathrm{SiO}_{2}$ 

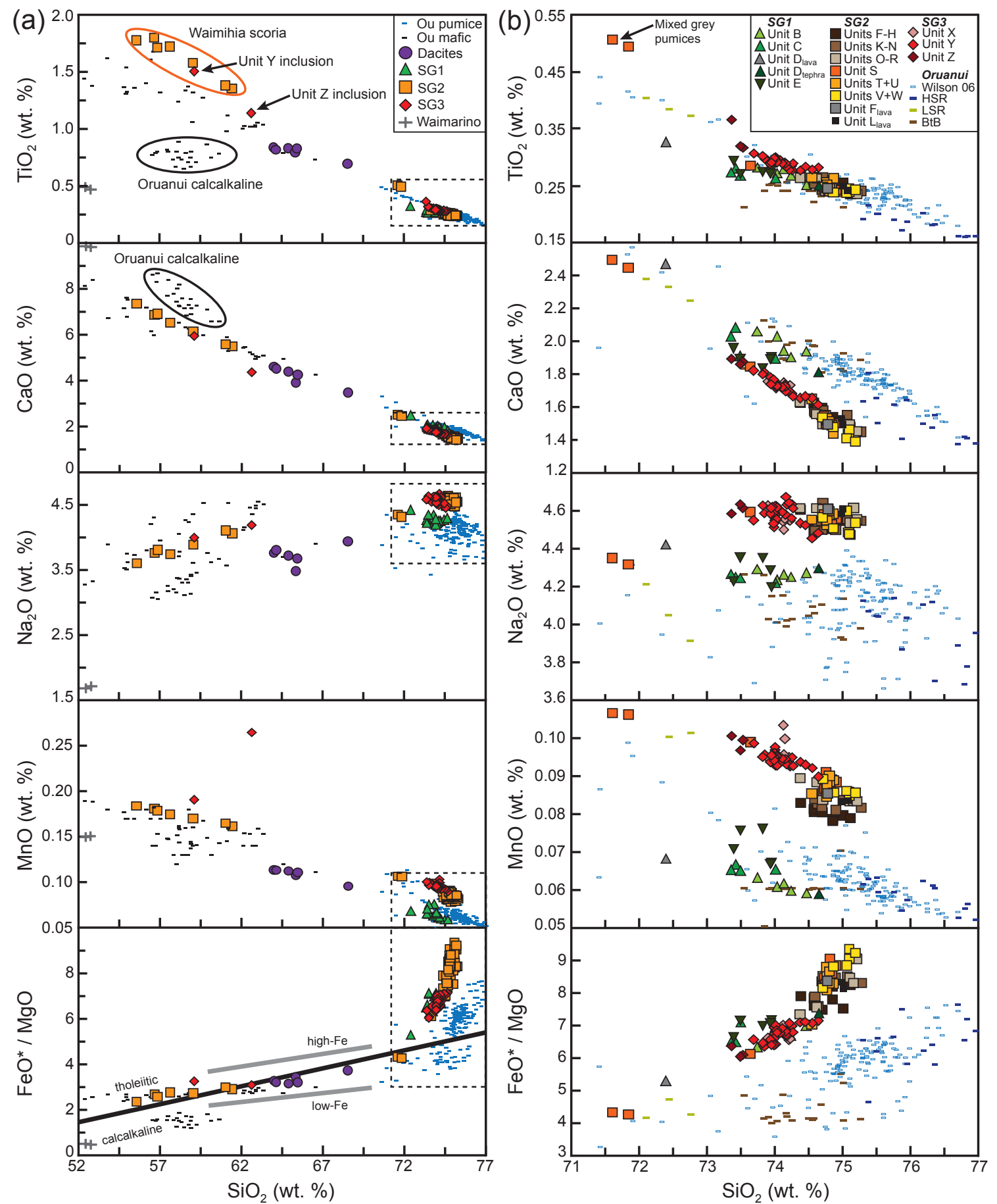

Figure 5.2. Selected major element variation diagrams for eruptive material from Taupo and Waimarino. a) Full compositional range of pumice, lava and scoria. Oruanui data is combined from Wilson et al. (2006) and Allan et al. (2014). Grey boundaries on $\mathrm{FeO} * \mathrm{MgO}$ are from Arculus (2003), and the solid black line marks the discriminant boundary from Miyashiro (1974). b) Close up of regions marked by dashed black box in (a) with symbols split by eruptions or groups. Filled Oruanui symbols are pumice types identified by Allan et al. (2014) where HSR is high-silica rhyolite, LSR is low-silica rhyolite and $\mathrm{BtB}$ is biotite-bearing. All values are recalculated based on oxide totals normalised to $100 \%$. See Appendix $\mathrm{G}$ for raw data, original totals and CHAPTER 3 for standards. 
Table 5.3. Representative major and trace element compositions of post-Oruanui eruptive units \begin{tabular}{lllllllllllll}
\hline Unit & $\Psi$ & $\Omega$ & A & B1 & C & D (L) & D (t) & E3 & $F(L)$ & $F(t)$ & $G$
\end{tabular} Sample P2163A P2112A P2147 P2116C P2142A R837 P2144 P2148E P2256 P2256A P2115A \begin{tabular}{llllllllllll} 
Age BP & 20500 & 18800 & 17000 & 11820 & 11420 & 11400 & 11400 & 9970 & 7070 & 7070 & 6670 \\
\hline
\end{tabular}

\section{Major elements (wt. \%)}

\begin{tabular}{lrrrrrrrrrrr}
\hline $\mathrm{SiO}_{2}$ & 64.00 & 64.89 & 68.55 & 74.24 & 73.42 & 72.39 & 74.65 & 73.94 & 74.78 & 74.86 & 74.58 \\
$\mathrm{TiO}_{2}$ & 0.84 & 0.83 & 0.70 & 0.27 & 0.28 & 0.33 & 0.25 & 0.27 & 0.24 & 0.26 & 0.26 \\
$\mathbf{A l}_{\mathbf{2}} \mathbf{O}_{3}$ & 16.77 & 16.18 & 14.86 & 13.67 & 14.26 & 14.34 & 13.47 & 14.01 & 13.24 & 13.30 & 13.50 \\
$\mathrm{Fe}_{\mathbf{2}} \mathbf{O}_{3}$ & 6.34 & 6.20 & 4.87 & 2.41 & 2.53 & 2.77 & 2.27 & 2.45 & 2.37 & 2.26 & 2.37 \\
$\mathrm{MnO}$ & 0.113 & 0.112 & 0.096 & 0.060 & 0.067 & 0.068 & 0.059 & 0.067 & 0.085 & 0.079 & 0.081 \\
$\mathbf{M g O}$ & 1.74 & 1.78 & 1.18 & 0.32 & 0.35 & 0.47 & 0.28 & 0.31 & 0.25 & 0.26 & 0.28 \\
$\mathbf{C a O}$ & 4.60 & 4.38 & 3.46 & 1.90 & 2.08 & 2.47 & 1.81 & 1.89 & 1.49 & 1.54 & 1.62 \\
$\mathrm{Na}_{\mathbf{2}} \mathbf{O}$ & 3.76 & 3.72 & 3.94 & 4.25 & 4.25 & 4.42 & 4.30 & 4.28 & 4.61 & 4.56 & 4.49 \\
$\mathbf{K}_{\mathbf{2}} \mathbf{O}$ & 1.74 & 1.81 & 2.21 & 2.84 & 2.72 & 2.67 & 2.87 & 2.74 & 2.86 & 2.85 & 2.77 \\
$\mathbf{P}_{\mathbf{2}} \mathbf{O}_{5}$ & 0.089 & 0.095 & 0.140 & 0.041 & 0.045 & 0.071 & 0.037 & 0.039 & 0.063 & 0.031 & 0.041 \\
LOI & 2.98 & 3.01 & 3.07 & 3.38 & 3.71 & 0.7 & 2.71 & 3.56 & 0.33 & 1.3 & 3.28 \\
Total & 100.25 & 100.35 & 100.46 & 99.53 & 100.18 & 100.23 & 100.19 & 99.72 & 100.11 & 99.42 & 100.66
\end{tabular}

Trace elements (ppm)

\begin{tabular}{|c|c|c|c|c|c|c|c|c|c|c|c|}
\hline$\overline{\mathbf{L i}}$ & 23.4 & 24.7 & 28.0 & 32.7 & 36.6 & 40.5 & 35.5 & 48.3 & 22.1 & 43.3 & 32.5 \\
\hline Sc & 20.8 & 18.1 & 14.6 & 9.0 & 10.2 & 9.8 & 9.3 & 10.3 & 11.4 & 10.7 & 11.0 \\
\hline $\mathbf{V}$ & 127.04 & 125.25 & 76.74 & 9.38 & 11.57 & 16.41 & 8.76 & 7.83 & 2.18 & 2.98 & 3.12 \\
\hline $\mathrm{Cr}$ & 11.29 & 9.82 & 9.62 & 7.67 & 4.16 & 6.74 & 7.53 & 26.10 & 9.20 & 2.23 & 4.64 \\
\hline $\mathbf{N i}$ & 10.92 & 10.01 & 8.71 & 8.49 & 7.77 & 4.63 & 7.27 & 1.00 & 9.74 & 0.16 & 8.72 \\
\hline $\mathrm{Cu}$ & 3.40 & 5.09 & 3.43 & 2.07 & 2.18 & 3.07 & 2.07 & 1.76 & 1.75 & 1.24 & 1.63 \\
\hline $\mathrm{Zn}$ & 82 & 87 & 74 & 53 & 58 & 61 & 55 & 57 & 71 & 67 & 69 \\
\hline $\mathbf{G a}$ & 20.7 & 18.6 & 17.8 & 15.8 & 17.3 & 16.4 & 17.2 & 17.0 & 17.2 & 17.7 & 16.6 \\
\hline $\mathbf{R b}$ & 66 & 63 & 76 & 98 & 106 & 95 & 112 & 106 & 102 & 109 & 102 \\
\hline $\mathrm{Sr}$ & 258 & 237 & 196 & 135 & 159 & 169 & 142 & 154 & 131 & 141 & 145 \\
\hline$Y$ & 24.5 & 21.7 & 27.7 & 29.5 & 32.3 & 28.6 & 31.3 & 32.9 & 32.6 & 33.0 & 33.5 \\
\hline $\mathrm{Zr}$ & 202 & 180 & 218 & 190 & 205 & 195 & 211 & 216 & 213 & 226 & 216 \\
\hline Nb & 7.79 & 7.66 & 8.71 & 8.20 & 9.31 & 8.71 & 9.10 & 8.46 & 9.83 & 9.25 & 9.89 \\
\hline Cs & 2.89 & 3.00 & 3.64 & 4.31 & 4.50 & 4.28 & 4.53 & 5.53 & 4.11 & 5.65 & 4.12 \\
\hline $\mathrm{Ba}$ & 466 & 432 & 490 & 598 & 671 & 585 & 654 & 646 & 641 & 648 & 622 \\
\hline La & 18.6 & 16.8 & 20.3 & 22.2 & 24.4 & 22.8 & 25.4 & 25.1 & 24.9 & 26.0 & 25.0 \\
\hline $\mathrm{Ce}$ & 45.4 & 42.1 & 43.1 & 47.4 & 53.1 & 49.2 & 53.8 & 54.3 & 54.1 & 54.0 & 56.2 \\
\hline Pr & 4.55 & 4.22 & 5.26 & 5.64 & 6.28 & 5.83 & 6.33 & 6.31 & 6.43 & 6.53 & 6.50 \\
\hline Nd & 18.3 & 17.2 & 21.1 & 21.4 & 23.3 & 23.3 & 24.5 & 24.5 & 24.8 & 25.4 & 26.0 \\
\hline Sm & 4.19 & 3.82 & 4.62 & 4.74 & 5.00 & 4.84 & 5.21 & 5.43 & 5.55 & 5.67 & 5.56 \\
\hline Eu & 1.17 & 1.09 & 1.13 & 0.99 & 1.17 & 1.18 & 1.11 & 1.10 & 1.28 & 1.28 & 1.26 \\
\hline Gd & 4.27 & 3.83 & 4.98 & 4.83 & 5.37 & 5.03 & 5.37 & 5.92 & 5.59 & 5.79 & 5.72 \\
\hline Tb & 0.66 & 0.58 & 0.77 & 0.77 & 0.81 & 0.82 & 0.86 & 0.86 & 0.83 & 0.89 & 0.92 \\
\hline Dy & 4.27 & 3.79 & 4.78 & 4.91 & 5.37 & 5.08 & 5.30 & 5.46 & 5.77 & 5.55 & 5.68 \\
\hline Ho & 0.88 & 0.78 & 0.93 & 0.98 & 1.13 & 1.07 & 1.10 & 1.17 & 1.09 & 1.16 & 1.16 \\
\hline Er & 2.56 & 2.41 & 2.78 & 3.21 & 3.33 & 3.20 & 3.37 & 3.38 & 3.34 & 3.41 & 3.62 \\
\hline Tm & 0.40 & 0.34 & 0.44 & 0.48 & 0.50 & 0.48 & 0.51 & 0.51 & 0.53 & 0.52 & 0.54 \\
\hline Yb & 2.62 & 2.42 & 3.06 & 3.07 & 3.23 & 3.02 & 3.33 & 3.52 & 3.56 & 3.48 & 3.38 \\
\hline Lu & 0.41 & 0.37 & 0.44 & 0.47 & 0.50 & 0.48 & 0.52 & 0.55 & 0.52 & 0.52 & 0.56 \\
\hline Hf & 5.38 & 4.63 & 5.53 & 5.36 & 5.71 & 5.25 & 5.67 & 6.04 & 5.77 & 6.06 & 5.86 \\
\hline Pb & 10.8 & 11.7 & 21.7 & 15.4 & 16.4 & 12.0 & 15.5 & 18.6 & 12.5 & 21.2 & 17.4 \\
\hline Th & 8.1 & 7.1 & 7.7 & 10.3 & 11.0 & 10.9 & 11.2 & 11.7 & 10.7 & 11.1 & 11.1 \\
\hline $\mathbf{U}$ & 1.62 & 1.57 & 1.85 & 2.38 & 2.52 & 2.39 & 2.65 & 2.68 & 2.53 & 2.51 & 2.54 \\
\hline $\mathrm{Rb} / \mathrm{Sr}$ & 0.26 & 0.26 & 0.39 & 0.73 & 0.67 & 0.56 & 0.79 & 0.69 & 0.78 & 0.77 & 0.70 \\
\hline Eu/Eu* & 0.84 & 0.87 & 0.72 & 0.63 & 0.69 & 0.73 & 0.64 & 0.59 & 0.70 & 0.68 & 0.68 \\
\hline
\end{tabular}

Oxide abundances normalised to $100 \%$ on a volatile free basis, with original analytical totals and LOI given. Eruption ages are given in years before present and sourced from Wilson (1993) and Hogg et al. (2012). Units denoted with (L) are lavas and (t) are tephras for the corresponding unit. Wai is Waimarino basalt. The full list of samples are presented in Appendix $\mathrm{G}$ and $\mathrm{H}$. Analytical standards are presented in CHAPTER 3. 
Table 5.3. Continued

\begin{tabular}{lccccccccccc}
\hline Unit & $\mathrm{H}$ & $\mathrm{K}$ & $\mathrm{L}(\mathrm{L})$ & $\mathrm{L}(\mathrm{t})$ & $\mathrm{M}$ & $\mathrm{N}$ & $\mathrm{O}$ & $\mathrm{P}$ & $\mathrm{Q}$ & $\mathrm{R}$ & $\mathrm{S}$ \\
Sample & $\mathrm{P} 2132$ & $\mathrm{P} 2206 \mathrm{~A}$ & $\mathrm{R} 602$ & $\mathrm{P} 2137$ & $\mathrm{P} 2171$ & $\mathrm{P} 2170$ & $\mathrm{P} 2169 \mathrm{~A}$ & $\mathrm{P} 2168 \mathrm{~A}$ & $\mathrm{P} 2136$ & $\mathrm{P} 2114$ & $\mathrm{P} 2209$ \\
Age BP & 6070 & 5370 & 5320 & 5320 & 5270 & 4870 & 4820 & 4770 & 4570 & 4470 & 3570 \\
\hline
\end{tabular}

Major elements (wt. \%)

\begin{tabular}{lrrrrrrrrrrr}
\hline $\mathbf{S i O}_{2}$ & 75.12 & 74.70 & 75.01 & 74.71 & 75.28 & 75.07 & 74.38 & 75.11 & 75.22 & 74.71 & 74.82 \\
$\mathrm{TiO}_{2}$ & 0.23 & 0.24 & 0.25 & 0.26 & 0.24 & 0.24 & 0.26 & 0.24 & 0.23 & 0.25 & 0.24 \\
$\mathbf{A l}_{2} \mathbf{O}_{3}$ & 13.27 & 13.55 & 13.11 & 13.21 & 13.03 & 13.13 & 13.47 & 13.13 & 13.07 & 13.40 & 13.29 \\
$\mathrm{Fe}_{\mathbf{2}} \mathbf{O}_{3}$ & 2.24 & 2.26 & 2.30 & 2.40 & 2.23 & 2.27 & 2.42 & 2.31 & 2.26 & 2.34 & 2.35 \\
$\mathrm{MnO}_{\mathbf{M g O}}$ & 0.079 & 0.082 & 0.084 & 0.086 & 0.082 & 0.084 & 0.089 & 0.083 & 0.083 & 0.084 & 0.087 \\
$\mathbf{M g O}$ & 0.24 & 0.24 & 0.25 & 0.26 & 0.24 & 0.24 & 0.30 & 0.24 & 0.22 & 0.25 & 0.23 \\
$\mathbf{C a O}$ & 1.48 & 1.55 & 1.49 & 1.58 & 1.45 & 1.55 & 1.63 & 1.49 & 1.45 & 1.50 & 1.50 \\
$\mathrm{Na}_{\mathbf{2}} \mathbf{O}$ & 4.47 & 4.50 & 4.61 & 4.64 & 4.55 & 4.56 & 4.61 & 4.54 & 4.55 & 4.61 & 4.55 \\
$\mathrm{~K}_{\mathbf{2}} \mathbf{O}$ & 2.83 & 2.82 & 2.85 & 2.81 & 2.87 & 2.81 & 2.80 & 2.83 & 2.87 & 2.82 & 2.88 \\
$\mathbf{P}_{\mathbf{2}} \mathbf{O}_{5}$ & 0.035 & 0.048 & 0.041 & 0.034 & 0.032 & 0.036 & 0.044 & 0.033 & 0.031 & 0.041 & 0.044 \\
LOI & 3.42 & 3.23 & 0.45 & 1.1 & 2.67 & 2.22 & 2.26 & 1.91 & 1.4 & 2.75 & 2.87 \\
Total & 100.38 & 100.05 & 99.87 & 100.63 & 100.28 & 100.65 & 99.95 & 100.44 & 100.30 & 99.71 & 99.75
\end{tabular}

Trace elements (ppm)

\begin{tabular}{|c|c|c|c|c|c|c|c|c|c|c|c|}
\hline$\overline{L i}$ & 34.1 & 40.2 & 41.2 & 39.8 & 43.7 & 40.1 & 44.3 & 36.1 & 35.7 & 40.0 & 38.9 \\
\hline Sc & 10.3 & 10.7 & 11.0 & 11.6 & 11.0 & 10.8 & 11.7 & 10.8 & 10.9 & 11.0 & 11.0 \\
\hline $\mathbf{V}$ & 2.35 & 2.26 & 1.91 & 2.17 & 1.83 & 1.74 & 2.45 & 1.82 & 1.54 & 2.07 & 1.79 \\
\hline $\mathrm{Cr}$ & 3.55 & 3.69 & 2.56 & 0.25 & 2.35 & 4.34 & 3.19 & 0.32 & 0.31 & 1.85 & 5.48 \\
\hline $\mathbf{N i}$ & 0.31 & 0.75 & 0.14 & 0.06 & 0.24 & 0.20 & 0.37 & 0.45 & 0.23 & 0.29 & 0.22 \\
\hline $\mathrm{Cu}$ & 1.25 & 1.52 & 1.13 & 1.05 & 1.34 & 1.24 & 1.37 & 1.15 & 1.17 & 1.84 & 1.36 \\
\hline $\mathrm{Zn}$ & 62 & 68 & 68 & 72 & 69 & 67 & 76 & 68 & 69 & 68 & 70 \\
\hline $\mathbf{G a}$ & 15.7 & 16.8 & 16.1 & 17.6 & 17.2 & 16.0 & 16.7 & 16.2 & 16.0 & 16.5 & 16.9 \\
\hline $\mathbf{R b}$ & 101 & 105 & 104 & 107 & 110 & 104 & 108 & 106 & 103 & 102 & 104 \\
\hline $\mathrm{Sr}$ & 127 & 140 & 130 & 147 & 133 & 138 & 156 & 136 & 125 & 135 & 135 \\
\hline $\mathbf{Y}$ & 32.2 & 32.9 & 33.2 & 33.6 & 34.5 & 32.6 & 34.8 & 33.3 & 32.4 & 33.2 & 32.7 \\
\hline $\mathrm{Zr}$ & 203 & 212 & 213 & 225 & 221 & 213 & 226 & 222 & 218 & 223 & 220 \\
\hline Nb & 7.96 & 9.08 & 9.07 & 11.99 & 9.23 & 8.92 & 8.90 & 8.46 & 8.40 & 8.46 & 11.18 \\
\hline Cs & 5.41 & 5.58 & 5.28 & 4.95 & 5.71 & 5.05 & 5.00 & 5.54 & 5.39 & 5.19 & 4.96 \\
\hline $\mathrm{Ba}$ & 620 & 631 & 633 & 629 & 665 & 602 & 658 & 642 & 622 & 630 & 620 \\
\hline La & 24.7 & 25.6 & 25.6 & 25.3 & 26.6 & 24.6 & 26.8 & 25.7 & 25.4 & 25.5 & 25.1 \\
\hline $\mathrm{Ce}$ & 52.7 & 53.0 & 54.7 & 53.1 & 56.1 & 51.4 & 57.1 & 55.4 & 54.5 & 54.6 & 55.7 \\
\hline Pr & 6.25 & 6.57 & 6.53 & 6.53 & 6.81 & 6.04 & 6.86 & 6.56 & 6.42 & 6.51 & 6.65 \\
\hline Nd & 24.5 & 25.3 & 25.6 & 25.7 & 25.9 & 24.4 & 26.3 & 25.1 & 24.6 & 25.6 & 26.1 \\
\hline Sm & 5.28 & 5.59 & 5.35 & 5.38 & 5.64 & 5.25 & 5.77 & 5.53 & 5.43 & 5.61 & 5.61 \\
\hline Eu & 1.19 & 1.23 & 1.24 & 1.27 & 1.29 & 1.26 & 1.35 & 1.27 & 1.21 & 1.29 & 1.22 \\
\hline Gd & 5.72 & 6.06 & 5.59 & 5.74 & 6.15 & 5.53 & 6.32 & 6.36 & 5.88 & 6.24 & 5.83 \\
\hline $\mathrm{Tb}$ & 0.84 & 0.87 & 0.86 & 0.86 & 0.90 & 0.83 & 0.93 & 0.89 & 0.86 & 0.91 & 0.87 \\
\hline Dy & 5.30 & 5.59 & 5.56 & 5.57 & 5.77 & 5.11 & 5.77 & 5.60 & 5.47 & 5.67 & 5.47 \\
\hline Ho & 1.13 & 1.13 & 1.13 & 1.15 & 1.19 & 1.06 & 1.23 & 1.19 & 1.15 & 1.19 & 1.16 \\
\hline Er & 3.36 & 3.30 & 3.46 & 3.45 & 3.51 & 3.20 & 3.57 & 3.49 & 3.34 & 3.46 & 3.38 \\
\hline Tm & 0.51 & 0.51 & 0.52 & 0.51 & 0.54 & 0.48 & 0.54 & 0.53 & 0.51 & 0.53 & 0.51 \\
\hline Yb & 3.38 & 3.45 & 3.38 & 3.44 & 3.62 & 3.18 & 3.59 & 3.50 & 3.41 & 3.51 & 3.57 \\
\hline Lu & 0.52 & 0.51 & 0.52 & 0.52 & 0.53 & 0.48 & 0.55 & 0.53 & 0.52 & 0.53 & 0.51 \\
\hline Hf & 5.58 & 5.54 & 5.80 & 5.92 & 5.88 & 5.32 & 6.03 & 5.95 & 5.79 & 6.05 & 5.91 \\
\hline $\mathrm{Pb}$ & 16.9 & 20.6 & 20.6 & 24.1 & 21.5 & 19.4 & 19.3 & 17.2 & 16.6 & 17.5 & 23.4 \\
\hline Th & 10.8 & 11.0 & 10.8 & 10.7 & 11.5 & 9.9 & 11.2 & 10.9 & 10.6 & 10.9 & 10.7 \\
\hline $\mathbf{U}$ & 2.41 & 2.46 & 2.49 & 2.43 & 2.57 & 2.23 & 2.48 & 2.52 & 2.42 & 2.48 & 2.39 \\
\hline $\mathrm{Rb} / \mathrm{Sr}$ & 0.79 & 0.75 & 0.80 & 0.73 & 0.83 & 0.75 & 0.69 & 0.78 & 0.82 & 0.76 & 0.77 \\
\hline Eu/Eu* & 0.66 & 0.65 & 0.69 & 0.70 & 0.67 & 0.71 & 0.68 & 0.68 & 0.66 & 0.67 & 0.65 \\
\hline
\end{tabular}

Oxide abundances normalised to $100 \%$ on a volatile free basis, with original analytical totals and LOI given. Eruption ages are given in years before present and sourced from Wilson (1993) and Hogg et al. (2012). Units denoted with (L) are lavas and (t) are tephras for the corresponding unit. Wai is Waimarino basalt. The full list of samples are presented in Appendix $\mathrm{G}$ and H. Analytical standards are presented in CHAPTER 3. 
Table 5.3. Continued

\begin{tabular}{lccccccccccc}
\hline Unit & S mafic & $\mathrm{T}$ & $\mathrm{U}$ & $\mathrm{V}$ & $\mathrm{W}$ & $\mathrm{X}$ & $\mathrm{Y} 1$ & $\mathrm{Y} 3$ & $\mathrm{Y} 7$ & $\mathrm{Z}$ & Wai \\
Sample & $\mathrm{P} 2202 \mathrm{~A}$ & $\mathrm{P} 2149 \mathrm{~A}$ & $\mathrm{P} 2150 \mathrm{~A}$ & $\mathrm{P} 2161 \mathrm{~A}$ & $\mathrm{P} 2155 \mathrm{~B}$ & $\mathrm{P} 2157 \mathrm{~A}$ & $\mathrm{P} 2119$ & $\mathrm{P} 2293$ & $\mathrm{P} 2287$ & $\mathrm{P} 2173 \mathrm{~A}$ & $\mathrm{R} 834$ \\
Age BP & 3570 & 3220 & 2870 & 2820 & 2770 & 2170 & 1790 & 1790 & 1790 & 1760 & $<25400$ \\
\hline
\end{tabular}

\section{Major elements (wt. \%)}

\begin{tabular}{lrrrrrrrrrrr}
\hline $\mathbf{S i O}_{2}$ & 55.57 & 74.77 & 74.76 & 74.71 & 75.06 & 74.21 & 74.38 & 74.02 & 73.99 & 73.53 & 52.75 \\
$\mathrm{TiO}_{2}$ & 1.78 & 0.26 & 0.25 & 0.25 & 0.24 & 0.28 & 0.28 & 0.29 & 0.29 & 0.32 & 0.47 \\
$\mathbf{A l}_{2} \mathbf{O}_{3}$ & 15.99 & 13.35 & 13.34 & 13.32 & 13.11 & 13.48 & 13.45 & 13.57 & 13.53 & 13.67 & 12.69 \\
$\mathrm{Fe}_{\mathbf{2}} \mathbf{O}_{\mathbf{3}}$ & 9.90 & 2.36 & 2.34 & 2.35 & 2.28 & 2.51 & 2.43 & 2.51 & 2.55 & 2.67 & 8.95 \\
$\mathbf{M n O}$ & 0.184 & 0.086 & 0.085 & 0.089 & 0.086 & 0.095 & 0.094 & 0.094 & 0.095 & 0.099 & 0.151 \\
$\mathbf{M g O}$ & 3.79 & 0.25 & 0.24 & 0.26 & 0.23 & 0.34 & 0.31 & 0.34 & 0.35 & 0.39 & 12.92 \\
$\mathbf{C a O}$ & 7.34 & 1.52 & 1.52 & 1.54 & 1.41 & 1.73 & 1.65 & 1.74 & 1.74 & 1.87 & 9.82 \\
$\mathrm{Na}_{\mathbf{2}} \mathbf{O}$ & 3.60 & 4.53 & 4.55 & 4.56 & 4.60 & 4.55 & 4.53 & 4.63 & 4.59 & 4.62 & 1.71 \\
$\mathbf{K}_{\mathbf{2}} \mathbf{O}$ & 1.04 & 2.85 & 2.88 & 2.88 & 2.94 & 2.76 & 2.83 & 2.76 & 2.80 & 2.75 & 0.44 \\
$\mathbf{P}_{\mathbf{2}} \mathbf{O}_{5}$ & 0.795 & 0.036 & 0.038 & 0.043 & 0.042 & 0.053 & 0.052 & 0.056 & 0.061 & 0.080 & 0.078 \\
LOI & 1.01 & 2.15 & 2.34 & 2.6 & 0.42 & 2.71 & 2.04 & 2.88 & 3.29 & 0.82 & 0.14 \\
Total & 99.02 & 99.32 & 98.90 & 99.14 & 99.00 & 99.56 & 99.20 & 99.81 & 99.79 & 99.49 & 99.96
\end{tabular}

Trace elements (ppm)

\begin{tabular}{|c|c|c|c|c|c|c|c|c|c|c|c|}
\hline$\overline{\mathrm{Li}}$ & 15.3 & 44.2 & 42.3 & 33.6 & 33.7 & 43.2 & 40.8 & 43.1 & 35.8 & 33.7 & 8.6 \\
\hline Sc & 31.1 & 11.5 & 11.5 & 10.2 & 10.1 & 11.3 & 11.4 & 11.6 & 11.7 & 11.7 & 34.2 \\
\hline $\mathbf{V}$ & 154.36 & 2.28 & 2.17 & 1.43 & 1.73 & 1.72 & 2.01 & 2.18 & 3.41 & 3.73 & 203.11 \\
\hline $\mathrm{Cr}$ & 13.95 & 2.30 & 1.90 & 2.34 & 2.69 & 1.96 & 1.92 & 3.40 & 16.53 & 4.63 & 745.22 \\
\hline $\mathbf{N i}$ & 10.28 & 0.15 & 0.12 & 0.20 & 0.26 & 0.17 & 0.19 & 0.13 & 0.22 & 0.32 & 302.44 \\
\hline $\mathrm{Cu}$ & 2.49 & 1.76 & 1.23 & 1.03 & 1.47 & 1.58 & 1.56 & 1.09 & 1.45 & 1.16 & 39.25 \\
\hline $\mathrm{Zn}$ & 104 & 71 & 72 & 65 & 63 & 72 & 72 & 75 & 74 & 74 & 70 \\
\hline $\mathbf{G a}$ & 20.4 & 17.1 & 16.8 & 15.1 & 15.2 & 16.9 & 16.8 & 17.6 & 16.7 & 16.6 & 13.6 \\
\hline $\mathbf{R b}$ & 33 & 108 & 105 & 96 & 100 & 104 & 103 & 104 & 101 & 94 & 11 \\
\hline $\mathrm{Sr}$ & 342 & 146 & 142 & 122 & 121 & 173 & 164 & 174 & 168 & 163 & 328 \\
\hline$Y$ & 24.9 & 34.5 & 34.6 & 31.0 & 31.5 & 34.7 & 34.3 & 34.9 & 33.7 & 31.5 & 11.4 \\
\hline $\mathrm{Zr}$ & 96 & 229 & 210 & 189 & 188 & 232 & 231 & 232 & 223 & 209 & 39 \\
\hline Nb & 5.33 & 9.84 & 9.75 & 7.72 & 7.95 & 9.73 & 12.65 & 4.02 & 12.47 & 7.95 & 2.24 \\
\hline Cs & 1.67 & 5.12 & 5.19 & 5.05 & 5.23 & 5.26 & 4.85 & 4.08 & 4.84 & 4.91 & 0.62 \\
\hline $\mathrm{Ba}$ & 253 & 658 & 650 & 571 & 588 & 637 & 621 & 611 & 615 & 578 & 106 \\
\hline La & 13.8 & 26.4 & 26.9 & 23.8 & 24.3 & 27.0 & 25.9 & 25.9 & 26.1 & 24.0 & 5.8 \\
\hline $\mathrm{Ce}$ & 32.3 & 57.2 & 56.8 & 51.2 & 52.7 & 58.2 & 55.0 & 55.7 & 55.3 & 52.4 & 11.9 \\
\hline Pr & 4.32 & 6.70 & 6.76 & 6.02 & 6.16 & 7.16 & 6.54 & 6.55 & 6.70 & 6.30 & 1.53 \\
\hline Nd & 19.3 & 27.0 & 26.2 & 23.4 & 23.9 & 27.1 & 26.1 & 26.7 & 26.4 & 24.6 & 6.5 \\
\hline Sm & 4.68 & 5.76 & 5.73 & 5.06 & 5.20 & 6.02 & 5.46 & 5.90 & 5.58 & 5.36 & 1.56 \\
\hline Eu & 1.58 & 1.30 & 1.32 & 1.14 & 1.17 & 1.38 & 1.26 & 1.33 & 1.35 & 1.31 & 0.51 \\
\hline Gd & 4.81 & 6.28 & 6.01 & 5.48 & 5.57 & 6.51 & 5.75 & 5.93 & 5.92 & 5.94 & 1.76 \\
\hline Tb & 0.74 & 0.92 & 0.92 & 0.81 & 0.84 & 0.96 & 0.87 & 0.94 & 0.91 & 0.87 & 0.29 \\
\hline Dy & 4.49 & 5.68 & 5.90 & 5.15 & 5.21 & 6.05 & 5.55 & 5.88 & 5.75 & 5.36 & 1.96 \\
\hline Ho & 0.91 & 1.18 & 1.24 & 1.08 & 1.11 & 1.26 & 1.16 & 1.24 & 1.19 & 1.13 & 0.43 \\
\hline Er & 2.54 & 3.59 & 3.60 & 3.14 & 3.27 & 3.60 & 3.55 & 3.74 & 3.48 & 3.30 & 1.25 \\
\hline Tm & 0.37 & 0.55 & 0.54 & 0.47 & 0.50 & 0.57 & 0.52 & 0.55 & 0.53 & 0.51 & 0.19 \\
\hline Yb & 2.27 & 3.64 & 3.57 & 3.12 & 3.26 & 3.81 & 3.40 & 3.70 & 3.42 & 3.32 & 1.23 \\
\hline Lu & 0.34 & 0.54 & 0.55 & 0.48 & 0.49 & 0.56 & 0.52 & 0.58 & 0.52 & 0.50 & 0.19 \\
\hline Hf & 2.64 & 6.17 & 5.82 & 4.97 & 5.17 & 6.32 & 5.99 & 6.26 & 6.02 & 5.56 & 1.20 \\
\hline $\mathbf{P b}$ & 9.7 & 22.1 & 22.7 & 15.5 & 16.6 & 23.1 & 21.5 & 21.1 & 22.4 & 16.0 & 3.0 \\
\hline Th & 3.8 & 11.4 & 11.2 & 9.6 & 10.2 & 11.2 & 10.7 & 11.0 & 10.8 & 9.8 & 1.6 \\
\hline U & 0.84 & 2.57 & 2.50 & 2.18 & 2.27 & 2.60 & 2.38 & 2.53 & 2.36 & 2.20 & 0.40 \\
\hline $\mathrm{Rb} / \mathrm{Sr}$ & 0.10 & 0.74 & 0.74 & 0.79 & 0.82 & 0.60 & 0.63 & 0.60 & 0.60 & 0.58 & 0.03 \\
\hline Eu/Eu* & 1.02 & 0.66 & 0.69 & 0.66 & 0.66 & 0.67 & 0.69 & 0.69 & 0.72 & 0.71 & 0.94 \\
\hline
\end{tabular}

Oxide abundances normalised to $100 \%$ on a volatile free basis, with original analytical totals and LOI given. Eruption ages are given in years before present and sourced from Wilson (1993) and Hogg et al. (2012). Units denoted with (L) are lavas and (t) are tephras for the corresponding unit. Wai is Waimarino basalt. The full list of samples are presented in Appendix $\mathrm{G}$ and $\mathrm{H}$. Analytical standards are presented in CHAPTER 3. 
than the SG1 rhyolites, and fall on distinctly different linear trends for many elements, most notably $\mathrm{MnO}, \mathrm{Na}_{2} \mathrm{O}$ and $\mathrm{CaO}$, and with higher $\mathrm{FeO} / \mathrm{MgO}$. In addition, some clasts from Unit $\mathrm{S}$ have slightly lower $\mathrm{SiO}_{2}$ and were noted for being mixed grey pumices or streaky pumices. SG3 rhyolites fall on similar linear trends to the SG2 rhyolites but with lower $\mathrm{SiO}_{2}$ and $\mathrm{FeO} / \mathrm{MgO}$ ratios, and higher $\mathrm{TiO}_{2}$ and $\mathrm{MnO}$.

Trace element data highlight distinct differences between the Oruanui and post Oruanui magmas (Figure 5.3a, Table 5.3). Trace element concentrations of the Unit S and $\mathrm{Z}$ mafic clasts confirm their close affinity to the Oruanui tholeiite mafic clasts, and mixed pumices or grey streaky pumices fall on a mixing trend between the mafic clasts and rhyolite pumices, as also observed in the Oruanui by Wilson et al. (2006). Rare Earth element (REE) patterns of the Unit S mafic clasts are identical to a subgroup of the tholeiitic Oruanui mafic material (Figure 5.3b). However, the Oruanui mafic suite also contain a population of clasts with significantly lower REE concentrations as well as positive Eu anomalies, indicating that more primitive melts with extensive plagioclase accumulation were involved in that eruption (Allan et al., 2014). The postOruanui rhyolites vary in their trace element compositions from the Oruanui HSR, generally having slightly higher $\mathrm{Sr}$ and $\mathrm{Zr}$, and also have lower light-REE (LREE) enrichments (Figure 5.3a, Table 5.3). The REE patterns of the post-Oruanui dacites are broadly parallel to the later erupted rhyolites, where SG2 and SG3 rhyolites show the most enriched REE patterns (Figure 5.3b). At a finer scale, there are small yet significant variations in trace element concentrations in the post-Oruanui eruption units over time (Figure 5.4). Differences between the dacites and the SG1 rhyolites are consistent with the dacites being less evolved and having higher crystal contents (Table 5.2), seen in the large in $\mathrm{Rb} / \mathrm{Sr}$ ratio and $\mathrm{V}$ concentration decrease between the dacites and rhyolites. Within the rhyolite subgroups, there are several time periods where trace element concentrations vary significantly. The largest variation is between the SG1 and SG2 rhyolites, with an increase in elements such as $\mathrm{Zn}, \mathrm{Zr}$ and Sc, and a minor decrease in the LREE and heavy-REE (HREE) enrichment. Towards the end of SG2, units V and $\mathrm{W}$ show an overall decrease in most compatible elements and higher $\mathrm{Rb} / \mathrm{Sr}$ ratios, and the SG2 to SG3 transition marks the opposite trend with an increase in concentrations of most compatible elements and lower $\mathrm{Rb} / \mathrm{Sr}$ ratios (Table 5.3).

\subsubsection{Glass and melt inclusion compositions}

To further investigate source variations and temporal changes in melt chemistry, melt inclusions in plagioclase and pyroxene and glass selvedges on the corresponding 


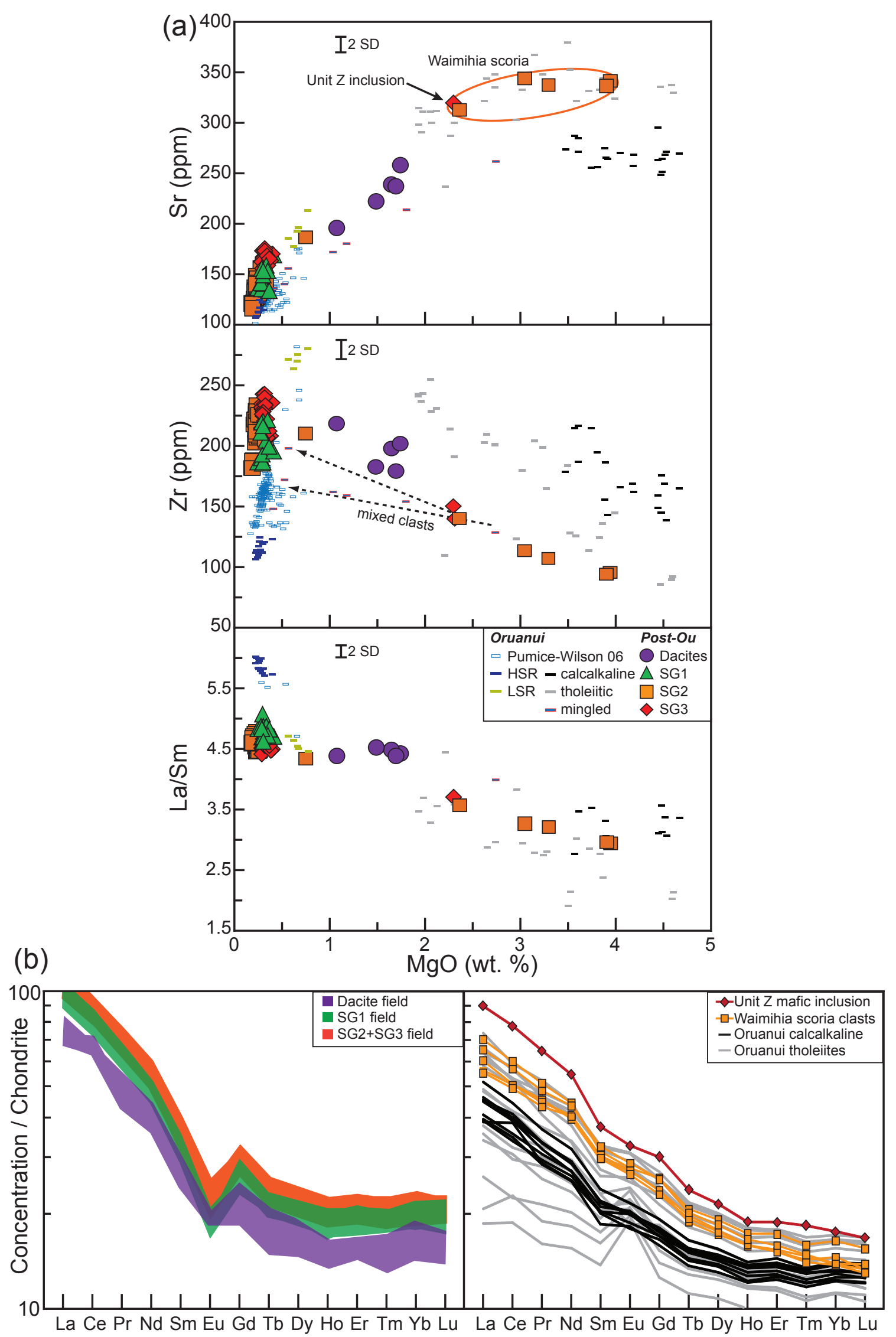

Figure 5.3. Trace element concentrations in Oruanui versus post-Oruanui pumice and mafic clasts. a) Variation diagrams of selected trace element concentrations versus $\mathrm{MgO}$ content. Oruanui data are from Wilson et al. (2006) and Allan et al. (2014). b) REE diagrams normalised to chondrite (Palme \& Beer, 1993), with Oruanui mafic clasts (right) from Allan et al. (2014). See Appendix H for raw data and CHAPTER 3 for standards. 


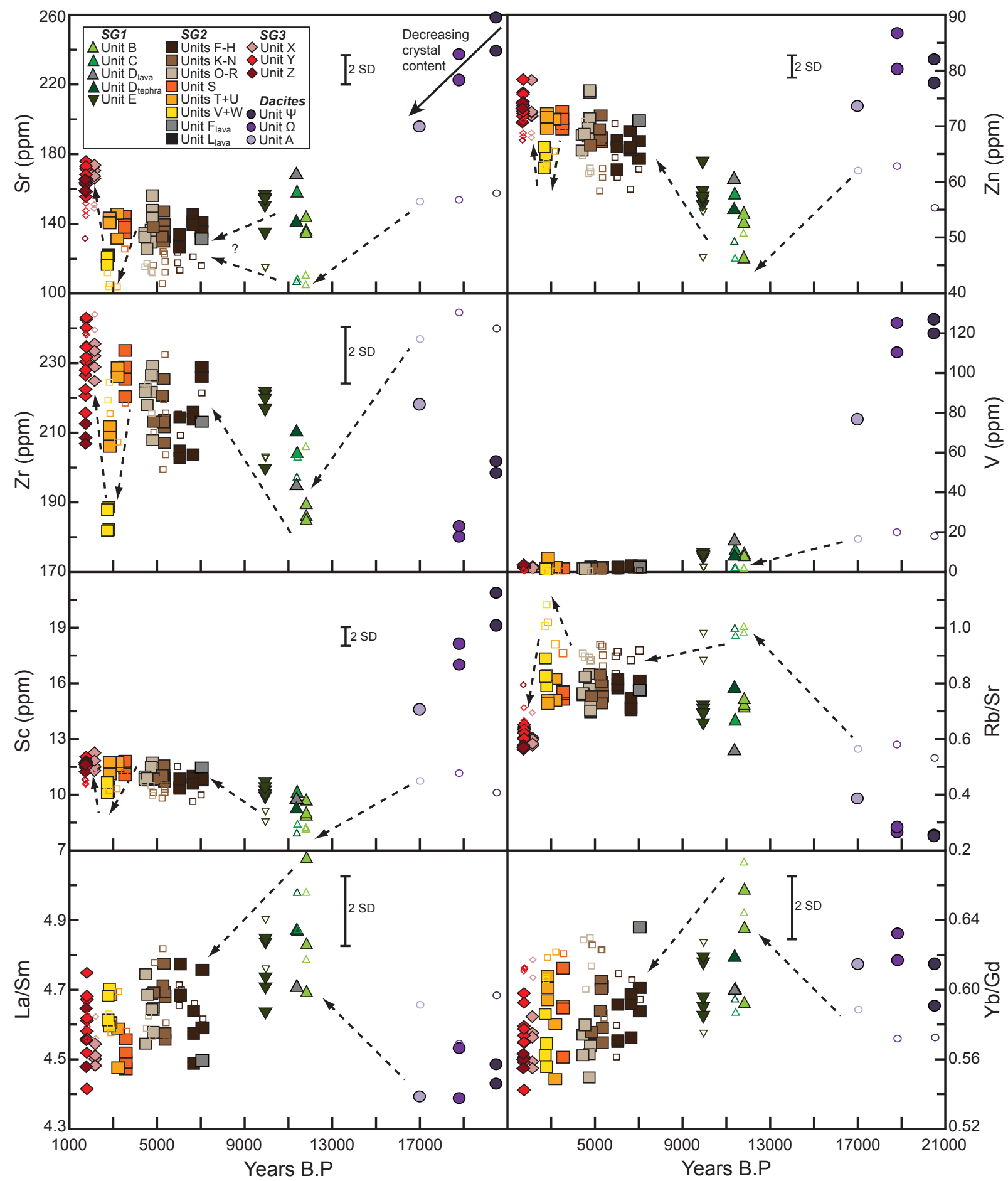

Figure 5.4. Trace element compositional ranges of bulk pumices and lavas (large filled symbols) compared to pure glass separates (small open symbols) from the post-Oruanui eruptions versus time. 2 SD analytical uncertainty is from repeated analyses of the Taupo ignimbrite secondary standard, but not shown for $\mathrm{V}$ or $\mathrm{Rb} / \mathrm{Sr}$ as it is approximately the size of the symbols. Dashed lines with arrows indicate the inferred direction of melt evolution with crystallisation or dissolution of the observed mineral phases through time. See text for discussion, Appendix $\mathrm{H}$ for raw data and CHAPTER 3 for standards. 
crystals were analysed for major elements. This was performed for all post-Oruanui eruptions apart from units I and $\mathrm{J}$ as their samples were too fine to yield reliable crystal separates and therefore individually picked glass shards were analysed instead for these two units. Crystals from the dacite units contain abundant melt inclusions up to $100 \mu \mathrm{m}$ in size, with compositions between $\sim 68-76 \mathrm{wt} . \% \mathrm{SiO}_{2}$ (Figure 5.5a). In contrast, glass selvedges from the dacites form a relatively narrow compositional field between 72-75 wt. $\% \mathrm{SiO}_{2}$ which broadly overlaps with the composition of LSR glass from the Oruanui eruption products. Melt inclusions from the dacites plot not only towards less evolved compositions than the selvedge glass, but a small number (mostly from Unit A) are slightly more evolved and have notably high $\mathrm{K}_{2} \mathrm{O}$ and low $\mathrm{CaO}$. Melt inclusions are less common and typically much smaller (mostly 10-30 $\mu \mathrm{m}$ ) in the SG1 rhyolite crystals, with compositions that overlap with the glass selvedge field from the dacites at $<75 \mathrm{wt}$. $\% \mathrm{SiO}_{2}$, and that extend towards the composition of SG1 glass selvedges at $\sim 75-77.5$ wt. $\% \mathrm{SiO}_{2}$ (Figure 5.5b). These melt inclusion compositions are similar to those of Oruanui plagioclase melt inclusions as reported by Allan et al. (2014), but are generally not as evolved as the Oruanui HSR pumice glass. Melt inclusions and glass selvedges in the SG2 rhyolites have a comparatively narrow range of compositions, with melt inclusions at $<75 \mathrm{wt}$. $\% \mathrm{SiO}_{2}$ being relatively rare (Figure 5.6a and $\mathrm{b}$ ). There are no measureable differences in glass chemistry within the SG2 rhyolites until the eruption units following Unit $\mathrm{S}$, where units $\mathrm{V}$ and $\mathrm{W}$ have the highest $\mathrm{SiO}_{2}$. Units $\mathrm{X}$ and $\mathrm{Y}$ from $\mathrm{SG} 3$, in contrast, show a decrease in the $\mathrm{SiO}_{2}$ of the glass selvedges to $\sim 75$ wt. $\% \mathrm{SiO}_{2}$, but with melt inclusions that overlap in composition with the earlier units. Unit $\mathrm{Z}$ glass forms a separate field at higher $\mathrm{SiO}_{2}$, but this figure is considered to reflect significant microlite growth of plagioclase and pyroxene during lava degassing and extrusion.

Pure glass separates were analysed in parallel with whole-rock samples for their trace element compositions to assess the effects of different crystal contents and phases between eruption groups and to investigate the evolution of the melt phase through time (Figure 5.4). Glasses from the dacites are significantly more evolved than the wholerock compositions and identical between the three eruption units, confirming that the differences in whole-rock compositions were due to relative crystal contents of the clasts analysed. Glass compositions from the rhyolite subgroups generally parallel many of the trends seen in whole-rock chemistry. The major exception is the SG1 rhyolites where the $\mathrm{Sr}$ concentration in the glass is significantly lower than that observed in the whole-rock, likely caused by high $\mathrm{Sr}$ abundances in plagioclase. As a result the whole- 

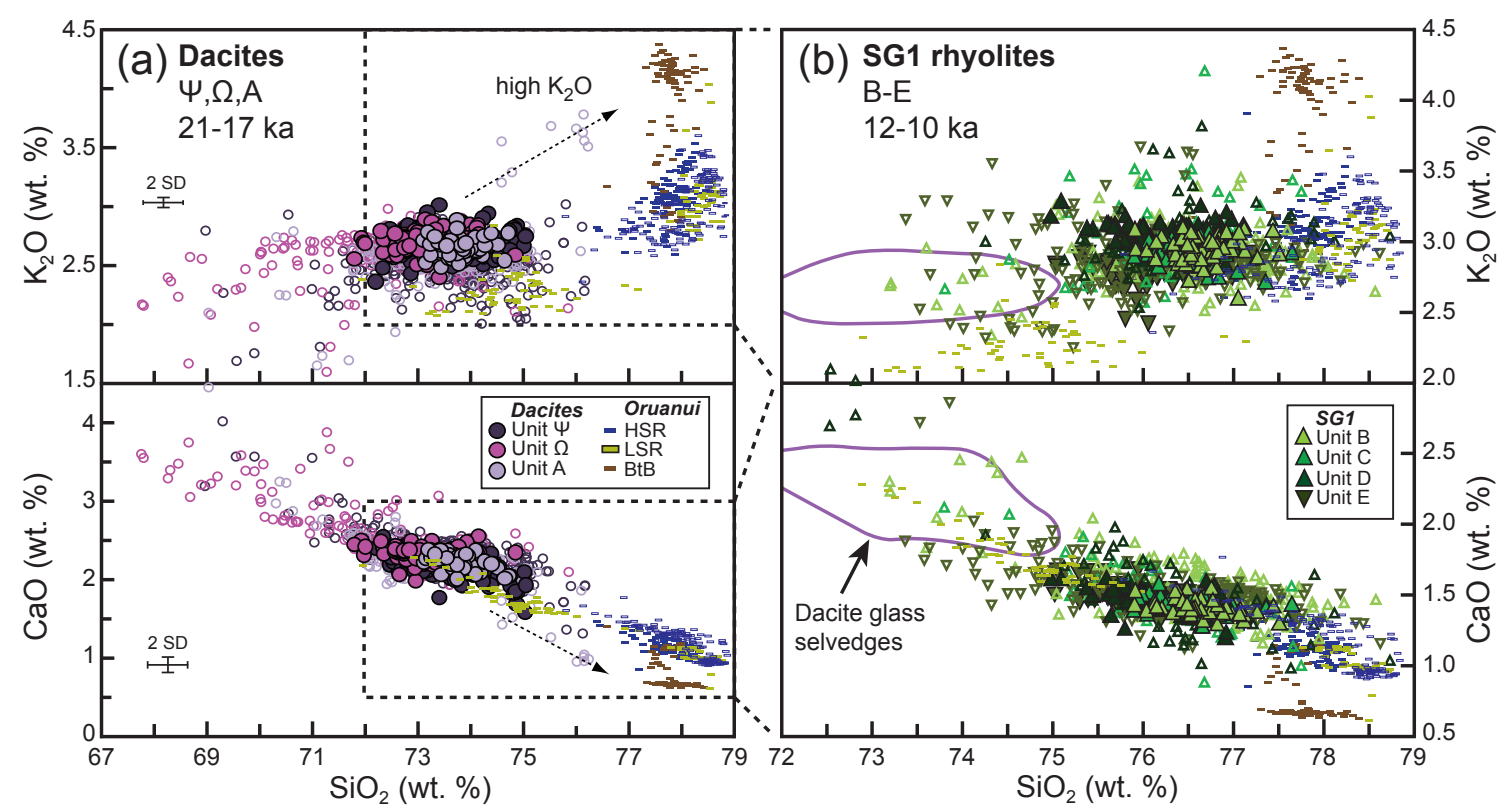

Figure 5.5. Major element variation diagrams showing the compositional range of melt inclusions (open symbols) and glass selvedges (filled symbols) from plagioclase and pyroxenes from a) dacite units $\Psi, \Omega$ and A and b) SG1 units B-E. Oruanui glass (filled symbols) and melt inclusion data (open symbols) from Allan et al. (2014) are shown for comparison. Dashed box in (a) refers to the enlarged area shown in (b) for reference. All data are normalised to $100 \%$ on a volatile-free basis. See Appendix I for raw data and CHAPTER 3 for standards.

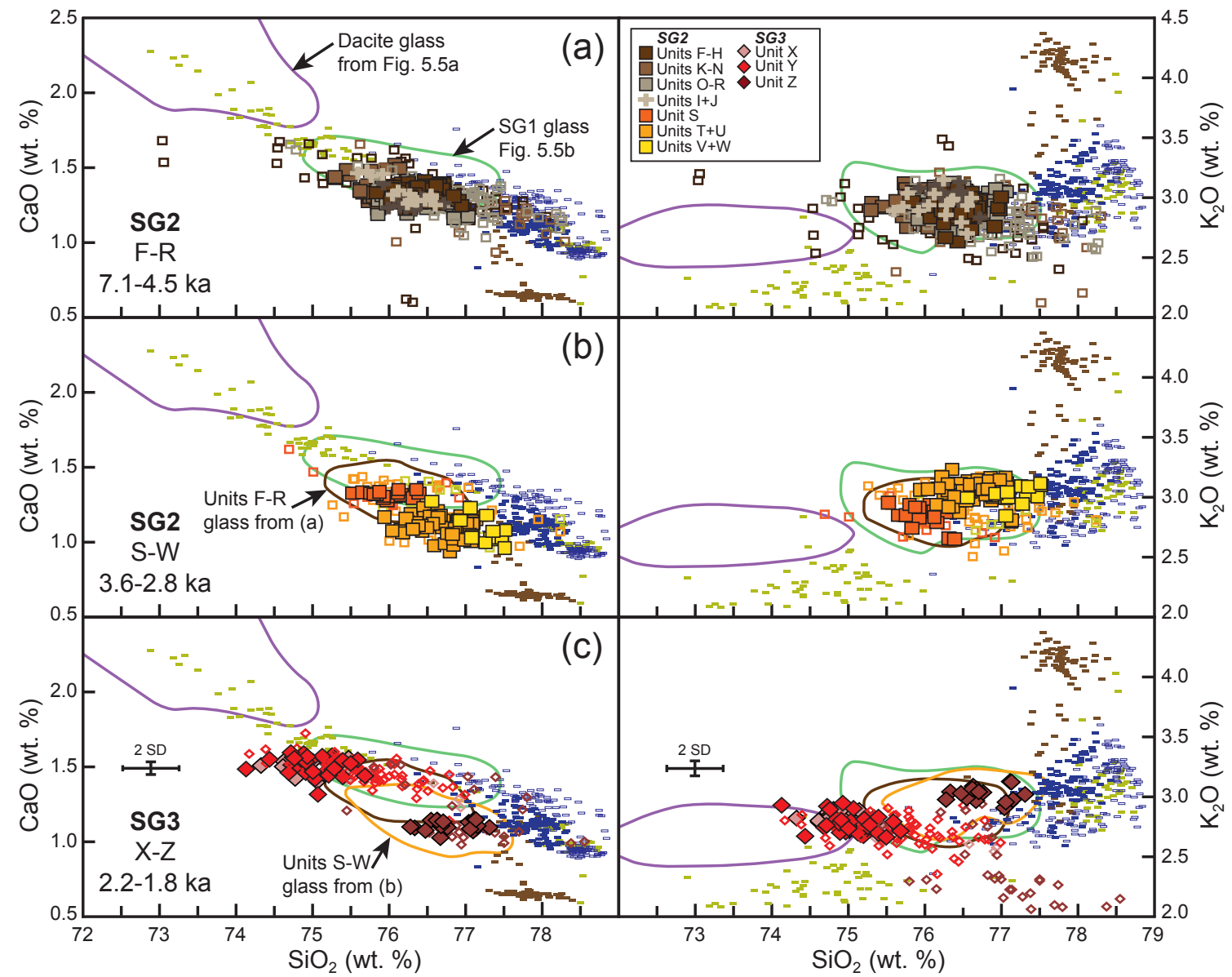

Figure 5.6. Major element variation diagrams showing the compositional range of melt inclusions (open symbols) and glass selvedges (filled symbols) from plagioclase and pyroxenes from a) Subgroup (SG) 2 units F-R, b) SG2 units S-W and c) SG3 units X, Y and Z. Only matrix glass was analysed for units I and $\mathrm{J}$ as they are too fine grained to obtain reliable mineral separates. All other details as in Figure 5.5. 
rock and glass $\mathrm{Rb} / \mathrm{Sr}$ trends from SG1 to SG2 rhyolites show opposite trends (Figure 5.4).

\subsubsection{Crystal chemistry and compositional zoning}

Changes in crystal contents from the dacites to SG1 rhyolites and the presence or absence of amphibole and clinopyroxene from SG1 are accompanied by significant changes in chemistry, zoning and textures observed in the major mineral phases. Crystals in the dacites display a range of zoning from strongly mottled and resorbed cores followed by normal zoning through to completely unzoned (Figure 5.7). However, crystal rims almost always converge towards a common and relatively narrow compositional range (Table 5.2). Clinopyroxene cores and interior zones on strongly zoned examples from the dacites overlap with the compositional range of clinopyroxene analysed from the Oruanui mafic clasts (Allan et al., 2014; Figures 5.7a and 5.8a). Similar trends can be seen in the dacite orthopyroxene and plagioclase crystals, where core compositions overlap with high-Enstatite (En) orthopyroxene (up to $\mathrm{En}_{70}$ ) and high-Anorthite (An) plagioclase cores (up to $\mathrm{An}_{90}$ ) from the Oruanui HSR and mafic clasts (Figures 5.7b and 5.9a-d). Crystal rims from the dacites appear to be subtly different in their narrow compositional range to orthopyroxene crystals observed in the LSR, with notably lower MnO. In comparison, the major crystal phases from the SG1 rhyolites B-D typically display less pronounced compositional zoning and textures are dominated by normal zoning and oscillatory zoning (Figure 5.7). Clinopyroxene cores and interior zones from SG1 largely overlap with the compositional field of the dacite crystal rims (Figure 5.8b). Similar overlapping trends are observed in orthopyroxene where the crystals follow and continue the unique low-MnO compositional trend that is distinctive from that in the Oruanui orthopyroxenes (Allan et al., 2014; Figure 5.9e). SG1 plagioclase have a wide range of compositions with common high-An cores and interior zones (up to $\mathrm{An}_{85}$ ), overgrown by low-An rims at $<\mathrm{An}_{50}$ with only a few crystals displaying reverse zoning (Figures 5.7c and 5.9f). However, plagioclase rims do not reach as low as the $\mathrm{An}_{35}$ compositions observed in the Oruanui HSR. A contrast is observed in clinopyroxene and orthopyroxene crystals from the later erupted Unit $\mathrm{E}$ at $10 \mathrm{ka}$, as compositions tend to split into two subgroups with an additional higher-MnO population than the earlier post-Oruanui units (Figures $5.8 \mathrm{c}$ and $5.9 \mathrm{~g}$ ), along with a narrower range of high-An plagioclase cores (Figure 5.9h). As observed in the dacites, crystal rims tend to form a relatively restricted overall compositional range within the whole of SG1 rhyolite samples (Table 5.2). 


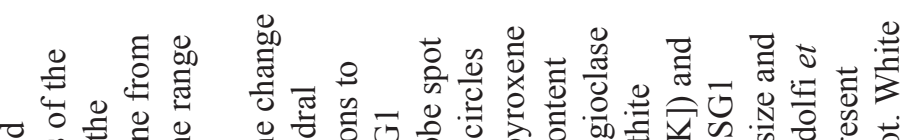

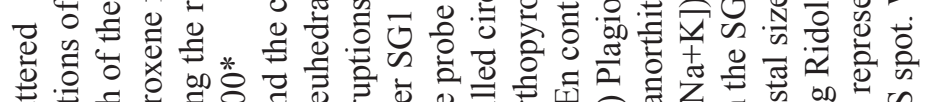

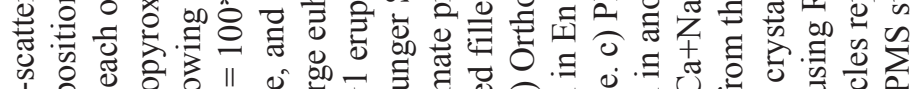

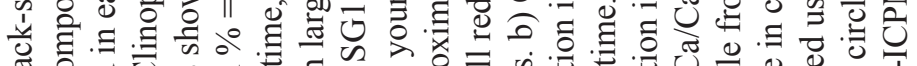

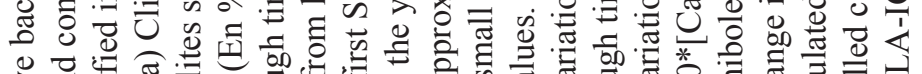

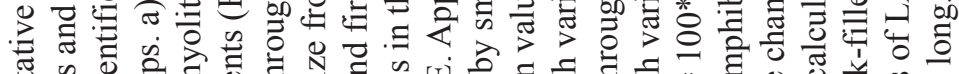

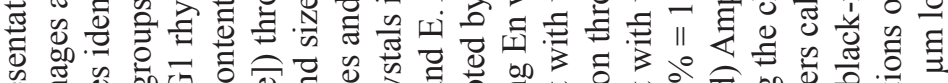

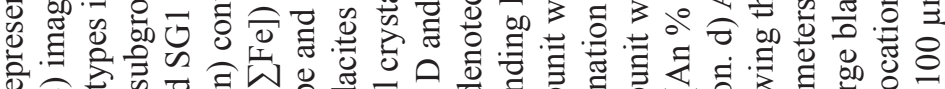

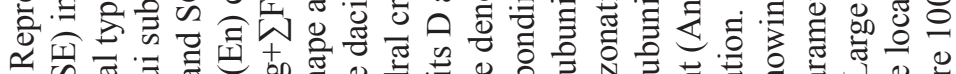

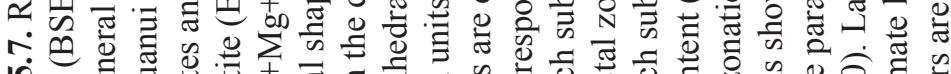

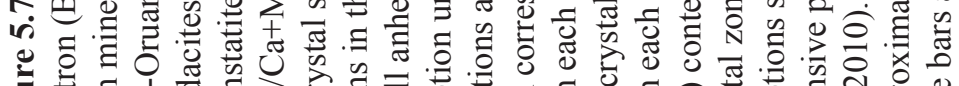

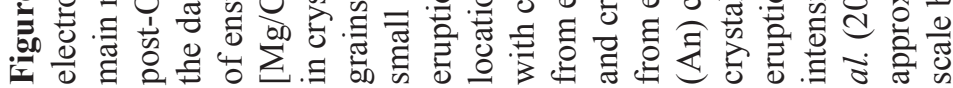
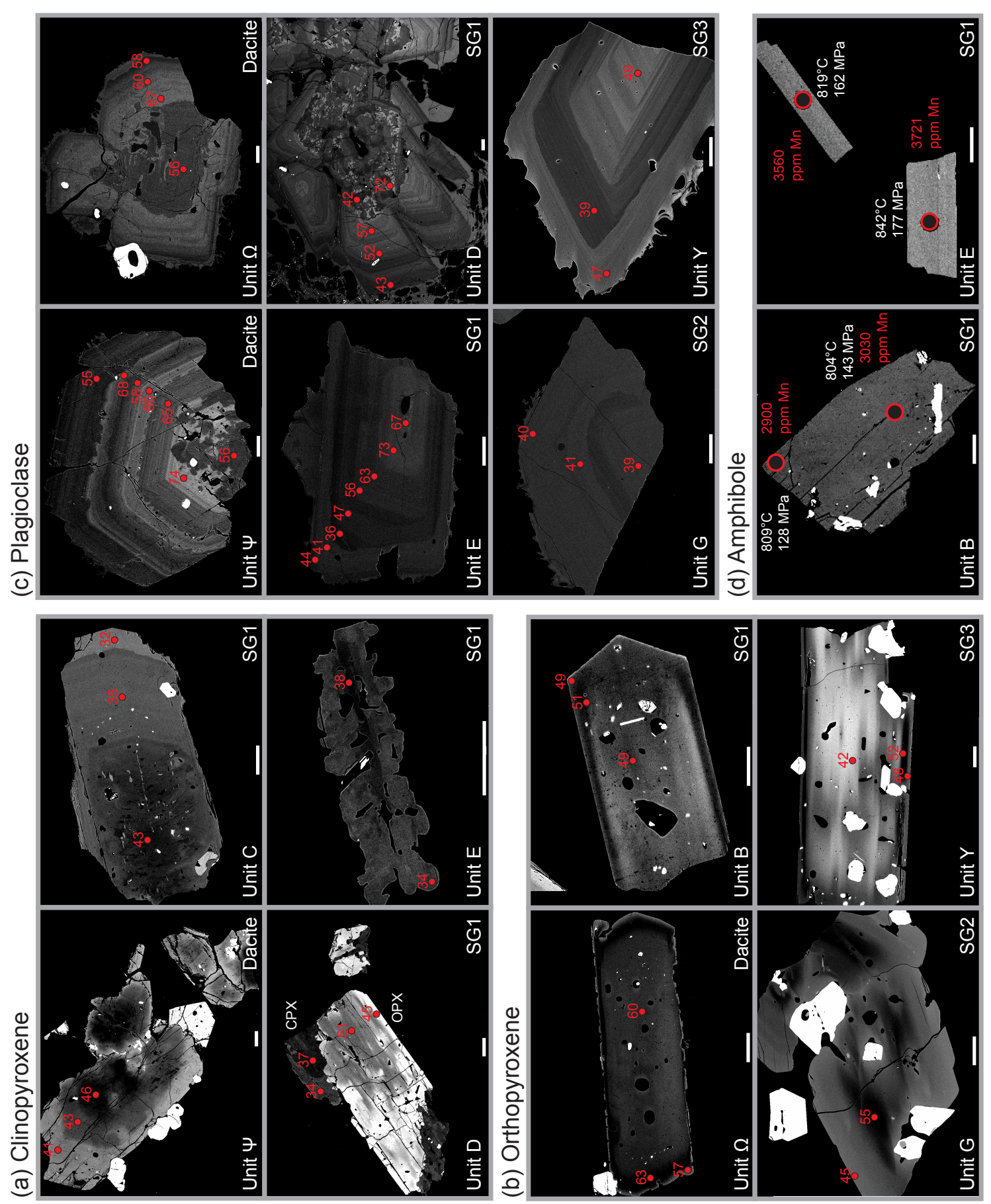


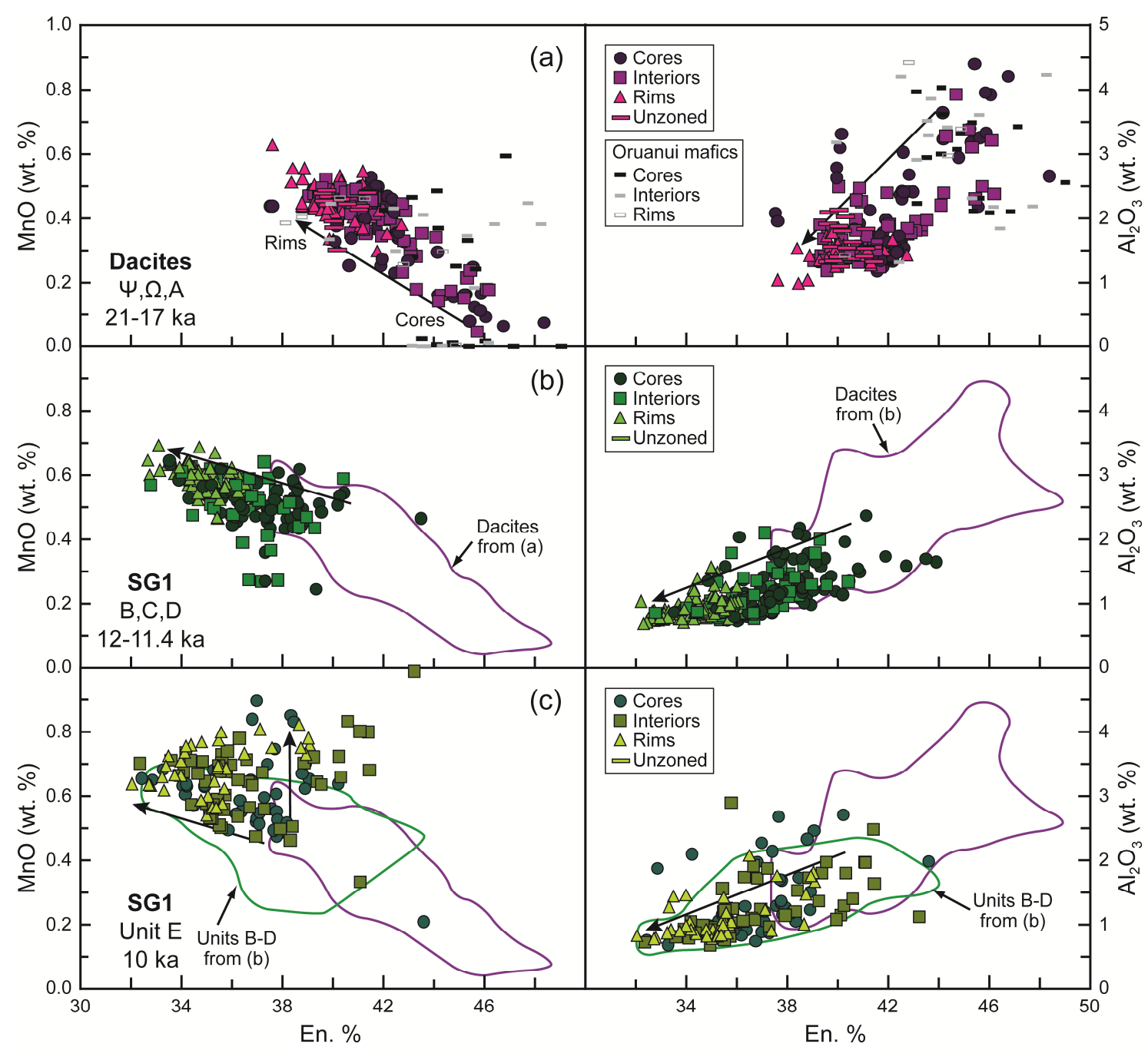

Figure 5.8. Variation diagrams showing the compositional range of zones within clinopyroxene crystals from (a) post-Oruanui dacites and mafic Oruanui clasts (the latter from Allan et al., 2014), (b) SG1 units B-D, and (c) Unit E. Arrows indicate general direction of normal crystal core to rim compositional zoning. Enstatite content (En \%) calculated as $100 *\left(\mathrm{Mg} / \mathrm{Ca}+\mathrm{Mg}+\sum \mathrm{Fe}\right)$. See Appendix $\mathrm{J}$ for raw data and CHAPTER 3 for standards.

Crystal compositions vary distinctively in the SG2 rhyolites, in parallel with the observed changes in mineralogy and whole-rock chemistry. Strong zonation is much less common in the SG2 crystals, with many grains showing either minor normal zoning, oscillatory zoning or being completely unzoned (Figure 5.7). This is reflected in the range of chemical compositions observed, as high-An or high-En cores and interior zones become increasingly less common through time (Figure 5.10a-d; Table 5.2). Crystal rim compositions are broadly similar to those observed in the SG1 rhyolites with plagioclase having slightly lower-An. The final three eruptions of SG2 (units-UW) have crystal rim compositions with lower-An plagioclase down to $\mathrm{An}_{35}$, and lowerEn orthopyroxene, down to $\mathrm{En}_{37}$ (Table 5.2; Figure 5.10c,d). The total range of SG2 orthopyroxene compositions follows a distinctly different trend to those in SG1, having higher levels of $\mathrm{MnO}$ at any given En level and in this regard being more similar to 


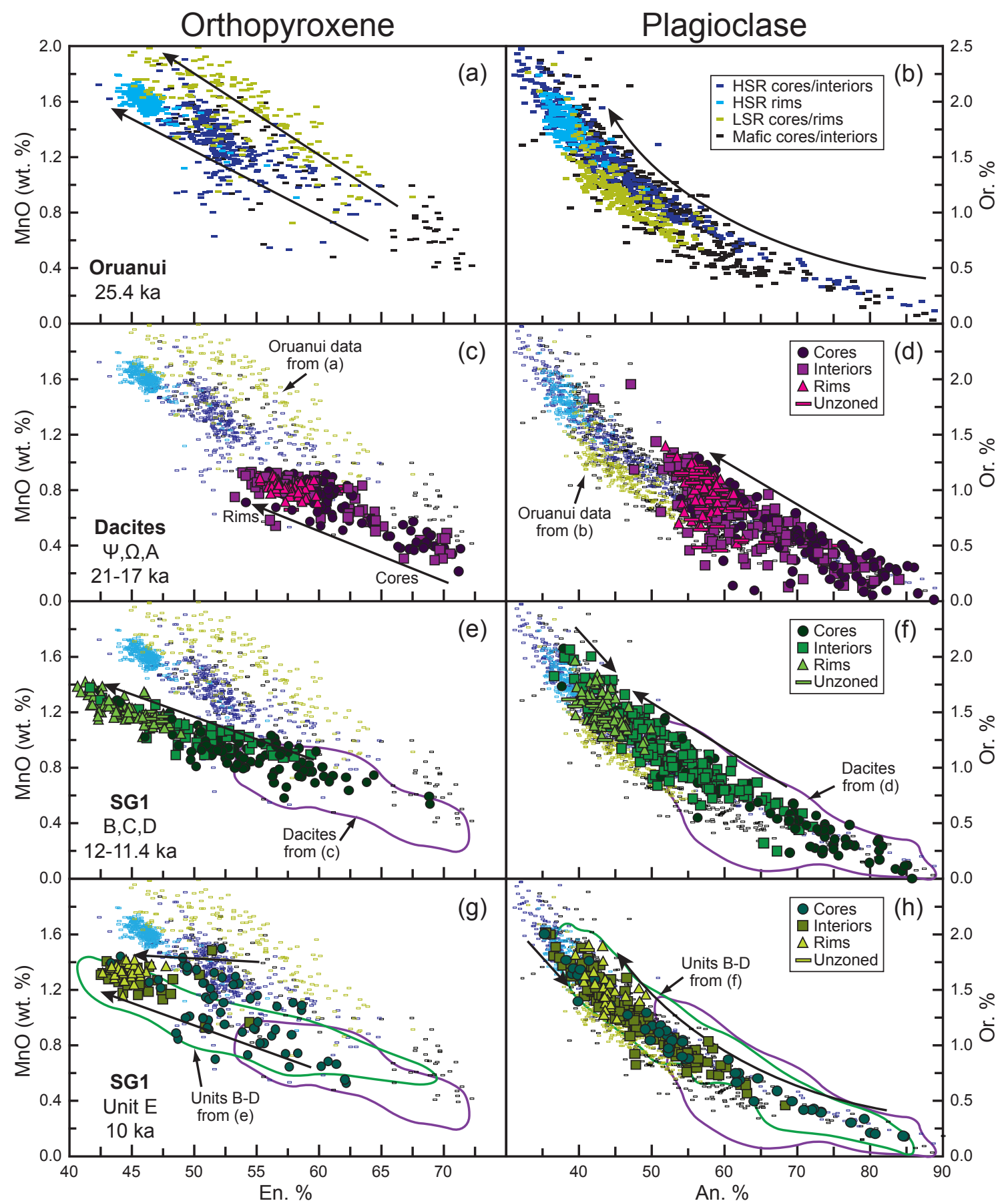

Figure 5.9. Variation diagrams showing the compositional ranges of zones within orthopyroxene and plagioclase crystals from (a)-(b) Oruanui rhyolite types and mafics (Allan et al., 2014), (c)-(d) post-Oruanui dacites, (e)-(f) SG1 units B-D, and (g)-(h) Unit E. Arrows indicate the general direction of crystal core to rim compositional change. Orthopyroxene Enstatite content (En \%) calculated as $100 *\left(\mathrm{Mg} / \mathrm{Ca}+\mathrm{Mg}+\sum \mathrm{Fe}\right)$. Plagioclase feldspar Anorthite content (An \%) calculated as $100 *(\mathrm{Ca} / \mathrm{Ca}+\mathrm{Na}+\mathrm{K})$, Orthoclase content $(\mathrm{Or} \%)$ calculated as $100 *(\mathrm{~K} / \mathrm{Ca}+\mathrm{Na}+\mathrm{K})$. Oruanui data from Allan et al. (2014) are shown as small open symbols in panels (c)-(h) for reference. See Appendix J for raw data and CHAPTER 3 for standards. 


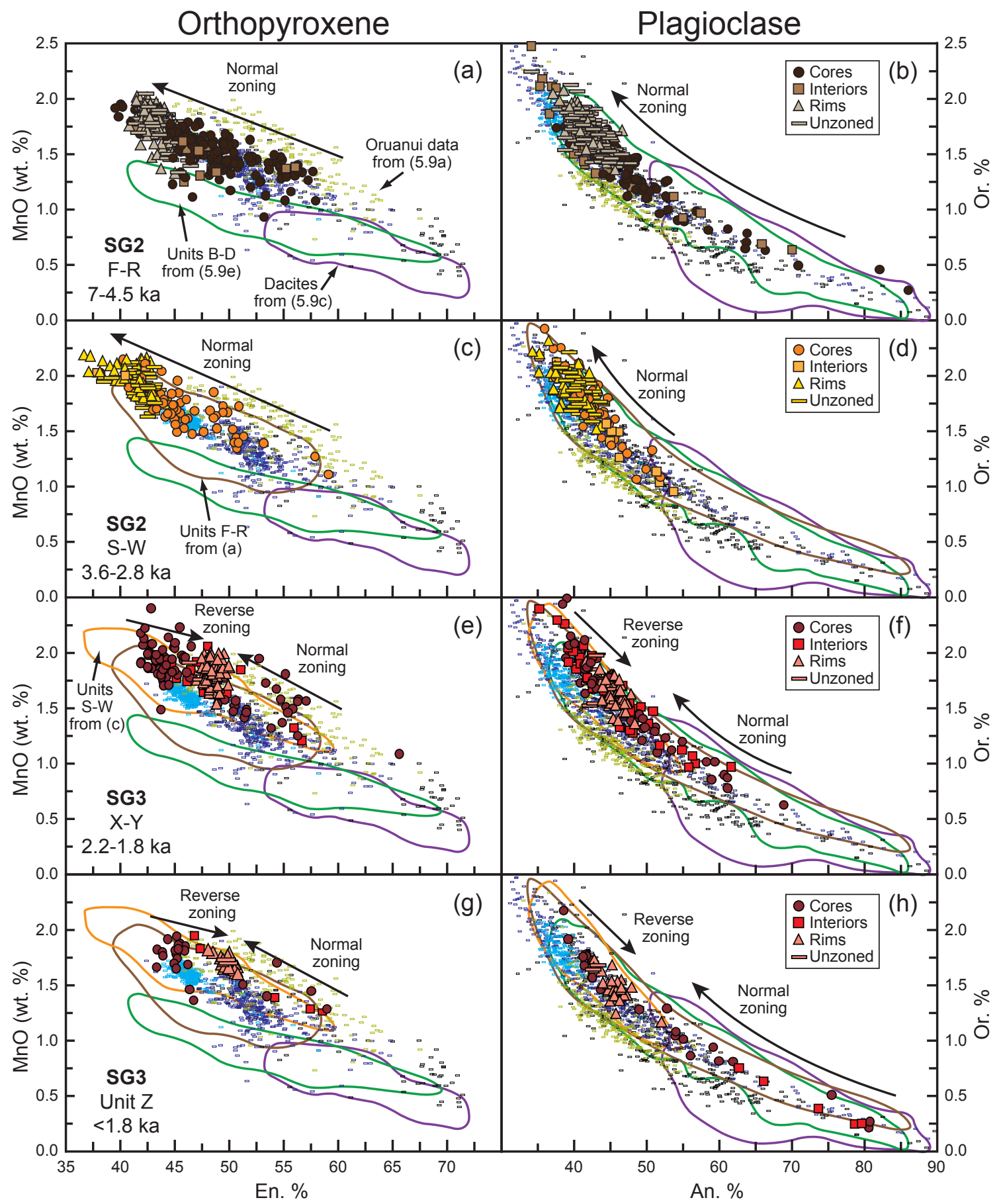

Figure 5.10. Variation diagrams showing the compositional range of zones within orthopyroxene and plagioclase crystals from (a)-(b) SG2 units F-R, (c)-(d) SG2 units S-W, (e)-(f) SG3 eruption units X and $\mathrm{Y}$, and (g)-(h) SG3 eruption Z. Oruanui data from Figure 5.9a and b are shown as small open symbols for reference. Note the contrasting compositional fields between the SG2 and SG3 orthopyroxenes with the SG1 orthopyroxenes and the change from normal zoning with low-En or low-An rims in SG2 to dominantly reverse zoning with high-En or high-An rims in the SG3 eruptions. Other details as in Figure 5.9 . 
Oruanui HSR orthopyroxenes (Figure 5.10a,c). The SG3 crystals display contrasting zonation to those in SG2, with both plagioclase and orthopyroxene dominantly displaying reverse zoning, with a minor population of normally zoned or unzoned crystals (Figure 5.7). These patterns are reflected in the crystal compositions, with cores derived from either a low-An, low-En reversely zoned population of crystals, or a highAn or high-En normally zoned population (Figure 5.10e-h). Crystal rim compositions are distinctly higher-An $\left(\sim \mathrm{An}_{50}\right)$ and higher-En $\left(\sim \mathrm{En}_{45}\right)$ than the SG2 or SG1 crystals (Table 5.2). In addition, normally zoned crystal cores typically span to higher-En or higher-An values than those the SG2 rhyolites (Figure 5.10e-h).

Other mineral phase compositions also parallel the changing melt compositions with time. For example, Fe-Ti oxide compositions change systematically both in their $\mathrm{MgO}$ and $\mathrm{MnO}$ concentrations between the dacite and within and between the rhyolitic subgroups (Figure 5.11a). Magnetite and ilmenite crystals mirror the trends seen in orthopyroxene where there is an increase in MnO between the SG1 and SG2/SG3 rhyolites. Accompanying such trends, $\mathrm{MgO}$ concentrations in magnetite and ilmenite
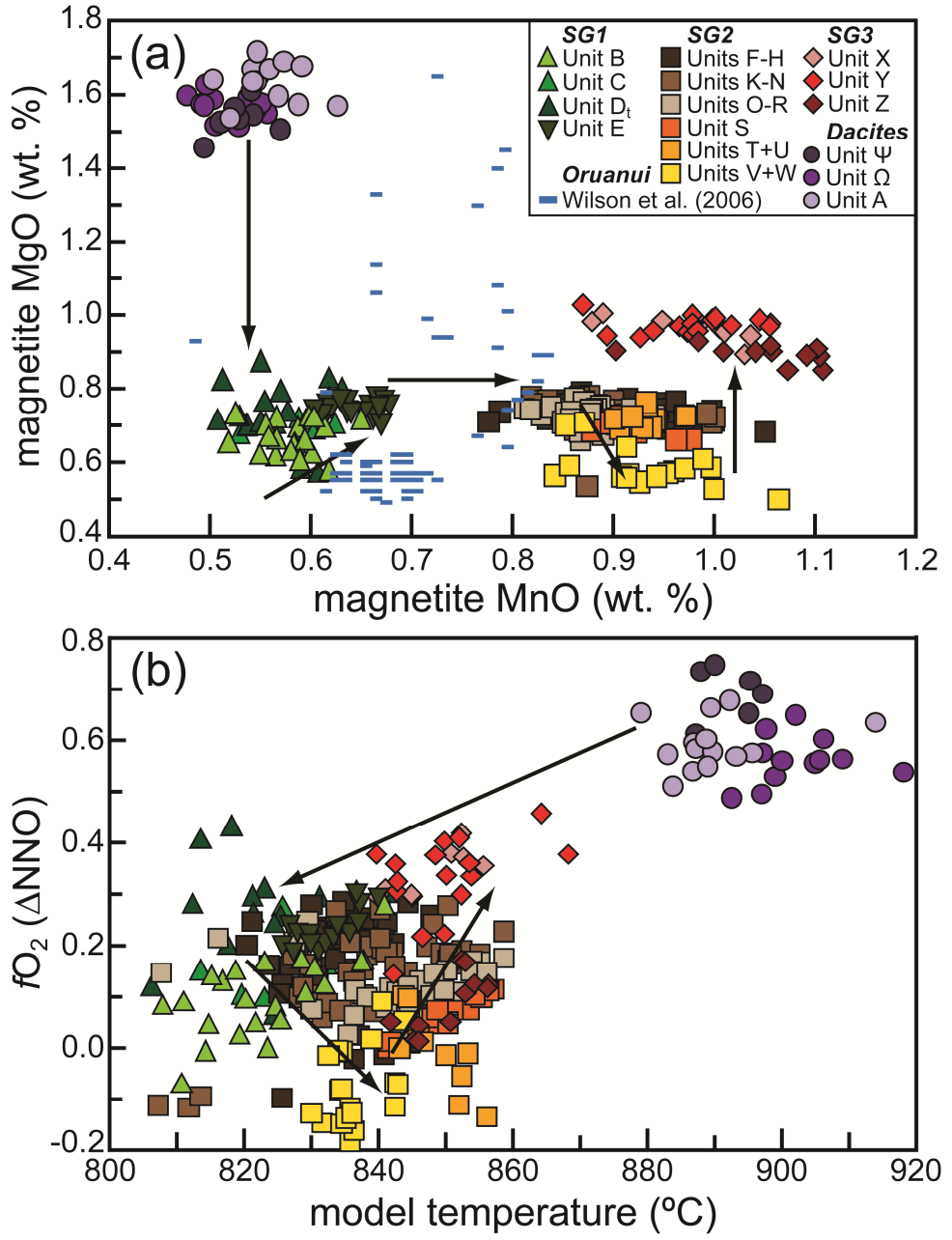

Figure 5.11. Compositions of FeTi oxides and intensive parameter estimates from the post-Oruanui dacites and rhyolite subgroups. Black arrows indicate general trends linking the eruptions through time. a) Variations in $\mathrm{MgO}$ and $\mathrm{MnO}$ concentrations in magnetite between the groups through time. Similar broad trends are also reflected in the composition of ilmenite (see Table 5.4 and Appendix J). b) Temperature and $\mathrm{fO}_{2}$ [plotted as $\log _{10} \mathrm{fO}_{2}$ relative to the $\mathrm{Ni}-\mathrm{NiO}$ oxygen buffer of O'Neill \& Pownceby (1993)] estimates calculated from matched pairs of magnetite and ilmenite using the Fe-Ti exchange based thermometer of Sauerzapf et al. (2008). Only coexisting Fe-Ti oxide pairs (either sharing a common boundary or occurring together in the same phenocryst) were used to ensure textural equilibrium (Blundy \& Cashman, 2008). Fe-Ti pairs were also tested for equilibrium using the $\mathrm{Mg} / \mathrm{Mn}$ partitioning test from Bacon \& Hirschmann (1988). See Appendix $\mathrm{J}$ for raw data and CHAPTER 3 for standards. 
decrease significantly from the dacites to the SG1 rhyolites, stay constant, then slowly decrease in the end of SG2 and increase again for the SG3 rhyolites. Amphibole shows a limited compositional range where present in minor quantities in units $\mathrm{B}$ and $\mathrm{C}$, overlapping in its broad major and trace element composition amphibole from the Oruanui eruption (Figure 5.12). However, amphibole found at trace levels in units D and $E$ shows a much wider range of compositions that overlap more with those reported from the Oruanui LSR or mafic clasts. Due to their scarcity, anhedral appearance and range of compositions they are considered to be out of equilibrium with their host melt and may be xenocrysts sourced from deeper in the system.

\subsubsection{Intensive parameters}

\subsubsection{Temperature}

Methods of estimating magmatic temperature in the post-Oruanui rhyolites are constrained by the mineral assemblages present through time (Table 5.2). This study has used both mineral-mineral equilibrium and mineral-melt equilibrium based models to calculate a range of temperature estimates for the different crystal phases as appropriate for each eruption (Table 5.4; Figures 5.11, 5.12 and 5.13). Where available multiple different model calibrations or varied sensitive parameters have been used, such as $\mathrm{H}_{2} \mathrm{O}$ content of the melt, to provide a full range of available and realistic estimates. In general, the different models used provide a reasonably consistent temperature estimate range (generally $\pm 30{ }^{\circ} \mathrm{C}$ ) where several major trends are immediately identifiable. The most obvious change is the large increase in model temperatures of $>100{ }^{\circ} \mathrm{C}$ between the Oruanui HSR magma (Allan et al., 2014) and the post-Oruanui dacites. The inferred temperature of the magmas then drops significantly $\left(>50^{\circ} \mathrm{C}\right)$ for the post-Oruanui rhyolites but these are still significantly hotter than the Oruanui HSR (Table 5.4; Figure 5.13).

Demarcation of temperature trends within the post-Oruanui rhyolites are hampered by the wide range of temperature outputs between models used, even for different models based on the same crystal phases. For example, changing the $\mathrm{H}_{2} \mathrm{O}$ melt content in the plag-melt thermometer from 4.5-5.5 wt. \% varies the output by $\sim 25^{\circ} \mathrm{C}$. Such changes are, however, expected and can be accounted for by using the observed mineral phases or other means of estimating $\mathrm{H}_{2} \mathrm{O}$ melt content. In contrast, the Fe-Ti oxide models show a significant difference between model calibrations using the same data (Figures 5.11 and 5.13). The Ghiorso \& Evans (2008) model consistently gives the 
Table 5.4. Temperature estimates calculated from mineral-mineral and mineral-melt equlibrium models

\begin{tabular}{|c|c|c|c|c|c|c|c|c|c|c|}
\hline Unit & Age & Fe-Ti oxide & -inperty & $\operatorname{res}\left({ }^{\circ} \mathrm{C}\right)$ & $2-P^{*}$ & CPX-melt* & Plag-melt & & OPX-melt & \\
\hline Dacites & & G\&E 08 & $\mathrm{Sz} 08$ & A\&L 88 & & & $4.5 \% \mathrm{H}_{2} \mathrm{O}$ & $5.5 \%$ & $4.5 \% \mathrm{H}_{2} \mathrm{O}$ & $5.5 \%$ \\
\hline$\Psi$ & 20.5 & $938 \pm 20(7)$ & $896 \pm 19$ & $905 \pm 13$ & $907 \pm 18(15)$ & $886 \pm 10(17)$ & $889 \pm 4(42)$ & $865 \pm 4$ & $890 \pm 3(11)$ & $880 \pm 3$ \\
\hline$\Omega$ & 18.8 & $943 \pm 16(12)$ & $903 \pm 14$ & $911 \pm 11$ & $911 \pm 22(37)$ & $891 \pm 10(35)$ & $894 \pm 4(31)$ & $870 \pm 3$ & $894 \pm 5(40)$ & $885 \pm 5$ \\
\hline A & 17 & $930 \pm 18(14)$ & $890 \pm 16$ & $900 \pm 13$ & $905 \pm 15(12)$ & $890 \pm 14(14)$ & $891 \pm 3(38)$ & $865 \pm 3$ & $899 \pm 6(13)$ & $890 \pm 5$ \\
\hline SG1 & & G\&l & Sz 08 & A\&L 88 & & & $4.5 \% \mathrm{H}_{2} \mathrm{O}$ & $5.5 \%$ & $4.5 \% \mathrm{H}_{2} \mathrm{O}$ & $5.5 \%$ \\
\hline B & 11.8 & $846 \pm 26(22)$ & $823 \pm 18$ & $836 \pm 22$ & $832 \pm 22(28)$ & $803 \pm 14(27)$ & $835 \pm 5(19)$ & $813 \pm 5$ & $6(45)$ & $805 \pm 6$ \\
\hline $\mathrm{C}$ & 11.4 & $849 \pm 19(6)$ & $824 \pm 14$ & $839 \pm 16$ & $837 \pm 18(15)$ & $794 \pm 25$ (16) & $835 \pm 4(9)$ & $814 \pm 4$ & $817 \pm 6(17)$ & $809 \pm 5$ \\
\hline $\mathrm{D}_{\text {lava }}$ & 11.4 & $847 \pm 12(6)$ & $818 \pm 10$ & $840 \pm 10$ & $842 \pm 16(14)$ & $803 \pm 11(14)$ & $838 \pm 4(29)$ & $817 \pm 4$ & $825 \pm 3(14)$ & $817 \pm 3$ \\
\hline $\mathrm{D}_{\text {tephra }}$ & 11.4 & $850 \pm 37(10)$ & $823 \pm 27$ & $840 \pm 29$ & $826 \pm 34(5)$ & $803 \pm 6(5)$ & $835 \pm 6(12)$ & $814 \pm 6$ & $813 \pm 5(9)$ & $805 \pm 5$ \\
\hline$\underline{E}$ & 10 & $861 \pm 11(17)$ & $832 \pm 8$ & $850 \pm 9$ & $821 \pm 18(29)$ & $810 \pm 17(36)$ & $839 \pm 3(24)$ & $817 \pm 3$ & $820 \pm 3(34)$ & $812 \pm 3$ \\
\hline SG2 & & G\& & Sz 08 & A\&L 88 & & & $4.5 \% \mathrm{H}_{2} \mathrm{O}$ & $5.5 \%$ & $\mathrm{H}_{2} \mathrm{O}$ & $5.5 \%$ \\
\hline $\mathrm{F}_{\text {lava }}$ & 7.1 & $859 \pm 22(7)$ & $840 \pm 15$ & $845 \pm 19$ & $\mathrm{n} / \mathrm{a}$ & $\mathrm{n} / \mathrm{a}$ & $\mathrm{n} / \mathrm{d}$ & $\mathrm{n} / \mathrm{d}$ & $826 \pm 3(29)$ & $818 \pm 3$ \\
\hline$F_{\text {tephra }}$ & 7.1 & $858 \pm 18(9)$ & $831 \pm 14$ & $847 \pm 14$ & $\mathrm{n} / \mathrm{a}$ & $\mathrm{n} / \mathrm{a}$ & $836 \pm 2(14)$ & $812 \pm 2$ & $827 \pm 3(19)$ & $819 \pm 3$ \\
\hline G & 6.7 & $861 \pm 1$ & $833 \pm 10$ & $849 \pm 10$ & $\mathrm{n} / \mathrm{a}$ & $\mathrm{n} / \mathrm{a}$ & $830 \pm 2(4)$ & $808 \pm 2$ & $(20)$ & $811 \pm 3$ \\
\hline $\mathrm{H}$ & 6.1 & $860 \pm 24(11)$ & $835 \pm 16$ & $848 \pm 21$ & $\mathrm{n} / \mathrm{a}$ & $\mathrm{n} / \mathrm{a}$ & $830 \pm 4(9)$ & $808 \pm 4$ & $822 \pm 3(20)$ & $814 \pm 3$ \\
\hline K & 5.4 & $849 \pm 37(13)$ & $829 \pm 23$ & $838 \pm 31$ & $\mathrm{n} / \mathrm{a}$ & $\mathrm{n} / \mathrm{a}$ & $832 \pm 4(29)$ & $810 \pm 4$ & $826 \pm 2(29)$ & $818 \pm 2$ \\
\hline $\mathrm{L}_{\text {tephra }}$ & 5.3 & $874 \pm 19$ (7) & $845 \pm 16$ & $858 \pm 15$ & $\mathrm{n} / \mathrm{a}$ & $\mathrm{n} / \mathrm{a}$ & $838 \pm 4$ (19) & $816 \pm 4$ & $824 \pm 3(17)$ & $816 \pm 3$ \\
\hline M & 5.3 & $864 \pm 20(9)$ & $838 \pm 14$ & $851 \pm 16$ & $\mathrm{n} / \mathrm{a}$ & $\mathrm{n} / \mathrm{a}$ & $832 \pm 3(18)$ & $811 \pm 3$ & $4(21)$ & $813 \pm 4$ \\
\hline $\mathrm{N}$ & 4.9 & $876 \pm 19(9)$ & $848 \pm 15$ & $860 \pm 14$ & $\mathrm{n} / \mathrm{a}$ & $\mathrm{n} / \mathrm{a}$ & $830 \pm 4(18)$ & $808 \pm 4$ & $826 \pm 3(26)$ & $818 \pm 3$ \\
\hline $\mathrm{O}$ & 4.8 & $862 \pm 34(12)$ & $838 \pm 30$ & $850 \pm 24$ & $\mathrm{n} / \mathrm{a}$ & $\mathrm{n} / \mathrm{a}$ & $828 \pm 2(16)$ & $806 \pm 2$ & $816 \pm 3(25)$ & $808 \pm 3$ \\
\hline $\mathrm{P}$ & 4.8 & $870 \pm 28(6)$ & $844 \pm 22$ & $854 \pm 22$ & $\mathrm{n} / \mathrm{a}$ & $\mathrm{n} / \mathrm{a}$ & $832 \pm 2(25)$ & $810 \pm 2$ & $826 \pm 2(24)$ & $818 \pm 2$ \\
\hline Q & 4.6 & $869 \pm 14(7)$ & $845 \pm 11$ & $854 \pm 11$ & $\mathrm{n} / \mathrm{a}$ & $\mathrm{n} / \mathrm{a}$ & $832 \pm 5(21)$ & $811 \pm 5$ & $825 \pm 3(25)$ & $817 \pm 3$ \\
\hline $\mathrm{R}$ & 4.5 & $876 \pm 12(7)$ & $850 \pm 9$ & $859 \pm 10$ & $\mathrm{n} / \mathrm{a}$ & $\mathrm{n} / \mathrm{a}$ & $832 \pm 4(20)$ & $810 \pm 4$ & $825 \pm 3(18)$ & $817 \pm 3$ \\
\hline S & 3.6 & $874 \pm 15(14)$ & $850 \pm 10$ & $857 \pm 12$ & $\mathrm{n} / \mathrm{a}$ & $\mathrm{n} / \mathrm{a}$ & $834 \pm 3(25)$ & $812 \pm 3$ & $826 \pm 2(23)$ & $818 \pm 2$ \\
\hline $\mathrm{T}$ & 3.2 & $876 \pm 7(6)$ & $852 \pm 6$ & $859 \pm 14$ & $\mathrm{n} / \mathrm{a}$ & $\mathrm{n} / \mathrm{a}$ & $819 \pm 4$ (19) & $798 \pm 4$ & $821 \pm 3(28)$ & $813 \pm 3$ \\
\hline $\mathrm{U}$ & 2.9 & $863 \pm 16(10)$ & $844 \pm 7$ & $848 \pm 14$ & $\mathrm{n} / \mathrm{a}$ & $\mathrm{n} / \mathrm{a}$ & $\mathrm{n} / \mathrm{d}$ & $\mathrm{n} / \mathrm{d}$ & $816 \pm 4(23)$ & $808 \pm 4$ \\
\hline V & 2.8 & $853 \pm 15(12)$ & $837 \pm 8$ & $839 \pm 13$ & $\mathrm{n} / \mathrm{a}$ & $\mathrm{n} / \mathrm{a}$ & $815 \pm 5(11)$ & $794 \pm 5$ & $813 \pm 5(16)$ & $805 \pm 5$ \\
\hline $\mathrm{W}$ & 2.8 & $851 \pm 15(7)$ & $836 \pm 9$ & $837 \pm 14$ & $\mathrm{n} / \mathrm{a}$ & $\mathrm{n} / \mathrm{a}$ & $814 \pm 4(15)$ & $793 \pm 4$ & $813 \pm 6(24)$ & $806 \pm 6$ \\
\hline SG3 & & G\&E 08 & Sz 08 & A\&L 88 & & & $4.5 \% \mathrm{H}_{2} \mathrm{O}$ & $5.5 \%$ & $4.5 \% \mathrm{H}_{2} \mathrm{O}$ & $5.5 \%$ \\
\hline $\mathrm{X}$ & 2.2 & $878 \pm 15(8)$ & $848 \pm 12$ & $863 \pm 11$ & $\mathrm{n} / \mathrm{a}$ & $\mathrm{n} / \mathrm{a}$ & $848 \pm 4(20)$ & $825 \pm 4$ & $849 \pm 2(18)$ & $840 \pm 2$ \\
\hline Y & 1.8 & $879 \pm 23(16)$ & $850 \pm 16$ & $865 \pm 18$ & $\mathrm{n} / \mathrm{a}$ & $\mathrm{n} / \mathrm{a}$ & $850 \pm 3(49)$ & $828 \pm 3$ & $852 \pm 3(60)$ & $843 \pm 2$ \\
\hline Z & 1.8 & $871 \pm 23(11)$ & $850 \pm 10$ & $856 \pm 14$ & $\mathrm{n} / \mathrm{a}$ & $\mathrm{n} / \mathrm{a}$ & $850 \pm 3(24)$ & $827 \pm 3$ & $852 \pm 3(24)$ & $844 \pm 3$ \\
\hline
\end{tabular}

Fe-Ti oxide temperature estimates are from either touching magnetite-ilmenite pairs or from coexisting oxide pairs on the same crystal or glomerocryst using the models of Ghiorso \& Evans (2008) (G\&E), Andersen \& Lindsley (1988) (A\&L) and Sauerzapf et al. (2008) (Sz). All magnetite-ilmenite pairs satisfied the Mg-Mn partitioning test of Bacon \& Hirschmann (1988). Temperatures from matched mineral-glass pairs fall within the equilibrium criterion for each thermometer as outlined by Putirka (2008), with clinopyroxene being an exception likely due to the equations not adequately accounting for partitioning of $\mathrm{Fe}^{2+}$ relative to $\mathrm{Fe}^{3+}$ in pyroxene (Gelman et al., 2013). Water in plagioclase-liquid and orthopyroxene-liquid thermometers from Putirka (2008) is shown for both 4.5 and $5.5 \mathrm{wt} . \% \mathrm{H}_{2} \mathrm{O}$ for comparison. Clinopyroxene-liquid and 2-pyroxene thermometers are shown for $5 \mathrm{wt} . \% \mathrm{H}_{2} \mathrm{O}$ only. Pressures were set at $100 \mathrm{MPa}$ for the rhyolites and $200 \mathrm{MPa}$ for the dacites for the mineral-melt thermometers. Number of temperature estimates shown for each thermometer in brackets, uncertainty is $2 \mathrm{SD} . \mathrm{n} / \mathrm{a}$ not available, $\mathrm{n} / \mathrm{d}$ not determined 


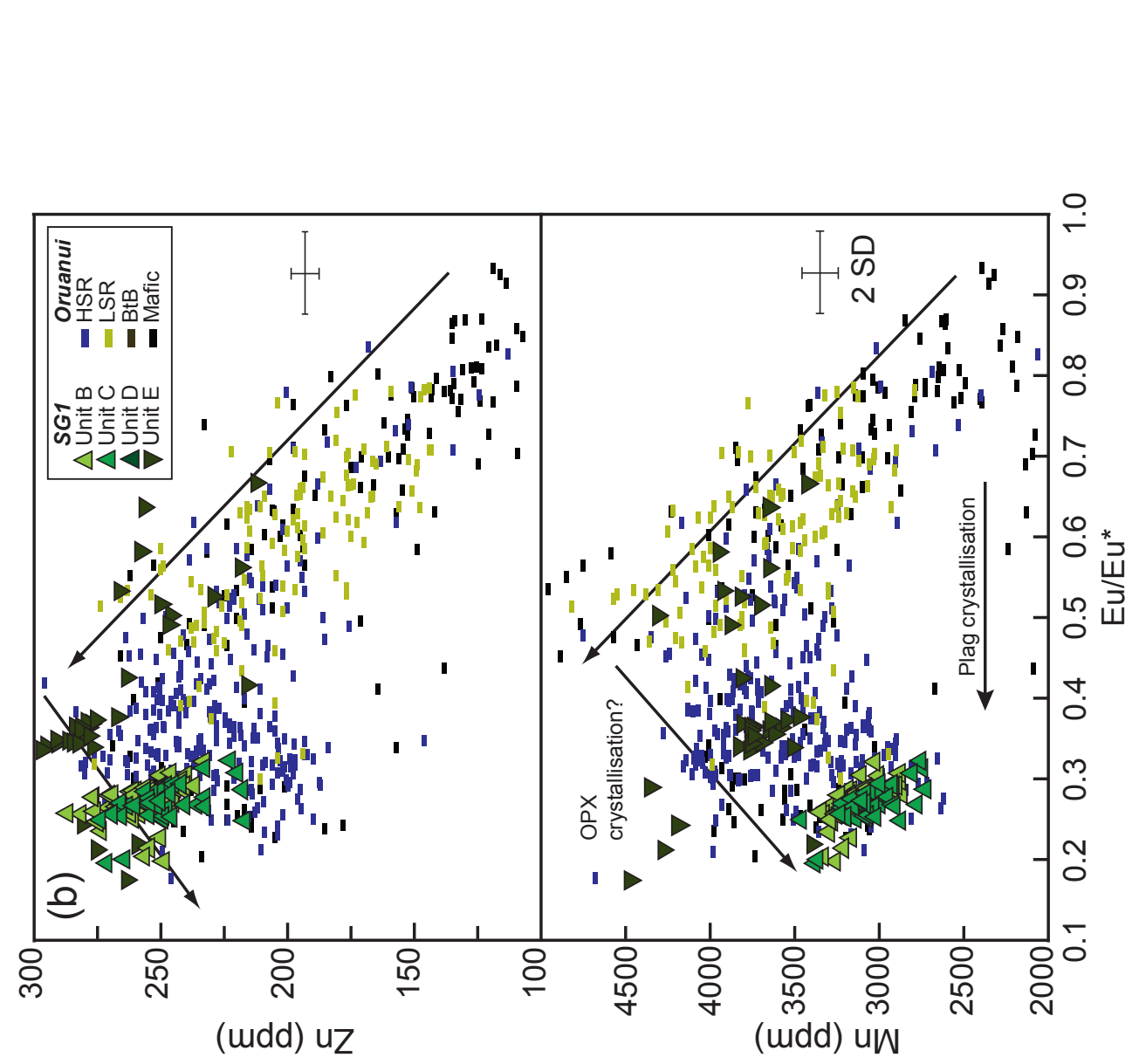

滎

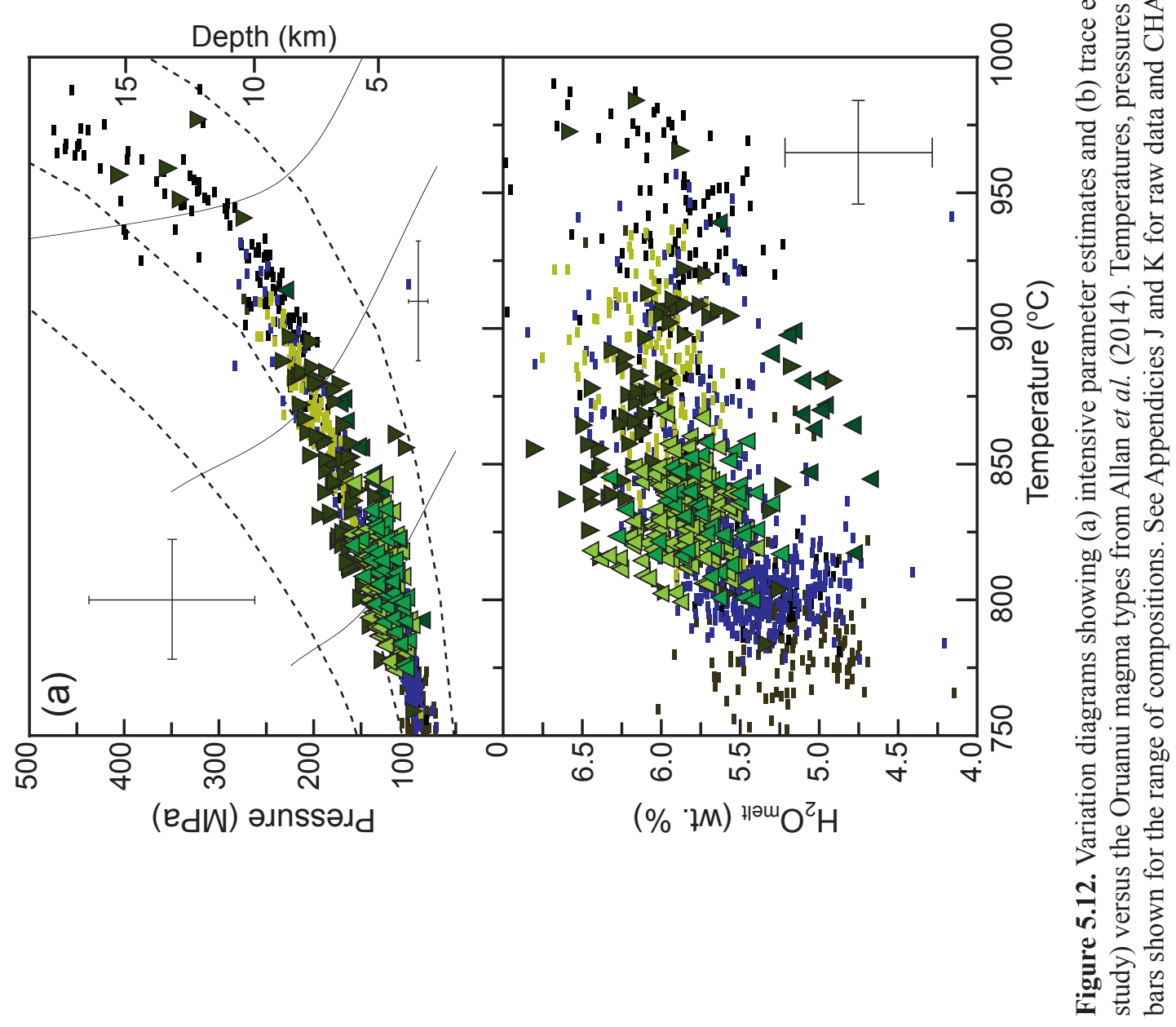




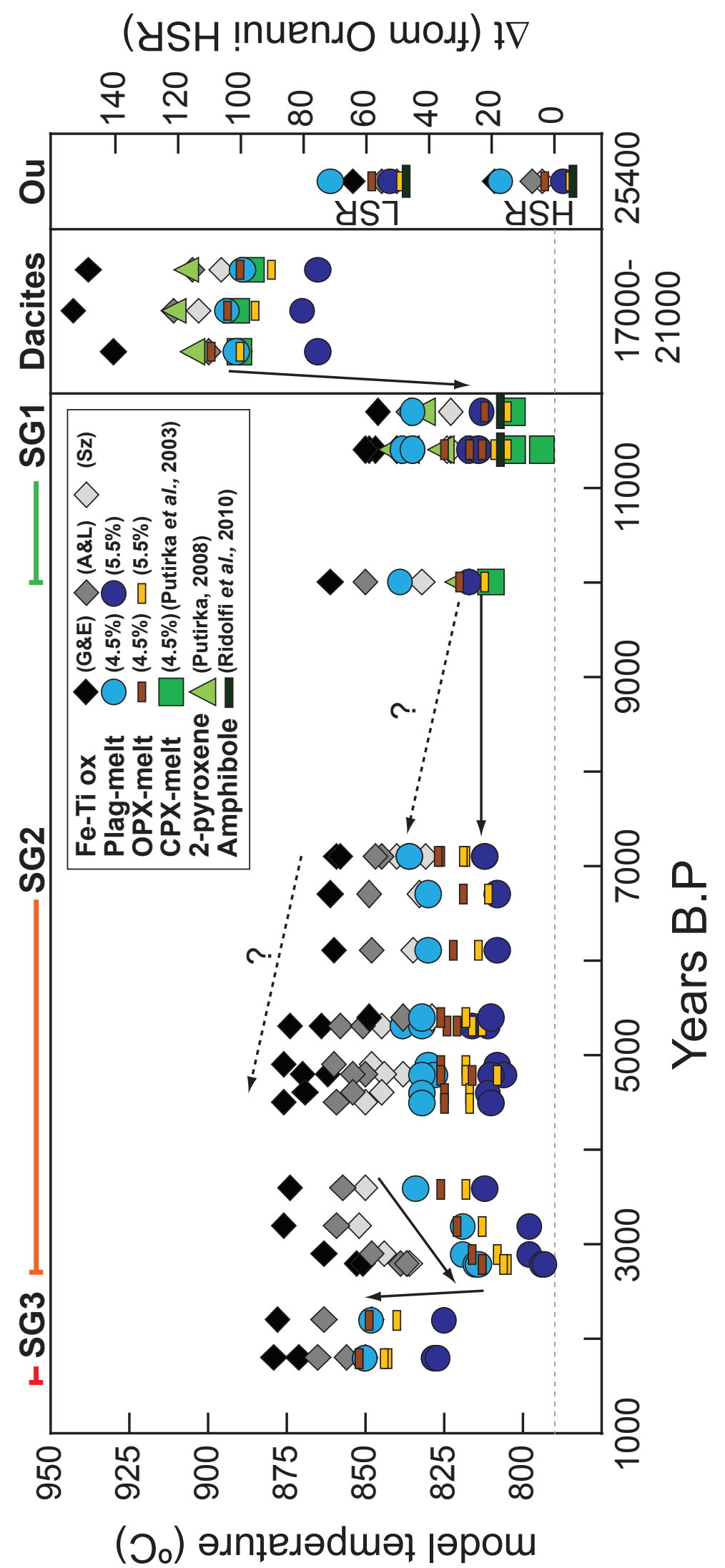

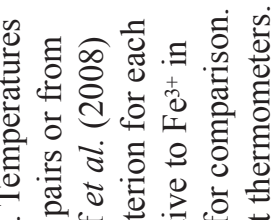

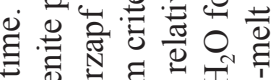

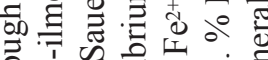

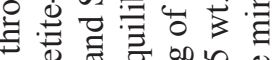
要

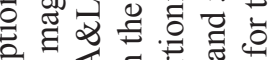

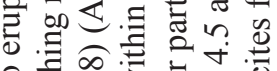

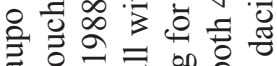

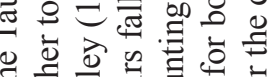

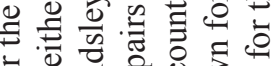

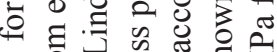

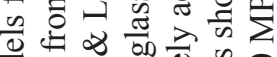
过 $\frac{1}{\pi}$

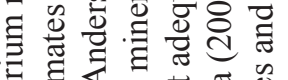

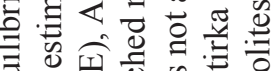

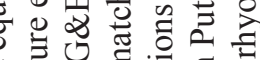

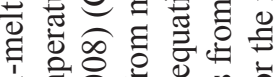

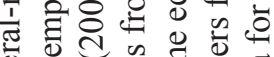

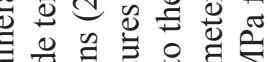

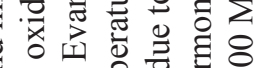

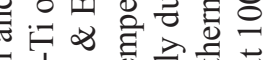
is 릉 중

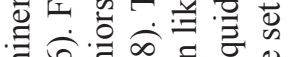
워웡워

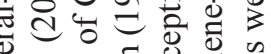
川 ర大 む

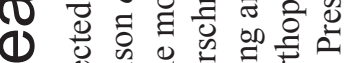
远 tᄒ 记 范 궁 이의

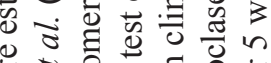

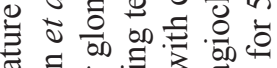
可 娄

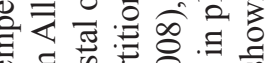
घ

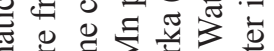

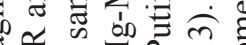

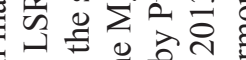
$\exists \exists$ 范完

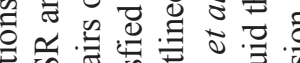

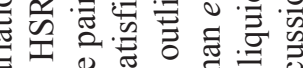

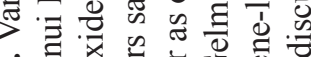

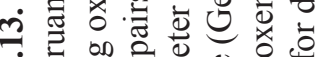

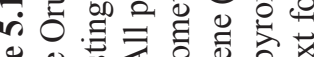

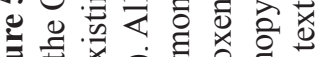

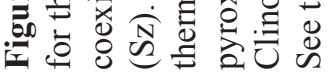


highest temperature estimates which are $20-40^{\circ} \mathrm{C}$ higher than the $\mathrm{Fe}-\mathrm{Ti}$ oxide thermometry model of Sauerzapf et al. (2008) or any of the other mineral-mineral or mineral-melt equilibrium based models. It is noted that Fe-Ti oxide temperature estimates for the Taupo magmas are largely sensitive to the calibration method used for EPMA analysis. In this study natural and well calibrated matrix-matched standards were used to calibrate analyses rather than synthetic oxides. As noted by Evans et al. (2006), use of synthetic-oxide calibrations of $\mathrm{Ti}$ (rutile) and $\mathrm{Fe}$ (hematite) resulted in total offsets of $\mathrm{TiO}_{2}$ by $\sim 1 \%$ and $\mathrm{FeO}$ of up to $-2 \%$ between natural ilmenite analysed by microprobe versus wet chemistry. Issues were also experienced in this study with not being able to replicate natural standards when calibrating EPMA analyses using synthetic oxides. Evans et al. (2006) suggested that such trends may be the result of a problem with the microprobe matrix-correction and therefore corrected their experimental data (used to calibrate the Ghiorso \& Evans, 2008, model) by the observed offset to account for the discrepancy. Interestingly, these issues with Fe-Ti oxide calibration result in temperature discrepancy of $20-30{ }^{\circ} \mathrm{C}$ by using one calibration procedure over the other, despite both resulting in reasonable analytical totals of $\sim 99$ $101 \%$. This discrepancy is, however, still within the uncertainty of the Fe-Ti oxide model used and estimated to be on the order of $\sim 50{ }^{\circ} \mathrm{C}$ (Ghiorso \& Evans, 2008), as well as the natural variability of the Fe-Ti oxide compositions measured (denoted by \pm 2 SD values in Table 5.4).

Despite variations between the models, relative differences between temperature estimates are consistent, and in alignment with the observed variation in mineral compositions and zonation patterns. Consequently, rather than using an absolute temperature, which is largely subject to the method used and the particular analytical approach, variation between the eruptions are expressed in this study as a relative difference in temperature (or $\Delta t$ ) to that from that of the Oruanui HSR (Figure 5.13). For the dacites, $\Delta \mathrm{t}$ is $\sim 115-140{ }^{\circ} \mathrm{C}$ for the Fe-Ti oxides and $\sim 80-105{ }^{\circ} \mathrm{C}$ for the Plag- and OPX-melt models (Figure 5.13). The $\Delta \mathrm{t}$ then drops for the SG1 rhyolites to $\sim 50-65{ }^{\circ} \mathrm{C}$ for the Fe-Ti oxides and $\sim 20-30{ }^{\circ} \mathrm{C}$ for the Plag- and OPX-melt models, as well as the Ridolfi et al. (2010) amphibole thermometer (Figure 5.13). The SG2 magmas then show two contrasting trends. For the Fe-Ti oxides, temperature estimates slowly increase over time from those in SG1 to $\Delta \mathrm{t}$ of $\sim 60-80{ }^{\circ} \mathrm{C}$, but then decrease in eruptions $\mathrm{U}, \mathrm{V}$ and $\mathrm{W}$. The Plag- and OPX-melt models for SG2, in contrast, stay constant through time and then $\Delta \mathrm{t}$ reduces to $<20^{\circ} \mathrm{C}$ for eruptions $\mathrm{U}, \mathrm{V}$ and $\mathrm{W}$. These contrasting model results 
may result from the increase in $\mathrm{MnO}$ in the SG2 ilmenites, as the Fe-Ti thermometry models are sensitive to the $\mathrm{MnTiO}_{3}$ mole fraction (Ghiorso \& Evans, 2008). In agreement with the trends observed in pumice and mineral chemistry, the SG3 rhyolites show a significant $\Delta \mathrm{t}$ that is $\sim 70-80{ }^{\circ} \mathrm{C}$ for the Fe-Ti oxides and $\sim 40-60{ }^{\circ} \mathrm{C}$ for the Plagand OPX-melt models (Figure 5.13).

\subsubsection{Oxygen fugacity}

In the Fe-Ti oxides, as with temperature, oxygen fugacity estimates vary with the oxybarometry model applied. In particular, the model of Sauerzapf et al. (2008) consistently gives oxygen fugacity estimates that are higher by $\Delta \mathrm{NNO} \approx 0.4 \log$ units than the model of Ghiorso \& Evans (2008). In both models the oxygen fugacity of the dacites is the highest, being well above the NNO buffer (Figure 5.11). The rhyolites are more reduced, being either slightly above or on the NNO-buffer (Sauerzapf et al., 2008), or slightly below or on the NNO-buffer (Ghiorso \& Evans, 2008). The SG2 rhyolites have the most reduced oxygen fugacity and $\triangle \mathrm{NNO}$ becomes more negative with time. The SG3 rhyolites Unit X and Y shift back beyond the NNO buffer and are the least reduced units observed in the rhyolite subgroups. As observed for the Oruanui magmas, the oxygen-fugacity estimated from the amphibole oxybarometer of Ridolfi et al. (2010) is also typically higher than that observed for the Fe-Ti oxides, by between 0.2 and $0.8 \log$ units. In general, the post-Oruanui rhyolites are more reduced than both the Oruanui HSR and LSR, despite being similar in temperature to the latter.

\subsubsection{Melt volatile content}

Large melt inclusions within plagioclase were noted around zones of dissolution (Figure 5.7a). These inclusions have a range of compositions (Figure 5.5a) and therefore likely reflect disequilibrium conditions. The large size and number of melt inclusions observed within single crystals allowed for multiple inclusions to be analysed several times for volatile concentrations by FTIR. In most cases, however, the melt inclusions appear to have leaked during decompression and ascent as denoted by the range of low $\mathrm{H}_{2} \mathrm{O}$ and $\mathrm{CO}_{2}$ (Appendix L). However, some inclusions gave multiple analyses of up to 5.8 wt. $\% \mathrm{H}_{2} \mathrm{O}$, although still with low $\mathrm{CO}_{2}$ values $(<50 \mathrm{ppm})$. It is therefore considered that these results give a minimum estimate of the volatile concentrations. Such values are in broad agreement with estimates using the plagioclase hydrometer of Putirka 
(2008) which gives a $\mathrm{H}_{2} \mathrm{O}$ content of $\sim 4.5$ wt. \% for a magma temperature of $900{ }^{\circ} \mathrm{C}$ (see also Table 5.4)

Melt inclusions are much smaller and far less common in the post-Oruanui rhyolites and were not investigated in this study, but were reported for Unit Y by Dunbar et al. (1989) and Dunbar \& Kyle (1993). Alternative estimates of water content have been made using amphibole hygrometry for the SG1 rhyolites and plagioclase hygrometry for the remaining eruptions. The amphibole model of Ridolfi et al. (2010) yields an $\mathrm{H}_{2} \mathrm{O}$ estimate of $\sim 5-6.5$ wt. \% for units $\mathrm{B}$ to $\mathrm{E}$ (Figure 5.12), similar to the upper range of volatile estimates for the Oruanui HSR (Liu et al., 2006; Allan et al., 2012, 2014) and in line with the plagioclase hydrometer of Putirka (2008) at magma temperatures of $<820{ }^{\circ} \mathrm{C}$ (Table 5.4). For the later eruptions, temperature estimates from Fe-Ti oxides are more consistent with lower melt $\mathrm{H}_{2} \mathrm{O}$ contents of $\leq 4.5 \mathrm{wt} . \%$, in agreement with changes in observed mineral phases as well as measured volatile concentrations in melt inclusions from Unit Y plagioclase by ion microprobe and FTIR (Dunbar \& Kyle, 1993; Saunders, 2009).

\subsubsection{Pressure}

Two methods have been used to estimate the crystallisation pressures for the post Oruanui magmas. First, the amphibole barometer of Ridolfi et al. (2010) yields model pressures for SG1 rhyolites that largely overlap with the range for the Oruanui magmas (Figure 5.12). Amphiboles in rhyolites of units B and C yield model pressures of $\sim 100$ $150 \mathrm{MPa}$, similar to the Oruanui HSR. The inferred xenocrystic amphiboles from the younger SG1 units give model values that overlap with the Oruanui LSR and mafic amphiboles, reflecting their likely source. Possible inheritance of amphibole xenocrysts in units $\mathrm{B}$ and $\mathrm{C}$ may be masked by the higher abundance of phenocrystic amphibole (Table 5.2). Saturation pressures for melt inclusions for the dacites have been calculated using the VolatileCalc model of Newman \& Lowenstern (2002). Although many of the melt inclusions fall along a degassing path due to post-entrapment leaking, the few inclusions with high $\mathrm{H}_{2} \mathrm{O}$ give $\mathrm{P}_{\mathrm{H}_{2} \mathrm{O}}$ estimates of $\sim 200 \mathrm{MPa}$ at an assumed temperature of $900{ }^{\circ} \mathrm{C}$ (Appendix L). These estimates are considered to be minima as low $\mathrm{CO}_{2}$ indicates that the majority of plagioclase melt inclusions have degassed. If $\mathrm{CO}_{2}$ levels are set to values like those observed in quartz melt inclusions from the Oruanui $(>100$ ppm: Liu et al., 2006), $\mathrm{P}_{\mathrm{H}_{2} \mathrm{O}}$ estimates increase to $>220 \mathrm{MPa}$. For comparative purposes, pressures observed in Oruanui melt inclusions are typically 120-150 MPa (Liu et al., 
2006) and $<150 \mathrm{MPa}$ for the Taupo ignimbrite (Unit Y), the latter assuming a water content of $\sim 4.3$ wt. $\%$ at temperatures of $\sim 850{ }^{\circ} \mathrm{C}$ (Dunbar \& Kyle, 1993; Saunders, 2009).

\subsection{Discussion}

The contrasting trends identified in whole-rock, glass and mineral compositions from the post-Oruanui eruptions highlight not only broad changes in magma chemistry in the aftermath of the Oruanui supereruption, but also subtle, yet important changes within the young rhyolitic system over short time intervals. Sutton et al. $(1995,2000)$ observed stepwise compositional changes between, and limited variation within three separate rhyolitic subgroups, and interpreted them to be derived from petrogenetically distinct magmatic systems. This study builds upon the interpretations of Sutton et al. to consider what processes were likely responsible for the observed changes in composition, with implications for the structure of the post-supereruption magma system through time and its modern state.

\subsubsection{Comparisons between Oruanui and post-Oruanui magma compositions}

The inferred huge volume of the Oruanui melt dominant magma body, the implicit size of the underlying mush system, and the geographical superposition of vents for the Oruanui and post-Oruanui eruptions makes it likely that residual melts or crystals from the Oruanui HSR or LSR should occur in the post-supereruption environment. Such an inference applies whether Oruanui compositions are represented by specific whole-rock, melt or mineral compositional trends, or contribute to unique mixing trends with any newly generated melts. The range of Oruanui rhyolite compositions, however, does not appear to be specifically represented in the post-Oruanui eruptions, which instead show several key contrasts. First, mineral compositions differ significantly from the Oruanui, with unique compositional trends in orthopyroxene $\mathrm{MnO}$ content for the dacites and SG1 rhyolites, and low-An plagioclase overlapping in composition with Oruanui plagioclase are rare (Figures 5.9 and 5.10). Second, whole-rock and glass compositions follow separate linear trends on many major and trace element variation diagrams (Figures 5.2 and 5.3), with whole- rock compositions never reaching silica values as high as in the Oruanui HSR. Both groundmass glass and melt inclusions in the postOruanui eruption deposits are chemically distinctive, with compositions overlapping with the high silica Oruanui glass being either rare or absent (Figures 5.5 and 5.6). The 
post-Oruanui magmas are also distinctly more radiogenic than the Oruanui magmas at ${ }^{87} \mathrm{Sr} /{ }^{86} \mathrm{Sr}>0.7059$ (Sutton et al., 1995). Third, the post-Oruanui magmas reflect different conditions of crystallisation to the Oruanui magma system, with significantly hotter model-temperatures and more reducing conditions, but notably at similar inferred depths within the crust (Figures 5.11-5.13; Table 5.4). Barker et al. (2014a) (CHAPTER 4) showed that the post-Oruanui magmas inherited very few Oruanui-aged zircons, and suggested that the Oruanui magmatic system was chronologically reset through thermally induced dissolution of zircon. Here, this interpretation is extended to suggest that the wider mush system experienced a significant shift in temperature and storage conditions to the extent that little or no chemical evidence of the Oruanui magma system remained.

An important aspect of proposing widespread thermal modification of the postOruanui magma system is identifying the heat source responsible for such processes. Hot mafic magmas of two compositional lineages are recorded as discrete pyroclasts and as inclusions in pumice from the Oruanui eruption (Sutton et al., 1995; Wilson et al., 2006; Allan et al., 2014). It is inferred that the total volume of mafic magma expressed in the Oruanui eruption would only represent a minor portion of the mafic melts likely involved in the parental magma system. As shown by quantitative field constraints, mafic magma intrusion into crystalline silicic mush can have significant effects on the structure and thermal stability of magma reservoirs and can result in large scale overturn (Bain et al., 2013). It is inferred that the huge decompression caused by the evacuation of $>530 \mathrm{~km}^{3}$ of magma could have resulted in large scale overturn of any remaining melt body in the immediate post-supereruption environment. In addition, the removal of the $530 \mathrm{~km}^{3}$ low-density rhyolite cap may have significantly changed the density structure of the magma reservoir permitting hotter and denser melts to rise to shallower levels and induce melting. Widespread heating and synchronous changes in storage conditions are supported by the relative shift in ${ }^{87} \mathrm{Sr} /{ }^{86} \mathrm{Sr}$ ratios, where the more radiogenic post-Oruanui magmas are consistent with increased melting and assimilation of country rock, most plausibly Mesozoic greywacke (Sutton et al., 1995; 2000; Charlier et al., 2010). In contrast to the apparent shift in felsic compositions, postOruanui mafic compositions analysed as discrete clasts from Unit S and mafic inclusions in pumice from units $\mathrm{Y}$ and $\mathrm{Z}$ overlap in their whole-rock major and trace element composition with the Oruanui tholeiitic mafic clasts (Figures 5.2 and 5.3; Allan et al., 2014). These observations highlight that although the felsic melts contrast between the Oruanui and post-Oruanui systems, the mafic magmas appear to have 
remained the same in the post-supereruption environment. They also highlight the contrasts between post-Oruanui mafic compositions and primitive calc-alkaline basalts erupted $<20 \mathrm{~km}$ to the south from the Waimarino basalt source during this time period, suggesting that there may be pronounced contrast in mafic melt chemistry and sources across this small geographical distance. Alternatively, these contrasts may reflect differences in crystal fractionation paths, crystal accumulation, mixing and filtering action in the crust due to largely different crustal structures and plumbing systems as demonstrated for the broader trends in basalt chemistry across the TVZ by Gamble et al. (1990). Notably, a calc-alkaline lineage of mafic clasts have been documented from the Oruanui supereruption indicating that different mafic compositions may either exist at depth or be laterally drawn in from other magma systems, as observed for silicic compositions in the early phases of the eruption (Allan et al., 2012, 2014).

\subsubsection{Post-supereruption reorganisation and reconstruction of Taupo's magmatic system}

\subsubsection{Origin and significance of the $\sim 21-17 \mathrm{ka}$ dacites}

A range of processes have been proposed to account for the formation of intermediate melt compositions including extensive fractional crystallisation from mafic mantle derived melts (Garrison et al., 2012), mixing between endmember mafic and silicic magmas and their crystal cargoes (Reubi \& Blundy, 2009; Millet et al., 2014), or extensive melting of crustal material (including still-hot plutonic material) or the hybridized mantle wedge (Graham et al., 1992, 1995; Price et al., 2005). All three processes (or a combination thereof) have been invoked for the generation of dacitic melts in the TVZ in particular (Reid \& Cole, 1983; Price et al., 2005; Deering et al., 2011; Millet et al., 2014). Below I take into account the evidence provided by wholerock, glass, melt inclusion and mineral chemistry to infer the origin of the three Taupo dacite units.

In comparison to the later rhyolites, the dacites are hotter $\left(\sim 900{ }^{\circ} \mathrm{C}\right)$, and relatively crystal-rich ( $25 \mathrm{wt} . \%)$, with a wide range of crystal core and melt inclusion compositions accompanying a comparatively narrow range of crystal rim and matrix glass compositions (Figures 5.5, 5.8 and 5.9). Charlier et al. (2010) showed that the post-Oruanui dacite Unit $\Omega$ is strongly zircon undersaturated and yet contains minor amounts of euhedral xenocrystic zircon. The U-Pb age spectra of these xenocrystic zircons can be correlated with the zircon age spectra for greywacke country rock (Jurassic Kaweka terrane and Cretaceous Pahau terrane: Adams et al., 2009) and 
pumice in the $350 \mathrm{ka}$ Whakamaru eruption (Brown \& Fletcher, 1999). Such observations provide unequivocal evidence for open system dacite melt genesis involving some proportion of assimilated crustal material, with the crustal source having to be melted to the point of disintegration to liberate individual zircons into the melt (Charlier et al., 2010). Gelman et al. (2013) extended these observations with mineral chemistry and thermal modelling of Unit $\Omega$ to propose that crustal involvement and zircon incorporation was due to down-temperature evolution of a mid-to lower crustal dacite magma via fractional crystallisation with some minor late assimilation. Our observations of mineral zonation in all three of the dacite deposits match those of Gelman et al. (2013) where crystal rim compositions are relatively restricted and most of the crystal cargo appears to be in equilibrium with the host melt, as suggested by MELTS thermodynamic modelling and mineral-melt equilibrium based thermometry (Table 5.4). However, the wide range of crystal core textures, compositions and melt inclusion compositions suggest that there were periods of significant mineral-melt disequilibrium during formation of the three dacite magmas (Figures 5.5 and 5.7). Resorbed plagioclase cores up to $\mathrm{An}_{90}$, orthopyroxenes up to $\mathrm{En}_{70}$ and clinopyroxenes up to $\mathrm{En}_{50}$ overlap in composition with their counterparts in Oruanui and post-Oruanui mafic materials, suggesting that mafic magmas played an important role (Figure 5.14). Such observations raise questions as to whether the dacite compositions at Taupo were formed solely through down-temperature fractional crystallisation from a less evolved basaltic parent or if open-system processes played an important role.
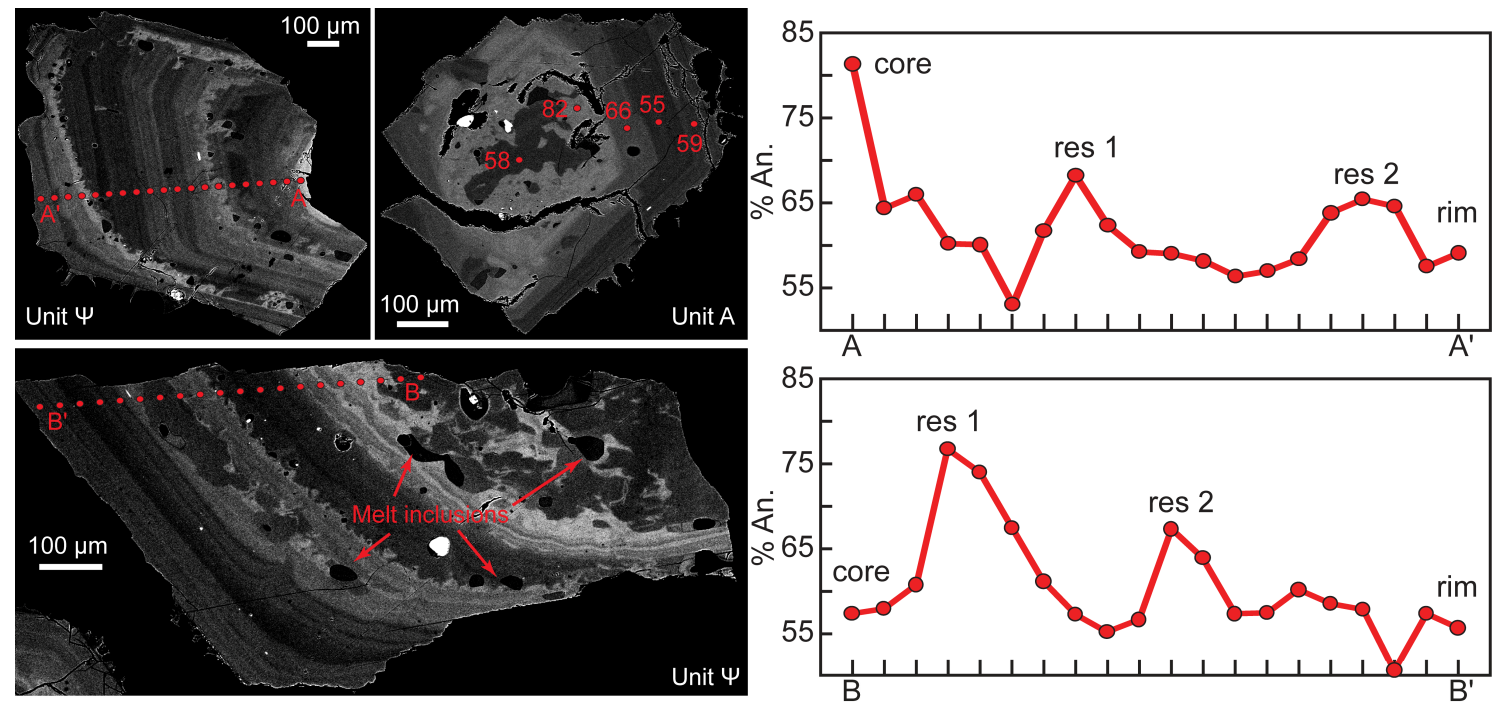

Figure 5.14. Representative BSE images and compositional profiles of plagioclase crystals from the postOruanui dacites showing variation in anorthite (An) content from crystal cores to rims, with multiple high-An resorption zones (res) inferred to represent dissolution resulting from recharge and mixing with less evolved mafic melts. See Appendix J for raw data. 
In considering the origin of the dacites two key variables are important:

1. The depth and conditions of crystallisation. From mineral equilibrium models, the model temperatures of the three final dacite melts were $\sim 900{ }^{\circ} \mathrm{C}$, with water contents from melt inclusions and plagioclase-melt equilibria ranging between 4.5-5.5 wt. \%. The maximum observed volatile contents from Unit $\Omega$ melt inclusions at a temperature value of $\sim 900{ }^{\circ} \mathrm{C}$ give estimates of $\sim 200-220 \mathrm{MPa}$ from water saturation pressures (using VolatileCalc: Newman \& Lowenstern, 2002). Assuming an overlying density of $2.65 \mathrm{~g} / \mathrm{cm}^{3}$, this pressure equates to depths of $\sim 7.5-9 \mathrm{~km}$ in the crust. This range is deeper than that calculated from Oruanui melt inclusions (4-6.5 km: Liu et al., 2006), but overlaps with those estimated for the Oruanui deeper mush body from amphibole barometry (Allan et al., 2014) and the depth of zones of low resistivity identified in the modern day TVZ north of Taupo (Heise et al., 2010). Similar depths for intermediate composition mush zones are also reported for Okataina volcanic centre in the TVZ (Shane et al., 2007, 2008; Smith et al., 2010; Cole et al., 2014). Rim compositions of the Taupo dacite plagioclase at $\sim \mathrm{An}_{60}$ are consistent with experimental studies of plagioclase compositions in similar composition melts at $\mathrm{P}_{\mathrm{H}_{2} \mathrm{O}}$ of $>180 \mathrm{MPa}$ at $900{ }^{\circ} \mathrm{C}$, a melt fraction of $\sim 0.8$, and 5.5 wt. $\% \mathrm{H}_{2} \mathrm{O}$ (Fig. 10 of Cashman \& Blundy, 2013). The melt inclusion pressures are therefore considered to reflect the final storage conditions of the dacites, consistent with the plagioclase rim compositions. However, high-An cores and resorbed internal boundaries also highlight a history of the dacites at either significantly higher pressures and temperatures or more plausibly reflect interaction with and/or inheritance of crystals from hotter, more mafic melts (Figure 5.14). The pressure range of 300-700 $\mathrm{MPa}$ (equivalent to depths of 11-26 km) used for modelling by Gelman et al. (2013) is not consistent with the observed compositional range of plagioclase or the crustal structure of the TVZ, where there is a rapid transition at $15 \mathrm{~km}$ depth to heavily intruded mafic lower crust (Harrison \& White, 2006). Even mafic compositions erupted from Taupo rarely yield barometry estimates of $>400 \mathrm{MPa}$ (Figure 5.12; Allan et al., 2014).

2. The compositional range of parental melts or assimilates. Four starting compositions are considered to be plausible for modelling AFC or partial melting processes in the genesis of the dacites. First, if the dacites were generated through fractionation from a basaltic or basaltic-andesite parent, then 
the most appropriate composition is likely to be similar to the Oruanui mafic clasts. The mafic clasts range in composition and themselves reflect differentiation and/or mixing processes, with the tholeiitic clasts notably heading towards the composition of the dacites (Wilson et al., 2006; Allan et al., 2014; Figures 5.2 and 5.3). However, pure fractional crystallisation does not account for the elevated ${ }^{87} \mathrm{Sr} /{ }^{86} \mathrm{Sr}$ values in the dacites over those values in the Oruanui magmas. Second, a greywacke parent or assimilant could be considered as a source, and would explain the elevated ${ }^{87} \mathrm{Sr} /{ }^{86} \mathrm{Sr}$ values and zircon age spectra (Sutton et al., 2000; Charlier et al., 2010). The isotopic ranges, final bulk composition of the dacites and their observed mineralogies, however, do preclude a source purely from the melting of greywacke (Conrad et al., 1988). Third, a plutonic residue of similar composition to the Whakamaru rhyolite could be involved given the geographically overlapping caldera margins (Figure 5.1; Wilson et al., 1986). Whakamaru compositions are broadly similar in their whole-rock and isotopic compositions to the Oruanui and post-Oruanui magmas, and small amounts of assimilation would be difficult to fingerprint. Indeed, the only evidence for Whakamaru assimilation in the post-Oruanui magmas is through zircon inheritance (Charlier et al., 2010; CHAPTER 4: Barker et al., 2014a), with no biotite present or Whakamaru crystal cores identified, and only a few melt inclusions in the dacites trending towards the characteristically higher $\mathrm{K}_{2} \mathrm{O}$ compositions of the Whakamaru magmas or those of the contemporary NEdome magma type. Fourth, mixing with, partial assimilation or melting of Oruanui mush compositions could have occurred, given the apparent depths at which the dacites were stored. However, as with the Whakamaru source, significant levels of melting or assimilation immediately prior to eruption would likely result in inheritance of Oruanui crystal cores and xenocrystic melt inclusions. Oruanui crystal compositions and Oruanui-aged zircons occur in the dacites and SG1 rhyolite magmas in only minor proportions $(<5 \%$ : Charlier et al., 2010; CHAPTER 4: Barker et al., 2014a). If Oruanui residues were important in genesis of the dacite magmas, all direct evidence for this source has been overprinted.

Given the evidence outlined above it is considered most plausible that the dacites were sourced from a region overlapping with the base of the old Oruanui mush system, at depths of $\geq \sim 8 \mathrm{~km}$ (Allan et al., 2014), as also recently documented by Millet et al. (2014) for dacites erupted from nearby Tauhara volcano (Figure 5.1a). The 
Oruanui crystal mush would, from its mineralogical characteristics, provide a logical level at which ascending mafic magmas would pond due to the density contrast. Newly incoming mafic melts stalling and differentiating at this level would help explain the inferred heating of the old Oruanui system and widespread thermal dissolution of the Oruanui-sourced crystal phases such as zircon. Although mixing clearly occurred at some point in their history (Figure 5.14), the composition of the dacites do not solely result from pre-eruptive mixing as inferred for the Tauhara dacites (Graham \& Worthington, 1988; Millet et al., 2014). The majority of the post-Oruanui dacite mineral rims are in equilibrium with their host melt and show evidence for extensive crystallisation to evolved compositions (Figure 5.14; Gelman et al., 2013). However, this does not discount the potential for the dacites originating from an earlier mixing event between old Oruanui melt (or mush) and mafic material, the product of which then underwent subsequent storage and crystallisation. Indeed, setting aside the isotopic evidence, the bulk composition of the dacites can be generated by $\sim 40-50 \%$ mixing between Oruanui rhyolite and the low $\mathrm{SiO}_{2}$ tholeiitic end-member (Figure 5.15a). Mixing is also indicated as a possible scenario from the overlapping compositions of the dacites with the highest $\mathrm{SiO}_{2}$ tholeiitic clasts or mingled pumices in the Oruanui, which are interpreted as mixed compositions (Figures 5.2 and 5.3; Wilson et al., 2006; Allan et al., 2014). Alternatively, the dacite magma compositions can be modelled by perfect fractional crystallisation from the most primitive Oruanui tholeiitic compositions, through $\sim 60 \%$ crystallisation (Sutton et al., 2000). As the Oruanui HSR and LSR magmas themselves were likely generated through extensive fractionation of a basaltic parental melt and minor assimilation (Wilson et al., 2006), mixing and fractionation scenarios for the origin of the dacites are difficult to distinguish. However, the parental basalt or final dacite must have incorporated at some stage significant amounts of a more radiogenic melt in order to achieve the observed isotopic signatures. As shown by Sutton et al. (2000), contamination of a basaltic Oruanui composition with $20 \%$ Torlesse greywacke can explain the elevated ${ }^{87} \mathrm{Sr} /{ }^{86} \mathrm{Sr}$ values. Greywacke and Whakamaru assimilation occurred right up to the point of eruption as evident through inheritance of euhedral xenocrystic zircons in the Unit $\Omega$ dacite (Charlier et al., 2010).

\subsubsection{Establishment of the (new?) rhyolitic mush system from $<17 \mathrm{ka}$}

After a further $\sim 5$ ka time break, Taupo resumed erupting with the rhyolites of SG1, which show three features that suggests they are closely genetically linked to the earlier dacites (Sutton et al., 2000). First, the mineralogies of the two subgroups are similar, 

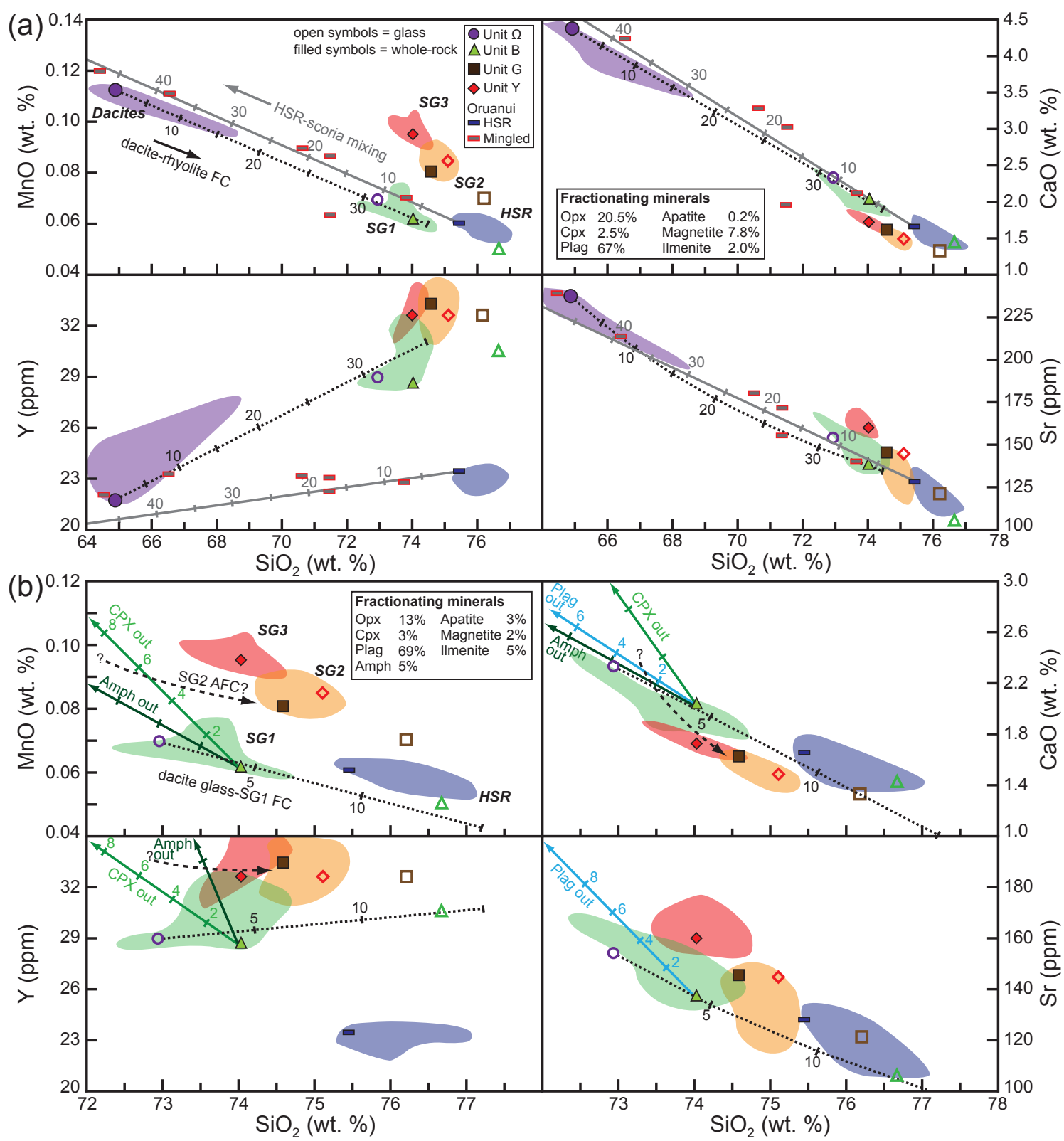

Figure 5.15. Variation diagrams of selected major and trace elements showing the inferred chemical evolution pathways of the post-Oruanui magmas with fractional crystallisation and/or magma mixing. a) Fractional crystallisation (FC) path linking the $\Omega$ dacite whole-rock composition with dacite-glass and rhyolite whole-rock compositions through $>30 \%$ crystallisation. The results of magma mixing between the Oruanui HSR and the least evolved Oruanui tholeiite scoria composition from Wilson et al. (2006) are shown for an alternative origin of the dacite melts. Mingled pumices refer to those Oruanui pumices that show physical evidence for mixing. b) Fractional crystallisation path linking the $\Omega$ dacite-glass composition with the SG1 rhyolite whole-rock and glass compositions. A representative whole-rock (filled symbol) and glass (open symbol) compositional pair are shown for each of the subgroups for reference. Mixing vectors refer to the compositional change inferred with the dissolution of the observed mineral phases, with tick marks at $2 \%$ increments. Note the elevated $\mathrm{MnO}$ and $\mathrm{Y}$ resulting from the dissolution of clinopyroxene and/or amphibole. Dashed FC path represents the inferred evolution path for the SG2 and SG3 magmas but is not modelled due to the range of potential starting compositions after dissolution. Mineral partition coefficients calculated from mineral rim-glass pairs for amphibole and clinopyroxene are from this study and Allan et al. (2014) for orthopyroxene. Plagioclase Sr partition coefficients calculated using Blundy \& Wood (1991) for $\mathrm{An}_{55}$ for the dacites and $\mathrm{An}_{40}$ for the rhyolites at $900{ }^{\circ} \mathrm{C}$ and $840{ }^{\circ} \mathrm{C}$ respectively. Models performed using PETROMODELER program from Ersoy (2013). See text for discussion. 
with compositions that form continuous trends where SG1 crystal core compositions overlap with those of dacite rims and interiors (Figures 5.8 and 5.9). Second, dacite glass compositions fall on a trend intermediate between the dacite and rhyolite compositions (Figure 5.4), while some melt inclusions from the SG1 rhyolites overlap with dacite glass selvedge compositions (Figure 5.5). Third, the two groups have similar ${ }^{87} \mathrm{Sr} /{ }^{86} \mathrm{Sr}$ values, with only a slight increase in SG1, explicable by assimilation of $\sim 2-5 \%$ extra greywacke melt (Sutton et al., 2000).

The link between the dacite whole-rock and glass compositions can be modelled by $\sim 30-35 \mathrm{wt} \%$ fractional crystallisation using rim compositions of the crystal phases observed in the dacite (Sutton et al., 2000; Figure 5.15a). Some elements (e.g. Sr, Ti) do not fit this modelling, likely due to slight enrichments through resorbed or inherited high-An or high-En crystal cores. The dacite glass can then be further fractionated by $\sim 5 \mathrm{wt} \%$ with the mineral phases present in the SG1 rhyolites to form the bulk rhyolite compositions, or $10-15 \mathrm{wt} \%$ to form the rhyolite glass compositions (Figure 5.15b). At this point the levels of crystallisation required to link the dacite whole-rock and rhyolite melt compositions reaches $\sim 50 \%$, and is considered to represent an important stage in the evolution of the new magma system. At crystallinity levels of $>50 \%$, the magma is likely to reach rheological locking point and form a rigid mush (e.g. Marsh, 1981; Vigneresse et al., 1996; Bachman \& Bergantz, 2008). The dacite magmas are therefore interpreted to represent a forerunner or pre-mush snapshot of the newly established rhyolitic system, which cooled and crystallised in the time period between the two groups from 17-12 ka. An enhanced period of crystallisation prior to the SG1 rhyolites is reflected in the model age spectra for zircons in the SG1 rhyolites, with a dominant age peak observed at $\sim 12-15 \mathrm{ka}$ (CHAPTER 4: Barker et al., 2014a). The rhyolite melts are thus interpreted to represent the final product of what started as a largely dacitic mush formed through assimilation and fractional crystallisation processes at the base of the old Oruanui mush system which then cooled sufficiently at some point in the time break between the two eruption groups.

The formation of the largely new mush system is considered to have several major structural influences on Taupo. First, the formation of a rhyolitic melt bearing mush would essentially form a density trap, largely inhibiting progenitor melts from reaching the surface. The dacite melts likely continued to exist at depth into the young system, providing further material for differentiation, but could not reach the surface due to the density contrasts. Second, the formation of the rhyolite represents a cooling trend with the more evolved magmas and their crystals equilibrating at shallower levels. 
Crystallisation and rebuilding of the rhyolite system may have occurred at different rates across the inferred extent of the magma system depending on the local conditions of crystallisation. A subpopulation of zircons in the post-Oruanui rhyolites cluster at $>16 \mathrm{ka}$, suggesting that certain regions of the magma system may have been sufficiently cool to allow zircon crystallisation during this time period (CHAPTER 4: Barker et al., 2014a). By 12 ka however, it is evident that a significant volume of mush had rebuilt beneath Taupo, with relatively uniform magma chemistries being erupted from geographically spaced vents around Lake Taupo and to the north for Unit D. The silicic mush system had likely rebuilt in the $\sim 10 \mathrm{kyr}$ following the supereruption and had moved into a new phase of productivity with a new cycle of eruptions only $\sim 13.5 \mathrm{kyr}$ after the Oruanui event.

The strong connection between the dacites and SG1 rhyolites can also be interpreted from the changes in apparent pressure. Amphibole barometry for units B and $\mathrm{C}$ indicates that the early rhyolite magmas were stored at pressures of $\sim 100-150 \mathrm{MPa}$, similar to the Oruanui HSR (Figure 5.12; Allan et al., 2014). The SG1 rhyolites also had a strong connection to deeper sourced melts as indicated by rare inherited amphibole in the young SG1 eruption units D and E, which yield model pressures (to $>200 \mathrm{MPa}$ ) that extend to similar values observed in the Oruanui LSR and mafic compositions. The absence of amphibole in the dacites is taken to reflect changing mineral stability (Figure 5.16). The post-Oruanui dacites are consistent with experimental studies (Conrad et al., 1988) in being likely too hot for amphibole or quartz crystallisation but able to crystallise plagioclase, clinopyroxene and orthopyroxene (Figure 5.16a). However, the experimental conditions of Conrad et al. (1988) were notably at much higher pressures than those considered likely for the post-Oruanui dacites or rhyolites. Experimental studies on granites suggest that amphibole stability is also highly dependent on and sensitive to minor changes in pressure (Dall'Agnol et al., 1999; Klimm et al., 2003). When the effects of variable pressure are considered, the dacites are still above the amphibole stability field at both high and low pressures at temperatures of $>900{ }^{\circ} \mathrm{C}$ (Figure 5.16b, c). The position of the amphibole stability field from experimental studies is also consistent with the trends observed in the SG1 rhyolites, where the magmas had cooled sufficiently and moved to lower pressures to enter the amphibole stability field (Figure 5.16b,c). The periodic stability of amphibole and accompanying instability of orthopyroxene match the textural features of the orthopyroxene in SG1 rhyolites, which commonly show resorbed cores (Figure 5.7). These features were also recorded in the Oruanui HSR orthopyroxene, consistent with changing pressures and 

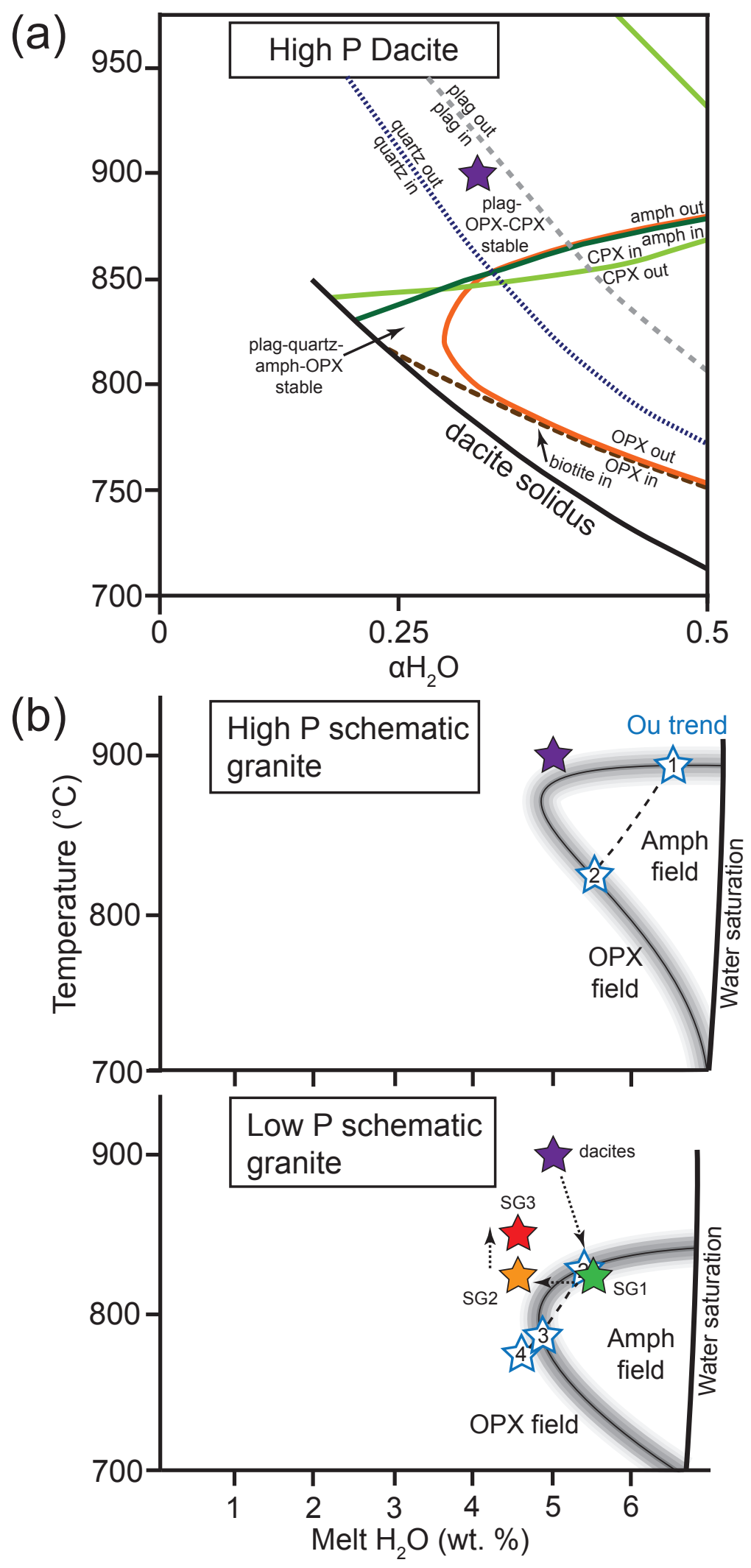

Figure 5.16. Comparison between magmatic conditions in the post-Oruanui magmas and experimental results for (a) Conrad et al. (1988) for average TVZ dacites at high pressures (10 kbars) and (b) amphibole in granites from the experiments of Dall'Agnol et al. (1999) and Klimm et al. (2003). Note that the position of the cotectic and amphibole stability field shown in (b) is schematic only and decreasing the pressure in either scenario would result in shifting the stability field to lower values of temperature and melt $\mathrm{H}_{2} \mathrm{O}$. The stars labelled 1-4 represent key points in the development and decompression of the Oruanui melt dominant body from Allan et al. (2013) for comparison. Points 1-2 represent major decompression from the mush zone at $\sim 140-300 \mathrm{MPa}$ and points 2-3 represent development and growth of the magma body at shallow levels ( $<6 \mathrm{~km}$ depth) until point 4 where orthopyroxene is stable over amphibole. Amphibole is only stable in the post-Oruanui SG1 units B and C. 
temperatures in the presence of amphibole (e.g. Allan et al., 2013; Figure 5.7). In addition, crystal fractionation paths between the dacites and SG1 rhyolites require amphibole crystallisation to explain the trends observed in amphibole-compatible elements such as Y and Mn (Figure 5.15b). The younger SG1 (and SG2/SG3) eruptions then apparently move away from the amphibole stability field again, which can be attributed to either lower melt $\mathrm{H}_{2} \mathrm{O}$ contents or higher temperatures (Figure 5.16c). The shape of the amphibole stability field precludes the magmas being sourced from a deeper zone at high melt $\mathrm{H}_{2} \mathrm{O}$ as amphibole becomes stable at higher pressures (Figure 5.16b; Dall'Agnol et al., 1999; Klimm et al., 2003). Only a minor increase in temperature is observed for Unit E and the SG2 rhyolites, (not resolvable within the uncertainties of the thermometry) and the gradual disappearance of amphibole may have also reflected a minor reduction in melt- $\mathrm{H}_{2} \mathrm{O}$ with continued volcanism, which pushed the magma (and then the deeper mush zone) beyond amphibole stability. Notably, in the experimental studies of Conrad et al. (1988), the stability of clinopyroxene is closely aligned with that of amphibole and the two only appear stable in a relatively narrow compositional window (Figure 5.16a). The coincidental appearance and disappearance of these two phases from the SG1 rhyolites can therefore be explained by changes in the conditions of crystallisation towards the end of SG1 and into the SG2 rhyolites.

\subsubsection{Relationships between the temporally separated rhyolitic subgroups $<10 \mathrm{ka}$}

The second (7.1 to $2.7 \mathrm{ka}$ ) and third (2.2 ka to present) rhyolite subgroups are chemically distinctive, forming separate linear arrays on most major element variation diagrams in comparison to the Oruanui and SG1 rhyolites (Figure 5.2), with accompanying stepwise changes in trace element concentrations (Figure 5.4). The apparent shift in composition from SG1 to SG2 was interpreted by Sutton et al. (2000) to mean that the rhyolite subgroups could not be related through fractional crystallisation, and instead, a subtle change in source was required in the $\sim 3 \mathrm{kyr}$ period between the subgroups. Such an interpretation has major implications for magma storage times and repose intervals between eruption groups. Did the SG2 and SG3 magmas originate from magma systems at different positions and depths within the crust (cf. Smith et al., 2005), or could they instead come from the same source as the SG1 magmas but with subtly different conditions of crystallisation?

Changes in whole-rock and glass chemistry within the SG1 rhyolites and between the SG1 and SG2 rhyolites are accompanied by changes in mineralogy, indicating that phase stability may play a role in explaining the observed shifts in 
chemistry. In comparison to earlier eruptions in the SG1 sequence, Unit E has lower whole-rock concentrations of $\mathrm{CaO}$, with higher $\mathrm{MnO}$, as well as subtle changes in concentrations of trace elements such as $\mathrm{Zn}, \mathrm{Zr}$, Sc and Y (Figures 5.2 and 5.4). In addition, the compositions of key mineral phases diverges from the trends seen in the earlier eruptions B and C (Figures 5.8, 5.9 and 5.11). As the final eruption in the SG1 sequence, Unit E has compositions trending towards the SG2 rhyolites, in line with the observed changes in crystal chemistry. The first of the SG2 eruptions then have significantly higher $\mathrm{MnO}, \mathrm{Na}_{2} \mathrm{O}, \mathrm{Zn}, \mathrm{Zr}, \mathrm{Y}, \mathrm{Sc}$ and lower $\mathrm{CaO}, \mathrm{La} / \mathrm{Sm}$ and $\mathrm{Yb} / \mathrm{Gd}$ (Figures 5.2-5.4). However, changes in these elements and elemental ratios can be explained by two processes that do not require a drastic change in source between the SG1 and SG2 subgroups:

1. Dissolution of amphibole and/or clinopyroxene due to changing melt conditions. If the magma moved out of the stability fields of amphibole and/or clinopyroxene, several specific elements would be liberated by dissolution, or not sequestered by growth, of these mineral phases (Figure 5.15b). Trace element analysis of crystal rims and glass separates for the SG1 rhyolites shows that for amphibole Mn, Y, Sc, Zn and MREE are highly compatible (with

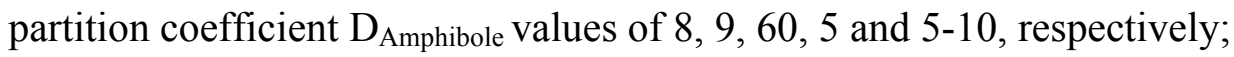
Appendix K). Clinopyroxene rims analysed under the same conditions are also enriched in Mn, Y, Sc and Zn and MREE-HREE (with $\mathrm{D}_{\mathrm{Cpx}}$ values of 12, 3, 50, 3 and 2-4, respectively). Liberation into or retention of these elements in the melt would explain the observed apparent changes between the subgroups and the changes in $\mathrm{La} / \mathrm{Gd}$ and $\mathrm{Yb} / \mathrm{Gd}$ ratios. Concentrations of $\mathrm{MnO}$ in $\mathrm{SG} 2$ orthopyroxene also record the changing composition of the melt as a result of dissolution. Although $\mathrm{D}_{\mathrm{Opx}}$ values of $\mathrm{Mn}$ remain constant between the $\mathrm{SG} 1$ and SG2 units at $25-30$, relative concentrations of MnO in SG2 orthopyroxenes increase as the host melt $\mathrm{MnO}$ contents increase by $\sim 20-30 \%$ relative to those in SG1 (Figures 5.9 and 5.10). The higher MnO contents of the SG2 melt could be achieved through dissolution alone if the original source contained $\leq 5 \%$ clinopyroxene or $\leq 7 \%$ amphibole (or a combination of both: Figure 5.15b). Similar results can be achieved for $\mathrm{Y}, \mathrm{Sc}$ and $\mathrm{Zn}$ through $\leq 5 \%$ dissolution of either mineral, consistent with the observed shift in mineralogy between SG1 and SG2/SG3 rhyolites.

2. Changes in crystal zonation, plagioclase crystallisation and maturation of the mush system. Many of the trends in whole-rock compositions can be explained 
by variable degrees of enrichment through inherited crystal cores from precursor magmas. SG1 units, for example, have a high proportion of crystals with highAn or high-En cores (Figures 5.8 and 5.9). Even though the pumices are generally crystal poor ( $<7 \mathrm{wt}$ \%: Table 5.2 ), minor enrichments of highly compatible trace elements such as $\mathrm{Sr}$ and $\mathrm{V}$ can be explained by inheritance of high-An plagioclase and high-En pyroxene, respectively (Figure 5.4). Inheritance of less evolved cores or interior zones is much less common in the SG2 eruptions, interpreted to reflect that the physical connection between the new rhyolite system and the precursor dacitic eruptions became less evident (Figure 5.10). It is inferred that this change is most likely due to maturation and thickening of the new mush system with cooling and extensive crystallisation, again reflected in the model-age spectra of zircon crystallisation (CHAPTER 4: Barker et al., 2014a). The observed changes in $\mathrm{CaO}$ and $\mathrm{Na}_{2} \mathrm{O}$ concentrations can then be explained by further crystallisation of a mineral assemblage dominated by plagioclase and orthopyroxene, consistent with a slight decrease in plagioclase An contents, especially towards the end of SG2 (Table 5.2; Figure $5.15 b)$. For SG3 rhyolites, the opposite is true, with melt compositions more consistent with dissolution of the observed crystal phases and accompanying increases in most highly compatible elements (Figures 5.2-5.4). Mineral compositional zoning and thermometry suggest that between the SG2 and SG3 eruptions the magmatic system underwent significant heating, resulting in partial mineral disequilibrium, dissolution and a corresponding shift in melt compositions (Figures 5.10, 5.11 and 5.15b). The connection between the subgroups remains evident through the composition of melt inclusions in the SG3 magmas (Figure 5.6) and the evolved composition of crystal cores observed in reversely zoned SG3 minerals that overlap with the compositions of the corresponding mineral phases in the final SG2 eruption deposits (Figure 5.10).

\subsubsection{The role of mafic magmas}

Given the inferred changes in the post-Oruanui magmatic system, important questions arise over the role of mafic magmas at Taupo. For example, why (and how) do mafic magmas sometimes make their way through to interact with the rhyolite system? Is the heat flux and mafic magma supply continuous through time or does it fluctuate in response to other factors such as tectonism? The only direct evidence for physical interaction of mafic magma with the post-Oruanui rhyolite system is through discrete 
andesitic clasts and hybrid rhyodacite material in Unit S, and small mafic inclusions of broadly similar composition in products of eruptions $\mathrm{Y}$ and Z. Notably, eruptions $\mathrm{S}$ and $\mathrm{Y}$ are much the largest post-Oruanui eruptions from Taupo. As shown by Rowland et al. (2010), volcanism in the central TVZ is interpreted to reflect a complex three-way coupling between the silicic system, the underlying mafic system and tectonic stress state. Mafic diking from source to the mid-crust can result in a change in the silicic mush zone with the potential for surface deformation and even triggering of rhyolitic diking to the surface (e.g. Leonard et al., 2002). Such interactions are critically dependent on the pre-determined 'potency' or readiness of the silicic system to generate an eruption as well as the tectonic stress state. Mafic diking and underplating of the silicic mush system importantly provides further material through differentiation and a heat source to ensure the longevity of the mush zone.

Mafic magma supply in the post-Oruanui system is difficult to temporally constrain given the rarity of its expression. However, it is clear from the results of this study that the flux of mafic magma supply to the mid- to lower- crust and its apparent interaction with the silicic magma system has varied through time. In the immediate post-Oruanui magma system mafic magma flux is likely to have been significantly elevated due to decompression of the silicic system, with widespread mixing and heating of the old Oruanui mush. Andesitic vents that were active in the Tongariro Volcanic Centre from 11.5-12 ka are distributed along a NNE trending lineament and are interpreted to relate to an episode of accelerated rifting and dike intrusion during this time period (Topping \& Kohn, 1978; Nairn et al., 1998; Rowland et al., 2010). A longer term periodicity of magma-assisted rifting processes and higher rates of influx of mafic magmas into the crust below Taupo could be the principal cause of the thousands to tens of thousands of years periodicity in magma heating and cooling cycles that is reflected in the zircon crystallisation histories of Taupo eruption products (Wilson \& Charlier, 2009; CHAPTER 4: Barker et al., 2014a).

The density trap formed by the newly developed mush system means that physical evidence for shallow mafic diking is rare, and small perturbations in mafic magma supply would be hard to interpret. For eruption S (Waimihia), however, mafic magma physically interacted with the pre- and syn-eruptive rhyolite system, resulting in a significant change in behaviour (Blake et al., 1992). Although the subsequent eruptions largely overlap in their vent positions (Figure 5.1a), there is no evidence in their mineral or bulk chemistry for widespread heating or mixing as a direct result of mafic magma interaction (Figure 5.10). In contrast, units $\mathrm{U}, \mathrm{V}$ and $\mathrm{W}$ have the highest 
$\mathrm{Rb} / \mathrm{Sr}$ ratios and the lowest $\mathrm{Zn}$ and $\mathrm{Zr}$ concentrations of the SG2 period (Figure 5.4). In addition, the youngest SG2 magmas have the highest ${ }^{87} \mathrm{Sr} /{ }^{86} \mathrm{Sr}$ values of all the postOruanui units, suggesting that there was either increased assimilation of greywacke, possibly through progressive contamination of magma chamber wall-rock and/or less rejuvenation of low ${ }^{87} \mathrm{Sr} /{ }^{86} \mathrm{Sr}$ magmas from depth (e.g. Knesel et al., 1999; Sutton et al., 2000). It appears that following the injection of mafic magma for eruption $S$, there was an overall reduction in heat flux from the underlying mafic system (Figure 5.13). In the period following this apparent cooling at $<2.8 \mathrm{ka}$, Taupo once again reversed behaviour. The overlapping trends of crystal and melt inclusion chemistry between the SG2 and SG3 magmas suggests that they are from similar sources but the SG3 magmas reflect significantly higher temperatures and mineral dissolution (Figure 5.13). The Unit Y eruption at $232 \pm 5 \mathrm{AD}$ (Hogg et al., 2012) is larger than all the other post-Oruanui eruptions combined (Figure 5.1b). A single mafic inclusion found within a pumice clast from the plinian fall deposit Y5 is the only direct evidence that mafic magma physically interacted with the rhyolitic magma (Figure 5.2). However, significant heating of the source region that gave rise to the eruption of $\sim 35 \mathrm{~km}^{3}$ of crystal poor (average $3.5 \mathrm{wt}$ $\%$ ) rhyolite must have occurred to generate the elevated model temperatures of the magma. The increased occurrence of mafic inclusions and mafic-derived crystals in material from eruption Z (e.g. Figure 5.10h) indicates that in the post-Unit Y magma system further mafic melt infiltration and heating occurred, resulting in physically mixing with the remaining rhyolite melt. This post-caldera heating and destabilisation is thought to be similar to, although on a much smaller scale, than that which occurred in the immediate post-Oruanui system.

\subsubsection{Summary of Taupo's magmatic system through time}

Given the geographically overlapping vent sites between the subgroups (Figure 5.1) it is suggested that the post-Oruanui rhyolites were tapped from a common and likely unitary mush system which changed and evolved through a series of stages as reflected in eruptive products as summarised below:

1. $25.4 \mathrm{ka}$ : Evacuation of the Oruanui magma system (Figure 5.17a). Prior to the Oruanui eruption there was a thermally and compositionally zoned crystal-rich mush body that developed over tens of thousands of years prior to eruption, likely spanning a large portion of the crust from as shallow as $3.5 \mathrm{~km}$ to a depth of $\sim 10 \mathrm{~km}$ (Liu et al., 2006; Wilson et al., 2006; Allan et al., 2014). The top of this mush body was quartz bearing and the roots quartz-free. The crystal-poor 

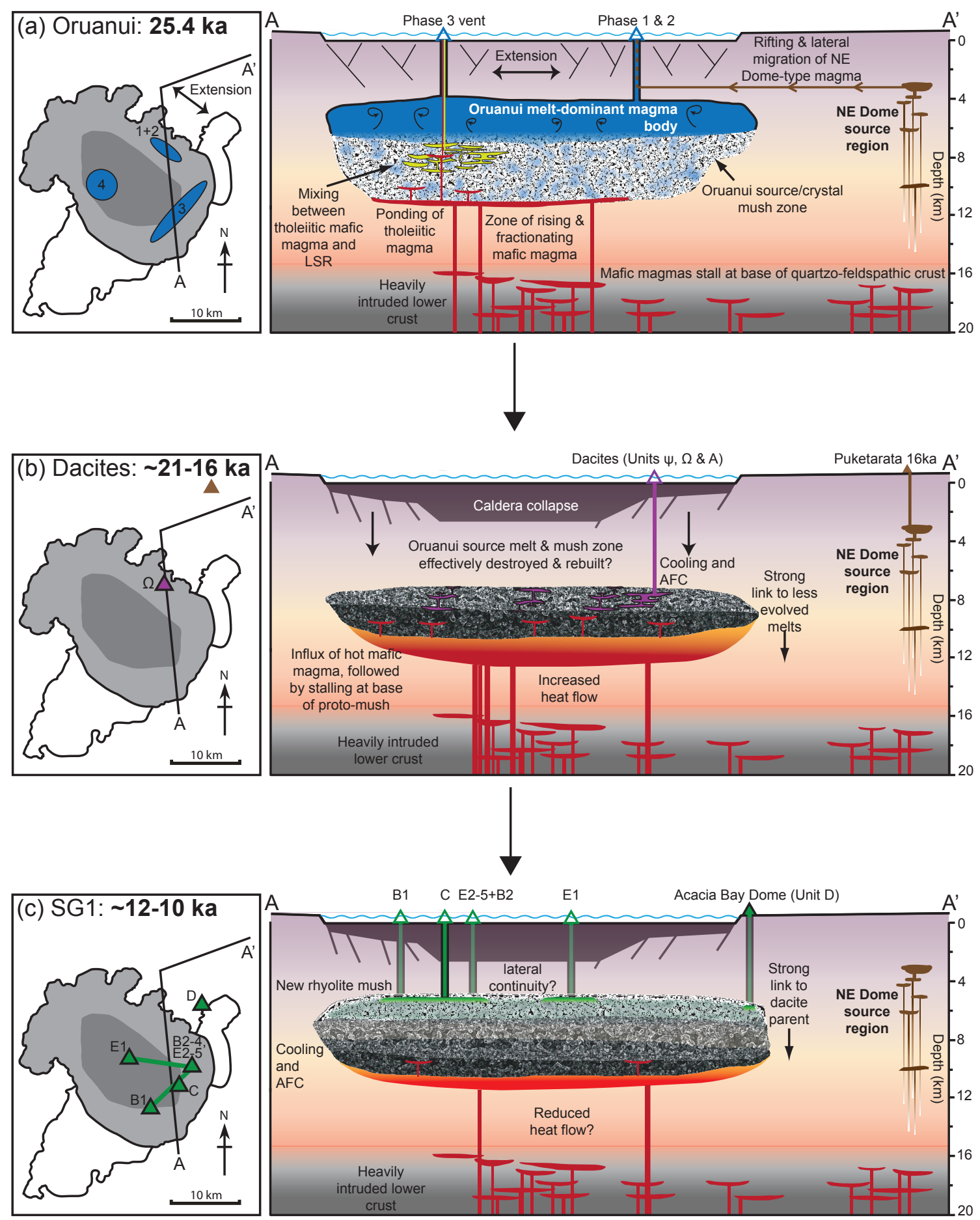

Figure 5.17. Schematic illustration of the inferred structural changes in Taupo's magmatic system between (a) the Oruanui magma system from Allan et al. (2014) at $25.4 \mathrm{ka}$, (b) the post-supereruption period of dacite magmatism from $\sim 21-16 \mathrm{ka}$ and (c) the first eruption of rhyolites at $\sim 12 \mathrm{ka}$. The depth of the melt dominant magma lenses and mush zones are inferred from amphibole barometry using Ridolfi et al. (2010) and melt inclusion $\mathrm{PH}_{2} \mathrm{O}$ data from Liu et al. (2006) and this study. Vent sites are from Wilson (1993, 2001); tie lines indicate a syn-eruptive shift in vent site. The horizontal extent of the magmatic systems are inferred from the shape of the Oruanui collapse structure from Davy \& Caldwell (1998) and subsequent positioning of vent sites. The lateral continuity of the melt dominant bodies and mush zones, and the exact depth of mafic magma intrusion and ponding are largely unknown. See text for discussion. 
HSR melt dominant body was then rapidly formed (over $<3000$ years) via melt extraction from the Oruanui mush, as evident by contrasting zircon age spectra between the Oruanui and the earlier Okaia eruption (Wilson \& Charlier, 2009), and compositional zoning patterns in Oruanui amphibole and orthopyroxene crystals (Allan et al., 2013). The uniformity of model temperatures at $\sim 790{ }^{\circ} \mathrm{C}$ (Figure 5.13) indicates that immediately prior to eruption the melt-dominant body was uniform in composition due to vigorous mixing and lacked any significant thermal gradient (Wilson et al., 2006; Allan et al., 2014). It is inferred from the presence of two lineages of mafic magmas in the Oruanui eruption and the lack of Oruanui compositions in the post-25.4 ka sequence that the Oruanui mush source was modified beyond recognition by immediately post-supereruptive intrusion of hot mafic magmas. Such an inference is consistent with the small proportion of Oruanui-aged zircons found in the postOruanui rhyolites (CHAPTER 4: Barker et al., 2014a).

2. 21-17 ka: Generation and eruption of the post-Oruanui dacites (Figure 5.17b). The higher magma temperatures, less evolved compositions and inferred depths of storage for the dacites reflect unique conditions in the post-Oruanui environment. Mineral zonation patterns are consistent with down-temperature fractional crystallisation combined with episodes of heating, disequilibrium and magma mixing. Minor assimilation of greywacke country rock and Quaternary plutonic material of Whakamaru age also imply that there were zones of preOruanui country rock still present underneath the Oruanui caldera area (Charlier et al., 2010). Given the $>8 \mathrm{~km}$ depth for equilibration of the dacite magmas, the residual Oruanui source region may have had a structural influence on where the magmas lodged, and may have also contributed material and/or melt through early magma mixing, but any evidence for large-scale inheritance (including zircons) was overprinted. Although the dacitic units only appear to have erupted from the northern end of the Oruanui caldera area, it is inferred that similar melt compositions were widespread through Taupo's magma system, as reflected by the close affinity of the dacites with the SG1 magmas which were later erupted from more widespread sources (Figure 5.1a). The consistency of the glass and mineral chemistry and apparent identical conditions of storage between the three dacite eruptions highlights that the process of their generation was repetitive in Taupo's early post-supereruptive environment. It is likely that similar dacite compositions extended through to the SG1 rhyolites and possibly remain in the 
modern system at depth. However, cooling, fractionation and then the formation of an evolved mush system at $<17$ ka means that their compositions are largely overprinted by processing, and the progenitor dacites can no longer make their way through to the surface because of the rhyolite density cap. Given the close temporal relationship of the dacites with the rhyolite eruption of Maroa at $~ 16$ ka (Puketarata), it is speculated that this renewal of activity may reflect rifting processes, particularly for Puketarata as its vents form a lineament that lie along a major fault structure (Figure 5.1a; Brooker et al., 1993; Leonard et al., 2010).

3. 12-10 ka: Eruption of the SG1 rhyolites (Figure 5.17c). The first erupted rhyolites show evidence for extensive crystallisation at depths as shallow as 4-5 $\mathrm{km}$, with subordinate amphibole reflecting temperatures of $<\sim 850^{\circ} \mathrm{C}$ and high melt $\mathrm{H}_{2} \mathrm{O}$ of $\sim 5.5$ wt. \%. Minor changes in temperature and/or melt $\mathrm{H}_{2} \mathrm{O}$ contents within the SG1 period possibly resulted in changes in phase stability following the eruption of units B and C. Eruptions which show evidence for a change in vent site (e.g. Unit E) do show significant variability in pumice compositions, indicating that the rhyolite system likely spanned a significant area across the Oruanui collapse structure. The only unit sourced from the northern region of Taupo (Acacia Bay dome: Unit D) is broadly similar in composition, but is more crystal rich than the other SG1 rhyolites and shows evidence for assimilation of Whakamaru-aged plutonic material (CHAPTER 4: Barker et al., 2014a). In addition, the positioning of vents along linear structures coincidental with modern faults indicates that the local tectonic stress regime may play an important role in determining where the eruptions were expressed (Rowland et al., 2010). For example, the syn-eruptive shift in vent sites for Unit E is linked by the Horomatangi Fault (Figure 5.1a). The SG1 rhyolites notably coincide with a period of elevated andesitic volcanism and regional rifting in the southern TVZ around the Tongariro area (Kohn \& Topping, 1978; Nairn et al., 1998). It is therefore considered that volcanism at Taupo during the SG1 time period may have been influenced by increased rifting and tectonic stress along the length of the Taupo Fault Belt (Rowland et al., 2010).

4. 7-2.8 ka: Eruption of the SG2 rhyolites (Figure 5.18a). During the $\sim 3 \mathrm{kyr}$ time gap between eruptions of SG1 and SG2, the magma system underwent widespread dissolution of amphibole and clinopyroxene and then crystallisation of a mineral assemblage limited to plagioclase, orthopyroxene, apatite and $\mathrm{Fe}-\mathrm{Ti}$ oxides. Given the consistent magma temperature estimates through time, the 


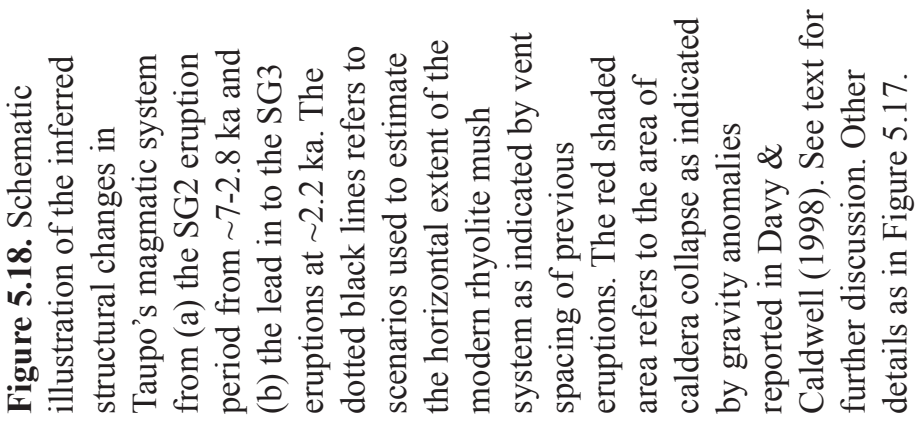
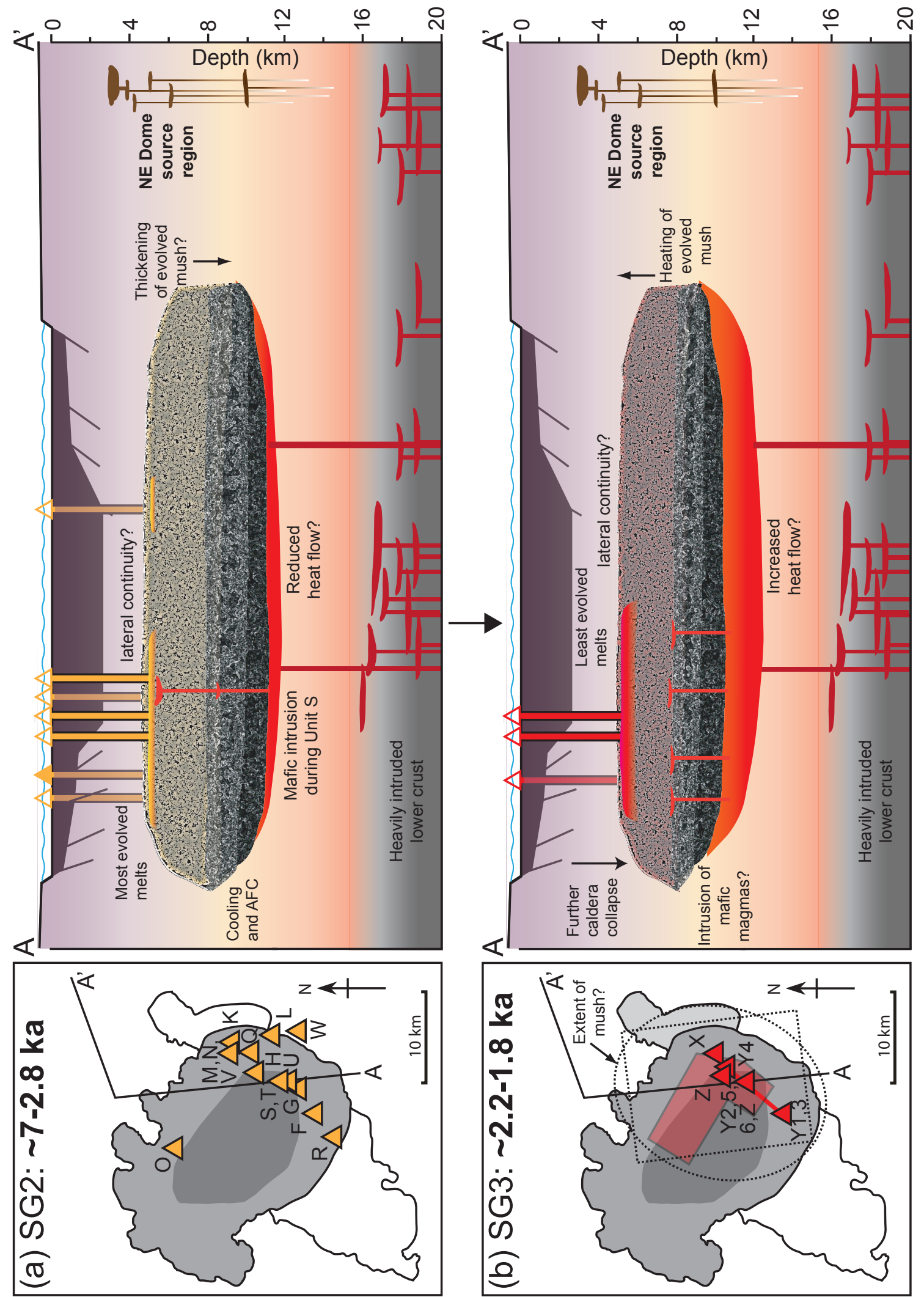
changes in mineral phase stability are considered to represent minor changes in melt $\mathrm{H}_{2} \mathrm{O}$ (Figure 5.16b). Inherited SG1- aged zircons and an additional population of zircons at $<10 \mathrm{ka}$ are apparent in the SG2 zircon age spectra indicating that this time period may have been accompanied by minor cooling and crystallisation following cessation of the SG1 eruptions. The SG2 rhyolites reflect a more established magmatic system with less evidence for precursor dacitic or mafic melts in inherited crystal cores or melt inclusions. The largest eruption in the SG2 sequence at $3.5 \mathrm{ka}$ (Unit S) shows evidence for mafic magma intrusion with discrete mafic clasts and mixed pumices (Blake et al., 1992). However, there is no evidence in the subsequent SG2 eruptions for widespread interaction with mafic magma through resorbed minerals or abrupt shifts in composition, despite geographically overlapping vent sites with eruption S. The final eruptions of SG2 (units U-W), in contrast, show evidence for further cooling and crystallisation.

5. 2.2-1.8 ka: Eruption of the $S G 3$ rhyolites (Figure $5.18 \mathrm{~b}$ ). The $\sim 600$ year time break between SG2 and SG3 saw significant changes at Taupo. During this break the rhyolitic magma system underwent significant heating $\left(>30-40{ }^{\circ} \mathrm{C}\right.$ increase in overall magma temperatures) and mineral dissolution as shown by mineral zonation and shifting melt compositions. Notably, the SG3 magmas have the lowest ${ }^{87} \mathrm{Sr} /{ }^{86} \mathrm{Sr}$ ratios of all the post-Oruanui rhyolites (Sutton et al., 2000). As shown by Knesel et al. (1999), decreasing ${ }^{87} \mathrm{Sr} /{ }^{86} \mathrm{Sr}$ ratios in evolved silicic magmas can result from increased levels of magma recharge through time. These observations are in line with the shift in temperature, trace element compositions and crystal zonation. No direct evidence has been found in this study for mafic interaction with the Unit X magma. However, small rare mafic inclusions in the pumices from Unit $\mathrm{Y}$ and the dome carapace pumiceous blocks from eruption $\mathrm{Z}$ suggest that mafic magmas were probably the cause of the heating trends seen in the Unit X eruption. The rapid heating of Taupo's magma system during this time may be linked also to the exceptionally large eruption volume of Unit $\mathrm{Y}$ in the post-Oruanui sequence. Eruption $\mathrm{Y}$ resulted in further caldera collapse, mostly around the NE side of Lake Taupo (Wilson, 1993; Davy \& Caldwell, 1998; Rowland et al., 2010). Following the Unit Y eruption, Taupo's magmatic system once again experienced an influx of hot mafic material as indicated by mafic inclusions in the Unit $\mathrm{Z}$ dome carapace pumices. 


\subsubsection{The contemporary magmatic system}

The latest eruptions from Taupo at $232 \pm 5 \mathrm{AD}$ (eruption Y) and somewhat younger (lava extrusions of eruption Z) collectively were the largest in the post-Oruanui sequence (collectively termed the Taupo eruption by Wilson \& Walker, 1985), resulting in the release of $>35 \mathrm{~km}^{3}$ magma and further destabilisation of the magmatic system. Important questions arise from the size and nature of this latest activity with regards to future activity and monitoring at Taupo. For example, did the associated caldera collapse change the structure of the deeper mush system? Was the Taupo eruption large enough for the volcano to require a long period of magmatic recovery or reconstruction and subsequent quiescence, to at least the present day? The uniform chemistry and mineralogy within single eruptions indicates that the crystal-poor rhyolites erupted from Taupo were assembled as largely unzoned melt dominant bodies prior to eruption. The key events within an eruptive cycle must therefore include the effective extraction of melt from the crystal mush and its rapid eruption before excessive cooling and crystallisation occur. Therefore, the size of the mush system is a critical factor to interpret with regard to the impact of a single eruption on the potential for future productivity and behaviour from the volcano.

As a simplified scenario, for an area ranging from $200-300 \mathrm{~km}^{2}$ (as given by estimates from the spacing of vents and extent of caldera collapse), the estimated thickness of the $530 \mathrm{~km}^{3}$ Oruanui melt-dominant body (assuming a uniform thickness) is $\sim 1.5-2.5 \mathrm{~km}$ (Allan et al., 2014). This estimate is in accord with the range of model pressures from melt inclusion and amphibole compositions (Liu et al., 2006; Allan et al., 2014; Figure 5.17a). An even bigger volume of crystal mush is then required below the melt dominant body down to $>8-10 \mathrm{~km}$, which in turn is buffered and heated by deeper mafic magmas. From the evidence provided in this study, the Oruanui mush system was mostly rebuilt in the post-supereruption environment. The newly rebuilt system likely extends over similar depths to the Oruanui system from at least $8 \mathrm{~km}$ (given the depth estimates for the dacite units) to $\sim 5 \mathrm{~km}$ depth as inferred from the inferred storage depths of the young rhyolites. A major question which remains is over what horizontal extent does this zone of hot mush material cover, and how much melt is potentially available for eruption? From the results presented in this study it is considered that there are several hypothetical scenarios for the modern structure of Taupo's magmatic system:

1. The area of melt-generating mush has re-established to a similar horizontal extent observed in the pre-Oruanui system. The post-Oruanui vents are spaced 
over a wide area of $\sim 280 \mathrm{~km}^{2}$ assuming a minimum area encompassed by a quadrilateral shape, or $\sim 330 \mathrm{~km}^{2}$ assuming an ellipsoidal shape (Figure 5.18b). Neither of these scenarios account for the additional extent of the Oruanui collapse structure and are considered as minimum areas using this approach. If the mush system is assumed to have an even thickness of $\sim 3 \mathrm{~km}$ (from $\sim 5 \mathrm{~km}$ to $8 \mathrm{~km}$ depth) over this area a volume of melt-bearing material of $>800-1000 \mathrm{~km}^{3}$ is implied. If such is the case, the $35 \mathrm{~km}^{3}$ of crystal-poor magma erupted in Unit Y likely represents only a relatively minor proportion of the extractable melt present at the time.

2. The area of the rebuilt mush is much smaller than the Oruanui system and the vent spacing does not reflect the true extent of the modern system, but instead has been exaggerated by lateral transport of magma to where it was erupted. Lateral magma transport demonstrably occurred in past events at Taupo (Wilson \& Charlier, 2009; Allan et al., 2012), and is seen in the alignment of vent sites in some post-Oruanui eruptions (Wilson, 1993; Houghton et al., 2014). However, in these examples magma transport through diking occurred in a NNE-SSW direction, perpendicular to the extension axis in the TVZ. In contrast, many of the Taupo vents are linked across a NW-SE direction and so a scenario of extensive lateral transport is considered to be less likely. The minimum area that collapsed in association with eruption $\mathrm{Y}$ is estimated at $\sim 70-80 \mathrm{~km}^{2}$ from the residual gravity anomaly overprint (Davy \& Caldwell, 1998; Figure 5.18b). A minimum volume estimate for the pre-Y mush system is $\sim 200-250 \mathrm{~km}^{3}$, assuming a $3 \mathrm{~km}$ thickness, is therefore inferred. As highlighted in scenario 1, $35 \mathrm{~km}^{3}$ of magma can be readily extracted from this volume of mush.

While these mush volume estimates are not well constrained and in need of confirmation by geophysical imaging, they are consistent with the trends in eruptive volume and areas in which recent unrest has occurred. Historic unrest episodes in 1982/1983 have been linked to magma intrusion at $\sim 8 \mathrm{~km}$ depth at Taupo (Smith et al., 2007), considered to be an area of particular volatility (Figure 5.18b). Smith et al. (2007) linked inferred subsidence in the north shore of the lake to dewatering of $>2.5$ $\mathrm{km}^{3}$ of melt, notably a larger volume than most of the post-Oruanui eruptions. These observations suggest that magma bodies are being generated and emplaced in historic times, but have not (yet?) erupted, begging the questions of what controls periods of unrest versus eruption at Taupo and what additional factors will push Taupo into its next phase of eruptive activity? 


\subsubsection{Taupo's post-supereruptive behaviour: typical or unique in a global context?}

Following the Oruanui supereruption Taupo's magma system was effectively rebuilt and no evidence comes through in the younger eruptives for a residual presence of the Oruanui melt-dominant body and only sparse evidence for specific crystal components derived from its parental mush zone (e.g. a minor proportion of zircon cores;

CHAPTER 4: Barker et al., 2014a). Syn- or post-supereruption decompression resulted in an increased flux of hot mafic magma resulting in widespread heating and dissolution of temperature sensitive mineral phases followed by cooling and formation of a newly evolved mush zone. Is this type of behaviour considered typical for worldwide examples of post-caldera magma systems or does it reflect Taupo's hyperactive eruptive behaviour and large inferred magma flux (Wilson et al., 2009)?

Part of the issue with comparing Taupo's post-supereruptive behaviour with worldwide examples is the relative rarity of such large volume eruptions in the geological record, combined with the post-caldera occurrence and preservation of smaller eruptions (Wilson, 2008). The time gap between the Oruanui eruption and the first erupted dacite unit is only $\sim 5000$ years and notably within the uncertainty of the age determinations of many worldwide large silicic eruptions. At Valles caldera, New Mexico, the 1.25 Ma Bandelier eruption was rapidly followed by large scale structural resurgence (1000 m maximum displacement) and post-caldera volcanism with lowsilica rhyolite ring fracture domes erupting $27 \pm 27 \mathrm{kyr}$ after the eruption (Phillips et al., 2007). For the $767 \pm 2$ ka Bishop supereruption at Long Valley (Chamberlain et al., 2014a), the post-caldera environment was dominated by both voluminous magmatic $\left(>100 \mathrm{~km}^{3}\right)$ and structural resurgence. Hildreth (2004) considered that the post-Bishop early rhyolites $(751 \pm 16 \mathrm{ka}$ to $652 \pm 14 \mathrm{ka}$ : Mankinen et al., 1986) reflected crystalpoor melts drawn from a similar but largely reorganised mush source to the Bishop but with limited physical interaction with deeper mafic magmas. Bachman et al. (2012) proposed that for the evolution of the Kos-Nisyros volcanic centre the evacuation of large amounts of volatile-charged silicic magma during the Kos Plateau Tuff eruption (161 ka) resulted in decompression-induced crystallisation within the remaining mush pile, and subsequent eruptions were hotter and drier, likely resulting from mafic recharge. In contrast, post-caldera activity at Yellowstone following the $639 \pm 2 \mathrm{ka}$ Lava Creek Tuff was dominated by structural resurgence, then longer term (hundreds of thousands of years) magma replenishment and recycling of modified and hydrothermally altered caldera fill or mush with the eruption of small volume domes 
from 516-473 ka (Bindeman et al., 2001; Girard \& Stix, 2009). At another extreme, post-caldera activity may be expressed by a switch in magmatic expression. At Aira caldera, for example, following the $>400 \mathrm{~km}^{3}$ caldera-forming event, the large andesitic cone Sakurajima began to grow $<10 \mathrm{kyr}$ later on the southern caldera rim and has been the main focus of activity to the modern day (Aramaki, 1984).

In the context of other large silicic magma systems, Taupo's apparent postcaldera recovery time and rate of renewed volcanism is exceptionally rapid. However, whether and to what extent this rapidity is not matched in other systems due to an absence of immediately post-caldera eruptions, their non-preservation, or uncertainties with age resolution is unclear. There are a wide range of post-caldera behaviours across worldwide large silicic magma systems which are inferred to result from a combination of many variables, unique to each specific caldera. Some of these variables may include (but are not limited to) magma supply rate, the size of the pre-caldera mush body and what proportion was erupted, the tectonic setting and stress state of the crust, magma system structure and components, heat flow in the crust and eruption triggers. As the TVZ represents one of the most productive and frequently active silicic areas on Earth, Taupo's rapid post-supereruptive recovery may be an extension of its high productivity and magma flux (Wilson et al., 2009). It is noted that supereruptions or even large-scale eruptions involving significant volumes of magma usually act to modify the structure of a magma system, with post-caldera reorganisation often resulting in an influx of new magma which can accompany structural and/or magmatic resurgence. Notably, structural resurgence is not observed in the post-Oruanui sequence, likely due to the fact that there is a feedback response between inflation and extensional tectonics so that surface uplift on short timescales can be followed by subsidence on longer timescales (Ellis et al., 2007).

Large silicic magma reservoirs are often considered to result from longevity of magmatic episodes and gradual thermomechanical evolution over time scales of hundreds of thousands to millions of years (e.g. de Silva \& Gregg, 2014). However, as shown here, supereruptions or large scale caldera-forming events may act to significantly alter the structure and subsequent behaviour of the magma system and style of volcanism on much shorter timescales. In the case of Taupo, the Oruanui eruption acted to largely destroy and reset the magmatic history of the silicic magma system so that the modern day volcano and its eruption products show little connection in timing and composition to their supereruptive progenitor. 


\subsection{Conclusions}

Following the $25.4 \mathrm{ka}$ Oruanui supereruption, Taupo volcano experienced significant changes, with eruptive products reflecting the fine-scale temporal reorganisation, reconstruction and evolution of a largely new and very active magma system. The first products of dacite composition between 21-17 ka reflect reorganisation of the magma system in a time period of high heat flow and a mafic melt intrusion. Dacite mineralogies and compositions reflect a rebuilding silicic system that cooled and crystallised, forming a silicic crystal mush and density trap from which subsequent rhyolitic magmas were tapped only $13.5 \mathrm{kyr}$ following the supereruption. Rhyolite magma groups from $12 \mathrm{ka}$ to the modern day then show fine-scale temporal changes in melt chemistry and mineral phase stability with fluctuating conditions of crystallisation, which are closely linked to the development, stabilisation and maturation of a new, probably unitary, rhyolite mush system. Rare mafic clasts in the post-Oruanui eruptions suggest that although the silicic magma system has changed, the deep mafic system that provides heat and largely controls the stability of the overlying silicic system has remained similar. Temporal changes in silicic magma chemistry and eruptive frequencies are considered to reflect the evolution of a recovering magma system combined with fluctuating mafic input and periods of rifting. The patterns of magmatism and volcanism through time are consistent with the reestablishment of a large mush system beneath Taupo ( $>200 \mathrm{~km}^{3}$ and possibly up to $1000 \mathrm{~km}^{3}$ ) which continues to actively produce significant volumes of melt through to the modern day, as demonstrated by recent unrest episodes. Despite the most recent explosive eruption of SG3 being the largest volume, it is considered that Taupo will continue its hyperactive eruptive behaviour and move into a new stage of evolution and volcanism within timescales of considerable interest and concern. 


\section{CHAPTER 6}




\title{
6: MAGMATIC TIMESCALES AND PROCESSES LEADING TO THE
}

\section{CATASTROPHIC 232 AD TAUPO ERUPTION}

\begin{abstract}
Rhyolite eruptions over the past 12 ka from Taupo volcano, New Zealand, vary in size by 3-4 orders of magnitude over 25 individual events (units $B$ through $Z$ ), and are clustered on the basis of age and subtle chemical and mineralogical changes into three subgroups (SGs). The largest event in this time period, the Taupo eruption (combined as Unit $\mathrm{Y}$ and Unit Z) occurred at $232 \pm 5 \mathrm{AD}$, with a volume of $\sim 35 \mathrm{~km}^{3}$ DRE. Deposits erupted prior to $2.75 \mathrm{ka}$ (SG2: units $\mathrm{V}$ and $\mathrm{W}$ ) and $<2.15 \mathrm{ka}$ (SG3: units $\mathrm{X}, \mathrm{Y}$ and Z) show stepwise changes in melt and mineral compositions, with the SG3 units having the lowest whole-rock $\mathrm{SiO}_{2}, \mathrm{Rb} / \mathrm{Sr}$, increased $\mathrm{TiO}_{2}, \mathrm{Sr}$ and $\mathrm{Zn}$, and the most $\mathrm{Mg}$-rich orthopyroxene and Ca-rich plagioclase. The two subgroups are inferred to have been derived from a similar mush source, and the changes in composition and mineral zonation are explained by elevated temperatures, averaging $30-40{ }^{\circ} \mathrm{C}$ higher in the SG3 magmas, resulting in mineral dissolution and stepwise changes in melt chemistry. Fe$\mathrm{Mg}$ diffusion timescales in strongly zoned orthopyroxene suggest that heating occurred over a maximum of $\sim 100$ years prior to the first SG3 eruption (Unit X) at $2.15 \mathrm{ka}$. The source of the heating is considered to be an elevated rate of mafic magma input at the base of the silicic mush system, which formed a density trap to newly arriving lessevolved melts. In the lead-up to the caldera-forming eruption $\mathrm{Y}$, further elevated mafic magma input and priming of the silicic mush resulted in rapid melt mobilisation and accumulation in the shallow crust within 100-200 years of eruption. The Taupo eruption culminated from a critical combination of high differential tectonic stress build up, and increased potency of the silicic magma system resulting from elevated levels of mafic magma input resulting in one of the largest and most violent worldwide Holocene eruptions. The post-Y magma system then responded to further disruption by a primitive melt of possible mantle origin, with the eruption of sub-lacustrine dome(s) in eruption Z. The recent history of Taupo volcano demonstrates that the volcano is capable of changing behaviour and generating historically large eruptible melt bodies on timescales as short as decades to centuries.
\end{abstract}




\subsection{Introduction}

One of the biggest challenges in modern volcanology is understanding what processes dictate the frequency and magnitude of eruptions at silicic caldera volcanoes. Such volcanoes often show in their stratigraphic record a wide range of inferred eruptive volumes and styles, from small dome-building events through to the largest explosive caldera-forming events (e.g. among many examples: Long Valley: Hildreth, 2004; Taupo: Wilson, 1993; Campi Flegrei: Di Vito et al., 1999; Yellowstone: Christiansen, 2001). However, trends in eruptive frequency, magnitude and repose intervals are often chaotic, rather than linear, making the forecasting of future activity inherently problematic (e.g. Wilson, 1993). In addition, perceptions of the behaviour of large silicic caldera volcanoes means that significant unrest episodes with no eruption, or the onset of volcanic activity (regardless of its actual magnitude), could trigger overwhelming social and economic reactions and consequences (e.g. Dominy-Howes \& Minos-Minopoulos, 2004; Hill \& Prejean, 2005; Lowenstern et al., 2006; Self, 2006). Developing an understanding of the conditions of magma storage and the processes which lead to large explosive eruptions is thus vital towards building a framework for consideration of the probability of future outbreaks at silicic caldera volcanoes.

Modern concepts of the magmatic systems that feed silicic volcanoes have been greatly enhanced by the study of past eruptions, and the history of magma systems, inferred largely from the chemical properties of the melts and minerals represented in volcanic ejecta (e.g. Hildreth \& Wilson, 2007; Girard \& Stix, 2009; Allan et al., 2013). However, many questions remain about the processes and timescales that operate during the lead-in to large versus small eruptions in large silicic systems. For example, are large explosive events determined by a unique set of circumstances, or do they merely represent the same processes as smaller eruptions, but with elevated volumes? In turn, how long does it take for significant volumes of melt to assemble and what processes control melt extraction and eruption? The stability and productivity of silicic magmatic systems can be governed by many variable processes such as mafic magma recharge (Sparks et al., 1977), magma mixing (Blake et al., 1992; Millet et al., 2014), melt overpressure or buoyancy (Caricchi et al., 2014; Malfait et al., 2014) along with external factors such as local faulting and changes in stress state (Watanabe et al., 1999; Rowland et al., 2010; Allan et al., 2012). The challenge with interpreting eruptive behaviour is therefore linking a specific pattern in magma chemistry or crystal zonation to a known variable (or set of variables), with a given timescale of events prior to 
eruption. Well constrained field studies and eruptive history are of vital importance in governing the reliability and context of interpretations arising from such geochemical and petrological studies.

Taupo volcano, in the central North Island of New Zealand, provides a unique opportunity to investigate finely-scaled eruptive and magmatic histories in a large silicic caldera system. The modern outline of Lake Taupo was mostly formed in the catastrophic $25.4 \pm 0.2 \mathrm{ka}$ Oruanui supereruption (Wilson, 2001; Vandergoes et al., 2013), which discharged $>530 \mathrm{~km}^{3}$ of dominantly rhyolitic crystal-poor magma in a prolonged 10-phase, episodic eruption (Wilson et al., 2006; Allan et al., 2012, 2013). Following the Oruanui eruption, Taupo generated three dacite pyroclastic eruptions from $\sim 21-17 \mathrm{ka}$, followed by a $\sim 5 \mathrm{ka}$ time break and then a sequence of 25 rhyolite eruptions from $\sim 12 \mathrm{ka}$ (Wilson, 1993). The post-25 ka volcanic record at Taupo is notable because estimated eruptive volumes span 3-4 orders of magnitude, and show no clear relationships with the repose period prior to or following each event (Wilson, 1993; Wilson et al., 2009). The Holocene rhyolites were split into three chemically distinct, temporally sequential subgroups (SG1-SG3) by Sutton et al. (1995), reflecting minor differences in whole-rock and mineral chemistry. These differences are now interpreted to reflect minor changes in mineral phase-stability and storage conditions in a largely rebuilt post-Oruanui silicic magma system (Barker et al., 2014a, b). The great majority of juvenile explosive material erupted is crystal poor $(<5 \mathrm{wt}$. \%) rhyolite, with only minor mafic material recorded in two eruptions (S and Z: Blake et al., 1992; Sutton et al., 1995; Barker et al., 2014b).

Although the third rhyolite subgroup $(2.15-<1.8 \mathrm{ka})$ is represented by only three eruptions (X, Y and Z), these are of key importance in establishing the young eruptive history and present-day magmatic behaviour of the volcano. The exceptionally complex eruption Y discharged roughly three times as much magma as all the other post-Oruanui eruptions combined (Wilson \& Walker, 1985; Wilson, 1993; Houghton et al., 2010). Together with the shortly subsequent eruption $Z$ (the two collectively known as the Taupo eruption: Wilson \& Walker, 1985) the most recent eruption products are considered vital for building an understanding of the dynamics of the present-day magma system. This study presents data on magma chemistry, crystal zoning and diffusion modelling for the SG3 eruptions to investigate the processes leading up to, and following, eruption Y. It is demonstrated how Taupo's magma system rapidly changed in eruptive behaviour, with elevated temperatures and increased mafic magma supply resulting in rapid melt extraction from a large silicic mush, culminating in one of the 
largest and most violent Holocene eruptions worldwide.

\subsection{Eruptive stratigraphy and sampling}

The 25 post-Oruanui rhyolite eruptive units are divided into three temporally and chemically distinct subgroups, erupted from multiple vent sites in discrete periods from 11.8 to $9.95 \mathrm{ka}$ (SG1: units B-E), 7.05 to $2.75 \mathrm{ka}$ (SG2: units F-W) and 2.15 to $1.8 \mathrm{ka}$ (SG3: units X-Z) (Wilson, 1993; Sutton et al., 1995, 2000). This stud focusses on the three eruptions of SG3; Unit X (2.15 ka), Y (1.8 ka) and Z (<1.8 ka). The SG3 eruptions were all erupted from vents located on the eastern side of Lake Taupo, geographically overlapping with the inferred vent region for phase 3 of the Oruanui eruption and the SG1 and SG2 vent envelopes (Figure 6.1). The first SG3 eruption (Unit X; the Mapara Tephra of Vucetich \& Pullar, 1973) was a complex, moderately powerful eruption that experienced variable eruption rates and degrees of magma:water interaction, and which came from a single vent in the northeast region of Lake Taupo,

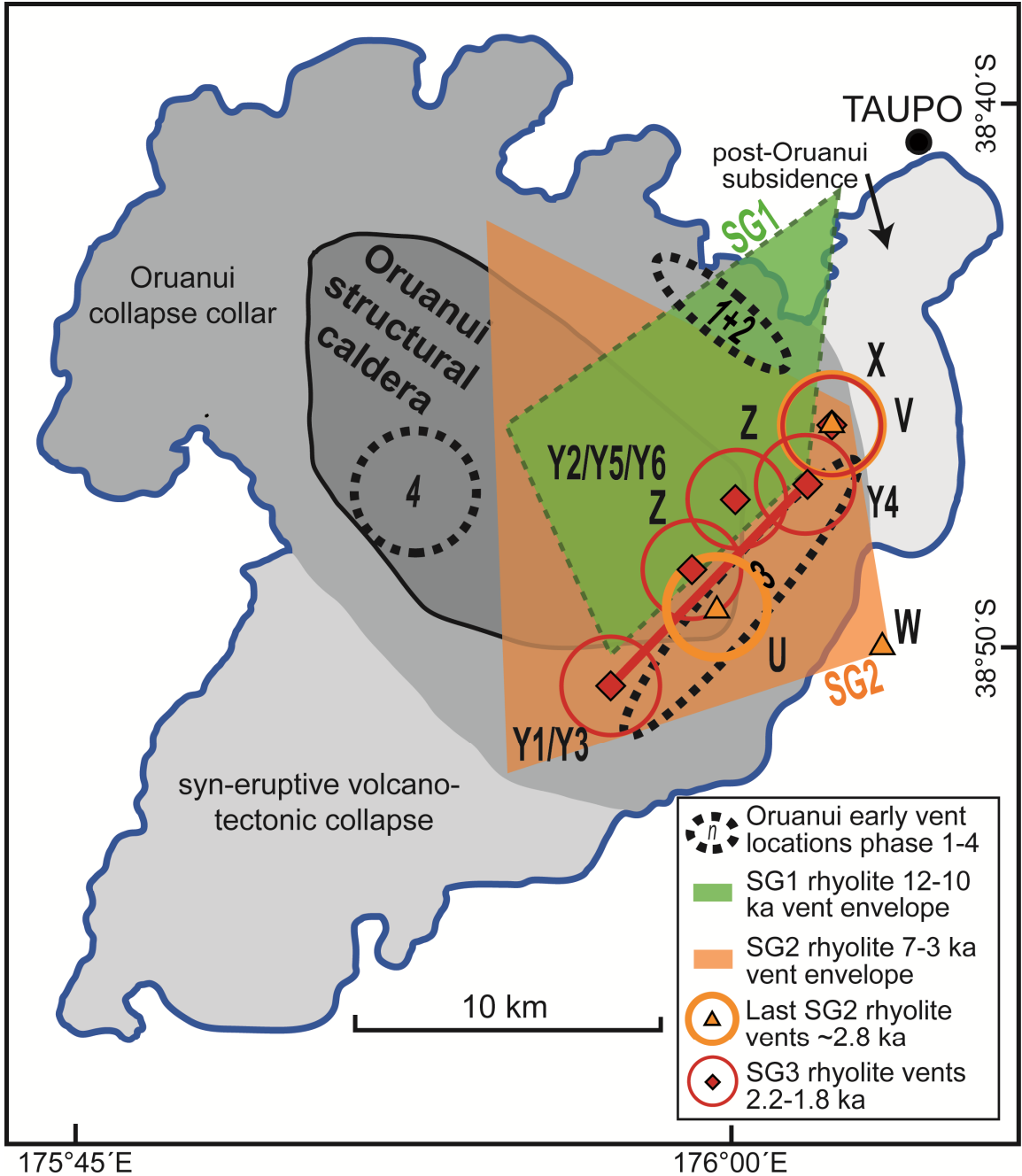

Figure 6.1. Map of Lake Taupo and the structural and volcanic features of Taupo caldera. Approximate vent areas for the first 4 phases of the Oruanui eruption are from Wilson (2001). Inferred vent sites with error ellipse, vent envelopes and ages for the postOruanui eruption groups are modified from Wilson (1993), with the red tie-line representing shifting vent sites between phases during eruption Y. Note the geographical alignment of vents along the eastern side of the lake and the overlapping positions of the final SG2 and SG3 vents. Figure modified from Barker et al. (2014b). 
overlapping with the earlier Unit V SG2 eruption (Figure 6.1; Wilson, 1993). Single pumices were collected from multiple levels through Unit X from a section in a fossil shoreline cliff on the eastern shore of Lake Taupo for whole-rock and mineral analyses (CHAPTER 2).

Eruption Y, as labelled by Wilson (1993), occurred $\sim 350$ years later at $232 \pm 5$ AD (Hogg et al., 2012), and is the second largest known eruption globally in the last 2000 years and the most powerful eruption in the past 5000 years. The associated pyroclastic deposits are split into seven subunits based on their field characteristics, which reflect pronounced changes in eruptive intensity, degrees of interaction with water and apparent shifting vent positions (Healy, 1964; Wilson \& Walker, 1985; Smith \& Houghton, 1995; Houghton et al., 2010, 2014). The Unit Y eruption is extreme in the post-Oruanui sequence of eruptions, having the largest eruptive volume by 5-6 fold and resulting in further collapse of Taupo caldera (Figure 6.1: Wilson \& Walker, 1985; Davy \& Caldwell, 1998). Subunits Y1 (Initial ash), Y2 (Hatepe plinian pumice) and Y3 (Hatepe ash) reflect fluctuations in wet to dry activity and were erupted from one or possibly two vents located in the central or southern parts of the eastern vent lineation (Figure 6.1: Walker 1981a; Smith \& Houghton, 1995; Smith, 1998). Subunit Y4 (Rotongaio ash) represents another phase of phreatomagmatic activity from a vent located to the northeast of the Y1-Y3 vents with significant fluctuations in magma:water interaction accompanying outgassing and dome extrusion (Walker, 1981b; Smith \& Houghton, 1995; Smith, 1998; Houghton et al., 2010). Activity then commenced (likely overlapping with the Y4 phase) from a new central vent overlapping with the modern Horomatangi Reefs area (Figure 6.1), producing subunit Y5 (Taupo plinian pumice) (Walker, 1980; cf. Houghton et al., 2014) and subordinate volumes of co-plinian pyroclastic density current deposits (Y6: Early ignimbrite flow units) (Wilson \& Walker, 1985). The Taupo eruption climaxed in its final stages with the generation of $\mathrm{a}>30 \mathrm{~km}^{3}$ widespread low-aspect ratio non-welded ignimbrite (Y7: Taupo ignimbrite) that was emplaced by an extremely energetic, pyroclastic density current travelling at more than 200-300 m/s over $\sim 20000 \mathrm{~km}^{2}$ (Wilson, 1985). The total volume of the Unit $Y$ (Taupo) eruption is $45 \mathrm{~km}^{3}$ of pyroclastic material, or up to $105 \mathrm{~km}^{3}$ if caldera infill and material now buried under the lake are considered (Wilson, 1993; Davy \& Caldwell, 1998). In this study, subunits Y1-Y5 and Y7 have been sampled at multiple levels to further investigate subtle chemical variations throughout the Taupo eruption (CHAPTER 2; Sutton et al., 1995). Subunits Y1, Y3 and Y7 were selected for detailed mineralogical investigations. 
Post-eruption Y blockage of the Waikato River outlet from Lake Taupo resulted in overfilling of the lake basin by $\sim 34$ m over a period of no more than approximately 15-20 years, before breaching triggered the release of $\sim 20 \mathrm{~km}^{3}$ of water in a catastrophic flood (Manville et al., 1999; Riggs et al., 2001). The time gap between caldera formation and the lake level refilling to above its old (and modern) level in the post-Unit Y period was used to suggest that giant pumices exposed at multiple locations around and up to $20 \mathrm{~m}$ above Taupo's modern lake level represent the products of a separate eruption, labelled $\mathrm{Z}$ by Wilson (1993). The giant pumices are up to $17 \mathrm{~m}$ long, and show chilled contacts and complex entablature-style jointing that suggest that the clasts were still hot when they were driven ashore and became waterlogged while the lake was higher than its modern level and still rising. The sizes of the clasts, their gentle emplacement, coupled with their vesicle textures and the presence of microlites are taken to indicate that the clasts represent portions of the carapace from a dome or domes erupted beneath the re-filling lake (Wilson \& Walker, 1985; Houghton et al., 2010). Both the Horomatangi Reefs and the Waitahanui Bank are inferred to post-date the caldera collapse associated with eruption $\mathrm{Y}$, are covered in glassy pumiceous rhyolite debris and are considered as likely sources for this material (Figure 6.1). Two floated giant pumices were sampled for this study for whole-rock and mineral analysis in this study (CHAPTER 2).

\subsection{Methods}

\subsubsection{Whole-rock major and trace element chemistry}

Lapilli or block-sized material were coarsely crushed in a Rocklabs Boyd crusher to $\sim 2$ $\mathrm{mm}$ fragments. The coarsely crushed lapilli/blocks were picked for any large mineral grains or inclusions (1-2 mm) and then crushed to $<2 \mathrm{~mm}$ size and powdered in an agate TEMA. Whole-rock powders were analysed for major element compositions by X-ray fluorescence (XRF) at the Open University, United Kingdom. Approximate 2 standard deviation (2SD) analytical precisions determined by replicate analyses of the same standards for elements are generally $<1-3$ relative $\%$ (see Appendix $G$ for data for CHAPTER 3 for standards). Trace element analyses were carried out by solution inductively coupled plasma mass spectrometry (ICP-MS). ${ }^{43} \mathrm{Ca}$ was used to perform an internal correction, as $\mathrm{CaO}$ concentrations were known to \pm 1 relative $\%$ from XRF. Diluted sample solutions were analysed using a Thermo Scientific Element2 sector-field ICPMS at Victoria University of Wellington (VUW). Total procedural blanks were 
within background levels on all measured elements. Abundances of individual trace elements were calculated by external normalisation relative to a bracketing standard (BHVO-2), which was prepared and analysed under identical conditions to the samples. Approximate 2 SD analytical precisions derived from replicate analyses of secondary standards BCR-2 and TPI are $< \pm 6-7 \%$ for most trace elements (see Appendix H for data for CHAPTER 3 for standards).

\subsubsection{Electron microprobe analysis}

All the SG3 magmas contain $<4-5$ wt. $\%$ crystals with an assemblage restricted to plagioclase, orthopyroxene and Fe-Ti oxides with minor amounts of apatite (Barker et $a l ., 2014 b)$. For the eruption $\mathrm{Z}$ clasts, however, small $(<2 \mathrm{~cm})$ dark grey mafic blebs were found as rare, discrete inclusions within sampled pieces. These mafic inclusions contain plagioclase, orthopyroxene and rare olivine set in a microcrystalline vesiculated groundmass. Minerals were separated from coarsely crushed pumice by heavy liquids to determine total mineral content and then picked and mounted by size and type on 25 mm epoxy disc mounts. High-resolution backscattered electron (BSE) images were taken to investigate crystal zonation features in each eruptive unit or subunit (see Appendix M for whole-mount BSE images). The oldest (cores) and the youngest (rims) portions of each crystal were targeted for analysis using a JEOL JXA 8230 electron probe micro-analyser (EPMA) at VUW using wavelength dispersive spectrometry techniques. Crystals were analysed with a $15 \mathrm{kV}$ accelerating voltage and a $20 \mathrm{nA}$ focused beam for orthopyroxene and olivine and $12 \mathrm{nA}$ beam for plagioclase, with measurements of $30 \mathrm{~s}$ on the peak and $15 \mathrm{~s}$ on backgrounds either side of the peak. If crystals contained any prominent zonation between cores and outermost rims, then these zones, referred to here as interior zones, were also analysed. Calibrated international standards were analysed as unknowns to monitor instrumental drift and the precision and accuracy of the analyses. Approximate 2 SD analytical precisions calculated from repeated analysis of calibration standards are generally $<5 \%$ for oxides that occur in concentrations of $>1$ wt. \%. For lower concentration oxides, precision degrades with decreasing relative concentration (CHAPTER 3).

\subsubsection{Diffusion modelling in orthopyroxene}

A strong negative linear relationship $\left(\mathrm{R}^{2}=0.95\right)$ has been observed between backscattered electron (BSE) image greyscale values and the $\mathrm{Mg} /(\mathrm{Mg}+\mathrm{Fe})$ content of orthopyroxene (Allan et al., 2013; Cooper, 2014; Chamberlain et al., 2014b), and 
therefore the zoning observed in BSE images is inferred to be an accurate representation of the Fe-Mg content. This linear relationship allows compositional gradients in Fe and $\mathrm{Mg}$ concentrations to be investigated at a much higher spatial resolution than is possible from spot analyses alone (Morgan et al., 2004; Martin et al., 2008; Saunders et al., 2012; Allan et al., 2013). Diffusional geochronometry is used here to model the evolution of compositional profiles within zoned orthopyroxene crystals to determine the time elapsed since compositional variations were introduced. Typically, diffusion modelling assumes that the compositional boundaries initially had step-wise gradients, which over time at magmatic temperatures were modified by element diffusion to form sigmoidal shaped concentration gradients until quenching on eruption (e.g. Zellmer et al., 1999; Costa et al., 2003; Morgan et al., 2004, 2006; Costa \& Dungan, 2005; Wark et al., 2007; Saunders et al., 2012; Allan et al., 2013). The initial compositional gradient is modelled forwards in time until it matches the observed profile and can be regarded as representing a maximum time, as the exact initial condition is not known.

In this study we use the methods of Allan et al. (2013) to calculate timescales of Fe-Mg diffusion in orthopyroxene. Image $\mathrm{J}$ (http://rsb.info.nih.gov/ij/) was used to extract spatially resolved profiles of BSE intensity across crystal zonation boundaries to quantify $\mathrm{Mg} /(\mathrm{Mg}+\Sigma \mathrm{Fe})$ profiles from rotated images. Fe-Mg profiles were obtained along the crystallographic $a$ - or $b$-axis to avoid anisotropy effects, as growth effects have been observed along the $c$-axis of orthopyroxene (e.g. Allan et al. 2013; Figure 6.2). Due to $f \mathrm{O}_{2}$ dependence of $\mathrm{D}_{\mathrm{Fe}-\mathrm{Mg}}$ in orthopyroxene (Ganguly \& Tazzoli, 1994), the formula of Ganguly \& Tazzoli (1994) modified as in Allan et al. (2013) is used to calculate $\mathrm{D}_{\mathrm{Fe}-\mathrm{Mg}}$ :

$$
D_{F e-M g}=\left(-5.54+2.6 X_{F e}-\frac{12530}{T}\right) \times\left(\frac{f_{O_{2}(\text { sample }, T)}}{f_{O_{2}(\text { IW buffer }, T)}}\right)^{\frac{1}{6}}
$$

where $\mathrm{X}_{\mathrm{Fe}}$ is the molar proportion of the $\mathrm{Fe}$ end member (ferrosilite), $\mathrm{T}$ is temperature in Kelvins, and $f \mathrm{O}_{2}$ is oxygen fugacity. Finite-difference software was used to generate a database of simulated diffusion profiles, which obey composition-dependent diffusion under 1-D (linear) diffusion geometry, as detailed in Allan et al. (2013). This study adopts average temperatures and $\mathrm{fO}_{2}$ values calculated using mineral-mineral and mineral-melt equilibria for each eruptive unit from Barker et al. (2014b). Oxygen fugacities were estimated using the Fe-Ti oxide equilibrium models of Ghiorso \& Evans (2008) and Sauerzapf et al. (2008). For uncertainty calculations on single model-age determinations, conservative uncertainties of $\pm 30{ }^{\circ} \mathrm{C}$ and $\pm 0.3 \Delta \mathrm{NNO} \log$ units for 


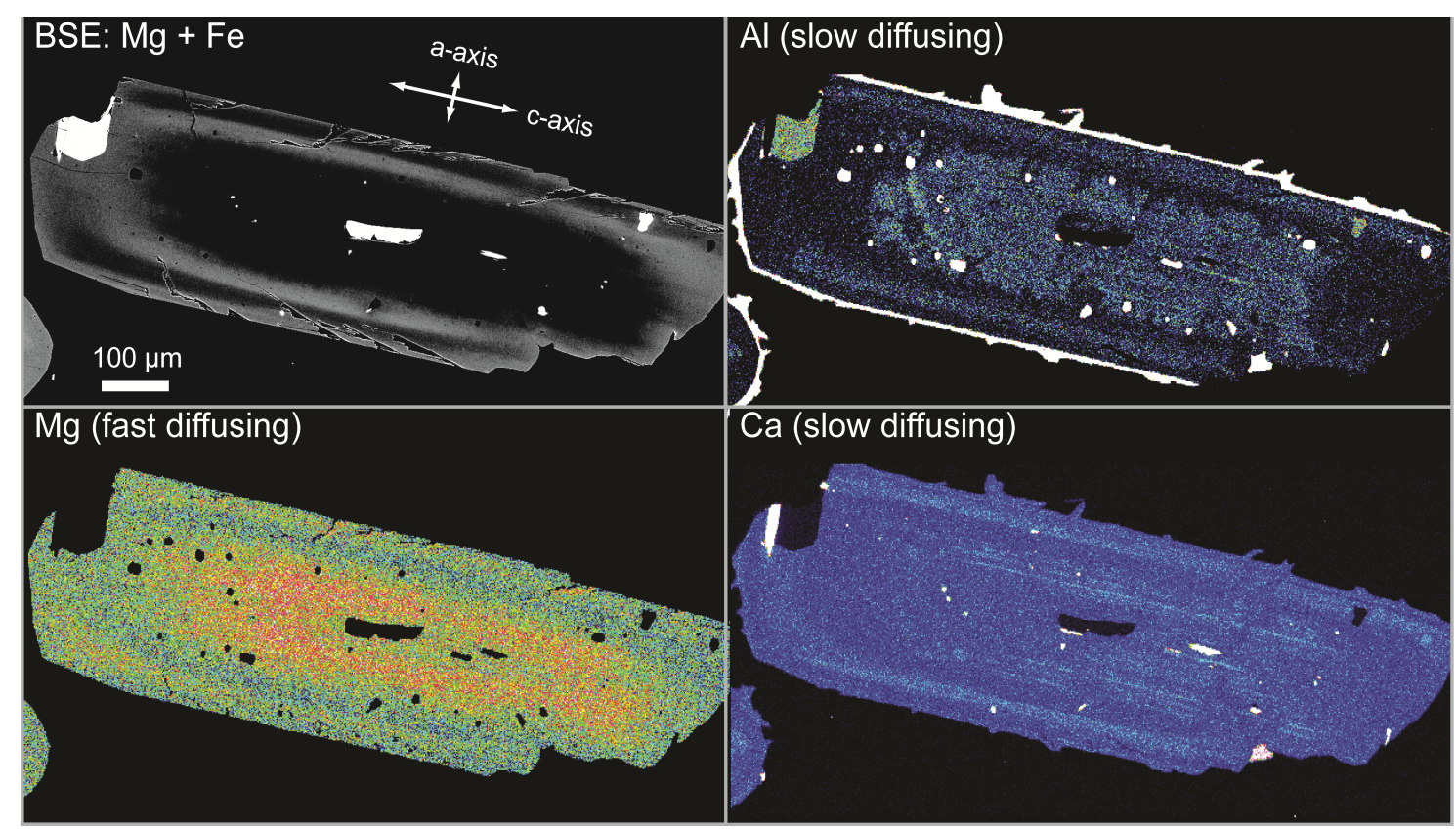

Figure 6.2. Element maps of a representative orthopyroxene crystal from Unit Y showing the contrasts between fast diffusing $(\mathrm{Mg})$ and slow diffusing $(\mathrm{Ca}+\mathrm{Al})$ elements and the relative preservation of initially sharp boundaries in a strongly zoned crystal. Light colours in WDS maps represent relatively high and dark colours are relatively low concentrations. Note the difference in zonation between the a-axis and caxis directions, where the zoning parallel to the $c$-axis is smeared out and is kinematically controlled by a rapid growth regime, whereas sharp boundaries in slow-diffusing elements are largely preserved parallel to the $a$-axis with the slow-diffusing elements (Allan et al., 2013).

oxygen fugacity were used to generate inferred maximum and minimum timescales.

Statistical analyses were also conducted across each profile, with the uncertainty on the greyscale profile essentially representing random thermal noise in the BSE detector. The plateaux at either end of a sigmoidal diffusion profile should be flat and profiles which had variation in the plateaux that exceeded the calculated 2 standard-error value, based on the number of averaged pixels were rejected. The relatively large width of the diffusion profiles investigated in this study (Figure 6.2; Appendix M) means that common problems reported in other studies of convolution and pixel size were not considered to be of significant effect (Morgan et al., 2004; Cooper, 2014). A comprehensive summary of the measured and modelled Fe-Mg diffusion profiles across the crystal boundaries are presented in Appendix N.

\subsection{Results}

\subsubsection{Trends in whole-rock chemistry}

The SG3 magmas form a unique compositional group in Taupo's eruptive history, being among the least evolved magmas in the post-Oruanui sequence (Figure 6.3; Sutton et al., 2000). Unit $\mathrm{X}, \mathrm{Y}$ and $\mathrm{Z}$ all fall on linear trends with the earlier erupted SG2 magmas 

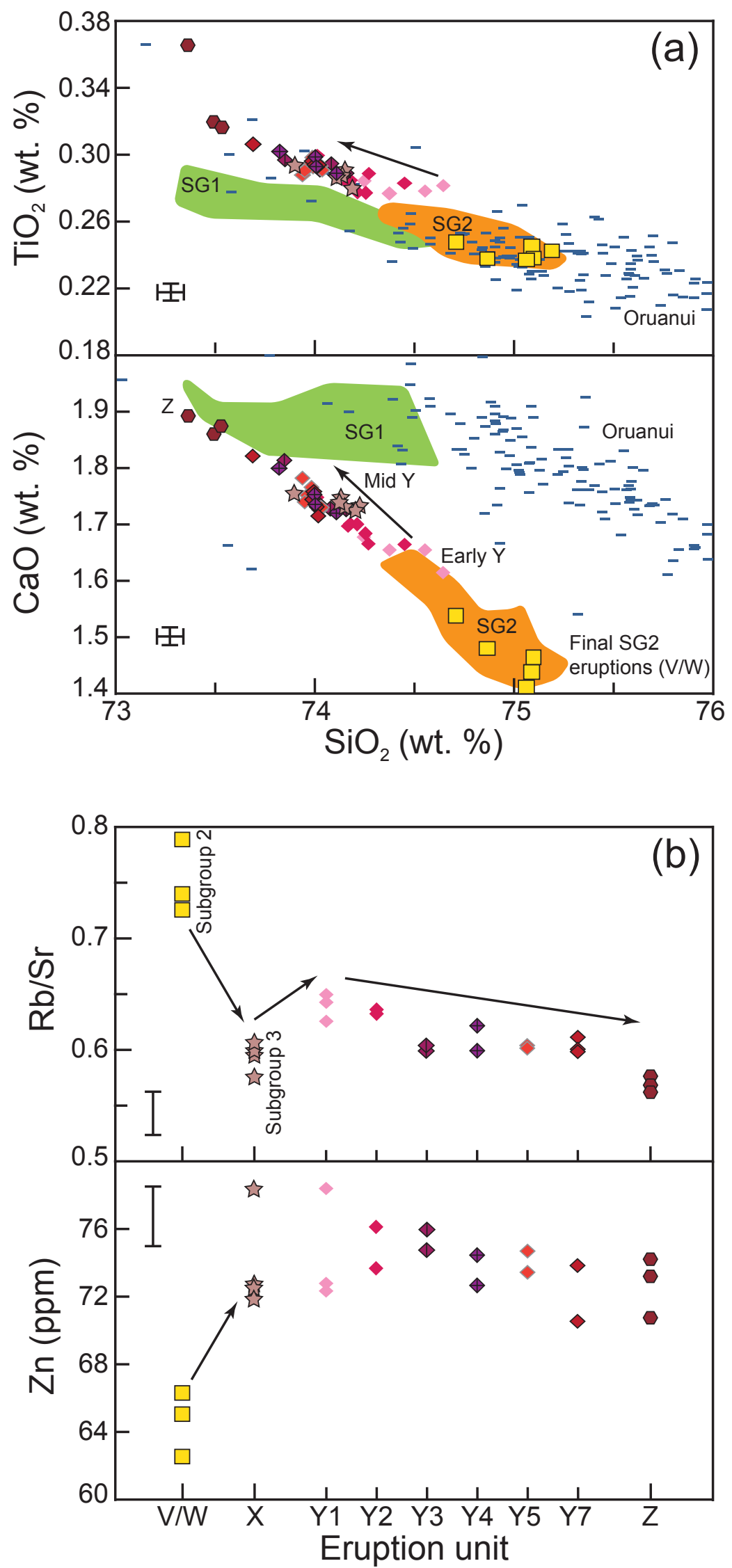

Figure 6.3. Whole-rock variations in (a) major element compositions and (b) trace element compositions for the SG3 eruptions in comparison to older magma compositions erupted from Taupo. SG3 subunits are distinguished by symbol type as labelled in (b). Error bars are 2 SD. 
but are up to $\sim 1 \%$ lower in $\mathrm{SiO}_{2}$ than the final eruptions of the SG2 period at $\sim 2.8 \mathrm{ka}$ (units V and W: Figure 6.3a; Barker et al., 2014b). The SG3 magmas also show stepwise increases in elements compatible in the observed mineral phases (e.g. Sr and $\mathrm{Eu}$ for plagioclase, $\mathrm{Zn}$ and $\mathrm{Mn}$ for orthopyroxene), and decreases in whole-rock $\mathrm{Rb} / \mathrm{Sr}$ ratio (Table 6.1; Figure 6.3b; Appendix H). The first erupted Y subunits (Y1 and Y2) are slightly more evolved at $\sim 74.5 \mathrm{wt} . \% \mathrm{SiO}_{2}$, and then there is a trend towards the remaining subunits (Y3 to Y7) and earlier Unit X compositions which cluster at $\sim 74$ wt. \%. The youngest magmas from the Unit $\mathrm{Z}$ floated pumice are notably the least evolved at $\sim 73.5$ wt. $\% \mathrm{SiO}_{2}$ and $\mathrm{Rb} / \mathrm{Sr}<0.6$ and increased levels of $\mathrm{TiO}_{2}$ and $\mathrm{CaO}$ (Table 6.1; Figure 6.3). A single analysis of multiple combined mafic inclusions up to 2 $\mathrm{cm}$ in size in Unit $\mathrm{Z}$ pumice gives an average bulk composition of andesite at $\sim 62.5 \mathrm{wt}$. $\% \mathrm{SiO}_{2}$ (Table 6.1), although this is considered to be a mixed composition due to minor amounts of adhering and infiltrating rhyolitic glass.

\subsubsection{Textural and compositional characteristics of crystals}

The textural features of orthopyroxene and plagioclase crystals contrast within and between the SG3 eruptions and the final explosive SG2 eruption Unit V (Figure 6.4). Phenocrysts in the Unit V products are typically euhedral, and are either completely unzoned or show only minor normal compositional zonation with rare melt inclusions or disequilibrium features (Figure 6.4a; Barker et al., 2014b). In contrast, the first of the SG3 magmas erupted as Unit $\mathrm{X}$ is dominated by reversely zoned crystals with narrow resorbed rims (no thicker than $20-30 \mu \mathrm{m}$ ) and a minor proportion of strongly normally zoned crystals (Figure 6.4b; Table 6.2; Appendix M). The compositions of Unit X reversely zoned cores overlap with the SG2 orthopyroxene and plagioclase compositions at $\mathrm{Mg}_{42-46}$ and $\mathrm{An}_{36-42}$, respectively (Figure 6.5), and the normally zoned crystal cores extend up to $\mathrm{Mg}_{60}$ and $\mathrm{An}_{60}$, respectively. Inclusions of melt, apatite and Fe-Ti oxide are common features in reversely zoned orthopyroxene. In both zoning types for Unit X, crystal rims converge on a narrow compositional range between $\mathrm{Mg}_{48-}$

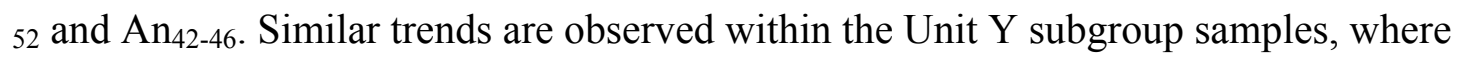
reversely zoned minerals are dominant, but normal zoning is slightly more common (Table 6.2). There are no major compositional differences observed between the subgroups, and chemical trends in reverse and normally zoned minerals overlap with those of the Unit X crystals (Figure 6.5). As with Unit X, the Unit Y reversely zoned cores overlap with the composition of the SG2 crystals. However, orthopyroxenes in the Unit Y magmas have more pronounced rim zones (commonly $>60$ to $90 \mu \mathrm{m}$ wide: 
Table 6.1. Representative major and trace element compositions of eruptive units from the final SG2 eruptions ( $V$ and $W$ ), the SG3 units and Unit $Y$ subunits

\begin{tabular}{|c|c|c|c|c|c|c|c|c|c|c|c|}
\hline Jnit & $\overline{\mathrm{V}}$ & $\mathrm{W}$ & $X$ & $\overline{\mathrm{Y1}}$ & Y2 & Y3 & Y4 & Y5 & $\overline{Y 6}$ & Z & Z \\
\hline a & $2161 A$ & 2155B & 157A & 2120 & 2129 & 2296 & $2226 c$ & 2231 & 2286 & 2173B & $2160 i$ \\
\hline ge BP & 2800 & 2750 & 2150 & 1770 & 1770 & 1770 & 1770 & 1770 & 1770 & 1740 & 1740 \\
\hline
\end{tabular}

\begin{tabular}{lrrrrrrrrrrr} 
Major elements (wt. \%) \\
\hline $\mathrm{SiO}_{2}$ & 74.71 & 74.87 & 74.21 & 74.55 & 74.45 & 74.08 & 74.00 & 74.02 & 74.03 & 73.49 & 62.61 \\
$\mathrm{TiO}_{2}$ & 0.25 & 0.24 & 0.28 & 0.28 & 0.28 & 0.29 & 0.29 & 0.29 & 0.29 & 0.32 & 1.14 \\
$\mathrm{Al}_{2} \mathbf{O}_{3}$ & 13.32 & 13.25 & 13.48 & 13.38 & 13.38 & 13.55 & 13.54 & 13.63 & 13.58 & 13.71 & 15.13 \\
$\mathrm{Fe}_{2} \mathrm{O}_{3}$ & 2.35 & 2.35 & 2.51 & 2.43 & 2.44 & 2.49 & 2.54 & 2.53 & 2.50 & 2.68 & 7.90 \\
$\mathrm{MnO}$ & 0.089 & 0.086 & 0.095 & 0.092 & 0.093 & 0.094 & 0.098 & 0.096 & 0.095 & 0.097 & 0.265 \\
$\mathrm{MgO}$ & 0.26 & 0.24 & 0.34 & 0.31 & 0.31 & 0.33 & 0.34 & 0.34 & 0.33 & 0.40 & 2.30 \\
$\mathrm{CaO}$ & 1.54 & 1.48 & 1.73 & 1.65 & 1.66 & 1.73 & 1.74 & 1.71 & 1.73 & 1.86 & 4.36 \\
$\mathrm{Na}_{2} \mathrm{O}$ & 4.56 & 4.51 & 4.55 & 4.46 & 4.52 & 4.60 & 4.63 & 4.55 & 4.56 & 4.64 & 4.19 \\
$\mathrm{~K}_{\mathbf{2}} \mathrm{O}$ & 2.88 & 2.94 & 2.76 & 2.80 & 2.79 & 2.77 & 2.76 & 2.77 & 2.83 & 2.73 & 1.61 \\
$\mathbf{P}_{2} \mathrm{O}_{5}$ & 0.043 & 0.046 & 0.053 & 0.051 & 0.055 & 0.057 & 0.058 & 0.059 & 0.056 & 0.075 & 0.491 \\
$\mathrm{LOI}_{\text {Total }}$ & 2.6 & 3.18 & 2.71 & 2.47 & 1.98 & 3.14 & 0.5 & 2.39 & 3.77 & 0.87 & 0.68 \\
& 99.14 & 99.75 & 99.56 & 99.4 & 99.51 & 99.84 & 99.28 & 99.38 & 99.13 & 99.74 & 99.68
\end{tabular}

Trace elements (ppm)

\begin{tabular}{|c|c|c|c|c|c|c|c|c|c|c|c|}
\hline$\overline{L i}$ & 33.6 & 33.7 & 43.2 & 40.3 & 43.1 & 45.8 & 41.4 & 39.5 & 38.9 & 33.6 & 26.3 \\
\hline Sc & 10.2 & 10.1 & 11.3 & 11.6 & 12.0 & 11.7 & 11.7 & 11.7 & 10.9 & 11.6 & 25.4 \\
\hline V & 1.43 & 1.73 & 1.72 & 2.08 & 1.96 & 2.26 & 2.27 & 1.83 & 1.89 & 3.72 & 99.52 \\
\hline $\mathrm{Cr}$ & 2.34 & 2.69 & 1.96 & 3.53 & 1.40 & 5.45 & 3.43 & 2.68 & 1.13 & 6.55 & 2.42 \\
\hline $\mathrm{Ni}$ & 0.20 & 0.26 & 0.17 & 0.95 & 0.15 & 0.09 & 0.11 & 0.17 & 0.21 & 0.35 & 0.73 \\
\hline $\mathrm{Cu}$ & 1.03 & 1.47 & 1.58 & 1.31 & 3.21 & 0.99 & 1.01 & 0.91 & 1.24 & 1.28 & 5.00 \\
\hline $\mathrm{Zn}$ & 65 & 63 & 72 & 78 & 76 & 76 & 73 & 75 & 70 & 73 & 144 \\
\hline Ga & 15.1 & 15.2 & 16.9 & 17.2 & 17.6 & 16.9 & 16.6 & 17.4 & 16.1 & 16.8 & 19.0 \\
\hline $\mathbf{R b}$ & 96 & 100 & 104 & 106 & 106 & 106 & 108 & 103 & 98 & 94 & 54 \\
\hline $\mathrm{Sr}$ & 122 & 121 & 173 & 163 & 166 & 176 & 173 & 172 & 160 & 166 & 294 \\
\hline$Y$ & 31.0 & 31.5 & 34.7 & 34.3 & 35.8 & 36.3 & 35.3 & 35.1 & 32.6 & 31.8 & 30.9 \\
\hline $\mathrm{Zr}$ & 189 & 188 & 232 & 235 & 243 & 243 & 240 & 234 & 215 & 213 & 140 \\
\hline $\mathrm{Nb}$ & 7.72 & 7.95 & 9.73 & 12.85 & 13.36 & 11.57 & 11.53 & 3.45 & 7.88 & 8.05 & 6.78 \\
\hline Cs & 5.05 & 5.23 & 5.26 & 4.94 & 5.11 & 5.21 & 5.37 & 4.11 & 3.82 & 4.79 & 2.54 \\
\hline $\mathrm{Ba}$ & 571 & 588 & 637 & 639 & 655 & 655 & 671 & 618 & 561 & 580 & 389 \\
\hline La & 23.8 & 24.3 & 27.0 & 26.9 & 27.4 & 27.7 & 27.7 & 26.5 & 24.2 & 24.3 & 22.1 \\
\hline $\mathrm{Ce}$ & 51.2 & 52.7 & 58.2 & 57.9 & 59.5 & 59.4 & 58.2 & 56.1 & 51.3 & 52.1 & 49.7 \\
\hline Pr & 6.02 & 6.16 & 7.16 & 6.80 & 6.94 & 7.12 & 7.30 & 6.61 & 6.11 & 6.30 & 6.26 \\
\hline Nd & 23.4 & 23.9 & 27.1 & 26.7 & 26.9 & 28.5 & 27.9 & 26.6 & 24.3 & 24.5 & 26.0 \\
\hline Sm & 5.06 & 5.20 & 6.02 & 5.95 & 5.86 & 6.07 & 6.00 & 5.85 & 5.45 & 5.34 & 5.77 \\
\hline Eu & 1.14 & 1.17 & 1.38 & 1.29 & 1.36 & 1.47 & 1.43 & 1.28 & 1.22 & 1.29 & 1.89 \\
\hline Gd & 5.48 & 5.57 & 6.51 & 6.31 & 6.33 & 6.33 & 6.35 & 5.76 & 5.38 & 5.84 & 6.14 \\
\hline Tb & 0.81 & 0.84 & 0.96 & 0.95 & 0.94 & 0.91 & 0.94 & 0.89 & 0.84 & 0.85 & 0.89 \\
\hline Dy & 5.15 & 5.21 & 6.05 & 5.85 & 5.79 & 5.98 & 6.04 & 5.89 & 5.43 & 5.32 & 5.43 \\
\hline Ho & 1.08 & 1.11 & 1.26 & 1.25 & 1.24 & 1.25 & 1.27 & 1.21 & 1.14 & 1.13 & 1.08 \\
\hline $\mathrm{Er}$ & 3.14 & 3.27 & 3.60 & 3.66 & 3.62 & 3.68 & 3.66 & 3.67 & 3.44 & 3.30 & 3.11 \\
\hline $\mathrm{Tm}$ & 0.47 & 0.50 & 0.57 & 0.53 & 0.54 & 0.57 & 0.56 & 0.56 & 0.53 & 0.50 & 0.47 \\
\hline$Y b$ & 3.12 & 3.26 & 3.81 & 3.59 & 3.55 & 3.63 & 3.62 & 3.73 & 3.46 & 3.29 & 2.88 \\
\hline Lu & 0.48 & 0.49 & 0.56 & 0.56 & 0.54 & 0.57 & 0.57 & 0.59 & 0.54 & 0.50 & 0.42 \\
\hline Hf & 4.97 & 5.17 & 6.32 & 6.26 & 6.20 & 6.55 & 6.31 & 6.41 & 5.78 & 5.54 & 3.70 \\
\hline $\mathrm{Pb}$ & 15.5 & 16.6 & 23.1 & 22.9 & 23.2 & 21.3 & 21.3 & 22.0 & 19.7 & 15.9 & 10.8 \\
\hline Th & 9.6 & 10.2 & 11.2 & 11.2 & 11.2 & 10.9 & 11.4 & 11.0 & 10.2 & 9.7 & 6.4 \\
\hline $\mathbf{U}$ & 2.18 & 2.27 & 2.60 & 2.53 & 2.52 & 2.42 & 2.58 & 2.52 & 2.31 & 2.26 & 1.41 \\
\hline $\mathrm{Rb} / \mathrm{Sr}$ & 0.79 & 0.82 & 0.60 & 0.65 & 0.64 & 0.60 & 0.62 & 0.60 & 0.61 & 0.57 & 0.18 \\
\hline Eu/Eu* & 0.66 & 0.66 & 0.67 & 0.64 & 0.68 & 0.73 & 0.71 & 0.68 & 0.69 & 0.70 & 0.97 \\
\hline
\end{tabular}

Oxide abundances normalised to $100 \%$ on a volatile free basis, with original analytical totals and LOI given. Eruption ages are given in years before present and sourced from Wilson (1993) and Hogg et al. (2012). The full list of samples are presented in Appendix $\mathrm{G}$ and $\mathrm{H}$. Analytical standards are presented in CHAPTER 3. 
(a) Unit V (2.8 ka)
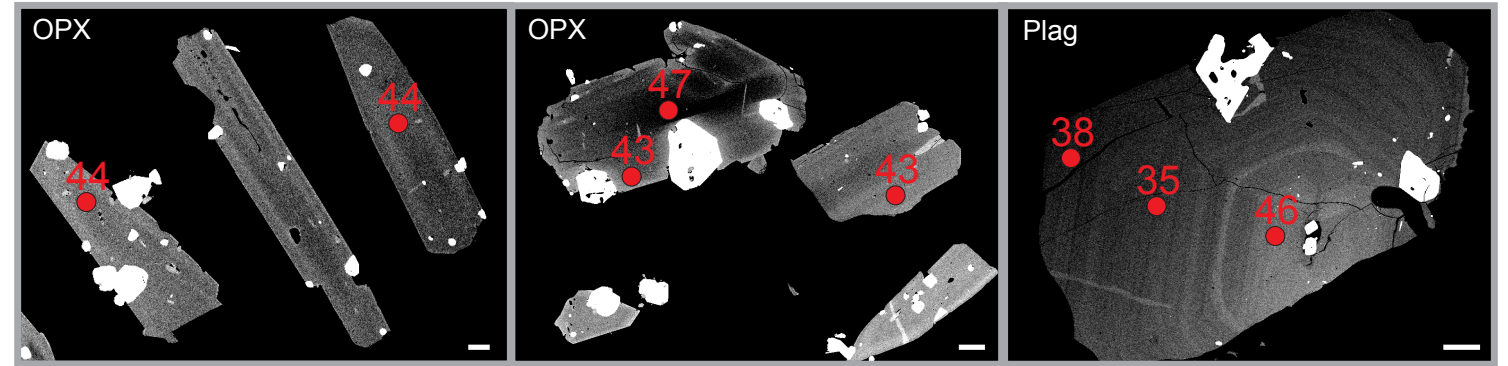

(b) Unit X (2.2 ka)
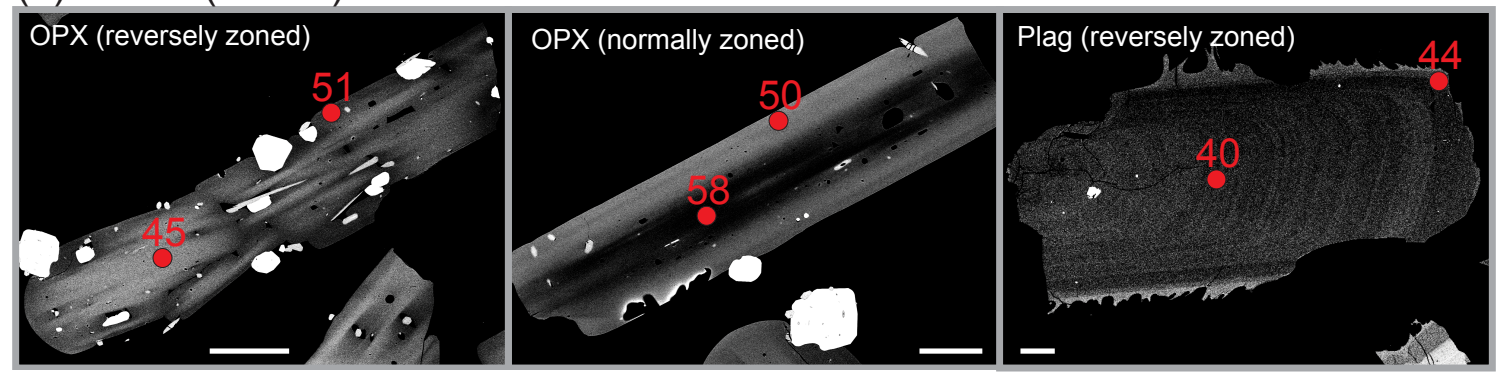

(c) Unit Y (1.8 ka)
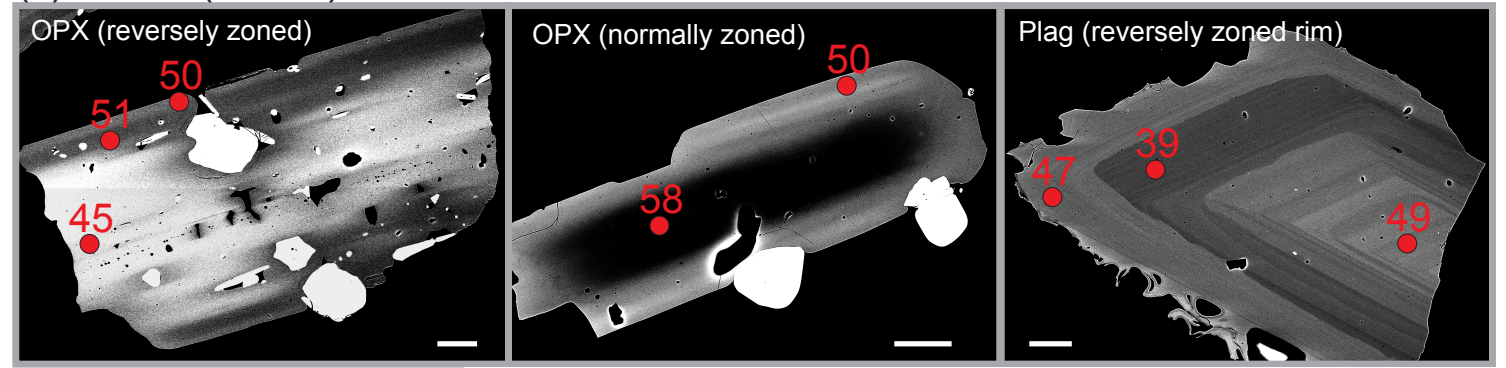

(d) Unit Z $(<1.8 \mathrm{ka})$
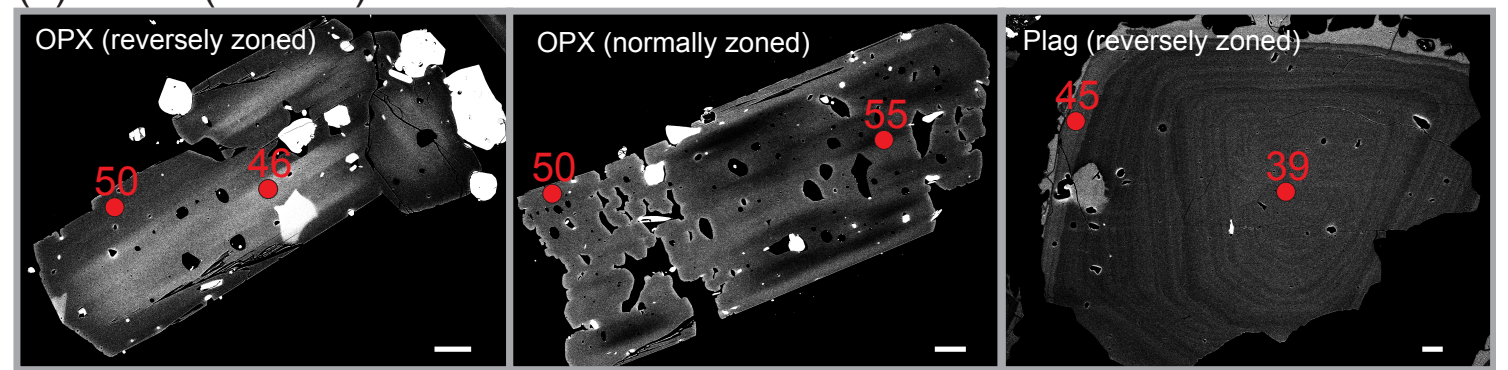

(e) Mafic inclusions (<1.8 ka)
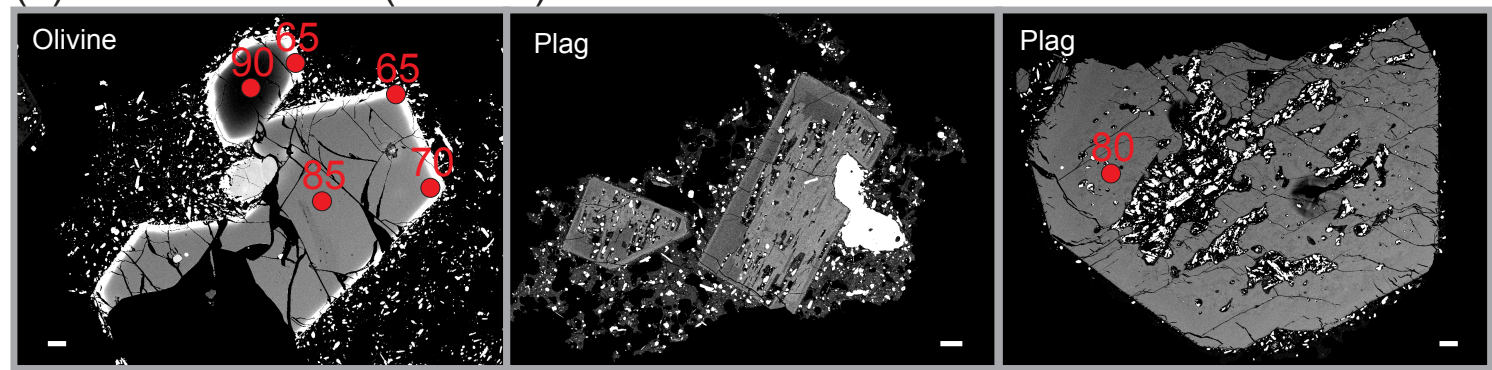

Figure 6.4. Representative back-scattered electron (BSE) images and compositions of minerals from (a) SG2 Unit V, versus SG3 units (b) X, (c) Y, (d) Z and (e) mafic inclusions from Unit Z. White scale bars are $100 \mu \mathrm{m}$ for reference. OPX is orthopyroxene and Plag is plagioclase. Approximate probe analysis spot locations are denoted by small red filled circles with corresponding $\mathrm{Mg}$ values for orthopyroxene (where $\mathrm{Mg}=100 * \mathrm{Mg} / \mathrm{Mg}+\mathrm{Fetotal}$ ), Anorthite \% for plagioclase (where An. $\%=100 * \mathrm{Ca} / \mathrm{Ca}+\mathrm{Na}+\mathrm{K}$ ) and Forsterite $\%$ for olivine (where $\mathrm{F}_{\mathrm{O}}=100 * \mathrm{Mg} / \mathrm{Mg}+\mathrm{Fe}$ ). See Appendix J for raw data. 
(a) Orthopyroxene

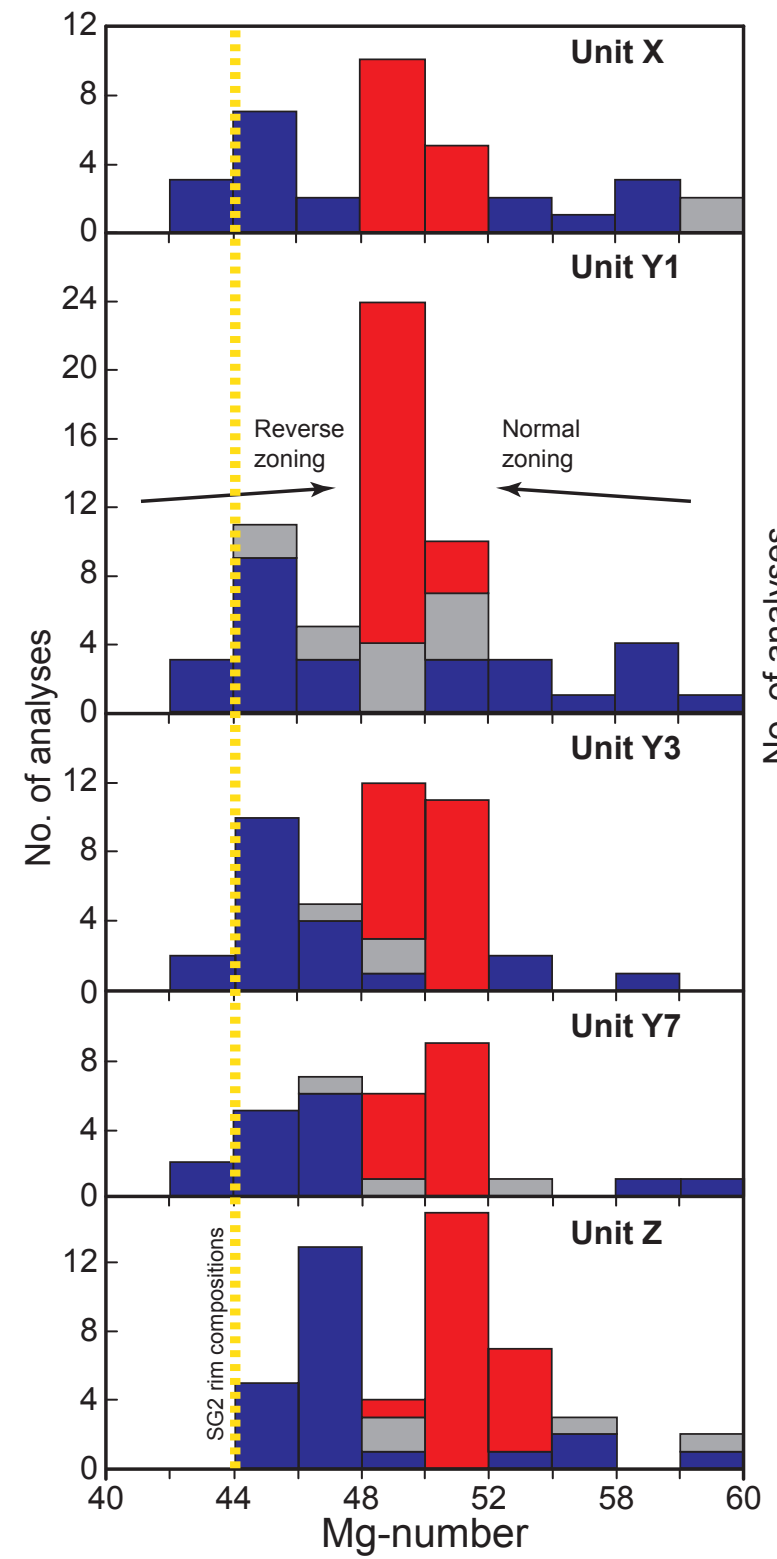

(b) Plagioclase
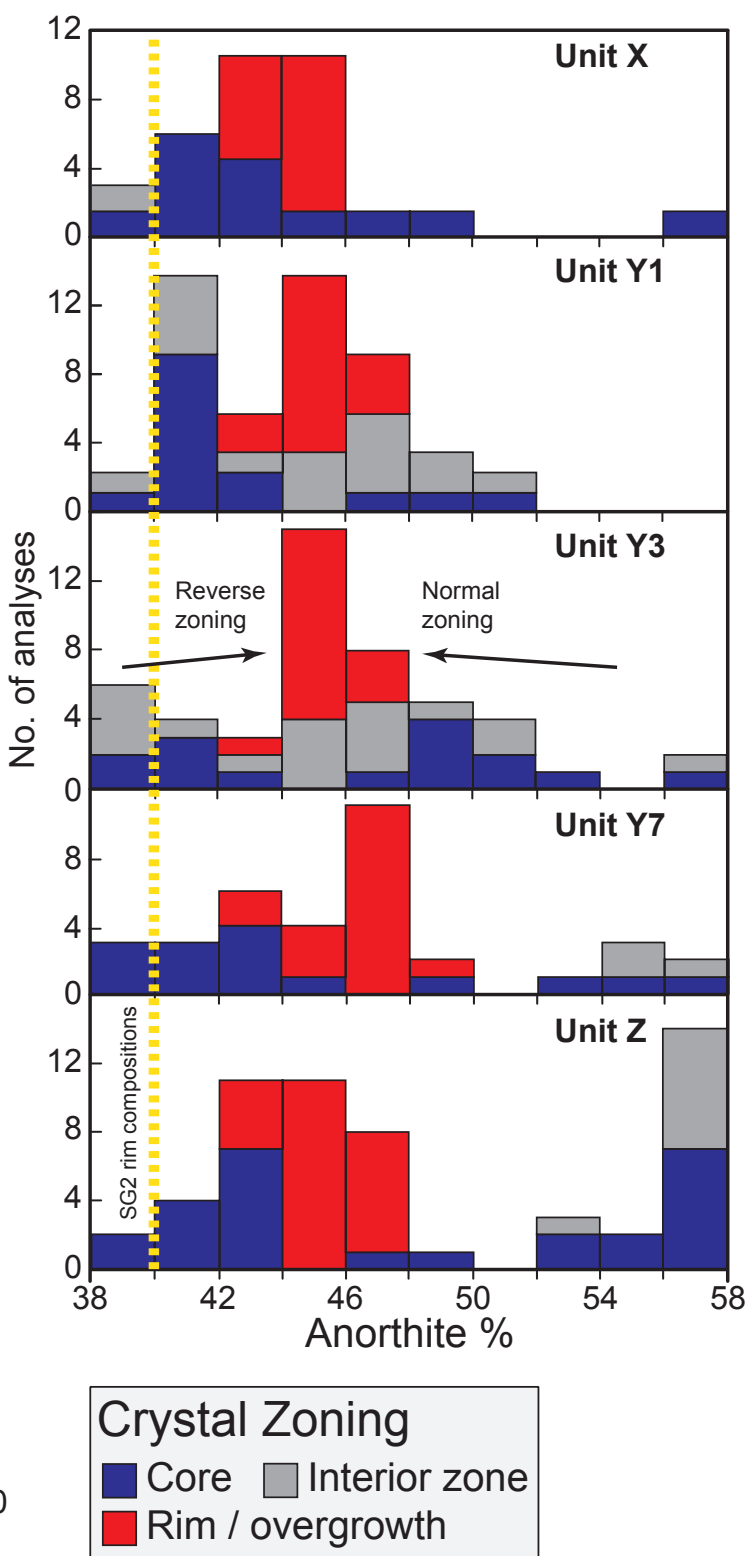

Figure 6.5. Stacked compositional histograms showing the range of compositions from zones analysed within (a) orthopyroxene and (b) plagioclase crystals from the SG3 eruptive units and subunits of Unit Y. $\mathrm{Mg}$ values for orthopyroxene are calculated as $\mathrm{Mg}=100 * \mathrm{Mg} / \mathrm{Mg}+\mathrm{Fe}_{\text {total }}$, and Anorthite \% for plagioclase is calculated as $\mathrm{An} . \%=100 * \mathrm{Ca} / \mathrm{Ca}+\mathrm{Na}+\mathrm{K}$. The dashed yellow line represents the average crystal rim composition of orthopyroxene and plagioclase analysed from the older SG2 units U,V and W (from Barker et al., 2014b). Note the overlapping composition of the SG3 reversely zoned crystals and the dashed SG2 average rim composition. Both normally and reversely zoned crystals converge on a common modal peak for rim compositions for all eruptive units. Raw data is presented in Appendix J. 
Table 6.2. Summary of orthopyroxene textural populations within each of the SG3 eruptive units (in \% of total, see Appendix M for BSE images of crystal populations).

\begin{tabular}{lrrr}
\hline Group & Reverse & Normal & Unzoned \\
\hline Unit X & 86.0 & 14.0 & 0 \\
\hline Unit Y & & & \\
Y1 & 78.4 & 17.6 & 3.9 \\
Y3 & 66.7 & 20.8 & 12.5 \\
Y7 & 83.3 & 14.3 & 2.4 \\
\hline & & & 4.3 \\
\hline
\end{tabular}

Appendix N), and sometimes have a thin $(<20 \mu \mathrm{m})$ weakly normally zoned band on the very edge of the crystal (Figure 6.4c). Rare unzoned macro crystals together with the groundmass crystals overlap in composition with zoned crystal rims between $\mathrm{Mg}_{48-52}$ and $\mathrm{An}_{42-46 .}$. Orthopyroxene and plagioclase crystals from the eruption $\mathrm{Z}$ floated pumice samples show many of the features observed in the other SG3 eruptions, but with the majority of the crystals showing strong disequilibrium features and resorbed inclusion rich cores (Figure 6.4d). Crystal compositions overlap with the other SG3 units, but high-An normally zoned plagioclase cores are more common and unzoned euhedral high-An (up to $\mathrm{An}_{80}$ ) plagioclase is present both as individual crystals and within mafic inclusions in a sheath of microcrystalline glass (Figure 6.4e; Figure 6.5). Rare olivine crystals within mafic inclusions show strong zonation, with Mg-rich cores up to Fo90 and thin Fe-rich reaction rims down to $\mathrm{Fo}_{65}$ (Figure 6.4e).

\subsubsection{Fe-Mg diffusion timescales in orthopyroxene}

Fe-Mg diffusion timescale modelling was carried out on both reverse and normally zoned orthopyroxenes from each of the SG3 eruptions (Figure 6.6; Appendix N). Plagioclase was not modelled for diffusive timescales as the compositional boundaries observed in most cases were not sharp and showed asymmetrical growth profiles. Orthopyroxene crystals in contrast, showed asymptotic profiles along crystallographic $a$ $+b$-axes in both interior normally zoned cores and reversely zoned rims (Appendix $\mathrm{N}$ ). However, common Fe-Ti oxide inclusions and glassy melt inclusions disrupted many diffusion profiles and care was taken to avoid crystal zones affected by inclusion induced growth smearing effects along the crystallographic $c$-axis. The maximum observed timescale in modelled profiles for Unit X orthopyroxene is $\sim 100$ years, with 
Fe-Mg inter-diffusion model timescales (years)

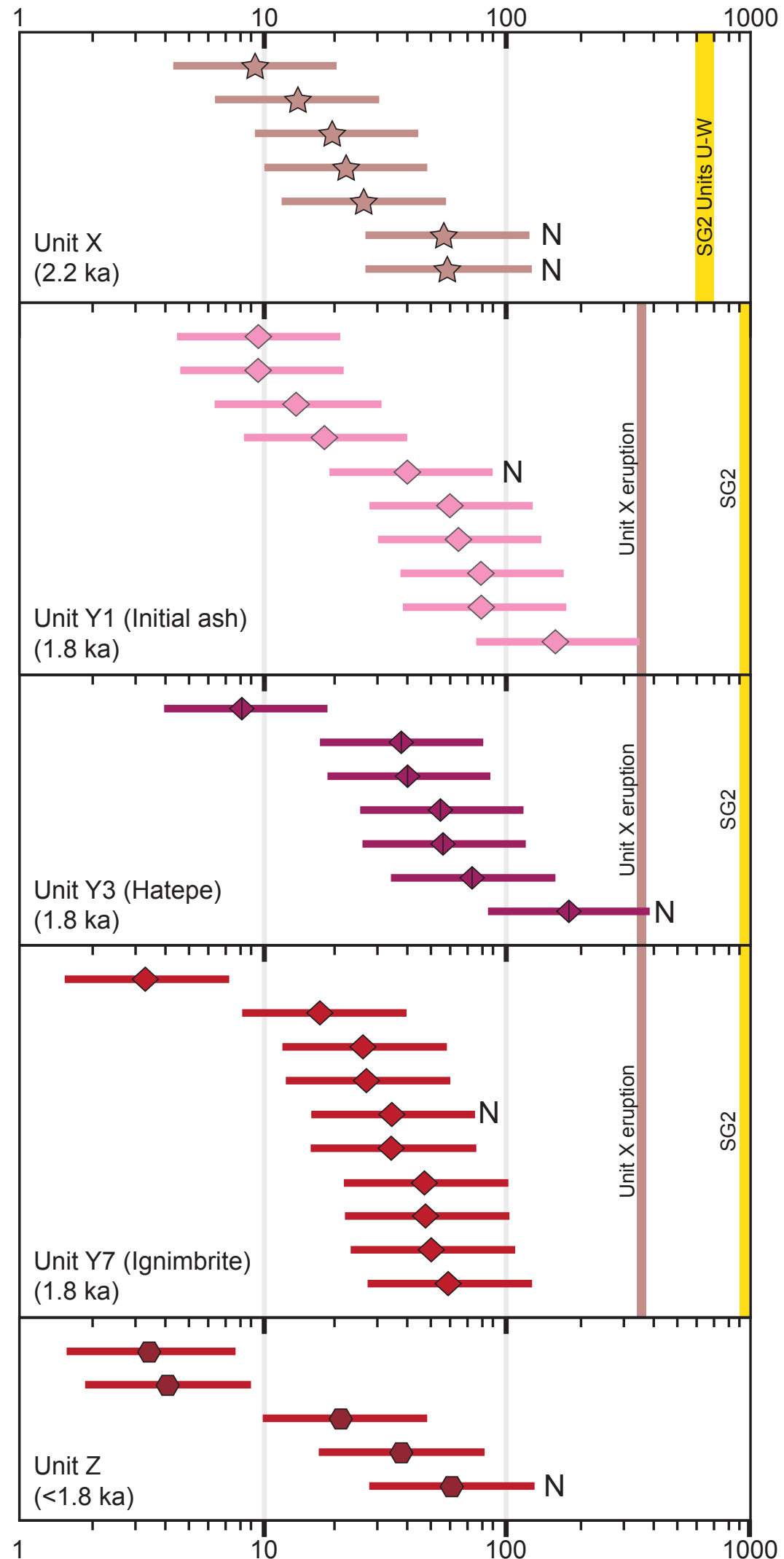

Figure 6.6. Model timescale estimates (log-scale) of Fe-Mg inter-diffusion in orthopyroxene from the SG3 eruptive units and Unit Y eruption subunits. Symbols represent average timescales using parameter estimates of $860{ }^{\circ} \mathrm{C}, 1.5 \mathrm{MPa}$ and $\log f \mathrm{O}_{2}$ of $0.2 \Delta \mathrm{NNO}$ for units $\mathrm{X}$ and $\mathrm{Y}$ and $0.0 \Delta \mathrm{NNO}$ for Unit Z (from Barker et al., 2014b). Error bars represent the inferred maximum and minimum timescales with varying conditions by uncertainties $\pm 30^{\circ} \mathrm{C}$ or $\pm 0.3 \Delta N N O$. N denotes crystals with normal zonation. See Electronic Appendix $\mathrm{N}$ for diffusion images and individual profiles. 
normally zoned timescales of between 50-100 years and reversely zoned crystal timescales all $<30$ years to $\sim 10$ years (Figure 6.6 , Appendix N). A similar range of timescales is observed in samples from the Unit Y subunits, with no major differences in model timescales between subunits and no notable correlation between timescale and zonation type (Figure 6.6). The maximum observed timescales overlap within uncertainty with the Unit X eruption $\sim 380$ years earlier, but most timescales are $<200$ years, with a few strongly resorbed crystals with thin dark resorbed bands yielding timescales down to $<10-20$ years (Figure 6.6; Appendix N). The average model timescale for all Unit Y orthopyroxene is $\sim 50$ years. Multiple profiles on single crystals, either on the same axis but at different lengths along the crystal face, or on opposing growth zones, show consistent timescale estimates that only differ by \pm 30 years, which is considered to be the same within uncertainty, given the maximum and minimum temperature and $f \mathrm{O}_{2}$ values used (Appendix $\mathrm{N}$ ). Unit $\mathrm{Z}$ orthopyroxenes have model timescale averages of $<60$ years down to $<10$ years.

\subsection{Discussion}

The changes in magma chemistry and crystal zonation features in the SG3 eruptives indicate that Taupo's magmatic system underwent significant changes in the lead-up to the voluminous $232 \mathrm{AD}$ eruption. Below, the origins of these changes are considered within a timeline of events from the transition from SG2 eruptions and build-up of the SG3 magma system through to the reaction and recovery of the post-Y magmatic system, with implications for the modern magmatic environment.

\subsubsection{Relationships between the SG2 and SG3 magma systems}

Consistent with trends identified in previous studies (e.g. Sutton et al., 2000; Smith et al., 2005; Barker et al., 2014b), significant differences in melt composition are observed between the SG2 (7-2.75ka) and SG3 (2.15-1.8 ka) magmas (Figure 6.3; Table 6.1). These differences are particularly pronounced in products of the final SG2 eruptions at $\sim 2.8 \mathrm{ka}(\mathrm{V}$ and $\mathrm{W}$ ), which have the highest $\mathrm{Rb} / \mathrm{Sr}$ ratios (Figure 6.3; Barker et al., 2014b), the most Na-rich plagioclases and Fe-rich orthopyroxenes, and the most elevated ${ }^{87} \mathrm{Sr} /{ }^{86} \mathrm{Sr}$ ratios of all the SG2 magmas (Sutton et al., 2000; Barker et al., 2014b; Figure 6.7). Magma temperatures estimated from multiple techniques including Fe-Ti oxide pairs, plagioclase-melt and orthopyroxene-melt thermometry are $\sim 830 \pm 20$ 


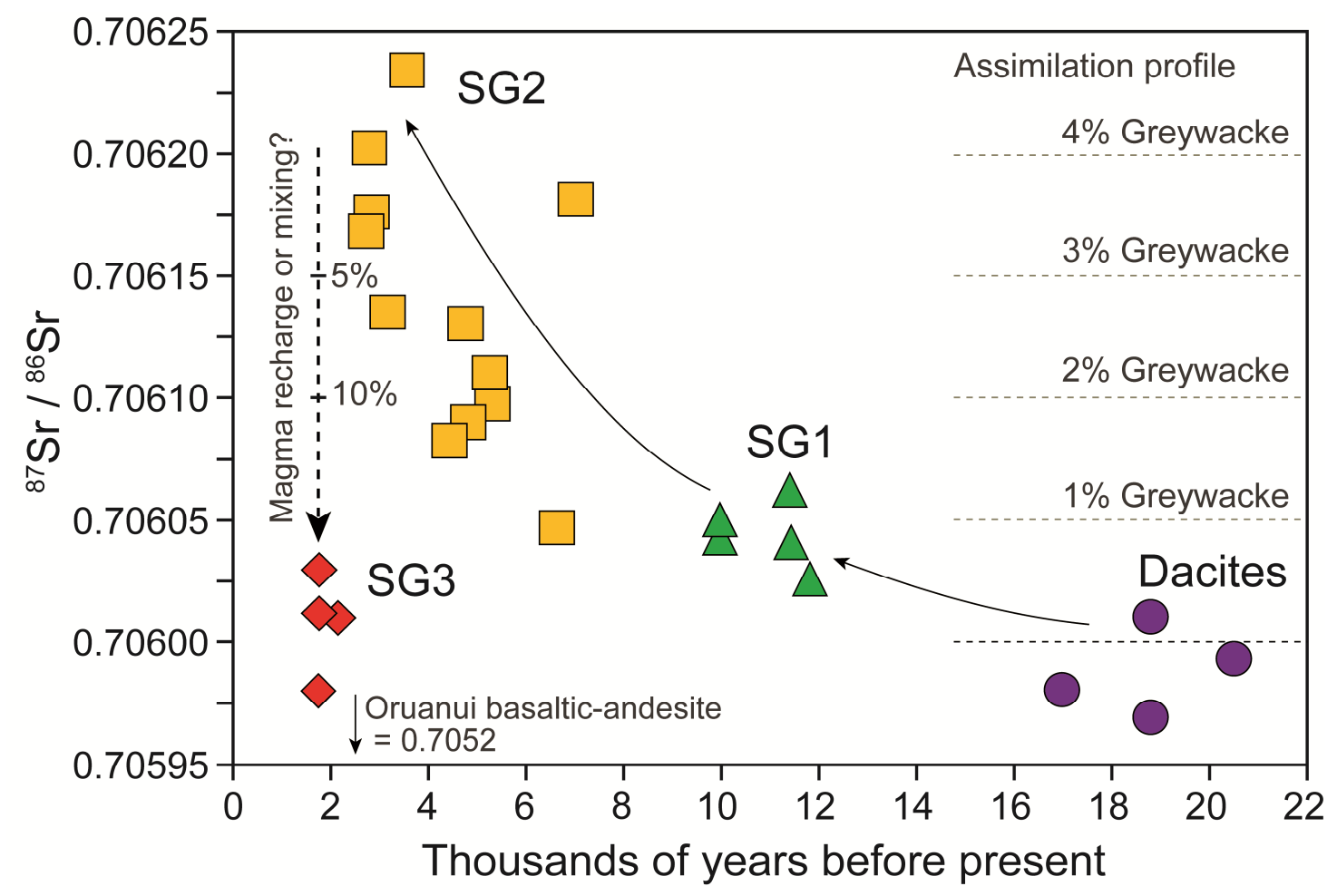

Figure 6.7. Variations in Sr-isotopic composition through time for the post-Oruanui magma subgroups. Eruption ages are from Wilson (1993) and Sr isotope data are from Sutton et al. (2000). Dashed grey lines refer to compositional changes resulting from binary mixing between the least radiogenic samples at $\sim 0.7060$ and the inferred greywacke basement value of 0.71105 from Browne et al. (1992). Note the stepwise compositional change between the SG2 and SG3 magma groups with the downward mixing trend representing binary mixing between the final SG2 magmas and a less radiogenic magma of isotopic composition similar to that of the Oruanui basaltic-andesite from Wilson et al. (2006).

${ }^{\circ} \mathrm{C}$ for units $\mathrm{U}, \mathrm{V}$ and $\mathrm{W}$ (Barker et al., 2014b). In contrast to the SG2 magmas, the first product of SG3 (Unit X) shows significant evidence for disequilibrium, with common melt inclusions, strongly reversely zoned crystals (Figure 6.4) and less evolved melt compositions (Figure 6.3). In addition, identical thermometry techniques indicate that the SG3 magmas were $\sim 30{ }^{\circ} \mathrm{C}$ hotter at $\sim 850$ to $860{ }^{\circ} \mathrm{C}$ (Barker et al., 2014b). Questions therefore arise as to the origin of the SG3 magmas. Were they tapped from a separate, hotter region of the magma system to the SG2 magmas (Sutton et al., 2000; Smith et al., 2005)? Or, alternatively, were they from a similar source and crustal region beneath Taupo that simply experienced changing conditions of crystallisation and disequilibrium prior to eruption?

The SG2 and SG3 magmas have whole-rock compositions that fall along a liquid line of descent, with sub-parallel, overlapping arrays on variation diagrams (Figure 6.3). As shown by Barker et al. (2014b), differences in whole-rock major and trace element chemistry in the post-12 ka eruption products at Taupo can largely be explained by dissolution of the observed mineral phases. In addition, SG3 melt inclusions show a broad range of compositions between $74-77$ wt. $\% \mathrm{SiO}_{2}$, with some 
melt inclusions more evolved than the matrix glass at 74-75.4 wt. \% $\mathrm{SiO}_{2}$, indicating that some minerals originally grew in more evolved melts than those in which they were erupted. Notably, the evolved SG3 melt inclusions overlap in composition with glass compositions from the SG2 magmas (Barker et al., 2014b). The cores of reversely zoned orthopyroxene and plagioclase crystals in SG3 materials overlap in composition with unzoned crystals observed in units $\mathrm{V}$ and $\mathrm{W}$, indicating that they too may share a common origin (Figure 6.5). Crystal inheritance, as evidenced by the dominance of these reversely zoned crystals, coupled with the effective overlap of the relevant inferred vent positions (Figure 6.1) precludes any concept of different magma reservoirs for the SG2 and SG3 magmas. The SG2 to SG3 transition is coincident with an apparent shift in ${ }^{87} \mathrm{Sr} /{ }^{86} \mathrm{Sr}$ ratios from $\sim 0.7062$ to $\sim 0.7060$, suggesting that the SG3 generation process reflects magmas which have seen less assimilation of greywacke country rock, or alternatively their compositions have been diluted from that of the SG2 compositions through magma recharge (Figure 6.7). As demonstrated by studies of single crystal Srisotopic systematics, a sudden decrease in ${ }^{87} \mathrm{Sr} /{ }^{86} \mathrm{Sr}$ ratios can result from recharge of less radiogenic magmas and be accompanied by changing crystal growth profiles (Knesel et al., 1999). It is suggested that similar processes occurred in the SG2 to SG3 transition, where increase melt extraction or mixing with a less radiogenic magma resulted in lower ${ }^{87} \mathrm{Sr} /{ }^{86} \mathrm{Sr}$ ratios accompanied by changes in magma bulk composition and increased temperatures.

Given the multiple lines of evidence, the SG2 and SG3 magmas are considered to be strongly related and likely derived from a similar source region. The consistent changes in Fe-Ti oxide, orthopyroxene and plagioclase compositions and textures can be best explained by elevated temperatures, with possible minor accompanying changes in $f \mathrm{O}_{2}$ or melt $\mathrm{H}_{2} \mathrm{O}$ content. With elevated temperatures resulting from magma recharge, the SG2 plagioclase and orthopyroxene experienced dissolution and reverse compositional zoning, liberating compatible elements into the melt and generating the apparent shift in whole-rock compositions (Figure 6.3; Barker et al., 2014b). A maximum timescale of evolution for the SG3 magma is therefore estimated at 600 years, from the time gap between eruptions of units V/W and Unit X. This 600 year time period does not require the formation of a new magma system, but represents the maximum timescale for heating and accompanying compositional changes to the magma system as a whole. Diffusion modelling, however, provides further constraints on the relative timing of dissolution and changing conditions of crystallisation during this period of volcanic quiescence, and between individual eruptive units within the 
SG3 sequence. Below, it is considered what processes the range of diffusion model timescales represent and what mechanisms lead to the rapid changes in magma composition and melt accumulation at Taupo.

\subsubsection{Rates and mechanisms of melt mobilisation prior to the 232 AD event}

Given the close affinity between the SG2 and SG3 magmas, timescale estimates from diffusion profiles are of relevance to measuring the period over which the cooler SG2 magma system experienced a significant temperature rise, resulting in mineral dissolution and/or reverse zonation. However, minerals within the SG3 magmas show both reverse and normal zonation profiles, as well as minor populations of unzoned crystals (Table 6.2; Figure 6.4). Importantly, all crystal rims converge on a similar compositional range, indicating that they finally grew in host magma of comparably uniform composition (Figure 6.5). Reversely zoned crystals are considered to be inherited from a disrupted and heated SG2 magma body or mush zone, as evidenced from their similar core compositions and more evolved melt inclusions. Crystals displaying normal zonation, in contrast, could originate from two possible sources. First, they could represent crystals that experienced almost complete dissolution and therefore did not preserve an inherited Fe-rich (orthopyroxene) or Na-rich (plagioclase) evolved cores. In such a case, the normally zoned cores should overlap in composition with the reversely zoned Mg-rich (orthopyroxene) or Ca-rich (plagioclase) overgrowths (Figure 6.5). Second, strongly normally zoned crystals could represent inherited crystals from the deeper, hotter roots of the magma system, or possibly even the magma(s) which induced the heating trend. Some normally zoned orthopyroxene cores have compositions of up to $\mathrm{Mg}_{60}$, consistent with temperatures increases of $30-40{ }^{\circ} \mathrm{C}$ over the final eruption temperatures using the orthopyroxene-melt thermometer of Putirka (2008). Notably, these elevated temperatures of $880-890^{\circ} \mathrm{C}$ are similar to those modelled in the post-Oruanui dacites (Barker et al., 2014b).

Regardless of their initial origins, the normally and reversely zoned orthopyroxenes should yield similar Fe-Mg diffusion model timescales, if related to the same heating process. The only recognized differences in timescale estimates are in Unit X orthopyroxenes, where the normally zoned crystal timescales are generally $>50$ years and the reversely zoned crystals are all shorter (Figure 6.6; Appendix N). Given that Unit X is the first of the SG3 magmas, the normally zoned crystals may represent the initial onset of magma recharge, heating and changing conditions, while the reversely zoned crystals represent the onset of dissolution and wide-scale changes. 
Interestingly the full range of timescales from the Unit X orthopyroxene indicates that the heating processes driving changing conditions of crystallisation initiated at a maximum of $\sim 100$ years prior to eruption. Unit $\mathrm{X}$ represents a relatively small volume eruption with an estimated volume of $<1 \mathrm{~km}^{3}$. However, only $\sim 350$ years later, the Unit $Y$ eruption occurred with an eruptive volume two orders of magnitude greater (Wilson, 1993). The Unit Y (Taupo) magma is notable for its uniformities for both whole-rock compositions (Sutton et al., 1995) and volatile contents (Dunbar \& Kyle, 1993), despite transitioning between explosive and effusive phases, with multiple vent locations and a wide range in inferred eruptive rates (Figure 6.1; Wilson \& Walker, 1985; Houghton et al., 2010). This study has found only very minor differences in whole-rock chemistry in subunits Y1-Y7, with Y1 and Y2 having slightly higher $\mathrm{Rb} / \mathrm{Sr}$ and $\mathrm{SiO}_{2}$ (Table 6.1). In addition, mineral compositions between the early, middle and final phases of the eruption show no systematic changes (Figure 6.5). Similar features are observed in products of the caldera-forming Oruanui eruption at $25.4 \mathrm{ka}$, and interpreted to result from vigorous convection in the melt dominant body (Wilson et al., 2006; Allan et al., 2014). Unit Y orthopyroxenes are distinct from those in Unit X, with larger Mg-rich outer zones and some crystals displaying thin rim growth zones with lower Mg contents indicative of cooling (Figure 6.4c). Diffusion timescales yielded by inner zones from both normally and reversely zoned Unit $\mathrm{Y}$ orthopyroxenes are $<350$ years, implying that the Unit Y magma was mostly developed in the time gap after eruption X. The majority of timescales are $<100-200$ years indicating that the physical changes driving crystal zonation patterns may have been considerably more rapid (Figure 6.6).

The changes in melt chemistry and apparent heating event between the SG2 and SG3 magmas raises several important questions about melt generation processes and the structure of Taupo's magmatic system. For example, what caused the heating and subsequent shift in compositions during this time? In turn, how did these changes affect the physical properties of the rhyolite magma and its rates of mobilisation and accumulation prior to the SG3 eruptions? As previously reported, silicic and mafic melts at Taupo have a close connection and sometimes physically interact, either prior to, or during eruption (Blake et al., 1992; Sutton et al., 1995; Wilson et al., 2006; Barker et al., 2014b). The Unit S (Waimihia) eruption at $3.5 \mathrm{ka}$ records magma mixing between relatively cool rhyolite magma $\left(830^{\circ} \mathrm{C}\right)$ and hot andesite $\left(\sim 1100{ }^{\circ} \mathrm{C}\right)$ (Blake et al., 1992). The Unit S rhyolites do not show evidence for pre-eruptive heating through strongly zoned minerals and it is therefore inferred that magma mixing and andesite injection into the base of the melt-dominant magma reservoir occurred only shortly 
prior to eruption. This particular injection of mafic magma did not significantly affect the composition of subsequent rhyolite eruptions and in a similar fashion no SG2 eruptions show evidence for mixing or significant heating (Barker et al., 2014b). The post-S SG2 eruptions have the lowest model temperatures and most evolved magmas of the post-Oruanui eruption sequence. A mafic magma of similar composition to the Waimihia andesite could be considered as a viable candidate for heating and compositional changes in the SG3 eruption groups. However, there is very little direct physical evidence for mafic magma interaction in the Unit $\mathrm{X}$ and Unit $\mathrm{Y}$ eruptions. Through extensive field observations and sampling, only a single cm-sized mafic clast has been recovered from Unit Y deposits with a whole-rock composition broadly similar to the Waimihia mafic material (Barker et al., 2014b). Mafic inclusions and xenocrystic plagioclase are considerably more common in the eruption $\mathrm{Z}$ floated pumices and the significance of these is considered below.

The lack of physical evidence for mafic magma involvement in Taupo's rhyolite system during the early SG3 period does not rule it out as a potential candidate driving heating and changes in magma composition. Given the large inferred size of the rhyolitic mush system at Taupo which likely extended from depths of $\sim 5$ to $>8 \mathrm{~km}$ (Barker et al., 2014b), mafic magma infiltration into the lower-density mush pile and mechanical mixing could only be facilitated under certain circumstances (e.g. Blake et al., 1992; Woods \& Cowan, 2009; Bain et al., 2013). If the magma system at Taupo experienced cooling and crystallisation (and thickening of the silicic mush?) during the final eruptions of SG2, relatively hot and dense mafic magma would be unlikely to physically mix with the silicic mush, but may be able to penetrate through to shallower levels via diking and fracturing through the relatively cool silicic mush (e.g. Bain et al., 2013). Hybridisation between mafic magmas and rhyolites is not observed in any SG3 magmas and heat transfer by conduction has been proposed to be a relatively inefficient and slow process in large silicic magma systems (Huber et al., 2011). However, increased rates of mafic magma injection and possibly partial penetration into the silicic mush pile could result in increased heat flow through the mush and then disruption through various mechanisms including convective mixing and large scale RayleighTaylor overturning (Couch et al., 2001; Bain et al., 2013), mafic 'wind' (Bachman \& Bergantz, 2006) or stable front remobilisation or 'unzipping' (Burgisser \& Bergantz, 2011). Rapid heating of the rhyolite mush by $30-40{ }^{\circ} \mathrm{C}$ could act to significantly reduce magma viscosity (or increase melt proportions in the mush) and trigger mobilisation and the development of a relatively buoyant melt dominant body (Burgisser \& Bergantz, 
Table 6.3. Summary of melt accumulation rates for the SG3 magmas and Oruanui eruption (in $\mathrm{m}^{3}$ of rhyolite per second)

\begin{tabular}{lccc}
\hline Eruption & Max & Min & Median \\
\hline Unit X $\left(\mathbf{0 . 3} \mathbf{~ k m}^{\mathbf{3}}\right)$ & 0.238 & 0.095 & 0.166 \\
Unit $\mathbf{Y}$ total volume $\left(\mathbf{3 5} \mathbf{~ k m}^{\mathbf{3}}\right)$ & 11.10 & 3.17 & 7.13 \\
Unit Y conservative $\left(\mathbf{1 5} \mathbf{~ k m}^{\mathbf{3}}\right)$ & 4.76 & 1.36 & 3.06 \\
Unit Z $\left.\mathbf{( 0 . 1} \mathbf{~ k m}^{\mathbf{3}}\right)$ & 0.317 & 0.106 & 0.21 \\
\hline Oruanui $\left(\mathbf{5 3 0} \mathbf{~ k m}^{\mathbf{3}}\right)$ & 33.61 & 5.60 & 19.61 \\
\hline
\end{tabular}

Accumulation rates are calculated from diffusion timescales presented in Figure 6.6. Maximum (max) timescales are set at 100,350 and 30 for units $X, Y$ and $Z$ respectively. Minimum ( $m i n$ ) timescales are 50,100 and 10 years respectively. The generation rate of the Oruanui melt dominant body is calculated using 500 years from diffusion profiles as the maximum (Allan et al., 2012) and 3000 years from the Okaia eruption as the minimum (Wilson \& Charlier, 2009). The two rates presented for the Unit $Y$ eruption are for the sum of the subunits volumes (15 $\left.\mathrm{km}^{3}\right)$ and also considering the volume of material now buried beneath Lake Taupo $\left(35 \mathrm{~km}^{3}\right)$ (from Wilson \& Walker, 1985).

2011; Bain et al., 2013), with reversely zoned minerals preserving the heating and mobilisation process. In such a case, the diffusive boundary observed in the orthopyroxenes are considered to represent the onset of heating and the development of a pre-eruptive melt dominant body in Taupo's magmatic system. This process is considered to have occurred only shortly prior to each eruption where melt was mobilised to form individual distinctive melt dominant magma bodies that were stored at shallow levels for a short period prior to eruption. Similar textural changes are inferred from orthopyroxenes in the Oruanui eruption at $25.4 \mathrm{ka}$ and inferred to represent decompression histories from the crystal mush to a shallow (3.5-6 km) melt dominant body (Allan et al., 2013). However, an absence of amphibole in the SG2 and SG3 magmas precludes comparison of amphibole model-pressures and trace element compositions for these eruptives.

Rates of melt mobilisation due to heating and disruption of the magma system can be inferred from the ranges of timescales observed in orthopyroxenes between individual eruptions, assuming that the melt-dominant magma body was formed during the gap between eruptions (Table 6.3). Due to their relatively small volumes, eruptions $\mathrm{X}$ and $\mathrm{Z}$ have inferred rhyolite melt generation rates ranging from $\sim 0.1-0.3 \mathrm{~m}^{3} / \mathrm{sec}$ ( $\sim 0.002-0.010 \mathrm{~km}^{3} /$ year). In contrast, the Unit Y eruption has over an order of magnitude faster generation rates up to $\sim 11 \mathrm{~m}^{3} / \mathrm{sec}\left(0.35 \mathrm{~km}^{3} /\right.$ year $)$, depending on the inferred eruptive volume and maximum or minimum timescale estimate used from diffusion modelling (Table 6.3; Figure 6.6). Such rapid rates of melt accumulation are similar to, although slightly less than, those inferred for the Oruanui eruption. The range 
of melt generation rates highlights several important aspects about magmatism and eruptive behaviour at Taupo:

1. Large volumes of melt can be very rapidly remobilized and assembled on timescales of decades to centuries that are relevant to humans and volcanic monitoring. Notably, the apparently rapid timescales of melt mobilisation at Taupo match numerically modelled timescales of mush remobilisation by unzipping for other large silicic systems including Pinatubo and Fish Canyon (Burgisser \& Bergantz, 2011).

2. Taupo can rapidly transition from an apparent cooling cycle to a heating cycle in only hundreds of years. Such processes may be triggered and buffered by the rate of mafic magma injection at the base of the rhyolitic mush system.

3. Mafic magma supply and interaction with the rhyolite system is not constant through time and its style of interaction with the rhyolite system can vary significantly, depending of the state or potency of the rhyolitic mush system with varied results. For Unit $\mathrm{S}$ the mafic magma physically interacted and mingled with the rhyolite melt, without inducing widespread heating or compositional changes in subsequent eruptions (Blake et al., 1992). Physical mixing and magma drainage from the mafic system into the silicic mush may have acted to deplete the heat source resulting in lower apparent temperatures for subsequent eruptions U and V (Barker et al., 2014b). In contrast, for units X and $\mathrm{Y}$ the mafic magma was apparently unable to physically mingle with and fully penetrate the rhyolite mush, yet their interaction is inferred to have resulted in widespread chemical changes and rapid melt extraction.

4. There is a fundamental difference in melt generation rates for large versus small eruptions, with over an order of magnitude difference between the two (Table 6.3). Unit $\mathrm{X}$ is chemically identical to the Unit Y magma but has an order of magnitude lower accumulation rates.

It is not clear from diffusion data alone what factors primarily control the accumulation rates and the timing of melt mobilisation versus eruption. However, given the close connection between the mafic and silicic magmas, it is considered that the rate of mafic magma supply and associated heat or volatile transfer may in turn affect the rate of rhyolite melt mobilisation and accumulation. Rates of mafic magma supply may also gradually increase through time resulting in the largely variable rhyolite melt mobilisation rates between units $\mathrm{X}$ and $\mathrm{Y}$. Alternatively, mush destabilisation and melt accumulation could follow a positive-feedback runaway acceleration type response (e.g. 
Allan et al., 2013).

A secondary feature observed in many of the Unit $\mathrm{Y}$ orthopyroxenes is the presence of a thin normal overgrowth on reversely zoned minerals where $\mathrm{Mg}$ contents drop slightly from $\sim \mathrm{Mg}_{51}$ to $\mathrm{Mg}_{50}$ (Figs. 4 and 5). These zones do not represent diffusive boundaries but appear to represent growth profiles in BSE images. The minor normal overgrowths indicate that the Unit Y melt dominant body may have been stored for a short time period (years) and experienced minor amounts of cooling prior to eruption. The earliest erupted Unit Y magma is slightly more evolved than the Unit X magma or later erupted Unit Y, but apparent temperature differences are indistinguishable within the uncertainties of the thermometry techniques used (Figure 6.3). Using the OPX-melt thermometer of Putirka (2008), a compositional drop from $\sim \mathrm{Mg}_{51}$ to $\mathrm{Mg}_{50}$ in the same Y1 melt composition is equivalent to a minor temperature drop of $\sim 5^{\circ} \mathrm{C}$. To a first order the heat loss due to the change in temperature of the magma in the melt dominant body can be estimated from combining the overall body of the magma $\left(35 \mathrm{~km}^{3}\right)$ with the change in heat capacity of rhyolite glass over a given temperature interval (Neuville et al., 1993). This approach does not take into account secondary-order effects such as loss of volatiles and latent heat exchange associated with crystallisation or dissolution of the crystal phases. The total heat loss over $35 \mathrm{~km}^{3}$ (e.g. $855-850^{\circ} \mathrm{C}$ ) amounts to $6.2 \mathrm{~J} / \mathrm{g}$ or $\sim 1.43 \times 10^{16} \mathrm{~J}$ for the whole magma body. If the heat loss was released over a time period of 5 years (from the shortest observed diffusion zones) then the thermal release would be $\sim 90 \mathrm{MW}$, somewhat less than the current geothermal heat output of Taupo which is estimated at $120 \mathrm{MW}$ (e.g. Horomatangi Reefs: Whiteford, 1996) to 400 MW (e.g. Wairakei-Tauhara; estimates from Bibby et al., 1995). Alternatively, the time taken for a $5{ }^{\circ} \mathrm{C}$ drop in the magma temperature using the current geothermal output estimates would only be on the order of a 1-2 years. Interestingly, the estimated heat output from the pre-Y magma system of $90 \mathrm{MW}$ over 5 years is comparable to that considered for the pre-Oruanui magma system of $\sim 100 \mathrm{MW}$ (Allan, 2013).

The variable rates of rhyolite melt accumulation and storage times raise questions over the controls of volcanism at Taupo. For example, how $\operatorname{did} 35 \mathrm{~km}^{3}$ of magma accumulate as a large melt dominant body and possibly undergo minor amounts of cooling prior to $232 \mathrm{AD}$ without erupting at an earlier stage or with a smaller volume as observed for Unit X? Field studies have shown that the Unit Y Taupo eruption involved multiple vent sites along the eastern side of Lake Taupo, with a wide diversity of inferred mass discharge rates (Figure 6.1; Wilson \& Walker, 1985; Wilson, 1993; Smith \& Houghton, 1995; Houghton et al., 2010, 2014). The relatively minor changes 
in whole-rock chemistry, consistent mineral compositions and diffusion timescales indicates that during the initial phases of the eruption, the majority of the melt dominant body had formed. However, the eruption was spasmodic, starting from a southerly vent then switching in mass discharge rate and then vent position to a location $\sim 10 \mathrm{~km}$ to the north, before switching vent again during the climax of the eruption and caldera collapse (Figure 6.1; Smith \& Houghton, 1995). In such a case, the controls on volcanism cannot be simply linked to magma driven overpressure or buoyancy and the strength of the overlying country rock (cf. Caricchi et al., 2014). As demonstrated by Rowland et al. (2010) and Allan et al. (2012), tectonic stress and normal faulting plays a major role in the timing and magnitude of large eruptions in the TVZ. The alignment of the SG3 vents along the eastern side of Lake Taupo indicates that faulting likely played a major role, possibly modulating the Unit Y eruption as inferred for the Oruanui supereruption (Allan et al., 2012). However, in contrast to the conceptual models presented in Rowland et al. (2010), it is apparent that the pressure and rate of mafic magma supply could also be highly variable at Taupo. The variable timing and size of eruptions and the large volume of Unit $Y$ could therefore be considered as a result of a combination of three crucial but variable factors including high differential tectonic stress, increased potency of the silicic system, and high mafic melt input (Figure 6.8ac).

\subsubsection{Post-232AD volcanism and magmatic adjustment}

The Unit $\mathrm{Z}$ pumiceous dome carapace samples investigated in this study have broadly similar compositions to the earlier SG3 units but are distinctive, for several reasons.

1. They have the least evolved whole-rock chemistry, with the lowest $\mathrm{SiO}_{2}, \mathrm{Rb} / \mathrm{Sr}$ ratio and highest $\mathrm{CaO}$ and $\mathrm{TiO}_{2}$ (Figure 6.3).

2. They have a significant number of plagioclase crystals with cores up to $\mathrm{An}_{80}$, and all mineral phases show multiple lines of evidence for disequilibrium (Figs. $4 \mathrm{~d}$ and 5). Melt inclusions and mineral inclusions are so common in the orthopyroxenes that finding diffusive boundaries unaffected by smearing along the c-axis was difficult and as a result only a few boundaries were modelled.

3. They contain small, sparsely distributed dark grey mafic inclusions with euhedral olivine, pyroxene and plagioclase (Figure 6.4e). The high Fo content of the olivines (up to $\mathrm{Fo}_{90}$ with $\mathrm{NiO}$ up to 0.44 wt. \%) indicate that these may have been sourced from, or interacted with, a very primitive melt. The bulk compositions of the inclusions are andesite, suggesting that they are likely 
(a)

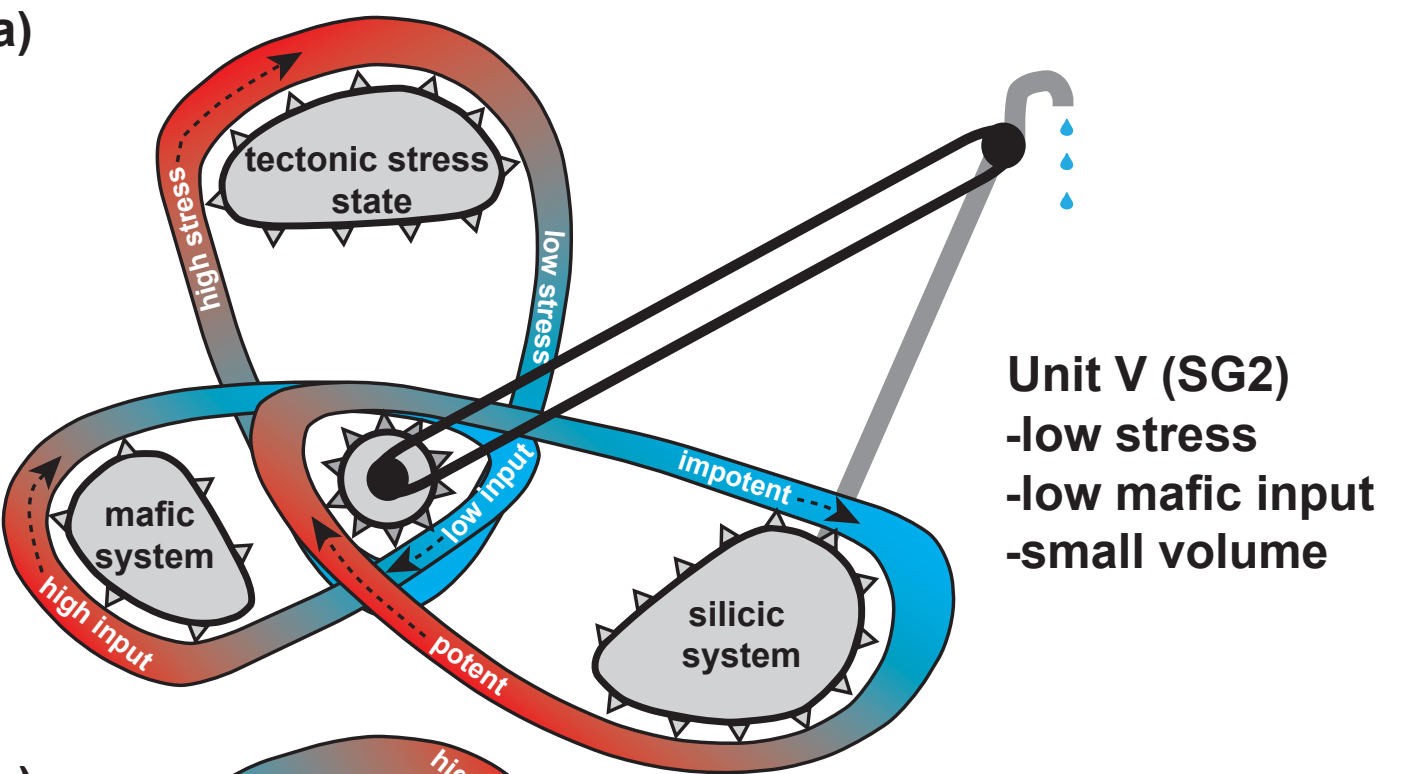

(b)

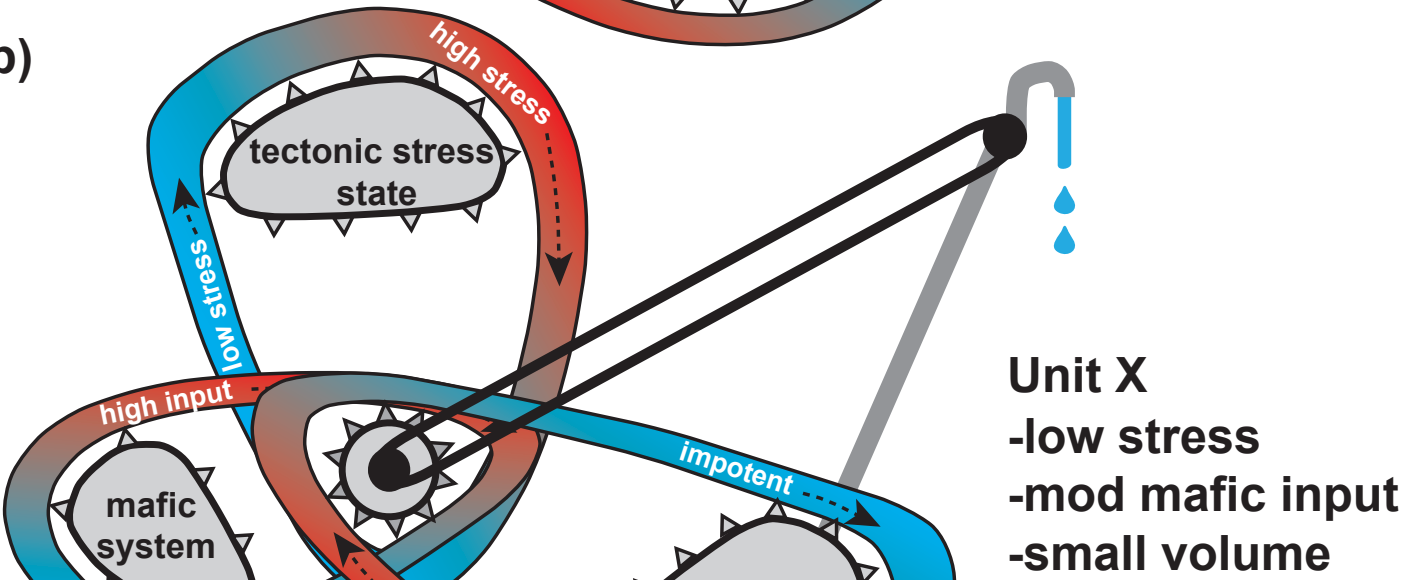

(c)

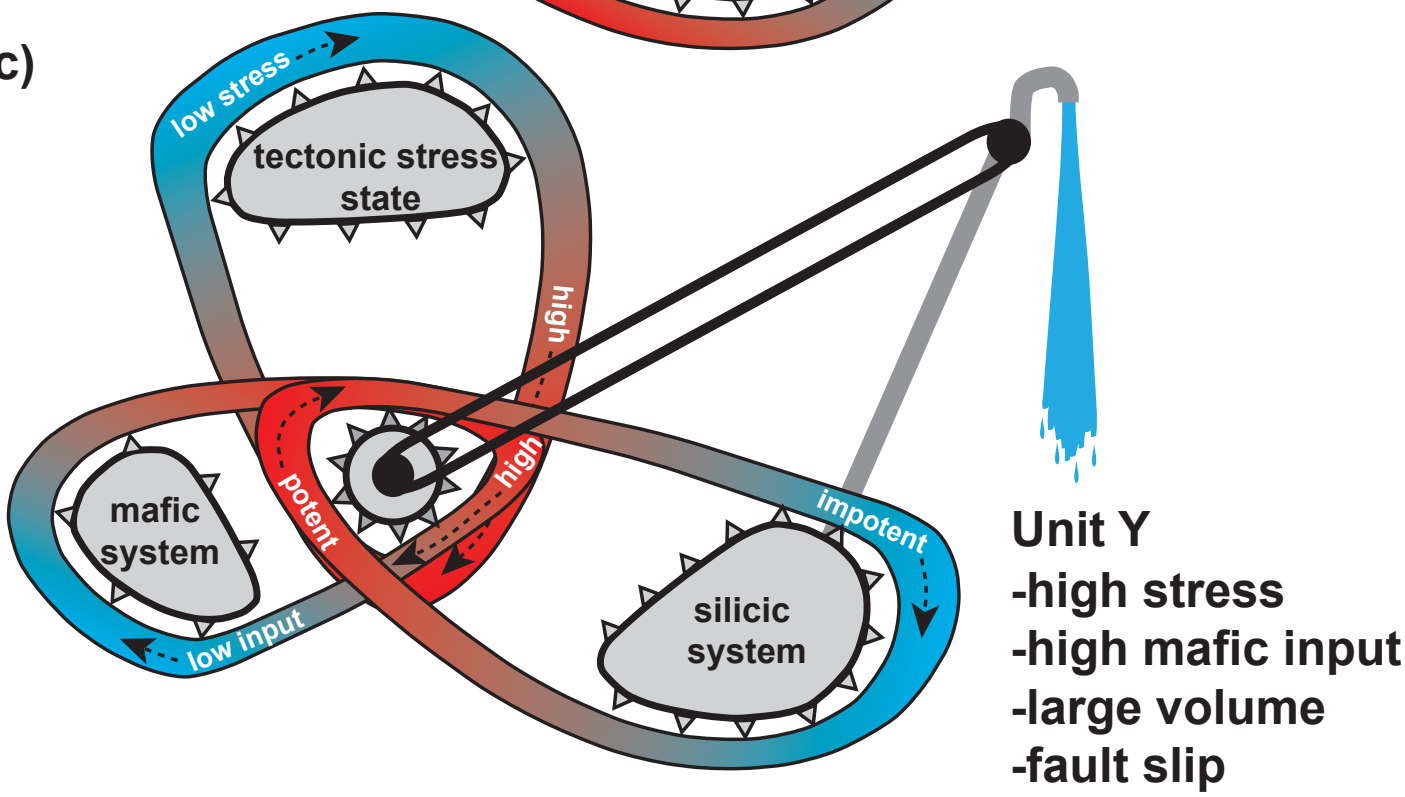

Figure 6.8. Conceptual models illustrating three-way coupling between tectonic stress state, mafic magmatism and silicic magmatism for (a) the modest volume, lower temperature spasmodic Unit V $2.8 \mathrm{ka}$ eruption, (b) the modest volume, higher temperature Unit X $(2.15 \mathrm{ka})$ eruption and (c) the large volume Unit Y caldera-forming 232 AD eruption. Variables in the system are represented by eccentric cycles that combine to determine the volume and frequency of eruptions at Taupo, as denoted by the tap feature from the silicic system. Concept modified from Rowland et al. (2010). 
hybrid magmas of mixed sources as observed for the Oruanui mafic clasts (Wilson et al., 2006).

Given the unique features of the Unit $\mathrm{Z}$ materials it is inferred that they reflect rapidly changing conditions in the post-caldera magmatic system. Orthopyroxene diffusion timescales are of a similar time range to the earlier eruptions at $<100$ years, and the relative timing of the Unit $\mathrm{Z}$ eruption is difficult to judge on these observations alone, but are consistent with only a short time break following Unit Y. Importantly, the Unit Z magma reflects a post-caldera system where mafic magma was able to physically penetrate and mingle with the rhyolite melt(s). The magma system following the Unit Y Taupo eruption therefore likely experienced a similar post-caldera reaction as that observed following the Oruanui supereruption, but on a smaller scale (Barker et al., 2014a, b). Mafic inclusions are taken to represent the influx of hot mafic magma into the remaining dregs of the Unit Y melt dominant body which acted to quench and preserve the newly arriving mafic magma. These observations suggest that a portion of the melt-dominant body remained in the post-Y environment and was reactivated upon re-pressurisation and mafic melt interaction.

Mafic inclusions observed in the eruption $\mathrm{Z}$ materials hold important clues about the origin of the heat source for the earlier SG3 eruptions and the extent of the magmatic feeder system beneath Taupo. The bulk composition of multiple mafic inclusions (although mixed compositions) overlaps with the composition of the earlier erupted Waimihia andesite (Barker et al., 2014b) and Oruanui (Wilson et al., 2006), indicating that mafic magma influx to Taupo's magmatic system is a long term feature. However, the Unit $\mathrm{Z}$ inclusions are distinct from other Taupo mafic compositions as they contain olivine up to $\mathrm{Fo}_{90}$ (cf. Sutton et al., 1995; Wilson et al., 2006), indicative of very primitive melts of possible mantle origin for the TVZ (Gamble et al., 1990). The large size of olivines (up to $500 \mu \mathrm{m}$ ) within these inclusions and their limited zonation and reaction rims of $<100 \mu \mathrm{m}$ thickness indicate they they were only introduced relatively shortly prior to eruption (Figure 6.4e). As shown by Coombs \& Gardner (2004), in experiments with conditions comparable with those for the SG3 magmas $\left(885{ }^{\circ} \mathrm{C}, 150 \mathrm{MPa}\right.$ and $\left.4.2 \mathrm{wt} . \% \mathrm{H}_{2} \mathrm{O}\right)$, olivine reaction rim growth rates were found to be relatively rapid at $\sim 1 \pm 0.5 \mathrm{~mm} / \mathrm{hr}^{-1}$. However, reaction rates could be slower if the olivines were encapsulated in a microcrystalline sheath of less evolved glass (e.g. Figure 6.4e).

It is considered that the introduction of unusually primitive olivines into Taupo's rhyolite system during this time period could be of two possible origins. First, they 
could be a feature unique to Taupo in the immediate post-caldera environment, where large decompression and reorganisation of the rhyolite magma system resulted in the immediate influx of primitive melts from depth. As the mafic inclusions from Unit Z, Unit S and the Oruanui have bulk compositions of andesite to basaltic-andesite, they are considered to represent more evolved magmas than those which were the original source to the $\mathrm{Fo}_{90}$ olivines. The olivines found in the inclusions were therefore likely inherited during magma mixing of unknown end-member compositions in the deeper mafic magma reservoir. In this case volcanism may be coincident with the arrival of hot mafic melts at depth. Second, as an alternative, the primitive parental melts to the olivines may be a longer term feature which themselves initiated the pre-SG3 heating event which led to rapid mobilisation of rhyolite magma. Both scenarios strongly highlight the deep connection of Taupo's rhyolitic magmatic system with basaltic to andesitic magmas which provide the long-term thermal energy and new material driving and sometimes destabilizing the differentiated rhyolitic mush pile.

\subsubsection{The current state of Taupo volcano and its future behaviour}

Interpreting the modern day state of Taupo volcano is challenging due to the uncertainties involved with understanding what type of events occur as regular background processes in a large silicic magma system associated with an area of active rifting, versus those that may lead to a future eruption. Multiple seismic swarms have been observed at Taupo during 1922, 1964-65 and 1983 and were often accompanied by uplift or subsidence (Ellis et al., 2007). Subsidence of the the shoreline observed between 1983-1999 by Smith et al. (2007) is modelled as the dewatering of a magma intrusion at depths of $8 \pm 1 \mathrm{~km}$ and an inferred volume of $\sim 2.5 \mathrm{~km}^{3}$. If these unrest events represent the input of heat via dike intrusion into the hot zone it suggests that Taupo has a mafic magma pressure cycling of tens of years (Ellis et al., 2007; Rowland et al., 2010). In turn, minor unrest episodes may reflect the common spatial association of Taupo within an area of active rifting, rather than any specific volcanic cause (Manville \& Wilson, 2003).

As shown in this study the inferred timescales and mechanisms driving melt evolution, mobilisation and storage for Taupo's young magmatic system have wide implications that should be considered for future unrest episodes, associated volcanic monitoring and hazard analyses (e.g. Johnston et al., 2002): 
1. The mechanisms and associated rates of melt evolution and extraction can change over timescales as short as decades to centuries at Taupo, but show no consistent trends through time (e.g. Wilson, 1993). The most recent eruptions resulted from mafic disruption, yet future eruptions may not show the same trend in the post-caldera environment if the state of the magma system has changed. The frequency, size and style of volcanism in the central TVZ is considered as a complex relationship between mafic magma flux, the potency or readiness of the silicic mush system to generate melts, and the tectonic stress state of local faults which permit magma to rise to the surface (Rowland et al., 2010; Figure 6.8). For the sequence of $\sim 28$ post-Oruanui eruptions, the range of eruption sizes and their spacing likely results from a unique combination of these three factors in a magmatic system that has rebuilt, evolved and changed in its structure through time (Barker et al., 2014b). As outlined by Rowland et al. (2010) the three-way coupled cycles are not in phase, but may be co-dependent, with a range of possible outcomes resulting in variable cyclicity and timescales, and multiple scenarios leading to unrest or eruption.

2. For the case of the SG3 eruptions, increased interaction occurred between the deeper mafic system and the shallow rhyolite mush system (Figure 6.8). Future seismicity in the shallower (4-7 km deep) and deeper ( $>8 \mathrm{~km}$ deep) parts of Taupo's magmatic system may be closely linked and could reflect magma mobilisation resulting from changing conditions. However, unrest events do not necessarily result in eruption due to a range of possible responses in the magmatic system(s) including diking or ground deformation but no eruption. The longer term potency of the mafic system and changes from the normal background heat input from the mafic system could be considered to occur over longer timescales as reflected in broad chemical changes in eruptive products and apparent zircon crystallisation trends through time (Wilson \& Charlier, 2009; Barker et al., 2014a,b).

3. Given the substantial inferred volume of the mush system beneath Taupo (Barker et al., 2014b), the modern magma system is capable of rapidly changing in behaviour and moving into a new eruptive cycle over timescales that are extremely relevant to humans. Rapid assessment of future eruptive products could hold vital clues as to the potential for subsequent eruptive behaviour. For example, Unit X eruptive products are unique in the post-Oruanui eruptive sequence as they show significant evidence for rapid heating and disequilibrium 
in the magma system which resulted in the evacuation of $\sim 35 \mathrm{~km}^{3}$ magma only 350 years later. However, given the multiple variables affecting eruptive frequency and volume at Taupo, the new post-caldera eruptive cycle could take many potential pathways with multiple implications for future hazard assessment.

\subsection{Conclusions}

This study has demonstrated that silicic magmatism at Taupo volcano is crucially linked to multiple factors including tectonic stress, the potency or readiness of the silicic mush to mobilize melt, and silicic magma interaction with the underlying mafic magma system. Eruptive products show an abrupt compositional shift from magmas erupted around the same geographical area between $\sim 2.75 \mathrm{ka}$ (SG2) and 2.15ka (SG3). Young SG3 magmas from three eruptions (X, Y and Z) are less evolved and hotter than the older SG2 magmas, but can be genetically linked to a similar mush source. Trends in whole-rock compositions, isotopic characteristics and mineral zonation are linked to difference in conditions of crystallisation and changing temperatures, likely resulting from a rapid increase in mafic magma input at the base of the silicic mush system. Fe$\mathrm{Mg}$ diffusion profiles in orthopyroxene suggest that heating of the silicic mush and inferred mobilisation of melt occurred only centuries to decades prior to each eruption. The $35 \mathrm{~km}^{3}$ caldera-forming Unit Y eruption at $232 \mathrm{AD}$ resulted from a combination of high melt accumulation rates, resulting from high mafic magma input, priming of the silicic mush system and high inferred differential tectonic stress build-up. Shortly following the caldera-forming eruption, mafic magma from a primitive source invaded the remaining silicic melt system due to rapid decompression. The hyperactive and largely variable behaviour of Taupo highlights the many challenges of future monitoring and determining what separates 'normal' cyclic unrest events versus a critical sequence of events that can lead to large scale catastrophic eruptions. 


\section{CHAPTER 7}




\section{7: SYNTHESIS AND CONCLUSIONS}

\subsection{Key findings}

This work demonstrates that a wide range of information can be gained about the dynamics and temporal evolution of large silicic magma systems through detailed fieldfocussed constraints, combined with geochemical analysis of whole-rock, glass and mineral components from juvenile eruptive products. Taupo volcano has provided an excellent case study to investigate how a large silicic magma system reacts to and recovers from the evacuation of $>530 \mathrm{~km}^{3}$ of magma. Taupo is unique worldwide among documented supervolcanoes in the rapidity and frequency of its postsupereruption volcanism, providing frequent snapshots of the magma system. By studying the products of each of the 28 post-Oruanui eruptions I have shown how and when Taupo's magmatic system rapidly changed in its structure, and in turn outlined the temporal evolution of the magmas produced through to the most recent eruptions.

This thesis research has documented multiple aspects of Taupo's postsupereruptive history. CHAPTER 4 used zircon ages and trace elements to show that the post-Oruanui magmas reflect a reconstructed magma system, with a chronological history that was largely reset by thermally induced dissolution of zircon in the postsupereruption environment. Zircon model-age populations in the young rhyolites reflect renewed growth in periods of cooling alternating with periods of heating where eruptions dominated, as well as continuing minor incorporation of xenocrysts from country rocks. CHAPTER 5 further investigated how whole-rock, glass and mineral chemistries evolved through time in this reset magmatic environment. The first products of dacitic composition between 21-17 ka were interpreted to reflect reorganisation of the magma system in a time period of high heat flow and a mafic melt intrusion. Rhyolite magma subgroups from $12 \mathrm{ka}$ to the modern day then showed fine-scale temporal changes in melt chemistry and mineral phase stability with fluctuating conditions of crystallisation, which were closely linked to the development, stabilisation and maturation of a new, probably unitary, rhyolite mush system. CHAPTER 6 revisited a unique feature identified in the previous chapter where the SG2 to SG3 transition from $2.75-2.15 \mathrm{ka}$ is marked by a distinct change in melt composition and temperature. By investigating detailed changes in magma chemistry, mineral zonation and $\mathrm{Fe}-\mathrm{Mg}$ 
diffusion in orthopyroxene it has been shown how the magma system rapidly changed in behaviour, primarily as the result of an increased rate of mafic magma supply. The overall response was rapid melt extraction that culminated in one of the largest and most violent worldwide Holocene eruptions at $232 \pm 5$ AD. Below, a summary of the findings of this thesis is presented in a way that incorporates the combined results of CHAPTERS 4-6, and returns to the key questions raised in the Introduction (CHAPTER $1)$.

\subsubsection{How did Taupo's magmatic system react to the evacuation of $\geq 530 \mathrm{~km}^{3}$ of magma?}

Taupo's magmatic system underwent significant physical and chemical changes in response to the 25.4 ka Oruanui supereruption and caldera collapse (Figure 7.1). Many of the mineral phases in the remaining silicic mush were pushed beyond stability, largely driven through widespread heating induced by the influx of hot mafic magmas with decompression, resulting in dissolution and changing magma chemistry. These processes are represented by the scarcity of zircons of Oruanui age in the post-Oruanui magmas, enriched trace elements in the first post-Oruanui zircons (CHAPTER 4), and a lack of Oruanui type magmas or mineral chemistries in either the 21-17 ka dacites or $<12$ ka rhyolites (CHAPTER 5). The source of heating is considered most likely to be the basaltic-andesite observed in in the Oruanui supereruption (Wilson et al., 2006). Mafic clasts of similar compositions to the Oruanui tholeiitic mafic lineage are observed in two post-Oruanui eruptions, and mafic magma is considered to provide the long term thermal and chemical driving force behind magmatism at Taupo. Calc-alkaline mafic compositions are not represented in the post-Oruanui eruptions from Taupo, but are recorded from the $<25 \mathrm{ka}$ Waimarino basalt formation $<20 \mathrm{~km}$ to the south. It is inferred that immediately post-Oruanui decompression of the silicic magma system resulted in a rapid response in the underlying mafic magma system, which shows a close connection with the behaviour of the silicic system through to the youngest eruptions (CHAPTER 6). The heating process and physical mixing of melts in the remaining mush is strongly reflected in mineral zoning observed in the dacite eruption products from $21-17 \mathrm{ka}$, which represent a snapshot of the deeper $(<8 \mathrm{~km})$ magma system (CHAPTER 5). The system was then able to effectively cool, crystallise, differentiate and rebuild a mush system. A subpopulation of zircons in the post-Oruanui rhyolites yield model ages that cluster at $>16 \mathrm{ka}$, suggesting that certain regions of the magma system may have been sufficiently cool to allow zircon crystallisation to resume during this time period 
Oruanui: 25.4 ka

- Supereruption $\left(530 \mathrm{~km}^{3}\right)$ and huge caldera collapse

- Modulated by tectonics

- Minor mafic magma mixing

- Rapid rhyolite melt

accumulation at $<3000$ years

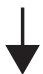

Post-supereruption mafic influx, heating, destabilisation of the Oruanui mush. Dissolution of Oruanui minerals + zircon

\section{Dacites: 21-17 ka}

- 3 small volume eruptions

- Deep reorganisation of the

magma system (>8km)

- Only xenocrystic zircon of greywacke/Whakamaru origin

Stalling of new melts, cooling, AFC. Growth of new zircon and development (unitary?) mush and density trap

\section{SG1: 12-10 ka}

- first rhyolites erupted

- Increased rates of rifting

- Linked to dacites through fractionation, similar

compositions erupted from large geographical area

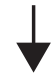

Minor heating and/or lower water results in mineral dissolution. New magmas go in/out of zircon stability.

\section{SG2: 7-2.8 ka}

- more developed mush system with less direct connection to deeper magmas - Single mafic intrusion during eruption S with large eruption - Late cooling from 3.5-2.8 ka

Significant heating of entire mush system, increased melt extraction. Mineral dissolution.

\section{SG3: 2.2-1.8 ka}

- rapid melt accumulation

- largest post-Oruanui

eruption (Unit Y)

- Post-caldera influx of mafic

magma, with primitive

mantle-derived olivine

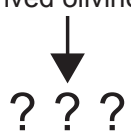

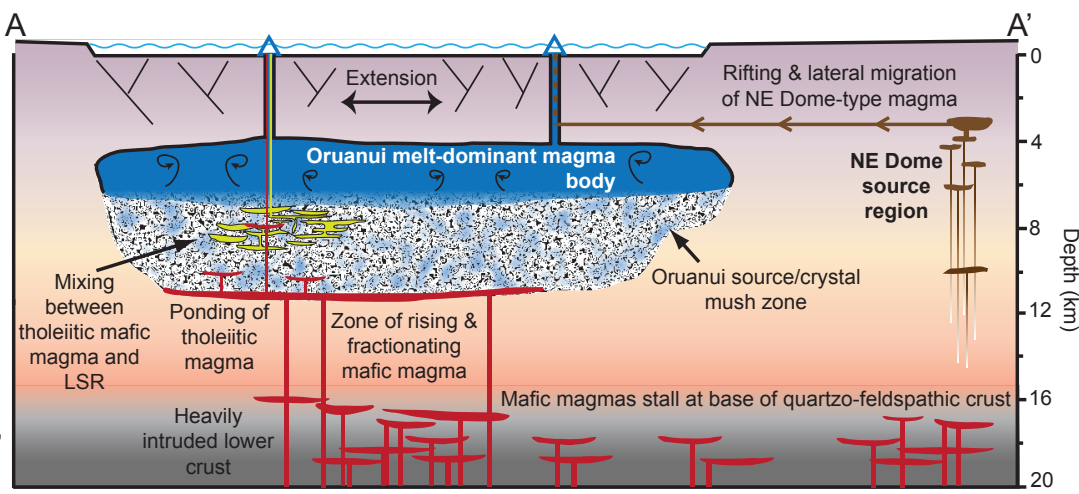
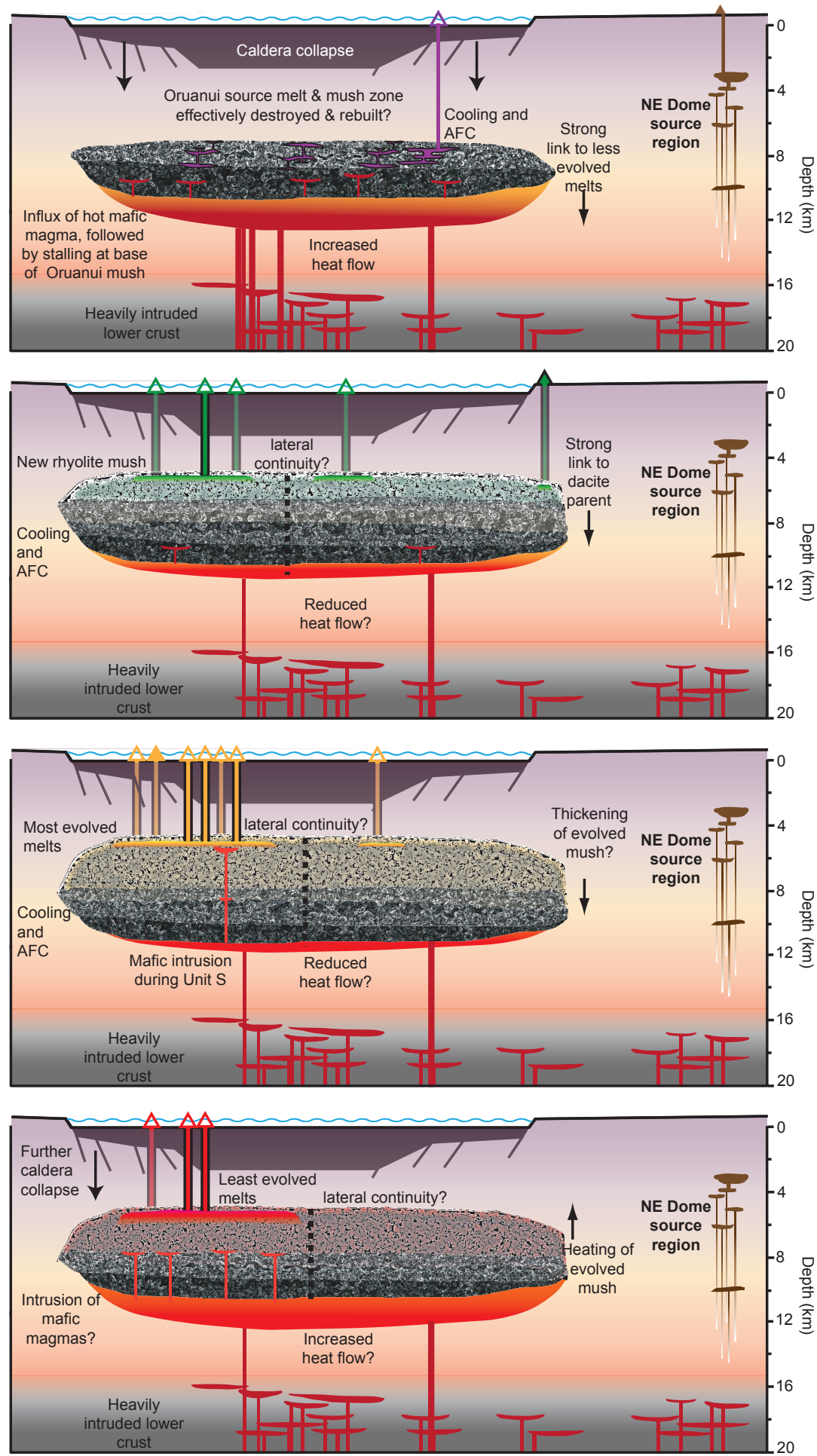

Figure 7.1. Schematic illustration of the inferred structural changes in Taupo's magmatic system through time as summarised from Figures 5.17 and 5.18. and CHAPTER 6. See text for discussion. 
(CHAPTER 4). By 12 ka however, it is evident that a significant volume of mush had rebuilt beneath Taupo, with relatively uniform magma chemistries being erupted from geographically spaced vents beneath the Lake Taupo area and to the north for Unit D. The formation of a rhyolitic melt-bearing mush would have formed a density trap, largely inhibiting progenitor melts from reaching the surface. The dacite melts likely continue to exist at depth in the young system, but are unable to reach the surface due to the density contrasts. The silicic mush system was rebuilt in the $\sim 10 \mathrm{kyr}$ following the supereruption and had moved into a new phase of productivity with a new cycle of eruptions only $\sim 13.5 \mathrm{kyr}$ after the Oruanui event (CHAPTER 5).

\subsubsection{Did the Oruanui eruption act to reset Taupo's silicic magma system, or was it just another large eruption from a long lived magma reservoir that has continued activity on a smaller scale to the present day?}

The Oruanui supereruption and the response of the wider magma reservoir acted to chemically and chronologically reset Taupo's silicic magma system (CHAPTER 4 and 5). The results of this study have shown how large silicic magma systems can operate on geologically short timescales. In the case of Taupo, not only were the processes that developed the supersized Oruanui magma body rapid (Wilson \& Charlier, 2009; Allan et al., 2013), but this huge magma system was effectively reset and rebuilt on a comparably short timescale. In a physical sense, parts of the Oruanui crystal mush must realistically have remained in the post- $25 \mathrm{ka}$ crust and likely contributed some material to subsequent magma bodies, but the specific Oruanui chemical signatures have been largely overprinted. Indeed, the post-Oruanui magmas are interpreted to broadly reflect mixed compositions between the Oruanui mush and the mafic magmas which heated the silicic magma system. The post-Oruanui magmas are distinctly more radiogenic than the Oruanui magmas, however, so mixing cannot be the sole driving force behind compositional shifts (Sutton et al., 1995). Greywacke and Quaternary-aged plutonic country rocks were assimilated at some stage as shown by the snapshot given by the xenocrystic zircons and elevated isotopic compositions in the Unit $\Omega$ dacite and younger units (Charlier et al., 2010; CHAPTER 4). Analogous studies of granite emplacement into the crust suggest that magma can be emplaced as a series of horizontal sills, leaving raft-trains of the original country rocks where pockets of ghost stratigraphy can be preserved within a large magmatic system (e.g. Pitcher \& Read, 1959). It is envisaged that the continued incorporation of country rock into the post-Oruanui magmas may result from a similar process. However, the chemical and chronological records of the 
Oruanui silicic mush system as a whole have been largely overprinted by postsupereruptive processes and modified beyond recognition in the changing environment. The shallow mush system was effectively reset in its ability to produce crystal poor silicic melts, where the dacite units represent a snapshot of the deeper regions of the system reorganising from the old system to the new (Figure 7.1).

\subsubsection{Can any of the components (crystals, melts) from the Oruanui magmatic} system be identified in the post-Oruanui sequence?

Only a small trace of evidence for the Oruanui magma system can be identified in the post-Oruanui magmas. In the zircon analyses presented in CHAPTER 4, less than $7 \%$ yield model ages that correspond within age uncertainty of the dominant histogram peaks identified in the Oruanui magma system by Wilson \& Charlier (2009). The majority of Oruanui-aged and older grains in the post-Oruanui magmas are from partially resorbed cores, representing crystals that did not fully dissolve in the postsupereruption environment. In addition, the post-Oruanui magmas do not reach the evolved compositions of the Oruanui HSR, and melt inclusions with $>78$ wt. $\% \mathrm{SiO}_{2}$ are rare (CHAPTER 5). The compositions of minerals in the new rhyolites also contrast significantly with those in the Oruanui (Wilson et al., 2006; Allan et al., 2013, 2014). Orthopyroxenes in the dacites and SG1 rhyolites have considerably lower MnO contents than the Oruanui crystals, and plagioclase compositions very rarely reach the low-An values seen in the Oruanui, indicating minimal inheritance. These findings are consistent with Taupo's magmatic system reflecting new conditions of crystallisation with little remaining direct chemical signature remaining from the old Oruanui silicic magma system. In contrast, it is considered that the deeper mafic melts that provided the chemical and thermal driving force behind silicic magmatism in the Taupo area have stayed active and relatively uniform in composition between the Oruanui and postOruanui systems (CHAPTER 5). Contrasting compositions between post-Oruanui mafic compositions and primitive calc-alkaline basalts erupted $<20 \mathrm{~km}$ to the south from the Waimarino basalt source during this time period (Graham \& Hackett, 1987) match those contrasts seen within the Oruanui eruption itself. This diversity highlights the variability of mafic magma compositions across small geographical distances. These magmas rarely reach the surface, either at Taupo or across the broader central TVZ due to the effective density cap and crustal thermal filter represented by the large silicic magma systems and their associated geothermal systems. 


\subsubsection{How long did it take the magmatic system to recover, reorganise or rebuild following the supereruption?}

Following a period of widespread changes with accompanying dissolution of crystal phases, Taupo's silicic magma system moved into a new cycle of volcanism at $\sim 21 \mathrm{ka}$. The dacites are considered to represent a period of reorganisation, where there was a time period in which relatively deep, hot and crystal-rich dacite magmas were able to ascend through the crust and be erupted due to the post-supereruptive change in the density stratification of the magma system (CHAPTER 5). From the strong chemical linkages between the $21-17$ ka dacites and the $<12$ ka SG1 rhyolites it is inferred that the new silicic mush body formed during the period between the two eruption groups, acting to form a density cap through which deeper and less evolved melts were unable to penetrate. A major subpopulation of zircons in the post-Oruanui SG1 rhyolites show model ages that cluster around a period broadly (within uncertainty) corresponding to the time gap between 17-12 ka showing that parts of the magma system became evolved enough and sufficiently cool to allow zircon crystallisation during this time period. However, given the widespread distribution of vents, crystallisation and rebuilding of the new mush system may have occurred at different rates for different parts of the system depending on the local conditions of crystallisation (CHAPTER 4). The Unit D (Acacia Bay dome) eruption, vented north of Lake Taupo, contains very few young zircons, supporting the notion that crystallisation and rates of rebuilding varied significantly. By $12 \mathrm{ka}$, however, it is evident that a significant volume of mush had rebuilt beneath the volcano, with relatively uniform magma chemistries being erupted from geographically widely spaced vents in and around Lake Taupo (CHAPTER 5: Figure 7.1). The silicic mush system at Taupo had thus recovered within $\sim 10 \mathrm{kyr}$ of the supereruption and re-organised itself to produce new rhyolite magmas only $\sim 13.5 \mathrm{kyr}$ after the Oruanui event. Through the SG2 time period from 7.0-2.8 ka, the silicic magma system likely grew in volume and became further evolved, as evidenced through the gradual disappearance of inherited mineral cores and antecrysts from less evolved progenitor melts.

\subsubsection{How and why do the post-Oruanui magmas change in composition through time and what processes do these changes reflect?}

Sutton et al. $(1995,2000)$ demonstrated that the post-Oruanui magmas vary in composition through time in a stepwise fashion between the chemical subgroups. Minor differences in whole-rock chemistry, mineral assemblages and intensive parameters 
through time have been used to suggest that the four magma groups were derived from petrogenetically distinct sources at different positions within the crust (e.g. Smith et al., 2005). This thesis research has shown that rather than representing chemically separate magma systems, the post-Oruanui magmas are genetically related and stepwise changes in whole-rock chemistry can be explained through variable mineral stability and changing conditions of crystallisation in the new unitary magmatic system (Figure 7.1). The dacite eruptions represent the first evidence of a rebuilding silicic mush and represent relatively deep $(>8 \mathrm{~km})$ and hot $\left(\sim 900{ }^{\circ} \mathrm{C}\right)$ magmas, with strongly resorbed mineral cores and abundant large melt inclusions of variable chemistry indicating periods of significant disequilibrium and influence of less evolved magmas. The overlaps between the compositions of mineral cores and melt inclusions in the SG1 rhyolites to mineral rims and selvedge glasses in the dacites indicates that the two magmas share a common origin and are closely linked genetically. The subsequent shallower ( $\sim 5 \mathrm{~km}$ depth) rhyolites from $12 \mathrm{ka}$ can be linked to the composition of the dacite matrix glass through $15-20 \%$ fractionation of the observed phenocryst mineral assemblage. Cooler conditions and lower pressures resulted in late amphibole growth in the early SG1 eruptions B and C. A minor increase in temperatures or decrease in water contents in the subsequent SG1 eruptions resulted in the overall instability and dissolution of amphibole and/or clinopyroxene in the source, liberating marker elements such as Mn, Y, Zn and Sc into the melt that are then seen to cause the minor shift in composition between the SG1 and SG2 melts. Minor differences in magma compositions through to the modern day can then be attributed to variable crystallisation or dissolution of the observed, limited mineral assemblage of plagioclase, orthopyroxene and Fe-Ti oxides with variable magma temperatures in the overall mush system. The close links between the rhyolite subgroups are also further supported by zircon model-age inheritance patterns between the SG2 and SG1 magmas, with definable $\sim 12 \mathrm{ka}$ and $\sim 18$ ka probability peaks in the SG2 zircon age spectra (CHAPTER 4). Zircon trace element concentrations also vary systematically with time (e.g. Sc), reflecting long term gradual chemical changes in phase stability and hence zircon recycling between eruption groups from a common source zone.

\subsubsection{How has the structure of the magmatic system changed through time, and what is its current state?}

The structure of the post-Oruanui magma system has varied through time with changing thermal conditions, and maturation and development of the new mush system 
(CHAPTER 5; Figure 7.1). The dacite magmas are considered to have originated from the lower regions of the silicic mush system at $>8 \mathrm{~km}$, during a time period of higher heat flow and reorganisation. The strong links between the dacites and younger rhyolites are used to provide a minimum depth from which the younger rhyolite system likely differentiated. The source depths of the SG1 rhyolite magmas as constrained by amphibole barometry are considered to be shallower at $\sim 4-6 \mathrm{~km}$. However, xenocrystic amphiboles in Unit E yield much higher model pressure estimates, and are thus interpreted as originating from the deeper regions of the mush system down to $\sim 8 \mathrm{~km}$, or possibly to be inherited through magma mixing from less-evolved melts at even deeper levels. The SG2 magmas contain a more restricted range of mineral and melt inclusion compositions which are interpreted to reflect the gradual development and stabilisation of a barrier between the shallow rhyolite system and the deeper less evolved magmas due to thickening and maturation of the mush. For the SG3 time period the magma system experienced significant heating from an influx of mafic magma as reflected in reversely zoned minerals and less evolved bulk rock compositions (CHAPTER 6). Following the caldera-forming Unit Y eruption the magmatic system once again experienced decompression induced influx of hot mafic magma of a very primitive nature with mafic inclusions containing olivine with compositions of up to Fo90. The modern system is therefore considered to be in a recovery stage in the post-Y environment. However, given the gradual thickening of the silicic mush through time and the inferred horizontal extent of the magma system from geographical distribution of vent locations, a large volume of partly molten mush is considered to remain beneath Taupo (CHAPTER 5). Given the relatively minor size of the Unit $Y$ eruption $\left(35 \mathrm{~km}^{3}\right.$ magma) when compared to the inferred volume of mush (up to $900 \mathrm{~km}^{3}$, from the maximum areal distribution of vent positions multiplied by the depth range inferred from mineral-melt equilibria: Figure 5.18), Taupo is considered to be capable of rapidly moving into a new eruptive sequence and continuing its hyperactive behaviour. The suggestion by Smith et al. (2007) of a magmatic intrusion as a causative factor in the most recent unrest episode (1982-1983) would imply that generation of magma bodies from this mush system is ongoing.

\subsubsection{What controls the wide variations in eruptive sizes and styles at Taupo?}

The eruptive sizes and timings in the post-Oruanui sequence span 3-4 orders of magnitude, with chemically uniform crystal poor rhyolites being erupted in small lava dome-building episodes as well as large caldera-forming explosive eruptions. In some 
deposits (e.g. Units P, T, U, W and Y), the compositions of glassy obsidian lithics are identical to those of the juvenile pumice, indicating that the same vent region hosted effusive and explosive behaviour (CHAPTER 5). One of the most immediately evident features of the post-Oruanui eruptions is the alignment of vents along linear structures parallel or sub-parallel to major fault lines identified around the lake (see Figure 5.1). Taupo volcano is intersected by the rifting axis of the Taupo Fault Belt. As outlined by Rowland et al. (2010), and further expanded upon in this thesis, volcanism and magmatism in in the central TVZ, and Taupo in particular, are the results of three largely variable but coupled factors. The three controlling factors are the amount of residual tectonic stress built up on local faults, the rate of diking and input from the deep mafic magma system, and in turn the 'potency' or readiness of the silicic magma system to produce eruptible magmas.

It is considered that the range of eruption volumes in the post-Oruanui sequence may result from largely variable combinations of this three-way coupled system (Figure 6.8). As suggested in CHAPTER 4, a longer term periodicity of magma-assisted rifting processes and associated higher rates of influx of mafic magmas into the crust below Taupo could be the cause of the 5-10 kyr periodicity that is seen in the zircon crystallisation history (during cooling and volcanic quiescence), and the clustering of eruptions into the subgroups (during rifting and volcanic activity). For the dacites, small volumes of magma were erupted, in each case probably accompanied by dome building from vents in the northern part of Lake Taupo. During this time period influxes of mafic magma periodically occurred as reflected in multiple zones of disequilibrium and dissolution seen in plagioclase cores (CHAPTER 5). The repeated small volume dacites are considered to reflect magma mobilization through mafic recharge and perturbations in the deep, rebuilding silicic system (Figure 7.1). These magmas were able to make their way to the surface due to the lack of a rhyolitic mush density and/or thermal filter in the post-supereruption environment (Hildreth, 1981; Bacon, 1985; Valentine, 1993). The SG1 rhyolites do not show direct evidence for rapid elevated mafic magma recharge but do notably broadly coincide with a period of intensive andesitic volcanism and associated regional rifting in the southern TVZ. It is therefore considered that volcanism at Taupo during the SG1 time period may have been initiated by enhanced rifting and tectonic stresses along the length of the Taupo Fault Belt (CHAPTER 4; Kohn \& Topping, 1978; Rowland et al., 2010; Figure 7.2). The SG2 eruptions, in contrast, have no directly evident features to indicate why eruptions were so frequent, although relatively small in volume, from $\sim 7 \mathrm{ka}$ to $\sim 4 \mathrm{ka}$. However, as shown by trends 


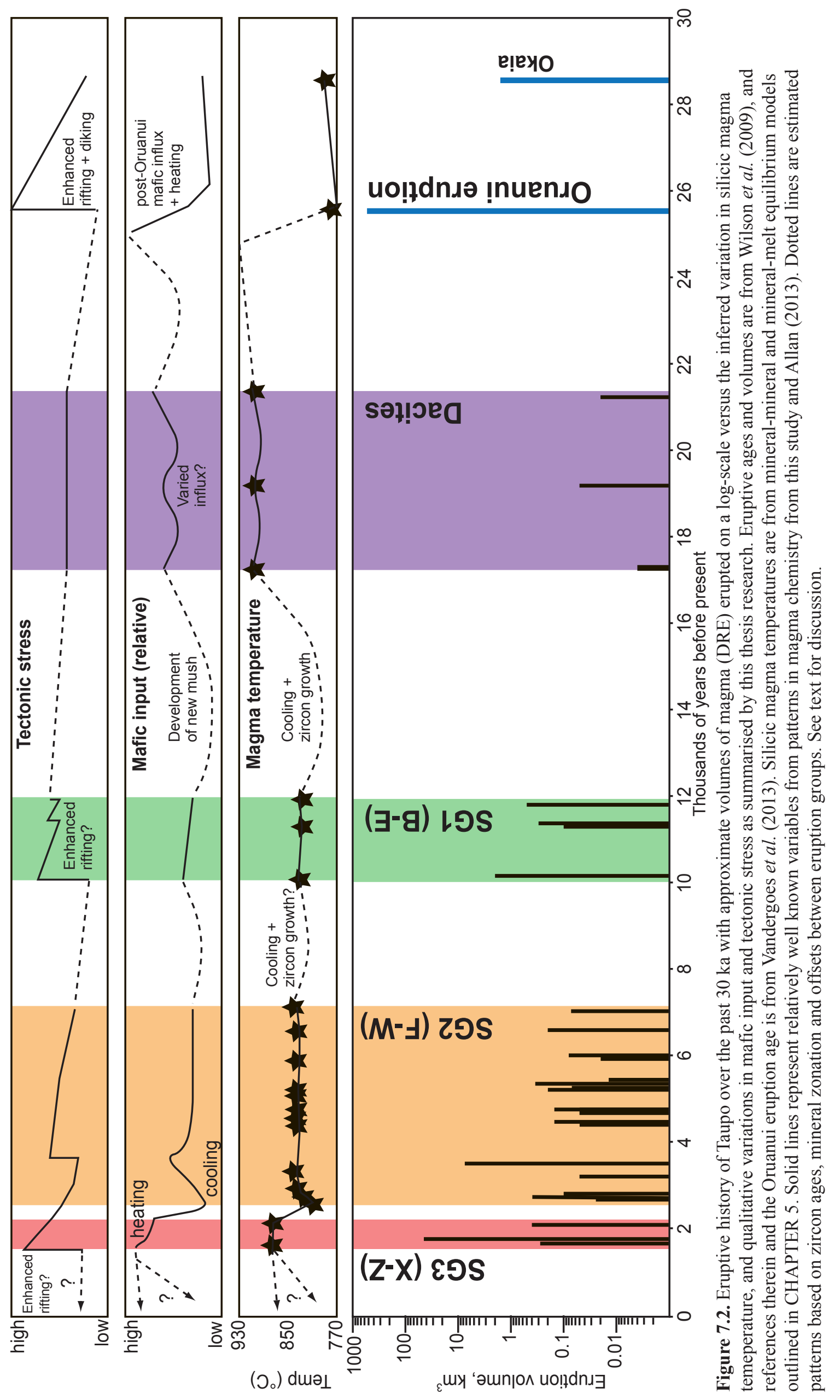


in mineral zonation and melt inclusion compositions, the silicic mush system during this time period reflects a more mature system that erupted relatively small volume magmas, with less direct evidence for mafic magma recharge and crystal inheritance from less evolved magmas (CHAPTER 5). In the exceptional Unit S (Waimihia) eruption, however, mafic magmas were able to physically interact with the melt-dominant body. Interestingly, the subsequent eruptions from $<3.5-2.75 \mathrm{ka}$ do not show evidence for mafic magma interaction or disequilibrium, but instead show a cooling trend through time, with the most evolved silicic melts in the post-Oruanui sequence being erupted during this time (Figure 7.2). The physical interaction of silicic and mafic magmas in the chamber that fed eruption $\mathrm{S}$ was followed by a reduction in the short term heating of the silicic system and influence of mafic magma from depth. In contrast, for the lead up to the SG3 eruptions at $<2.15 \mathrm{ka}$, the magma system once again underwent significant widespread heating from mafic injection, plausibly through diking, resulting in increased melt extraction from the silicic mush (cf. Allan et al., 2013). In combination with high residual tectonic stresses, these conditions led to the largest post-Oruanui eruptions, and one of the largest eruptions worldwide during the Holocene at $232 \pm 5$ AD (CHAPTER 6; Figure 6.8).

\subsubsection{Over what time scales is Taupo capable of producing another eruption and what might control its size and eruptive behaviour?}

One of the key findings of this thesis research is identifying how rapidly processes of melt evolution and accumulation can occur in a large silicic magmatic system. In the case of Taupo, a supersized silicic magma system was largely destroyed, reorganised and rebuilt on a timescale of only about ten thousand years. The feedback responses between tectonic stress, mafic input and silicic potency in the new and matured magmatic system has resulted in a range of magma chemistries, melt production rates and apparent repose interval through time (Figures 6.8 and 7.2). For the latest eruptions it is apparent that the system can transition from periods of volcanic quiescence to explosive activity with significant rates of melt mobilisation, generating eruptible meltdominant bodies in only decades to centuries (CHAPTER 6). Such short timescales are of significant interest and concern to humans.

Given the fact that one of the latest series of eruptions from Taupo was the largest observed in the post-Oruanui sequence and resulted in caldera collapse (and hence tectonic stress relief), it could be considered that Taupo will now move into a period of cooling and quiescence. However, with the rapid rate of magmatic processes 
that occur at Taupo, 1800 years is enough time for the magmatic system to move into a new and unpredictable cycle of behaviour. With the variable nature of the multiple components that can greatly affect the probability of eruption, Taupo is considered capable of rapidly resuming its hyperactive eruptive behaviour in the future. Recent episodes of unrest highlight the continuing active nature of the magmatic system and the need for close monitoring and improved knowledge of the modern day state and structure of the system as a whole.

\subsection{Limitations, issues and remaining questions}

Throughout this thesis research there have been multiple challenges that have affected interpretations of results, and left several questions remaining over the way in which either data is acquired, used in models or compared with other sources in the literature. Some particular issues that affected the outcome of this thesis research and its interpretations are highlighted and discussed below.

\subsubsection{Challenges with estimating intensive parameters}

The relatively restricted mineral assemblage in the post-Oruanui magmas means that only certain techniques could be used to estimate values of and variations in intensive parameters such as temperature, pressure, oxygen fugacity and melt volatile contents. The subtle variations in magma chemistry through time in the rhyolitic subgroups also meant that in many cases variations in model outputs between eruption groups were within uncertainty of the techniques used. Because of this small variability, multiple models using different mineral-mineral or mineral melt equilibrium principles were used to constrain relative differences through time, with generally good agreement between models in the relative changes (see Figure 5.13). However, some of the biggest offsets in absolute temperature and oxygen fugacity were between models using the same mineral phases. Fe-Ti oxide thermometry models, in particular, yielded absolute temperatures that varied by an average of $\sim 30^{\circ} \mathrm{C}$ between the three models used (Andersen \& Lindsley, 1988; Ghiorso \& Evans, 2008; Sauerzapf et al., 2008).

When investigated in further detail, it also became apparent that large differences in temperature estimates could be obtained for all of the Fe-Ti oxide thermometry models simply by using different techniques to calibrate the microprobe for analysis of Fe-Ti oxides. Model temperature differences of up to $40-50{ }^{\circ} \mathrm{C}$ could be obtained using two different calibrations. The first method used synthetic standards with 
rutile and hematite for calibration of $\mathrm{Ti}$ and $\mathrm{Fe}$ respectively. However, this method resulted in incorrect secondary standards with $\mathrm{TiO}_{2}$ averaging 1-2 wt. \% too high and $\mathrm{FeO}$ averaging $\sim 1 \%$ too low. The second technique used natural standards with ilmenite standard USNM 96189 for Fe and Ti in ilmenite, and magnetite standard NMNH 114887 for Fe in magnetite, resulting in comparatively lower $\mathrm{TiO}_{2}$ and higher $\mathrm{FeO}$ values for all samples. Notably, both techniques yield appropriate totals of $\sim 99-101$ $\%$ when $\mathrm{Fe}$ is recalculated for $\mathrm{Fe}^{2+}$ and $\mathrm{Fe}^{3+}$. The differences between the two calibrations are considered to originate from two possible scenarios. First, the $100 \%$ synthetic standards do not give accurate results because the offsets in the x-ray emission intensity between the standard and natural samples are not correctly accounted for using the ZAF matrix correction technique (Heinrich, 1991). Second, the original wet chemical analyses of the standards are slightly in error, or the standards are inhomogeneous in composition, yielding incorrect results for unknowns calibrated using the natural standards.

Similar issues were reported in Evans et al. (2006), the data from which were used to calibrate the Fe-Ti oxide thermometry models of Ghiorso \& Evans (2008). In Evans et al. (2006), wet chemistry paired with microprobe analyses (using synthetic standards) on multiple international ilmenite standards resulted in there being a relative offset of $\mathrm{TiO}_{2}$ by $+1-2 \%$ and $\mathrm{FeO}$ by $-1 \%$ between microprobe and wet chemistry techniques, respectively. To account for this offset, Evans et al. (2006) normalised all their microprobe analyses of experimental oxides by the reported offsets of $+1-2 \%$ (unspecified value) for $\mathrm{TiO}_{2}$ and $-1 \%$ for $\mathrm{FeO}$. It is therefore considered that an issue with probe calibration likely originates from calibration using synthetic standards and not the natural standards. To match these practices all microprobe calibrations were performed in this study using natural standards to essentially achieve the same outcome as Evans et al. (2006). However, one of the difficulties in cross-correlating model temperatures published on natural examples is knowing exactly how all analytical data were collected and what probe calibration procedures were used for each Fe-Ti oxide thermometry model, as the different techniques can yield significant differences in model outputs. In many cases, the details of probe calibration or standardisation (and data correction) are unavailable in the literature and therefore the correct method to use is unknown. As the Ghiorso \& Evans (2008) paper did not outline these issues in detail (only referring to an appendix in the earlier Evans et al. paper), it is inferred that many studies applying this thermometry model do not apply the same correction factor, or 
employ the same probe calibration methods, essentially leading to inconsistent or incorrect results when the ZAF matrix correction is used.

\subsubsection{A lack of experimental constraints on the behaviour of Taupo rhyolite compositions}

Many of the issues with estimating absolute pressures and temperatures for the Taupo magmas could be addressed through experimental studies using the composition of the Taupo rhyolites. As current thermodynamic models (e.g. MELTS or rhyolite-MELTS: Gualda et al., 2012; Gualda \& Ghiorso, 2014) do not correctly predict the observed mineral assemblages or conditions of crystallisation at Taupo (Gelman et al., 2013), experimental studies would also be extremely valuable for explaining phase changes, the stability of amphibole and further constraining the origin of the rhyolites in the TVZ. Current experimental results relevant to TVZ dacites, although valuable for firstorder observations, are limited to very high pressures of $1000 \mathrm{MPa}$ (e.g. Conrad et al., 1988), quite inappropriate for the depths where dacite generation is likely to occur in the TVZ. Experimental work would be extremely valuable for confirming the estimated conditions of crystallisation from petrological techniques, and further constraining the depths at which important magmatic processes occur. For example, plagioclase and orthopyroxene zoning could be extremely valuable indicators of changing conditions as they are extremely sensitive to changes in temperature, pressure, oxygen fugacity and melt water contents. Comprehensive experimental data on plagioclase compositions for Mount St Helens dacites allowed Cashman \& Blundy (2013) to explore the controls on plagioclase compositions and track the evolution of single plagioclase grains prior to the 1980 eruptions. Similar techniques could be used to track the evolution of minerals prior to eruption at Taupo and could provide important insights as to the variable conditions of crystallisation for the dacite and rhyolitic subgroups. Additional experimental work on Taupo basaltic compositions at variable pressures and temperatures could also help constrain the origin of the mafic melts and the processes of rhyolite genesis in the TVZ.

\subsubsection{The need for high resolution geophysical imaging at Taupo}

Part of the challenges with estimating the pressures of crystallisation and the size of the current magma reservoir directly beneath Taupo is the lack of suitable high resolution shallow- to mid-crustal surveys. Petrological evidence for the various components of the magma system and their apparent depths was unable to be confirmed or compared in 
this study using existing geophysical evidence, with the exception of the overall depths of the quartzo-feldspathic crust (Harrison \& White, 2006). Gravity, magnetic and seismic surveys of the caldera complex (Davy \& Caldwell, 1998) and heat flow measurements of the lake sediments (Whiteford, 1996) provide important insights into the detail of the very upper crustal structure of the caldera and the effects of past eruptions on the properties of the lake floor down to $<1 \mathrm{~km}$ depth. In contrast, the deep structure of the crust just to the North of Taupo has been imaged along the NIGHT transect (Harrison \& White, 2004; Stratford \& Stern, 2004; Stern et al., 2005; Stratford \& Stern, 2006; Harrison \& White, 2006). Low P-wave velocities of 1.5-3.0 km/s occur in the top few kilometres and are interpreted as sediment or pyroclastic fill due to down faulting or caldera collapse (see also Robinson et al., 1981). Intermediate velocities (5.0 to $6.5 \mathrm{~km} / \mathrm{s}$ ) occur down to $\sim 15-16 \mathrm{~km}$ and are interpreted as representing dominantly quartzo-feldspathic crust. However, these large-scale surveys lack the detail needed to interpret zones of partial melting or magma storage. Surveys imaging the electrical resistivity structure within TVZ have been undertaken using magnetotelluric techniques (Ogawa et al., 1999; Heise et al., 2007, 2010). A profile to the north of Taupo along the central TVZ (Ogawa et al., 1999; Heise et al., 2010) showed near-surface conductivity anomalies corresponding to thick sequences of volcaniclastic rocks and conductive geothermal fluids, and regions of increased conductivity at depths of $\sim 10-13 \mathrm{~km}$, interpreted as representing bodies containing up to $\sim 50 \%$ melt. However, these depths are below the inferred depth of the silicic mush zone and are to the North of Taupo, not directly beneath the inferred current focus of magmatism and volcanism. Detailed geophysical investigations are needed to image the crustal structure between $\sim 3.5$ to 10 $\mathrm{km}$ depth if the silicic magma system and parental mush zone are to be confirmed and contrasted with the results and implications of this thesis research. Geophysical studies at Taupo offers many challenges though, because of the presence of Australasia's largest body of freshwater combined with significant volumes of weak, low-velocity volcaniclastic deposits which degrade the quality of signal for seismological studies (Davy \& Caldwell, 1998; Ellis et al., 2007). In addition, given the inferred extent of the magmatic system beneath Taupo, multiple surveys would need to be conducted across the extent of the caldera to fully assess the system as a whole.

\subsubsection{The need for better determination of Fe-Mg diffusion coefficients}

The model timescales obtained from Fe-Mg diffusion in orthopyroxene are dependent on many known factors. To account for the full range of potential temperatures and 
oxygen fugacities, timescales are provided in CHAPTER 6 with maximum and minimum estimates based on varying conditions by the inferred maximum uncertainties of the thermometry and oxybarometry techniques. However, one parameter that is not well constrained for orthopyroxene in rhyolitic systems is the Fe-Mg interdiffusion coefficient $D_{\mathrm{Fe}-\mathrm{Mg}}($ Chamberlain et al., 2014b). In this study, the calibration of Ganguly \& Tazzoli (1994) was used, as modified by Allan et al. (2013) and adjusted for oxygen fugacity. Allan et al. justified the usage of the modified Ganguly \& Tazzoli (1994) over the more recent experimental results of Schwandt et al. (1998) as the latter used experimental conditions of $\mathrm{En}_{88}$ at an oxygen fugacity on the iron-wustite (IW) buffer, which is potentially problematic for volcanic applications. Most volcanic systems will contain orthopyroxene that is significantly more iron-rich (e.g. Taupo rhyolites: En $_{40-70}$ ), and typically have oxygen fugacities within two log units of the NNO buffer, which sits some five orders of magnitude above the IW buffer. Later studies have shown that the Ganguly \& Tazzoli (1994) results (adjusted for oxygen fugacity) seem to be consistent with diffusion in olivine and clinopyroxene (Klugel, 2001).

Using the Ganguly \& Tazzoli (1994) calibrations modified for oxygen fugacity, $D_{\mathrm{Fe}-\mathrm{Mg}}$ values used in this study are $\sim 1 \times 10^{-19} \mathrm{~m}^{2} \mathrm{~s}^{-1}$ to $\sim 5 \times 10^{-19} \mathrm{~m}^{2} \mathrm{~s}^{-1}$. In contrast, using the calibration of Schwandt et al. (1998), $D$ values at the relevant temperatures used here range between two to three orders of magnitude smaller and hence would result in timescales two to three orders of magnitude longer (i.e. up to 100000 years). As outline in CHAPTER 6, the contrasting physical conditions in the SG2 and SG3 magmatic systems place an upper limit for orthopyroxene dissolution and heating at the last eruption of SG2 at $2.75 \mathrm{ka}$. Model timescales from orthopyroxene in this study are in good agreement with the timescales from stratigraphically constrained units, and yield geologically reasonable timescales of widespread heating of the magma system at $\sim 100-200$ years prior to eruption. As shown by Chamberlain et al. (2014b), however, the usage of the modified formation of Ganguly \& Tazzoli (1994) on Bishop Tuff (Long Valley) orthopyroxene yields timescale estimates that are much shorter than any of the other diffusion techniques including $\mathrm{Ti}$ in quartz and $\mathrm{Ba}$ and $\mathrm{Sr}$ diffusion in sanidine. The discrepancy in the Bishop system is considered to either result from contrasting histories of behaviour for the minerals concerned, or a discrepancy in the $D$-values used for Fe-Mg diffusion. The contrasting timescales highlight the pressing need for calibration of Fe-Mg inter-diffusion, particularly at temperatures and pressures representative of evolved (specifically rhyolitic) compositions to confirm the accuracy of timescales observed in systems like Taupo and Long Valley. 


\subsection{Future directions and suggestions for further research}

In drawing this thesis to a conclusion I bring to attention some potential areas for future research at Taupo volcano and for the general theme of magma genesis and eruption in large silicic magma systems:

1. Determining the origins and rates of interaction between mafic magmas and silicic magmas in the TVZ. Mafic and silicic magmas at Taupo and in the broader TVZ clearly have a close relationship, sometimes physically mixing and mingling. A pressing question which arises from this is why, when and how do the two magma types interact? The contrasting physical properties of the melts yeilds a spectrum of textures in the quenched mafic clasts. Can microlite growth or mineral zoning be used to determine how long prior to eruption this process occurs? The second major question is what are the origins of the mafic magmas beneath large silicic magma systems? Multiple compositions from calc-alkaline to tholeiitic end members occur at and around Taupo volcano. Do these originate from different regions of the crust? Do mineral populations reflect a single source or multiple sources? At what depth do the mafic magmas stall and differentiate? What is the composition of the most primitive melts?

2. Determining the timing of assimilation between greywacke and Taupo magmas. The elevated Sr-isotopic signature of the post-Oruanui magmas highlights the significance of country rock assimilation in magma genesis, which in the TVZ setting is most likely of greywacke origin (Ewart \& Stipp, 1968; McCulloch et al., 1994; Sutton et al., 1995). A major question which arises from this observation is when exactly does the greywacke become sufficiently molten to become assimilated into Taupo magmas? Sr-isotopes have not been a major focus of this study, and the evolution of the Taupo magmas through further $\mathrm{Sr}$ isotopic systematics (and possibly other isotopic systems) is warranted. Single crystal Sr-isotopes or micro milling of mafic-derived minerals versus evolved silicic minerals could provide important insights into the role greywacke assimilation plays, and its timing in the post-Oruanui sequence and magma genesis in the TVZ in general (e.g. Charlier et al., 2008). 
3. How does the magmatic history of Okataina compare and contrast with Taupo? The other active caldera system in the TVZ, Okataina, has notably similar features and contrasting eruptive patterns to Taupo (Wilson et al., 2009). Eruptive behaviour through time at Okataina seems to coincide with periods of quiescence at Taupo (Charlier et al., 2010), and the two systems seem to be strongly linked. Okataina differs from Taupo in that there is lack of commonality in the young young zircon age spectra in the post-caldera eruptive rocks, precluding their origin from a single melt-bearing mush system (Charlier et al., 2010; Storm et al., 2011). The inferred structure of Okataina and its variable components have been recently summarized in a review by Cole et al. (2014). However, the fine-scale post-caldera evolution of the mush system and the mechanisms driving large versus small eruptions invite further investigation and speculation. Does the same three-way coupling system apply at Okataina as observed at Taupo? If so, how does it differ through time and contrast with Taupo? Can further evidence be found in the Okataina magmas for rifting and elevated rhyolitic volcanism during times of increased mafic flux or high residual tectonic stresses (e.g. Nairn et al., 2005; Villamor et al., 2011)?

4. What causes the small scale changes in potency in the silicic mush system at Taupo?

The range of eruption sizes at Taupo can be attributed to a range of potential combinations in the three-way coupling system, with periods of elevated eruptive volume likely resulting from increased mafic magma flux and residual tectonic stress build-up (CHAPTER 6). However, one of the remaining questions is why did the SG2 eruptive sequence in Units F-R (Hinemaiaia) have numerous and frequent, small volume eruptions of almost identical chemistry? Did this period represent a unique set of circumstances? No evidence is present for elevated mafic input or unique states of tectonic stress. However, from historic unrest events, the natural cycle of deep intrusion of mafic magma and diking may be as short as tens to hundreds of years (Rowland et al., 2010). Does the Hinemaiaia sequence represent a time period in which the silicic magma system was particularly potent and venerable to small scale disruptions? 
5. How does Taupo's behaviour compare to other supereruptive systems? Typical or unique?

The rapid post-supereruptive volcanism, young age and good preservation of eruptive products at Taupo means it can be investigated at a resolution not possible for other supervolcanic systems. Is the post-supereruptive heating and reconstruction of Taupo's magmatic system typical or unique in global examples of not only supervolcanoes but large igneous systems? Detailed petrological studies of other well stratigraphically constrained post-caldera systems (in addition to those mentioned in CHAPTER 5) could provide valuable comparisons for this study and help define the range of behaviours and responses in large silicic magma systems.

6. What causes the exceptionally high heat flow and magma production in the TVZ?

An outstanding question from this study and many others on Taupo and the TVZ in general, is what causes the anomalously high heat flow and exceptional rates of rhyolitic volcanism (Wilson et al., 2009)? In addition, why is the heat flow focussed along a particular $120 \mathrm{~km}$ long segment of the arc system? There is currently no consensus as to why the heat flux should be so high in the TVZ, with diverse and controversial explanations ranging from crustal fusion and plastic deformation (Hochstein et al., 1993, Hochstein, 1995), through to mantle upwelling and decompression (Reyners, 2013). The timescales of mantle melt production, processes in the deep crust, effect of the Hikurangi Plateau on subduction rates and influence of rifting on the TVZ all require further work and investigation to answer this question.

7. What would the geophysical signs be prior to eruption at Taupo? Many of the processes that occur prior to eruption at Taupo happen on timescales that are of relevance and concern to humans. Historic examples of unrest resulted from magma intrusions at $\sim 8 \mathrm{~km}$ depth at Taupo (Smith et al., 2007), considered to be an area of particular volatility that could result in eruption given the right circumstances (Figure 5.18). An outstanding question is therefore what determines eruption versus unrest at Taupo? Could the 1983 earthquake swarm and associated uplift lead to a future eruption and if so what would the geophysical signs be? As outlined by Ellis et al. (2007) there is a 
feedback response at Taupo between inflation and extensional tectonics so that surface uplift on short timescales can be followed by subsidence on longer timescales making geophysical detection of inflation difficult. In combination with a better understanding of the structure of the crust beneath Taupo volcano, further work is needed to determine what the exact geophysical signs would be prior to an eruption at Taupo, in light of the new data provided by petrological observations in this study. Further studies of volcanism and unrest at Taupo are vital towards preparing for future activity at what is clearly one of the most productive and hazardous volcanoes on Earth. 


\section{References}

Adams, C. J., Mortimer, N., Campbell, H. J. \& Griffin, W. J. (2009). Age/isotopic characterisation of Torlesse Supergroup and Waipapa Group metasediments in the central North Island, New Zealand. New Zealand Journal of Geology and Geophysics 52, 149-170.

Allan, A. S. R. (2013). The Oruanui eruption: insights into the generation and dynamics of the world's youngest supereruption. Ph. D. thesis, Victoria University of Wellington, Wellington, New Zealand.

Allan, A. S. R., Wilson, C. J. N., Millet, M. -A. \& Wysoczanski, R. J. (2012). The invisible hand: tectonic triggering and modulation of a rhyolitic supereruption. Geology 40, 563-566.

Allan, A. S. R., Morgan, D. J., Wilson, C. J. N. \& Millet, M. -A. (2013). From mush to eruption in centuries: assembly of the super-sized Oruanui magma body. Contributions to Mineralogy and Petrology 166, 143-164.

Allan, A. S. R., Wilson, C. J. N., Barker, S. J., Millet, M-A., Morgan, D. J. (2014). Micro-analytical insights into pre- and syn-eruptive magmatic processes of the Oruanui eruption, New Zealand. Journal of Petrology (under review).

Andersen, D. J. \& Lindsley, D.H. (1988). Internally consistent solution models for FeMg-Mn-Ti oxides: Fe-Ti oxides. American Mineralogist 73, 714-726.

Annen, C., Blundy, J. D. \& Sparks, R. S. J. (2006). The genesis of intermediate and silicic magmas in deep crustal hot zones. Journal of Petrology 47, 505-539.

Aramaki, S. (1984). Formation of the Aira Caldera, southern Kyushu, 22,000 years ago. Journal of Geophysical Research 89, 8485-8501.

Arculus, R. J. (2003). Use and abuse of the terms calcalkaline and calcalkalic. Journal of Petrology 44, 929-935.

Bachmann, O. \& Bergantz, G. W. (2004) On the origin of crystal-poor rhyolites: extracted from batholithic crystal mushes. Journal of Petrology 45, 1565-1582.

Bachmann, O. \& Bergantz, G. W. (2006). Gas percolation in upper-crustal silicic crystal mushes as a mechanism for upward heat advection and rejuvenation of nearsolidus magma bodies. Journal of Volcanology and Geothermal Research 149, 85-102.

Bachmann, O. \& Bergantz, G. W. (2008). The magma reservoirs that feed supereruptions. Elements 4, 17-21.

Bachmann, O., Dungan, M. A. \& Lipman, P. W. (2002). The Fish Canyon magma body, San Juan volcanic field, Colorado: rejuvenation and eruption of an upper crustal batholith. Journal of Petrology 43, 1469-1503.

Bachmann, O., Miller, C. F. \& de Silva, S. L. (2007). The volcanic-plutonic connection as a stage for understanding crustal magmatism. Journal of Volcanology and Geothermal Research 167, 1-23.

Bachmann, O., Deering, C. D., Ruprecht, J. S., Huber, C., Skopelitis, A. \& Schnyder, C. (2012). Evolution of silicic magmas in the Kos- Nisyros volcanic center, Greece: 
a petrological cycle associated with caldera collapse. Contributions to Mineralogy and Petrology 163, 151-166.

Bacon, C. R. (1985). Implications of silicic vent patterns for the presence of large crustal magma chambers. Journal of Geophysical Research 90, 11243-11252.

Bacon, C. R. \& Druitt, T. H. (1988) Compositional evolution of the zoned calcalkaline magma chamber of Mount Mazama, Crater Lake, Oregon. Contributions to Mineralogy and Petrology 98, 224-256.

Bacon, C. R. \& Hirschmann, M. M. (1988). Mg/Mn partitioning as a test for equilibrium between coexisting Fe-Ti oxides. American Mineralogist 73, 57-61.

Bacon, C. R. \& Lowenstern, J. B. (2005). Late Pleistocene granodiorite source for recycled zircon and phenocrysts in rhyodacite lava at Crater Lake, Oregon. Earth and Planetary Science Letters 233, 277-293.

Bain, A. A., Jellinek, A. M. \& Wiebe, R. A. (2013). Quantitative field constraints on the dynamics of silicic magma chamber rejuvenation and overturn. Contributions to Mineralogy and Petrology 165, 1275-1294.

Ballance, P. F. (1993). The New Zealand Neogene forearc basins. In: Ballance, P.F. (ed), South Pacific Sedimentary Basins, Amsterdam: Elsevier, 177-193.

Barker, S. J., Wilson, C. J. N., Baker, J. A., Millet, M-A., Rotella, M. D., Wright, I. C. \& Wysoczanski, R. J. (2013). Geochemistry and petrogenesis of silicic magmas in the intra-oceanic Kermadec arc. Journal of Petrology 54, 351-391.

Barker, S. J., Wilson, C. J. N., Smith, E. G. C., Charlier, B. L. A., Wooden, J. L., Hiess, J. \& Ireland, T. R. (2014a). Post-supereruption magmatic reconstruction of Taupo volcano (New Zealand), as reflected in zircon ages and trace elements. Journal of Petrology 55, 1511-1533.

Barker, S. J., Wilson, C. J. N., Allan, A. S. R. \& Schipper, C. I. (2014b). Fine-scale temporal recovery, reconstruction and evolution of a post-supereruption magmatic system: Taupo (New Zealand). Contributions to Mineralogy and Petrology (under review).

Barth, A. P. \& Wooden, J. L. (2010). Coupled elemental and isotopic analyses of polygenetic zircons from granitic rocks by ion microprobe, with implications for melt evolution and the sources of granitic magmas. Chemical Geology 277, 149159.

Barth, A. P., Wooden, J. L., Jacobson, C. E. \& Economos, R. C. (2013). Detrital zircon as a proxy for tracking the magmatic arc system: The California arc example. Geology 41, 223-226.

Baumgart I. L. (1954). Some ash showers of the central North Island. New Zealand Journal of Science and Technology B35, 456-467.

Beanland. S. (1995). The North Island Dextral Fault Belt, Hikurangi Subduction Margin, New Zealand. PhD thesis, Victoria University of Wellington, Wellington, New Zealand. 
Behrens, H., Ohlhorst, S., Holtz, F. \& Champenois, M. (2004). $\mathrm{CO}_{2}$ solubility in dacitic melts equilibrated with $\mathrm{H}_{2} \mathrm{O}-\mathrm{CO}_{2}$ fluids: Implications for modeling the solubility of $\mathrm{CO}_{2}$ in silicic melts. Geochimica et Cosmochimica Acta 68, 4687-4703.

Belousova, E. A., Griffin, W. L., O’Reilly, S. Y. \& Fisher, N. I. (2002). Igneous zircon: trace element composition as an indicator of source rock type. Contributions to Mineralogy and Petrology 143, 602-622.

Bibby, H. M., Caldwell, T. G., Davey, F. J. \& Webb, T. H. (1995). Geophysical evidence on the structure of the Taupo Volcanic Zone and its hydrothermal circulation. Journal of Volcanology and Geothermal Research 68, 29-58.

Bibby, H. M., Caldwell, T. G., \& Risk, G. F. (1998). Electrical resistivity image of the upper crust within the Taupo Volcanic Zone, New Zealand. Journal of Geophysical Research 103, 9665-9680.

Bindeman, I. N., Valley, J. W., Wooden, J. L. \& Persing, H. M. (2001). Post-caldera volcanism: in situ measurement of U-Pb age and oxygen isotope ratio in Pleistocene zircons from Yellowstone caldera. Earth and Planetary Science Letters 189, 197-206.

Black, L. P., Kamo, S. L., Allen, C. M., Davis, D. W., Aleinikoff, J. N., Valley, J. W., Mundil, R. M., Campbell, I. H., Korsch, R. J., Williams, I. S. \& Foudoulis, C. (2004). Improved ${ }^{206} \mathrm{~Pb} /{ }^{238} \mathrm{U}$ microprobe geochronology by the monitoring of a trace-element-related matrix effect: SHRIMP, ID-TIMS, ELA-ICP-MS, and oxygen isotope documentation for a series of zircon standards. Chemical Geology 205, 115-140.

Blake, S., Wilson, C. J. N., Smith, I. E. M. \& Walker, G. P. L. (1992). Petrology and dynamics of the Waimihia mixed magma eruption, Taupo Volcano, New Zealand. Journal of the Geological Society, London 149, 193-207.

Blundy, J. \& Cashman, K. V. (2008). Petrologic reconstruction of magmatic system variables and processes. Reviews in Mineralogy and Geochemistry 69, 179-231.

Blundy, J. D. \& Wood, B. J. (1991). Crystal-chemical controls on the partitioning of Sr and $\mathrm{Ba}$ between plagioclase feldspar, silicate melts, and hydrothermal solutions. Geochimica et Cosmochimica Acta 55, 193-209.

Boehnke, P., Watson, E. B., Trail, D., Harrison, T. M. \& Schmitt, A. K. (2013). Zircon saturation re-revisited. Chemical Geology 351, 324-334.

Bohrson, W. A. \& Spera, F. J. (2001). Energy-constrained open-system magmatic processes II: application of energy-constrained assimilation-fractional crystallization (EC-AFC) model to magmatic systems. Journal of Petrology 42, 1019-1041.

Bowen, N. L. (1928). The evolution of the igneous rocks: Princeton, New Jersey: Princeton University Press.

Brooker, M. R., Houghton, B. F., Wilson, C. J. N. \& Gamble, J. A. (1993). Pyroclastic phases of a rhyolitic dome-building eruption: Puketarata tuff ring, Taupo Volcanic Zone, New Zealand. Bulletin of Volcanology 55, 395-406. 
Brophy, J. G. (1991). Compositional gaps, critical crystallinity, and fractional crystallization in orogenic (calc-alkaline) magmatic systems. Contributions to Mineralogy and Petrology 109, 173-182.

Brophy, J. G. (2009). Decompression and $\mathrm{H}_{2} \mathrm{O}$ exsolution driven crystallization and fractionation: development of a new model for low-pressure fractional crystallization in calc-alkaline magmatic systems. Contributions to Mineralogy and Petrology 157, 797-811.

Brown, S. J. A. \& Fletcher, I. R. (1999). SHRIMP U-Pb dating of the pre-eruption growth history of zircons from the $340 \mathrm{ka}$ Whakamaru Ignimbrite, New Zealand: Evidence for $>250$ k.y. magma residence times. Geology 27, 1035-1038.

Browne, P. R. L., Graham, I. J., Parker, R. J. \& Wood, C. P. (1992). Subsurface andesite lavas and plutonic rocks in the Rotokawa and Ngatamariki geothermal systems, Taupo Volcanic Zone, New Zealand. Journal of Volcanology and Geothermal Research 51, 199-215.

Burgisser, A. \& Bergantz, G. W. (2011). A rapid mechanism to remobilize and homogenize highly crystalline magma bodies. Nature 471, 212-217.

Cameron, K. L. (1984). Bishop Tuff revisited: new rare earth element data consistent with crystal fractionation. Science 224, 1338-1340.

Caricchi, L., Annen, C., Blundy, J., Simpson, G. \& Pinel, V. (2014). Frequency and magnitude of volcanic eruptions controlled by magma injection and buoyancy. Nature Geoscience 7, 126-130.

Carpenter, P. K. (2008). Electron-probe microanalysis (EPMA): an overview for beginners and a status report for experts. Microscopy and Microanalysis 14, 11501151.

Cashman, K. \& Blundy, J. (2013). Petrological cannibalism: the chemical and textural consequences of incremental magma body growth. Contributions to Mineralogy and Petrology 166, 703-729.

Cawood, P. A., Nemchin, A. A., Leverenz, A., Saeed, A. \& Ballance, P. F. (1999). U/Pb dating of detrital zircons: Implications for the provenance record of Gondwana margin terranes. Geological Society of America Bulletin 111, 1107-1119.

Chakraborty, S. (2008). Diffusion in solid silicates: a tool to track timescales of processes comes of age. Annual Review of Earth and Planetary Sciences 36, 153190.

Chambefort, I., Lewis, B., Wilson, C. J. N., Rae, A. J., Coutts, C., Bignall, G. \& Ireland, T. R. (2014). Stratigraphy and structure of the Ngatamariki geothermal system from new zircon $\mathrm{U}-\mathrm{Pb}$ geochronology: implications for Taupo Volcanic Zone evolution. Journal of Volcanology and Geothermal Research 274, 51-70.

Chamberlain, K. J., Wilson, C. J. N., Wooden, J. L., Charlier, B. L. A. \& Ireland, T. R. (2014a). New perspectives on the Bishop Tuff from zircon textures, ages and trace elements. Journal of Petrology 55, 395-426.

Chamberlain, K. J., Morgan, D. J. \& Wilson, C. J. N. (2014b). Timescales of mixing and mobilisation in the Bishop Tuff magma body: perspectives from diffusion chronometry. Contributions to Mineralogy and Petrology 168, 1034. 
Chanier, F., Ferrière, J. \& Angelier, J. (1999). Extensional deformation across an active margin, relations with subsidence, uplift, rotations: The Hikurangi subduction, New Zealand. Tectonics 18, 862-876.

Charlier, B. L. A. \& Wilson, C. J. N. (2010). Chronology and evolution of calderaforming and post-caldera magma systems at Okataina volcano, New Zealand from zircon U/Th model-age spectra. Journal of Petrology 51, 1121-1141.

Charlier, B. L. A., Wilson, C. J. N., Lowenstern, J. B., Blake, S., van Calsteren, P. W. \& Davidson, J. P. (2005). Magma generation at a large, hyperactive silicic volcano (Taupo, New Zealand) revealed by U-Th and U-Pb systematics in zircons. Journal of Petrology 46, 3-32.

Charlier, B. L. A., Wilson, C. J. N. \& Davidson, J. P. (2008). Rapid open-system assembly of a large silicic magma body: time-resolved evidence from cored plagioclase crystals in the Oruanui eruption deposits, New Zealand. Contributions to Mineralogy and Petrology 156, 799-813.

Charlier, B. L. A., Wilson, C. J. N. \& Mortimer, N. (2010). Evidence from zircon U-Pb age spectra for crustal structure and felsic magma genesis at Taupo volcano, New Zealand. Geology 38, 915-918.

Cherniak, D. J. (2010). Diffusion in accessory minerals: zircon, titanite, apatite, monazite and xenotime. Reviews in Mineralogy and Geochemistry 72, 827-869.

Chesner, C. A. (2012). The Toba caldera complex. Quaternary International 258, 5-18.

Christiansen, R. L. (2001). The Quaternary and Pliocene Yellowstone Plateau Volcanic Field of Wyoming, Idaho, and Montana. United States Geological Survey Professional Paper 729-G, 1-143.

Cole, J. W. (1990). Structural control and origin of volcanism in the Taupo Volcanic Zone, New Zealand. Bulletin of Volcanology 52, 445-459.

Cole, J. W., Darby, D. J. \& Stern, T. A. (1995). Taupo Volcanic Zone and Central Volcanic Region: backarc structures of North Island, New Zealand. In: Taylor, B. (ed.), Backarc Basins: Tectonics and Magmatism. New York: Plenum Press, 1-28.

Cole, J. W., Deering, C. D., Burt, R. M., Sewell, S., Shane, P. A. R. \& Matthews, N. E. (2014). Okataina Volcanic Centre, Taupo Volcanic Zone, New Zealand: A review of volcanism and synchronous pluton development in an active, dominantly silicic caldera system. Earth-Science Reviews 128, 1-17.

Conrad, W. K., Nicholls, I. A. \& Wall, V. J. (1988). Water-saturated and undersaturated melting of metaluminous and peraluminous crustal compositions at $10 \mathrm{~kb}$ : evidence for the origin of silicic magmas in the Taupo Volcanic Zone, New Zealand, and other occurrences. Journal of Petrology 29, 765-803.

Coombs, M. L. \& Gardner, J. E. (2004). Reaction rim growth on olivine in silicic melts: implications for magma mixing. American Mineralogist 89, 748-759.

Cooper, G. F. (2014). The dynamics of large-scale silicic magmatic systems: case studies from Mangakino volcanic centre, Taupo Volcanic Zone, New Zealand. $\mathrm{PhD}$ thesis, Victoria University of Wellington, Wellington, New Zealand. 
Cooper, G. F., Wilson, C. J. N., Millet, M-A, Baker, J. A. \& Smith, E. G. C. (2012). Systematic tapping of independent magma chambers during the 1 Ma Kidnappers supereruption. Earth and Planetary Science Letters 313-314, 23-33.

Costa, F. (2008). Residence times of silicic magmas associated with calderas. Developments in Volcanology 10, 1-55.

Costa, F. \& Dungan, M. (2005). Short time scales of magmatic assimilation from diffusion modeling of multiple elements in olivine. Geology 33, 837-840.

Costa, F., Chakraborty, S. \& Dohmen, R. (2003). Diffusion coupling between trace and major elements and a model for calculation of magma residence times using plagioclase. Geochimica et Cosmochimica Acta 67, 2189-2200.

Couch, S., Sparks, R. S. J. \& Carroll, M. R. (2001). Mineral disequilibrium in lavas explained by convective self-mixing in open magma chambers. Nature 411, 10371039.

Dall'Agnol, R., Scaillet, B. \& Pichavant, M. (1999). An experimental study of a lower Proterozoic A-type granite from the eastern Amazonian craton, Brazil. Journal of Petrology 40, 1673-1698.

Darby, D. J. \& Meertens, C. M. (1995). Terrestrial and GPS measurements of deformation across the Taupo back arc and Hikurangi forearc regions in New Zealand. Journal of Geophysical Research 100, 8221-8232.

Darby, D. J., Hodgkinson, K. M. \& Blick, G. H. (2000). Geodetic measurement of deformation in the Taupo Volcanic Zone, New Zealand: the north Taupo network revisited. New Zealand Journal of Geology and Geophysics 43, 157-170.

Davy, B. W. \& Caldwell, T. G. (1998). Gravity, magnetic and seismic surveys of the caldera complex, Lake Taupo, North Island, New Zealand. Journal of Volcanology and Geothermal Research 81, 69-89.

Deering, C. D., Cole, J. W. \& Vogel, T. A. (2011). Extraction of crystal-poor rhyolite from a hornblende-bearing intermediate mush: a case study of the calderaforming Matahina eruption, Okataina volcanic complex. Contributions to Mineralogy and Petrology 161, 129-151.

DeMets, C., Gordon, R. G., Argus, D. F. \& Stein, S. (1994). Effect of recent revisions to the geomagnetic reversal time scale on estimates of current plate motions. Geophysical Research Letters 21, 2191-2194.

de Silva, S. L. \& Gregg, P. M. (2014). Thermomechanical feedbacks in magmatic systems: Implications for growth, longevity, and evolution of large calderaforming magma reservoirs and their supereruptions. Journal of Volcanology and Geothermal Research 282, 77-91.

Di Vito, M. A., Isaia, R., Orsi, G., Southon, J., de Vita, S., D'Antonio, M. D., Pappalardo, L. \& Piochi, M. (1999). Volcanism and deformation since 12,000 years at the Campi Flegrei caldera (Italy). Journal of Volcanology and Geothermal Research 91, 221-246.

Dominy-Howes, D. \& Minos-Minopoulos, D. (2004). Perceptions of hazard and risk on Santorini. Journal of Volcanology and Geothermal Research 137, 285-310. 
Dunbar, N. W. \& Kyle, P. R. (1993). Lack of volatile gradient in the Taupo plinianignimbrite transition: Evidence from melt inclusion analysis. American Mineralogist 78, 612-618.

Dunbar, N. W., Hervig, R. L. \& Kyle, P. R. (1989). Determination of pre-eruptive $\mathrm{H}_{2} \mathrm{O}$, $\mathrm{F}$ and $\mathrm{Cl}$ contents of silicic magmas using melt inclusions: examples from Taupo volcanic centre, New Zealand. Bulletin of Volcanology 51, 177-184.

Eggins, S. M., Woodhead, J. D., Kinsley, L. P. J., Mortimer, G. E., Sylvester, P., McCulloch, M. T., Hergt, J. M. \& Handler, M. R. (1997). A simple method for the precise determination of $\geq 40$ trace elements in geological samples by ICPMS using enriched isotope internal standardisation. Chemical Geology 134, 311-326.

Eichelberger, J. C., Izbekov, P. E. \& Browne, B. L. (2006). Bulk chemical trends at arc volcanoes are not liquid lines of descent. Lithos 87, 135-154.

Ellis, S. M., Wilson, C. J. N., Bannister, S., Bibby, H. M., Heise, W., Wallace, L. \& Patterson, N. (2007). A future magma inflation event under the rhyolitic Taupo volcano, New Zealand: numerical models based on constraints from geochemical, geological, and geophysical data. Journal of Volcanology and Geothermal Research 168, 1-27.

Ersoy, E. Y. (2013). PETROMODELER (Petrological Modeler) a Microsoft Excel spreadsheet program for modelling melting, mixing, crystallization and assimilation processes in magmatic systems. Turkish Journal of Earth Science 22, 115-125.

Evans, B. W., Scaillet, B. \& Kuehner, S. M. (2006). Experimental determination of coexisting iron-titanium oxides in the systems FeTiAlO, FeTiAlMgO, FeTiAlMnO, and FeTiAlMgMnO at 800 and $900^{\circ} \mathrm{C}, 1-4 \mathrm{kbar}$, and relatively high oxygen fugacity. Contributions to Mineralogy and Petrology 152, 149-167.

Ewart, A. \& Stipp, J. J. (1968). Petrogenesis of the volcanic rocks of the central North Island, New Zealand, as indicated by a study of $\mathrm{Sr}^{87} / \mathrm{Sr}^{86}$ ratios, and $\mathrm{Sr}, \mathrm{Rb}, \mathrm{K}, \mathrm{U}$ and Th abundances. Geochimica et Cosmochimica Acta 32, 699-736.

Farrell, J., Smith, R. B., Husen, S. \& Diehl, T. (2014). Tomography from 26 years of seismicity reveal that the spacial extent of Yellowstone crystal reservoir extends well beyond the Yellowstone caldera. Geophysical Research Letters 41, 30683073 .

Ferry, J. M. \& Watson, E. B. (2007). New thermodynamic models and revised calibrations for the Ti-in-zircon and Zr-in-rutile thermometers. Contributions to Mineralogy and Petrology 154, 429-437.

Froggatt, P. C. (1981a). Karapiti Tephra Formation: a 10000 years BP rhyolitic tephra from Taupo. New Zealand Journal of Geology and Geophysics 24, 95-98.

Froggatt, P. C. (1981b). Review of Holocene eruptions from Taupo. In: Howorth, R., Froggatt, P. C., Vucetich, C. G. \& Collen, J. D. (eds), Proceedings of tephra work-shop. Geology Department, Victoria University of Wellington Publication 20, 21-28.

Froggatt, P. C. (1981c). Motutere Tephra Formation and redefinition of Hinemaiaia Tephra Formation, Taupo Volcanic Centre, New Zealand. New Zealand Journal of Geology and Geophysics 24, 99-105. 
Froggatt, P. C. (1981d). Stratigraphy and nature of Taupo Pumice Formation. New Zealand Journal of Geology and Geophysics 24, 231-248.

Froggatt, P. C. \& Lowe, D. J. (1990). A review of late Quaternary silicic and some other tephra formations from New Zealand: their stratigraphy, nomenclature, distribution, volume, and age. New Zealand Journal of Geology and Geophysics 33, 89-109.

Gamble, J. A., Smith, I. E. M., Graham, I. J., Kokelaar, B. P., Cole, J. W., Houghton, B. F. \& Wilson, C. J. N. (1990). The petrology, phase relations and tectonic setting of basalts from the Taupo Volcanic Zone, New Zealand and the Kermadec Island Arc - Havre Trough, SW Pacific. Journal of Volcanology and Geothermal Research 43, 253-270.

Gamble, J. A., Woodhead, J. D., Wright, I. C. \& Smith, I. E. M. (1996). Basalt and sediment geochemistry and magma petrogenesis in a transect from oceanic island arc to rifted continental margin arc: the Kermadec-Hikurangi margin, SW Pacific. Journal of Petrology 37, 1523-1546.

Ganguly, J. \& Tazzoli, V. (1994). $\mathrm{Fe}^{2+}-\mathrm{Mg}$ interdiffusion in orthopyroxene: retrieval from the data on intracrystalline exchange reaction. American Mineralogist 79, 930-937.

Garrison, J. M., Reagan, M. K. \& Sims, K. W. W. (2012). Dacite formation at Ilopango Caldera, El Salvador: U-series disequilibrium and implications for petrogenetic processes and magma storage time. Geochemistry Geophysics Geosystems 13, Q06018.

Gelman, S. E., Deering, C. D., Gutierrez, F. J. \& Bachmann, O. (2013). Evolution of the Taupo volcanic center, New Zealand: petrological and thermal constraints from the Omega dacite. Contributions to Mineralogy and Petrology 166, 1355-1374.

Ghiorso, M. S. \& Evans, B.W. (2008). Thermodynamics of rhombohedral oxide solid solutions and a revision of the Fe-Ti two-oxide geothermometer and oxygen barometer. American Journal of Science 308, 957-1039.

Girard, G. \& Stix, J. (2009). Buoyant replenishment in silicic magma reservoirs: Experimental approach and implications for magma dynamics, crystal mush remobilization, and eruption. Journal of Geophysical Research 114, B08203.

Glazner, A. F., Bartley, J. M., Coleman, D. S., Gray, W. \& Taylor, R. Z. (2004). Are plutons assembled over millions of years by amalgamation from small magma chambers? GSA Today 14 (4/5), 4-11.

Govindaraju, K., Potts, P. J., Webb, P. C. \& Watson, J. S. (1994). Report on Whin Sill Dolerite WS-E from England and Pitscurrie Microgabbro PM-S from Scotland: assessment by one hundred and four internal laboratories. Geostandards Newsletter 18, 211-300.

Graham, I. J. \& Hackett, W. R. (1987). Petrology of calc-alkaline lavas from Ruapehu volcano and related vents, Taupo Volcanic Zone, New Zealand. Journal of Petrology 28, 531-567.

Graham, I. J. \& Worthington, T. J. (1988). Petrogenesis of Tauhara dacite (Taupo Volcanic Zone, New Zealand) - evidence for magma mixing between high 
alumina andesite and rhyolite. Journal of Volcanology and Geothermal Research 35, 279-294.

Graham, I. J., Gulson, B. L., Hedenquist, J. W. \& Mizon, K. (1992). Petrogenesis of Late Cenozoic volcanic rocks from the Taupo Volcanic Zone, New Zealand, in the light of new lead isotope data. Geochimica et Cosmochimica Acta 56, 27972819 .

Graham, I. J., Cole, J. W., Briggs, R. M., Gamble, J. A. \& Smith, I. E. M. (1995). Petrology and petrogenesis of volcanic rocks from the Taupo Volcanic Zone: a review. Journal of Volcanology and Geothermal Research 68, 59-87.

Gravley, D. M., Wilson, C. J. N., Leonard, G. S. \& Cole, J. W. (2007). Double trouble: paired ignimbrite eruptions and collateral subsidence in the Taupo Volcanic Zone, New Zealand. Geological Society of America Bulletin 119, 18-30.

Grindley, G. W. (1960). Sheet 8 Taupo; Geological Map of New Zealand 1:250,000: Department of Scientific and Industrial Research, Wellington, New Zealand.

Gualda, G. A. R. \& Ghiorso, M. S. (2014). Phase-equilibrium geobarometers for silicic rocks based on rhyolite-MELTS. Part 1: Principles, procedures, and evaluation of the method. Contributions to Mineralogy and Petrology 168, 1033.

Gualda, G. A. R., Ghiorso, M. S., Lemons, R. V. \& Carley, T. L. (2012). RhyoliteMELTS: a modified calibration of MELTS optimized for silica-rich, fluid bearing magmatic systems. Journal of Petrology 53, 875-890.

Hackett, W. R. (1985). Geology and petrology of Ruapehu Volcano and related vents. $\mathrm{PhD}$ thesis, Victoria University of Wellington, Wellington, New Zealand

Harrison, A. J. \& White, R. S. (2004). Crustal structure of the Taupo Volcanic Zone, New Zealand: stretching and igneous intrusion. Geophysical Research Letters 31, L13615.

Harrison, A. \& White, R. S. (2006). Lithospheric structure of an active backarc basin: the Taupo Volcanic Zone, New Zealand. Geophysical Journal International 167, 968-990.

Harrison, T. M., Watson, E. B. \& Aikman, A. B. (2007). Temperature spectra of zircon crystallization in plutonic rocks. Geology 35, 635-638.

Hawkesworth, C. J., Blake, S., Evans, P., Hughes, R., Macdonald, R., Thomas, L. E., Turner, S. P. \& Zellmer, G. (2000). Time scales of crystal fractionation in magma chambers - integrating physical, isotopic and geochemical perspectives. Journal of Petrology 41, 991-1006.

Healy, J. (1964). Stratigraphy and chronology of late Quaternary volcanic ash in Taupo, Rotorua, and Gisborne districts. Part 1. Dating of the younger volcanic eruptions of the Taupo region. New Zealand Geological Survey Bulletin 73, 7-42.

Healy, J., Schofield, J. C. \& Thompson, B. N. (1964). Sheet 5 Rotorua (1st Ed.). Geological map of New Zealand 1:250,000: Department of Scientific and Industrial Research, Wellington, New Zealand.

Heinrich, K. F. J. (1991). Strategies of electron probe data reduction. In: Heinrich, K. F. J. and Newbury, D. (eds) Electron Probe Quantitation. Springer, Berlin 9-18. 
Heise, W., Bibby, H. M., Caldwell, T. G., Bannister, S. C., Ogawa, Y., Takakura, S. \& Uchida, T. (2007). Melt distribution beneath a young continental rift: the Taupo Volcanic Zone, New Zealand. Geophysical Research Letters 34, L14313.

Heise, W., Caldwell, T. G., Bibby, H. M. \& Bennie, S. L. (2010). Three dimensional electrical resistivity image of magma beneath an active continental rift, Taupo Volcanic Zone, New Zealand. Geophysical Research Letters 37, L1030.

Hellstrom, J., Paton, C., Woodhead, J. D. \& Hergt, J. M. (2008). Iolite: software for spatially resolved LA-(quad and MC) ICPMS analysis. In: Sylvester, P. (ed.), Laser Ablation ICPMS in the Earth Sciences: Current Practices and Outstanding Issues. Mineralogical Association of Canada Short Course Series 40, 343-348.

Hiess, J., Cole, J. W. \& Spinks, K. D. (2007). Influence of the crust and crustal structure on the location and composition of high-alumina basalts of the Taupo Volcanic Zone, New Zealand. New Zealand Journal of Geology and Geophysics 50, 327342.

Hildreth, W. (1981). Gradients in silicic magma chambers: implications for lithospheric magmatism. Journal of Geophysical Research 86, 10153-10192.

Hildreth, W. (2004). Volcanological perspectives on Long Valley, Mammoth Mountain, and Mono Craters: several contiguous but discrete systems. Journal of Volcanology and Geothermal Research 136, 169-198.

Hildreth, W. \& Moorbath, S. (1988). Crustal contributions to arc magmatism in the Andes of central Chile. Contributions to Mineralogy and Petrology 98, 455-489.

Hildreth, W. \& Wilson, C. J. N. (2007). Compositional zoning of the Bishop Tuff. Journal of Petrology 48, 951-999.

Hill, D. P. \& Prejean, S. (2005). Magmatic unrest beneath Mammoth Mountain, California. Journal of Volcanology and Geothermal Research 67, 8-15.

Hochstein, M. P. (1995). Crustal heat transfer in the Taupo Volcanic Zone (New Zealand): comparison with other volcanic arcs and explanatory heat source models. Journal of Volcanology and Geothermal Research 68, 117-151.

Hochstein, M. P., Smith, I. E. M., Regenauer-Lieb, K. \& Ehara, S. (1993). Geochemistry and heat transfer processes in Quaternary rhyolitic systems of the Taupo Volcanic Zone, New Zealand. Tectonophysics 223, 213-235.

Hogg, A. G., Lowe, D. J., Palmer, J., Boswijk, G. \& Ramsey, C. B. (2012). Revised calendar date for the Taupo eruption derived by ${ }^{14} \mathrm{C}$ wiggle-matching using a New Zealand kauri ${ }^{14} \mathrm{C}$ calibration data set. Holocene 22, 439-449.

Hoskin, P. W. O. \& Schaltegger, U. (2003). The composition of zircon and igneous and metamorphic petrogenesis. Reviews in Mineralogy and Geochemistry 53, 27-62.

Houghton, B. F., Wilson, C. J. N., Lloyd, E. F., Gamble, J. A. \& Kokelaar, B. P. (1987). A catalogue of basaltic deposits within the central Taupo Volcanic Zone. New Zealand Geological Survey Record 18, 95-101.

Houghton, B. F., Wilson, C. J. N., McWilliams, M. O., Lanphere, M. A., Weaver, S. D., Briggs, R. M. \& Pringle, M. S. (1995). Chronology and dynamics of a large silicic 
magmatic system: central Taupo Volcanic Zone, New Zealand. Geology 23, 1316.

Houghton, B. F., Carey, R. J., Cashman, K. V., Wilson, C. J. N., Hobden, B. J. \& Hammer, J. E. (2010). Diverse patterns of ascent, degassing, and eruption of rhyolite magma during the $1.8 \mathrm{ka}$ Taupo eruption, New Zealand: evidence from clast vesicularity. Journal of Volcanology and Geothermal Research 195, 31-47.

Houghton, B. F., Carey, R. J. \& Rosenberg, M. D. (2014). The 1800a Taupo eruption: "Ill wind" blows the ultraplinian type event down to Plinian. Geology 42, 459461.

Huber, C., Bachmann, O. \& Dufek, J. (2011). Thermo-mechanical reactivation of locked crystal mushes: melting-induced internal fracturing and assimilation processes in magmas. Earth and Planetary Science Letters 304, 443-454.

Ihinger, P. D., Hervig, R. L. \& McMillan, P. F. (1994). Analytical methods for volatiles in glasses. Reviews in Mineralogy and Geochemistry 30, 67-121.

Ingamells, C. O. (1980). Analyzed minerals for electron microprobe standards. Geostandards Newsletter 2, 115.

Ireland, T. R. \& Williams, I. S. (2003). Considerations in zircon geochronology by SIMS. Reviews in Mineralogy and Geochemistry 53, 215-241.

Jarosewich, E., Nelen, J. A. \& Norberg, J. A. (1980). Reference samples for electron microprobe analysis. Geostandards Newsletter 4, 43-47.

Jasra, A., Stephens, D. A., Gallagher, K. \& Holmes, C. C. (2006). Bayesian mixture modelling in geochronology via Markov chain Monte Carlo. Mathematical Geology 38, 269-300.

Jochum, K. P., Stoll, B., Herwig, K., Willbold, M., Hofmann, A. W., Amini, M., Aarburg, S., Abouchami, W., Hellebrand, E., Mocek, B., Raczek, I., Stracke, A., Alard, O., Bouman, C., Becker, S., Ducking, M., Bratz, H., Klemd, R., de Bruin, D., Canil, D., Cornell, D., de Hoog, C. J., Dalpe, C., Danyushevsky, L., Eisenhauer, A., Gao, Y. J., Snow, J. E., Goschopf, N., Gunther, D., Latkoczy, C., Guillong, M., Hauri, E. H., Hofer, H. E., Lahaye, Y., Horz, K., Jacob, D. E., Kassemann, S. A., Kent, A. J. R., Ludwig, T., Zack, T., Mason, P. R. D., Meixner, A., Rosner, M., Misawa, K. J., Nash, B. P., Pfander, J., Premo, W. R., Sun, W. D., Tiepolo, M., Vannucci, R., Vennemann, T., Wayne, D. \& Woodhead, J. D. (2006). TI MPI-DING reference glasses for in situ microanalysis: New reference values for element concentrations and isotope ratios. Geochemistry, Geophysics, Geosystems 7, Q02008.

Johnston, D., Scott, B., Houghton, B., Paton, D., Dowrick, D., Villamor, P. \& Savage, J. (2002). Social and economic consequences of historic caldera unrest at the Taupo volcano, New Zealand and the management of future episodes of unrest. Bulletin of the New Zealand Society for Earthquake Engineering 35, 215-230.

Klimm, K., Holtz, F., Johannes, W. \& King, P. L. (2003). Fractionation of metaluminous A-type granites: an experimental study of the Wangrah Suite, Lachlan Fold Belt, Australia. Precambrian Research 124, 327-341. 
Klügel, A. (2001). Prolonged reactions between harzburgite xenoliths and silicaundersaturated melt: Implications for dissolution and Fe-Mg interdiffusion rates of orthopyroxene. Contributions to Mineralogy and Petrology 141, 1-14.

Klügel, A., Hansteen, T. H. \& Galipp, K. (2005). Magma storage and underplating beneath Cumbre Vieja volcano, La Palma (Canary Islands), Earth and Planetary Science Letters 236, 211-226.

Knesel, K. M., Davidson, J. P. \& Duffield, W. A. (1999). Evolution of silicic magma through assimilation and subsequent recharge: Evidence from $\mathrm{Sr}$ isotopes in sanidine phenocrysts, Taylor Creek Rhyolite, NM. Journal of Petrology 40, 773786.

Kohn, B. P. \& Topping, W. W. (1978). Time-space relationships between late Quaternary rhyolitic and andesitic volcanism in the southern Taupo Volcanic Zone, New Zealand. Geological Society of America Bulletin 89, 1265-1271.

Lepage, L. D. (2003). ILMAT: an excel worksheet for ilmenite-magnetite geothermometry and geobarometry. Computers and Geosciences 29, 673-678.

Lees, J. M. (2007). Seismic tomography of magmatic systems. Journal of Volcanology and Geothermal Research 167, 37-56.

Leonard, G. S. (2003). The evolution of Maroa Volcanic Centre, Taupo Volcanic Zone, New Zealand. PhD thesis, University of Canterbury, Christchurch, New Zealand.

Leonard, G. S., Cole, J. W., Nairn, I. A. \& Self, S. (2002). Basalt triggering of the c. AD 1305 Kaharoa rhyolite eruption, Tarawera Volcanic Complex, New Zealand. Journal of Volcanology and Geothermal Research 115, 461-486.

Leonard, G. S., Begg, J. G. \& Wilson, C. J. N. (compilers) (2010). Geology of the Rotorua area. Institute of Geological \& Nuclear Sciences 1:250,000 geological map 5. GNS Science. Lower Hutt, New Zealand.

Lindsay, J. M., Schmidt, A. K., Trumbull, R. B., de Silva, S. L., Siebel, W. \& Emmermann, R. (2001). Magmatic evolution of the La Pacana Caldera system, Central Andes, Chile: compositional variation of two cogenetic, large-volume felsic ignimbrites. Journal of Petrology 42, 459-486.

Lipman, P.W. (2007). Incremental assembly and prolonged consolidation of Cordilleran magma chambers: evidence from the Southern Rocky Mountain volcanic field. Geosphere 3, 42-70.

Liu, Y., Anderson, A. T., Wilson, C. J. N., Davis, A. M. \& Steele, I. M. (2006). Mixing and differentiation in the Oruanui rhyolitic magma, Taupo, New Zealand: evidence from volatiles and trace elements in melt inclusions. Contributions to Mineralogy and Petrology 151, 71-87.

Lowenstern, J. B. \& Hurwitz, S. (2008). Monitoring a supervolcano in response: Heat and volatile flux at the Yellowstone caldera. Elements 4, 35-40.

Lowenstern, J. B., Smith, R. B. \& Hill, D. P. (2006). Monitoring super-volcanoes: geophysical and geochemical signals at Yellowstone and other large caldera systems. Philosophical Transactions of the Royal Society of London, Series A 364, 2055-2072. 
Ludwig, K. R. (2008). Isoplot/Ex version 3.70, A Geochronological Toolkit for Microsoft Excel. Berkeley Geochronology Center Special Publication 4.

Luo, Y. \& Ayers, J. C. (2009). Experimental measurements of zircon/melt trace element partition coefficients. Geochimica et Cosmochimica Acta 73, 3656-3679.

Malfait, W., Seifert, R., Petitgirard, S., Perrillat, J.-P., Mezouar, M., Ota, T., Nakamura, E., Lerch, P. \& Sanchez-Valle, C. (2014). Supervolcano eruptions driven by melt buoyancy in large silicic chambers. Nature Geoscience 7, 122-125.

Mankinen, E. A., Grommé, C. S., Dalrymple, G. B., Lanphere, M. A. \& Bailey, R. A. (1986). Paleomagnetism and $\mathrm{K}-\mathrm{Ar}$ ages of volcanic rocks from Long Valley caldera, California. Journal of Geophysical Research 91, 633-652.

Manville, V. \& Wilson, C. J. N. (2003). Interactions between volcanism, rifting and subsidence: implications of intracaldera palaeoshorelines at Taupo volcano, New Zealand. Journal of the Geological Society, London 160, 3-6.

Manville, V., White, J. D. L., Houghton, B. F. \& Wilson, C. J. N. (1999). Paleohydrology and sedimentology of a post-1.8 ka breakout flood from intracaldera Lake Taupo, North Island, New Zealand. Geological Society of America Bulletin 111, 1435-1447.

Marsh, B. D. (1981). On the crystallinity, probability of occurrence, and rheology of lava and magma. Contributions to Mineralogy and Petrology 78, 85-98.

Marsh, B. D. (1988). Crystal size distribution (CSD) in rocks and the kinetics and dynamics of crystallization I. Theory. Contributions to Mineralogy and Petrology 99, 277-291.

Marsh, B. D. (1996). Solidification fronts and magmatic evolution. Mineralogical Magazine 60, 5-40.

Marsh, B. D. (2004). A magmatic mush column Rosetta Stone: the McMurdo Dry Valleys of Antarctica. EOS, Transactions American Geophysical Union 85, 497 502 .

Martin, D. \& Nokes, R. (1988). Crystal settling in a vigorously convecting magma chamber. Nature 332, 534-536.

Martin, V. M., Morgan, D. J., Jerram, D. A., Caddick, M. J., Prior, D. J. \& Davidson, J. P. (2008). Bang! Month-scale eruption triggering at Santorini Volcano. Science 321, 1178.

Mason, B. G., Pyle, D. M. \& Oppenheimer, C. (2004). The size and frequency of the largest explosive eruptions on Earth. Bulletin of Volcanology 66, 735-748.

Matthews, N. E. (2011). Magma chamber assembly and dynamics of a supervolcano: Whakamaru, Taupo Volcanic Zone, New Zealand. Ph. D. thesis, University of Oxford, UK.

Matthews, N. E., Pyle, D. M., Smith, V. C., Wilson, C. J. N., Huber, C. \& van Hinsberg, V. (2012). Quartz zoning and the pre-eruptive evolution of the $~ 340-k a$ Whakamaru magma systems, New Zealand. Contributions to Mineralogy and Petrology 163, 87-107. 
McConnell, V. S., Shearer, C. K., Eichelberger, J. C., Keskinen, M. J., Layer, P. W. \& Papike, J. J. (1995). Rhyolite intrusions in the intracaldera Bishop Tuff, Long Valley caldera, California. Journal of Volcanology and Geothermal Research 67, 41-60.

McCulloch, M. T., Kyser, T. K., Woodhead, J. \& Kinsley, L. (1994). Pb-Sr-Nd-O isotopic constraints on the origin of rhyolites from the TaupoVolcanic Zone of New Zealand: evidence for assimilation followed by fractionation from basalt. Contributions to Mineralogy and Petrology 115, 303-312.

Michael, P. J. (1983). Chemical differentiation of the Bishop Tuff and other high-silica magmas through crystallization processes. Geology 11, 31-34.

Miller, C. F. \& Wark, D. A. (2008). Supervolcanoes and their explosive supereruptions. Elements 4, 11-16.

Millet, M. -A., Tutt, C. M., Handler, M. H. \& Baker, J. A. (2014). Processes and time scales of dacite magma assembly and eruption at Tauhara volcano, Taupo Volcanic Zone, New Zealand. Geochemistry, Geophysics, Geosystems 15, 213237.

Miyashiro, A. (1974). Volcanic rock series in island arcs and active continental margins. American Journal of Science 274, 321-355.

Moore, G. \& Carmichael, I. S. E. (1998). The hydrous phase equilibria (to $3 \mathrm{kbar}$ ) of an andesite and basaltic andesite from western Mexico: constraints on water content and conditions of phenocryst growth. Contributions to Mineralogy and Petrology 130, 304-319.

Morgan, D. J. \& Blake, S. (2006). Magmatic residence times of zoned phenocrysts: introduction and application of the binary element diffusion modeling (BEDM) technique. Contributions to Mineralogy and Petrology 151, 58-70.

Morgan, D. J., Blake, S., Rogers, N. W. B., DeVivo, B., Rolandi, G., Macdonald, R. \& Hawkesworth, C. J. (2004). Time scales of crystal residence and magma chamber volume from modelling of diffusion profiles in phenocrysts: Vesuvius 1944. Earth and Planetary Science Letters 222, 933-946.

Morgan, D. J., Rogers, N. W., Blake, S., De Vivo, B., Rolandi, G. \& Davidson, J. P. (2006). Magma recharge at Vesuvius in the century prior to AD79. Geology 34, 845-848.

Mouslopoulou, V., Nicol, A., Little, T. A. \& Walsh, J. J. (2007a). Displacement transfer between intersecting regional strike-slip and extensional fault systems. Journal of Structural Geology 29, 100-116.

Mouslopoulou, V., Nicol, A., Little, T. A. \& Walsh, J. J. (2007b). Terminations of large strike-slip faults: an alternative model from New Zealand. In: Cunningham, W. D. \& Mann, P. (eds), Tectonics of Strike-Slip Restraining and Releasing Bends. Geological Society of London, Special Publication 290, 387-415.

Nairn, I. A., Wood, C. P. \& Bailey, R. A. (1994). The Reporoa caldera, Taupo Volcanic Zone: source of the Kaingaroa Ignimbrites. Bulletin of Volcanology 56, 529-537.

Nairn, I. A., Kobayashi, T. \& Nakagawa, M. (1998). The $\sim 10$ ka multiple vent pyroclastic eruption sequence at Tongariro Volcanic Centre, Taupo Volcanic 
Zone, New Zealand: Part 1. Eruptive processes during regional extension. Journal of Volcanology and Geothermal Research 86, 19-44.

Nairn, I.A., Hedenquist, J.W., Villamor, P., Berryman, K. R. \& Shane, P. A. (2005). The $\sim$ AD 1315 Tarawera and Waiotapu eruptions, New Zealand: contemporaneous rhyolite and hydrothermal eruptions driven by an arrested basalt dike system? Bulletin of Volcanology 67, 186-193.

Naish, T. R., Field, B. D., Zhu, H., Melhuish, A., Carter, R. M., Abbott, S. T., Edwards, S., Alloway, B. V., Wilson, G. S., Niessen, F., Barker, A., Browne, G. H. \& Maslen, G. (2005). Integrated outcrop, drill core, borehole and seismic stratigraphic architecture of a cyclothemic, shallow-marine depositional system, Wanganui Basin, New Zealand. Journal of the Royal Society of New Zealand 35, 91-122.

Newman, S. \& Lowenstern, J. B. (2002). VolatileCalc: a silicate melt- $\mathrm{H}_{2} \mathrm{O}-$ $\mathrm{CO}_{2}$ solution model written in Visual Basic for Excel. Computers and Geosciences 28, 597-604.

Neuville, D. R., Courtial, P., Dingwell, D. B. \& Richet, P. (1993). Thermodynamic and rheological properties of rhyolite and andesite melts. Contributions to Mineralogy and Petrology 113, 571-582.Nichols, A. \& Wysoczanski, R. J. (2007). Using micro-FTIR spectroscopy to measure volatile contents in small and unexposed inclusions hosted in olivine crystals. Chemical Geology 242, 371-384.

Ogawa, Y., Bibby, H. M., Caldwell, T. G., Takakura, S., Uchida, T., Matsushima, N., Bennie, S. L., Tosha, T. \& Nishi, Y. (1999). Wide-band magnetotelluric measurements across the Taupo Volcanic Zone, New Zealand - preliminary results. Geophysical Research Letters 26, 3673-3676.

Okumura, S., Nakamura, M. \& Nakashima, S. (2003). Determination of molar absorptivity of IR fundamental $\mathrm{OH}$-stretching vibration in rhyolitic glasses. American Mineralogist 88, 1657-1662.

O’Neill, H. S. \& Pownceby, M. I. (1993). Thermodynamic data from redox reactions at high-temperatures 1 . An experimental and theoretical assessment of the electrochemical method using stabilized zirconia electrolytes, with revised values for the $\mathrm{Fe}-$ "FeO", $\mathrm{Co}-\mathrm{CoO}, \mathrm{Ni}-\mathrm{NiO}$ and $\mathrm{Cu}-\mathrm{Cu}_{2} \mathrm{O}$ oxygen buffers, and new data for the $\mathrm{W}-\mathrm{WO}_{2}$ buffer. Contributions to Mineralogy and Petrology 114, 296-314.

Palme H. \& Beer H. (1993). Abundances of the elements in the Solar System. In: Voigt, H. H. (ed.) Astronomy and Astrophysics, Berlin: Springer 3, 196-221.

Parson, L. M. \& Wright, I. C. (1996). The Lau-Havre-Taupo back-arc basin: A southward propagating, multi-stage evolution from rifting to spreading. Tectonophysics 263, 1-22.

Pearce, N. J. G., Westgate, J. A. \& Perkins, W. T. (1996) Developments in the analysis of volcanic glass shards by laser ablation ICP-MS: quantitative and single internal standard multi-element methods. Quaternary International 34, 213-227.

Phillips, E. H., Goff, F., Kyle, P. R., McIntosh,W. C., Dunbar, N. W. \& Gardner, J. N. (2007). The ${ }^{40} \mathrm{Ar} /{ }^{39} \mathrm{Ar}$ age constraints on the duration of resurgence at the Valles caldera, New Mexico. Journal of Geophysical Research 112, B08201. 
Pitcher, W. S. \& Read, H. H. (1959). The main Donegal granite. Quarterly Journal of the Geological Society 114, 259-305.

Price, R. C., Gamble, J. A., Smith, I. E. M., Stewart, R. B., Eggins, S. M. \& Wright, I. C. (2005). An integrated model for the temporal evolution of andesites and rhyolites and crustal development in New Zealand's North Island. Journal of Volcanology and Geothermal Research 140, 1-24.

Putirka, K. (2008). Thermometers and barometers for volcanic systems. Reviews in Mineralogy and Geochemistry 69, 61-111.

Putirka, K., Ryerson, F. J., Mikaelian, H. (2003). New igneous thermobarometers for mafic and evolved lava compositions, based on clinopyroxene + liquid equilibria. American Mineralogist 88, 1542-1554.

Rampino, M. R. \& Self, S. (1992). Climate-volcanism feedback and the Toba eruption of $\sim 74,000$ years age. Quaternary Research 40, 269-280.

Ramsey, M. H., Potts, P. J., Webb, P. C., Watkins, P., Watson, J. S. \& Coles, B. J. (1995). An objective assessment of analytical method precision: comparison of ICP-AES and XRF for the analysis of silicate rocks. Chemical Geology 124, 1-19.

Reid, F. W. \& Cole, J. W. (1983). Origin of dacites of Taupo Volcanic Zone, New Zealand. Journal of Volcanology and Geothermal Research 18, 191-214.

Reid, M. R. (2008). How long does it take to supersize an eruption? Elements 4, 23-28.

Reid, M. R. \& Coath, C. D. (2000). In situ U-Pb ages of zircons from the Bishop Tuff: no evidence for long crystal residence times. Geology 28, 443-446.

Reid, M. R., Coath, C. D., Harrison, T. M. \& McKeegan, K. D. (1997). Prolonged residence times for the youngest rhyolites associated with Long Valley caldera: ${ }^{230} \mathrm{Th}-{ }^{238} \mathrm{U}$ ion microprobe dating of young zircons. Earth and Planetary Science Letters 150, 27-39.

Reubi, O. \& Blundy, J. (2009). A dearth of intermediate melts at subduction zone volcanoes and the petrogenesis of arc andesites. Nature 461, 1269-1273.

Reyners, M. (2013). The central role of the Hikurangi Plateau in the Cenozoic tectonics of New Zealand and the Southwest Pacific. Earth and Planetary Science Letters 361, 460-468.

Ridolfi, F., Renzulli, A. \& Puerini, M. (2010). Stability and chemical equilibrium of amphibole in calc-alkaline magmas: an overview, new thermobarometric formulations and application to subduction-related volcanoes. Contributions to Mineralogy and Petrology 160, 45-66.

Riggs, N. R., Ort, M. H., White, J. D. L., Wilson, C. J. N., Houghton, B. F. \& Clarkson, R. (2000). Post-1.8-ka marginal sedimentation in Lake Taupo, New Zealand: effects of wave energy and sediment supply in a rapidly rising lake. In: White, J. D. L. \& Riggs, N. R. (eds), Volcaniclastic Sedimentation in Lacustrine Settings. International Association of Sedimentologists Special Publication 30, 151-178. 
Risk, G. F., Bibby, H. M. \& Caldwell, T. G. (1999). Resistivity structure of the central Taupo Volcanic Zone, New Zealand. Journal of Volcanology and Geothermal Research 90, 163-181.

Robinson, R., Smith, E. G. C. \& Latter, J. H. (1981). Seismic studies of the crust under the hydrothermal areas of the Taupo Volcanic Zone, New Zealand. Journal of Volcanology and Geothermal Research 9, 253-267.

Rogan, A. M. (1982). A geophysical study of the Taupo Volcanic Zone, New Zealand. Journal of Geophysical Research 87, 4073-4088.

Rotella, M. D., Wilson, C. J. N., Barker, S. J., Wright, I. C. (2013). Highly vesicular pumice generated by buoyant detachment of magma in subaqueous volcanism. Nature Geoscience 6, 129-132.

Rowland, J. V. \& Sibson, R. H. (2001). Extensional fault kinematics within the Taupo Volcanic Zone, New Zealand: soft-linked segmentation of a continental rift system. New Zealand Journal of Geology and Geophysics 44, 271-283.

Rowland, J. V., Wilson, C. J. N. \& Gravley, D. M. (2010). Spatial and temporal variations in magma-assisted rifting, Taupo Volcanic Zone, New Zealand. Journal of Volcanology and Geothermal Research 190, 89-108.

Sambridge, M. S. \& Compston, W. (1994). Mixture modelling of multi-component data sets with application to ion-probe zircon ages. Earth and Planetary Science Letters 128, 373-390.

Sano, Y., Terada, K. \& Fukuoka, T. (2002). High mass resolution ion microprobe analysis of rare earth elements in silicate glass, apatite and zircon: lack of matrix dependency. Chemical Geology 184, 217-230.

Sauerzapf, U., Lattard, D., Burchard, M. \& Engelman, R. (2008).The titanomagnetiteilmenite equilibrium: new experimental data and thermo-oxybarometric application to the crystallization of basic to intermediate rocks. Journal of Petrology 49, 1161-1185.

Saunders, K. E. (2009). Micro-analytical studies of the petrogenesis of silicic arc magmas in the Taupo Volcanic Zone and southern Kermadec Arc, New Zealand. $\mathrm{PhD}$ Thesis, Victoria University of Wellington, Wellington, New Zealand

Saunders, K. E., Baker, J. A. \& Wysoczanski, R. J. (2010). Microanalysis of large volume silicic magma in continental and oceanic arcs: melt inclusions in Taupo Volcanic Zone and Kermadec Arc rocks, South West Pacific. Journal of Volcanology and Geothermal Research 190, 203-218.

Saunders, K., Blundy, J., Dohmen, R. \& Cashman, K. (2012). Linking petrology and seismology at an active volcano. Science 336, 1023-1027.

Schärer, U. (1984). The effect of initial ${ }^{230} \mathrm{Th}$ disequilibrium on young U-Pb ages: the Makalu case, Himalaya. Earth and Planetary Science Letters 67, 191-204.

Schmitt, A. K., Stockli, D. F., Lindsay, J. M., Robertson, R., Lovera, O. M. \& Kislitsyn, R. (2010). Episodic growth and homogenization of plutonic roots in arc volcanoes from combined U-Th and (U-Th)/He zircon dating. Earth and Planetary Science Letters 295, 91-103. 
Schwandt, C. S., Cygan, R. T. \& Westrich, H. R. (1998). Magnesium self-diffusion in orthoenstatite. Contributions to Mineralogy and Petrology 130, 390-396.

Seebeck, H., Nicol, A., Villamor, P., Ristau, J \& Pettinga, J. (2014). Structure and kinematics of the Taupo Rift, New Zealand. Tectonics 33, 1178-1199.

Self, S. (2006). The effects and consequences of very large explosive volcanic eruptions. Philosophical Transactions of the Royal Society of London, Series A 364, 2073-2097.

Self, S. \& Blake, S. (2008). Consequences of explosive supereruptions. Elements 4, 4146.

Shane, P., Martin, S. B., Smith, V. C., Beggs, K. F., Darragh, M. B., Cole, J. W. \& Nairn, I. A. (2007). Multiple rhyolite magmas and basalt injection in the $17.7 \mathrm{ka}$ Rerewhakaaitu eruption episode from Tarawera volcanic complex, New Zealand. Journal of Volcanology and Geothermal Research 164, 1-26.

Shane, P., Nairn, I. A., Smith, V. C., Darragh, M., Beggs, K. F. \& Cole, J.W. (2008). Silicic recharge of multiple rhyolite magmas by basaltic intrusion during the 22.6 ka Okaraka eruption episode, New Zealand. Lithos 103, 527-549.

Shaw, H. R. (1985). Links between magma-tectonic rate balances, plutonism, and volcanism. Journal of Geophysical Research 90, 11275-11288.

Sherburn, S., Bannister, S. \& Bibby, H. (2003). Seismic velocity structure of the central Taupo Volcanic Zone, New Zealand, from local earthquake tomography. Journal of Volcanology and Geothermal Research 122, 69-88.

Simon, J. I. \& Reid, M. R. (2005). The pace of rhyolite differentiation and storage in an 'archetypical' silicic magma system, Long Valley, California. Earth and Planetary Science Letters 235, 123-140.

Simon, J. I., Renne, P. R. \& Mundil, R. (2008). Implications of pre-eruptive magmatic histories of zircons for $\mathrm{U}-\mathrm{Pb}$ geochronology of silicic extrusions. Earth and Planetary Science Letters 266, 182-194.

Simon, J. I., Vazquez, J. A., Renne, P. R., Schmitt, A. K., Bacon, C. R. \& Reid, M. R. (2009). Accessory mineral U-Th-Pb ages and ${ }^{40} \mathrm{Ar} /{ }^{39} \mathrm{Ar}$ eruption chronology, and their bearing on rhyolitic magma evolution in the Pleistocene Coso volcanic field, California. Contributions to Mineralogy and Petrology 158, 421-446.

Sisson, T. W. \& Bacon, C. R. (1999). Gas-driven filter pressing in magmas. Geology 27, 613-616.

Sisson, T. W. \& Grove, T. L. (1993). Experimental investigations of the role of $\mathrm{H}_{2} \mathrm{O}$ in calc-alkaline differentiation and subduction zone magmatism. Contributions to Mineralogy and Petrology 113, 143-166.

Smith, E. G. C., Williams, T. D. \& Darby, D. J. (2007). Principal component analysis and modeling of the subsidence of the shoreline of Lake Taupo, New Zealand, 1983-1999: Evidence for dewatering of a magmatic intrusion? Journal of Geophysical Research 112, B08406.

Smith, R. L. (1979). Ash-flow magmatism. Geological Society of America Special Paper 180, 5-27. 
Smith, R. T. (1998). Eruptive and depositional models for units 3 and 4 of the $1.85 \mathrm{ka}$ Taupo eruption: implications for the nature of large-scale 'wet' eruptions. $\mathrm{Ph}$. D. thesis, University of Canterbury, Christchurch, New Zealand.

Smith, R. T. \& Houghton, B. F. (1995). Vent migration and changing eruptive style during the 1800a Taupo eruption: new evidence from the Hatepe and Rotongaio phreatoplinian ashes. Bulletin of Volcanology 57, 432-439.

Smith, V. C., Shane, P. \& Nairn, I. A. (2005). Trends in rhyolite geochemistry, mineralogy, and magma storage during the last $50 \mathrm{kyr}$ at Okataina and Taupo volcanic centres, Taupo Volcanic Zone, New Zealand. Journal of Volcanology and Geothermal Research 148, 372-406.

Smith, V. C., Shane, P. \& Nairn, I. A. (2010). Insights into silicic melt generation using plagioclase, quartz and melt inclusions from the caldera-forming Rotoiti eruption, Taupo volcanic zone, New Zealand. Contributions to Mineralogy and Petrology 160, 951-971.

Sparks, R. J., Melhuish, W. H., McKee, J. W. A., Ogden, J., Palmer, J. G. \& Molloy, B. P. J. (1995). ${ }^{14} \mathrm{C}$ calibration in the Southern Hemisphere and the date of the last Taupo eruption: Evidence from tree-ring sequences. Radiocarbon 37, 155-163.

Sparks, R. S. J., Sigurdsson, H. \& Wilson, L. (1977). Magma mixing: a mechanism for triggering acid explosive eruptions. Nature 267, 315-318.

Sparks R. S. J., Self, S., Grattan, J. P., Oppenheimer, C., Pyle, D. M. \& Rymer, H. (2005). Supereruptions: global effects and future threats. Report of a Geological Society of London Working Group, The Geological Society, London, 24 p.

Stacey, J. S. \& Kramers, J. D. (1975). Approximation of terrestrial lead isotope evolution by a two-stage model. Earth and Planetary Science Letters 26, 207-221.

Stagpoole, V. M. (1994). Interpretation of refraction seismic and gravity data across the eastern margin of the Taupo Volcanic Zone, New Zealand. Geothermics 23, 501510.

Stern, T. A. (1979). Regional and residual gravity fields, central North Island, New Zealand. New Zealand Journal of Geology and Geophysics 22, 479-485.

Stern, T.A. (1985) A back-arc basin formed within continental lithosphere: the Central Volcanic Region of New Zealand. Tectonophysics 112, 385-409.

Stern, T. A. \& Davey, F. J. (1987). A seismic investigation of the crustal and upper mantle structure within the Central Volcanic Region of New Zealand. New Zealand Journal of Geology and Geophysics 30, 217-231.

Stern, T. A., Quinlan, G. M. \& Holt, W. E. (1993). Crustal dynamics associated with the formation of the Wanganui Basin, New Zealand. In: Ballance, P. F. (ed.), South Pacific Sedimentary Basins. Elsevier, Amsterdam, 213-223.

Stix, J., Goff, F., Gorton, M. P., Heiken, G. \& Garcia, S. R. (1988). Restoration of compositional zonation in the Bandelier silicic magma chamber between two caldera-forming eruptions: geochemistry and origin of the Cerro Toledo Rhyolite, Jemez Mountains, New Mexico. Journal of Geophysical Research 93, 6129-61. 
Storm, S., Shane, P., Schmitt, A. K. \& Lindsay, J. M. (2011). Contrasting punctuated zircon growth in two syn-erupted rhyolite magmas from Tarawera volcano: Insights to crystal diversity in magmatic systems. Earth and Planetary Science Letters 301, 511-520.

Stratford, W. R. \& Stern, T. A. (2004). Strong seismic reflections and melts in the mantle of a continental back-arc basin. Geophysical Research Letters 31, L06622.

Stratford, W. R. \& Stern, T. A. (2006). Crust and upper mantle structure of a continental backarc: central North Island, New Zealand. Geophysical Journal International 166, 469-484.

Stratford, W. R. \& Stern, T. A. (2008). Geophysical imaging of buried volcanic structures within a continental back-arc basin: the Central Volcanic Region, North Island, New Zealand. Journal of Volcanology and Geothermal Research 174, 257-268.

Sutton, A. N., Blake, S. \& Wilson, C. J. N. (1995). An outline geochemistry of rhyolite eruptives from Taupo volcanic centre, New Zealand. Journal of Volcanology and Geothermal Research 68, 153-175.

Sutton, A. N., Blake, S., Wilson, C. J. N. \& Charlier, B. L. A. (2000). Late Quaternary evolution of a hyperactive rhyolite magmatic system: Taupo volcanic centre, New Zealand. Journal of the Geological Society, London 157, 537-552.

Schwandt, C. S, Cygan, R. T., Westrich, H. R. (1998). Magnesium self-diffusion in orthoenstatite. Contributions to Mineralogy and Petrology 130, 390-396.

Talbot, J. P., Self, S. \& Wilson, C. J. N. (1994). Dilute gravity and rain-flushed ash deposits in the 1.8 ka Hatepe Plinian deposit, Taupo, New Zealand. Bulletin of Volcanology 56, 538-551.

Tamic, N., Behrens, H. \& Holtz, F. (2001). The solubility of $\mathrm{H}_{2} \mathrm{O}$ and $\mathrm{CO}_{2}$ in rhyolitic melts in equilibrium with a mixed $\mathrm{CO}_{2}-\mathrm{H}_{2} \mathrm{O}$ fluid phase. Chemical Geology 174, 333-347.

Thompson, M., Potts, P. J., Kane, J. S., Webb, P. \& Watson, J. S. (2000). GeoPT4. International proficiency test for analytical geochemistry laboratories - Report on round 4. Geostandards Newsletter 24, E1-E37.

Topping, W. W. (1973). Tephrostratigraphy and chronology of late Quaternary eruptives from the Tongariro Volcanic Centre, New Zealand. New Zealand Journal of Geology and Geophysics 16, 397-423.

Trial, A. F. \& Spera, F. J. (1990). Mechanisms for the generation of compositional heterogeneities in magma chambers. Geological Society of America Bulletin 102, 353-367.

Valentine, G. A. (1993). Note on the distribution of basaltic volcanism associated with large silicic centers. Journal of Volcanology and Geothermal Research 56, 167170.

Van Eaton, A. R. \& Wilson, C. J. N. (2013). The nature, origins and distribution of ash aggregates in a large-scale wet eruption deposit: Oruanui, New Zealand. Journal of Volcanology and Geothermal Research 250, 129-154. 
Vandergoes, M. J., Hogg, A. G., Lowe, D. J., Newnham, R. M., Denton, G. H., Southon, J., Barrell, D. J. A., Wilson, C. J. N., McGlone, M. S., Allan, A. S. R., Almond, P. C., Petchey, F., Dabell, K., Dieffenbacher-Krall, A. C. \& Blaauw, M. (2013). A revised age for the Kawakawa/Oruanui tephra, a key marker for the Last Glacial Maximum in New Zealand. Quaternary Science Reviews 74, 195 201.

Vazquez, J. A. \& Reid, M. R. (2002). Time scales of magma storage and differentiation of voluminous high-silica rhyolites at Yellowstone caldera, Wyoming. Contributions to Mineralogy and Petrology 144, 274-285.

Vazquez, J. A. \& Reid, M. R. (2004). Probing the accumulation history of the voluminous Toba magma. Science 305, 991-994.

Vazquez, J. A., Kyriazis, S. F., Reid, M. R., Sehler, R. C. \& Ramos, F. C. (2009). Thermochemical evolution of young rhyolites at Yellowstone: Evidence for a cooling but periodically replenished postcaldera magma reservoir. Journal of Volcanology and Geothermal Research 188, 186-196.

Vigneresse, J. L., Barbey, P. \& Cuney, M. (1996). Rheological transitions during partial melting and crystallization with application to felsic magma segregation and transfer. Journal of Petrology 37, 1579-1600.

Villamor, P. \& Berryman, K. R. (2001). A late Quaternary extension rate in the Taupo Volcanic Zone, New Zealand, derived from fault slip data. New Zealand Journal of Geology and Geophysics 44, 243-269.

Villamor, P. \& Berryman, K. R. (2006). Evolution of the southern termination of the Taupo Rift, New Zealand. New Zealand Journal of Geology and Geophysics 49, 23-37.

Villamor, P., Berryman, K. R., Nairn, I.A., Wilson, K., Litchfield, N. \& Ries, W. (2011). Associations between volcanic eruptions from Okataina volcanic center and surface rupture of nearby active faults, Taupo rift, New Zealand: insights into the nature of volcano-tectonic interactions. Geological Society of America Bulletin 123, 1383-1405.

Vucetich, C. G. \& Howorth, R. (1976). Late Pleistocene tephrostratigraphy in the Taupo district, New Zealand. New Zealand Journal of Geology and Geophysics 19, 5169.

Vucetich, C. G. \& Pullar, W. A. (1964). Stratigraphy and chronology of late Quaternary volcanic ash in Taupo, Rotorua, and Gisborne districts. Part 2. Stratigraphy of Holocene ash in the Rotorua and Gisborne districts. New Zealand Geological Survey Bulletin 73, 43-81.

Vucetich, C. G. \& Pullar, W. A. (1969). Stratigraphy and chronology of late Pleistocene volcanic ash beds in central North Island, New Zealand. New Zealand Journal of Geology and Geophysics 12, 784-837.

Vucetich, C. G. \& Pullar, W.A. (1973). Holocene tephra formations erupted in the Taupo area and interbedded tephras from other volcanic sources. New Zealand Journal of Geology and Geophysics 16, 745-780. 
Walker, G. P. L. (1980). The Taupo Pumice: product of the most powerful known (ultraplinian) eruption? Journal of Volcanology and Geothermal Research 8, 6994.

Walker, G. P. L. (1981a). The Waimihia and Hatepe plinian deposits from the rhyolitic Taupo volcanic centre. New Zealand Journal of Geology and Geophysics 24, 305324.

Walker, G. P. L. (1981b). Characteristics of two phreatoplinian ashes and their waterflushed origin. Journal of Volcanology and Geothermal Research 9, 395-407.

Wallace, L. M., Beavan, J., McCaffrey, R. \& Darby, D. J. (2004). Subduction zone coupling and tectonic block rotations in the North Island, New Zealand. Journal of Geophysical Research 109, B12406.

Wallace, P. J., Anderson, A. T. \& Davis, A. M. (1999). Gradients in $\mathrm{H}_{2} \mathrm{O}, \mathrm{CO}_{2}$, and exsolved gas in a large-volume silicic magma system: interpreting the record preserved in melt inclusions from the Bishop Tuff. Journal of Geophysical Research 104, 20097-20122.

Wark, D. A., Hildreth, W., Spear, F. S., Cherniak, D. J. \& Watson, E. B. (2007). Preeruption recharge of the Bishop magma system. Geology 35, 235-238.

Watanabe, T., Koyaguchi, T. \& Seno, T. (1999). Tectonic stress controls on ascent and emplacement of magmas. Journal of Volcanology and Geothermal Research 91, $65-78$.

Watson, E. B. (1996). Dissolution, growth and survival of zircons during crustal fusion: kinetic principles, geological models and implications for isotopic inheritance. Transactions of the Royal Society of Edinburgh: Earth Sciences 87, 43-56.

Watson, E. B. \& Harrison, T. M. (1983). Zircon saturation revisited: temperature and composition effects in a variety of crustal magma types. Earth and Planetary Science Letters 64, 295-304.

Watts, K. E., Bindeman, I. N. \& Schmitt, A. K. (2012). Crystal scale anatomy of a dying supervolcano: an isotope and geochronology study of individual phenocrysts from voluminous rhyolites of the Yellowstone caldera. Contributions to Mineralogy and Petrology 164, 45-67.

Whiteford, P. C. (1996). Heat flow in the sediments of Lake Taupo, New Zealand. Tectonophysics 257, 81-92.

Wilson, C. J. N. (1985). The Taupo eruption, New Zealand II. The Taupo ignimbrite. Philosophical Transactions of the Royal Society of London, Series A 314, 229310.

Wilson, C. J. N. (1993). Stratigraphy, chronology, styles and dynamics of late Quaternary eruptions from Taupo volcano, New Zealand. Philosophical Transactions of the Royal Society of London, Series A 343, 205-306.

Wilson, C. J. N. (2001). The 26.5 ka Oruanui eruption, New Zealand: an introduction and overview. Journal of Volcanology and Geothermal Research 112, 133-174.

Wilson, C. J. N. (2008). Supereruptions and supervolcanoes: Processes and products. Elements 4, 29-34. 
Wilson, C. J. N. \& Charlier, B. L. A. (2009). Rapid rates of magma generation at contemporaneous magma systems, Taupo volcano, New Zealand: insights from U-Th model-age spectra in zircons. Journal of Petrology 50, 875-907.

Wilson, C. J. N. \& Walker, G. P. L. (1985). The Taupo eruption, New Zealand I. General aspects. Philosophical Transactions of the Royal Society of London, Series A 314, 199-228.

Wilson, C. J. N., Ambraseys, N. N., Bradley, J. \& Walker, G. P. L. (1980). A new date for the Taupo eruption, New Zealand. Nature 288, 252-253.

Wilson, C. J. N., Rogan, A. M., Smith, I. E. M., Northey, D. J., Nairn, I. A. \& Houghton, B. F. (1984). Caldera volcanoes of the Taupo Volcanic Zone, New Zealand. Journal of Geophysical Research 89, 8463-8484.

Wilson, C. J. N., Houghton, B. F. \& Lloyd, E, F. (1986). Volcanic history and evolution of the Maroa-Taupo area, central North Island. In: I.E.M. Smith (ed.), Late Cenozoic Volcanism in New Zealand. Royal Society of New Zealand Bulletin 23, 194-223.

Wilson, C. J. N., Houghton, B. F., McWilliams, M. O., Lanphere, M. A., Weaver, S. D. \& Briggs, R. M. (1995). Volcanic and structural evolution of Taupo Volcanic Zone, New Zealand: a review. Journal of Volcanology and Geothermal Research 68, $1-28$.

Wilson, C. J. N., Riggs, N. R., Ort, M. H., White, J. D. L. \& Houghton, B. F. (1997). An annotated atlas of post-1.8 ka shoreline features at Lake Taupo, New Zealand. Institute of Geological and Nuclear Sciences Science Report 97/19, Lower Hutt, New Zealand.

Wilson, C. J. N., Blake, S., Charlier, B. L. A. \& Sutton, A. N. (2006). The 26.5 ka Oruanui eruption, Taupo volcano, New Zealand: development, characteristics and evacuation of a large rhyolitic magma body. Journal of Petrology 47, 35-69.

Wilson, C. J. N., Rowland, J. V. \& Gravley, D. M. (2008). The Taupo Volcanic Zone, New Zealand: a geological and geophysical review, with emphasis on its central segment. Institute of Earth Science \& Engineering, University of Auckland, Report 2008-01, 135 pp.

Wilson, C. J. N., Gravley, D. M., Leonard, G. S. \& Rowland, J. V. (2009). Volcanism in the central Taupo Volcanic Zone, New Zealand: tempo, styles and controls. In: Thordarson, T., Self, S., Larsen, G., Rowland, S. K. \& Hoskuldsson, A. (eds) Studies in Volcanology: The Legacy of George Walker. Special Publications of IAVCEI 2, 225-247.

Wolff, J. A. (1985). The effect of explosive eruption processes on geochemical patterns within pyroclastic deposits. Journal of Volcanology and Geothermal Research 26, 189-201.

Woods, A. W. \& Cowan, A. (2009). Magma mixing triggered during volcanic eruptions. Earth and Planetary Science Letters 288, 132-137.

Wysoczanski, R. \& Tani, K. (2006). Spectroscopic FTIR imaging of water species in silicic volcanic glasses and melt inclusions: an example from the Izu-Bonin arc. Journal of Volcanology and Geothermal Research 156, 302-314. 
Zellmer, G. F., Blake, S., Vance, D., Hawkesworth, C. \& Turner, S. (1999). Plagioclase residence times at two island arc volcanoes (Kameni Islands, Santorini, and Soufriere, St. Vincent) determined by Sr diffusion systematics. Contributions to Mineralogy and Petrology 136, 345-357.

Zielinski, G. A., Mayewski, P. A., Meeker, L. D., Whitlow, S., Twickler, M. S., Morrison, M., Meese, D. A., Gow, A. J. \& Alley, R. B. (1994). Record of volcanism since 7000 B.C. from the GISP2 Greenland ice core and implications for the volcano-climate system. Science 264, 948-952. 